\title{
IntechOpen
}

\section{Sustainable Growth and Applications in Renewable Energy Sources}

Edited by Majid Nayeripour and Mostafa Kheshti

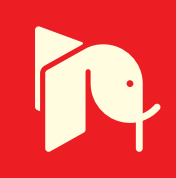





\section{SUSTAINABLE GROWTH AND APPLICATIONS IN RENEWABLE ENERGY SOURCES}

Edited by Majid Nayeripour and Mostafa Kheshti 
Sustainable Growth and Applications in Renewable Energy Sources

http://dx.doi.org/10.5772/2433

Edited by Majid Nayeripour and Mostafa Kheshti

\section{Contributors}

Ali Osman Yilmaz, Sergio Capareda, Frederic Coupan, Ahmed Abbas, Henri Clergeot, Idris Sadli, Isabelle Marie-Joseph, Jerzy P Lukaszewicz, Saka Ambali Abdulkareem, Habib Uthman, Ayo Samuel Afolabi, Awenebe Lucky Okhakumhe, Wan Azlina Wan Ab Karim Ghani, Reza Alipour Moghadam, Mohamad Amran Mohd Salleh, Joseph Zayed, Bouchra Bakhiyi, Carlo Andrea Bollino, Silvia Micheli, Cansino, Maria De P. Pablo-Romero, Rocio Roman, Rocio Yniguez, Szilvia Stranczinger, Marianna Kocsis, Agnes Farkas, Sándor Csete, Attila Borhidi, Balint Szalontai, Péter Tóvári, Robert Pal, Eva Salamon-Albert, Ilona Walcz, Tibor Vojtela, József Dezső, János Janowszky, Zsolt Janowszky, Tobias Aurelius Knoch, Pius Olugbenga Fatona, Alan Fung, Christian Gordon, Laia Ferrer-Marti, Walter Canedo, Carlos Reza, Milton Dominguez, Lorenzo Perone, Jaime Salinas, Bruno Domenech, Mitha Tellez, Stanislav Darula, Richard Kittler

\section{(c) The Editor(s) and the Author(s) 2011}

The moral rights of the and the author(s) have been asserted.

All rights to the book as a whole are reserved by INTECH. The book as a whole (compilation) cannot be reproduced, distributed or used for commercial or non-commercial purposes without INTECH's written permission.

Enquiries concerning the use of the book should be directed to INTECH rights and permissions department (permissions@intechopen.com).

Violations are liable to prosecution under the governing Copyright Law.

\section{(c) $B Y$}

Individual chapters of this publication are distributed under the terms of the Creative Commons Attribution 3.0 Unported License which permits commercial use, distribution and reproduction of the individual chapters, provided the original author(s) and source publication are appropriately acknowledged. If so indicated, certain images may not be included under the Creative Commons license. In such cases users will need to obtain permission from the license holder to reproduce the material. More details and guidelines concerning content reuse and adaptation can be foundat http://www.intechopen.com/copyright-policy.html.

\section{Notice}

Statements and opinions expressed in the chapters are these of the individual contributors and not necessarily those of the editors or publisher. No responsibility is accepted for the accuracy of information contained in the published chapters. The publisher assumes no responsibility for any damage or injury to persons or property arising out of the use of any materials, instructions, methods or ideas contained in the book.

First published in Croatia, 2011 by INTECH d.o.o.

eBook (PDF) Published by IN TECH d.o.o.

Place and year of publication of eBook (PDF): Rijeka, 2019.

IntechOpen is the global imprint of IN TECH d.o.o.

Printed in Croatia

Legal deposit, Croatia: National and University Library in Zagreb

Additional hard and PDF copies can be obtained from orders@intechopen.com

Sustainable Growth and Applications in Renewable Energy Sources

Edited by Majid Nayeripour and Mostafa Kheshti

p. cm.

ISBN 978-953-307-408-5

eBook (PDF) ISBN 978-953-51-6081-6 


\section{We are IntechOpen, \\ the world's leading publisher of Open Access books}

Built by scientists, for scientists

\section{$3,800+$}

Open access books available

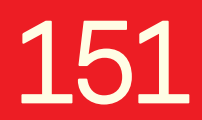

Countries delivered to

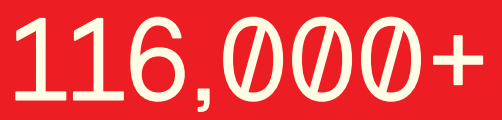

International authors and editors
$120 \mathrm{M}+$

Downloads

Our authors are among the

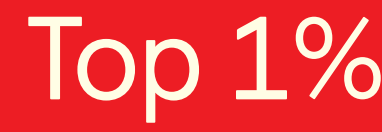

most cited scientists

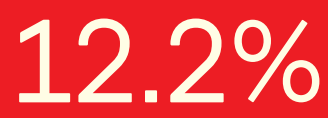

Contributors from top 500 universities

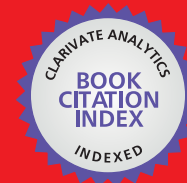

WEB OF SCIENCE ${ }^{\mathrm{TM}}$

Selection of our books indexed in the Book Citation Index in Web of Science ${ }^{\mathrm{TM}}$ Core Collection (BKCI)

Interested in publishing with us?

Contact book.department@intechopen.com

Numbers displayed above are based on latest data collected.

For more information visit www.intechopen.com

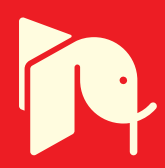





\section{Meet the editors}

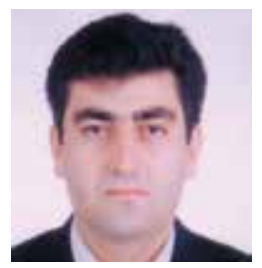

Dr. Majid Nayeripour was born in Shiraz, Iran. He received his $\mathrm{PhD}$ in Electrical Engineering form Tarbiat Modares University, Tehran, Iran and is currently an assistant professor at Shiraz University of Technology, Shiraz, Iran. He has published more than 60 journal and conference papers, as well as three books. His research interests include Renewable Energy, FACTS Devices and Power Quality and Impacts of DGs in Power System.

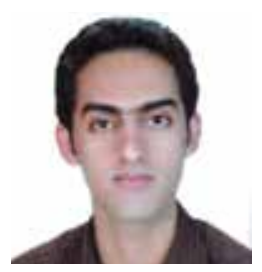

BSc. Mostafa Kheshti was born in Noorabad Mamasani, Iran in 1987. He received his BSc in Electrical Engineering from Shiraz University of Technology. Apart from serving as a technical expert for the Fars Regional Electric Company, he has also published several papers and books, as well as managed several projects. Currently, he is a Master Student at Xi'an Jiaotong University, China. His research interests include Renewable Energy, Distributed Generation, Smart Grids, Power System and Protection. 



\section{Contents}

\section{Preface XI}

Part 1 Sustainable Growth 1

Chapter 1 EU Energy Policies and Sustainable Growth $\mathbf{3}$

Carlo Andrea Bollino and Silvia Micheli

Chapter 2 Sustained Renewability:

Approached by Systems Theory and Human Ecology 21

Tobias A. Knoch

Chapter 3 Renewable Energy Use and Energy Efficiency -

A Critical Tool for Sustainable Development 49

Pius Fatona

Chapter 4 Renewable Energy and Coal Use in Turkey 61

Ali Osman Yılmaz

Chapter 5 Experiences of Community Wind

Electrification Projects in Bolivia:

Evaluation and Improvements for Future Projects $\mathbf{8 5}$

Laia Ferrer-Martí, Bruno Domenech,

Walter Canedo, Carlos Reza, Mirtha Tellez,

Milton Dominguez, Lorenzo Perone and Jaime Salinas

Chapter 6 Taxes Incentives to Promote

Res Deployment: The Eu-27 Case 107

José M. Cansino, María del P. Pablo-Romero,

Rocío Román and Rocío Yñiguez

\section{Part 2 Applications 123}

Chapter 7 Structural Design of a Dynamic Model of the Battery for State of Charge Estimation 125

Frédéric Coupan, Ahmed Abbas, Idris Sadli, Isabelle Marie Joseph and Henri Clergeot 
Chapter 8 Parameterisation of the Four Half-Day Daylight Situations 147

Stanislav Darula and Richard Kittler

Chapter 9 Energetic Willow (Salix viminalis) Unconventional Applications 181

Andrzej Olejniczak, Aleksandra Cyganiuk, Anna Kucińska and Jerzy P. Łukaszewicz

Chapter 10 Biomass Energy Conversion 209

Sergio Canzana Capareda

Chapter 11 Air Gasification of Malaysia Agricultural Waste in a Fluidized Bed Gasifier: Hydrogen Production Performance 227

Wan Azlina Wan Ab Karim Ghani,

Reza A. Moghadam and Mohamad Amran Mohd Salleh

Chapter 12 Extraction and Optimization of Oil from Moringa Oleifera Seed as an Alternative Feedstock for the Production of Biodiesel 243

A.S. Abdulkareem, H. Uthman, A.S. Afolabi and O.L. Awenebe

Chapter 13 Tall Wheatgrass Cultivar Szarvasi-1 (Elymus elongatus subsp. ponticus cv. Szarvasi-1) as a Potential Energy Crop for Semi-Arid Lands of Eastern Europe 269 Sándor Csete, Szilvia Stranczinger, Bálint Szalontai, Ágnes Farkas, Róbert W. Pál, Éva Salamon-Albert, Marianna Kocsis, Péter Tóvári, Tibor Vojtela, József Dezső, Ilona Walcz, Zsolt Janowszky, János Janowszky and Attila Borhidi

Chapter 14 Analysis of Time Dependent Valuation of Emission Factors from the Electricity Sector 295

C. Gordon and Alan Fung

Chapter 15 Photovoltaic Conversion: Outlook at the Crossroads Between Technological Challenges and Eco-Strategic Issues 313

Bouchra Bakhiyi and Joseph Zayed 


\section{Preface}

Worldwide attention to environmental issues combined with the energy crisis force us to reduce greenhouse emissions and increase the usage of renewable energy sources as a solution to providing an efficient environment. This book addresses the current issues of sustainable growth and applications in renewable energy sources. The fifteen chapters of the book have been divided into two sections to organize the information accessible to readers.

The book provides a variety of material, for instance on policies aiming at the promotion of sustainable development and implementation aspects of RES. Authors contributing to the book have tried to prepare the information in an accessible way. We would like to extend our appreciation to all the authors for their cooperation and the attention that they have given to this book.

During this project, it was a pleasure for us to work with InTech - Open Access Publisher. We express our appreciation to all our colleagues in this publication, especially Ms. Ivana Zec, the Publishing Process Manager in charge of this book project.

Majid Nayeripour

Faculty of Electrical and Electronic Engineering, Shiraz University of Technology,

Iran

Mostafa Kheshti

Xi'an Jiaotong University,

China 



\section{Part 1}

Sustainable Growth 



\title{
EU Energy Policies and Sustainable Growth
}

\author{
Carlo Andrea Bollino and Silvia Micheli \\ Department of Economics, Finance and Statistics, University of Perugia \\ Italy
}

\section{Introduction}

The concentration of greenhouse gases (GHG) in the atmosphere was at 438 parts per million (ppm) of $\mathrm{CO}_{2}$ equivalent in 2008, that is almost twice the pre-Industrial Revolution level (IEA, 2010). Such an increase is mainly caused by fossil fuel combustion for energy purposes in the power, industry, building and transport sectors (Stern, 2007). In the Reference Scenario, which gives economic and environmental assessments of a world in which the economy continues on its current course without polluting emission reductions policies, fossil fuel use is projected to grow, and the dirtiest fuel, i.e. coal, is expanding its share to face rising energy demand driven by emerging countries such as China and India.

The global response to climate change started with the so called Rio Earth Summit in 1992: governments realized the need to work together for an environmental and sustainable economic development. The Summit was a first move towards an environmental policy at global level, by setting the emission reduction targets for developed countries and establishing a framework of wider reduction for the future from a sustainable development point of view. Its weak point was that the Summit promised a lot at little cost, since it was an agreement without stringent measures (Helm, 2008). The Summit has been followed by several discussions with the purpose of finding optimal shared environmental policy for facing climate change.

Afterwards, the Kyoto Protocol, an international agreement adopted in Kyoto on December 1997, has committed (instead of encouraging) 37 industrialized countries and the European Union (EU) to reduce GHG emissions through national measures. The EU has undoubtedly made a big effort in developing a progressive environmental policy, but many of its own policies are still far from making a difference to climate change. Following the ratification of the Kyoto Protocol in 2002, the EU committed itself to reduce emissions to $8 \%$ below 1990 levels by 2008-2012, allowing different national emissions target within the EU accounting for different income level, country size and environmental attitude (Borghesi, 2010).

The current policy action toward green Europe is the so-called 20-20-20 Climate and Energy Package. The EU aims to limit its 2020 greenhouse gas emissions to 20\% below 1990 levels and to meet a $20 \%$ renewables target of total energy supply by 2020 . The Package includes a $20 \%$ energy efficiency target and a biofuel target of $10 \%$ by 2020 (Hepburn et al., 2006). To meet these targets, governments in EU countries use a large variety of support instruments. 
The first part of the chapter is then devoted to a critical review of the main international agreements to reduce climate change and their implementation in the EU environmental policy. The search for a consensus among EU governments is tricky since energy policies advocated by EU members differ. Some of them urge on the implementation of nuclear power, while others advocate the use of renewables instead of nuclear technologies; anyway, all of them are convinced that the economy cannot rely on fossil fuels anymore (Nordhaus, 2006).

The second part of the chapter evaluates the range of strategies implemented in different EU countries to tackle climate change. The primary objective of these strategies is to increase the use of renewable energy in order to enjoy the environmental benefits and for energy security reasons (Held et al., 2006). The analysis reviews the EU climate-change package and the main policy instruments contained in it. We categorize policy instruments through the most frequently used typology, i.e. price-oriented or quantityoriented (Dinica, 2006). Some of them are claimed to be more market friendly than others, while other schemes are claimed to be more efficient in promoting the development of renewable energy (Meyer, 2003). Currently, there is no general agreement on the effectiveness of each scheme. By analyzing the different schemes that have been used in EU Member States in order to achieve the 20-20-20 targets, the research takes into account the extent of financial support given by each EU member region by considering some exogenous factors, as the availability and distribution of renewable resources, and the institutional context. The strategies planned by governments imply different costs that might be prohibitive if other countries are not making comparable efforts.

Finally, the research highlights the problem of coordination among policy makers that undermines the achievement of the 20-20-20 Climate and Energy Package targets, using a theoretic model of Nordhaus (2009). It is well-known that EU countries should take complementary and coordinated actions to green themselves by implementing their own national plan (Böhringer et al., 2009). Every country would want to spur new activities, new investment, more employment in its own territory, by using an appropriate mix of local taxation and subsidies, in conjunction with other command and control instruments. However, EU countries have the incentive to free-ride, or to impose as few costs as possible on their home economy while enjoying the benefits created at the other countries' cost (Barrett, 1994). So, the research highlight the formidable problems of opportunistic behavior and inefficient outcomes.

\section{Energy trends}

According to projections of the Reference Scenario (which gives economic and environmental assessments of a world in which the economy continues on its current course without polluting emission reductions policies), energy demand should increase by $1.5 \%$ per year between 2007 and 2030 and fossil fuels remain the main sources of energy. They represent three quarters of global energy consumption during the same projection period and the dirtiest fuel, i.e. coal, is expanding its share to face the raising in energy consumption mainly driven by developing countries, such as China and India. Actually, non-OECD countries are the main drivers in the increase of energy demand as a result of their economic and population growth. 


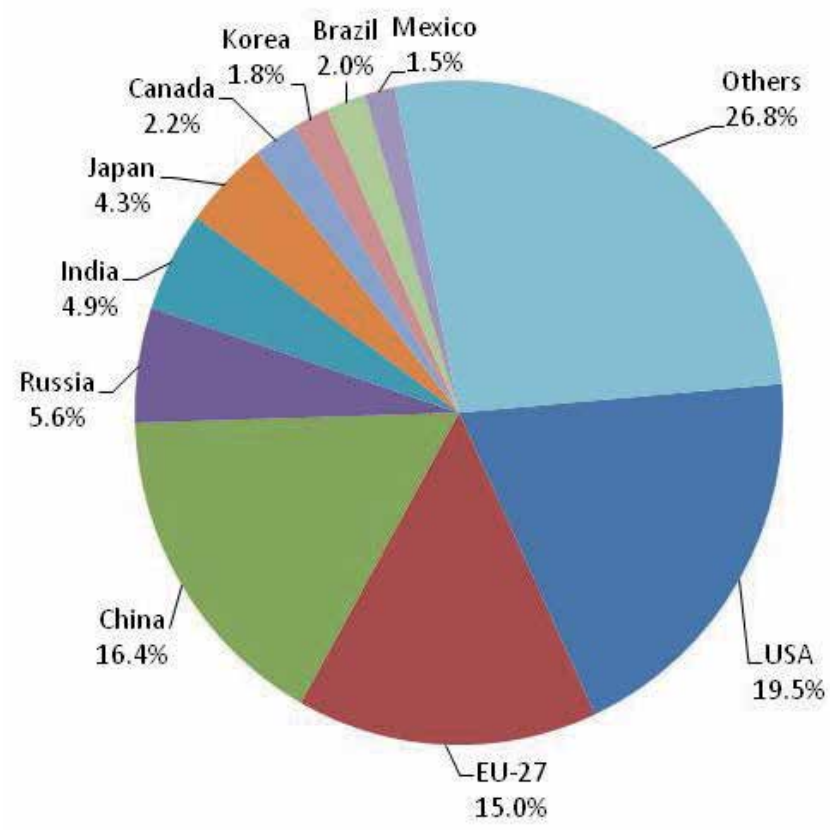

Fig. 1. Gross Inland Consumption in 2007. Source: Eurostat (2009).

Renewable energies, including hydroelectric, geothermal, biomass, solar energy and wind energy, grow at a fast pace relative to electricity production, but their share in energy consumption is still low.

\begin{tabular}{|c|c|c|c|c|c|c|c|}
\hline Country & Solids & Oil & Gas & Nuclear & Hydro & Biomass & Other \\
\hline United States & 23.7 & 38.9 & 23.0 & 9.3 & 0.9 & 3.5 & 0.7 \\
\hline EU-27 ** & 18.3 & 36.4 & 23,9 & 13.4 & 1.5 & 5.4 & 1.1 \\
\hline Japan & 22.3 & 44.8 & 16.2 & 13.4 & 1.2 & 1.4 & 0.7 \\
\hline Russia & 15.2 & 19.7 & 54.4 & 6.3 & 2.3 & 1.0 & 1.2 \\
\hline China * & 65.6 & 18.2 & 3.1 & 0.8 & 2.1 & 9.9 & 0.2 \\
\hline India & 40.8 & 23.7 & 5.6 & 0.7 & 1.8 & 27.2 & 0.3 \\
\hline Korea & 25.3 & 42.5 & 14.0 & 16.8 & 0.1 & 1.2 & 0.0 \\
\hline Brazil & 5.8 & 39.3 & 7.5 & 1.4 & 13.7 & 30.7 & 1.7 \\
\hline Canada & 11.2 & 35.1 & 29.3 & 9.0 & 11.8 & 4.3 & -0.7 \\
\hline Mexico & 4.9 & 56.9 & 27.4 & 1.5 & 1.3 & 4.5 & 3.5 \\
\hline Others & 13.5 & 39.6 & 25.7 & 1.6 & 2.4 & 16.5 & 0.8 \\
\hline World & $\mathbf{2 6 . 5}$ & $\mathbf{3 4 . 0}$ & $\mathbf{2 0 . 9}$ & $\mathbf{5 . 9}$ & $\mathbf{2 . 2}$ & $\mathbf{9 . 8}$ & $\mathbf{0 . 7}$ \\
\hline
\end{tabular}

Table 1. Gross income consumption by country in 2007. Source: Eurostat (2009)

Almost $18 \%$ of total electricity in 2007 was generated by renewable energy and, according to the Reference Scenario, it is supposed to rise to $22 \%$ in 2030 . Actually energy production from renewables is more expensive than fossil fuel based technologies, and the reasons for 
such disadvantages are several. Methods used by economic engineering to evaluate costaccounting of energy technology projects are outdated; as a consequence, renewable technology projects seems more expensive (Awerback, 2003). Moreover, it has to be taken into account that production costs of energy from fossil fuels do not internalize both the environmental and human health externalities. A higher penetration of renewable resources in the energy mix would lead to both environmental and economic benefits, as a reduction of polluting emissions and a mitigation of energy import dependency.

The concentration of greenhouse gases (GHG) in the atmosphere was at 438 parts per million (ppm) of $\mathrm{CO}_{2}$ equivalent in 2008, that is almost twice the pre-Industrial Revolution level (IEA, 2009). Mostly of the world emissions originates from China and United States, which together produce about $12.1 \mathrm{Gt} \mathrm{CO} 2$ that is $41 \%$ of world $\mathrm{CO} 2$ emissions. The relation between GHG emissions and economic growth may be well understood through the Kaya identity, which expresses $\mathrm{CO}_{2}$ emissions of the energy sector in terms of GDP, energy intensity of output, and carbon intensity of energy consumption (Stern, 2007):

Carbon Dioxide Emissions $=$ population $\cdot$ per capita GDP $\cdot$ energy intensity $\cdot$ carbon intensity

From this identity it is clear that the increase in world GDP tends to increase global emissions, unless increase in income stimulates a reduction in carbon intensity or total energy (Nakicenovic et al., 2006).

\begin{tabular}{|c|c|c|c|c|c|}
\hline Country & $\begin{array}{c}\text { CO2 emissions } \\
\text { (Gt CO2) }\end{array}$ & $\begin{array}{c}\text { GDP per } \\
\text { capita }\end{array}$ & $\begin{array}{c}\text { Carbon } \\
\text { intensity }\end{array}$ & $\begin{array}{c}\text { Energy } \\
\text { intensity }\end{array}$ & Population \\
\hline USA & 1.4 & 1.8 & 0.0 & -1.5 & 1.2 \\
\hline EU & 0.2 & 1.8 & -0.7 & -1.2 & 0.3 \\
\hline UK & -0.4 & 2.4 & -1.0 & -2.3 & 0.2 \\
\hline Japan & 0.7 & 0.7 & -0.5 & 0.2 & 0.3 \\
\hline China & 3.7 & 8.5 & 1.1 & -6.4 & 0.9 \\
\hline India & 4.3 & 3.9 & -0.3 & -2.5 & 1.7 \\
\hline World & $\mathbf{1 . 4}$ & $\mathbf{1 . 9}$ & $\mathbf{- 0 . 1}$ & $\mathbf{- 1 . 7}$ & $\mathbf{1 . 4}$ \\
\hline
\end{tabular}

Table 2. Rate of growth of $\mathrm{CO}_{2}$ emissions (\%). Source: Stern (2007)

The contribution to global warming by countries is controversial. The United States represent the second largest $\mathrm{CO}_{2}$ emitter. On the one hand, the high share of $\mathrm{CO}_{2}$ emissions is related to the share of GDP that is the largest in the world. On the other hand, the United States generates around $20 \%$ of global $\mathrm{CO}_{2}$ emissions while the population is only $5 \%$ of the total world population. China produces $22 \%$ of world polluting emissions but it accounts for $20 \%$ of the population of the world (Kawase et al., 2006).

The sectors that contribute more to $\mathrm{CO}_{2}$ emissions are transport and electricity and heat generation, that together account for two-thirds of global emissions in 2008 (IEA, 2010). The former represents $22 \%$ of $\mathrm{CO}_{2}$ emissions in 2008 worldwide, and the World Energy Outlook 2009 projections reveal that the share is estimated to grow to $45 \%$ by 2030 . Actually, the level of passengers travel is growing according to population growth, and only the EU is encouraging fuel economy (as a response to high fuel price as well) through voluntary 
agreement with manufacturers. Electricity and heat generation constitute the largest polluting sectors in 2008, by making a $41 \%$ contribution to the world $\mathrm{CO}_{2}$ emissions in 2008, relying on carbon fuel, especially in developing countries such as China and India.

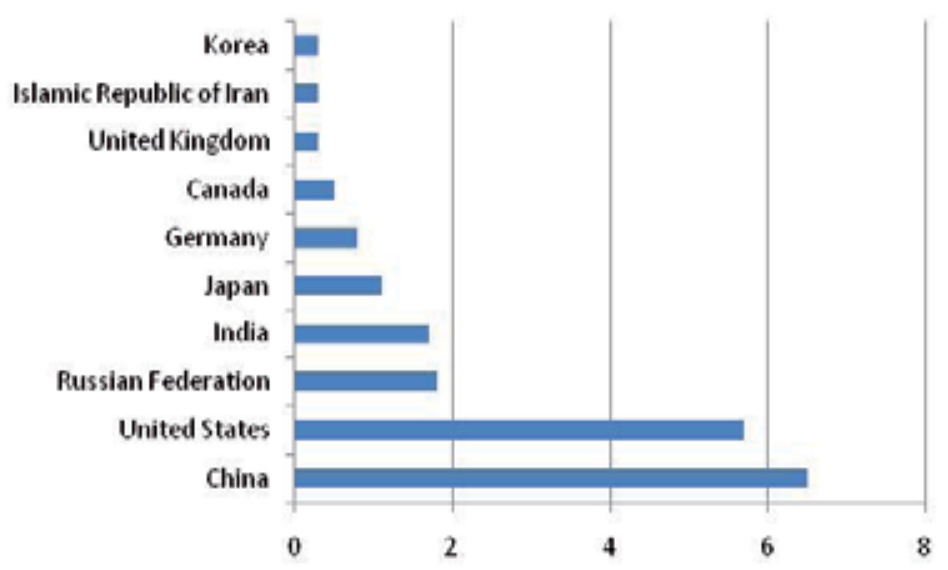

Fig. 2. Top 10 emitting countries in $2008\left(\mathrm{Gt} \mathrm{CO}_{2}\right)$. Source: IEA, 2010.

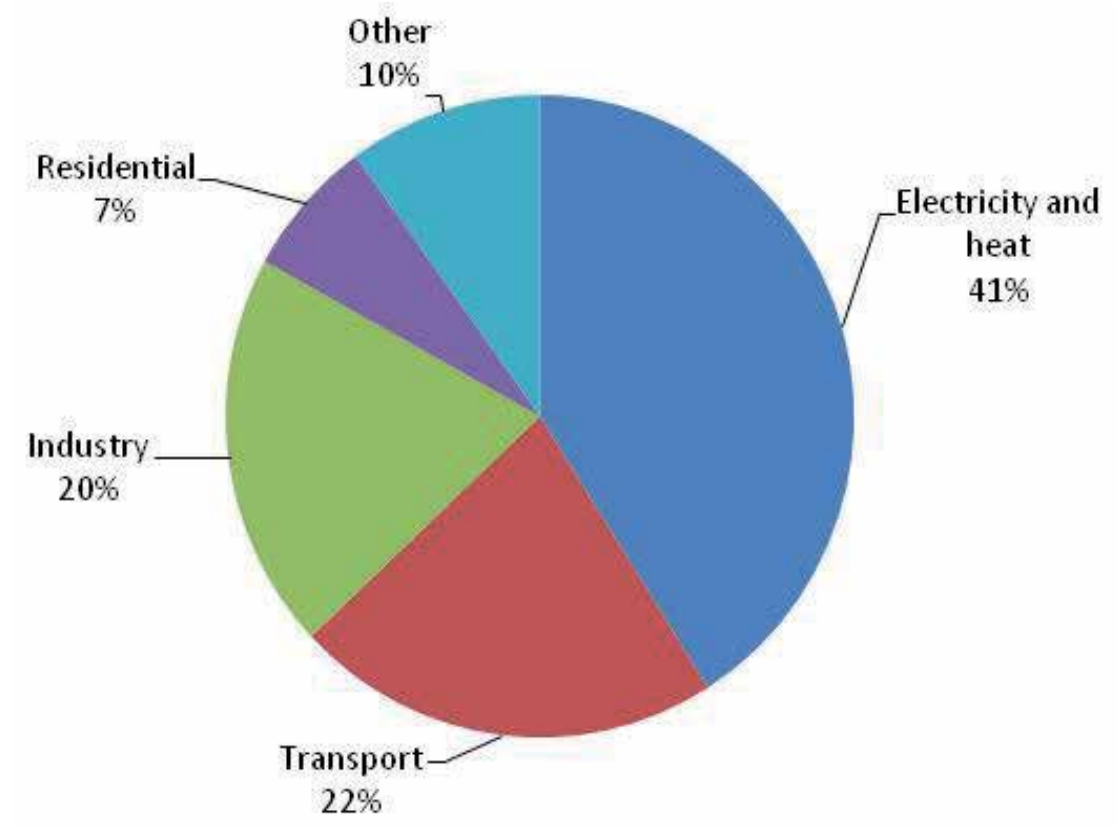

Fig. 3. World $\mathrm{CO}_{2}$ emissions by sector in 2008. Source: IEA, 2010.

We deem imperative that a global response to face climate change is needed at the European level. The EU energy portfolio relies strongly on fossil fuels, and it has important consequences both in terms of "importing" $\mathrm{CO}_{2}$ emissions and for energy security reasons. 


\begin{tabular}{|c|c|c|c|c|c|c|c|c|c|}
\hline Origin & $\mathbf{2 0 0 0}$ & $\mathbf{2 0 0 1}$ & $\mathbf{2 0 0 2}$ & $\mathbf{2 0 0 3}$ & $\mathbf{2 0 0 4}$ & $\mathbf{2 0 0 5}$ & $\mathbf{2 0 0 6}$ & $\mathbf{2 0 0 7}$ & Share 2007(\%) \\
\hline Russia & 112.4 & 136.8 & 154.7 & 170.8 & 188.9 & 188.0 & 189.6 & 185.3 & 33.9 \\
\hline Norway & 115.9 & 108.1 & 103.1 & 106.4 & 108.6 & 97.5 & 89.1 & 84.3 & 15.5 \\
\hline Libya & 45.5 & 43.8 & 39.1 & 45.9 & 49.9 & 50.6 & 53.1 & 55.5 & 10.2 \\
\hline Saudi Arabia & 65.1 & 57.5 & 53.1 & 61.5 & 64.5 & 60.7 & 51.1 & 39.4 & 7.2 \\
\hline Other, Middle East & 54.7 & 48.2 & 43.2 & 27.8 & 28.5 & 29.9 & 32.5 & 34.4 & 6.3 \\
\hline Iran & 33.5 & 31.4 & 25.9 & 34.7 & 35.9 & 35.3 & 36.3 & 34.1 & 6.3 \\
\hline Kazahkhstan & 9.9 & 9.1 & 13.4 & 15.9 & 22.2 & 26.4 & 26.8 & 18.3 & 3.4 \\
\hline Nigeria & 22.4 & 25.7 & 18.4 & 23.2 & 14.9 & 18.6 & 20.2 & 15.5 & 2.8 \\
\hline Other Origin & 58.2 & 62.3 & 64.2 & 56.6 & 56.6 & 66.2 & 65.9 & 78.1 & 14.4 \\
\hline Total Imports & 519.8 & 522.9 & 515.3 & 542.9 & 570.2 & 573.4 & 564.7 & 545.1 & 100 \\
\hline
\end{tabular}

Table 3. Crude oil imports in the EU27 (in Mt) in 2007. Source: Eurostat (2009)

\begin{tabular}{|c|c|c|c|c|c|c|c|c|c|}
\hline Origin & $\mathbf{2 0 0 0}$ & $\mathbf{2 0 0 1}$ & $\mathbf{2 0 0 2}$ & $\mathbf{2 0 0 3}$ & $\mathbf{2 0 0 4}$ & $\mathbf{2 0 0 5}$ & $\mathbf{2 0 0 6}$ & $\mathbf{2 0 0 7}$ & Share 2007(\%) \\
\hline Russia & 4539709 & 4421515 & 4554744 & 4895252 & 4951044 & 4952879 & 4937711 & 4685365 & 40.8 \\
\hline Norway & 1985231 & 2136379 & 2601569 & 2699473 & 2801723 & 2671779 & 2844237 & 3061751 & 16.7 \\
\hline Algeria & 2203075 & 1957181 & 2132477 & 2158803 & 2042137 & 2256826 & 2132236 & 1943976 & 16.9 \\
\hline Nigeria & 172020 & 216120 & 217882 & 335929 & 410260 & 436319 & 563905 & 588317 & 5.1 \\
\hline Libya & 33442 & 33216 & 25536 & 30390 & 47809 & 209499 & 321150 & 383615 & 3.3 \\
\hline Qatar & 12443 & 27463 & 87952 & 80414 & 160170 & 195713 & 232721 & 275496 & 2.4 \\
\hline Egypt & & & & & & 202419 & 327394 & 221305 & 1.9 \\
\hline Trinidad and Tobago & 36334 & 24498 & 19120 & 1365 & & 29673 & 163233 & 104917 & 0.9 \\
\hline Other Origin & 112810 & 199256 & 125425 & 100023 & 313245 & 409387 & 227147 & 213995 & 12.0 \\
\hline Total Imports & 9095064 & 9015628 & 9764705 & 10301649 & 10726388 & 11364494 & 11749734 & 11478737 & 100 \\
\hline
\end{tabular}

Table 4. Gas imports in the EU27 (in TJ) in 2007. Source: Eurostat (2009)

\begin{tabular}{|c|c|c|c|c|c|c|c|c|c|}
\hline & $\mathbf{2 0 0 0}$ & $\mathbf{2 0 0 1}$ & $\mathbf{2 0 0 2}$ & $\mathbf{2 0 0 3}$ & $\mathbf{2 0 0 4}$ & $\mathbf{2 0 0 5}$ & $\mathbf{2 0 0 6}$ & $\mathbf{2 0 0 7}$ & Share 2007 (\%) \\
\hline Total EU-27 & 151575 & 173041 & 171629 & 180360 & 196062 & 197043 & 213809 & 214358 & 100 \\
\hline Russia & 14976 & 20875 & 23033 & 26545 & 40382 & 48304 & 55544 & 56117 & 26.2 \\
\hline South Africa & 40177 & 49273 & 53961 & 56932 & 54190 & 51698 & 53080 & 46121 & 21.5 \\
\hline Australia & 28600 & 29450 & 29337 & 31004 & 30838 & 27013 & 27147 & 29069 & 13.6 \\
\hline Colombia & 23132 & 22633 & 21398 & 22908 & 24224 & 24147 & 26068 & 29018 & 13.5 \\
\hline United States & 20447 & 20119 & 14082 & 12619 & 15416 & 15673 & 17370 & 20833 & 9.7 \\
\hline Indonesia & 9097 & 10254 & 11540 & 13004 & 13980 & 14704 & 21092 & 17594 & 8.2 \\
\hline Other & 15146 & 20437 & 18278 & 17348 & 17032 & 15504 & 13508 & 15606 & 7.3 \\
\hline
\end{tabular}

Table 5. Coal imports in the EU27 (in kT) in 2007. Sources: Eurostat (2009)

\section{Policy}

The global response to climate change started with the so called Rio Earth Summit in 1992: governments realized the need to work together for an environmental and sustainable economic development. The Summit was a first move towards an environmental policy at global level, by setting emission reduction targets for developed countries and establishing a framework of wider reduction for the future from a sustainable development point of view. Its weak point was that the Summit promised a lot at little costs, since it was an agreement without stringent measures (Helm, 2008). The Summit has been followed by several discussions with the purpose of finding optimal shared environmental policy for facing climate change. 
Afterwards, the Kyoto Protocol, an international agreement adopted in Kyoto on December 1997, has committed (instead of encouraging) 37 industrialized countries and the European Union (EU) to reduce a basket of six greenhouse gases. The Kyoto Protocol entered into force in February by committing contracting parties as a group to achieve an overall reduction in polluting emissions of 5\% in the period 2008-12 with respect to 1990 levels(IEA, 2010). The Protocol has helped sensitive public awareness of problems related to climate change. Despite the Protocol has detailed commitment for each country member in terms of GHG reductions, it is limited in its potential to climate change mitigation since not all major emitters as United States were included in reduction commitments. In March 2001, the United States explicitly declared their non-participation in the Kyoto Protocol, because of the too high potential compliance costs and the domestic voters' low willingness to pay (Böhringer and Vogt, 2004).

The European Community has taken part in the Kyoto Protocol through positive measures. Between 2008 and 2012, countries that were already EU members, have to cut $8 \%$ off GHG emissions. Countries that have joined EU later undertake to cut emissions for the same amount, apart from Poland and Hungary (6\%). Kyoto Protocol suggests tools of action:

- strengthening of national policies to reduce emissions, as improvement of energy efficiency, promotion of sustainable forms of agriculture, development of renewable energies etc.,

- cooperation with other contracting parties, as exchange of experience and information, coordination of national policies through the right to emit.

During the period 1990-2007 the European Commission has recorded emission reductions as follows:

- $7 \%$ in the energy sector;

- $11 \%$ in the industrial process;

- $11 \%$ in agriculture (reduced use of mineral fertilizers);

- $39 \%$ in the waste sector.

The EU results should be interpreted not only in the light of Kyoto and all following agreements. The emission reductions are likely to be attributed to two factors as well: the global economic and financial crisis that has reduced industrial production, and the new member States entered in the European Union that have decreased on average the EU level of emissions because of their less productive economies.

\subsection{The European climate and energy package}

Actually, the European environmental and energy policy is represented by the so-called "2020-20 Climate and Energy Package", through which the EU is showing to be ready to assume the global leadership to face climate change, tackle the challenges of energy security, making Europe a model of sustainable development for the 21st Century. The EU aims to achieve by 2020 :

- a commitment to reduce by at least $20 \%$ greenhouse gas emissions compared to 1990 levels by 2020 , and the goal of reducing emissions by $30 \%$ by 2020 if other developed countries make comparable efforts;

- a binding target for the EU of $20 \%$ of energy from renewable sources by 2020 , including a target for biofuels. 


\begin{tabular}{|c|c|c|c|c|}
\hline & 1990 & 2008 & $\begin{array}{c}\text { \% change } \\
90-08\end{array}$ & $\begin{array}{l}\text { Kyoto } \\
\text { Target }\end{array}$ \\
\hline Kyoto Parties with targets & 8858.3 & 7980.1 & $-9.2 \%$ & $-4.7 \%$ \\
\hline North America & 432.3 & 550.9 & $27.4 \%$ & \\
\hline Canada & 432.3 & 550.9 & $27.4 \%$ & $-6 \%$ \\
\hline Europe & 3153.6 & 3222.9 & $2.2 \%$ & \\
\hline Austria & 56.5 & 69.3 & $22.7 \%$ & $-13 \%$ \\
\hline Belgium & 107.9 & 111.0 & $2.8 \%$ & $-7.5 \%$ \\
\hline Denmark & 50.4 & 48.4 & $-4.0 \%$ & $-21 \%$ \\
\hline Finland & 54.4 & 56.6 & $4.0 \%$ & $0 \%$ \\
\hline France & 352.3 & 368.2 & $4.5 \%$ & $0 \%$ \\
\hline Germany & 950.4 & 803.9 & $-15.4 \%$ & $-21 \%$ \\
\hline Greece & 70.1 & 93.4 & $33.2 \%$ & $+25 \%$ \\
\hline Iceland & 1.9 & 2.2 & $17.0 \%$ & $+10 \%$ \\
\hline Ireland & 29.8 & 43.8 & $46.7 \%$ & $+13 \%$ \\
\hline Italy & 397.4 & 430.1 & $8.2 \%$ & $-6.5 \%$ \\
\hline Luxembourg & 10.5 & 10.4 & $-0.6 \%$ & $-28 \%$ \\
\hline Netherlands & 155.8 & 177.9 & $14.1 \%$ & $-6 \%$ \\
\hline Norway & 28.3 & 37.6 & $33.0 \%$ & $+1 \%$ \\
\hline Portugal & 39.3 & 52.4 & $33.5 \%$ & $+27 \%$ \\
\hline Spain & 205.8 & 317.6 & $54.3 \%$ & $+15 \%$ \\
\hline Sweden & 52.8 & 45.9 & $-13.0 \%$ & $+4 \%$ \\
\hline Switzerland & 40.7 & 43.7 & $7.4 \%$ & $-8 \%$ \\
\hline United Kingdom & 549.3 & 510.6 & $-7.0 \%$ & $-12.5 \%$ \\
\hline Pacific & 1346.6 & 1582.0 & $17.5 \%$ & \\
\hline Australia & 260.1 & 397.5 & $52.9 \%$ & $+8 \%$ \\
\hline Japan & 1064.4 & 1151.1 & $8.2 \%$ & $-6 \%$ \\
\hline New Zealand & 22.0 & 33.3 & $51.5 \%$ & $0 \%$ \\
\hline Economic in Transition & 3852.9 & 2624.3 & $-31.9 \%$ & $-6 \%$ \\
\hline
\end{tabular}

\begin{tabular}{|l|c|c|c|c|}
\hline $\begin{array}{l}\text { Other Countries (non- } \\
\text { participating) }\end{array}$ & $\mathbf{1 1 5 6 6 . 6}$ & $\mathbf{2 0 3 6 8 . 2}$ & $\mathbf{7 6 . 1 \%}$ & \\
\hline United States & 4868.7 & 5595.9 & $14.9 \%$ & $-7 \%$ \\
\hline China & 2244.4 & 6550.5 & $191.9 \%$ & \\
\hline Latin America & 869.5 & 1476.5 & $69.8 \%$ & none \\
\hline Africa & 545.6 & 889.9 & $63.1 \%$ & none \\
\hline Middle East & 592.5 & 1492.3 & $151.8 \%$ & none \\
\hline Non-OECD Europe & 106.1 & 92.2 & $-13.1 \%$ & none \\
\hline Asia (excl. China) & 1510.1 & 3521.1 & $133.4 \%$ & none \\
\hline
\end{tabular}

\begin{tabular}{|l|l|l|l|l|}
\hline WORLD & 20964.8 & 29381.4 & $40.1 \%$ & \\
\hline
\end{tabular}

Table 6. World $\mathrm{CO}_{2}$ emissions from fuel combustion (in Mt) and Kyoto targets. Source: IEA, 2010 
The 20-20-20 Package, introduced in 2008 through the Communication (COM(2008)30), answers to the call made by the European Parliament about real measures for the transition toward a sustainable development. The Package includes a number of important policy proposals closely interlinked:

- $\quad$ a revised directive on the EU Emission Trading System (EU ETS);

- a proposal on the allocation of efforts by member states in order to reduce GHG emissions in sectors not covered by the EU ETS (as transport, building, services, small industrial plants, agriculture and food sectors);

- a directive on the promotion of renewable energy to achieve the goals of GHG emission reductions.

The EU ETS scheme has been a pioneering instrument prior to the 20-20-20 Climate and Energy Package. It is a market instrument that has been already implanted in the US quite successfully, and it has been introduced in Europe in 2003 in order to find market solutions to encourage firms cutting GHG emissions. The Cap and Trade system sets a maximum amount of emissions per period (2005-07 and 2008-12) per country. Then, each country establishes a national emission scheme and it allocates to firms the emission allowances which could be traded between the companies covered by the scheme. Once the emission permits are allocated, firms can trade them within the EU according to their criteria of economic efficiency. In the first and second ETS trading periods (2005-2012), mostly of the EU permits are allocated for free.

The importance of the EU ETS scheme is that is has been able to create a market and an artificial price for a public good as clean air. Thus, firms covered by the EU ETS have to face costs when emitting $\mathrm{CO}_{2}$ emissions: on the one hand, a firm that needs for its activity more permits than those at its disposal faces the cost of purchasing them. On the other hand, opportunity costs arise because permits could be sold in case of non-production. The 20-2020 Climate and Energy Package has modified the Emission Trading Scheme through the Directive 2009/29/EC and it will enter into force from 2013 to 2020, in order to overcome the application problems that rose during the first few years of its application. The first problem is related to the EU allocation mechanisms that have been used so far. Emission permits have been allocated for free, the allocation could be done on the basis of historic emissions, that is grandfathering. This mechanism may create vicious circle since it does not spur adoption of new technologies with a low environmental impact. Moreover, it favors large firms that at the first stage receive many permits to preserve their activity level over the small firms.

Another problem is related to the inconsistencies between the emission permits and the National Allocation Plan: governments have created too many emission permits to protect the welfare of the firms operating in the country who wanted to receive as more permits as possible.

Finally, the large and persistent fluctuations of market price have created havoc in the market and uncertainty on the goodness of the environmental policy.

In this direction, a research carried out by Hesmondhalgh et al. (2009) shows how different factors may influence CO2 prices, as it is shown in the following table 7.

The main elements of the reformed Emission trading Scheme are:

- a new emission cap set at $20 \%$ below with respect to the 2005 levels by 2020;

- the use of credits from the Clean Development Mechanisms and Joint Implementation is limited to $50 \%$ of the overall EU emission reductions in the period 2008-2020;

- inclusion of new sector as aviation and aluminium sector; 


\begin{tabular}{|l|l|}
\hline \multicolumn{1}{|c|}{ Factor } & \multicolumn{1}{|c|}{ Effect on $\mathrm{CO}_{2}$ prices } \\
\hline Higher than expected economic growth & $\begin{array}{l}\text { Upward - increased demand for } \\
\text { allowances }\end{array}$ \\
\hline Coal prices fall relative to gas prices & $\begin{array}{l}\text { Upward - increased demand for } \\
\text { allowances }\end{array}$ \\
\hline International agreement on abatement post-2012 & $\begin{array}{l}\text { Upward - EU will tighten cap on } \\
\text { emissions }\end{array}$ \\
\hline $\begin{array}{l}\text { Failure to meet renewables and/ or energy } \\
\text { efficiency targets }\end{array}$ & $\begin{array}{l}\text { Upward - increased demand for } \\
\text { allowances }\end{array}$ \\
\hline Overall fuel prices & $\begin{array}{l}\text { Uncertain - lower prices may increase } \\
\text { energy demand but will mitigate } \\
\text { effect of fuel price differentials and } \\
\text { vice versa for higher prices }\end{array}$ \\
\hline Economic downturn & $\begin{array}{l}\text { Downward - reduced demand for } \\
\text { allowances }\end{array}$ \\
\hline Coal prices rise relative to gas prices & $\begin{array}{l}\text { Downward - reduced demand for } \\
\text { allowances }\end{array}$ \\
\hline
\end{tabular}

Table 7. Potential influences on $\mathrm{CO}_{2}$ prices. Source: Hesmondhalgh et al., (2009)

- firms operating in the electricity sector are obliged to acquire $88 \%$ of emissions allocated to each installation through the auction mechanism; $10 \%$ of permits is redistributed from countries with higher per capita income to the one with lower per capita income and the remaining $2 \%$ is given to member States that successfully reached the $20 \%$ GHG reduction target in 2005 (i.e. the East European Countries).

The adoption of the auction mechanism in the EU ETS means a better distributional effect compared to grandfathering, because government entries generated by auctioning may be used both to reduce distortionary taxes and to promote research and development (R\&D) activities in clean technologies.

The Directive on renewable energies to reach the target of $20 \%$ on energy consumption by 2020 shares the burden between Member States. In particular, 50\% of this effort has to be shared equally between Member States, while the other 50\% is modulated according to GDP per capita. Moreover, the objectives are modified to take into account a proportion of the efforts already made by Member States which have increased the share of renewable energy fuels in recent years.

The promotion in the European Union of electricity production based on renewable energy sources takes place in an energy market that is more and more competitive, since 1996 when the Council of Ministers reached an agreement on the Directive specifying rules for electricity liberalization in EU. 


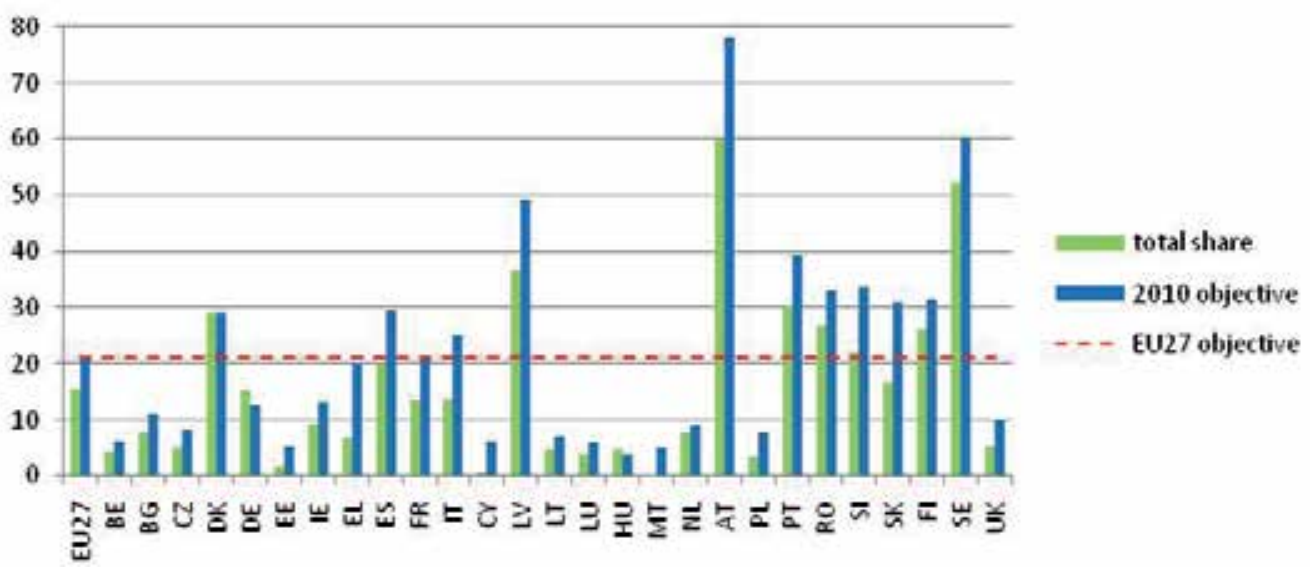

Fig. 4. Share of electricity from renewable energy sources in total electricity consumption (\%) - EU27 in 2007. Source: Eurostat (2009)

On the basis of the experience from electricity liberalization around the world, the goal of the European Union is to achieve higher efficiency and lower consumption prices by introducing conditions of intensified commercial competition, but it is quite hard for firms that produce energy from renewable resources to compete within the energy industry that produce energy mainly from fossil fuel.

Governments in EU countries use a large variety of instruments to stimulate the adoption of renewable energies; there are different schemes implemented by the European Union in order to use renewable energies and make them competitive on the energy market (Espey, 2001). The fundamental distinction that can be made among the European support mechanisms is between direct and indirect policy instruments. Basically, direct instruments stimulate the installation of energy from renewable resources immediately, while indirect policy measures focus on improving long-term framework conditions. There exist also voluntary approaches; this type of strategy is based on the consumers' willingness to pay premium rates for renewable energy, like donation projects and share-holder programs.

The important classification criteria are whether policy instruments are price-oriented or quantity-oriented.

With the regulatory price-driven strategies, financial support is given by investment subsidies, soft loans or tax credits. Economic support is also given as a fixed regulated feedin tariff (FIT) or a fixed premium that governments or utilities are legally obliged to pay for renewable energy produced by eligible firms. Among the price-oriented policy, the most used within the European members is the Feed-in Tariff. The Feed-in Tariff is a price-driven incentive in which the supplier or grid operators are obliged to buy electricity produced from renewable sources at a higher price compared to the price they pay for energy from fossil fuel. The criticisms made to the feed-in tariff scheme underline that a system of fixed price level is not compatible with a free market. Moreover, these favorable tariffs generally do not decrease with the improvements of the efficiency of the technologies that produce green energy (Fouquet and Johannson, 2008). A particular kind of feed-in tariff model used in Spain consist in a fixed premium, in addition to the market price for electricity, given to the producers relying on renewable energy sources. Also in this case, premiums should be adjusted in accordance with the performance of different technologies. 
With regard to the regulatory quantity-driven strategies, the desired level of energy generated from renewable resources or market penetration is defined by governments. The most important are tender system and tradable certificate system. In the tender system, calls for tender for defined amounts of capacity are made at regular interval, and the contract is given to the provider that offer the lowest price. The winners of tenders are getting a fixed price per $\mathrm{kWh}$ for the period of the contract and the contract offers winner several favorable investment conditions; this system is in a sense quite close to the feed-in tariff model. In the tradable certificate system, firms that produce energy are obliged to supply or purchase a certain percentage of electricity from renewable resources. Then, at the date of settlement, they have to submit the required number of certificates to demonstrate compliance. The firms involved in the tradable certificate system can obtain certificate from their own renewable electricity generation; they may as well purchase renewable electricity and associated certificates from another generator, or they can purchase certificates that have been traded independently of the power itself.

\begin{tabular}{|c|c|c|c|c|}
\hline & & \multicolumn{2}{|c|}{ Direct } & \multirow{2}{*}{ Indirect } \\
\hline & & Price-driven & Quantity-driven & \\
\hline \multirow{4}{*}{ Regulatory } & \multirow{2}{*}{$\begin{array}{l}\text { Investment } \\
\text { focussed }\end{array}$} & - Investment incentives & \multirow{2}{*}{ Tendering system } & \multirow{4}{*}{ Environmental taxes } \\
\hline & & - Tax incentives & & \\
\hline & \multirow{2}{*}{$\begin{array}{l}\text { Generation } \\
\text { based }\end{array}$} & - Feed-in tariffs & \multirow{2}{*}{$\begin{array}{l}\text { Tendering system and } \\
\text { Quota obligation based } \\
\text { on TGCs }\end{array}$} & \\
\hline & & -Rate-based incentives & & \\
\hline \multirow{3}{*}{ Voluntary } & \multirow{2}{*}{$\begin{array}{l}\text { Investment } \\
\text { focussed }\end{array}$} & - Shareholder programmes & & \multirow{3}{*}{ Voluntary agreements } \\
\hline & & \begin{tabular}{|l|} 
- Contribution \\
programmes
\end{tabular} & & \\
\hline & $\begin{array}{l}\text { Generation } \\
\text { based }\end{array}$ & - Green tariffs & & \\
\hline
\end{tabular}

Table 8. Classification of promotion strategies. Source: Held et al., 2006.

The economic incentives for renewable resources differ among the EU members. In Germany, the main electricity support scheme is represented by a price-driven incentive, the feed-in tariff. The main features of the German support mechanism are stated in the Renewable Energy Source Act of 2000. The Act establishes that the feed-in tariffs are not dependent on the market price of energy but are defined in the law and that feed-in tariffs are different for wind, biomass, photovoltaic etc. Moreover, the feed-in tariffs are decreased over the years in order to take into account the technological learning curves (Petrakis et al., 1997).

The United Kingdom was the first European country to pursue liberalization in the electricity market by the end of 1998. In UK, energy from renewable resources is supported by quantitative-driven strategies. Over the last decades, the scheme adopted by UK was the tender system, but, since 1999, the system in use is a quota obligation system with Tradable Green Certificates. The obligation (based in tradable green certificate) target increases during years, and electricity companies that do not comply with the obligation have to payout penalties. 
In Denmark the support schemes are mainly related to the wind power sector. To implement renewable resources, the strategy adopted is price-driven, that is a premium feed-in tariff for on-shore wind, and fixed feed-in tariffs for the other renewable resources.

In France, the strategy adopted is mainly price-oriented; the electricity support schemes are feed-in tariffs plus tenders for large projects.

Italy has not a significant experience in producing energy from renewable resources with the exception of large hydro. Several factors obstruct the development of renewables in Italy, as administrative constraints and high connection costs. During the 1990s, the energy sector in Italy was entirely restructured in order to introduce competition, as set by the EU Directive 96/02/EC (Lorenzoni, 2003). The promotion of electricity produced from renewables has taken place through support schemes as the quota obligation system and feed-in tariff. Concerning wind energy, in 2002 the Italian government abandoned the feedin-tariff, introducing the quota obligation system with tradable green certificates. Under this certificate system, electricity producers and importers are obliged to source an increasing proportion of their energy from renewable resources. Green certificates are used to fulfill this obligation. Italy has adopted a ministerial measure that balances supply and demand in order to tame speculative fluctuations on the value of green certificates.

The recent literature argues that EU ETS mechanism and the promotion of renewable energies may lead to different results (Carraro et al., 2006). While the EU ETS could be interpreted in the light of the "polluter pays principle", which requires the cost of pollution to be borne by those who cause it, the implementation of renewable energies aims at eliminating GHG emissions (Borghesi, 2010). Keeping constant the supply of emission permits, the implementation of renewables may lead to a decrease in emission permits' demand and thus their price without generating a significant GHG emissions reduction. Assuming that to be true, the two instruments should be substitutes instead of complements, unless government reduce the supply of permits on the long run.

Government involvement is essential to spur use of renewable energies. The EU energy consumption is still heavily based on fossil fuels, as it is shown in figure 5 .

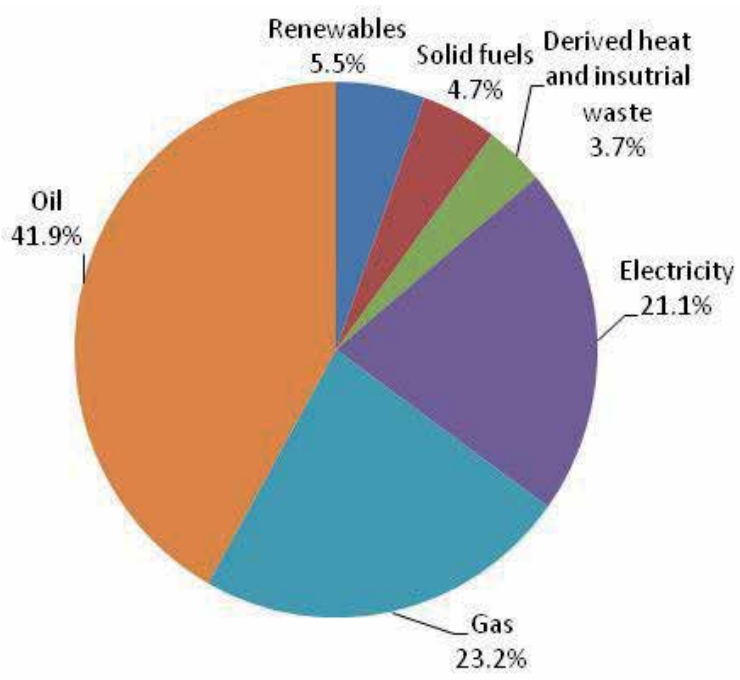

Fig. 5. Final energy consumption by fuel in 2007. Source: Eurostat, 2009 
The main advantage of renewable sources with respect to fossil fuels is that they contribute to mitigate climate change. The liberalization of the electricity market may appear as a partial response to climate change since it allows consumers to purchase cleaner electricity directly from suppliers. Anyway, most consumers are not willing to pay higher prices for green electricity since they are burdened with higher prices to preserve a public good (i.e. clean air) which everyone benefits from. Consequently, the proportion of renewable sources in the energy portfolio is low, unless there are governments subsidies (Carraro and Siniscalco, 2003).

Actually, subsidies are needed because fossil fuel prices do not internalize environmental damages to society. In fact, polluting emissions create a damage to society; without a price system, firms face a suboptimal opportunity cost for pollution and this leads to a wrong amount of pollution (Grimaud and Rougé, 2008). Since the right level of pollution will not emerge in a spontaneous way, government must increase pollution cost by raising a tax, in order to reduce pollution generation. If the tax is set at the optimal level, it is called a Pigouvian tax. The optimal amount of pollution is the amount that minimizes total costs from producing one more unit of pollution and total damages from pollution. Thus, the condition that marginal cost (or marginal saving) equals to marginal damage leads to the generation of the right amount of emissions. This is the main idea of the Pigouvian tax: "A Pigouvian fee is a fee paid by the polluter per unit of pollution exactly equal to the aggregate marginal damage caused by the pollution when evaluated at the efficient level of pollution. The fee is generally paid to the government" (Kolstad, 2000). Note that the Pigouvian tax is also equal to the marginal cost from pollution generation at the optimal level of pollution. The difficulty for the government to levy a Pigouvian fee is that there are reasons why it is not feasible. First of all, it is not easy to quantify marginal damage. The number of activities and the number of people affected by pollution are so great that it is quite hard to came up with monetary estimation of damage from pollution. Moreover, the optimal tax level on polluting emissions is not equal to the marginal net damage that the polluting activity generates initially, but to the damage it would cause if the level of the activity had been adjusted to its optimal level (Baumol and Oates, 1971). If we are not at the optimum, the Pigouvian tax will be neither the marginal cost of pollution nor the marginal damage from pollution.

Basically we can say that in a perfect environment, like an economy in which there is perfect information and no constraints on government tax policy, the Pigouvian tax is only necessary to achieve efficiency. If there are other distortions in the economy or limitation for the social planner, then other taxes and subsidies are needed to achieve efficiency (Sandmo, 1976).

Incentive systems are needed to stimulate technical change so that renewable energies lower future production costs. The reasons often put forward are the learning by doing effects from the production of energy from renewable resources on the cost of future production. The main idea is that a critical mass of production has to be reached first, and then costs will be reduced thanks to research and development activities (Fundenberg and Tirole, 1983).

The reasons related to the implementation of renewable energy does not lie only in the mitigation of climate change. There are also political reasons related to energy security issue. Nowadays, energy security does not mean anymore protecting existing energy supplies. The political instability of the Organization of the Petroleum Exporting Countries (OPEC) countries has a strong impact on the global energy markets by leading to supply shortage in importing countries, as the recent conflict in Libya has shown. 
The implication of energy policy measures are thoughtful: economic efficiency and political interests may conflict in climate change policies, especially when there are costs imposed in the future (Helm, 2008).

\subsection{Coordination between the EU member states}

Within the bounds of the 20-20-20 Climate and Energy Package, each Member State should work to support competition in energy markets and harmonize shared rules at European level. From the Package it is clear that Member States could take different mechanisms to reduce GHG emissions and implement renewable energies in the portfolio energy mix. Most countries have chosen the feed-in tariff scheme, while the minority has implemented green certificates. Assessment that results both on the effectiveness and costs of different mechanisms are quite controversial (Dinica, 2006). The availability and quality of renewable energies differ among countries: two countries may offer the same support scheme but they face heterogeneous quality of the energy resource. It translates in different production costs incurred by renewable energies that lead to misleading evaluations of the support instruments. Moreover, support mechanisms are implemented in different economic context which can then bring dissimilar results.

During the last three years the estimated costs to reach the 20/20/20 target have been reduced: in 2007, before the economic and financial crisis started, costs to reach the Climate and Energy Package goals were estimated at around 70 billion euro; nowadays, by taking into account the economic recession, costs come to 48 billion euro (i.e. $0.32 \%$ of EU GDP in 2020). The lower costs are due to several factors, including the reduction of world energy consumption due to economic and financial crisis and the rising in oil prices.

In the future, forecast costs of climate change will probably change upward according to the economic recovery, which should also serve as a stimulus to the global energy investment, essential to develop technologies with low environmental impact and increase energy efficiency.

The implementation of less high carbon technologies, such as wind and solar energies furthers the time horizon of the target to 2020. The costs related to the 20-20-20 Climate and Energy Package have to be mainly supported by customers and taxpayers, and such costs are higher if not all Member States make comparable efforts (Böhringer et al. 2009). There exists the incentive to free-ride by EU regions, or to impose as few costs as possible on their home economy while enjoying the benefits created at the other countries' cost, as demonstrated by a fair chunk of literature (Helm, 2008; Kemfert, 2003; Haas et al., 2004).

An interesting research made by Nordhaus (2009) analyzes the impact of non participation on the costs of slowing global warming. The Kyoto Protocol assigns different commitments to developed countries and developing countries. The 20-20-20 Climate and Energy Package involves coordination among all Member States; the implication for policy makers if not all countries participate to the Package are profound in term of costs. Nordhaus assesses the economic impact that arise when some countries do not participate in the agreement to mitigate climate change through a functional form for the cost function that allows to estimate the costs of nonparticipation.

It is quite straightforward that limiting participation produce inefficiencies by rising the costs for the participating countries. His research allows to calculate the cost penalty from nonparticipation (that is equal to the inverse of the square of the participation rate). Intuitively, if many countries do not participate in a treaty, the cost penalty is high, because 
the emission reduction target hardly could be achieved. As Nordhaus says: “..there are lowhanging fruits all around the world, but a regimen that limits participation to the highincome countries passes up the low-hanging fruit in the developing world".

We think that European Member States must then take coordinated actions to reach the 2020-20 goals by implementing national policies at national level.

\section{Conclusion}

The European Union (EU) has undoubtedly made a big effort in developing a progressive environmental policy, but many of its own policies are still far from making a difference to climate change. The policy into action to "green" Europe is the so-called 20-20-20 climate and energy package. The 20-20-20 Package, introduced in 2008 through the Communication (COM(2008)30), answers to the call made by the European Parliament about real measures for the transition toward a sustainable development. The Package includes a number of important policy proposals closely interlinked, that are: a revised directive on the EU Emission Trading System (EU ETS); a proposal on the allocation of efforts by member states in order to reduce GHG emissions in sectors not covered by the EU ETS (as transport, building, services, small industrial plants, agriculture and food sectors); a directive on the promotion of renewable energy to achieve the goals of GHG emission reductions.

So far, a large strand of literature on climate change states that we need several economic policy instruments to correct for existing types of market failures, for instance, an environmental tax on the carbon emissions and a research subsidy for research and development (R\&D) spillovers in the renewable energy sector (Cremer and Gahvari, 2002). Policy instruments implemented to these aims are generally classified as price-oriented or quantity-oriented. Some of them are claimed to be more market friendly than others, while other schemes are claimed to be more efficient in promoting the development of renewable energy (Meyer, 2003). Currently, there is no general agreement on the effectiveness of each scheme. Evidently, every region would want to spur new activities, new investment, more employment in its own territory, by using an appropriate mix of local taxation and subsidies, in conjunction with other command and control instruments. However, EU regions have the incentive to free-ride, or to impose as few costs as possible on their home economy while enjoying the benefits created at the other countries' cost. So, there are formidable problems of opportunistic behavior and inefficient outcomes.

To conclude, the 20-20-20 Climate and Energy Package requires simultaneous and coordinated action. Both politically and institutionally the EU Member States are quite heterogeneous. Unless cooperation is sustained by institutions which can punish free-riding, every region will earn even higher profits by free-riding on the virtuous behavior of the remaining cooperators.

\section{References}

Awerbach S., 2003. Does renewables cost more? Shifting the grounds of debate. Presentation at the Sonderborg on Renewable Energy - Renewable Energy in the market: New Opportunities, Sondenborg, Denmark, September 2003

Barrett S., 1994. Self-Enforcing International Environmental Agreements. Oxford Economic Papers, Special Issue on Environmental Economics, Vol.46, pp.878-894 
Baumol William J., Oates Wallace E., 1971. The Use of Standard and Prices for Protection of the Environment, The Swedish Journal of Economics, Vol.73, No.1, pp. $42-54$

Borghesi S., 2010. The European Emission Trading Scheme and Renewable Energy Policies: Credible Targets for Incredible Results?, Fondazione Eni Enrico Mattei, Working Papers. Working paper 529

Böhringer C., 2009. Strategic partitioning of emission allowances under the EU Emission Trading Scheme. Resource and energy economics, Vol.31, No.3. pp. 182-197

Böhringer C., Löschel A., Moslener U., Rutherford T., 2009. EU climate policy up to 2020: An economic impact assessment. Energy Economics, Vol.31, Supplement 2, pp.295-305

Böhringer C., Vogt C., 2004. The Dismantling of a Breakthrough: the Kyoto Protocol - Just Symbolic Policy. European Journal of Political Economy, Vol.20, No.3, pp.597-617

Carraro C., Eychmans J., Finus M., 2006. Optimal transfers and participation decisions in international environmental agreements. The Review of International Organization, Vol.1, No. 4, pp.379-396

Carraro C., Siniscalco D., 1993. Strategies for the International Protection of the Environment. Journal of Public Economics, Vol.52, No. 3, pp.309-321

Cremew H., Gahvari F., 2002. Imperfect Observability of Emissions and Second-best Emission and Output Taxes, Journal of Public Economics, Vol. 85, No. 3, pp. 385-407.

Dinica V., 2006. Support systems for the diffusion of renewable energy technologies - an investor perspective. Energy Policy, Vol.34, No. 4, pp.461-480

Espey S., 2001. Renewables portfolio standard: a means for trade with electricity from renewable energy sources?, Energy Policy, Vol. 29, No. 7, pp. 557-566

Eurostat - European Commission, 2009. Europe in figure. Eurostat yearbook 2009. Eurostat Statistical Books, Luxembourg.

Fouquete D., Johannson T., 2008. European renewable energy policy at crossroads-Focus on electricity support mechanisms. Energy Policy, Vol.36, No.11, pp. 4079-4092

Fundenberg D., Tirole J., 1983. Learning-by-Doing and Market Performance, The Bell Journal of Economics, Vol 14, No. 2, pp. 522-530.

Grimaud A., Rougé L., 2008. Environment, directed technical change and economic policy. Environmental and Resource Economics, Vol.41, No.4, pp. 439-463.

Haas, R.; Eichhammer, W.; Huber, C.; Langniss, O.; Lorenzoni, A.; Madlener, R.; Menanteau, P.; Morthorst, P.-E.; Martins, A.; Oniszk, A., 2004. How to promote renewable energy systems successfully and effectively. Energy Policy, Vol.32, No.6, pp.833-839

Held A., Haas R., Ragwitz M., 2006. On the success of policy strategies for the promotion of electricity from renewable energy sources in the EU. Energy \& Environment, Vol. 17, No. 6, pp. 849-868

Helm D., 2008. Climate-change policy: why has so little been achieved? Oxford Review of Economic Policy, Vol.24, No.2, pp.221-238

Hesmondhalgh S., Browun T., Robinson D., 2009. EU Climate and Energy Policy to 2030 and the Implications for Carbon Capture and Storage. The Battle Group, 2009

Hepburn C., Grubb M., Neuhoff K., Matthes F., Tse M., 2006. Auctioning of EU ETS phase II allowances: how and why? Climate Policy, Vol.6, No. 1, pp.137-160

Kawase R., Matsuoka Y., Fujino J., 2006. Decomposition analysis of $\mathrm{CO}_{2}$ emission in longterm climate stabilization scenarios. Energy Policy, Vol.35, No.15, pp.2113-2122

Kemfert C., 2004. Climate coalitions and international trade: assessment of cooperation incentives by issue linkage. Energy Policy, Vol.32, No.4, pp.455-465 
Kolstad Charles D., 2000. Environmental Economics, Oxford University Press, ISBN -19511954-1, Oxford.

IEA, 2010. CO2 emissions from fossil fuel combustion - Highlights. International Energy Agency, Paris, 2010 edition

Lorenzini A., 2003. The Italian Green Certificates market between uncertainty and opportunities, Energy Policy, Vol.31, No. 1, pp. 33-42.

Morthorst P.E. (2008). Wind Energy - the Facts. The Economics of Wind Power, World Wind Energy Association, Technical University of Denmark

Nakicenovic N., Kolp P., Riahi K., Kainuma M., Hanaoka T., 2006. Assessment of emissions scenario revisited. Environmental Economics and Policy Studies, Vol. 7, No. 3, pp. 137173

Nordhaus W.D., 2006. After Kyoto: Alternative Mechanisms to Control Global Warming. The American Economic Review, Vol.96, No.2, pp.31-34

Nordhaus W.D., 2009. The impact of Treaty nonparticipation on the Costs of Slowing Global Warming. The Energy Journal, Vol.30, No.2, pp.39-52

Petrakis Emmanuel, Rasmusen Eric, Roy Santanu, 1997. The Learning Curve in a Competitive Industry, The RAND Journal of Economics, Vol.28, No.2, pp. 248-268.

Sandmo A., 1976. Optimal taxation: An introduction to the literature, Journal of Public Economics, Vol. 6, No. 1-2, pp. 37-54

Stern N., 2007. The Economics of Climate Change: The Stern Review. Cambridge University Press, Cambridge, UK 


\title{
Sustained Renewability: Approached by Systems Theory and Human Ecology
}

\author{
Tobias A. Knoch ${ }^{1,2}$ \\ ${ }^{1}$ Biophysical Genomics, Dept. Cell Biology E Genetics, Erasmus MC, Rotterdam, \\ ${ }^{2}$ BioQuant $\mathcal{E}$ German Cancer Research Centre (DKFZ), Heidelberg \\ ${ }^{1}$ The Netherlands, \\ ${ }^{2}$ Germany
}

\section{Introduction}

With the growth of the world population and the ever-new technologies emerging from $R \& D$ - both creating ever higher needs and expectations - also the energy amount to be acquired, stored, transformed, and finally used is exponentially growing and thus believed to be always at the limit. Actually this capability to use energy, has since the origin of our universe been the central drive of nature: first in its physical evolution, then in the evolution of biological life and finally in the emergence of human societies and cultures. In our modern industrialized life from primary food to industrial good production, via transport and information processing, to every form of cultural activity, everything is depending on this agent allowing the change of the physical state of matter or organisms. This is underlined by the fact that mass and energy are two sides of the same medal as shown by $\mathrm{E}=\mathrm{mc}^{2}$ (Einstein, 1905) and always conserved (Noether, 1918a, $1918 b)$. Without energy no work, no process, no change, and no time would exist and consequently the thirst for energy, surpasses the currently accessible resources by far. Interestingly, there is only one other basic resource, which might be equally important as matter and energy: information - the way of how energy is used for change. Also the information amount to be stored and processed is growing exponentially and believed to be always at the limit. Without doubt information technologies have become the key to success in nearly all sectors of modern live: R\&D is meanwhile mostly based on the storage and analysis of huge data amounts. In health care, diagnosis and treatment rely on imaging facilities, their sophisticated analysis and treatment planning. In logistics, the shipment of goods, water, electricity and fuels is driven by distribution management systems. The financial and insurance sectors are unthinkable without modelling. Finally, the IT sector itself is inevitably carried by the creation and manipulation of data streams. Thus, also here the demands outweigh the useable resources and especially the public sector struggles to increase their capabilities.

Limits showing e.g. syntropic/entropic materialistic, energetic or other barriers as those of the energy or IT sectors, are well known (Egger, 1975; Faber \& Manstetten, 2003). They have constrained first nature and later life since their beginnings and are one of the evolutionary drivers by the "survival of the fittest". Exponential demand growth until reaching a limit seems 
to be an inherent property of life and evolution in general (Faber, 1987). The other side of demand growth - waste and pollution - complies with this, although it is not using a resource but destroying the purity of another one. Obviously, this sustainability challenge beyond the materialistic regime can be found on all evolutionary levels up to the psychological, societal, and cultural level. All these levels act as a possible cause for exponential growth. Especially, the abilities of man in his modern societies have accelerated the use of common resources tremendously reaching the planetary carrying capacity (IPCC). Climate change and the sustainability challenge, thus is a complex combination of various effects, which in their holistic consequences have reached an unsustainable level threatening survival. The (Classic) Tragedy of the Commons (Hardin, 1968, 1994, 1998; Ostrom, 1990; Commons) describes this dilemma, in which (multiple) independently acting individuals due to their own self-interest can ultimately destroy a shared limited resource despite it is clear that it is not in the long-term interest of the local community or for the whole society. On universal time scales syntropy/entropy laws obviously predict that mankind will reach fundamental limits. Nevertheless, on short time scales huge resources are available: Already the sun delivers $\sim 3.910^{6}$ Exajoules to earth per year, i.e. $\sim 10,000$ times the current human energy consumption $\left(\sim 5.010^{2}\right.$ Exajoules/a). The natural geogene radioactive decay is also considerable and has kept the earth core molten now for 4.5 billion years. Both the energy inflow and outflow is balanced. Thus, with the little usage efficiency of our human societies of $\sim 10 \%$ the current renewable energy capacity surpasses the human consumption still $\sim 1$ million fold! Not only are those resources renewable on a human scale but also free of primary resource costs. Thus, more efficient usage of renewables here is undoubtedly the key to the further success of our societies.

Again there are striking similarities to the IT sector: Due to the pervasiveness of PCs, their number has grown beyond 1.5 billion, outweighing the capacity of computing centres $>100$ times. Since the capacity is peak performance oriented, less than $5 \%$ are used, i.e. $>95 \%$ of the capacity would be available $99 \%$ of the time. In a generic IT sense the term, a resource is any capability that may be shared and exploited by a network - normally termed "grid". These resources have been already paid for including their external follow-up costs (environmental etc.). The same holds to less extent for cluster infrastructures due to virtualization strategies. The Erasmus Computing Grid (de Zeeuw et al., 2007) with 20,000 PCs ( $\sim 50,000$ cores, $\sim 50$ Teraflops), corresponds to a $\sim 30 \mathrm{M} €$ investment. Especially in the notoriously under-funded public domain more efficient resource usage by means of grid would satisfy a big demand challenge. Thus, both in the energy, IT, as in any resource sector more efficient usage is of major importance for advancements. Thus, at least locally the disaster of reaching the (physical) limit can be delayed largely. A prime example from the production of fundamental raw materials is e.g. the integrated production in the chemical industry (Faber et al., 1987): Here byproduct usage, i.e. the waste of one process, is reused in another one as basic resource or often even as main process component (Jentzsch, 1995). Integrated production can reach the level of an extremely fine-tuned ecological organism (as in the highly sophisticated chlorine chemistry) that little changes have severe "survival" consequences for the whole system (Egger \& Rudolph, 1992; Faber \& Schiller, 2006). In real biological systems, however, there is more flexibility as in the highly integrated and sophisticated agro-forestry systems e.g. in Indonesia, which have been developed over centuries reaching extremely high efficiencies and are one of the biggest cultural achievements ever. In both cases the efficiency, i.e. the relation between system input and output, are maximized and beat every other process or management (Faber et al., 1998). 
Here, the internalization challenge of underused energy resources in general and especially of the vastly underused renewable energies is analysed by the new concept of Sustained Renewability combining systems theory with Human Ecology and describing adequately the integrated holistic ecology like system parameters and strategies necessary. Therefore, fossil, renewable energy as well as grid and cloud IT resources (Foster \& Kesselmann, 2004), their exploitation networks and organizational exploitation structures are analysed generically in relation to their technical systemic challenge. To approach the internalization challenge of underused renewable resources, the novel generic notion of the Inverse Tragedy of the Commons, i.e. that resources are underused in contrast to their overexploitation, is introduced. It is combined with the challenges on the micro level of the individual with its security/risk/profit psychology (Egger, 2008) as well as on the macro level of autopoietic social subsystems (Egger, 1996; Luhmann, 2004, 2008; Maturana \& Varela, 1992). To derive points of action, the classical Human Ecology framework (Bruckmeier \& Serbser, 2008; Egger, 1996) will be extended to describe the interactions between invironment-individual-society-environment completely and then is combined with the systemic complexity challenge. This leads inevitably to the new concept of Sustained Renewability and defined point of actions. Thus, sustained systemic renewability of resources in general can be really reached and thus leaves at least on the human scale much room for advancement for a big part of our future.

\section{Fossil and renewable energy resources and their means of exploitation}

Energy is always bound to and thus stored in a state of matter and has to be extracted thereof and transformed into the corresponding form for a certain usage. Primarily the energy we have access to comes either from nuclear fusion as in our sun (heating and driving the atmosphere), from nuclear decay within earth (keeping a molten core, volcanism, plate tectonics), and from the gravitational fields of our planetary system (tidal changes). This primary access is far from endless or renewable: e.g. hydrogen fusion has been done $2 / 3$ already, i.e. only $\sim 2$ billion years are left for hydrogen fusion and thus already in $\sim 300$ million years the earth atmosphere will start to be heated up so much that life as one knows cannot exist anymore. Radioactive decay and the gravitational energy are also slowly used up. Consequently, the term renewable in that sense is only a relative terminology in respect to human time scales: Considering sun energy present for another 100 million years means $\sim 30$ million human generations or $\sim 30$ times the evolutionary development to homo sapiens. Nevertheless, on a human scale the term renewable thus really makes sense. In contrast, fossil energy resources (despite geogene gas and radioactives) consist mainly of organic substances produced through biogene conversion of sun energy by photosynthesis and their further transformation by geological process to coal, gas and oil. I.e. they are in principle a tertiary energy resource already. Due to the slow geogene processes and geological exploitation degree, the accessible size of these resources is fairly limited and especially concerning the human energy consumption very limited compared to the size of primary energy resources, their lasting and also not changeable natural production. Also the forms of energy which are termed renewables are in that sense secondary resources: i) sun energy is stored in photons, i.e. light, ii) wind energy is due to the sun energy transformed to heat creating atmospheric pressure imbalances, iii) hydro energy is due to water evaporation and gravitational lifting to higher altitudes and rain, iv) tidal energy is based on the earth-moon gravitational energy and stored in ocean movement, 
v) geothermal energy is heat from radioactive decay stored in the geosphere itself, and vi) biomass is sun energy transformed by photosynthesis into biological matter as e.g. wood.

\subsection{Renewable energy resources and their distributed exploitation}

Renewable energy resources are due to their primary and secondary origins in principle homogenously distributed in an extensive and variant mixture compared to the very localized fossil resources: i) sun energy depends mostly on the geographic altitude, ii) wind energy is strong at coasts, great plains or mountains, iii) hydro electric energy needs rain, mountains, or rivers, iv) tidal energy needs tidal differences, v) geothermal energy is best at geological active sites, and vi) biomass counts on a vivid agro- and forestry capability, i.e. thus fertile soils and water. Actually in biological terms the presence of ample energy resources at each location, which are available in principle everywhere and in principle exploitable similarly, are the deeper basis for the thriving of life, i.e. the success of evolution (neglecting now extreme life forms). Three different exploitation means of these renewables can be distinguished e.g. in electricity production: i) direct conversion of e.g. sun energy by photovoltaics or heat by thermotaics, ii) conversion of kinetic energy via a generator as for hydro, tidal, or wind power, and iii) chemical conversion into heat as for biomass or directly for geothermal power, then into kinetic energy before electricity generation. Consequently, to reach the highest exploitation and conversion efficiency it is obvious to use the local resource mixture according to the usage profile, and only transport the overproduction to where it currently might be needed or stored for local demand rich times, i.e. to secure supply for the peak demand. Thus, here also the most systemic integration, that means the best adaption to the local usage scenarios can be reached, since the conversion plants, i.e. photovoltaic modules, wind turbines, small hydroelectric plants etc. are relatively small in size and can be aggregated in the most modular and thus sensible way. Also the exploiters and/or producers are either the same as the users or at least very near to them, thus ownership and participation in the exploitation-transformation-usage cycle can be maximal.

\subsection{Fossil energy resources and their central exploitation}

In contrast, the fossil resources are highly localized due to their origin: coal, gas, oil and uranium deposits are regional and need with their decline increased exploitation efforts. Despite being a local resource in a globalized world they are transported to the power plants. Thus, local economic thriving depends on an efficient transport system. Fossil energy conversion is based on chemical (in the case of nuclear decay, physical) transformation into heat, which is then transformed into kinetic energy driving turbines connected to generators for electric energy. Whereas renewable conversion is high-tech, the latter is still based on the steam engine and the electric generator. The best efficiencies are reached for big plants or a systemic combination of electricity and heat. Thus, due to the size the transformed energy transport itself becomes a major challenge and cost factor due to the large losses involved. From evolutionary optimized biological systems it is known that their scaling and success is based on: i) the distribution system is fractal, ii) the transport loss is minimized, and iii) the smallest part of the transport system has the same minimum size. Unfortunately, for the modern distribution networks this is mostly due to redundancy issues not the case anymore. Due to the plant size and the transport issues, the investments are high and only doable by international private companies, with relatively low integration with the local usage structures or participation of the local users. Thus, the production and usage can hardly be 
integrated in a systemic manner anymore with high efficiency. Beyond, fossil resources have one big drawback: they produce waste, i.e. $\mathrm{CO}_{2}$ is the leftover, whereas renewables only convert the energy form but not a resource additionally to the energy form. Thus, in a limited world this unavoidable leads to pollution and thus e.g. climate challenge.

\section{Generic organization of the fossil and renewable energy sectors}

As described briefly before, there are huge renewable energy resources available, which are based on the earth own geological nuclear decay, the suns nuclear fusion energy reaching us as light, and planetary gravitation. Simultaneously, there is a great shortage of exploitable resources as constantly claimed by users and providers - similar to the IT sector. Consequently, this paradoxical situation must have a reason, despite even the relative slow turnover rates of technical solutions in the energy sector, which are $\sim 30-50$ years for a production facility and perhaps the double for a complete new technology generation, compared to the 3-5 year fast turnover rates for a full technology replacement cycle in the IT sector. Thus, comparing the production solutions and organization of fossil and renewable energy resources is important. Both are based on dedicated organizations which handle the technical as well as management challenges and posses the same fundamental organization principles similar to the IT sector: i) ownership and control, ii) size of plant, iii) diversity and distribution, iv) technological broadness, and v) spatial distribution. To understand further the challenges, which still exist despite the crucial longing for energy and IT, the main three different electricity production approaches in Germany are analysed:

The renewable energy sector has grown tremendously in Germany in the last 10-15 years mainly by guarantying a fixed price for the produced energy allowing return of investment of $\sim 6 \%$ per year over 20 years: Today $\sim 25,000$ wind turbines with $\sim 30 \mathrm{GW}$ peak performance and $\sim 800,000$ photovoltaic plants with $\sim 18$ GW peak performance of electricity deliver $\sim 7 \%$ and $\sim 3.5 \%$ of the German electricity consumption. Together with biogas and biofuel production, combined heat and electricity production $(\mathrm{KWK})$ and hydroelectric plants from lakes and rivers - each from some $\mathrm{kW}$ to some MW peak capacity - in total $~ 17 \%$ of the German electricity are now renewable and emission free. Whereas wind mills have a peak performance of $300 \mathrm{~kW}$ to 7.5 MW and are usually aggregated in parks of up to 50-100 mills, photovoltaic plants range from 1-2 kW to $\sim 30-50$ MW peak performance. Wind parks naturally reside in wind rich regions but are meanwhile spreading to the southern continental regions. Photovoltaic plants are installed throughout the country on the roofs of private households, government, or industry buildings. Bigger ones are also placed on farmland and conversion zones e.g. unused industrial estates. Investment costs range from some thousand Euros for a photovoltaic plant on a family home, some million for a medium sized windmill, to some hundred million for a big photovoltaic plant or wind park. Consequently, the production plants fit different business models and investor groups from the individual up to institutionalized funds. The electricity is mainly introduced into the grid and has priority by law over conventional electricity production. The electricity grid providers measure the production and the producers are monthly refunded by the local grid or electricity company. The grid belonged to the four big German electricity companies ENBW, EON, RWE, and Vattenfall until recently, but is now in other private hands. The free energy flow to the consumer - so called grid-neutrality - is guarantied by law. The price guaranty to the producer is shared by an addition to the bill of all electricity consumers in a social manner and often also sold as special green electricity product then by green energy sellers. Besides the knowledge gain in Germany and being the world 
leader in renewable energy facility production with $\sim 350,000$ employed people meanwhile, the resource, i.e. sun or wind, has not to be paid for, which leads to a big economic advantage. Due to the range of business models in principle everybody can be an electricity producer, which means a democratization of electricity or renewable energy production within society.

The public city producers, which often have been owned by the cities or regions especially in the past have a very conventional portfolio consisting of coal or gas power plants, which are sized to serve the local or regional electricity and sometimes thermal, i.e. heating, energy needs. Historically they developed when electricity and heat was starting to be needed by major parts of society, i.e. between 1850 and 1950. The electricity is put into the electricity grid, which has often belonged also to the public city producers. The distribution network for the heat, which is a byproduct of the conventional electricity production, has also been build up by them, since this was relatively easy to implement concerning the technical and organizational efforts for a well thermally isolated pipeline system underground from production to consumers throughout a city. Electricity, nevertheless, is mainly traded at the European Energy Exchange and production depends on the national demand price, which depends again on the coal, oil, and gas trading prices, i.e. depends on a European/worldwide market price and thus is a major part of the production costs. The local city producers are also the major seller for their electricity. Meanwhile, many of them possess also renewable energy production capabilities (photovoltaic plants or wind parks, usually regional), besides the classic hydroelectric production facilities at lakes and rivers, which again has regulatory reasons. Since they are connected to the regional government and thus are controlled by the local inhabitants they are relatively much bound into the regional development process as well and also impact the regional industry.

In contrast, the four large-scale producers of electricity in Germany - ENBW, EON, RWE, and Vattenfall, who are often termed the big "German Four" - are meanwhile world wide acting producers of mainly conventional coal, gas, oil, and also atomic electric power. Their plants have investment costs of billions and their regional placement depends besides the energy production process and consumption needs mostly on business and regulatory reasons. Thermal energy is only in some cases used locally for heating since the amount surpasses by far the local demand, thus the electricity, which is put to the electricity grid, is often internationally transported through the network to the consumer. The network for a long time mainly belonged also to them until recently, and had been bought from regional city producers over the years, thus the "German Four" controlled production and transport in a very monopolistic manner. Naturally, they also have to buy the energy resource and thus depend critically on the resource price of energy resources, although due to their size they are in the position to influence that by their large demand. In selling terms they are the big sellers of electricity and due to their market position (and especially while being owners of the distribution network) can influence the price to some extent to their gusto. That this is not excessively abused, the German government has implemented a regulation agency controlling their market and price models. Due to the unavoidable switch to renewables due to the climate challenge they also invest meanwhile into very large photovoltaic plants, wind parks especially offshore, and hydroelectrics - again based on their business model of large-scale with a monotechnic approach. According to their financial power they act such that their market position, i.e. their monopolistic centrality is hardly touchable and thus that they can control the heart of the electricity sector in Germany. The dependencies this creates and the risk for society is retrospectively also one reason for the huge success of renewables with their decentral relative small-scale and thus democratic production. 


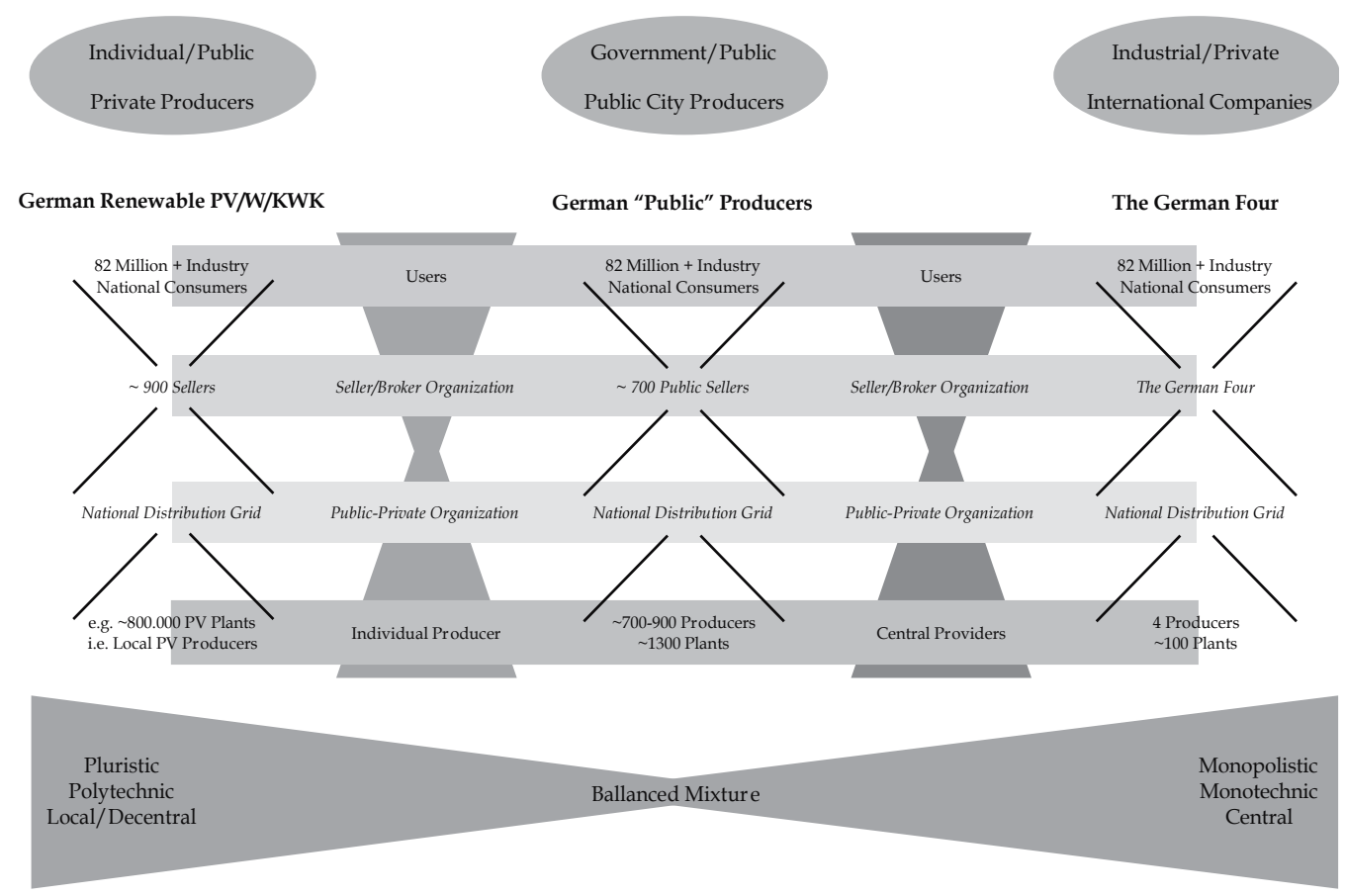

Fig. 1. Abstraction and detailed structure of the German electricity sector, showing three pillars and the four levels of infrastructures involved from production to usage. The three pillars are characterized by: i) individual/public "private" producers, ii) government/public city/regional producers, and the very few industrial privately owned international companies. All share four levels of infrastructure from production to usage: i) users, ii) seller organizations, iii) the semi-private, i.e. public-private network organizations, and iv) individual producers. The three pillars are already characterized by their means of energy production: i) renewable and small scale, ii) regional and medium sized, and iii) classic large scale fossil and atomic. Whereas the first can be characterized by pluristic, polytechnic local/decentral means, the last is characterized by monopolistic, monotechnic, and central terms. Although, the details may vary, the structure leads to similar challenges on the micro and macro level, which can be understood by the Human Ecology rectangle

Generalizing, the renewables obviously belong to the class of individual/public distributed producers with a pluristic, polytechnic and local/decentral approach, whereas the "German Four" large scale producers are clearly industrial/private with a monopolistic, monotechnic, and central attitude. The German government/public city producers are a mixture of both: government and public, not too pluristic, polytechnic, and local/decentral and neither industrial/private, nor monopolistic, monotechnic, and central. Consequently, this shows already the similar property and power structures in the energy and IT sectors. Especially the "German Four" show the similarity to the newest development concerning IT resources, i.e. clouds, with the same monopolistic structures etc. and blocking effects on development. The analysis of these and other such many an infrastructure shows that four levels of organization are involved also in energy producing and distributing organizations: i) users, 
ii) organizing broker organizations, iii) provider organizations, and iv) individual providers. In a more abstract form this shows that actually there are i) individuals and ii) societies of individuals, which are both involved on each of the four levels of organization, with a different degree of influence. Consequently, there is a micro level from which a macro level emerges, having again an influence on the micro level, i.e. that both levels are connected in a complex and cyclical manner as in any evolutionary evolving system. Thus, the micro level is constituted by an invironment and the macro level creates an environment. This will later constitute already the Human Ecology rectangle.

\section{Generic organization of grid and cloud IT infrastructures}

Obviously, there are also huge resources available in the IT sector - similar as in the renewable energy sector, although there is - at the same time - a shortage of resources as constantly claimed by users and providers. Consequently, this paradoxical situation must have again a reason and especially for the IT sector where the opportunities for technical solutions with fast turnover rates of 3-5 years for full technology replacement cycles are large compared to the $\sim 30-50$ years in the energy sector. Grid and cloud infrastructures are one solution to ease the resource shortage by more efficient usage of available resources and are based on dedicated organizations, which handle the technical as well as management challenges involved. They also posses the same fundamental organization principles and can be classified by the same characterization as already the energy sector: i) ownership and control, ii) size of grid/cloud, iii) diversity and distribution, iv) technological broadness, and v) spatial distribution. Thus, it is very interesting to see that despite the much higher turnover rates and the innovative potential of the IT sector in principle the same challenges exist as in the energy sector. Therefore, now two grid and one cloud infrastructure will be investigated in greater detail to show the similarities:

The Erasmus Computing Grid (ECG) is one of the largest desktop grids for the biomedical research and care sectors worldwide (de Zeeuw et al., 2007; Fig. 2). The computing cycles of the desktop computers of the Erasmus Medical Centre and the Hogeschool Rotterdam (the local University for Applied Sciences) are donated to the ECG. Technically, these cycles are exploited by the middleware CONDOR and a newly developed management system, which administrates on the one side all the computers in the grid as well as the users and on the other hand posses an easy accessible back-end/front-end system for usage. The latter is especially important for efficient use and security: The users only need to deliver their application, which then is implemented in a work flow scenario, thus the users for production only need to upload via a portal their new data and parameters for the analysis. The users are informed about status and final plausibility result checks. The rest is shielded for security reasons. Currently, the ECG has a capacity of $\sim 15$ Tera FLOPS already available for user applications (total existing capacity: 20,000 desktop PCs, 230,000 computing cores, $\sim 50$ Tera FLOPS). This corresponds to a $\sim 30 \mathrm{M} €$ investment. In absolute terms this is also one of the largest dedicated computer resources world wide available to users via a central entry port managed by the Erasmus Computing Grid Office (ECGO). The ECGO is the secretariat in front of the technical infrastructure, supporting users, technical maintainers of the desktops, and serves as the development hub for grid as well as special user wishes. The aim of the ECG is to serve the areas of research, education, and diagnostics according to the mission of the donating public organizations. Beyond, the aim is to develop the ECG as a general broker organization for computing resources also for industry and other sectors. 
Therefore, the ECG is also connected to other grid and cloud infrastructures and respective European initiatives as e.g. the German MediGRID/D-Grid initiative, the European EGEE and EDGES infrastructures and several other local resources.

MediGRID (Krefting, 2008; Sax, 2007, 2008) and its services branch Services@MediGRID operate the national German biomedical research and care grid and is one of $\sim 20$ community grids of the German nation wide D-Grid initiative. The resources are cluster computers, which are located and maintained at local universities. Their size varies from 16 CPUs with 2 or 4 computing cores each (i.e. 32-64 cores) to 2048 CPUs with 4 cores (i.e. 8192 cores). These resources run different middlewares and can be accessed by the users via a central access portal or a central access to the resources directly (Fig. 2). Here again the userfriendliness is of major importance to gain a broad group of especially noncomputing experts. Special security protocols allow data transfer between the clusters under high-security medical conditions. Thus, the German MediGRID is said to be one of the most advanced health grids in the world combining data storage, computing power and sharing of applications in an entire nation. To serve the aims of research, education, and diagnostics in the biomedical research and care sectors MediGRID is organized in different modules, which are distributed via different institutions throughout Germany and thus form a more or less decentral organization. Nevertheless, special services, business modules and strategies were developed within the Services@MediGRID project allowing the grouping into different service classes and thus to apply different business and accounting models to distribute and organize appropriate the usage of the grid most efficiently. This also includes the possibility for billing and thus in principle commercial usage. Since MediGRID is located in the national research arena the latter is currently mostly valuable for accounting within the research community to balance and monitor the money flow within German research.

The Amazon EC2 cloud favours now an even more concentrated production facility since it exists of a few data centres around the world with massive cluster computing capacity of hundred thousands of computing cores at one centre. The centres are localized according to environmental and business aspects, i.e. that cheap energy supply for cooling, operation, and local subsidies are the main location factor despite a high capacity connection to the rest of the internet. The administration is done centrally in each facility, with different operating systems available and generic portals for user access. The centres are shielded entities and guaranty maximum security despite the country and legal setting they are in. Due to the size, users have access to a free scaling system, for which they are billed per computing hour on different accounting and business models. Amazon also helps to develop together with users their solution of interest, however, focuses mostly on providing pure hardware, the operating system and the access to the resource.

Obviously, the ECG belongs to the class of individual/public desktop grids with a pluristic, polytechnic and local/decentral approach, whereas the Amazon EC2 cloud is clearly industrial/private with a monopolistic, monotechnic, and central attitude. The German MediGRID and thus D-GRID is a mixture of both: government and public, not too pluristic, polytechnic, and local/decentral and neither industrial/private, nor monopolistic, monotechnic, and central. Consequently, this shows similar property and power structures as in the energy sectors including the current phenomenon to set up overcome giant monopolistic structures in the new cloud infrastructures, which are blocking fast development towards new more efficient opportunities. Thus, generically 


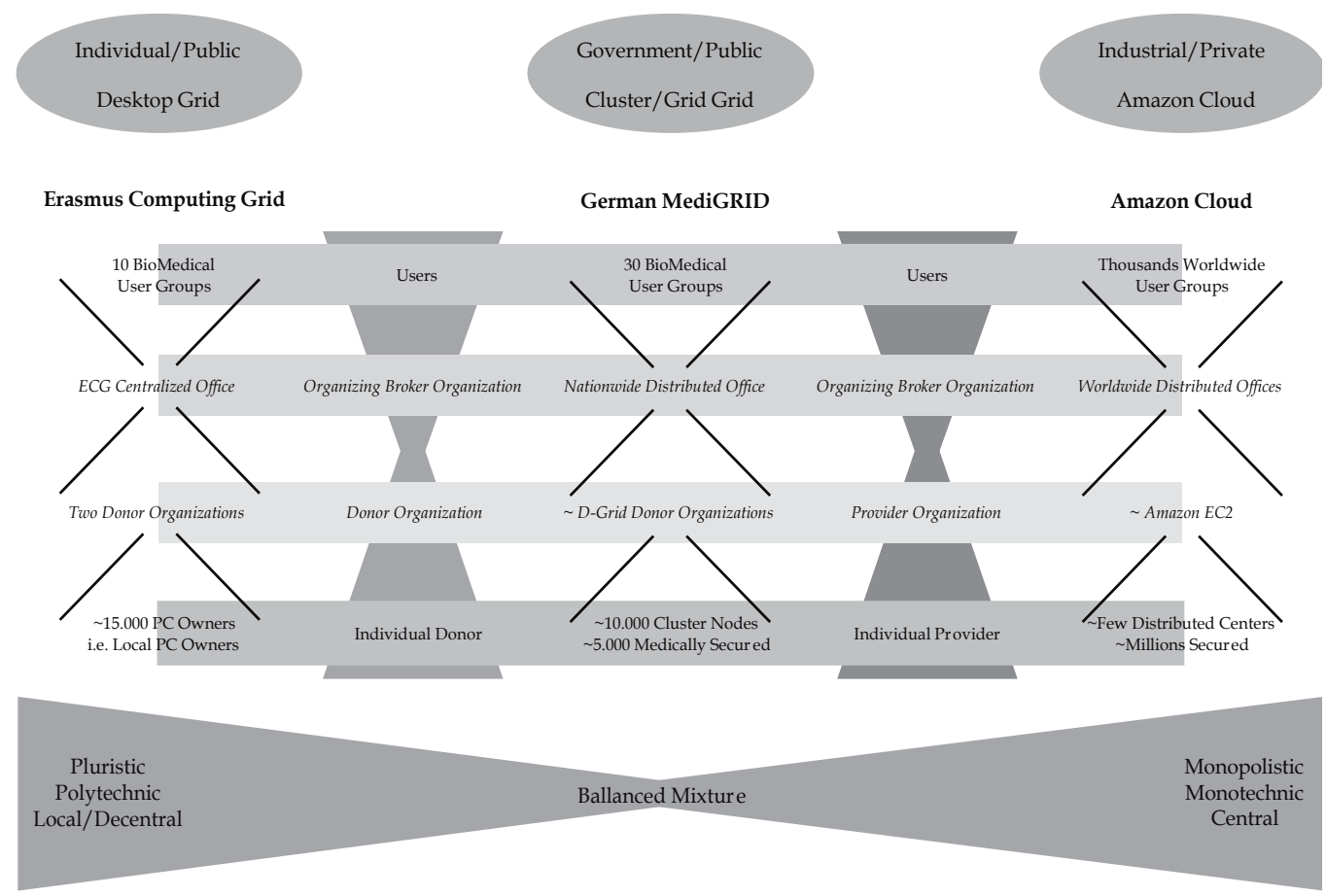

Fig. 2. Abstraction and detailed structure of the Erasmus Computing Grid, the German MediGRID, and the well known Amazon EC2 cloud. The three pillars are characterized by i) individual/public "private" grids, ii) government/public grids and iii) the very few industrial privately owned international clouds. Again all show the four levels involved in grid infrastructures: i) users, ii) organizing broker organizations, iii) donor organizations, and iv) individual donors. Again the three pillars are characterized by their means of capacity: i) small scale desktop and small mainframes, ii) regional and medium sized clusters, and iii) classic large scale cloud centres. And again whereas the first can be characterized by pluristic, polytechnic local/decentral means, the last is characterized by monopolistic, monotechnic and central terms. Although, the details may vary the structure leads to similar changes on the micro and macro level, which can be understood by the Human Ecology rectangle.

again four levels of organization are involved also in grid organizations: i) users, ii) organizing broker organizations, iii) donor organizations, and iv) individual donors. In a more abstract form this shows again that actually there are i) individuals and ii) societies of individuals, which are both involved on each of the organization levels, with a different degree of influence. Consequently, there is again a micro level from which a macro level emerges, with influence on the micro level, i.e. that both levels are connected in a complex and cyclical manner as in any evolutionary evolving system. Thus, the micro level is constituted by an invironment and the macro level creates an environment. This we will later see constitutes already again the Human Ecology rectangle as in the case of the energy sector. 


\section{Tragedy of the systemic complexity and the solution for a systemic sustained resource exploitation}

Primary energy or IT resource exploitation in reality involves a complex chain of events already on a technical level from the resource to usage, and involves e.g. resource i) acquisition, ii) basic exploitation, iii) storage and provision, iv) transformation to usable form, and v) transport to or access from users. Consequently, for a highly efficient exploitation of this chain, i.e. reaching a high efficiency from the primary resource to the end usage and thereby minimizing both the recyclable and unrecyclable losses, these five steps have to be optimized in a systemic manner to guaranty a careful exploitation of the primary resource. Optimization means here that not only the different steps are optimized within themselves but beyond, that the overall efficiency of the chain is optimized, since the optimum in on step of the chain might as a side effect reduce even the level of efficiency in another step or the rest of the chain far below the optima of these single steps and thus reduce the overall efficiency of the entire exploitation chain. Thus, the exploitation chain is already a complex system, where different parts influence all other parts.

It is obvious that usually the chain is seen mostly from each end, i.e. that the perception of the exploitation chain is either i) resource oriented or ii) usage oriented: i) it is easy to look only on the energy or IT resource and then think about its exploitation without looking at the usage, and ii) it is equally easy to take only the perspective of the usage and user and neglect the meaning for the primary resource exploitation. The first perspective is often taken e.g. in fossil energy business models where power plants have at the beginning been built near the coalmines. Equally, big hydroelectric dams can only been built locally whether there is a usage at hand or not. Often then potential users take the opportunity to move to that location. The second perspective, however, is often taken due to the low transport costs of fossil resources, i.e. coal is just transported around the world to the user. In contrast, renewable energy or grid IT approaches try to combine both perspectives: here first the two questions are asked at the same time: i) what demand exist locally, and ii) what resources are available locally? If availability and demand cannot be brought in agreement locally then the radius can be broadened from local to regional and so forth. In either case then the details of the different steps have to be questioned and the best mix of resources - if there are different ones - has to be considered, thus the whole exploitation chain can be optimized. This is, of course, a dynamic process, i.e. the optimized exploitation chain will most likely vary over time, i.e. that the time factor of a technology replacement or entire new introduction has also to be considered. In the case of renewables this involves less the primary resource, which is one of the biggest advantages of renewables and leads already to a sustained availability of the primary resource, which nevertheless is only one chain part.

The complex exploitation chain is, however, still a too simple rationalization, since the chain from the resource to usage involves on each of the five described technical levels again other chains of events, which need again various resources i) energy, ii) information, and iii) materials. Thus, respectively, the exploitation chain itself needs to exploit energy, information and material resources to exploit the resource of interest, as e.g. energy or IT resources. Consequently, this means that the exploitation chain is in reality a complex network of exploitation chains based on the availability of the same and other resources. And on these secondary levels again exploitation sub-chains exist and so forth and so forth... Thus, an exploitation network makes naturally the situation tremendously more complex then just a complex exploitation chain, not only because there are even more 
components to be considered, but mostly because the number of non-linear interactions of these components are even higher, more complex, and more dependent on each other. Especially the recursive dependence on the primary exploitation chain by the secondary, i.e. that also the secondary exploitation chains nested on each of the primary exploitation chain levels, need e.g. energy or IT resources to be able to function, is here of major importance in terms of complexity increase. The influence is now not only non-linear but also adds many an exponential interaction, which can in- or decrease the importance of a small tiny factor somewhere in the exploitation network enormously.

Beyond, an exploitation network connected to a specific e.g. energy or IT resource now involves many other resources, which have as well their limits and renewability aspects. Especially, material resources play here a fundamental role as - additional to energy and information resources - e.g. steel for the primary resource exploitation within machines and transport systems, rare metals for the transformation as e.g. metal catalysts or the dotation of the silicium in photovoltaic cells as well as copper for energy or information transmission or lithium for high capacity storage energy, to name only a few. Consequently, the whole resource and exploitation sector already on the technical level is a multi-recursive network of resources and their exploitations, where finally the single small component, its resources status, and renewability, might be as important as the major resource to be exploited. Nevertheless, there is a caveat in this on first sight depressing and seemingly unsolvable complexity. There is a natural hierarchy of the importance of and the amount of resources: If a resource is renewable or at least highly recyclable then these limits are tameable as well as in the case of resource replacement. Whereas for a fundamental resource like energy or information this can be tremendously difficult, for the materialistic part in exploitation networks that might in most cases be possible due to the fact that with the building box nature provides us in the many physical elements and thus the chemical products one can make thereof. So it is possible nowadays to replace steel by carbon fibre, i.e. heavy industry products by light chemical materials. The same holds for many components, although all follow again the resource limit, exploitation network, and renewable or recycling generic challenges as already discussed.

Consequently, for a highly efficient exploitation of such a complex systemic network, i.e. reaching a high efficiency from the primary resource to usage, all single steps have to be optimized in a systemic manner to guaranty a careful exploitation of the primary and all other involved resources. Actually the exploitation network becomes now also a general resource network. Thus, optimization means here that not only the different steps are optimized within themselves but beyond, that the overall efficiency of the entire network is optimized, since the optimum in one step might as a side effect reduce even the level of efficiency in another step or the rest of the network far below optima of these single steps and thus reduce the overall efficiency of the entire resource and exploitation network. Thus, the resource and exploitation network is already a hyper complex system, where different parts influence all other parts, which creates in principle what can be termed the Tragedy of Systemic Complexity:

\section{The Tragedy of the Systemic Complexity:}

Resource exploitation is a complex systemic network with a huge number of technical components and beyond huge exponential non-linear interactions between these components, thus highest efficiency can only be achieved by a systemic optimization with contradictions appearing on the level of single components

leading to huge individual and social paradoxical challenges of perceptions and understandings. 
This now has huge consequences for the implementation of a highly systemic exploitation network by individuals and society, since now all individual components have to be optimized themselves with respect to all other components and the complete complex hyper systemic exploitation network. Therefore, the classic reductionistic approach is unavoidable as long as it finally ends in a holistically reintegrated systemic result. Consequently, for a highly efficient energy and IT resource exploitation this is the vital core to Sustained Renewability, since only then also primary renewable resources are not compromised by the limits in the complex resource and exploitation network and since only then enough resources will on human time scales always be available to exploit this primary resource and thus sustain its exploitation and usage for again on human time scales indefinite time. Thus, the technical level requires a holistic systemic approach for Sustained Renewability.

\section{The inverse tragedy of the commons in the renewable energy and grid IT sectors}

Analysing both the energy and IT resources, their means of exploitation and usage scenarios in a systemic manner, clearly shows beyond a pure estimate of scale, that obviously there are affluent resources and also solutions for their efficient exploitation available. The Tragedy of the Systemic Complexity thereby shows that already the pure technical means in the entire chain from the resource to usage has to be taken special care of, since otherwise the loses are far too big, i.e. the efficiency is far too low. E.g. considering overall efficiencies below $1 \%$ would mean that a system of resources would be 100 times faster depleted than in the, of course, impossible case of $100 \%$ efficiency. Again it should be stressed that this must include beyond the basic energy or IT resource themselves, their entire exploitation chain and thus the resources needed for this exploitation as well. Renewables and grid are means of doing that in a very sophisticated manner at least to a larger extent then the classic large-scale power plants, computing centres, or cloud infrastructures. Thus, the fundamental basis for Sustained Renewability means solving the technical systemic complexity in a productive manner, i.e. the technical chain from the resource to usage must be exploited in a systemic manner already on the pure technical level. Without such a systemic approach for resource exploitation, no Sustained Renewability can be reached. Thus also all the limits have to be considered in the entire exploitation network, since even if there is a huge resource their might be a tiny but nevertheless bottleneck within a resource network as e.g. a rare metal or substance which is crucially needed somewhere in a corner of the exploitation network. Nevertheless, exploiting the renewable energy or IT resources in a systemic approach purely technical, i.e. by integrated holistic ecology like systems e.g. by using the renewable resource or sharing the available IT infrastructure, seems hard since both renewable energy and grid infrastructures slowly emerge, which is due to their importance and especially in the IT sector with its great opportunities and fast turnover rates, paradoxical.

The analysis of energy and grid organizations showed already generically that there is a micro level from which a macro level emerges. Actually, the organizational chain suggests that this is true for every resource exploitation network and thus is its fundamental cultural root, especially if the resources, which are to be exploited, are part of the commons as the renewable energy (i.e. in the climate change dilemma) or IT resources (i.e. the dilemma of e.g. to little information transforming capacities) in principle are. Both this micro and macro level now wraps the technical exploitation into the dialectics from invironment to environment. In the case of over-exploitation of common resources, the exactly same 
complex interplay between the individual and the society as well as the invironment and the environment appears. This his is well known as the so called Classic Tragedy of the Commons (Hardin, 1968, 1994, 1998; Ostrom, 1990; IASC; Commons), in which (multiple) independently acting individuals due to their own self-interest can ultimately destroy a shared limited resource even though it is clear that it is not in the long term interest of the local community and society as a whole. The phenomenon in principle is nothing new and appears already in ancient myth and religions, since it concerns the basis of life, i.e. the usage of resources in general and in particular that of energy and food. The violation of the carrying capacity, the theft of resources connected with the decline or death of those who lose their resource basis, and the squandering of resources are deeply integrated in all cultures reaching the level of archetypical traits. E.g. the Irish measure for the size of a piece of land in callop's describes the size in terms of the carrying capacity for different animals: the same sized piece of land, i.e. e.g. one callop might be 10 cows, 12 horses, or 40 sheep. In the case of under exploited resources there seems to be the same phenomenology of the Classic Tragedy of the Commons challenge put forward. This phenomenon is now theoretically defined - as a logical consequence - as the Inverse Tragedy of the Commons (Fig. 3):

The (Classic) Tragedy of the Commons:

A resource belonging to all and being on limited demand is

OVEREXPLOITED by the user due to responsibility diffusion!

$$
<=>\text { TRANSFORMATION }<=>
$$

:The INVERSE Tragedy of the Commons

A resource belonging to all and being in affluent availability on limited demand is UNDEREXPLOITEDby potential users due to responsibility diffusion!

Interestingly, not only is responsibility diffusion the most likely and general reason for the appearance of both tragedies, but also the psychological description for both the micro and the macro level hits the same archetypical traits (Fig. 3) as mentioned above. Whereas the Classic Tragedy of the Commons corresponds to i) indifferent hedonists, ii) careless players, and iii) the chronic overstrained, the Inverse Tragedy of the Commons corresponds to i) hedonists, ii) the cool calculating, and iii) the tragic hopeless. The under-used potentials, i.e. the general basis (matter, energy, information, biological, psychological, and societal level) and over-used resources (materials, reservoirs, memes, organisms, behaviours, cultures), clearly show how from a virgin resource opportunity, concrete objects emerge with their attached limitation burden (Fig. 3). Nevertheless, they all cluster around a systemic technical development. Thus, the complex field created, describes exactly the tension found in resource limitation phenomena and evolutionary emergence.

Consequently, it becomes now also clear what constitutes the micro and macro levels: on the micro-social level the systemic and the open sharing attitude of the individual play the key roles, whereas on the macro-social level the organization culture of the embedding institutions and in the end society as a whole as well as its cultures are the central points. I.e. that beyond the technical implementation of an exploitation network in a systemic technical manner, but nevertheless still technically focused approach, the individual and society with their invironment and environment they consist of and create respectively, need to be considered as the crucial to be investigated fields to understand why still with even a systemic technical exploitation scheme with highest efficiencies existing, even the best solved Tragedy of Systemic Complexity is not implemented (not to speak of the development 


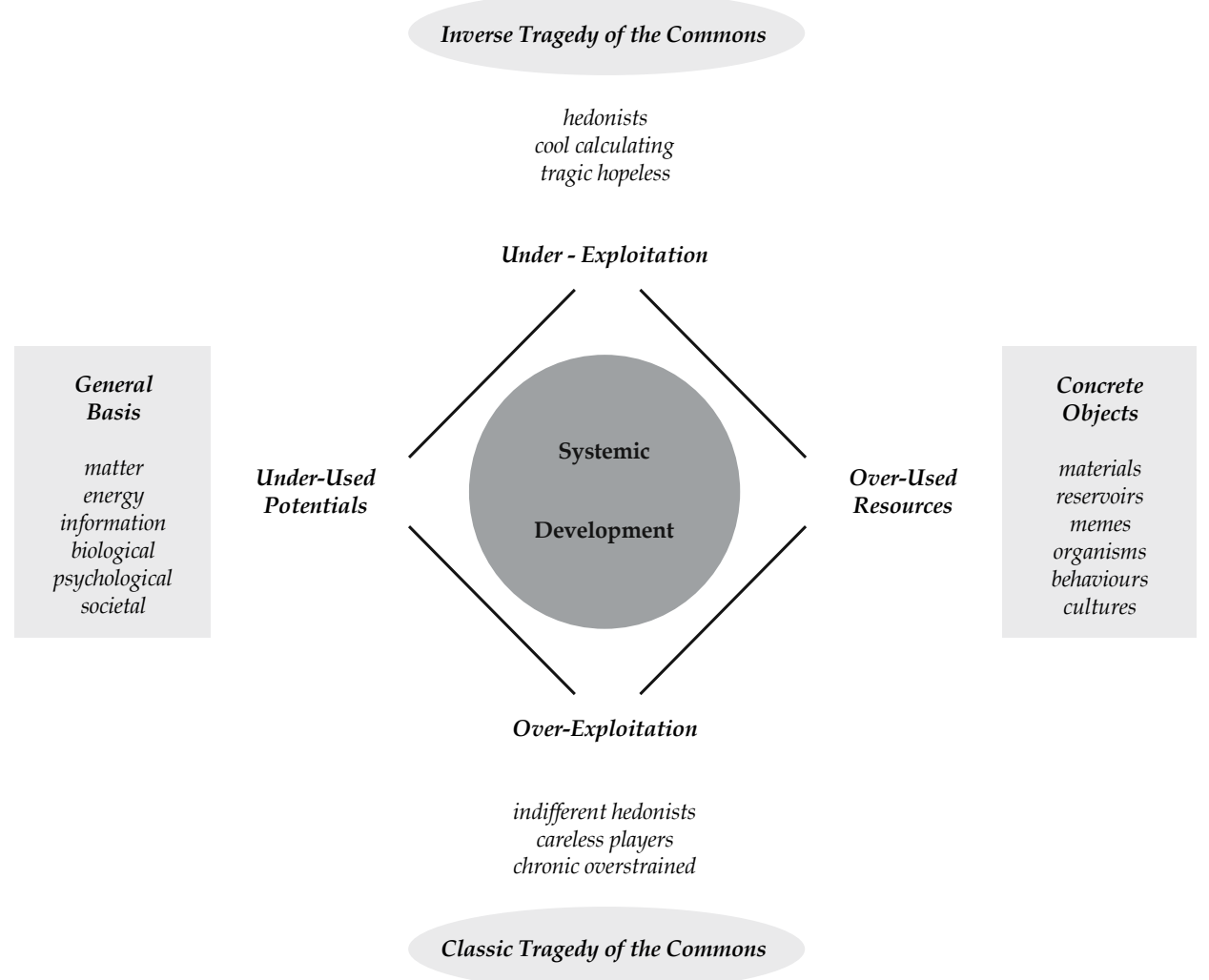

Fig. 3. Generalization of the Inverse Tragedy of the Commons: the Classic and Inverse Tragedy of the Commons are directly complementary to each other and can on the deep psychology level be associated with complementary pears of archetypical behavioural traits. This is in line with the complementary under-used potentials and over-used resources, which emerge from the potentials by freezing of potentials into concrete objects with corresponding limits. Both correspond to the general basis and concrete objects. Whereas the Classic Tragedy of the Commons corresponds to i) indifferent hedonists, ii) careless players, and iii) the chronic overstrained, the Inverse Tragedy of the Commons corresponds to i) hedonists, ii) the cool calculating, and iii) the tragic hopeless. All cluster around a systemic technical development as the technical core.

of a solution for the Tragedy of Systemic Complexity). Thus, the system of i) technical system, ii) micro level, and iii) macro level has now to be investigated as a system in a holistic systemic manner itself. Therefore, pinpointing the phenomenon of under exploited potentials to the same phenomenological root as the well known phenomenon of over exploited resources opens now the complete opportunities and tool set to examine the challenge of introducing a Sustained Renewability approach into practice (as e.g. in the renewable energy or grid IT sectors) as well as its principle day-to-day management. Thus, practical implications can be derived from an analysis of the micro and macro levels, which then have to be embedded in a systemic manner and approached on a theoretic level. Appliance of this concept with practical guidelines, the implementation of Sustained Renewability practically, can be realized in principle for every resource management sector. 


\section{The tragedy of autopoietic social subsystems}

The challenge to integrate exploitation measures of energy or IT resources, which follow technically a systemic approach and thus beat the Tragedy of Systemic Complexity, into society involves naturally all stakeholders of society (Fig. 1, 2). The existence of a Tragedy of Systemic Complexity and an Inverse Tragedy of the Commons and its macro social aspects, point to the major importance of the interaction complexity of the social subsystems theory by Niklas Luhmann (Luhmann, 2004, 2008), i.e. a systemic approach analysing and describing the social system and the subsystems it consists of: It is based on the autopoietic concept of Humberto Maturana and Francisco Varela (Maturana \& Varela, 1992), and is the most advanced social systems theory, describing the huge complexity of the macro sociality of the renewable energy as well as grid IT phenomenon. An autopoietic system is a network of processes consisting of: i) interactions and transformations continuously regenerating and realizing its networks of existence, and ii) the constitution of the system as a unity in space in which the component exist by specifying the topological domain of its realization. Central to this description of evolutionary emergence, i.e. self-reproducing systems, is the material and information exchange between the components. Social systems are obviously communication systems, with society being the most encompassing one. Immediately that makes clear what challenge that suggests: what are the social systems, is there more than one, if so how do they interact, and most importantly who can they act together in a systemic manner to achieve a goal which is either emerging from one system internally or introduced from the outside. Consequently, many of the conundrums appearing during the society internalization become evident and are in agreement with the Tragedy of Systemic Complexity and the Inverse Tragedy of the Renewable and Grid Commons:

Around seven social subsystems can be defined and reflect the evolutionary emergence from deep psychology to society (Luhmann, 2008): i) religion, ii) education, iii) science, iv) art, v) economy, vi) jurisdiction, and vii) policy. All of these systems have their internal code of communication and their own connectivity interface to the other subsystems. Thus, the Tragedy of Systemic Complexity struck now in principle again, although this time on a social level, which results in huge barriers: e.g. the religious code of believe or notbelieve is incompatible with the have or not have money code of the economic sector. This is even truer for science (true vs. non-true), jurisdiction (just vs. un-just) and politics (power vs. no-power), which have nothing to do with education (knowledge vs. noknowledge). Renewable energy exploitation belongs to several subsystems, mainly those of science and economy in contrast to grid IT infrastructures, which belong currently mostly to the academic sector (de Zeeuw et al., 2007; Krefting et al. 2008; Sax et al., 2007, 2008). Despite the success of both renewable energy exploitation approaches as well as the widespread usage of grid IT infrastructures within society, the broad rollout, i.e. the internalization of systemic approaches into society, is decelerated by the lack of interoperability between these subsystems. Consequently, the Inverse Tragedy of the Commons results in

\section{The Tragedy of Autopoietic Social Subsystems:}

Subsystems have their own code of communication and are separated from each other in a way blocking in principle a consistent integration although they form a society, with all their contradictions, which thus leads to blockage of the system. 
This macro level tragedy clarifies that renewable energy and grid IT organizations are just another example for complex infrastructures whose efficiency increase depends beyond more or less complex technical solutions on the participation of all subsystems concerning their societal internalization. In detail this means that each of those social subsystems must be analysed according to their internal constituents in respect towards the implementation of a systemic approach in respect to the status quo as well as to the ability to react to an until then not used or entire novel systemic approach. Thus, it might be, that such a systemic approach might not at all be implementable within such a subsystem at first, that major transformation need to be made, or that in the best case already existing structures can be used. The same holds for the communication between the subsystems, since here different internal preparedness levels might either ease or worse the communication in respect to such an implementation. Consequently, the challenge of implementation of Sustained Renewability approaches into society involves again two levels: On the micro level of individual subsystems the move towards implementation depends on the subsystem "stickiness" of individuals. On the macro subsystem level the integration of institutionalized subsystems via soft interfaces, which allow the communication barriers to be lowered, is central. Both has to be taken care of since this is given beyond the systemic pathways within the subsystem and the setting how subsystems can be moved or interact with others.

The acceptance of this is an important knowledge opening huge opportunities to examine and approach the challenge of introducing renewables or grids and their management. Beyond, this clarifies the challenges in all other exploitation sectors (probably residing in other subsystems) since all subsystems should always be involved. Thus, the Tragedy of the Systemic Complexity in terms of systemic integration into society can be understood and has to be taken into account. Beyond, the Classic and Inverse Tragedy of the Commons are a societal challenge with the opportunity to be resolved, if as well the technical systemic approach is combined on the social system level in a sustainable systemic manner.

\section{The tragedy of security/risk/profit psychology}

Since the macro level of social subsystems emerges evolutionarily from the micro level (Egger, 2008), one needs to consider the individual for whom each implementation and internalization of a new technology is based on a positive relation between the risk and the profit involved from the perspective of the individual. This is the core of any action a human individual takes and defines the degree of motivation a person commits to an action, i.e. the change of something in contrast to doing nothing. Thus, the level of altruism leading to successful implementation as in the renewable energy case or the sharing in the grid IT case on the individual level and its commitment beyond its own job/agenda, as well as that of its own institution without incentive structure to take responsibilities, is essential and leads to responsibility diffusion: Even the obvious winwin situation renewables like photovoltaic on the roof, or small hydroelectrics on the grounds of an individual, are hard to communicate and even the clear effects of producing with no energy resource costs the own energy result in slow implementation of renewables compared to the benefits and the climate issue at face. Even more so, the clear win-win situations for individual grid users are under these circumstances hard to communicate and even the additional networking effects result hardly in the set-up or usage of grids. It is also unlikely that people take the risk to exceed their own budget and corresponding responsibilities, when future results and its benefits are unclear to them. 
As long as exploiting the renewable energy resources or sharing in the grid IT sector is voluntary and in hand with uncertainty and risks, it is less likely that individuals will behave altruistically on behalf the societal benefit. Consequently, on the micro level the situation is that of a perverse Inverse Tragedy of the Commons: the commons is not abused or overexploited, but in contrast the tremendous resources are not used at all despite the needs and obvious benefits, due to secondary (mostly "irrational") interests.

Thus, the integration challenge involves the individual of the different institutionalized society stakeholders in a very deep way since these individuals shape the individual actions according to their function in a social subsystem. How an individual perceives the security/risk/profit ratio depends on its personal security/risk/profit psychology matrix:

Deep Psychology Security/Risk/Profit Cascade:

emotional individual $s / r / p$ perception

rational $\mathrm{s} / \mathrm{r} / \mathrm{p}$ knowledge acceptance

internalized incidental $s / r / p$ behaviour

accepted legal and political $s / r / p$ scenarios

lived religious and cultural $\mathrm{s} / \mathrm{r} / \mathrm{p}$ archetypi
:Autopoietic Subsystem Correspondence

genetics and deep psychology education and science economics

jurisdiction and politics religion, art and culture

Thus, this matrix describes a similar challenge on the micro level similar to the macro level with conflicting personal positions and internal balancing the invironment with the environment. This creates on the micro level again a tragedy:

The Tragedy of Security/Risk/Profit Psychology:

Individuals balance constantly a complex combination of invironmental and environmental security/risk/profit deep psychology factors, whose contradictions lead to responsibility diffusion.

In detail this means that each of those levels need to be considered especially from key individuals, i.e. of those, who hold important positions within social subsystems, to just the collective invironment of an entire population. And again this poses two obvious challenges in a systematic concept: on the micro level, the risk perception and the emotional well-being of the individual has to be considered, whereas on the macro level, the risk perception in the procedural and institutionalization in organizations have to be considered, i.e. the interaction of the individual with the organization it is working in. Thus, it might be that such a systemic approach might not at all be implementable with certain individuals or collective emotions in place at first, that major transformations need to be made, or that in the best case already existing structures can be used. Unfortunately, the identification and analysis of this tragedy is by far more challenging in every respect and especially concerning management guidelines, due to the hardly changeable basis, due to its genetic and evolutionary basis and the time scales involved to change archetypical societal concepts, in contrast to the macro level, where bypassing measures and changes can in principle be implemented at will, i.e. major screws can be relatively easy adjusted by order with or without societal participation and/or agreement. Consequently, this tragedy has to be tackled with big care and shows that the Tragedy of Systemic Complexity as well as that of the Inverse Tragedy of the Commons can really be addressed by a Human Ecology rectangle approach integrating the different tragedies in a systemic manner and thus to reach systemic renewability by such super-systemic approach, as will be shown in the following. 


\section{Human ecology for a sustained renewable energy and grid IT resource network exploitation}

To overcome the Tragedy of Systems Complexity and the Inverse Tragedy of the Commons together with the base tragedies of the latter, the Tragedy of Autopoietic Social Subsystems as well as the Tragedy of Security/Risk/Profit Psychology in the renewable energy and grid IT sectors a systemic approach on the technical level combined with an approach to tackle the micro and macro social levels is crucial to reach Sustained Renewability in these and in principle generically any exploitation sector. The basis of all these is the level of complexity in the corresponding areas leading to the heart of the matter - responsibility diffusion. For this the inter- and transdisciplinary field of Human Ecology (Egger, 1992, 1996, 2004; Bruckmeier \& Serbser, 2008) gives a framework for their combination, followed by understanding and approaching direct guidelines for the management of renewable energy and grid IT resources. I.e. Human Ecology embeds the technical systemic solutions with a systemic approach on the micro and macro level of societies. Human Ecology was developed originally by Robert Park (1864-1944) and Ernest Burgess (1886-1966) and evolved in Chicago in the 1920's in close connection to the field of city development. Here complex questions and challenges arose, ranging from e.g. i) fundamental technical questions of how to structure a city in terms of spatial use, transport of the basic supplies as energy and water, and the removal of waste, ii) of how to structure and organize social needs from governmental services and schools to commercial shopping malls to economic entities for production, as well as iii) cultural issues as how to plan a modern human city which allows everybody to achieve a fair share of the pursuit of happiness, whether one belonged to the poor or the wealthy part of society. By analysing the different stakeholders playing the fundamental roles there, the complex system challenges appearing were abstracted on the social level, since this was seen as the main issue of the - at that time - not yet in detail defined and worked out Tragedy of the Commons. Thus, Human Ecology classically deals with the complex interplay between i) the individual, ii) the society, and iii) the environment, which usually is symbolized in the so called Human Ecology triangle. This triangle is the paper tool representation and believed to be the core of the complex interplay factors in society. The framework has been used to investigate many a complex mankind related challenges as e.g. the exponential demand growth until reaching a limit, its inherent property of life and evolution, as well as waste and pollution related issues, i.e. in principle all the above mentioned tragedies. Obviously, these sustainability questions beyond the materialistic world are found on all evolutionary levels up to the psychological, societal and cultural one and involve also every cause for exponential growth, which is the major reason for reaching the natural unchangeable and thus unavoidable limits extremely fast.

Already, the Tragedy of the Systemic Complexity on the technical level shows that this rationalization and projection to three major constituents needs at least to be extended by a systemic approach on the technical level or better, the technical systemic approach must be embedded within the triangle. Beyond, the detailed analysis of the generic organization of the fossil and renewable energy as well as grid and cloud IT infrastructures proposed a micro and a macro level. Thus additionally, the detailed dissection of the Inverse Tragedy of the Commons by investigating the Tragedy of Autopoietic Social Subsystems and the Tragedy of Security/Risk/Profit Psychology, proposes the extension of the classical Human Ecology triangle to a rectangle consisting of: i) invironment, ii) individual, iii) society, and iv) environment 
(Fig. 4). Consequently, here the invironment is added, since it is the core on which the individual is based or in other terms, due to the presence of the irrational part of the individual in respect to its security/risk/profit psychology, the latter can also be accounted for. Thus, the Human Ecology rectangle describes the relation between the invironment (Innenwelt), the individual, the society and the environment (Umwelt). The invironment and the environment as well as the individual and the society are complementary pairs and create a field. The invironment thereby constitutes the Innenwelt, the individual forms society, the individual society creates an environment as the invironment constitutes much of the society. And consequently, the rectangle reflects the micro level (invironment and individual) and the macro level (society and environment) correctly, or in retrospect the micro and macro level constitute each half of the Human Ecology rectangle. This fits the field of the Classic and Inverse Tragedy of the Commons, with its under-used potentials and overused resources, i.e. means that both can be correspondingly overlaid and connections can be made accordingly. Consequently, the invironment is the missing link to reach systemic completeness of Human Ecology, and thus round it up to its full power in terms of usability concerning the management of systemic challenges as put forward by the renewable and grid IT challenges on a practical level. That means that the Tragedy of Autopoietic Social Subsystems as well as the Tragedy of Security/Risk/Profit Psychology which are the heart of the Classic and Inverse Tragedy of the Commons can not only be wrapped in a systemic framework which is complete in its constituents, but moreover, that this framework now can be really applied to the solution of the Classic and Inverse Tragedy of the Commons much better then with the Human Ecology triangle alone. This is important since without such a systemic framework and the internalized knowledge always perceived paradoxes will appear, which cannot be understood and thus cannot be resolved adequately on the level required. To reach its full power also in respect to the Tragedy of the Systemic Complexity on the technical level, additionally, now this needs to be extended again by a systemic approach on the technical level or better, the systemic approach must be embedded within the rectangle again, since without this technical level the complete system of technology, micro and macro level would again be not complete. Now this means nothing else than that the complete system of technical development and implementation has to be considered as well as the security/risk/profit psychology of the individual with its invironment and the autopoietic subsystem organization of society with its environment. On first sight this insight to take a holistic viewpoint and make that the basis for solving the issues involved with the renewable energy, grid IT or any other complex exploitation network seems natural and in principle is completely obvious - actually not even be worth thinking about. However, the fundamental issues and challenges faced in exploitation networks to be implemented to reach Sustained Renewability, i.e. to solve the problems of resource network limitations and thus to overcome the fundamental limits of energetic and material consumption growth reaching carrying capacity limits by the classic approach, are obviously there and demand urgent solutions in respect to the urge of the problems involved if nothing substantial is changed. Thus, the pure existence of the climate challenge shows the importance of a Sustained Renewability approach which overcomes the technical Tragedy of Systemic Complexity and the Inverse Tragedy of the Commons, in which resources are not unsustainably overexploited but in contrast used in a Sustained Renewability way holistically integrating the i) technical resource exploitation networks and ii) all the autopoietic social subsystems on a macro level as well as the psychology of individuals on the micro level, in an holistically 


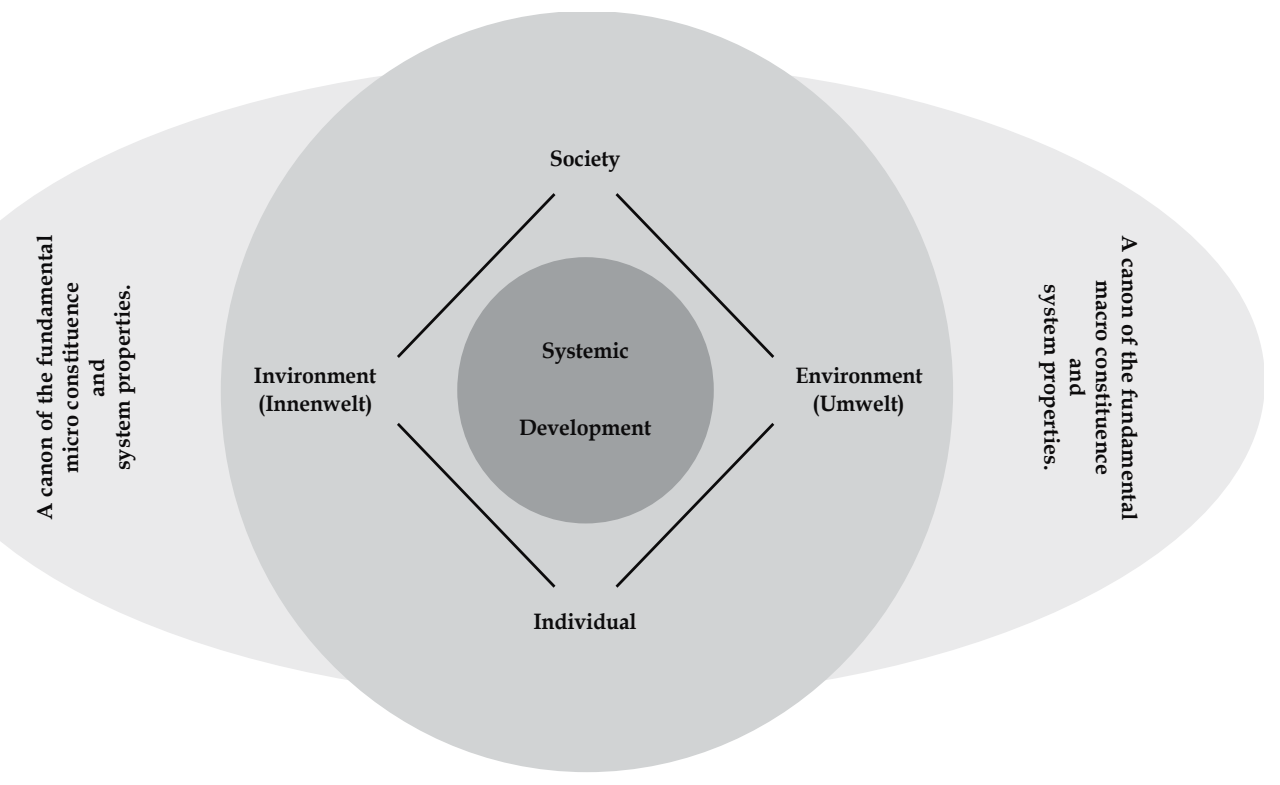

Fig. 4. The Human Ecology rectangle describes the relation between the invironment (Innenwelt), the individual, the society, and the environment (Umwelt). It is the extension of the incomplete classical Human Ecology triangle, which consists only of the individual, the society, and the environment but not the invironment. The invironment and the environment as well as the individual and the society are complementary pairs spanning a field between them. The invironment thereby constitutes the Innenwelt, the individual forms society, to the individual society gets a general environment as the invironment constitutes much of the society. Within the rectangle on each level the systemic aspects of each system and development thereof need to be encountered. To handle the invironment and the environment a canon of their micro and macro constituents and system properties is necessary.

systemic ecology like manner. Consequently, Sustained Renewability can be fundamentally defined according to the most fundamental and classic definition of the classic (biogene) ecology (Haeckel, 1866, 1898; Knoch, 2009, 2010): 
The Definition of Sustained Renewability and thus the Combination of Technical Systemic Theory with Human Ecology:

"Under Sustained Renewability, i.e. Technical Systemic Human Ecology, we understand the complete science of the relationships of Sustained Renewability to the surrounding environment to

which we can count all conditions of existence in the widest sense."

(Sustained Renewability is)... the relationship between the technical system complexity and all micro/macro constituents of Human Ecology."

\section{Sustained renewability by systemic theory and human ecology means}

Without doubt both the growth of the world population and the ever-new technologies emerging from $R \& D$ - both creating ever higher needs as well as expectations - also the energy and information amount to be acquired, stored, transformed, and finally used is exponentially growing and due to the classic reductionist approach reaching the fundamental limits and due to pollution also the carrying capacity of earth. Nevertheless, it is also obvious that there are huge renewable energy and grid IT resources available as in most other resource networks, concerning technical production or any social level. This results in many opportunities of which most, however, are not realized, i.e. introduced and internalized into society. In contrast, ever more resources are said to be required but believed to be at their limit and thus already unavailable for further exploitation. Especially in the energy and IT sector the demand still grows exponentially and is satisfied still with antiquated solutions. Although exponential growth inevitably will lead to limits sooner or later, there seems to be also many an opportunity to sustainably manage resources on very long time scales. Thus, clever resource management can increase the efficiency tremendously and in consequence avoid limiting barriers as e.g. integrated chemical production or sophisticated agro-forestry systems show. Renewable energy and grid IT infrastructures are believed to be such solutions which exploit under-used and available resources by a Systemic Renewability approach, which in principle is based on a simple holistic systemic analysis of the technical systemic complexity combined with a Human Ecology approach. Both have in common that their technological turnover rates are faster than in classic dinosaur approaches, although especially the grid IT sector with its fast technological turnover rates, however, allows to bring innovation opportunities very fast to the market and thereby increase the efficiency from the resource to usage tremendously. This could results on the one hand in lower investments into infrastructure, which obviously would provoke large resistance by the producing industry, or on the other hand results in a much higher output and thus return of investment made by society in these infrastructures, which would give a big "present" with only minor further investment to society as a whole. Nevertheless, it remains a big issue despite all the efforts of the renewable, the grid IT, and any other resource exploitation sector, why the obvious huge benefits of much higher resource exploitation network efficiencies is so hard to internalize into societies despite its crystal clear benefits concerning the fundamental limits of resource exploitation, carrying capacities as well as economic, social and cultural benefits already in the short but even much more so in the long term.

The Tragedy of the Systemic Complexity shows already what complex exploitation networks mean, since in reality a complex network of resources and exploitation based on the availability of the same and other resources exist instead of a nevertheless complex 
exploitation chain. Thus, an exploitation network makes naturally the situation tremendously more complex than just a complex exploitation chain due to the number of i) non-linear, ii) nested, and thus in the end iii) exponentially recursively linked interactions of these components since they are even higher, more complex, and more dependent on each other. Especially the recursive dependence on the primary exploitation chain by the secondary, i.e. that also the secondary exploitation chains nested on each of the primary exploitation chain levels need e.g. energy or IT resources to be able to function, is here the main driver of complexity increase. The influence is now not only non-linear but also adds many an exponential interaction, which can in- or decrease the importance of a small tiny factor somewhere in the exploitation network enormously. Consequently, for a highly efficient exploitation of such networks, all single steps have to be optimized in a systemic manner to guaranty a careful exploitation of the primary and all other involved resources. Actually the exploitation network becomes now also a general resource network. This has huge consequences for the implementation of a highly systemic exploitation network by individuals and society, since all individual components have to be optimized themselves with respect to all other components as well as the complete complex hyper systemic exploitation network. Therefore, the classic reductionistic approach is unavoidable as long as it finally ends in a holistically reintegrated systemic result. Consequently, for a highly efficient energy and IT resource exploitation this is the vital core of Sustained Renewability, since only then also primary renewable resources are not compromised by the limits and since only then enough resources will be - on human time scales - always be available to exploit this primary resource and thus sustain its exploitation. Thus, the technical level requires a holistic systemic approach for Sustained Renewability.

Beyond, the organizational architecture analysis of renewable energy and grid IT infrastructures as well as their management shows that there are four levels of stake-holders involved: i) users, ii) organizing broker organizations, iii) producer or provider organizations, and iv) individual producers or providers. That is a much more complicated than the integrated production in chemical industry, since here one has a large spatial and cultural coverage in contrast to the "internal" situation of one single company. There is also a big difference to sophisticated agro-forestry systems as e.g. those in Indonesia, since these systems had a huge temporal time span for development. Although they involve in principle the entire society, the decisions are still taken by the single farmer and community despite their a posteriori internalization in tradition and cultural rules. Abstraction of the four levels involved in grid infrastructures leads to a micro level from which a macro level emerges, having again an influence on the micro level and vice versa. The micro level is constituted by an invironment and the macro level creates an environment, which already constitutes the Human Ecology rectangle as was shown. Consequently, here from the pure theoretical viewpoint not only complete consistency was reached proving the validity of the arguments, but also access to a "tool box" was gained to be used successfully for complex internalization issues. This is important for generalization and for justification of the thereof derived management measures. Beyond, the fact that renewable and grid IT resources are completely underused attributes to the phenomenon of the Inverse Tragedy of the Commons, i.e. that the resources are not overexploited unsustainably until their destruction. Together with the finding of the micro and macro level in the organization of grid organizations which plays the important role in both the Classic and Inverse Tragedy of the Commons lead to 
responsibility diffusion and thus inefficient resource management. This, consequently, makes clear that the grid challenge concerning implementation and integration of grids lies in the social embedding of the micro and macro level phenomena: i) the attitude/socialisation based on the security/risk/profit psychology of the individual, and ii) the culture of the embedding institution and society based on the interaction of the autopoietic social subsystems. This is similar for the renewables as well as the grid IT sector and also has huge implications for any other complex resource exploitation network sector. Considering the macro level more in detail reveals that the autopoietic subsystems theory describes the social environment best. Unfortunately, the social subsystems i) religion, ii) education, iii) science, iv) art, v) economy, vi) jurisdiction, and vii) policy, have a more or less incompatible code of communication which leads to the Tragedy of the Autopoietic Social Subsystems and thus to large inconsistencies and blockings. Consequently, the challenge lies in the integration of autopoietic subsystems towards a working society on the micro and macro level by i) approaching the subsystem stickiness of individuals, and ii) the soft bridging of subsystems. In the daily work individuals have first to realize their own working and borders of their and other social subsystems. In a second step the possible bridges between social subsystems need to be realized and concrete ways to circumvent inherent blockings have to be explored to reach the level of a joined effort realization. On the micro level the security/risk/profit psychology matrix plays the major role since for the individual each internalization of a new technology is based on a positive relation between the security/risk/profit involved. Even for clear win-win situations the phenomenon of responsibility diffusion can appear. Since individuals have to balance constantly between the invironment and the environment, i.e. between psychology and social subsystems, there appears also a hard to tackle Tragedy of the Security/Risk/Profit Psychology. Consequently, the challenge on the micro and macro level are given by i) the individual perception and the individual well being, and ii) the procedural and institutionalized careful management. I.e. for the daily work that the individual need to rationalize its own behavioural background and invironmental constituency, and that institutions need to accept and develop the invironment of their employees as well as the psychological status of the environment they create. Thus, the creation of awareness might not change the individual but by team formation with different characters and corresponding procedures, the openness in an institutionalized form can increase the internalization of new technologies.

Consequently, to overcome the challenges put forward by the Tragedy of the Systems Complexity, and the Classic and Inverse Tragedy of the Commons with its base tragedies, the Tragedy of Autopoietic Social Subsystems and the Tragedy of Security/Risk/Profit Psychology in the renewable energy and grid IT sector, a Sustained Renewability approach in a holistic ecology-like manner combining the micro and macro level is crucial for in principle every resource and exploitation network. The interdisciplinary field of Human Ecology gives a framework also for the understanding and approaching of the Classic and Inverse Tragedy of the Commons for direct guidelines in the day-to-day management of grids as well as other areas and combine the above into a unified framework. Theoretically, the analysis carried out here showed that it is necessary to extent the classical Human Ecology triangle to a rectangle with i) the invironment ii) the individual, iii) the society, and iv) the environment. Thus, from the pure theoretical viewpoint, not only complete consistency was reached proving the validity of the arguments, but also access to a "tool box" - which has been used already successfully - was gained. This is important for generalization and justification of 
thereof derived management measures. To reach its full power also in respect to the Tragedy of the Systemic Complexity this needs to also embed a systemic approach on the technical level, since without this technical level the complete system of technology, micro and macro level would again be not complete. Now this means nothing else than that the complete system of technical development and implementation has to be considered as well as the security/risk/profit psychology of the individual with its invironment and the autopoietic subsystem organization of society with its environment. On first sight this insight to take a holistic viewpoint and make that the basis for solving the issues involved with the renewable energy, grid IT, or any other complex exploitation network seems natural and in principle completely obvious - actually not even to be worth thinking about. However, the fundamental issues and challenges faced in exploitation networks to be implemented to reach Sustained Renewability, i.e. to solve the problems of resource network limitations and thus to overcome the fundamental limits of energetic and material consumption growth reaching carrying capacity limits by the classic approach, are obviously there and demand urgent solutions in respect due to the urge of the problems involved if nothing substantial is changed. Thus, the pure existence of the climate challenge shows the importance of a Sustained Renewability approach, which is characterized by investigating all detailed factors involved for a certain resource and the challenges of an exploitation super-network can be overcome. Thus, then the technical Tragedy of Systemic Complexity and the Inverse Tragedy of the Commons can be overcome since resources are not unsustainably overexploited but used in a Sustained Renewability way by holistically integrating the i) technical resource exploitation networks and ii) all autopoietic social subsystems on a macro level as well as the psychology of individuals on the micro level, in an holistically systemic ecology like manner - or in short in a Sustained Renewability approach.

\section{Conclusion}

The worldwide amount of energy and IT resources to sustain human life is - with the classic exploitation and usage strategies - fast reaching the limits and carrying capacity. Nevertheless, huge underused energy and IT resources are obviously available and often even renewable on a human scale. Therefore, the Tragedy of Systemic Complexity already on the technical level and the Inverse Tragedy of the Commons have to be overcome for the renewable energy as well as the grid IT sectors by combining solutions of the systemic resource and exploitation networks with solutions of all autopoietic social subsystems on a macro level as well as the psychology of individuals on the micro level, i.e. a technical systemic solution is combined with an extended Human Ecology paradigm. Thus, not only advanced underused resources can be implemented and internalized, but also Sustained Renewability, i.e. a long lasting resource exploitation and renewable cycles can be managed - for on human scales - large time spans with paradisiacal opportunities for the life on earth.

\section{Acknowledgements}

K. Egger and V. Baumgärtner are thanked for the discussions, which have lead to this work. My parents W. Knoch and W. F. Knoch are thanked for their contributions and support as well as: F. G. Grosveld, A. Abuseiris, N. Kepper, the German and 
International Societies for Human Ecology, the International Health Grid organization, the Erasmus Computing Grid, the German MediGRID and Services@MediGRID, the European EDGEs consortium, and the European EpiGenSys consortium. This work was supported by the Erasmus Medical Centre and the Hogeschool Rotterdam, The Netherlands, the BioQuant / German Cancer Research Centre (DKFZ), Germany, and the German Ministry for Education and Research (BMBF) under grant \# 01 AK 803 A-H (German MediGRID) and \# 01 IG 07015 G (German Services@MediGRID), the Dutch Ministry for Science and Education, the Netherlands Science Organization (NWO), the Britisch Biotechnology and Biological Sciences Research Council (BBSRC), the EraSysBio+ program (all EpiGenSys grant), and the European Commission (EpiGenSys and FP7 EDGEs grants) to TAK.

\section{References}

Bruckmeier, K. \& Serbser, W. H. (eds.) (2008). Ethik und Umweltpolitik: Humanökologische Positionen und Perspektiven. Oekom Verlag, ISBN 978-386-5811-19-6

de Zeeuw, L. V., Knoch, T. A., van den Berg, J. \& Grosveld, F. G. (2007). Erasmus Computing Grid - Het bouwen van een 20 TeraFLOP virtuelle supercomputer," In: H. Frederik (ed.), NIOC proceedings 2007 - het perspective of lange termijn, NIOC, Amsterdam, The Netherlands, pp. 52-59

Egger, K. \& Glaeser, B. (1975). Ideologiekritik der Grünen Revolution: Wege zur technologischen Alternative, Technologie und Politik. rororo actuell, Reinbeck

Egger, K. \& Rudolph, S. (1992). Zum anschaulichen Umgang mit komplexen Aspekten der Kultur- und Ökokrise. In: B. Glaeser and P. Teherani-Krönner, (eds.), Humanökologie und Kulturökologie - Grundlagen, pp. 191-220

Egger, K. (1996). Evolution, Menschenbild und Umweltkrise - ein Versuch zur humanökologischen Hypothesenbildung. In: H. Wehrt (ed.), Humanökologie Beiträge zum ganzheitlichen Verständnis unserer geschichtlichen Lebenswelt. Birkhäuser, Basel, pp. 155-189

Egger, K. (2008). Die moralische Inversion - Ursachen unserer normativen Orientierungskrise und deren Folgen für die Agrarentwicklung Alternativpositionen durch Dialog mit anderen Kulturen. In: K. Bruckmeier, and W. H. Serbser, (eds.), Ethik und Umweltpolitik: Humanökologische Positionen und Perspektiven. Oekom Verlag, ISBN 978-3-86581-119-6

Einstein, A. (1905). Ist die Trägheit eines Körpers von seinem Energieinhalt abhängig. Annalen der Physik, Vol. 323, No. 13, pp. 639-641

Faber, M., Stephan, G. \& Michaelis, P. (1989). Umdenken in der Abfallwirtschaft. Vermeiden, Verwerten, Beseitigen. Springer, ISBN 978-354-0518-39-6

Faber, M., Niemes, H., Stephan, G. \& Freytag, L. (1987). Entropy, Environment, and Resources. An Essay in Physico- Economics. Springer Verlag,ISBN 978-354-0182-48-1

Faber, M., Manstetten, R. \& Proops, J. (1998). Ecological Economics: Concepts and Methods. Edward Elgar Publishing, ISBN 978-185-8989-98-3

Faber, M. \& Manstetten, R. (2003) Mensch - Natur - Wissen: Grundlagen der Umweltbildung. Vandenhoeck and Ruprecht, ISBN 978-352-5301-41-8 
Faber, M. \& Schiller, J. (2006). Joint Production and Responsibility in Ecological Economics: On the Foundations of Environmental Policy (Advances in Ecological Economics). Edward Elgar Publishing, ISBN 978-184-0648-72-0

Foster, I. \& Kesselmann, C. (2004). The grid: blueprint for a new computing infrastructure. The Elsevier Series in Grid Computing. Morgan Kaufmann, Amsterdam and Boston, ISBN 1-5586-0933-4

Haeckel, E. (1866). Generelle Morphology der Organismen, Band 2, Allgemeine Entwicklungsgeschichte. Berlin, pp. 286

Haeckel, E. (1998). Natürliche Schöpfungsgeschichte. 9. Auflage, Berlin, pp. 793

Hardin, G. (1968). Tragedy of the Commons. Science, Vol. 162, pp. 1243-1248

Hardin, G. (1994). The Tragedy of the Unmanaged Commons. Trends in Ecology E Evolution, Wol. 9, pp. 199

Hardin, G. (1998). Extensions of "The Tragedy of the Commons." Science, Vol. 280, pp. 682

International Association for the Study of the Commons (IASC), http:/ / www.iascp.org

IPCC: http://www.ipcc.ch and http://www.ipcc.ch/ ipccreports/index.htm

Jentzsch, W. I. (1995). BASF Antwerp - an integrated chemical plant. Industrial Lubrication and Tribology, Vol. 47, pp. 4-5

Knoch, T. A., Baumgärtner, V., de Zeeuw, L. V., Grosveld, F. G. \& Egger, K. (2009). e-Human Grid Ecology - understanding and approaching the inverse tragedy of the commons in the e-Grid Society. Studies in Health Technology and Informatics, Vol. 147, pp. 269-276

Knoch, T. A., Baumgärtner, V., Grosveld, F. G. \& Egger, K. (2010). Approaching the internalization challenge of grid technologies into e-Society by e-Human "Grid" Ecology. In J. Altmann, and O. F. Rana, (eds.), Economics of grids, clouds, and services, Springer, ISBN 978-364-2156-80-9, pp. 116-128

Krefting, D., Bart, J., Beronov, K., Dzhimova, O., Falkner, J., Hartung, M., Hoheisel, A., Knoch, T. A., Lingner, T., Mohammed, U., Peter, K., Rahm, E., Sax, U., Sommerfeld, D., Steinke, T., Tolxdorff, T., Vossberg, M., Viezens, F. \& Weisbecker, A. (2008). MediGRID - Towards a user friendly secured grid infrastructure. Future Generation Computer Systems, Vol. 25, pp. 326-336

Luhmann, N. (2004). Ökologische Kommunikation. VS Verlag für Sozialwissenschaften, ISBN 978-353-1517-75-9

Luhmann, N. (2008). Soziale Systeme: Grundriß einer allgemeinen Theorie. Suhrkamp, ISBN 978351-8282-66-3

Maturana, H. R. \& Varela, F. (1992). Tree of Knowledge. Shambhala, ISBN 978-087-773642-4

Noether, E. (1918). Invariante Variationsprobleme. Gött. Nachr., pp. 235-257

Noether, E. (1918). Invarianten beliebiger Differentialausdrücke. Gött. Nachr., pp. 37-44

Ostrom, E. (1990). Governing the commons: The evolution of institutions for collective action. Cambridge University Press, ISBN 978-052-1405-99-7

Sax, U., Weisbecker, A., Falkner, J., Viezens, F., Yassene, M., Hartung, M., Bart, J., Krefting, D., Knoch, T. A. \& Semler, S. C. (2007). “Grid-basierte Services für die elektronische 
Patientenakte der Zukunft," E-HEALTH-COM - Magazin für Gesundheitstelematik und Telemedizin, Vol. 4, pp. 61-63

Sax, U., Weisbecker, A., Falkner, J., Viezens, F., Mohammed, Y., Hartung, M., Bart, J., Krefting, D., Knoch, T. A. \& Semler S. C. (2008). Auf dem Weg zur individualisierten Medizin - Grid-basierte Services für die EPA der Zukunft. In A. Jäckel (ed.), J Telemedizinführer Deutschland 2008. Deutsches Medizinforum, Minerva KG, Darmstadt, ISBN 978-393-7948-06-5, pp. 47-51

Tragedy of the commons, http://en.wikipedia.org/ wiki/Tragedy_of_the_commons 


\title{
Renewable Energy Use and Energy Efficiency - A Critical Tool for Sustainable Development
}

\author{
Pius Fatona \\ School of Environmental Health Science, Ogun State College Of Health Technology, \\ Nigeria
}

\section{Introduction}

Energy efficiency and renewable energy are the "twin pillars" of a sustainable energy policy. Both strategies must be developed concurrently in order to stabilize and reduce carbon dioxide emission (American Council for an Energy-Efficient Economy, 2007). Efficient energy use is essential to slowing the energy demand growth so that rising clean energy supplies can make deep cuts in fossil fuel use. If energy use grows too rapidly, renewable energy development will chase a receding target. Likewise, unless clean energy supplies come online rapidly, slowing demand growth will only begin to reduce total carbon emissions; a reduction in the carbon content of energy sources is also needed. A sustainable energy economy thus requires major commitments to both efficiency and renewable (American Council for an Energy-Efficient Economy, 2007).

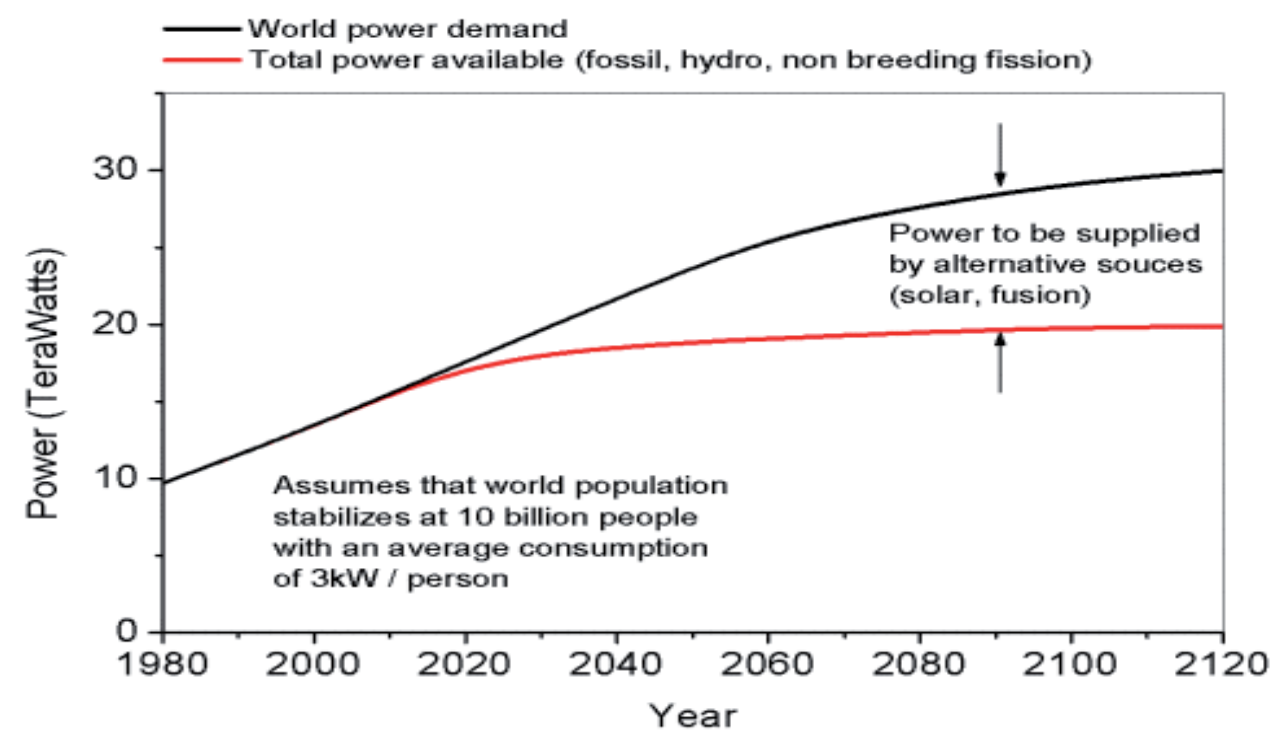

Estimates of the world energy use indicate that the demand for energy, by the middle of the 21st Century, may significantly exceed the energy supplied by conventional sources. The shortfall in energy becomes larger after the depletion of fossil fuels, about 100 years in the future. Source: http://www.plasma.inpe.br 
Renewable energy is energy which comes from natural resource such as sunlight, winds, plants growth, rain, tides and geothermal heat which are naturally replenished.

The first law of thermodynamic says that the total amount of energy on our planet remains constant. The second law states that as forms of energy are expended they become less easily available. That is entropy: the slow winding down of available energy (Jacobson, 2009).

- First law of thermodynamics: A change in the internal energy of a closed thermodynamic system is equal to the difference between the heat supplied to the system and the amount of work done by the system on its surroundings.

The first law of thermodynamics asserts the existence of a state variable for a system, the internal energy, and tells how it changes in thermodynamic processes. The law allows a given internal energy of a system to be reached by any combination of heat and work. It is important that internal energy is a variable of state of the system whereas heat and work change the state of the system.

The first law observes that the internal energy obeys the principle of conservation of energy, which states that energy can be transformed (changed from one form to another), but cannot be created or destroyed.

- Second law of thermodynamics: Heat cannot spontaneously flow from a colder location to a hotter location.

The second law of thermodynamics is an expression of the universal principle of decay observable in nature. The second law is an observation of the fact that over time, differences in temperature, pressure, and chemical potential tend to even out in a physical system that is isolated from the outside world. Entropy is a measure of how much this process has progressed. The entropy of an isolated system which is not in equilibrium will tend to increase over time, approaching a maximum value at equilibrium.

When coal, gas or oil is burnt, it rapidly converts a relatively easily available and concentrated source of energy into a much less available form: dispersed exhaust gases.

A high concentrated energy source, built up over millions of years quickly gone up in smoke. So, burning fossil fuels is high-entropy way of using energy.

Using renewable energy however merely taps into a natural flow of energy, sunlight, moving water, wind, biological or geothermal process. These are part of natural cycles of highs and lows. Their energy is truly renewable as it remains available to the same degree and is not depleted any more than it otherwise would be by using it.

Renewable energies include wind, ocean, wave and tides, solar, biomass, rivers, geothermal (heat of the earth) etc. They are renewable because they are regularly replenished by natural processes and are therefore in endless supply (Fatona, 2009; Jacobson, 2009). They also can operate without polluting the environment. Technologies have been developed to harness these energies and such technologies are called renewable energy technologies (RET) or sometime also called "Clean technologies" or "Green energy" (Pearce et al, 1989). Because renewable energy are constantly being replenished from natural sources, they have security of supply, unlike fossil fuels, which are negotiated on the international market and subject to international competition, sometimes may even resulting in wars and shortages. They have important advantages which could be stated as follows:-

1. Their rate of use does not affect their availability in future, thus they are inexhaustible.

2. The resources are generally well distributed all over the world, even though wide spatial and temporal variations occur. Thus all regions of the world have reasonable access to one or more forms of renewable energy supply. 
3. They are clean and pollution-free and therefore are sustainable natural form of energy.

4. They can be cheaply and continuously harvested and therefore sustainable source of energy.

Unlike the nuclear and fossil fuel plants which belong to big companies, governments, or state around enterprises, renewable energy can be set up in small units and is therefore suitable for community management and ownership. In this way, value from renewable energy projects can be kept in the community.

Transition from fossil fuels to renewable energy will not result in net job losses or cause harm to the economy. Renewal energy technologies (RETs) are labour intensive, and can produce more jobs than fossil fuel or nuclear industries. When RETs are properly integrated into national development plans and implemented, they can substantially reduce greenhouse gas emissions and simultaneously increase employment (Pearce et al, 1989). Moreover, it will also enhance energy security by reducing reliance on oil, preserve the competitiveness of energy, lead to savings for consumers and provide transitional assistance to workers in negatively affected industries and communities. With the right approach the interest of working families and the environment can come together (Pearce et al, 1989).

\section{What is energy efficiency?}

Energy efficiency means improvement in practice and products that reduce the energy necessary to provide services like lightning, cooling, heating, manufacturing, cooking, transport, entertainment etc. Energy efficiency products essentially help to do more work with less energy. Thus, the efficiency of an appliance or technology is determined by the amount of energy needed to provide the energy service. For instance, to light a room with an incandescent light bulb of $60 \mathrm{w}$ for one hour requires $60 \mathrm{w} / \mathrm{h}$. A compact florescent light bulb would provide the same or better lighting at $11 \mathrm{w}$ and only use $11 \mathrm{w} / \mathrm{h}$. This means that $49 \mathrm{w}$ ( $82 \%$ of energy) is saved for each hour the light is turned on.

Making homes, vehicles, and businesses more energy efficient is seen as a largely untapped solution to addressing the problems of pollution, global warming, energy security, and fossil fuel depletion. Many of these ideas have been discussed for years, since the 1973 oil crisis brought energy issues to the forefront. In the late 1970s, physicist Amory Lovins popularized the notion of a "soft energy path", with a strong focus on energy efficiency. Among other things, Lovins popularized the notion of negawatts - the idea of meeting energy needs by increasing efficiency instead of increasing energy production (Krech, 2004).

Lovins viewed the energy problem not one of an insufficient supply of oil and other conventional energy sources, but rather as one of inefficient energy use, coupled with lack of development of renewable energy sources. Lovins argued that conventional energy production was both energy intensive and a source of substantial pollution. With his reformulation of the energy problem, "environmentalists criticized plans for large-scale energy developments, especially those relying heavily on nuclear power".

The "soft energy path" assumes that energy is but a means to social ends, and is not an end in itself. Soft energy paths involve efficient use of energy, diversity of energy production methods (matched in scale and quality to end uses), and special reliance on co-generation and "soft energy technologies" such as solar energy, wind energy, bio-fuels, geothermal energy, wave power, tidal power, etc (Nash, 1979). 
Soft energy technologies (appropriate renewables) have five defining characteristics. They (1) rely on renewable energy resources, (2) are diverse and designed for maximum effectiveness in particular circumstances, (3) are flexible and relatively simple to understand, (4) are matched to end-use needs in terms of scale, and (5) are matched to end-use needs in terms of quality (Nash, 1979).

Residential solar energy technologies are prime examples of soft energy technologies and rapid deployment of simple, energy conserving residential solar energy technologies is fundamental to a soft energy strategy. Active residential solar technologies use special devices to collect and convert the sun's rays to useful energy and are located near the users they supply. Passive residential solar technologies involve the natural transfer (by radiation, convection and conduction) of solar energy without the use of mechanical devices.

Lovins argued that besides environmental benefits, global political stresses might be reduced by Western nations committing to the soft energy path. In general, soft path impacts are seen to be more "gentle, pleasant and manageable" than hard path impacts. These impacts range from the individual and household level to those affecting the very fabric of society at the national and international level.

Lovins recognised that major energy decisions are always implemented gradually and incrementally, and that major shifts take decades. A chief element of the soft path strategy is to avoid major commitments to inflexible infrastructure that locks us into particular supply patterns for decades.

Lovins explained that the most profound difference between the soft and hard paths - the difference that ultimately distinguishes them - is their different socio-political impact. Both paths entail social change, "but the kinds of social change for a hard path are apt to be less pleasant, less plausible, less compatible with social diversity and freedom of choice, and less consistent with traditional values than are the social changes which could make a soft path work".

Moving towards energy sustainability will require changes not only in the way energy is supplied, but in the way it is used, and reducing the amount of energy required to deliver various goods or services is essential. Opportunities for improvement on the demand side of the energy equation are as rich and diverse as those on the supply side, and often offer significant economic benefits.

In most places, a lot of energy is wasted because industries, power companies, offices and households use more energy than is actually necessary to fulfill their needs. The reasons is because they use old and inefficient equipment and production processes; buildings are poorly designed; and because of bad practices and habits. With energy efficiency practices and products, nations can save over $50 \%$ of the energy being consumed. Using energy more efficiently would:

1. Reduce electricity bills.

2. Leave more energy available to extend energy supply to all parts of the population.

3. Increase the efficiency and resilience of the economy - including reduced reliance on oil and thus improve balance of payments.

4. Improve industries competitiveness internationally.

5. Minimize the building of new power stations and thus free up capital for other investments like health and welfare. 
6. Reduce the negative environmental and human health impacts from energy production and use.

7. Increase employment through interactions e.g. in industry, housing, transport.

\section{Renewable energy and sustainable development}

The World Summit on Sustainable Development (WSSD) in Johannesburg in 2002 recognized the important role of energy for reaching millennium development goals. Access to affordable, reliable and sustainable energy is essential to sustainable development (Hasna, 2007). An adequate solving of energy problems will contribute to achieving progress across all pillars of sustainable development; social, economic and environmental and in meeting the UN millennium goals. Although there are no MDGs on access to energy, WSSD recognized that inadequate access to energy is both a cause and an effect of poverty and recommended the following:

"Take joint actions and improve efforts to work together at all levels to improve access to reliable and affordable energy service for sustainable development sufficient to facilitate the achievement of the Millennium Development Goals, including the goal of halving the proportion of people in poverty by 2015, and as a means to generate other important services that mitigate poverty, bearing in mind that access to energy facilitates the eradication of poverty" .

"Sustainable development" has been defined best by the Brundtland Commission as development that meets the needs of the present without compromising the ability of future generations to meet their own needs (Hasna, 2007). Adequate and affordable energy supplies has been key to economic development and the transition from subsistence agricultural economics to modern industrial and service oriented societies. Energy is central to improved social and economic well being and is indispensable to most industrial and commercial wealth organization. It is the key for relieving poverty, improving human welfare and raising living standards. But however essential it may be for development, energy is only a means to an end. The end is good health, high living standards, a sustainable economy and a clean environment.

Much of the current energy supply and use, based as it is, on limited resources of fossil fuels, is deemed to be environmentally unsustainable. There is no energy production or conversion technology without risk or waste. Somewhere along all energy chains - from resource extractions to the provision of energy service - pollutants are produced, emitted or disposed of, often with severe health and environmental impacts (Dasgupta, 2001; Fatona, 2009). Combustion of fossil fuels is chiefly responsible for urban air pollution, regional acidification and the risk of human - induced climate change (Dasgupta, 2001; Fatona, 2009). Achieving sustainable economic development on a global scale will requires the judicious use of resources, technology, appropriate economic incentives and strategic policy planning at the local and national levels. It will also require regular monitoring of the impacts of selected policies and strategies to see if they are furthering sustainable development or if they should be adjusted (Arrow et al, 2004).

When choosing energy fuels and associated technologies for the production, delivery and use of energy services, it is essential to take into account economic, social and environmental consequences (Ott, 2003; Wallace, 2005). There is need to determine whether current energy use is sustainable and, if not, how to change it so that it is. This is the purpose of energy indicators, which address important issues within three of the major dimensions of sustainable development: economic, social and environmental. 


\section{Energy indicators for sustainable development}

\subsection{Social dimension}

SOC1: Share of households (or population) without electricity or commercial energy, or heavily dependent on non-commercial energy

- Households (or population) without electricity or commercial energy, or heavily dependent on non-commercial energy

- Total number of households or population

SOC2: Share of household income spent on fuel and electricity

- Household income spent on fuel and electricity

- Household income (total and poorest $20 \%$ of population)

SOC3: Household energy use for each income group and corresponding fuel mix

- $\quad$ Energy use per household for each income group (quintiles)

- Household income for each income group (quintiles)

- Corresponding fuel mix for each income group (quintiles)

SOC4: Accident fatalities per energy produced by fuel chain

- Annual fatalities by fuel chain

- Annual energy produced

\subsection{Economic dimension}

ECO1: Energy use per capita

- Energy use (total primary energy supply, total final consumption and electricity use)

- Total population

ECO2: Energy use per unit of GDP

- $\quad$ Energy use (total primary energy supply, total final consumption and electricity use)

- GDP

ECO3: Efficiency of energy conversion and distribution

- Losses in transformation systems including losses in electricity generation, transmission and distribution

ECO4: Reserves-to-production ratio

- Proven recoverable reserves

- Total energy production

ECO5: Resources-to-production ratio

- Total estimated resources

- Total energy production

ECO6: Industrial energy intensities

- Energy use in industrial sector and by manufacturing branch

- Corresponding value added

ECO7: Agricultural energy intensities

- Energy use in agricultural sector

- Corresponding value added

ECO8: Service and commercial energy intensities

- Energy use in service and commercial sector

- Corresponding value added

ECO9: Household energy intensities

- Energy use in households and by key end use 
- Number of households, floor area, persons per household, appliance ownership

ECO10: Transport energy intensities

- $\quad$ Energy use in passenger travel and freight sectors and by mode

- Passenger-km travel and tonne-km freight and by mode

ECO11: Fuel shares in energy and electricity

- Primary energy supply and final consumption, electricity generation and generating capacity by fuel type

- Total primary energy supply, total final consumption, total electricity generation and total generating capacity

ECO12: Non-carbon energy share in energy and electricity

- Primary supply, electricity generation and generating capacity by non-carbon energy

- Total primary energy supply, total electricity generation and total generating capacity

ECO13: Renewable energy share in energy and electricity

- Primary energy supply, final consumption and electricity generation and generating capacity by renewable energy

- Total primary energy supply, total final consumption, total electricity generation and total generating capacity

ECO14: End-use energy prices by fuel and by sector

- $\quad$ Energy prices (with and without taxes or subsidies)

ECO15: Net energy import dependency

- $\quad$ Energy imports

- Total primary energy supply

ECO16: Stocks of critical fuels per corresponding fuel consumption

- $\quad$ Stocks of critical fuel (e.g. oil and gas)

- Critical fuel consumption

\subsection{Environmental dimension}

ENV1: Greenhouse gas (GHG) emissions from energy production and use, per capita and per unit of GDP

- Population and GDP

ENV2: Ambient concentrations of air pollutants in urban areas

- Concentrations of pollutants in air

ENV3: Air pollutant emissions from energy systems

- Air pollutant emissions

ENV4: Contaminant discharges in liquid effluents from energy systems

- Contaminant discharges in liquid effluents

ENV5: Soil area where acidification exceeds critical load

- Affected soil area

- Critical load

ENV6: Rate of deforestation attributed to energy use

- Forest area at two different times

- Biomass utilization

ENV7: Ratio of solid waste generation to units of energy produced

- Amount of solid waste

- Energy produced 
ENV8: Ratio of solid waste properly disposed of to total generated solid waste

- Amount of solid waste properly disposed of

- Total amount of solid waste

ENV9: Ratio of solid radioactive waste to units of energy produced

- Amount of radioactive waste (cumulative for a selected period of time)

- $\quad$ Energy produced

ENV10: Ratio of solid radioactive waste awaiting disposal to total generated solid radioactive waste

- Amount of radioactive waste awaiting disposal

- Total volume of radioactive waste

\section{Dimensions of sustainable development}

Sustainable development is essentially about improving quality of life in a way that can be sustained, economically and environmentally, over the long term supported by the institutional structure of the country (Adams, 2006; Chambers et al, 2000).

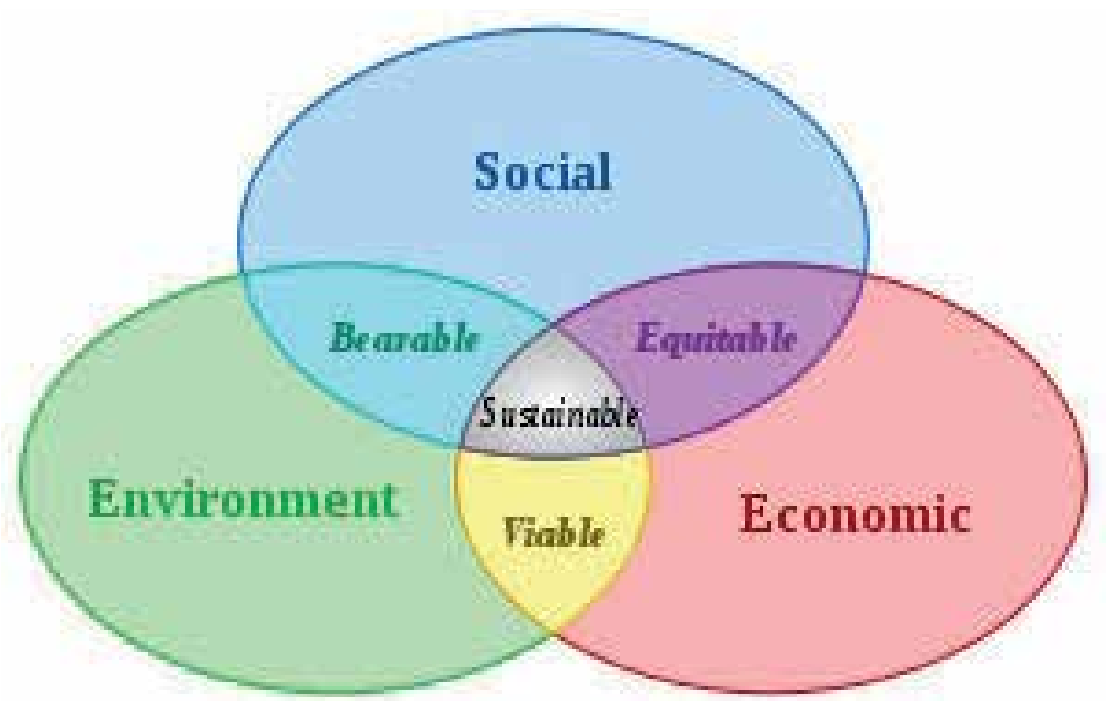

Scheme of sustainable development: at the confluence of three constituent parts 
Social dimension:- Availability of energy has a direct impact on poverty, employment opportunities, demographic transition, pollution and health. Social equity is one of the principal values underlying sustainable development, involving the degree of fairness and inclusiveness with which energy resources are distributed, energy systems are made accessible and pricing schemes are formulated to ensure affordability. Energy should be available to all at a fair price.

The use of energy should not damage human health, but rather should improve it by improving conditions. Yet the production of non renewable has the potential to cause injury or disease through pollution generation or accidents. A social goal is to reduce or eliminate these negative impacts. The health indicators have the sub theme of safety, which covers accident fatalities caused by the extraction, conversion, transmission / distribution and use of energy. Oil rigs and particularly coal mines are subjected to accidents that injure, main or kill people. Oil refineries and power stations may release emissions into the air that cause lung or respiratory diseases.

Economic dimension:- Modern economics depend on a reliable and adequate energy supply, and developing countries need to secure this as a prerequisite for industrialization. All sectors of the economy - residential, commercial, transport, service and agriculture demand modern energy services. These services in turn foster economic and social development at the local level by raising productivity and enabling local income generation. Energy supply affects jobs, productivity and development.

The prices of end-use energy by fuel and sector have obvious economic importance. Efficient energy pricing is a key to efficient energy supply and use and socially efficient levels of pollution abatement.

Addressing energy security is one of the major objectives in the sustainable development criteria of many countries. Interruptions of energy supply can cause serious financial and economic issues. To support the goals of sustainable development, energy must be available at all times, in sufficient quantities and at affordable prices. Secure energy supplies are essential to maintain economic activities and providing reliable energy services to society.

Environmental dimension:- The production, distribution and use of energy create pressures on the environment in the household, workplace and city and at the national, regional and global levels. The environmental impacts can depend greatly on how energy is produced and used, the fuel mix, the structure of the energy systems and related energy regulatory actions and pricing structure. Gaseous emissions from the burning of fossil fuels pollute the atmosphere. Large hydropower dams cause silting. Both the coal and nuclear fuel cycles emit some radiation and generate waste. And gathering firewood can lead to deforestation and desertification Daly \& Cobb, 1990; Hilgenkamp, 2005).

Water and land quality are important sub-themes of the environmental dimensions. Land is more than just physical space and surface topography; it is in itself an important natural resource, consisting of soil and water essential for growing food and providing habitat for diverse plant and animal communities. Non - renewable energy activities may result in land degradation and acidification that affect the quality of water and agricultural productivity.

Land is also affected by energy transformation processes that often produce solid wastes, including radioactive wastes, which require adequate disposal. Water quality is affected by the discharge of contaminants in liquid effluents from energy systems, particularly from the mining of non renewable energy resources, which is environmentally unsustainable (Daly \& Cobb1990; Hilgenkamp, 2005). 
Environmental sustainability is the process of making sure current processes of interaction with the environment are pursued with the idea of keeping the environment as pristine as naturally possible based on ideal-seeking behavior.

\section{Consumption of renewable resources}

More than nature's ability to replenish

Equal to nature's ability to replenish

Less than nature's ability to replenish
State of environment

Environmental degradation

Environmental

equilibrium

Environmental renewal
Sustainability

Not sustainable

Steady state economy

Environmentally

sustainable

An "unsustainable situation" occurs when natural capital (the sum total of nature's resources) is used up faster than it can be replenished. Sustainability requires that human activity only uses nature's resources at a rate at which they can be replenished naturally (Barbier, 2007). Inherently the concept of sustainable development is intertwined with the concept of carrying capacity. Theoretically, the long-term result of environmental degradation is the inability to sustain human life. Such degradation on a global scale could imply extinction for humanity.

\section{Conclusion}

There is an intimate connection between energy, the environment and sustainable development. A society seeking sustainable development ideally must utilize only energy resources which cause no environmental impact. Clearly, a strong relation exists between energy efficiency and environmental impact since, for the same services or products, less resource utilization and pollution is normally associated with increased energy efficiency. Sustainable energy is the provision of energy that meets the needs of the present without compromising the ability of future generations to meet their needs. Sustainable energy sources are most often regarded as including all renewable energy sources, such as hydroelectricity, solar energy, wind energy, wave power, geothermal energy, bio-energy, and tidal power. It usually also includes technologies that improve energy efficiency.

Renewable energy technologies are essential contributors to sustainable energy as they generally contribute to world energy security, reducing dependence on fossil fuel resources and providing opportunities for mitigating greenhouse gases. As such, sustainable energy promotes sustainability. Sustainability, here, is twofold, as it constitutes self-sustenance and the ability to foster sustainable development.

By being self-sustaining the energy source is in essence limitless. Solar energy, wind energy, geothermal energy, hydropower and biomass are all self-sustaining. They all have sources that cannot be depleted. These energy sources allow for the conservation of other energy sources, like trees that would have been used for charcoal production. Using these "renewable" energies also encourages the protection of the environment which traditional energy sources have helped to destroy. The use of some traditional energy sources, like oil and charcoal, the Natural Resources Conservation Authority (NRCA) reported "carries with 
it a number of environmental problems, such as water and air pollution and the contamination of soils." Utilizing sustainable energy would then lead to the conservation of the environment which would eventually lead to a development which meets the needs of the present, without compromising the ability of future generations to meet their own needs. In other words, sustainable energy use leads to sustainable development.

\section{References}

Adams, W.M. (2006). The future of sustainability: Rethinking environment and development in the twenty-first century. Report of the IUCN renowned Thinkers Meeting, 29-31 January 2006

American Council for an Energy-Efficient Economy (2007). The twin pillars of sustainable energy: Synergies betweenenergy efficiency and renewable energy technology and policy report E074

Arrow KJ, P. Dasgupta, L. Goulder, G Daily, PR Ehrlich, GM Heal, S Levin, K-G Maler, S Schneider, DA Starrett, B Walker. (2004). Are we consuming too much? Journal of Economic Perspectives, 18(3):147-172

Associated Plasma Laboratory (LAP) (n.d.) http://www.plasma.inpe.br Accessed June June 24, 2011

Barbier, E. (2007). Natural Resources and Economic Development, Cambridge University Press

Chambers N., C. Simmons \& M. Wakernagel (2000). Sharing Nature's Interest: Ecological Footprint as an Indicator of Sustainability. Earthscan, London.

Dasgupta, P. (2001). Human Well-Being and the Natural Environment. Oxford University Press, Oxford.

Daly H. \& J.B. Cobb Jr (1990). For the Common Good, Green Print. The Merlin Press, London.

Fatona, P. Olugbenga (2009). Energy exploitation, utilization and its environmental effects the choice to make and the decision to take. Toxicological \& Environmental Chemistry, 91: 5, 1015-1019

H. Nash (Ed.) (1979). The Energy Controversy: Soft Path Questions and Answers, Friends of the Earth, San Francisco, CA.

Hasna, A. M. (2007). "Dimensions of sustainability". Journal of Engineering for Sustainable Development: Energy, Environment, and Health 2 (1): 47-57.

Hilgenkamp, K. (2005). Environmental Health: Ecological Perspectives. London: Jones \& Bartlett.

Jacobson, Mark Z. (2009). Review of solutions to global warming, air pollution, and energy security. Energy and environmental science (Royal Society of Chemistry) 2: 148

Krech, Shepard (2004). "Encyclopedia of World Environmental History: A-E". Routledge.

Ott, K. (2003). "The Case for Strong Sustainability." In: Ott, K. \& P. Thapa (eds.) (2003).Greifswald's Environmental Ethics. Greifswald: Steinbecker Verlag Ulrich Rose. 
Pearce, D., A. Markandya and E. Barbier (1989). Blueprint for a green economy, Earthscan, London, Great Britain

Wallace, Bill (2005). Becoming part of the solution: the engineer's guide to sustainable development. Washington, DC: American Council of Engineering Companies. Initiative 62(3): 282-292. 


\title{
Renewable Energy and Coal Use in Turkey
}

\author{
Ali Osman Yilmaz \\ Karadeniz Technical University/Department of Mining Engineering, Trabzon \\ Turkey
}

\section{Introduction}

The development level of a country is directly related to its economical and social level. One of the most important factors that takes an active role in achieving such development level is energy. Energy, which is the requirement of sustainable development, can only be an impulsive force in industrialization and overall development of societies if it is supplied on time, with sufficient quantity and under reliable economical conditions and considering the environmental impacts. The demand for energy increases rapidly in parallel with the population increase, industrialization and technological developments in Turkey and the other developing countries in the world.

Turkey has been developing since the foundation of the Republic of Turkey in 1923. Turkish Government played a leading role in energy production and in energy use, as well as in other fields, and implemented several policies to increase electricity production. By 1950s, thermal power plants were used commonly in electricity production. In the following years, hydroelectric power plants were put into operation in order to use the considerable amount of water resources of the country. Coal-fired power plants using national resources accounted for $70-80 \%$ of the thermal electricity production. After 1960s, oil, an imported resource, was replaced with national resources due to two petroleum crises. Therefore, the proportion of use of lignite in the energy field increased. By 1980s, energy production lead by the government went on. Afterwards, applications of liberal economy policies resulted in implementation of different energy production methods, and the country had a increasing tendency to meet energy demand by imports as a result of improvement in international economic relations. Natural gas became prevalent in the country as well as all over the world and accounted for $50 \%$ of the electricity production in 2009 (Fig 1, Table 1).

On the eve of 21st century, Turkey was unable to meet its energy requirement with its limited sources as a result of the increasing population and industrialization and thus the deficit between the energy production and energy consumption increased rapidly. Under such conditions, utilizing own resources more effectively had become more important increasingly day by day. Turkey became more dependent on imports year to year. It still supplies about $71 \%$ of its primary energy consumption from imported energy sources. This percentage is $59 \%$ for electricity production. It is now vital for Turkey to attach importance to coal and renewable energy sources, which are the largest domestic energy sources of Turkey, in order to meet this increasing energy deficit. Especially, it is possible to produce electricity using the said domestic sources. 
- Population

- Gross national product (GNP)

- GNP per capita

- Primary energy production

- Distribution of primary energy production

- Primary energy consumption

- Distribution of primary energy consumption

- Distribution of primary energy consumption by sectors

- Rate of primary energy [production/consumption]

- Primary energy consumption per capita

- World primary energy consumption per capita

- Installed capacity

- Distribution of installed capacity by primary energy sources

- Electricity generation

- Distribution of electricity generation by primary energy sources

- Electricity gross consumption

- Electricity gross generation per capita

- Electricity net consumption per capita

- Word electricity generation

- Word electricity consumption

- World electricity generation by primary energy sources

- World electricity production per capita

- World electricity consumption per capita

Table 1. Energy Profile of Turkey (2009)
$73.722 .988(2010)$

615 billion $\$$

$8.215 \$$ / person

30.328 ktoe (thousand tons of oil equivalent)

Lignite $52 \%$, wood $12 \%$, hydraulic $10 \%$, Petroleum $8 \%$,hard coal $4 \%$, other $14 \%$

104.117 Ktoe

Petroleum $29 \%$, natural gas $31 \%$, lignite $15 \%$, hard coal $14 \%$, hydraulic $3 \%$, other $8 \%$.

Industry $23 \%$,residential $27 \%$,

transportation $15 \%$,

energy $25 \%$, other $10 \%$

$29 \%$

1435 Koe (Kilogram oil equivalent)

1710 Koe

44.761 MW

Renewable $35 \%$, natural gas $26 \%$, lignite $18 \%$, petroleum $4 \%$, imported coal $5 \%$, hard coal $1 \%$, other $11 \%$

194.813 GWh

Natural gas $49 \%$, renewable $19 \%$,

lignite $20 \%$, petroleum $3 \%$, imported coal $6 \%$, hard coal $2 \%$, other $1 \%$.

194.079 GWh

$2.685 \mathrm{kWh} /$ person

$2.162 \mathrm{kWh} /$ person

20.202 billion kWh (2008)

16.880 billion $\mathrm{kWh}$ (2008)

Coal $42 \%$,natural gas $21 \%$, nuclear14 \%,

hydraulic $16 \%$,

petroleum $6 \%$, biomass $3 \%$, other $4 \%$. (2007)

$3012 \mathrm{kWh} /$ person (2008)

$2516 \mathrm{kWh} /$ person (2008) 


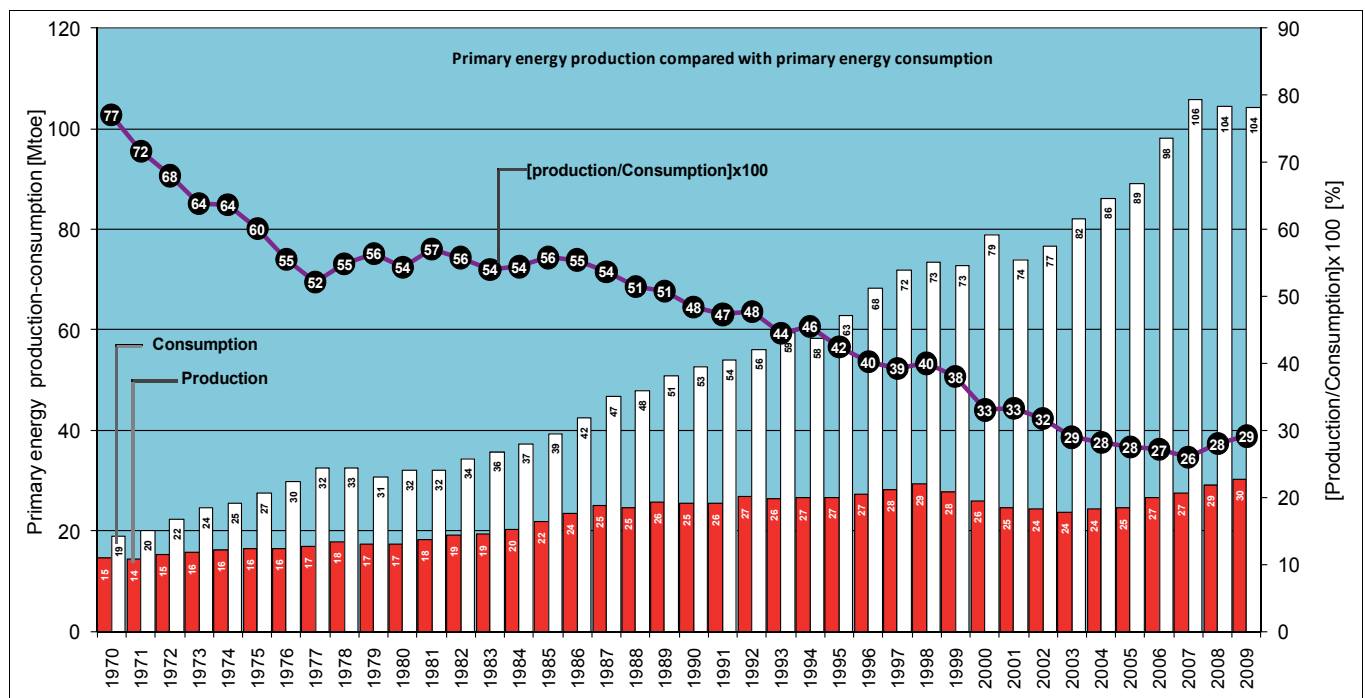

Fig. 1. During period of 1970-2009, primary energy production-consumption and rates of production and consumption (data from MENR,1970-2009)

In this chapter, the primary energy production- consumption of renewable energy sources of Turkey and coal as well as the development of their use rates in electricity production are discussed for a definite time period. In addition, some information is given about the projected use rates of such energy sources in energy production and projected consumption in Turkey for the years 2015 and 2020.

\section{Energy outlook of Turkey}

When the Republic of Turkey was founded in 1923, Turkey's population was 12 million. Installed capacity of electricity production, total electricity production, per capita electricity production and per capita electricity consumption were $33 \mathrm{MW}, 45 \mathrm{GWh}, 3.6 \mathrm{kWh}$ and 3.3 $\mathrm{kWh}$, respectively. Initially, almost all electricity demand was met by thermal power plants. The foundation of the Turkish Republic became the start of the development of the country. In 2009 year, the population has reached 73,7 million increasing about by six fold. In 2009 year, installed capacity reached 44.761MW increasing about by 1356-fold, electric production reached to 194.813 GWh increasing by 4329-fold. Per capita electricity production and electricity consumption reached 2685 and $2162 \mathrm{kWh}$ increasing by 745 -fold and by 655-fold, respectively. In 2009 year, primary energy production and consumption were 30.328 Ktoe and 104.117 Ktoe respectively. Also, distributions of primary energy production were lignite $52 \%$, wood $12 \%$, hydraulic $10 \%$, hard coal $4 \%$, and petroleum $8 \%$. Distribution of primary energy consumptions were petroleum, natural gas, lignite, hard coal, hydraulic and other $29 \%, 32 \%, 15 \%, 14 \%, 3 \%$ and $8 \%$, respectively (Table 1 ). The net effect of all these factors is that Turkey's energy demand has grown rapidly almost every year and is expected to continue growing (Arığlu and Yılmaz, 1997a; SIS, 2003,2004; Yilmaz, 2003, 2004,2011; TEIAS, 2004, 2009; Y1lmaz and Uslu 2007; BP, 2009).

Energy has been the most important investment sector over the world. Turkey's energy needs are increasing quickly. Primary energy production-consumption and rates of production and 
consumption are illustrated in Fig.1. Since Turkey is an energy importing country more than about $70 \%$ of the country's energy consumption is met by imports, and the share of imports is growing in the following years. While the primary energy consumption in 1970 was 18.84 mtoe, it reached 104 mtoe (million ton oil equivalent) with an increase rate of $552 \%$ in 2009 . Primary energy production and consumption rates realized $1.39 \%$ and $4.29 \%$ per year, respectively. In other words, increase in consumption is three times bigger than the increase in production. While the ratio that production meets consumption was $77 \%$ in 1970, this ratio reduced and reacted to $29 \%$ in 2009. In other words, Turkey has been a country that depends on other countries in energy fields, especially in terms of oil and natural gas. (Fig. 1). (Yilmaz, et al, 2005; Yılmaz, 2003; Yılmaz and Arığlu 2003; Y1lmaz and Uslu, 2007; Yılmaz 2006; Yılmaz 2009; Yılmaz 2011; Arığlu 1994; Arıŏlu 1996).

Distribution of total electricity generation by energy resources during the period 1940-2009 is shown in Fig 2. As seen in the figure, renewable, oil-natural gas and coal accounted for $8 \%$, $6 \%, 86$ of electricity production in 1940. The share of the coal reduced continuously in the following years and reached as 55\% in 1960, 25\% in 1980 and again increased to 29\% (imported coal included) in 2009. The increase rate of use of renewable energy sources was accelerated especially from 1960s, as seen in the electricity production capacity, and use rate of renewable energy sources was recorded as $8 \%$ in 1940,37\% in 1960, 52\% in 1980 and decreased to $19 \%$ in 2009. Because, after the year 2000, a sharply increase in share of imported natural gas in electricity production, lowered the use of domestic lignite and hard coal. Turkey is dependent on foreign countries especially in terms of oil and natural gas. In 1960, imported oil made up $8 \%$ of electricity production and this rate abruptly increased in the after years and it's had been reached 30\% in 1970. During period 2000s years, imported of the natural gas sharply increased and reacted to $50 \%$ in 2009 . Natural gas has been fast-growing fuel of energy market in Turkey. The tremendous growth and increased trend in gas demand during the period 19902009 showed that Turkey will need much more gas in the following years. Especially the share of the natural gas consumed in electricity generation has sharply increased and is considered to increase also in the future (Yilmaz 2008; Y1lmaz 2011).

Turkey became more dependent on imports year to year. It still supplies about $71 \%$ of its primary energy consumption from imported energy sources. This percentage is $59 \%$ for electricity production. These rates are exactly seen in Fig 3. and Fig. 4 during of the period 1970-2009. In Fig 3 show that Turkey's primary energy consumption was $77 \%$ share of the domestic energy sources in 1970. While 54\% of the consumed energy in 1980 was by the domestic energy sources, this percentage decreased to $33 \%$ and $29 \%$ in 2000 and 2009 respectively. On the other hand, share of the imported energy sources was increased from $23 \%$ in 1970 to $71 \%$ in 2009 . In Figure 4 distribution of electricity production by domestic and imported energy sources are given in historical order. As seen in Figure, while domestic energy sources had a share of $68 \%$ in electricity production in 1970, imported energy sources had a share of $42 \%$ in electricity generation. After the 1970 s years, oil crisis started. Turkey gave importance on lignite, coal and own renewable energy potential sources. So the rate of electricity production using Turkey's domestic sources was increased. But in 1990s use of imported natural gas in electricity production has sharply increased to $45 \%$ and $59 \%$ in 2000 and 2009 respectively. It is now vital for Turkey to attach importance to coal and renewable energy sources, which are the largest domestic energy sources of Turkey, in order to meet this increasing energy deficit. Especially, it is possible to produce electricity using the said domestic sources (Yılmaz 2006; Yılmaz 2011, Yılmaz and Arığlu 1997b). 


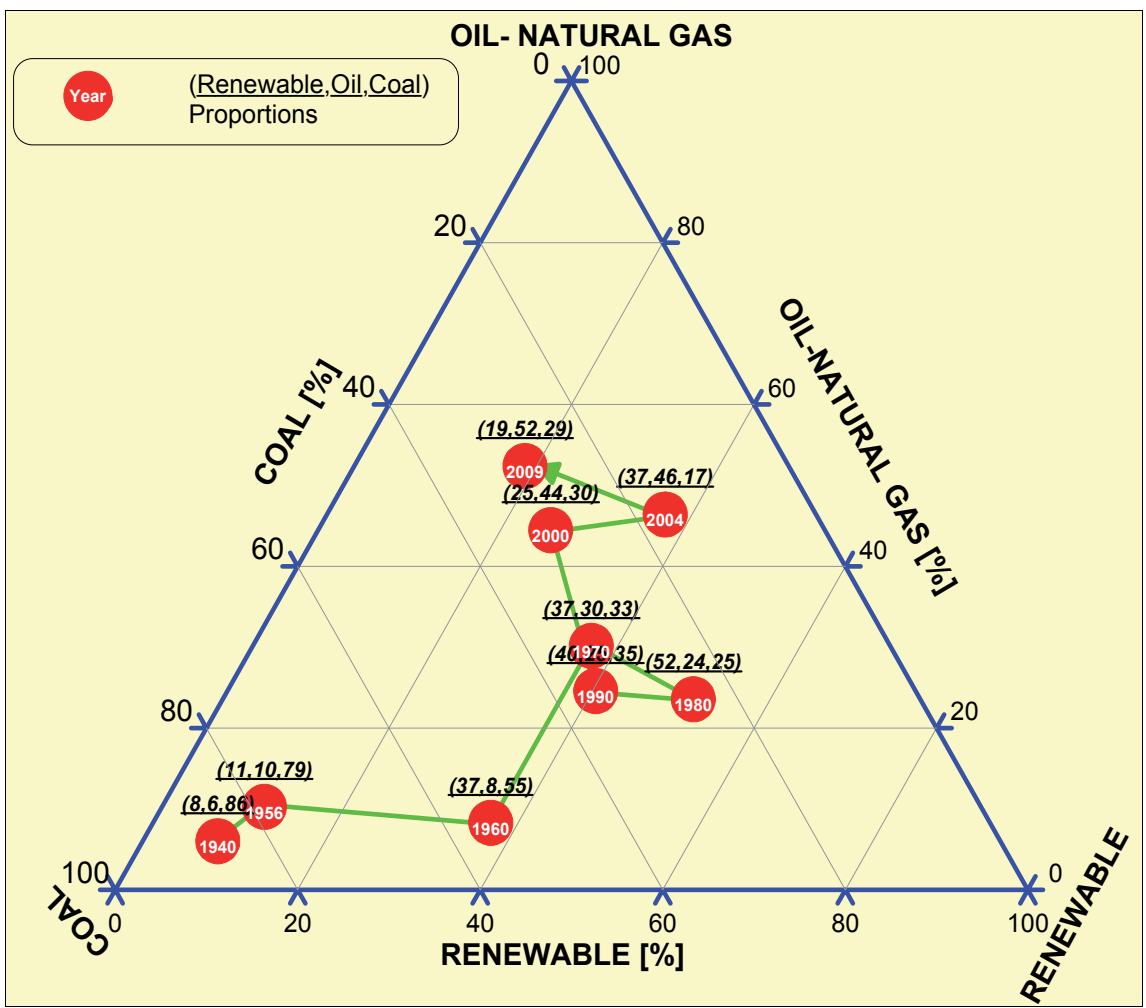

Fig. 2. Distribution of primary energy sources in electricity production by years (data from TEIAS, 2009)

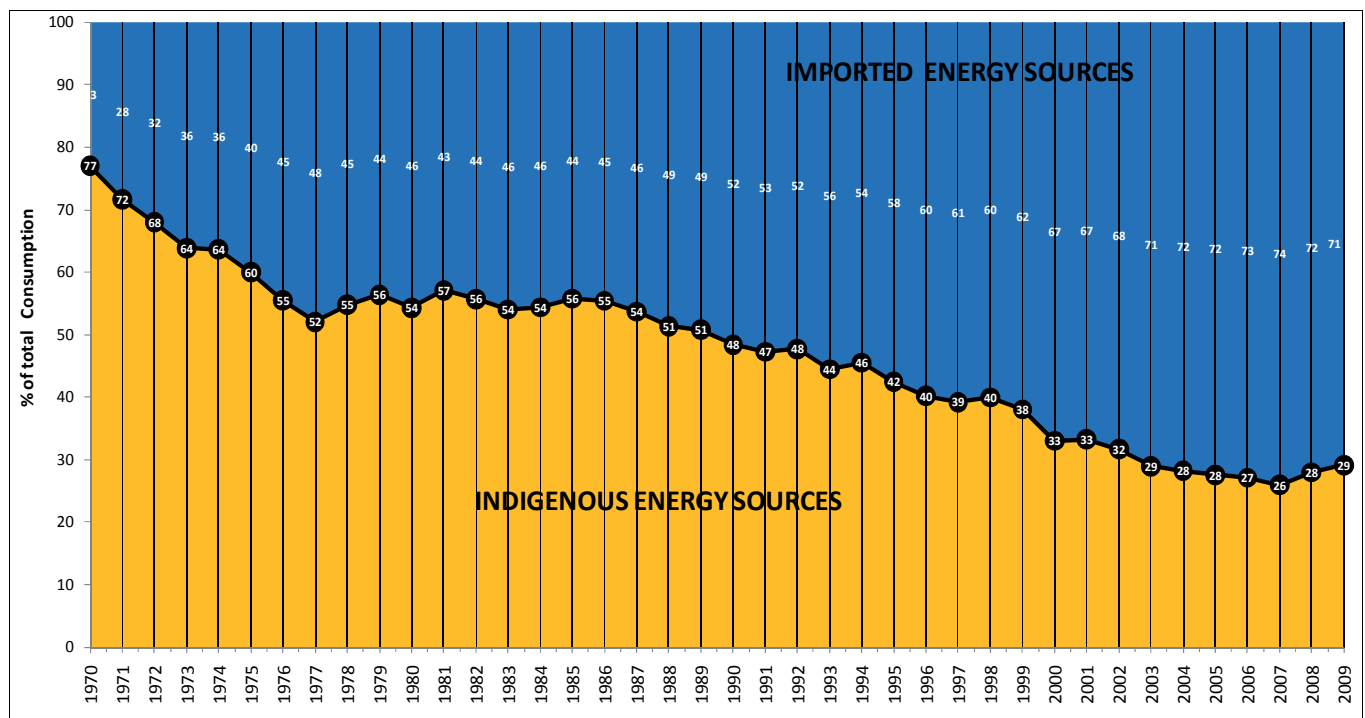

Fig. 3. During the period 1970 and 2009, primary energy consumption with domestic and imported energy sources (data from MENR, 1970-2009) 


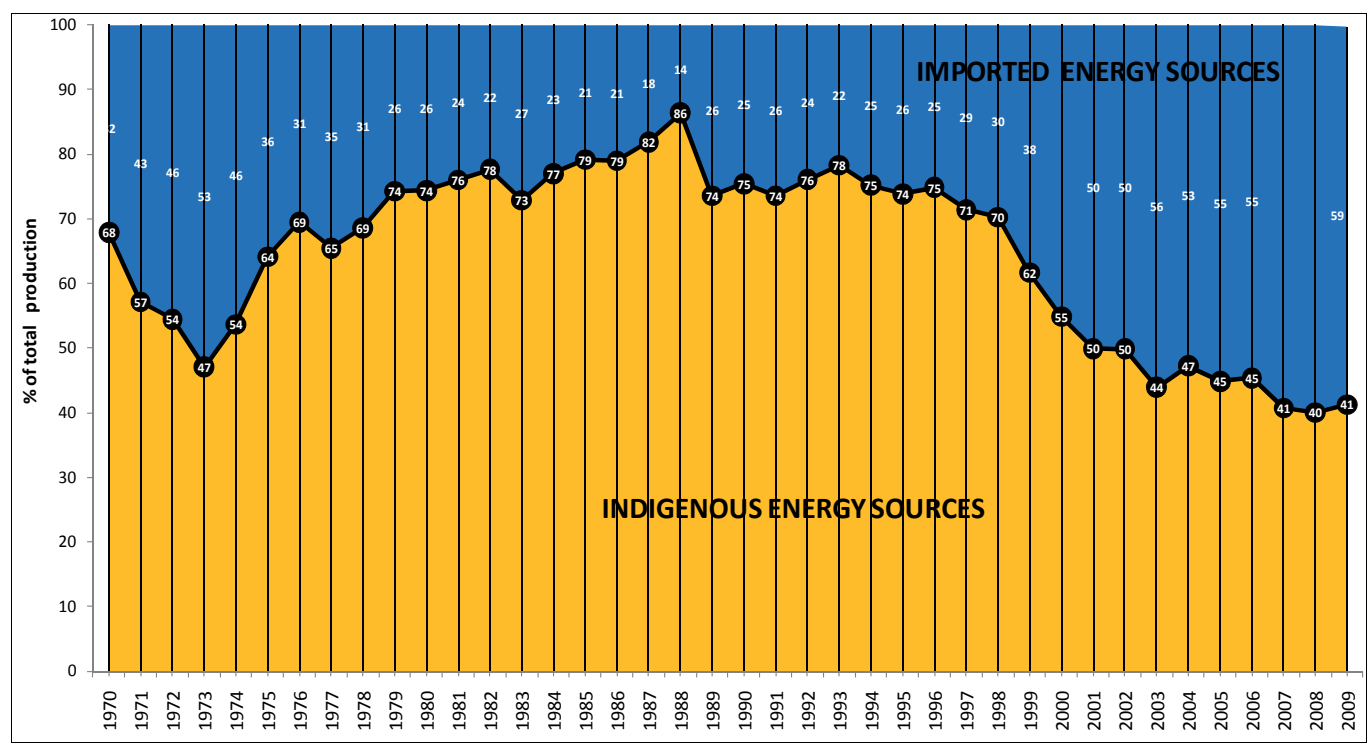

Fig. 4. During the period 1970 and 2009, in electricity generation imported and indigenous energy sources (data from TEIAS, 1970-2009)

\section{Renewable energy use in Turkey}

Totally energy demand of Turkey was making up about $29 \%$ of domestic resources and about $71 \%$ import resources. Turkey's primary energy production is 30.3 Mtoe (Table 1, Fig 1.). Turkey got a great share coal which is consisted of $57 \%$. The primary energy that follows the coal and their shares are as follows; oil $8 \%$, natural gas $2 \%$ and renewable energy $33 \%$. Distribution of the share on the renewable energy are hydraulic, geothermal, wood, animal and vegetable waste and other $10 \%, 6 \%, 12 \%, 1 \%$ and $1 \%$, respectively in primary energy production (Fig 5.). On the other hand, primary energy consumption of Turkey is 104.1 Mtoe in 2009. The biggest energy consumption resource is natural gas with $32 \%$ and followed of this gas; oil $29 \%$, coal $30 \%$, and renewable energy $9 \%$ in consumption (Fig5). Distribution of the share on the renewable energy are hydraulic, geothermal, wood, animal and vegetable waste and other $3 \%, 1 \%, 3 \%, 1 \%$ and $1 \%$, respectively in primary energy consumption (MENR, 2010; TKI, 2004,2009). Turkey is dependent on the import of foreign primary energy sources especially; oil, natural gas and hard coal. Recently, according to research estimates, this trend is likely to continue in the near future.

Turkey has two main energy resources with large capacities. These are coal and renewable energy resources. Both energy resources constitute $90 \%$ of the primary energy production. The total primary energy production was 31\% in 1970 and increased to $50 \%$ and $57 \%$ in 1989 and in 2009 respectively and this rate was met by coal. The share of the renewable energy resources was 43\% in 1970 and decreased to 33\% in 2009 (Fig. 6) (Yilmaz 2006; Yilmaz 2011). 


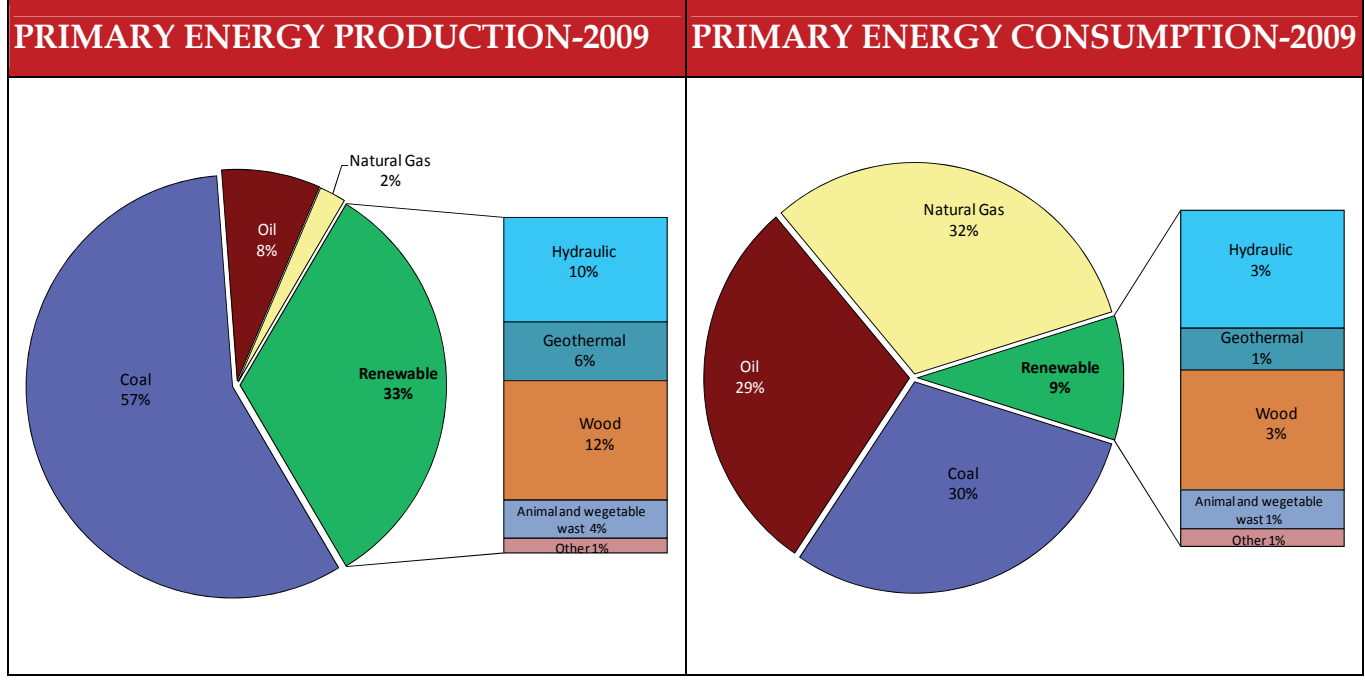

Fig. 5. Total primary energy production and consumption by energy sources in 2009 (data from MENR, 2009)

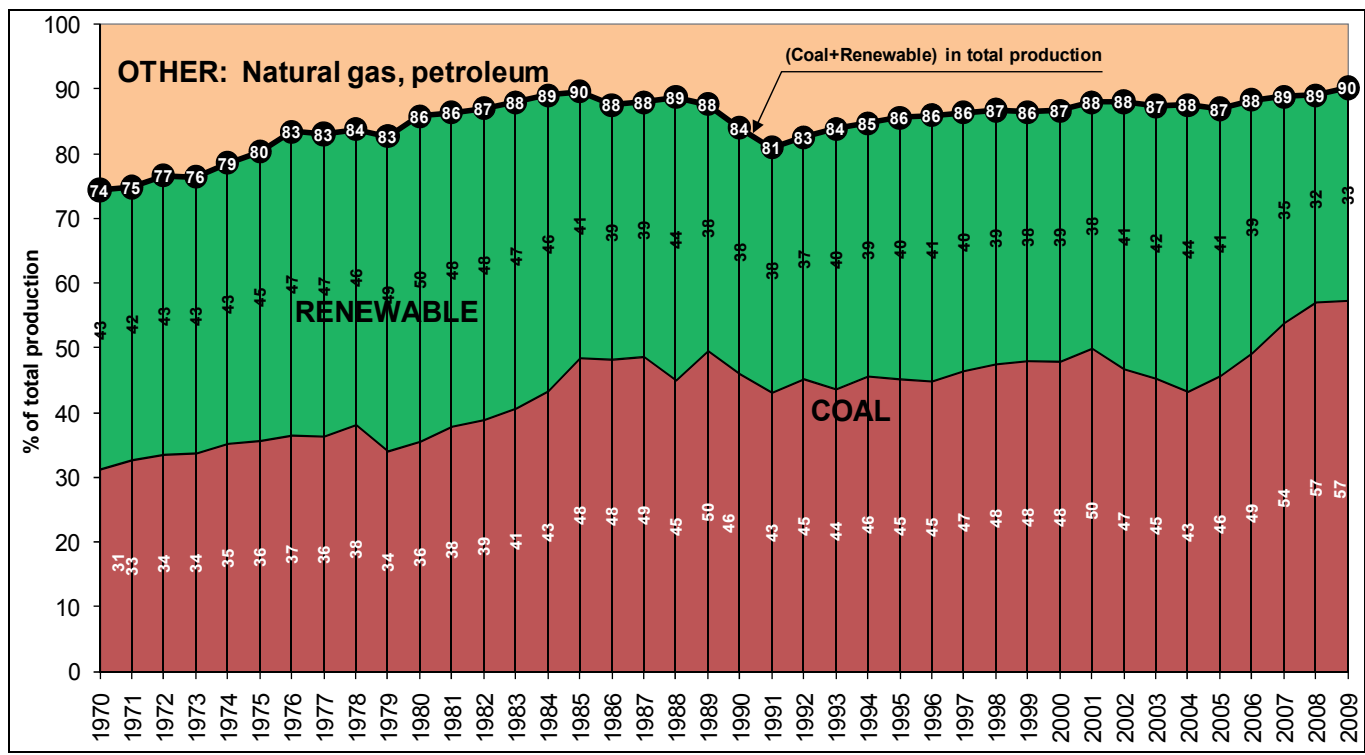

Fig. 6. During of the period 1970-2009, total primary energy production with rates of renewable energy and coal (data from MENR 1970-2009)

The distribution of renewable energy sources in primary energy production in Turkey is illustrated in Fig. 7 for the term 1970 and 2009. The energy sources used for the primary energy production are hydraulic energy, geothermal energy, wood, animal and vegetable waste. On average $43 \%$ of the primary energy production was met by the renewable energy in 1970. This percentage increased to $50 \%$ in 1980 and due to the imported natural gas, this rate was decreased to $33 \%$ in 2009 . The shares of the energy sources in this production rate 
were as follows: $10 \%$ hydraulic, $6 \%$ geothermal, $12 \%$ wood and $4 \%$ animal and vegetable waste in 2009. According to this data, the largest energy source used in primary energy production was wood and hydraulic. While the share of the wood and waste and drung has decreased, the share of the hydraulic, geothermal has increased (Y1lmaz 2008; MENR,19702009; SIS, 2003-2004; TEIAS, 2004,2009).

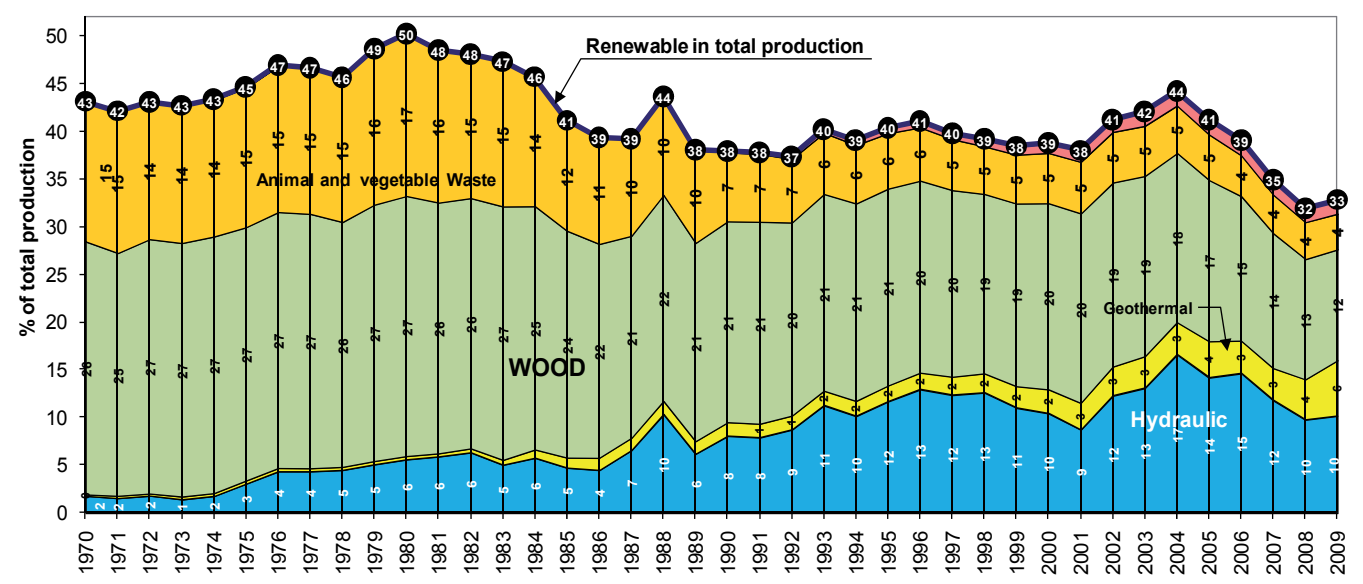

Fig. 7. During of the period 1970-2009, renewable energy sources and rates used in primary energy production (data from MENR 1970-2009)

The development of the total share of renewable energy sources in primary energy consumption in Turkey is illustrated in Fig. 8 for the term 1970 and 2009. Turkey's main energy production resources are hard coal, lignite and renewable energy. The total domestic energy production was $77 \%$ (hard coal $15 \%$, lignite $8 \%$, renewable $33 \%$ and other oil-gas $21 \%$ ) in 1970. The share of total domestic energy sources in overall primary energy production was $48 \%$ (hard coal $4 \%$, lignite 18\%, renewable 18 and other $8 \%$ ) in 1990, and it decreased to $29 \%$ (hard coal $1 \%$, lignite $15 \%$, renewable $10 \%$ and other $4 \%$ ) in 2009 . In other words, the share of the renewable energy resources was 33\% in 1970 and decreased to $10 \%$ in 2009. As seen in Figure 8, Turkey's total domestic energy sources in overall production has decreased from 1970 and 2009 term. When use of renewable domestic energy sources is considered in terms of primary energy production, it decreased to $10 \%$ levels in the recent years.

The primary energy consumption of Turkey has increased day by day and it will follow in the future. The development of the total share of renewable energy sources in primary energy consumption in Turkey is illustrated in Fig. 9 for the term 1970 and 2009. The energy sources used for the primary energy production are hydraulic energy, geothermal energy, wood, animal and vegetable waste. The share of total renewable energy sources in overall consumption was 33\% in 1970 (hydraulic 1\% wood 20\%, waste and drug 11\%) and it decreased to $23 \%$ (hydraulic $4 \%$ wood $11 \%$, waste and drug $5 \%$ ) in 1990 . In 2009, the share of renewable energy sources in total primary energy consumption decreased and reached to 9\% (Yilmaz 2008; MENR, 2006-2009; SIS, 2003-2004; TEIAS, 2004-2009). 


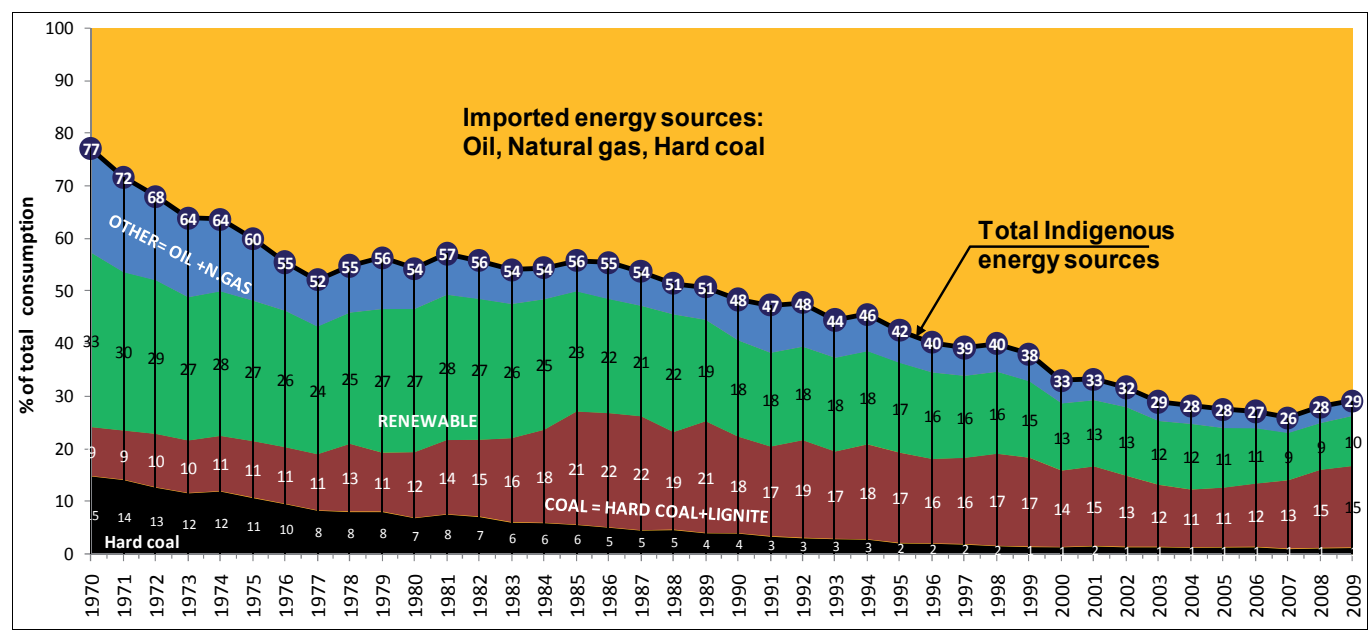

Fig. 8. During of the period 1970 and 2009 development of the total share of renewable energy sources in primary energy production (data from MENR 1970-2009)

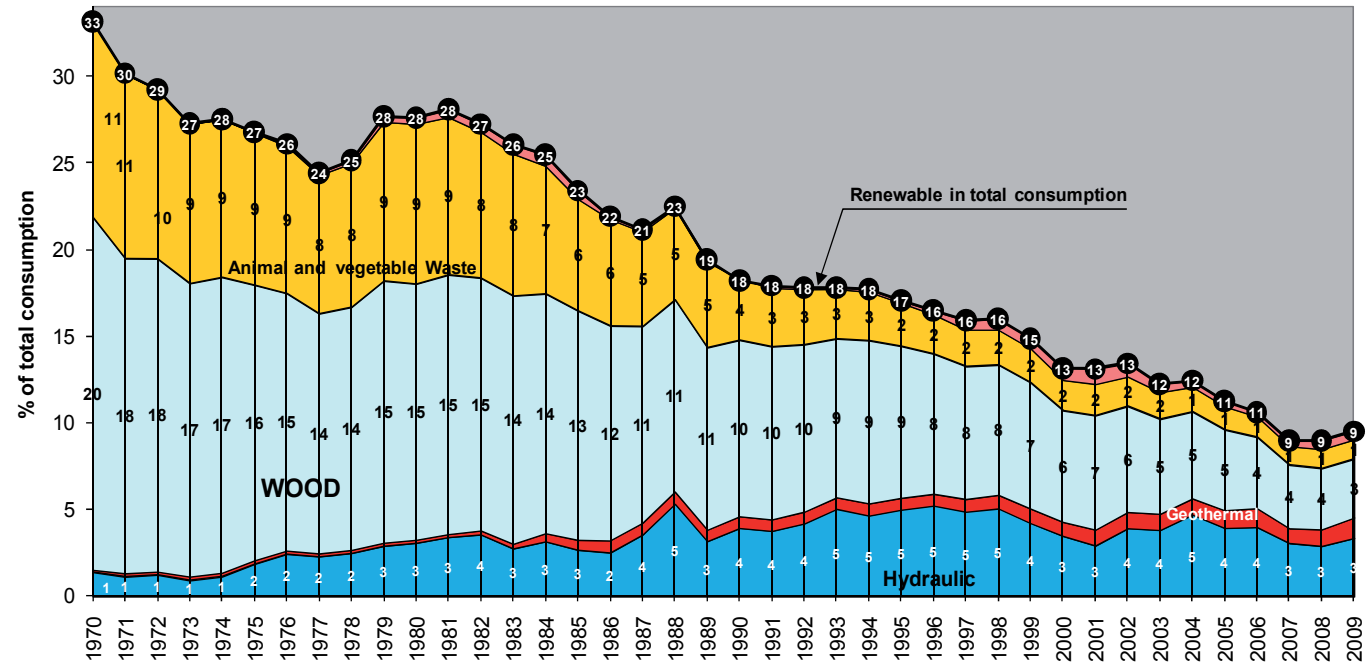

Fig. 9. During of the period 1970 and 2009 development of the total share of renewable energy sources in primary energy consumption (data from MENR 1970-2009)

\subsection{Energy production using renewable energy sources}

Distribution of installed capacity of Turkey by energy sources during the period 1940 and 2009 is illustrated in Fig. 10. The overall installed capacity was 217 MW in 1940 and the rate of renewable energy source was 3\%. The overall installed capacity increased 164 times in 2003 and reached $35587 \mathrm{MW}$. The renewable source, which was 7.8 MW at the beginning of the term, increased 1614 times and reached 12594 MW (35\%). The increase rate of use of renewable energy sources was accelerated especially in the middle of 1950s. This rate increased to 33\%, 38\%, and 35\% in 1973, 1986 and in 2009 respectively. Especially, the electricity production using natural gas caused that this rate decreased. While hard coal 
accounted for $50 \%$ of total installed capacity and $80 \%$ of electricity production in 1950, its share reduced continuously in the following years and realized $1.1 \%$ in installed capacity and $1.9 \%$ in electricity production. Lignite proved its importance during the petroleum crisis in 1973-1979. After 1973, its importance increased. The share of lignite in electricity production increased to $45 \%$ from $20 \%$ and its share in installed capacity reached $35 \%$ in the 1980s. After the year 2000, an increase in share of natural gas, both installed capacity and in electricity production, lowered the use of lignite. In 2009, the share of installed capacity by resources was $1 \%, 19 \%, 35 \%, 4 \%, 26 \%$ and $11 \%$ for hard coal, lignite, renewable, crude oil, natural gas and other, respectively (Yilmaz et al., 2005; Y1lmaz, 2004,2011; Y1lmaz 2008; Yilmaz and Aydıner, 2009; Yilmaz and Uslu, 2006).

The most important and the largest energy capacities of Turkey's are coal and renewable energy resources. Both energy resources constitute 61\% (hard coal 16\%, lignite 13\% and renewable $32 \%$ ) of the total installed capacity in 1970. The total installed capacity increased and reached to $78 \%$ (hard coal $2 \%$, lignite $29 \%$ and renewable $47 \%$ ) until 1995 . In this rate just only hard coal percentage decreased, lignite and renewable increased as domestic energy sources. But, after this time the total installed capacity decreased and reached to $54 \%$ (hard coal 1\%, lignite 18\% and renewable 34\%) in 2009 as illustrated in Fig 11.

In Figure 12, distribution of electricity production of Turkey by energy resources is given in a long historical order for 1940 and 2009 term. As seen in the Figure, coal (especially hard coal) had a share of $80 \%$ in electricity production in 1940 . In the same year, the share of electricity production by resources was $6 \%, 3 \%, 6 \%, 5 \%$, for lignite, renewable, crude oil and other, respectively. The rate of electricity production using renewable energy resources and lignite had begun increasing in time reached to $21 \%$ and $14 \%$ respectively in 1973 . The share of hard coal sharply decreased and reached to $12 \%$ in 1973 . By the middle of 1960s, use of oil

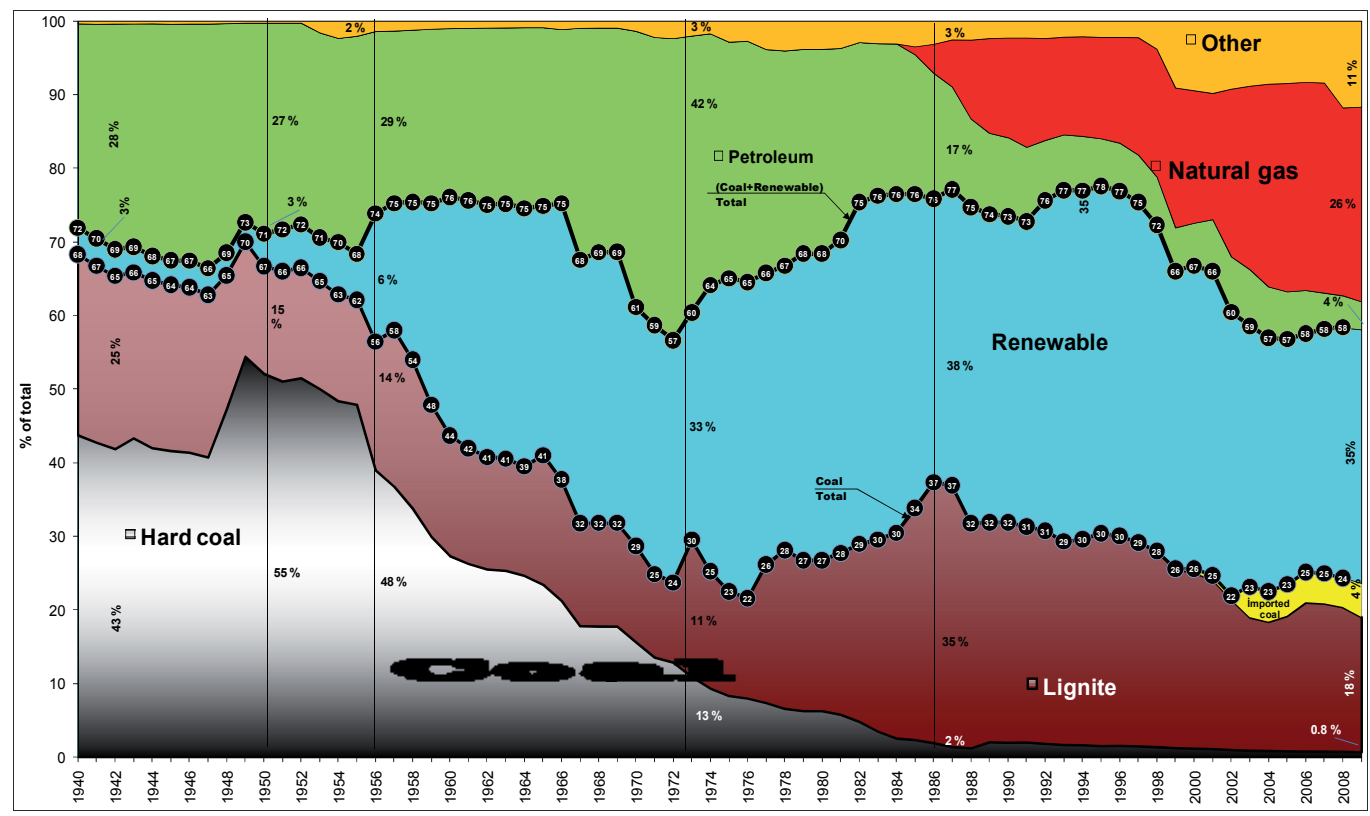

Fig. 10. During period of the 1940- 2009 distribution of installed capacity by energy sources (data from TEIAS 2009) 


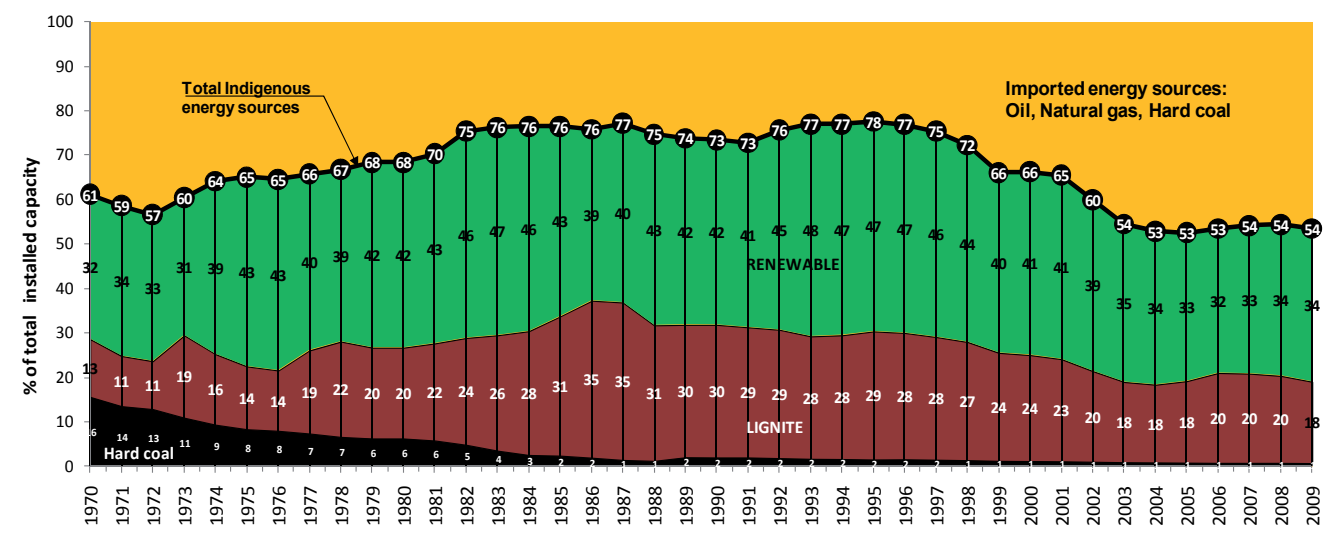

Fig. 11. During of the period 1970 and 2009 development of the share of renewable energy and coal by the total installed capacity (data from TEIAS, 2009)

in electricity production increased, since it is a cheaper than other resources, and this was quickly renounced after the oil crisis in 1973. After the crisis, Turkey gave importance on lignite, one of its own energy resources, and the share of coal in electricity production began increasing and reached $50 \%$. After 2000s, use of natural gas began using in electricity production as in all other areas and its share in electricity production reached $45 \%$ in a very short time until 2003. Also imported hard coal began to use in electricity production with $6 \%$ in 2003 . The share of natural gas has increased and reached to $49 \%$ in electricity generation in 2009 . At the same year, distribution by resources was as follows natural gas: coal (hard coal \%2 + lignite \%20) renewable \%19, oil \%3, and imported hard coal 7\% (Yılmaz 2008; Yılmaz, and Aydıner, 2009).

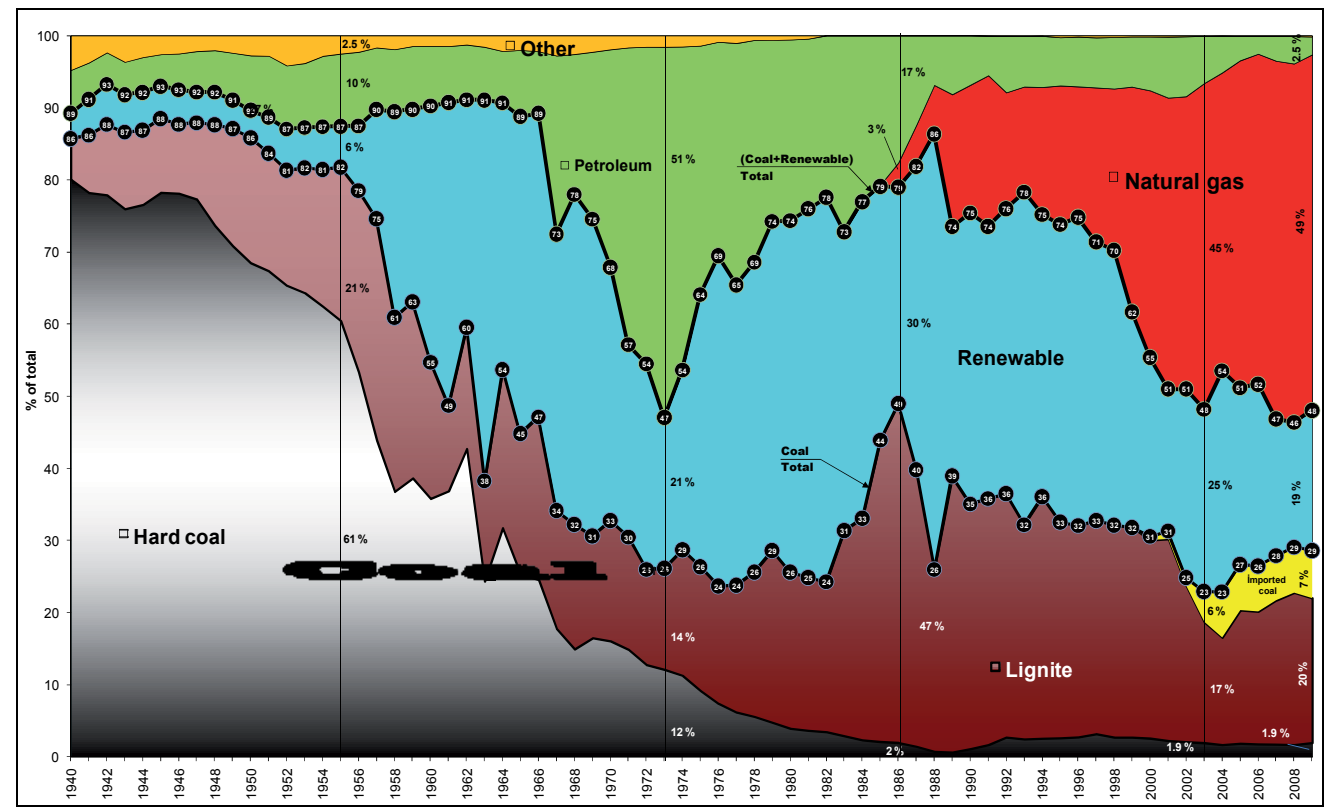

Fig. 12. During period of the 1940- 2009 electricity production by energy sources (data from TEIAS 2009) 
The first of the areas where coal and renewable energy can be used most intensively is electricity production. In Figure 13, distribution of the total electricity production by renewable energy and coal sources are given in a historical order. As seen in the Figure, coal (especially hard coal) and renewable energy had a share of $68 \%$ (hard coal $16 \%$, lignite $17 \%$ and renewable $18 \%$ ) in electricity production in 1970 . The rate of electricity production using renewable energy resources and lignite had begun increasing in time and the share of the hard coal decreased to $1 \%$ until beginning of 1988 and the share of renewable energy resources and lignite increased to $42 \%$ and $38 \%$ respectively. But, after that time the total electricity generation by renewable energy and coal resources decreased and reached to $41 \%$ (hard coal $2 \%$, lignite $20 \%$ and renewable 19\%) in 2009. Turkey has become a country, which imports $70 \%$ of its energy resources, during this term. Because after the crisis in 1973, Turkey gave importance on lignite, one of its own energy resources, and the share of coal in electricity production began increasing. However, after 2000s, use of natural gas began prevailing in electricity production as in all other areas and its share in electricity production reached $45 \%$ in a very short time.

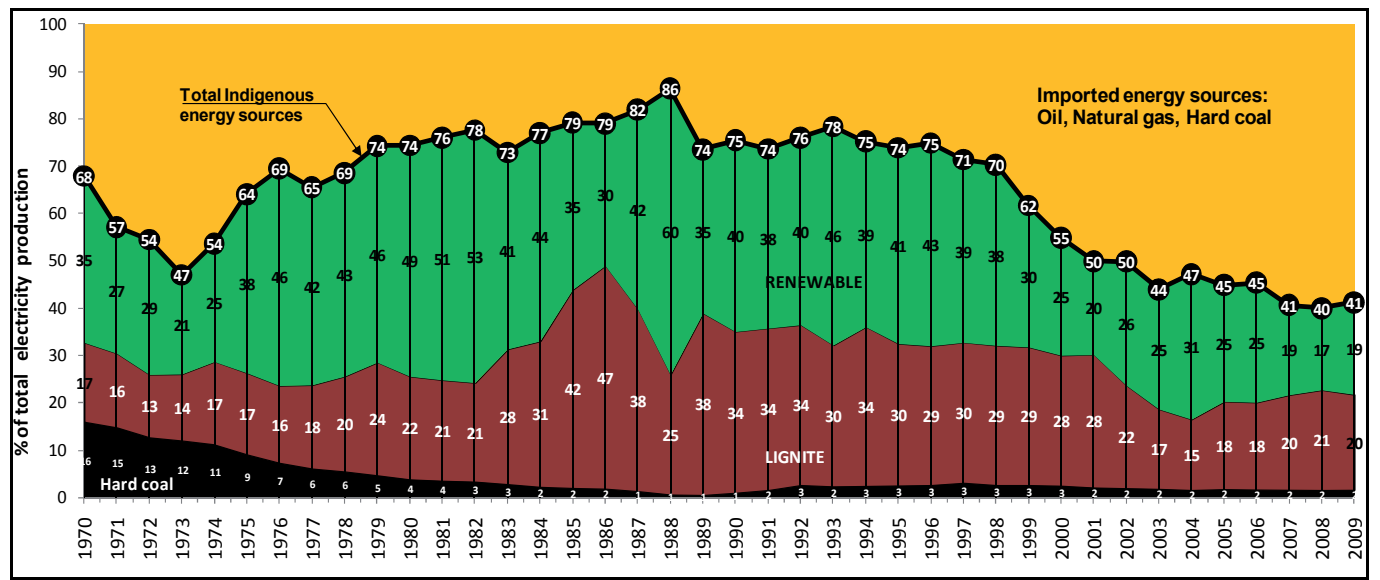

Fig. 13. During of the period 1970 and 2009 development of the share of renewable energy and coal in the total electricity production (data from TEIAS 2009)

\subsection{Renewable energy potential of Turkey}

The potentials of the main renewable energy sources of Turkey are collectively given in Table 2. The economical potential given in the Table equals the usable potential. The mostly used renewable energy sources in Turkey are biomass energy and hydraulic energy. While geothermal is the third source in the listing, its use is very limited. Use of solar energy is at an emblematic level and use of wind energy is being commenced recently. The overall economical and/or usable potential of the listed renewable energy sources is at a level of 68 Mtoe/year (TUSIAD,1998).

The overall annual electricity production potential of renewable energy sources is 486.3 billon kWh economically. Solar energy, geothermal energy and wind energy potentials are not used or used scarcely. The most used renewable energy source in Turkey is hydraulic energy. Today, the economical hydroelectric potential of Turkey is 129.9 billion $\mathrm{kWh}$ and $35 \%(45.930 \mathrm{GWh})$ of it is operative, $8 \%(10.518 \mathrm{GWh})$ of it is under construction and $57 \%$ $(73.459 \mathrm{GWh})$ of it is at project level Table 2. 


\begin{tabular}{|c|c|c|c|}
\hline Renewable Energy Source & Gross & Technical & Economic available \\
\hline $\begin{array}{l}\text { Hydropower } \\
\text { (MW) } \\
\text { (billion kWh/year) }\end{array}$ & $\begin{array}{c}107500 \\
430\end{array}$ & $\begin{array}{c}53730 \\
215\end{array}$ & $\begin{array}{l}36652 \\
129.9\end{array}$ \\
\hline $\begin{array}{l}\text { Geothermal } \\
\text { Heat (MW) } \\
\text { (Mtoe/year) } \\
\text { Electricity (MW) } \\
\text { (billion kWh/year) }\end{array}$ & $\begin{array}{l}31500 \\
\quad- \\
4500 \\
-\end{array}$ & $\begin{array}{c}7500 \\
5.4 \\
500 \\
-\end{array}$ & $\begin{array}{c}2843 \\
1.8 \\
350 \\
1.4\end{array}$ \\
\hline \begin{tabular}{|l} 
Solar \\
Heat + electricity (MW) \\
(billion kWh/year) \\
(Mtoe/year)
\end{tabular} & $\begin{array}{c}111500 \times 10^{3} \\
977000 \\
80000\end{array}$ & $\begin{array}{c}1400000 \\
6105 \\
500\end{array}$ & $\begin{array}{c}116000 \\
305 \\
25\end{array}$ \\
\hline $\begin{array}{l}\text { Wind } \\
\quad \text { Electricity (MW) } \\
\quad \text { (billion kWh/year) }\end{array}$ & $\begin{array}{c}220000 \\
400\end{array}$ & $\begin{array}{c}115000 \\
290\end{array}$ & $\begin{array}{c}20000 \\
50\end{array}$ \\
\hline $\begin{array}{l}\text { Classic Biomass } \\
\text { Fuel (Mtoe/year) } \\
\text { Modern Biomass } \\
\text { Fuel (Mtoe/year) }\end{array}$ & $\begin{array}{l}30 \\
90\end{array}$ & $\begin{array}{l}10 \\
40\end{array}$ & $\begin{array}{l}7 \\
25\end{array}$ \\
\hline
\end{tabular}

Table 2. Potential of Renewable Energy Sources (MENR,2009)

\section{Coal and energy}

\subsection{Energy production based on coal}

The coal production culture in Turkey was introduced with the exploration of hard coal by Uzun Mehmet in Köseağzı quarter of Kestaneci village in Zonguldak province on $8^{\text {th }}$ November 1829. Up to date, hard coal has been produced in Turkey. There is no definite information about the first use of lignite. It is known that lignite was being produced in many locations in Turkey, especially in Soma -Kütahya (Y1lmaz, 2008).

Hard coal is used intensively in industry and heating and especially in electricity production. Lignite coals are used mostly for electricity production since its calorific value is low. The share of coal in overall primary energy production was 31\% (lignite 12\%, hard coal 19\%) in 1970 , and it increased to $46 \%$ (lignite 38\%, hard coal 8\%) in 1990 with an increase rate of $48 \%$. In 2009 , the share of coal in total primary energy sources has increased and reached to $57 \%$ (lignite 53\%, hard coal 4\%) as shown in Fig 14. The primary energy production of Turkey has been limited and the largest share in this increase belonged to lignite. It is hope that this rate of percentage increase will continue in the following years. On the other hand, the share of coal in overall consumption was $24 \%$ (lignite $9 \%$, hard coal 15\%) in 1970, and it increased to $31 \%$ 
(lignite 19\%, hard coal 12\%) in 1990 with an increase rate of 16\%. In 2009, the share of coal in total primary energy sources decreased and reached to $29 \%$ (lignite $15 \%$, hard coal 14\%) (Fig. 15). Turkey's primary energy consumption is higher than energy production. In other words, the increase rate of primary energy consumption is about 6 times of that of the production. And Turkey consumes 6 times of its production. If this rate increased in the following years, Turkey would become an import dependent country in terms of energy in the following years (Arığlu, Yılmaz, 2002a, 2002b,2002c; MENR, 2009; Yılmaz 2008).

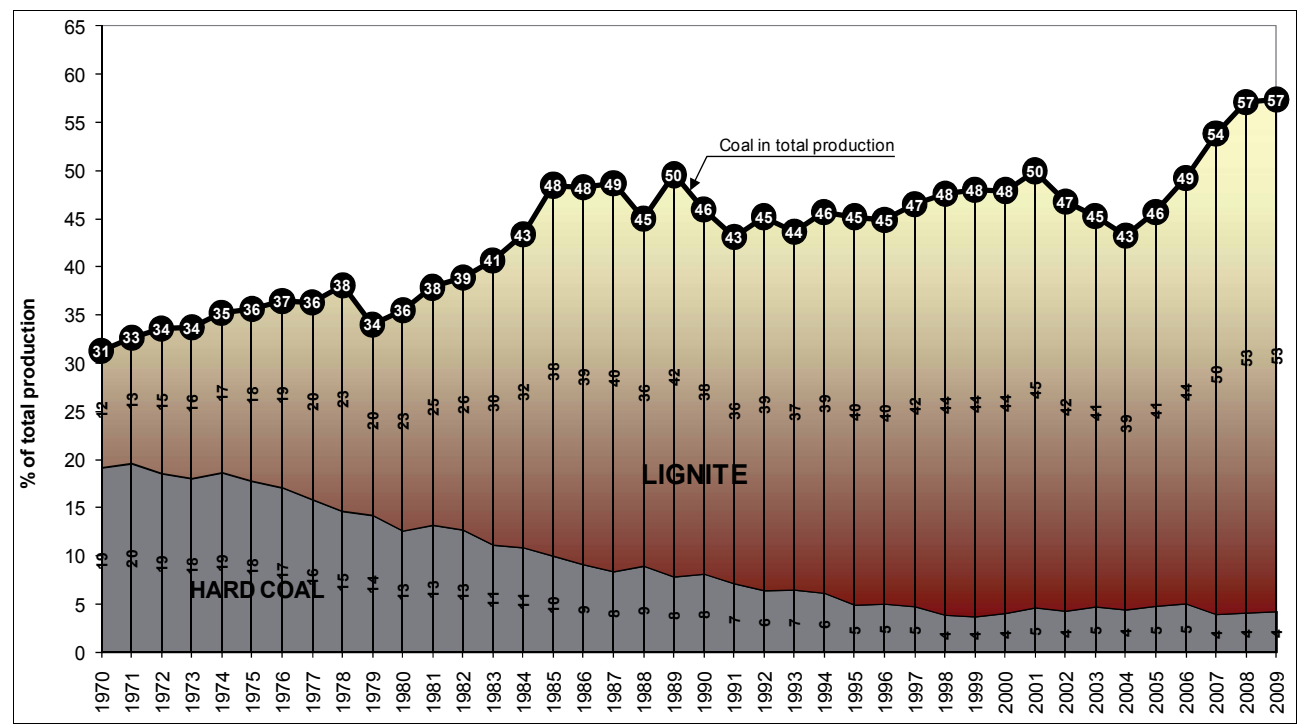

Fig. 14. During of the period 1970 and 2009, development of the share of coal energy sources in primary energy production (data from MENR, 1970-2009)

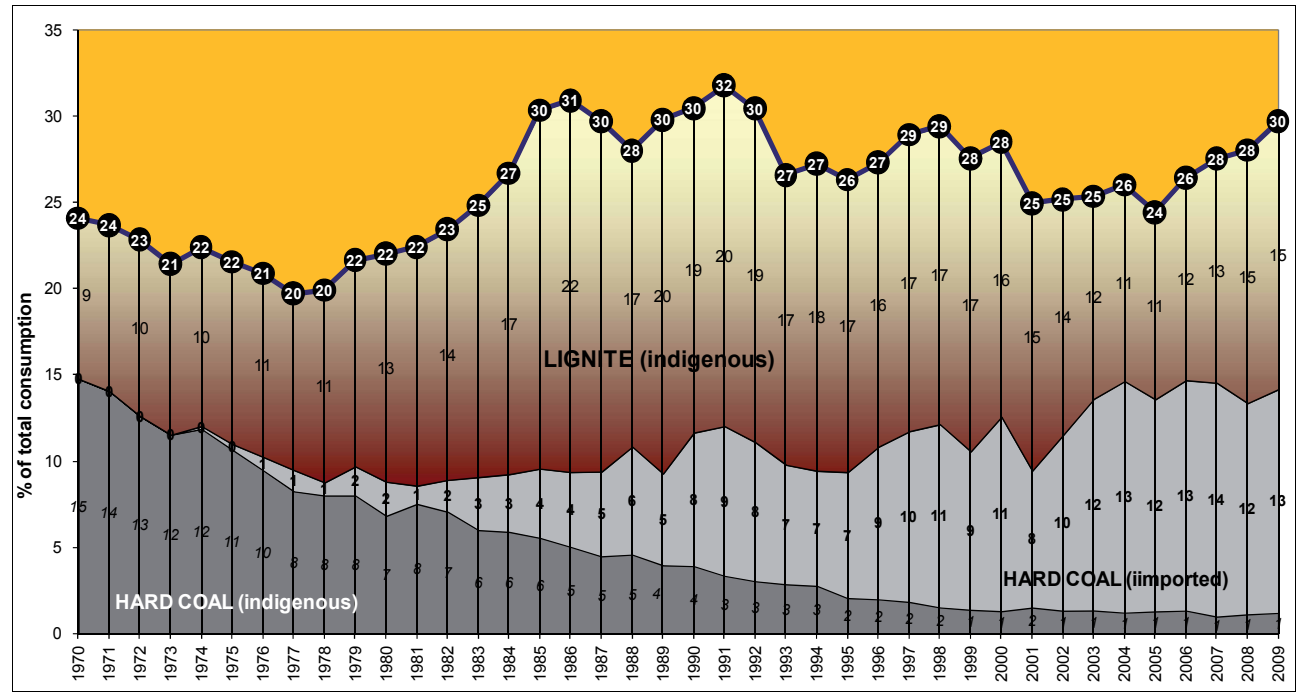

Fig. 15. During the period of 1970 -2009 development of share of coal in primary energy consumption (data from MENR, 1970-2009) 


\subsection{Coal potential, production and consumption}

Turkey has an important potential from the point of view of coal reserves (Fig. 16). Apart from the hard coal and lignite reserves, asphaltite, bituminous shale and peat reserves are also present in the country. Turkey's significant hard coal basin exists in Zonguldak province which is on the Western Back Sea Region. The total reserve (ready + proven + probable + possible) is about 1.3 billion ton (Table 3 ). Hard coal reserves are distributed into five districts. Distributions of total reserves among these five districts are: Ereğli 34 million tons; Zonguldak 884 million tons; Amasra 408 million tons; Kurucaşile 1 million tons; Azdavay 5 million tons. The calorific value of the hard coal differs from 6.500 to 6.650 $\mathrm{kcal} / \mathrm{kg}$ (Table 3) (TTK, 2004,2009; TKI, 2004,2009).

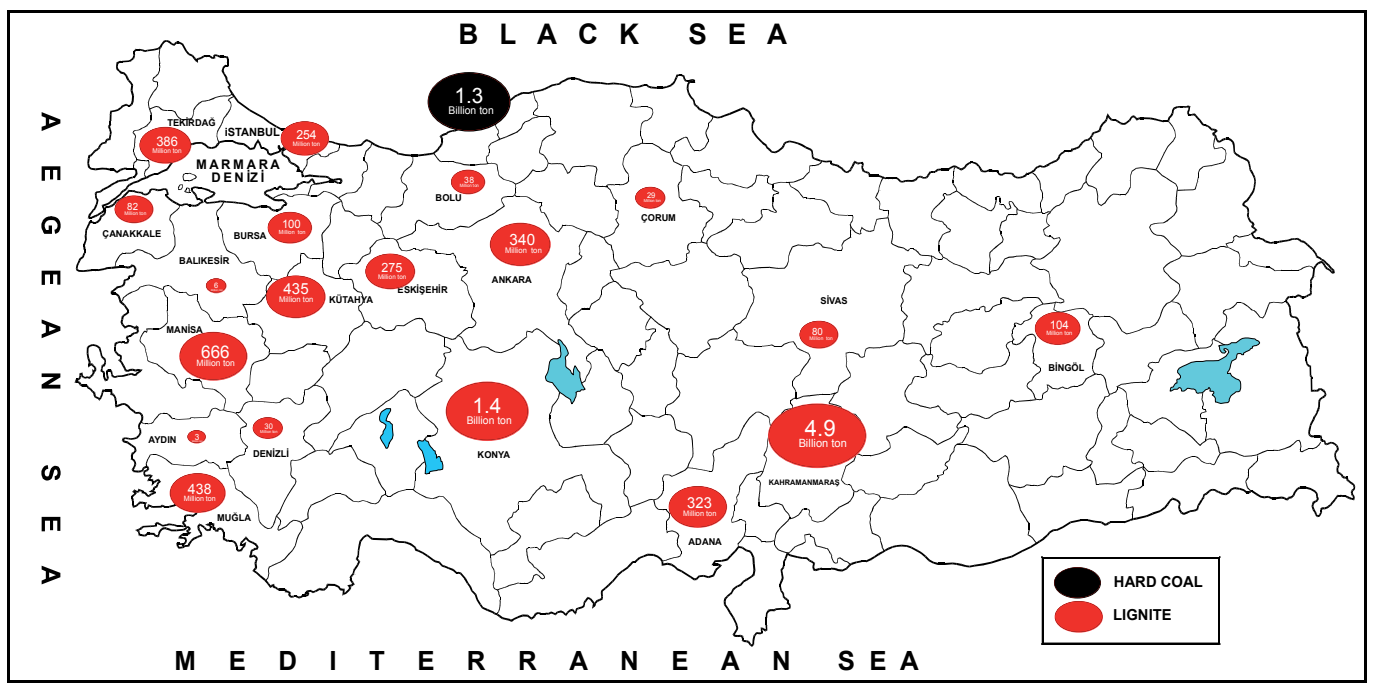

Fig. 16. Distribution of hard coal and lignite reserves of Turkey

\begin{tabular}{|l|l|l|l|l|l|c|}
\hline \multicolumn{2}{|c|}{ Location } & \multicolumn{4}{c|}{ RESERVES (1000 TON) } & Calorific \\
value, kCal/kg \\
\hline Province & Dictrict & Proven & Probable & Possible & Total & \\
\hline Zonguldak & Ereğli & 11.241 & 15.86 & 7.883 & 34.984 & 6650 \\
\hline Zonguldak & Center & 351.272 & 294.043 & 239.029 & 884.345 & 6650 \\
\hline Bartın & Amasra & 172.107 & 115.052 & 121.535 & 408.694 & 6000 \\
\hline Bartın & Kurucaşile & & 1 & & 1 & 6500 \\
\hline Kastamonu & Azdavay & & 5.593 & & 5.593 & 6500 \\
\hline \multicolumn{2}{|r|}{ TOPLAM } & $\mathbf{5 3 4 . 6 2}$ & $\mathbf{4 3 1 . 5 4 8}$ & $\mathbf{3 6 8 . 4 4 7}$ & $\mathbf{1 . 3 3 4 . 6 1 5}$ & - \\
\hline
\end{tabular}

Table 3. Distribution of hard coal reserves of Turkey (MENR 2010)

Hard coal Production is maintained under very difficult geological conditions. The production depth reached 600-1000 $\mathrm{m}$ in some regions. Such difficult working conditions caused that the unit costs increased and this affected the competitive power of the country in world's markets. In addition, the expected increase in production could not be achieved and contrary to expectations the production was decreased to 3 million tons from 9 million tons (Table 4). This 
production level can meet only $10 \%-12 \%$ of the overall consumption of Turkey, which are 22-23 million tons. While, especially in the recent years, a significant part of the produced hard coal is used for electricity production, the remaining coal is consumed for other purposes, such as iron and steel industry, household fuel etc as illustrated in Fig.17 and Table 4. In 2009, the share of hard coal consumption by sectoral were $70 \%, 27 \%$ and $4 \%$ for industry, power station and house hold, respectively (Y1lmaz 2011; TTK 2009; MENR 2010).

\begin{tabular}{|c|c|c|c|c|c|c|c|c|c|}
\hline \multirow{2}{*}{ Years } & \multicolumn{2}{|c|}{\begin{tabular}{|c|} 
Hard coal \\
production/consumption \\
$(x 1000$ ton/year $)$
\end{tabular}} & \multirow{2}{*}{$\begin{array}{c}\text { [production } \\
\text { /consumption] } \\
\text { x100], \% }\end{array}$} & \multicolumn{3}{|c|}{$\begin{array}{l}\text { Consumption } \\
\text { [x1000 ton/year] }\end{array}$} & \multicolumn{3}{|c|}{$\begin{array}{l}\text { Distribution of total } \\
\text { consumption, } \%\end{array}$} \\
\hline & Production & Consumption & & Industry & $\begin{array}{l}\text { Power } \\
\text { station }\end{array}$ & $\begin{array}{c}\text { House } \\
\text { hold }\end{array}$ & Industry & $\begin{array}{l}\text { Power } \\
\text { station }\end{array}$ & $\begin{array}{c}\text { House } \\
\text { hold }\end{array}$ \\
\hline 2000 & 2,392 & 15,525 & 15.41 & 12,777 & 2,034 & 714 & 82.3 & 13.1 & 4.6 \\
\hline 2001 & 2,494 & 11,176 & 22.32 & 8,106 & 2,274 & 796 & 72.5 & 20.3 & 7.1 \\
\hline 2002 & 2,319 & 13,830 & 16.77 & 10,920 & 2,051 & 859 & 79.0 & 14.8 & 6.2 \\
\hline 2003 & 2,059 & 17,535 & 11.74 & 12,845 & 3,706 & 984 & 73.3 & 21.1 & 5.6 \\
\hline 2004 & 1,946 & 18,904 & 10.29 & 13,435 & 4,565 & 904 & 71.1 & 24.1 & 4.8 \\
\hline 2005 & 2,170 & 19,421 & 11.17 & 13,227 & 5,259 & 935 & 68.1 & 27.1 & 4.8 \\
\hline 2006 & 2,319 & 22,798 & 10.17 & 16,315 & 5,618 & 865 & 71.6 & 24.6 & 3.8 \\
\hline 2007 & 2,462 & 25,388 & 9.70 & 18,611 & 5,912 & 865 & 73.3 & 23.3 & 3.4 \\
\hline 2008 & 2,601 & 22,720 & 11.45 & 15,658 & 6,197 & 865 & 68.9 & 27.3 & 3.8 \\
\hline 2009 & 2,863 & 23,698 & 12.08 & 16,472 & 6,361 & 865 & 69.5 & 26.8 & 3.7 \\
\hline
\end{tabular}

Table 4. Hardcoal production, consumption and using areas

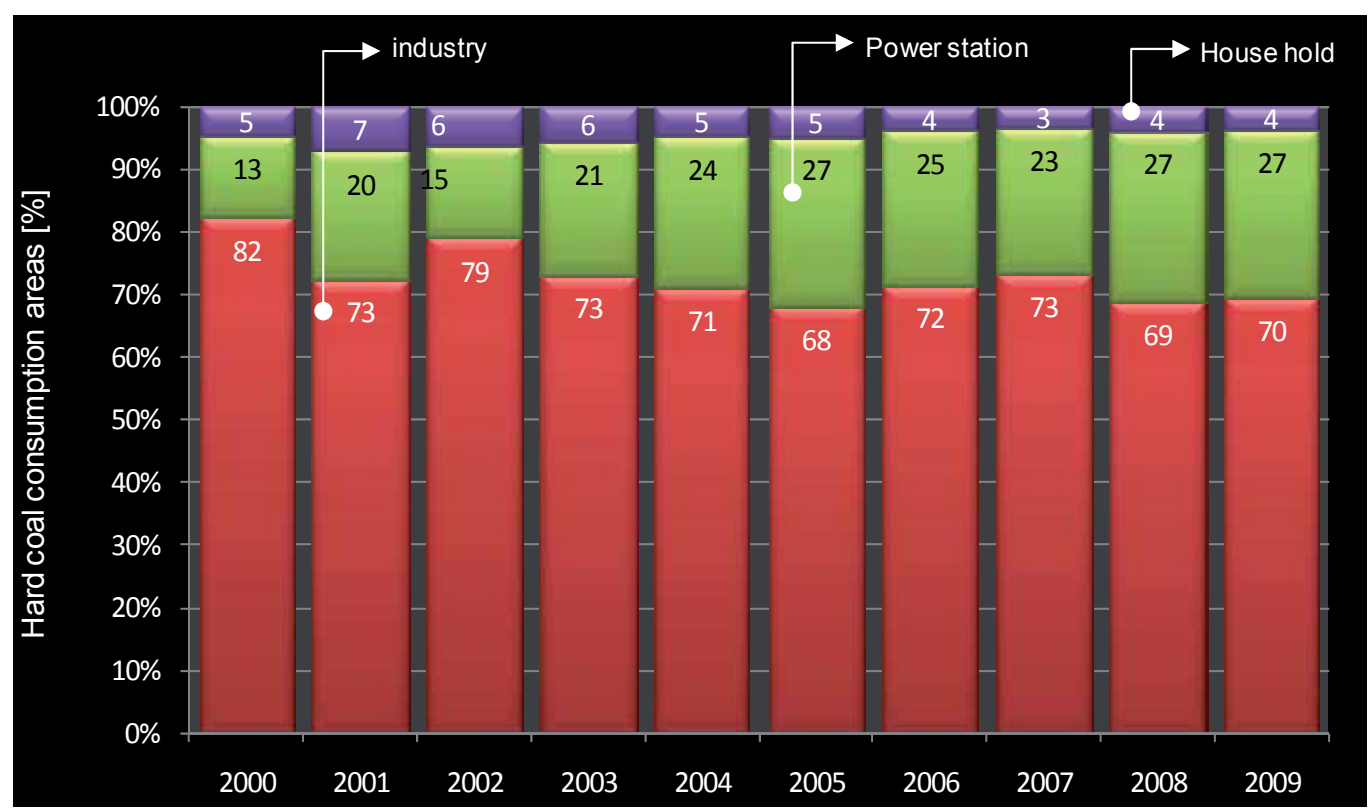

Fig. 17. Distribution of hard coal consumptions by sectoral (data from MENR 2000-2010) 
Lignite reserves constitute the large portion of total coal reserves. Lignite deposits dispersed all over the country (Y1lmaz, 2006). The most important known lignite deposits reserves are located in Afşin Elbistan, Muğla Soma, Tunçbilik, Seyitömer, Beypazarı and Sivas regions (Fig. 16). About 40\% (4.9 billion tons) lignite reserve is located around AfsinElbistan which is in the southeast of the Turkey (Yilmaz and Uslu 2007). Although total lignite reserves were about 8.07 billion tons (TKI 2009; TKI, 2010), Turkey's new total lignite reserves including proven, probable and possible reserves have reached about 11.4 billion tons after recent exploration activities. Turkey has a share of $2.5 \%$ in the world reserves and $8.2 \%$ in the world production (Yllmaz, 2011). Distribution of the lignite reserves in the Turkey is shown in Table 5 (TKI, 2004; 2010). Turkey's coal deposits are operated by companies which are Turkish Hard Coal Enterprise (TTK), Turkish Coal Enterprises (TKI) and the Electricity Generation Company (EUAS) and Private sectors. TTK is authorized for hard coal production, processing and distribution. More than half of lignite reserves are produced by TKI. Production of remains are belongs to private companies and EUAS for we in power plants. The distribution of reserves is as follows: TKI $21.5 \%$, EUAŞ $42 \%$, MTA 23\% and Private sector 13.5\% (Table 5.) (Y1lmaz 2008, EUAS 2004,2009; Anaç 2003).

\begin{tabular}{|c|c|c|c|c|c|c|}
\hline \multicolumn{7}{|c|}{ LIGNITE } \\
\hline \multirow{2}{*}{ Coal field } & \multicolumn{4}{|c|}{ Reserves (1000 TON) } & \multirow{2}{*}{$\begin{array}{c}\text { Ration in } \\
\text { total, } \%\end{array}$} & \multirow{2}{*}{$\begin{array}{c}\text { Calorific } \\
\text { value, } \\
\text { Kcal/kg }\end{array}$} \\
\hline & Proven & Probable & Possible & Total & & \\
\hline EÜAŞ & 4.718 & 104 & - & 4.822 & 42.0 & \multirow{5}{*}{$1031-4900$} \\
\hline TKİ & 2.239 & 218 & 1 & 2.458 & 21.5 & \\
\hline MTA & 1.803 & 685 & 123 & 2.611 & 23.0 & \\
\hline $\begin{array}{l}\text { Private } \\
\text { sector }\end{array}$ & 1.077 & 337 & 138 & 1.554 & 13.5 & \\
\hline TOPLAM & 9837 & 1344 & 262 & 11.445 & 100 & \\
\hline \multicolumn{7}{|c|}{ ASPHALTITE } \\
\hline \multicolumn{2}{|c|}{ Location } & \multicolumn{4}{|c|}{ Reserves (1000 TON) } & \multirow{2}{*}{$\begin{array}{c}\text { Calorific } \\
\text { value, } \\
\text { Kcal/kg }\end{array}$} \\
\hline Province & Dictrict & Proven & Probable & Possible & Total & \\
\hline Şırnak & Silopi & 31.812 & 16.21 & 1 & 49.022 & 5310 \\
\hline Şırnak & Merkez & 7.724 & 13.26 & 6.3 & 27.284 & 5330 \\
\hline TOPLAM & & 39.536 & 29.47 & 7.3 & 76.306 & - \\
\hline
\end{tabular}

Table 5. Distribution of Lignite and Asphaltite Reserves of Turkey (Data from, TTK, 2004; TKI, 2010).

The lignite mined from most lignite deposits is low calorific value lignite and the calorific value of $90 \%$ of them is between 1000 and $3000 \mathrm{Kcal} / \mathrm{kg}$ (Fig.18). In this context, a significant part of the lignite production is used for electricity production (Fig 19.). Lignite production depends on electricity production. Lignite production reached to 76 million ton/year especially in 1970 and 2009 term, when the lignite production is very effective in electricity production. Its production decreased to 45 million ton/year after 2000, since its use in electricity production repressed after 2000. The overall lignite consumption can be met by the domestic production (Fig.19.) 
Lignite production depends on electricity production While 1\% of produced lignite in 1970 was used in power stations, $5 \%$ was used as house hold and industry. In 2000, the share of lignite consumption by sectoral were $82 \%$ and $18 \%$ power station and house hold and industry, respectively. In 2009, the share of the power station in lignite consumption increased and reached to $83 \%$ (Fig. 19).

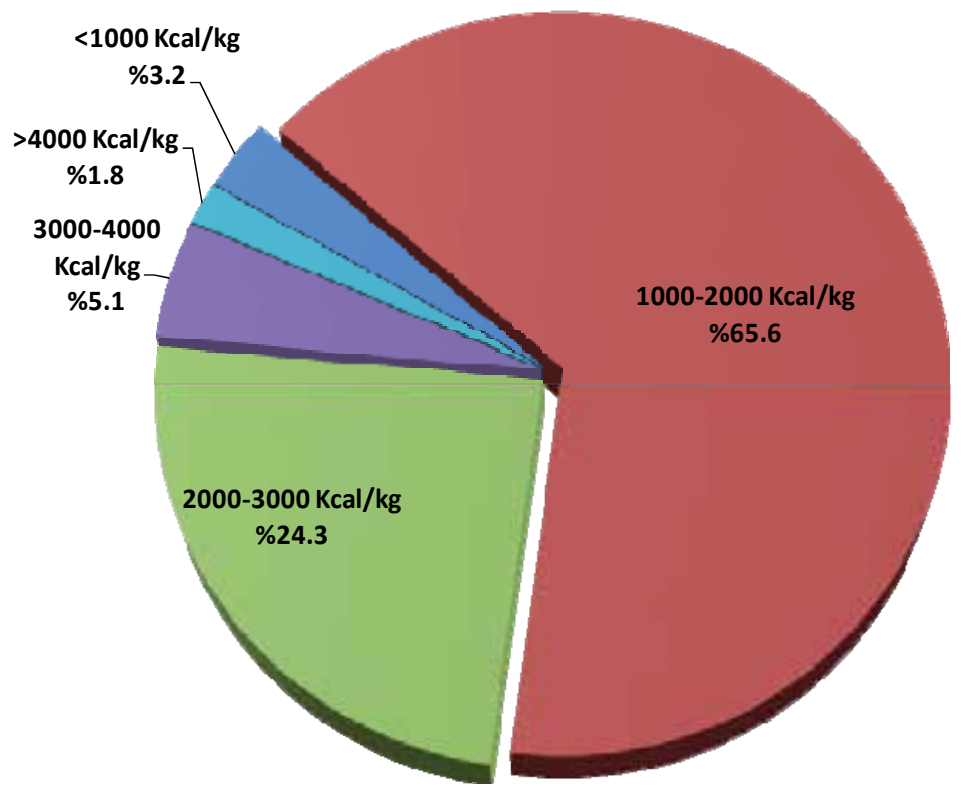

Fig. 18. Lignite by calorific value

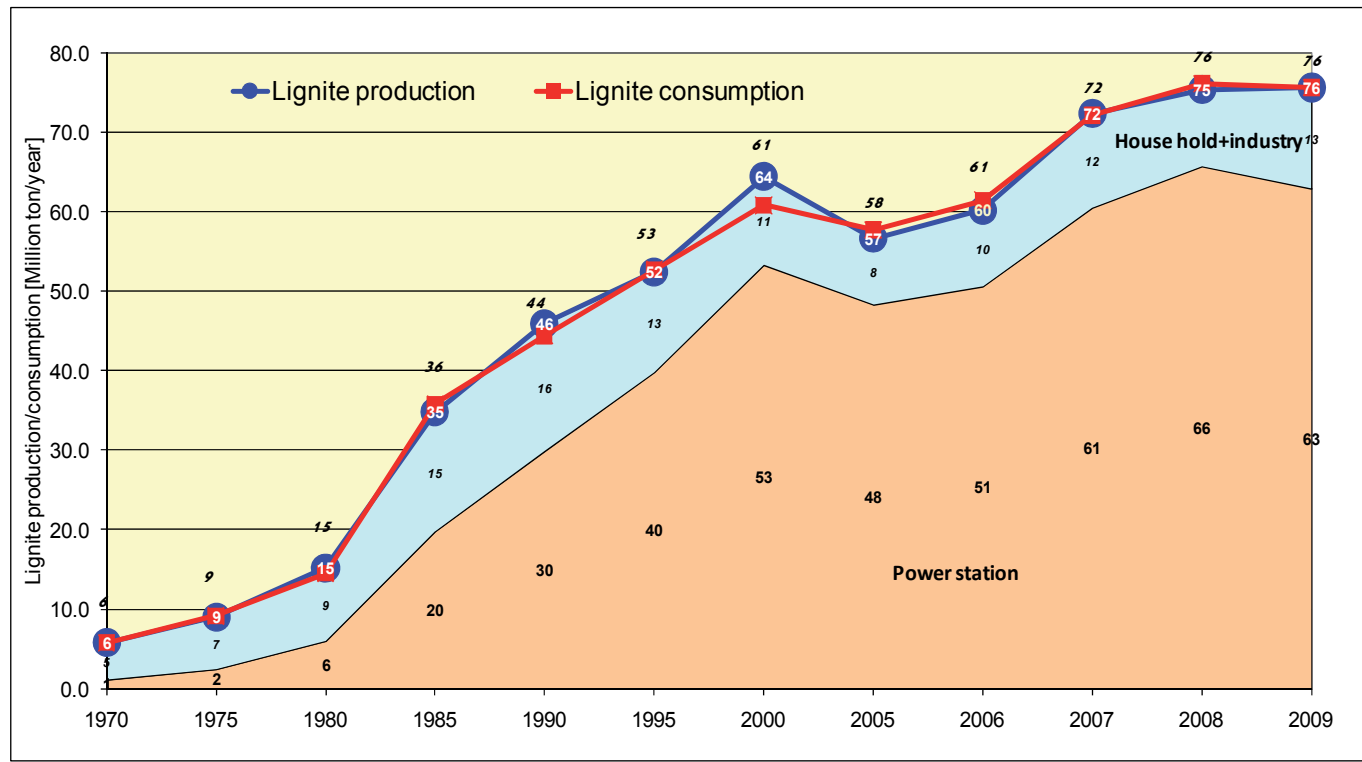

Fig. 19. Lignite production/consumption and consumption areas (data from TKI, 1970-2009) 


\section{Future projection}

The primary energy production-consumption of Turkey and distribution of electricity production of Turkey by sources projected for the years 2015 and 2020 are given in Figs. 20-21. No major change is seen or foreseen in the development of share of domestic energy sources in primary energy production. It is planned that this rate will be $32 \%$ in 2015 and $30 \%$ in 2020. In other words, $70 \%$ of the primary energy production of Turkey will be dependent on imports. On the other hand, renewable energy sources and hard coal constitute $90 \%$ of the primary energy consumption; $5-10$ points increase is foreseen in the share of coal in primary energy production 2015 and 2020. It is planned that this share will be $54 \%$ and $61 \%$, respectively, for the years. The dependence on imported energy sources for electricity production projected for the years 2015 and 2020 are $47 \%$ and 50\%, respectively (Fig.22). It is projected that the share of coal in electricity production will increase to $28 \%$ in 2020 and no significant change is planned in electricity production using renewable sources and it is projected that this share will decrease to $23 \%$ in 2020 . In other words, Turkey does not plan to introduce any expansion in energy production until 2020 when compared with today's conditions according to its energy projections (Y1lmaz,2008; TPAO 2006).

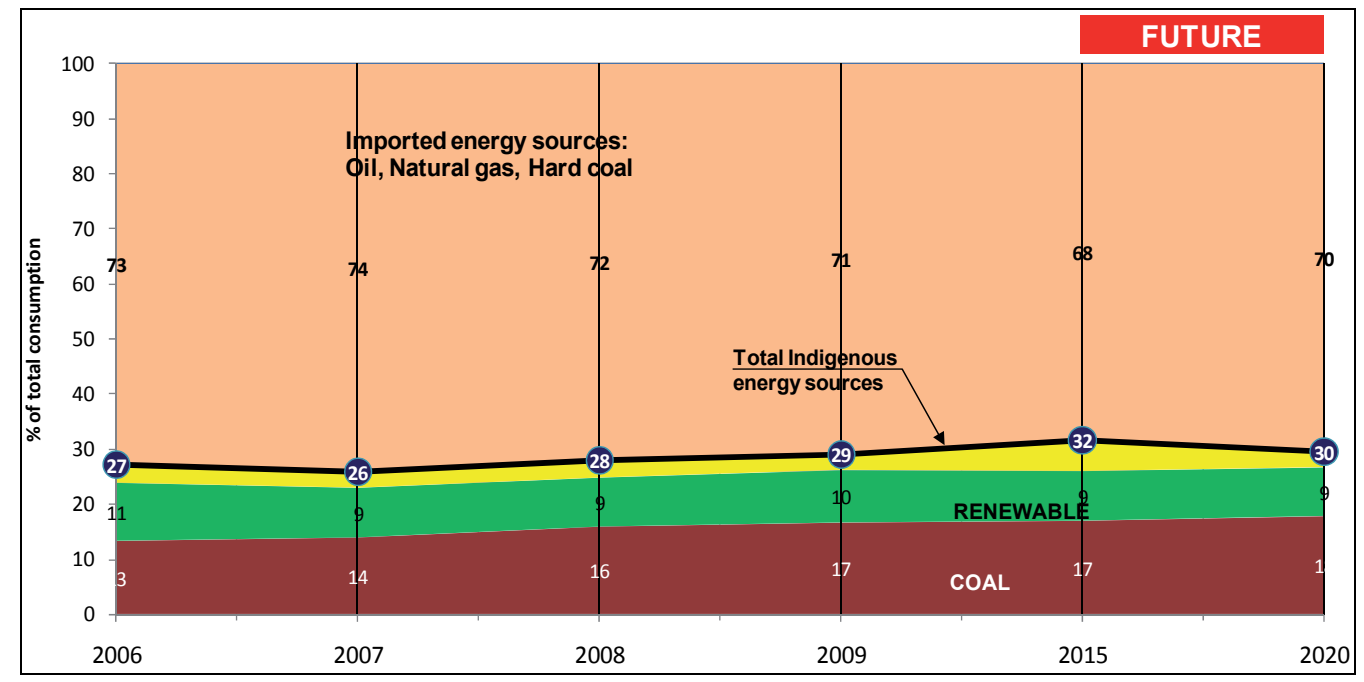

Fig. 20. Projection of development of the share of domestic energy sources in overall primary energy consumption (data from MENR, 2006,2010). 


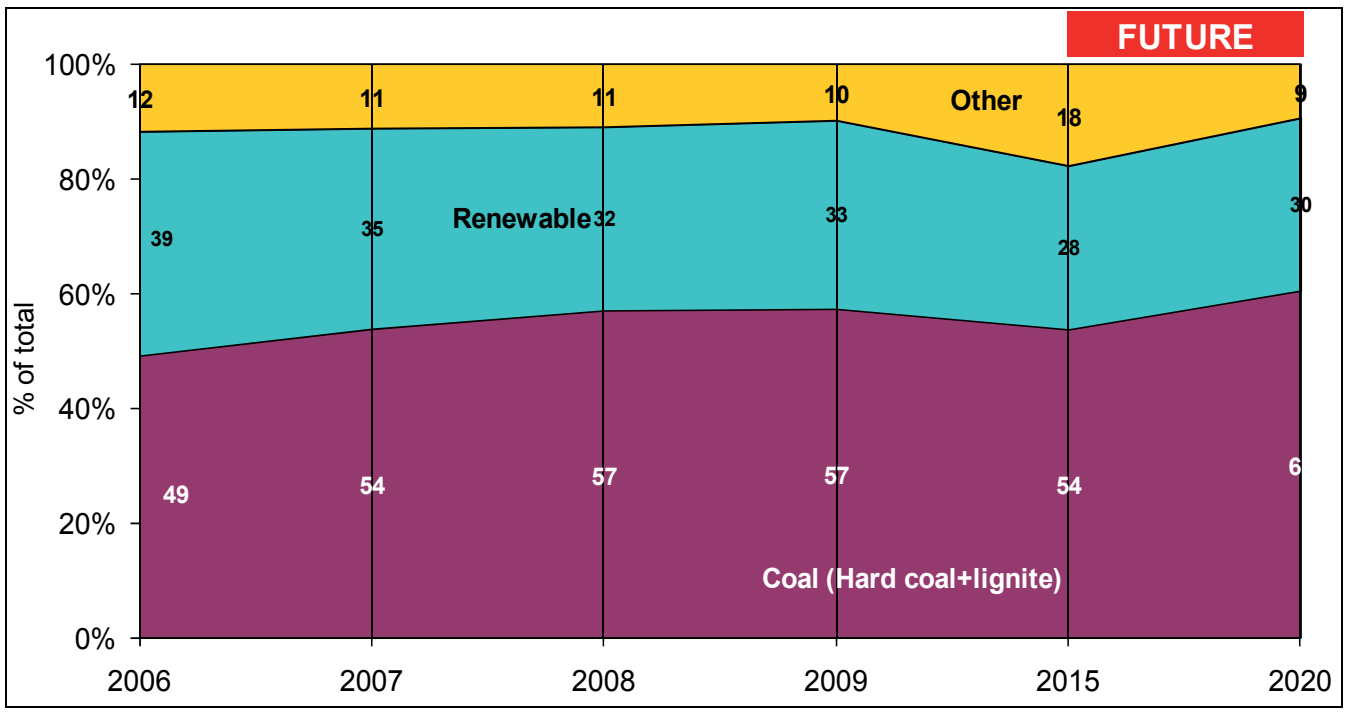

Fig. 21. Projection of distribution of domestic energy sources in overall primary energy production (data from MENR, 2006,2010).

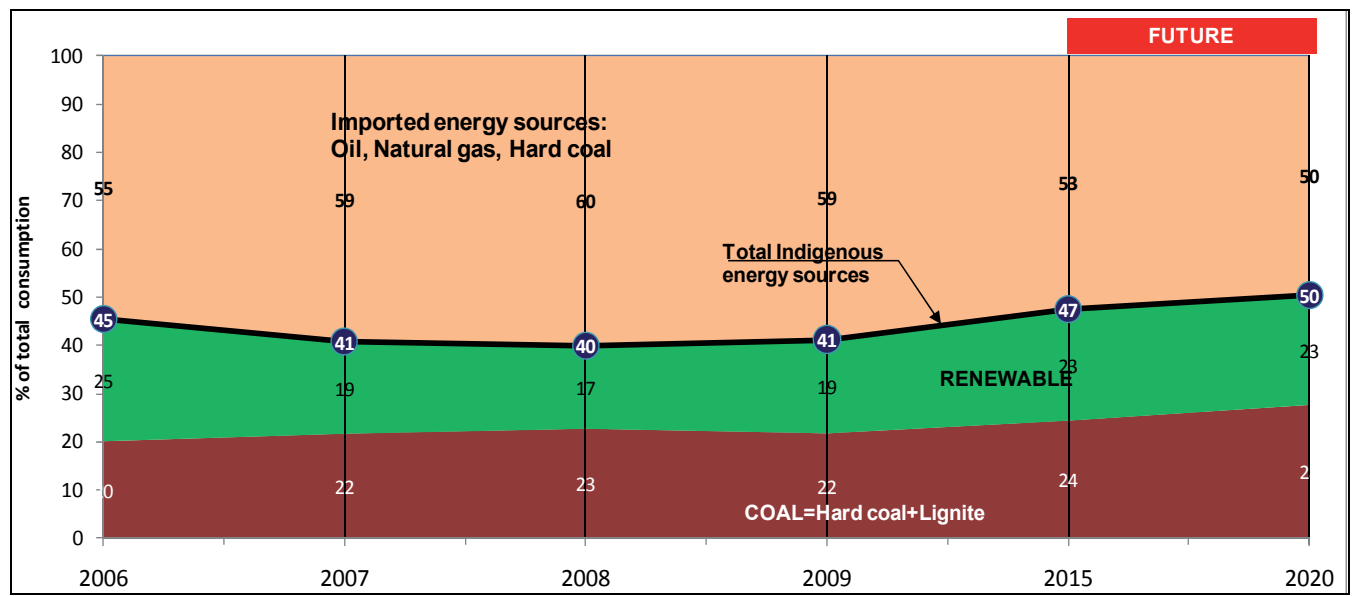

Fig. 22. Projection of development of domestic energy sources in electricity production (data from MENR, 2006,2010).

\section{Discussion and conclusion}

Turkey imports about $70 \%$ of the energy sources it uses in primary energy consumption. This percentage is $59 \%$ for electricity production. The imported energy sources are oil, natural gas and hard coal. The load of imports on Turkey's economy as of 2000-2009 is illustrated in Fig. 23. Turkey spent 29 billion dollars overall for energy imports in 2009. This amount constitutes $29 \%$ of the overall exports in 2009 and $21 \%$ of the overall imports. In other words, Turkey spends approximately one-third of the income it obtains from overall exports for energy imports. Oil and natural gas are the most imported energy sources with a 
percentage of $89 \%$ ( 26 billion dollars) of the overall energy source imports and it is followed by hard coal with a percentage of $11 \%$ ( 3 billion dollars). The incredible increase rate of natural gas consumption in the recent years constitutes an important expense item in the imports items of Turkey. More importantly, use of natural gas in industry and electricity production makes Turkey completely dependent on the foreign countries in terms of energy security. Especially Turkey's supplying over $50 \%$ of its electricity production from natural gas causes very severe security problems and Turkey should question this issue very seriously. On the other hand, although Turkey has sufficient hard coal reserves, it increasingly imports hard coal in order to consume it in industry and electricity production due to some reasons such as production difficulties and insufficient investments. Turkey should immediately take action in order to meet such requirements from its own sources. It should not be expected that the domestic production covers the consumption within a very short time, but it should be aimed at meeting or minimizing the deficit between the production and import within a long time. On the other hand, although Turkey has sufficient lignite reserves for electricity production, importing hard coal for this purpose is a completely strategic mistake (Y1lmaz,2008).

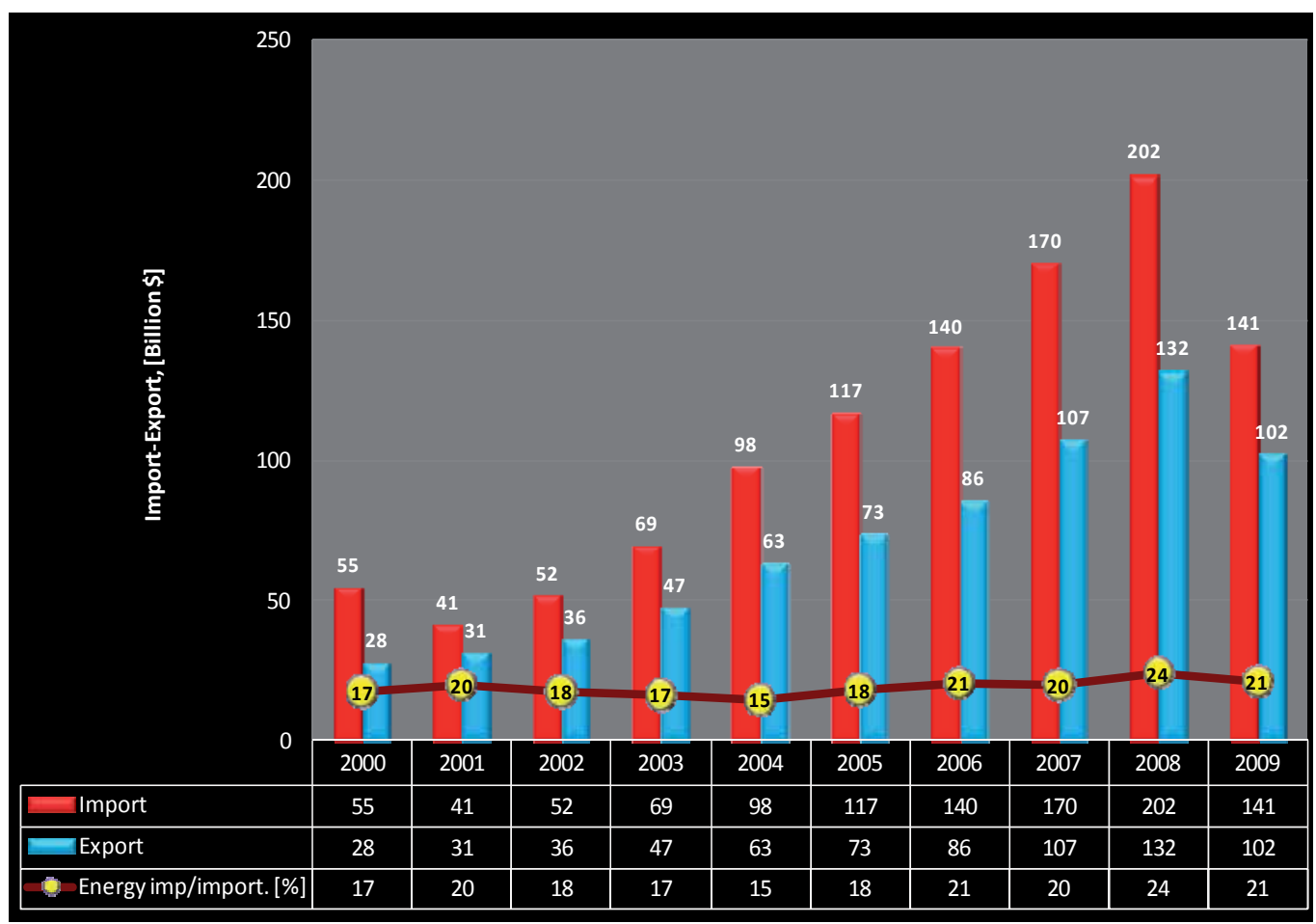

Fig. 23. Load of energy source imports on Turkey's economy 
The largest energy sources of Turkey are coal and renewable energy. Turkey should use these energy sources in areas where it can substitute them for oil and natural gas. The first of these areas is electricity production. In projections of Turkey (Fig. 22), it is proposed that $50 \%$ of the electricity production will be imported. It is planned that the overall demand for electricity will be 500 billion $\mathrm{kWh}$ in 2020 . However, there is a potential for producing reliable electricity from renewable energy sources (480 billion $\mathrm{kWh}$ ) and lignite thermal power plants (100 billion $\mathrm{kWh})$, which are operative and of which the projects are completed, economically (Table 2.). In other words, Turkey has a potential for producing electricity it demands by using only its own sources. It is obligatory to comply with the environmental pollution and emission limits in use and production of coal. The required measures in this regard has been taken in most of the operative power plants and the studies for taking such measures continue rapidly in the other power plants. It is vital for Turkey to take operating the coal reserves by using environment-friendly technologies and utilizing its sources at the highest level among its priorities (Y1lmaz, 2008).

\section{References}

Anaç, S. (2003). The Place of Coal in Energy Policies in Turkey, Turkish Coal Enterprise, Available from http:/ / www.tki.gov.tr.

Arıoğlu E. (ed).(1994). General Outlook to Turkish Lignite Sector, Privatisation in the World and Turkey, Turkish Mine Workers Union Publication, Ankara.

Arıoğlu, E.(1996) General Outlook For Worldwide Hard Coal Mining and The Evaluation of The Zonguldak Coal Enterprise/TURKEY, Privatization in The UK and Turkey With Particular Reference to The Coal Sector (Ed.M.Dartan), Marmara University European Community Institute, Istanbul, May

Arıoğlu, E., \& Yılmaz, A.O. (1997a). A Short Statistical Evaluation of Turkish Lignite Sector During 1983-1993. Istanbul Branch of Mining Engineers Chamber of Turkey, Working Report No. 2, Istanbul.

Arıoğlu, E; Yılmaz, A.O. (1997b). Turkish Economy With Macro Economic Indications and Statistical Evaluation of Turkish Mining Sector, Istanbul Branch of Mining Engineers Chamber of Turkey, Working Report No :5, Istanbul

Arıoğlu, E., \& Yılmaz, A.O. (2002a). General Outlook for Worldwide Hard Coal Mining and the Evaluation of the Zonguldak Coal Enterprise. Proceedings of the 13th coal congress of Turkey, Zonguldak Branch of Mining Engineers Chambers of Turkey, Zonguldak,

Arıoğlu, E, \& Yılmaz, A.O. (2002b). Realities in Zonguldak coal basin. Zonguldak Branch of Mining Engineers Chamber of Turkey, Zonguldak,

Arıoğlu, E; \& Yılmaz, A.O. (2002c). Evaluation of Turkish Lignite Mining, Tunçbilek Municipality $2^{\text {nd }}$ Lignite Festival, Tunçbilek, Kütahya.

BP (2009, 2010$)$. Statistical Review of World energy, Annual Report. Available from http://www.bp.com 
EUAS.(2004,2009). Statistic Data, Electricity Generation Co. Inc. Available from http:/ / www.euas.gov.tr.

MENR. (1970,2000,2002, 2006, 2009, 2010). Ministry of Energy and Natural Resources (MENR), Energy report of Turkey, Ankara. Available from http://www.enerji.gov.tr.

SIS. $(2003,2004)$. State Institute of Statistics yearbook of Turkey, Prime Ministry, Available from http:// www.tuik.gov.tr / [in Turkish and English]. Republic of Turkey, Ankara.

TEIAS. (1970, 2004, 2009). Electricity Generation-Transmission Statistics of Turkey, Turkish Electricity Transmission Co. General Management Rpc Department, Ankara. Available from: http://www.teias.gov.tr/ [in Turkish and English].

TKI. (2004,2009, 2010). Turkish Coal Enterprises. Coal (lignite) Annual Sector Report. Available from: http:/ / www.tki.gov.tr

$\mathrm{TPAO}(2006)$ Primary Energy Production-Consumption in Turkey. Available from http://petrol.tpao.gov.tr/ rprte/ energytr2.htmS.

TTK, (2004, 2009). Turkish Hard Coal Enterprises, Annual Reports, Zonguldak. Available from: http://www.taskomuru.gov.tr

TUSIAD. 1998. The Evaluation of Turkey's Energy Strategies Toward to 21st Century. Publication Number TUSIAD-T/98-12/239, İstanbul.

Yılmaz, A.O, \& Arığlu E.(2003). The Importance of Lignite in Energy Production and Turkish Coal Enterprise. In: Proceedings of the 18th International Mining Congress and Fair of Turkey. Mining Engineers Chamber of Turkey. Antalya.

Yilmaz, A. O, \& Aydiner, K. (2009). The Place of Hard Coal in Energy Supply Pattern of Turkey, Energy Sources, part B, 4, 179-189.

Yilmaz, A. O., \& Uslu, T.(2006). The Role of Coal in Energy Production-Consumption and Sustainable Development of Turkey. Energy Policy, 35, 1117-1128.

Yılmaz, A. O.\& Uslu, T.(2007). Energy policies of Turkey During the Period 1923-2003. Energy Policy, 35, 258-264.

Yılmaz, A.O. \&Uslu, T. \& Savaş M.(2005). The Role of Coal in Sustainable Development of Turkey, Turkish 5th Energy Symposium, Electricity Engineers Chamber of Turkey, Ankara.

Yilmaz, A.O.(2003). General Outlook to Turkish Energy Sector and the Importance of Coal in Energy Production. In: Turkish Fourth Energy Symposium, Electricity Engineers Chamber of Turkey, Ankara.

Yilmaz, A.O., (2004,2011) . Energy Statistics of Turkey, Unpublished Documents, Trabzon.

Yilmaz, A. O.(2006). Coal potential of Turkey: Coal and Energy, Energy Exploration Exploitation, Volume 24, Number 6, 371-390

Yilmaz, A.O.(2008). Renewable Energy and Coal Use in Turkey, Renewable Energy, 33, 950959.

Yilmaz, A.O.(2009). Present Coal Potential of Turkey and Coal Usage in Electricity Generation, Energy Sources, part B, 4, 135-144. 
Yılmaz, A.O.(2011), Evaluation of Turkish Lignite Mining, Tunçbilek Municipality 8 $^{\text {rd }}$ Lignite Festival, Tunçbilek, Kütahya. 


\title{
Experiences of Community Wind Electrification Projects in Bolivia: Evaluation and Improvements for Future Projects
}

\author{
Laia Ferrer-Martí et al.* \\ Universitat Politècnica de Catalunya - Barcelona Tech, \\ Spain
}

\section{Introduction}

Currently, early in the XXI century, an estimated 2400 million people depend on traditional biomass for heating and cooking and 1500 million people lack access to electricity (IEA, 2009). Lack of electricity particularly affects rural areas of developing countries (Kanagawa and Nakata, 2008), exacerbating the urban-rural gap. In Bolivia, 35\% of the population, more than 3.5 million people do not have access to electricity.

Electrification systems based on renewable energy have proved being adequate to provide decentralized electricity to isolated rural communities around the world (Chaureya et al., 2004). These autonomous systems are often much cheaper than the interconnected grid extension and use local resources, avoiding external dependencies which, in turn, promotes long-term sustainability of projects. In particular, micro-wind systems are an alternative with great potential to generate power in rural areas (Lew, 2000), although their use has been limited to date. In South America, a significant institutional effort was made in Argentina to develop rural electrification projects using wind energy in the province of Chubut (Seitz, 2006). In Peru, there are some demonstrative projects of the use of wind power to electrify isolated communities, the first one in El Alumbre (Ferrer-Martí et al., 2010).

In Bolivia, the government's policies on rural electrification are governed by the Rural Electrification Regulation, which states that the Department of Energy is responsible for promoting sustainable development, seeking expanded coverage of electricity services throughout the country. Therefore it has the responsibility to update and develop the rural energy strategy, including the Indicative Rural Electrification Plan to facilitate the work of agents in the development of rural electrification. The basic principles that are taken into account are:

\footnotetext{
“Bruno Domenech'1, Walter Canedo², Carlos Reza², Mirtha Tellez³, Milton Dominguez, Lorenzo Perone ${ }^{4}$ and Jaime Salinas

1 Universitat Politècnica de Catalunya - Barcelona Tech, Spain

${ }^{2}$ CINER, Bolivia

${ }^{3}$ Mosoj Causay, Bolivia

4Engineering Without Borders, Spain
} 
- Legitimacy of demand, which is to prioritize energy projects according to the law of popular participation and decentralization of administrative management.

- Accessibility, facilitating access to potential consumers to energy services in market conditions.

- Adaptation of technology, using energy resources in accordance with the conditions of each region and the lowest cost alternative.

- Co-financing, which is to encourage public and private funding for energy projects.

- Sustainability, through the application of the principles of environmental conservation.

Despite commitments made by Bolivia at the international level to reverse the rates of coverage in basic services until 2015, the millennium goals are far from being met.

In this context, the NGOs CINER (Bolivia), Mosoj Causay (Bolivia) and Engineers Without Borders (Spain) promoted the "Andean Program for Rural Electrification and Access to Renewable Energy" in Bolivia. This program was initiated by Engineers Without Borders (Spain) in different countries of the Andean Community of Nations (CAN) that present a common and problematic context. The program pursued Universal Access to sustainable energy services, through capacity development and validation of appropriate technologies for Andean environment. In 2005 the program began in Peru and Ecuador; next the program was extended to the Andean region of Bolivia, which presents very similar geographical and socioeconomical characteristics to the Andean areas of Peru and Ecuador. In this framework, in 2007 CINER, Mosoj Causay and Engineers Without Borders developed actions related to access to renewable energy in rural communities, extending the program to Bolivia to implement the knowledge acquired in both countries, and to adapt it to the special characteristics of Bolivia. The overall objective in Bolivia is to develop and disseminate knowledge, as well as human and technological capabilities to initiate demonstration projects, working with different stakeholders from the perspective of utilization of renewable energy sources, and promoting and participating in the selection and management of technology solutions.

Within the overall program, the project "Improving Access to Renewable Energy in Rural Communities in Bolivia" aims to improve the quality of life of rural population by having access to energy in remote areas through renewable energy. The specific objectives of this project were:

1. To improve technical and management capabilities of the Bolivian plateau for access to the energy in the population, local governmental bodies and other stakeholders.

2. To increase access to efficient and sustainable energy through improved use of biomass and the production of electricity through renewable energy sources.

The actions were carried out with specialists in social and technological issues to promote that users, through processes of participation and training, learn to manage, to maintain and to make sustainable their energy systems. These actions will contribute improving their level of human development, life expectancy, increasing opportunities for women, and access to education for children and adults, protecting natural environment through more friendly family economies. All the actions were performed jointly with the efforts of the beneficiaries - in coordination with the municipal government.

Specifically, this paper examines the interventions in the municipalities of Turco and Challapata led by Engineers Without Borders, CINER and Mosoj Causay, with the collaboration of both municipal governments, the financing of the Spanish Agency for International Development (AECID) and the Government of Navarra (Spain). Within the 
municipalities of Turco and Challapata, two communities were selected with 13 and 9 households, respectively, that were electrified with individual wind systems. The electrification with renewable energy corresponded to the priorities and needs of the beneficiary population; before running the project, beneficiaries considered the lack of electric power as one of the main problems of both communities. The system installation was completed in December 2009. A year later, an external evaluation was conducted to analyze the performance and progress of the projects and it confirmed the level of satisfaction of the beneficiaries of the renewable energy equipment.

This article aims to describe and evaluate two community projects on wind power generation, both in technical and social aspects. These two examples provide lessons on management models at the community level. Moreover, we analyze the alternative design of projects that try to solve some of the drawbacks identified for the assessment of future project designs and implementations. The experience in Bolivia has shown the interest and willingness of rural indigenous populations to participate in electrification projects.

The remainder of this paper is organized as follows. Section 2 presents the economical analysis of the communities. Section 3 explains the wind resource assessment and section 4 describes the electrification project. Section 5 presents the evaluation methodology and section 6 presents the results and their analysis. Section 7 discusses alternative project designs. Finally, Section 8 summarizes the conclusions.

\section{Socioeconomical analysis of the communities}

This section presents the socioeconomical characteristics of the two communities, highlighting the differences between them. The purpose of this study was to analyze the characteristics of communities and families: the economy, consumption and energy demand, the level of organization, and individual and group capabilities. The instruments used to collect the information include socioeconomical surveys to each family, interviews with the local authorities and the representatives of the inhabitants, and a focus group with local organizations. This study was a key first step in the design and development of the management model with the administration.

\subsection{Rural area in Bolivia}

The household energy consumption in rural areas with no conventional energy supply is dominated by the demand for cooking ( $89 \%$ of total energy consumption). Lighting, communication (audiovisual, mobile, etc.) and other energy uses account for $11 \%$ of energy demand. Although not large amounts, lighting (5\%) and entertainment $(2 \%)$ are key demands to improve the quality of rural life and the integration of people through media. Productive uses of energy in these families represent a marginal percentage of total consumption; whenever they exist they are very specific, and must be analysed in particular way.

The structure of economic costs of energy source in rural scattered communities is different from population centers: batteries represent the largest amount of expenditure $(34.3 \%)$, followed by the consumption of diesel (20\%), LPG (18.8\%), kerosene $(15.3 \%)$ and candles $(11.6 \%)$. In the highlands, average annual spending in U.S. dollars on traditional energy sources is the lowest in the country with a total of \$ 40 U.S. for the population in extreme poverty. 
Due to low income of people in remote rural areas, the ability to pay is weak. However the amount of money previously used for the purchase of other energy sources (candles, kerosene, batteries, gas, etc.) may now be used to cover the cost of the electricity service. It is estimated that nearly all population strata might pay a US\$2.5 monthly fee, considering that the payment will be for more convenient energy services than those previously used. It is noteworthy that the percentage of expenses for energy supply with respect to income is higher when the income level is lower.

Some people have expressed their desire to obtain higher rates of public or international cooperation funding for electrification systems; this is probably due to very welfare practices developed by institutions in the past plans in these rural areas. However, it is obvious the willingness of communities and families to finance their consumption in case of having electricity. Moreover, it is worth to consider that making periodic payments for the energy service is not a common practice; traditional energy sources were acquired on specific occasions when families had available economic resources.

\subsection{Area and population}

The municipality of Turco is located in the western area of department of Oruro, in the province of Sajama, at an altitude of $3860 \mathrm{~m}$. Turco has an area of around $3873 \mathrm{~km}^{2}$, its topography is flat and rugged, with a large flat surface combined with hills and low hills with slopes of 5 to $15 \%$ and mountain slopes up to $60 \%$. Most towns and villages of Turco are located at altitudes ranging between 3738 and 4200 meters, the mountain range has peaks reaching $5300 \mathrm{~m}$. In general, the weather is cold, with annual mean minimum temperature of $1.6^{\circ} \mathrm{C}$ and maximum of $19.8^{\circ} \mathrm{C}$. Turco is characterized by two very distinct seasons: a dry season from April to September and a rainy season between October and March.

On the other hand, the Municipality of Challapata belongs to the province of Avaroa, in the south-eastern department of Oruro. Challapata has an area of around $3014 \mathrm{~km}^{2}$. The municipality has a semi-rugged relief in the mountainous territory of the central plateau, which stretches from north to south. Most towns and villages of Challapata are located between 3700 and $4300 \mathrm{~m}$. The municipality has a cold and dry weather with average annual temperatures of around $4.4^{\circ} \mathrm{C}$ in July and $11.6^{\circ} \mathrm{C}$ in February, but sometimes can drop to $-10^{\circ} \mathrm{C}$ in the cold months. The rainy season starts in October or November and runs until March, and is characterized by heavy rains followed by periods of 10-20 days without rain. The remaining months are dry season flows.

According to the national census of population and housing, in 2001 Turco has 3818 inhabitants, composed almost evenly of men and women and represented by young under 25 years that form nearly $50 \%$ of the population. However, the estimated population in 2009 was 3771 inhabitants, a slightly decrease is mainly explained by migration to the cities in search of jobs and better opportunities. There are few major population centers and most populations are small villages with few houses. The estimated density of the municipality is 0.98 inhabitants per $\mathrm{km}^{2}$. According to the 2001 census, the life expectancy at birth in the municipality of Turco is 49.6 years. Challapata has a much larger population with 24370 inhabitants almost evenly distributed between men and women being $50 \%$ of the population under 20 years. In contrast, in Challapata the population is increasing, it was estimated for 2009 a total of 27517 inhabitants. The density of the population of the municipality is 8.08 inhabitants per $\mathrm{km}^{2}$. According to the 2001 census, the life expectancy at birth in the municipality of Challapata is 53.7 years. 
The 2001 census data showed that the global literacy rate for the entire Turco municipality is $86.4 \%$ that is below the departmental average of $94.0 \%$. The average years of study at the municipality are 5.7. Women still are disadvantaged in their access to education, as an example their illiteracy rate is $10.7 \%$, while for men it has decreased to $4.2 \%$. In the municipality of Challapata the situation is even more limited, with the overall literacy rate of $76.9 \%$ and the average years of schooling of 4.4 .

The lack of permanent jobs and income security causes migration of the population of both municipalities to larger towns and cities from the department of Oruro, other departments of Bolivia, or even neighbouring cities of Chile. According to the Municipal Development Program (PDM) of 2007, 7.48\% of the population of Turco has emigrated temporarily or permanently. This occurs more frequently among men (74.59\%) from 10 to 50 years, children and youth because of higher level studies and for jobs to supplement the family income. In Challapata, according to the PDM 2002, the migration amounts to $29.21 \%$ of the population.

\subsection{Basic services}

According to the laws of municipal management, basic services are under the responsibility of municipal government. However, the municipality of Turco has not assumed responsibility for developing municipal policies aimed to ensure the coverage of basic services to the population, while the municipality of Challapata, has developed this task with moderate success. It is clear that in both cases the resources are not sufficient to meet the needs of the communities and, moreover, the operational capacity of the technical teams of the municipalities is limited.

The attention of medical services is poor and does not cover the expectations of the population. Firstly, the equipment they have is limited, and secondly, the treatment provided by officials and health professionals to patients does not meet the desired quality. In short, it is estimated that by 2007 there was approximately 1 doctor for 1909 people in the municipality of Turco and 1 doctor to 2437 people in the municipality of Challapata. Most of the population lives in communities of few houses that lack basic services; people must travel long distances to reach education and health services.

According to the PDM (2007), communities, farms and other remote areas have no electricity and rely on the use of kerosene or other methods of illumination at night. A study and evaluation of future energy demand estimated it (to meet the needs of households) as about $180 \mathrm{Wh} /$ household / day. This study assumed a rational and efficient use of the energy and considered the power supply for each benefited the use of little appliances (radio, television, etc.).

\subsection{Economy}

Given the predominantly rural characteristic of both municipalities, economic activity is based on agriculture (99\% of families according to the PDM 2007 in the case of Turco). Cattle ranching hs two main purposes: sale and household consumption (to a lesser extent). Both live animals and in meat as well as other products (portion of meat, fibber and leather for processing before being marketed) are used for sale. Own consumption is complemented by an interfamilial exchange. Marketing is carried out fortnightly and annual fairs especially in urban centres. Agricultural activity is highly subject to climate risks, and therefore the incomes of families are in constant insecurity, making families to diversify their economy by 
engaging in minor or complementary activities, such as handicrafts. Agricultural production is geared directly to consumption. Potato and quinoa are the products that are prevalent among families in the municipality of Turco and barley in the case of Challapata.

\subsection{Community organization and leadership}

A community workshop in each municipality of Turco and Challapata was realized to know the institutional actors in municipality that should be considered allies when designing in the management model of the electricity service. These institutions are considered depending on the area in which they operate, from the communal, municipal, provincial, departmental, national and international levels. The participants of the workshop did not identify all the institutions, but only those related to the Municipal Government and Ayllu, the indigenous and original management and decision organization at community level. Therefore, to complete the institutional landscape the PDM was used as well as observations and findings in the towns.

\section{Wind resource assessment}

Since June 2010 Bolivia has a new Wind Atlas, which identifies the potential of wind anywhere in the country, with the usable energy to generate electricity or direct use in a mechanical way. The Atlas was commissioned by TDE (Transportadora de Energía nationalized by the Bolivian Government) and the World Bank to the consultancy 3 TIER specialist on meteorological simulation models. The model was developed ased on geological, topographic and satellite statistics over the past 30 years, and the results were validated with records from weather stations in Bolivia.

The Atlas is based on data and maps on a platform of universal and indefinite access via the Internet and through entities that have offered themselves as managers of the base (www.3tier.com/firstlook). Bolivia Wind Atlas identifies areas of high potential use of wind, as is the case of the Santa Cruz region, the provinces of North and South Lopez in Potosí, a corridor between Santa Cruz, Cochabamba and La Paz, a northern-southern corridor between the shores of Lake Titicaca, Oruro and west of the city of Potosí, where the project area is.

Although the atlas gives an indication of interesting potential areas and communities, for the study of the project it is necessary to carry out a detailed micro-scale wind resource evaluation in the community. The first identification visits to Turco and Challapata and in particular the communities of the project, confirmed that the area appears to have good wind potential. Anemometers were installed to assess the wind resource in the communities in 10 meters high towers. Given the dispersion of electrified homes, two anemometers were installed in Turco (Figure 1), one in Iruni and one in Villacollo. Another anemometer was installed in Challapata (Figure 2). Wind measurements were taken for over a year. To ensure that generates enough electricity to meet demand throughout the year, wind resource evaluation focused on the periods of the year with less wind resource. Thus, although the energy generation varies along the year, the minimum generation to fulfil demand is always met. The least windy month was March in Turco (in both anemometers) and April in Challapata, with an average speed of about 2.5 to $3.5 \mathrm{~m} / \mathrm{s}$. This is the data considered in the project design. 
To get the detailed wind map not only from specific points but also for the whole community, a specific wind simulation software WAsP, The Wind Atlas Analysis and Application Program, by RISO, were used. This software extrapolates wind data collected by the anemometer located at a point and calculates the distribution of the wind resource throughout the surrounding area, considering the height map of the region. The topographic maps of the area were acquired in the Military Geographic Institute (La Paz, Bolivia). The energy generated by a wind turbine at each point of the community is also calculated by WAsP considering the power curves of wind turbines.

Next, we presented the height and maps of Turco (Figure 1) and Challapata (Figure 2) obtained with WAsP. As shown in the pictures, the highest elevation points are usually the areas with most wind potential.
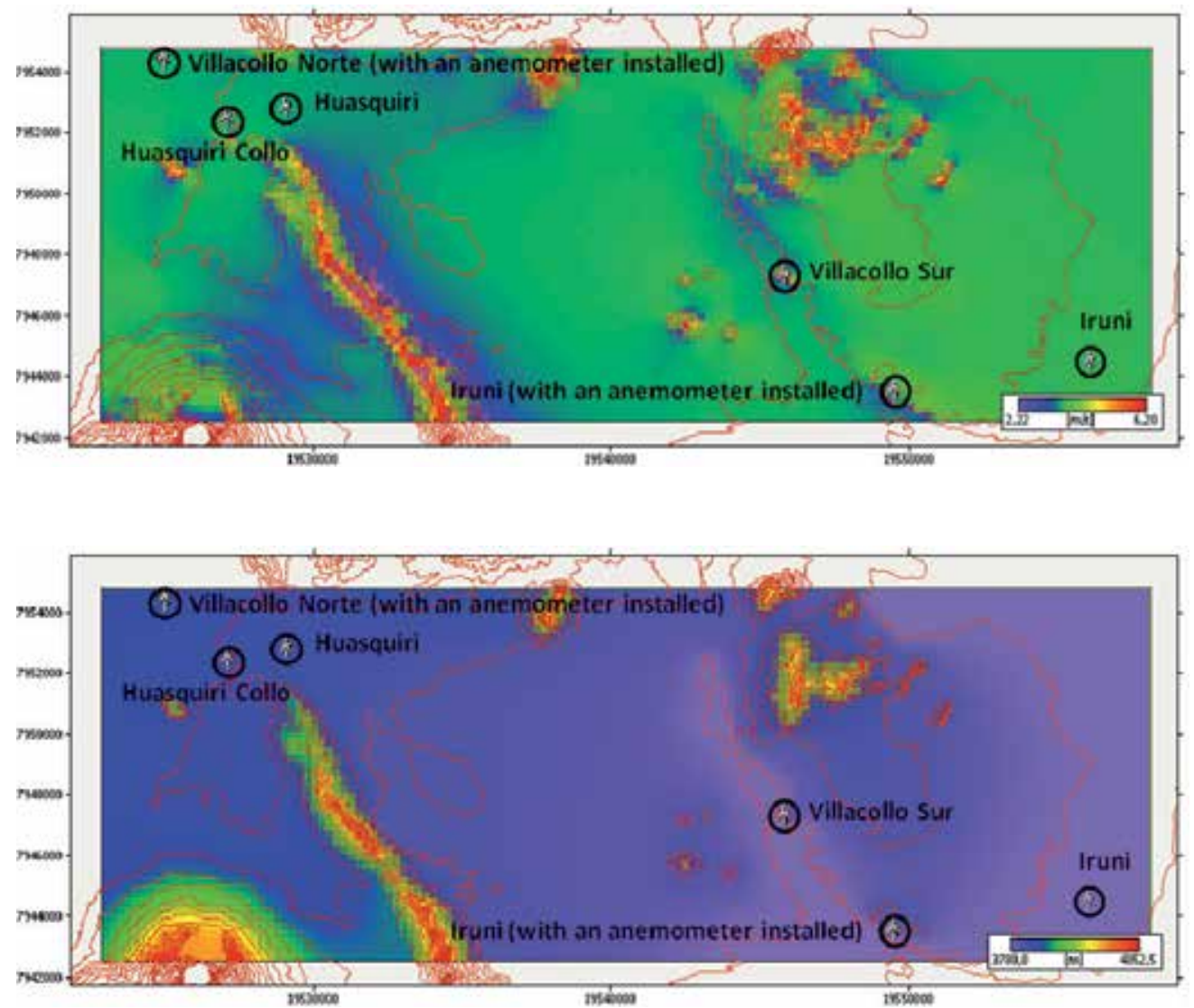

Fig. 1. Wind (up) and height (down) maps of the community of Turco. 


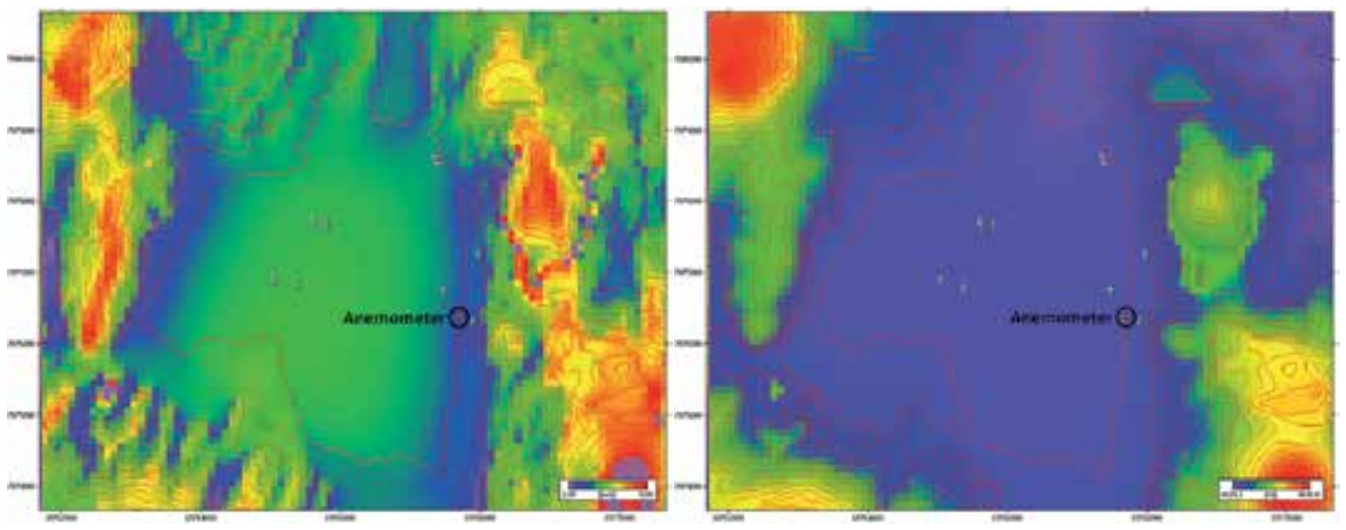

Fig. 2. Wind (left) and height (right) maps of the community of Challapata.

From the different technological options and according to the result of the wind resource evaluation, the promoters of the project decided to use wind energy to electrify these households of the communities (in front of photovoltaic solar systems, for instance).

\section{Electrification project description}

In 2009, 22 wind turbines were installed, 13 in the municipality of Turco and 9 in Challapata; in total, 80 people were beneficed. To ensure proper operation and maintenance of systems throughout the year, only households with permanent residents throughout the year were electrified.

\subsection{Technical description}

In Turco, the 13 beneficiaries of the project are grouped in five villages: Iruni, Villacollo Norte, Villacollo Sur, Huasquiri and Huasquiri Collo with 5, 3, 2, 2 and 1 households, respectively. In Challapata the 9 beneficiaries are dispersed and only two of them are close to each other. Given the dispersion of the households, the project promoters decided to install one individual wind turbine at each household. The chosen were the AIR-X-South West Windpower, which were distributed by SIE, a Bolivian company which offers the distribution, installation and maintenance service.

The design of wind systems at each household was carried out taking into account that turbines operate at a rated voltage of $12 \mathrm{~V}$ direct current-CC, and includes the generation system, regulation (directly incorporated into the wind turbine) and energy storage. The home system components are as follows:

- Generation. It consists of a wind turbine that converts the kinetic energy of wind into electrical energy.

- Regulation. Regulation to avoid over charging the battery is performed by a controller included in the turbine itself. If necessary, an inverter may be installed to prevent deep discharge by cutting consumption. However, in these projects, simple controllers that act as a viewfinder of the state of battery charge were installed.

- Storage. The accumulation and storage of electrical energy is done in batteries. Batteries are loaded when there is generation and discharged to supply power when the generation is insufficient. 
- Conversion. Inverters are used to convert direct current (coming out of batteries) to alternating current (which work for most electric devices) to allow the use of conventional devices, but having a power limit.

- Distribution. The electricity is distributed within the household at a nominal voltage level of $220 \mathrm{~V}$.

Figure 3 shows a breakdown of the basic outline of individual wind electrification, with connections between different equipments.

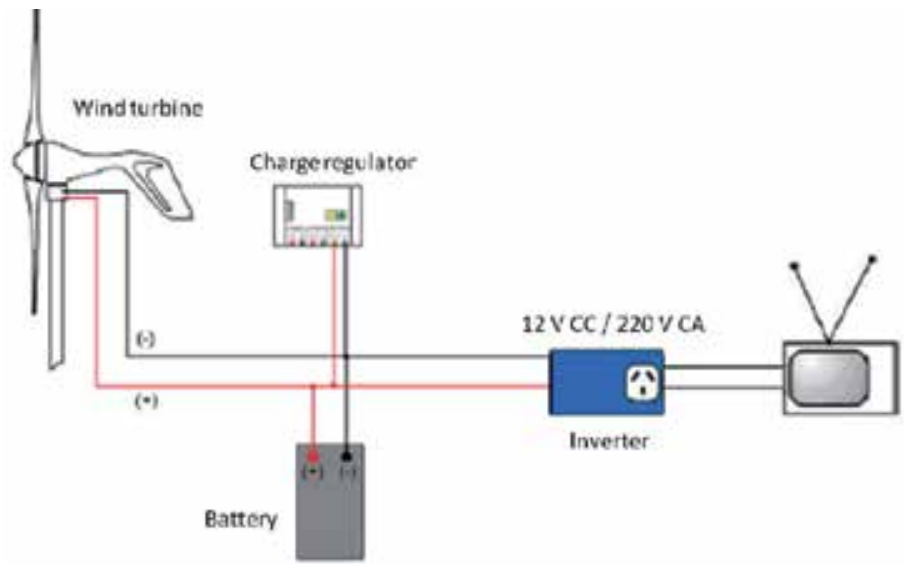

Fig. 3. Configuration of a wind individual electrical system.

\subsection{Management model description}

A common challenge in isolated electrification systems is to ensure the long-term project, for instance, in terms of sufficient maintenance and access to spare parts. To reinforce this challenge, the organizers of the project focused on developing an appropriate "management model".

The management model is a management tool developed in consensus with all stakeholders involved in the project, which aims to develop business service structure, and skills and abilities for the collective and individual sustainability. It contains regulations and operational rules governing the role of each different actor. Specifically, there is an operatormanager of the community that is in charge of the maintenance and management of all the systems. Users pay a monthly fee that goes to a fund for the maintenance of systems and possible replacements of equipment (batteries, etc.). A committee of users is also formed to supervise the technical and financial performance. The municipalities and town halls are the owners of the systems and are responsible for their long term sustainability.

The coordination mechanisms among stakeholders in these projects are:

- During the design and development of the project a fluid communication was guaranteed within a board of directors composed by beneficiaries and technicians responsible for implementing the planned activities.

- Once the installation finished and once the company that installed the systems and promoter institutions left the communities, the municipality and the town hall became the responsible of sustainability of the systems. The commitment is embodied in an agreement to support the management committees in which they agree to take charge of a consideration when replacing parts of the system (whenever required). 
- Once the project finished, the management committees are required to perform preventive maintenance and to collect monthly contributions from users. In addition, each committee has at least one technical operator per municipality, who is also a beneficiary and each member received additional training which has been provided to them focusing on equipment maintenance and financial management.

\section{Evaluation methodology}

The purpose of external evaluation is to determine and assess the degree of progress of the project in relation to fulfilment of the outcomes of intervention in the implementation period (2008-2010). This analysis allows to detect the strengths and weaknesses of the project and to make corrections of the deviations detected, aiming to improve future interventions in the area. The evaluation team that conducted the evaluation presented in this paper focused most of his work on analyzing the following main sections:

- Real coverage of the project, in terms of direct and indirect beneficiaries, whether individuals or institutions.

- Degree of appropriation of activities by the beneficiaries.

- The scope of the intervention at the regional level and the integration of the logical intervention and complementarities between the different levels.

- The degree of impact of the first actions, depending on the time of project implementation, with special attention to indicators and real achievement.

- The effectiveness of tracking and monitoring mechanisms initially planned, and improvements in relation to the interaction with regional participants throughout the implementation process.

- The level of involvement of local and regional activities planned, as well as the beneficiaries.

\subsection{Evaluation activities}

The work consisted of office work and field work. The office work consisted of:

- Identification and analysis of available documentation on the context.

- Analysis of available information on the interventions to evaluate: formulation of the project, the technical and economic progress reports, annual programming documents and sources of verification.

- Design of methodological tools for collecting, processing and analyzing information to ensure the reliability of sources and the rigor and analysis in the field.

- Planning of field work and structuring of the surveys.

- Design of indicators for the analysis of the evaluation criteria.

Fieldwork was conducted in October 2010 in the municipalities of Turco and Challapata and essentially consisted of:

- Interviews with key officials of the municipalities involved: the Mayor, Council Members, and the indigenous heads.

- Interviews with technicians of the project team.

- Semi-structured interviews to members of the Management Committee or representatives of their organizations according to their customs.

- Visit to households of the beneficiaries in order to inspect the installed equipment, and collect information via surveys to each of the users. 
The data collected from the surveys was processed and systematized in a database; SPSS was the information processing computer software used. In the same way, data collected from interviews was processed and compared providing greater reliability evaluation.

\subsection{Definition of the evaluation criteria}

The evaluation criteria were defined between the technical and social specialists of the promoter institutions and the external evaluator team. Criteria were defined before starting to collect information and results to ensure maximum objectivity. The defined evaluation criteria were:

1. RELEVANCE. This criterion assesses the suitability of the intervention in terms of local needs. It evaluates whether the proposal is technically valid, solves real problems and is appropriate to the context in which it is framed.

2. EFFICIENCY. This criterion examines the relationship between enforcement activities and compliance with the results and the relationship of these with the investment.

3. EFFECTIVENESS. This criterion measures the degree of compliance with the initial specific objectives of the projects and the actual outcome of the expected benefits to the beneficiaries.

4. IMPACT. This criterion examines the net effects of the project from a broad perspective, taking into account all stakeholders, and projects in the medium term.

5. SUSTAINABILITY. This criterion analyses the possibility of consistent positive effects of the project once the foreign aid ends, taking into account all relevant factors.

6. COHERENCE. This criterion analyses the compatibility between the objectives, activities and expected results of public policies and recommendations of international organizations.

7. FACILITIES: This criterion checks the compliance with the Bolivia IBNORCA NB - 1056.

Table 1. summarizes the indicators and related components for each of the criteria.

\begin{tabular}{|c|c|c|}
\hline CRITERIA & INDICATORS & COMPONENTS \\
\hline \multirow{10}{*}{ Relevance } & \multirow{3}{*}{$\begin{array}{l}\text { Adequacy of the project } \\
\text { to local needs }\end{array}$} & $\begin{array}{l}\text { Does the intervention correspond to priorities and needs of the } \\
\text { population? }\end{array}$ \\
\hline & & $\begin{array}{l}\text { Have the needs of communities changed after the first } \\
\text { identification? What changes have there been? }\end{array}$ \\
\hline & & $\begin{array}{l}\text { Have the actions proposed in the project been able to solve the } \\
\text { problems identified? Have they taken into account the } \\
\text { socioeconomic context? }\end{array}$ \\
\hline & \multirow{3}{*}{$\begin{array}{l}\text { Adequacy of the project } \\
\text { to local priorities }\end{array}$} & $\begin{array}{l}\text { Which are the priorities of government intervention in the } \\
\text { territory and the sector involved in the project? }\end{array}$ \\
\hline & & $\begin{array}{l}\text { Which are the priority interventions of local government in the } \\
\text { area? }\end{array}$ \\
\hline & & $\begin{array}{l}\text { Is the project aligned with the priorities of national and local } \\
\text { government? }\end{array}$ \\
\hline & \multirow[b]{2}{*}{$\begin{array}{l}\text { Complement with other } \\
\text { actions }\end{array}$} & Does the project being completed in a real way in the area? \\
\hline & & $\begin{array}{l}\text { Are there mechanisms for coordination between different } \\
\text { actors? }\end{array}$ \\
\hline & \multirow{2}{*}{$\begin{array}{l}\text { Design of the } \\
\text { intervention }\end{array}$} & $\begin{array}{l}\text { Has the project taken into account the views and opinions of } \\
\text { local staff? Which have been the levels of participation of them } \\
\text { in their formulation? }\end{array}$ \\
\hline & & $\begin{array}{l}\text { Do the planned activities actually lead to the fulfillment of the } \\
\text { intended outcomes? Is internal logic of the program the best } \\
\text { way to address the identified problems? }\end{array}$ \\
\hline
\end{tabular}




\begin{tabular}{|c|c|c|}
\hline CRITERIA & INDICATORS & COMPONENTS \\
\hline & & $\begin{array}{l}\text { Are the results feasible and relevant to the achievement of the } \\
\text { logical framework? Are they formulated in terms of impact? }\end{array}$ \\
\hline \multirow{7}{*}{ Efficiency } & \multirow{3}{*}{$\begin{array}{l}\text { Analysis of the } \\
\text { achievement of } \\
\text { individual results from } \\
\text { realized activities }\end{array}$} & $\begin{array}{l}\text { What was the level of compliance with each of the activities? } \\
\text { What factors facilitated and hindered compliance? }\end{array}$ \\
\hline & & $\begin{array}{l}\text { What was the degree of compliance with each of the results? } \\
\text { What factors facilitated or hindered performance? }\end{array}$ \\
\hline & & Were there any unanticipated results? Which ones? \\
\hline & \multirow{2}{*}{$\begin{array}{l}\text { Analysis of the relationship } \\
\text { between results and } \\
\text { resources invested }\end{array}$} & $\begin{array}{l}\text { What was the relationship between invested resources and } \\
\text { obtained results? }\end{array}$ \\
\hline & & What were the results in relation to time spentlike? \\
\hline & \multirow{2}{*}{$\begin{array}{l}\text { Analysis of management } \\
\text { in relation to the results }\end{array}$} & $\begin{array}{l}\text { Has the management of staff been adequate? Which was the } \\
\text { commitment of staff with the communities? }\end{array}$ \\
\hline & & $\begin{array}{l}\text { Has the project follow-up been adequate? How was the } \\
\text { relationship with the field team? }\end{array}$ \\
\hline \multirow{4}{*}{ Effectiveness } & \multirow[b]{2}{*}{$\begin{array}{l}\text { Performance analysis of } \\
\text { the specific objectives }\end{array}$} & What is the level of compliance of the specific objectives? \\
\hline & & $\begin{array}{l}\text { Which factors have facilitated/ impeded the fulfilment of the } \\
\text { specific objectives? }\end{array}$ \\
\hline & \multirow{2}{*}{$\begin{array}{l}\text { Usefulness and } \\
\text { availability of the specific } \\
\text { objectives }\end{array}$} & $\begin{array}{l}\text { Were the benefits of the project well received by the } \\
\text { population? Were there problems to access to these benefits? }\end{array}$ \\
\hline & & $\begin{array}{l}\text { What is the perception of utility that people and community } \\
\text { leaders have about the objectives of the project? }\end{array}$ \\
\hline \multirow{6}{*}{ Impact } & \multirow{2}{*}{$\begin{array}{l}\text { Analysis of compliance } \\
\text { of logical framework }\end{array}$} & $\begin{array}{l}\text { Contribution of the project to the achievement of logical } \\
\text { framework }\end{array}$ \\
\hline & & $\begin{array}{l}\text { Factors that have facilitated / impeded the project's } \\
\text { contribution to the achievement of logical framework }\end{array}$ \\
\hline & \multirow{4}{*}{$\begin{array}{l}\text { Impacts from a broad } \\
\text { perspective }\end{array}$} & $\begin{array}{l}\text { Project's positive impacts on beneficiaries, on the economic, } \\
\text { environmental, social, and organizational aspects. }\end{array}$ \\
\hline & & $\begin{array}{l}\text { Project's negative impacts on the social, economic, } \\
\text { organizational and environmental aspects }\end{array}$ \\
\hline & & $\begin{array}{l}\text { Unexpected impacts (positive and negative, on all players and } \\
\text { dynamics) }\end{array}$ \\
\hline & & $\begin{array}{l}\text { Factors and interventions outside the project have been able to } \\
\text { generate positive or negative effects on the impacts }\end{array}$ \\
\hline \multirow[t]{2}{*}{ Sustainability } & $\begin{array}{l}\text { Analysis of the possibility } \\
\text { that each of the processes } \\
\text { and their positive impacts } \\
\text { are sustainable }\end{array}$ & $\begin{array}{l}\text { Is there a local government department responsible of the } \\
\text { processes established by the project? }\end{array}$ \\
\hline & $\begin{array}{l}\text { Factors that facilitate / } \\
\text { impede the permanence } \\
\text { of the positive effects }\end{array}$ & $\begin{array}{l}\text { Political factors, Institutional factors, Gender factors, Economic } \\
\text { factors, Technological factors, Other factors }\end{array}$ \\
\hline Coherence & $\begin{array}{l}\text { Relation with the } \\
\text { strategical policies of } \\
\text { public sector }\end{array}$ & $\begin{array}{l}\text { Do the identified problems correspond to the purposed } \\
\text { objectives? }\end{array}$ \\
\hline \multirow{3}{*}{ Facilities } & $\begin{array}{l}\text { The design of the } \\
\text { facilities meet the } \\
\text { regulation }\end{array}$ & $\begin{array}{l}\text { The design of the facilities meet the needs of the usersand the } \\
\text { standard IBNORCA NB-1056 }\end{array}$ \\
\hline & $\begin{array}{l}\text { Facilities are in } \\
\text { accordance with the } \\
\text { design }\end{array}$ & Facilities are in accordance with the design and standards \\
\hline & $\begin{array}{l}\text { Facilities are operating } \\
\text { according to design }\end{array}$ & Facilities are operating according to the design \\
\hline
\end{tabular}

Table 1. Criteria, indicators and assessment components. 


\section{Results of the evaluation}

This chapter provides the information, the analysis and the results of the external evaluation in terms of each of the criteria and carries out global evaluation.

\subsection{Relevance}

The results of the evaluation confirmed that these projects have made a direct benefit for the families supplying access to electricity in their households. The field assessment after the implementation of the project has revealed that electric service has given them the ability to access telephone communication (cell phones had network coverage only needed electricity to recharge) and audiovisual media (television, radio, etc.).

However, the degree of satisfaction of the beneficiaries is not for all the same. Some of the beneficiaries are completely satisfied with the recent access to electricity, whereas others are only partially satisfied because their expectations were superior to actual performance and possible uses of electricity. Some of the beneficiaries confirm they use electricity for lighting and some low power appliances, as it was planned in the logical framework of the project but, at the same time, they claim that they wish to have more energy for other uses. In Turco, 6 out of 11 beneficiaries are completely satisfied and 5 are partially satisfied. In contrast, In Challapata almost all beneficiaries are completely satisfied, 7 out of 8 . Among other factors, the difference is probably due to the difference in wind potential in the communities; the wind potential available in the Challapata is greater than in Turco, thus, the same generation equipment generates much more energy.

\subsection{Efficiency}

The results indicate that the projects justify the investment and that the management of staff has been adequate. It is noteworthy the commitment of the staff to the beneficiary communities that was reflected in the interviews. Results of the evaluation confirmed that the objectivities and results defined in the logical framework of the project were achieved with an optimal degree of compliance.

However, the short time available to carry out the activities has been identified as a negative factor. The key aspects that influence and make the time needs critic are:

- The fieldwork itself needs a lot of time, in particular due to the remoteness of the communities. The need of technological and logistic external support and their availability also constrained the schedule.

- In terms of community activities, the communication process that involves speaking Spanish as well as native language (Quechua, Aymara) requires more time. Moreover, gaining the confidence and trust of the beneficiaries and overcoming some internal conflicts in the communities also require dedication and perseverance. The education and training according to the needs of the community and implementation of management models must be repeated in a lengthy process to ensure the correct appropriation.

- The coordination with municipal governments, as well as making effective their economic commitment was also a long process.

However, the only weakness found caused by the short time spent in the project was that the management committee was concerned about not being self-sufficient to keep equipment running. Although the interviewees say their organization does work, the correct 
performance may be threatened by the lack of commitment tools that would help to ensure the fulfilment of the obligations of the users. In particular, they claim more training and time for a proper comprehension of the rules of the new organization because the management committee has no element of coercion to require monthly contributions, and the technical operator receives no remuneration for his work as inspector. These deficiencies are repeated in Turco and Challapata but with different intensity.

\subsection{Effectiveness}

One of the specific objectives of this project aimed to train the users in the maintenance of wind power systems and organizational management techniques for the sustainability of the systems. A key point is the emphasis on training and awareness of people through workshops and seminars. The results of the evaluation confirmed the population received good training, are aware of the benefits of the project and have a positive perception of usefulness. Users are also aware of the existence and significance of the management committee although no regularity when making the respective contributions has been achieved. These delays have had no negative consequences so far because there have been no need to replace elements, because the projects have been running for a short time.

In terms of uses of electricity, the beneficiaries use the energy depending on their economic possibilities to buy electric appliances, from lighting to communication and leisure. The most noteworthy nightlife activities are spinning, knitting or sewing by women and schoolwork by children. Table 2 shows the number of users per municipality using different types of appliances.

\begin{tabular}{|l|c|c|c|c|c|c|}
\cline { 2 - 7 } \multicolumn{1}{c|}{} & Focus & TV & Radio & Cell Phone & Battery chargers & Others \\
\hline Turco & 11 & 0 & 1 & 10 & 1 & 0 \\
\hline Challapata & 8 & 0 & 4 & 2 & 1 & 0 \\
\hline
\end{tabular}

Table 2. Number of users of each appliance in each community.

\subsection{Impact}

In terms of the logical framework, the project has largely achieved its objectives and actually incorporated renewable energy in Turco and Challapata communities as demonstration projects in Bolivia.

The main factors that facilitated the success were:

- Training of all users and technicians from the municipal governments.

- The development of management manuals.

The most noteworthy positive impacts of the project are:

- Improved quality of life, preserving the environment.

- The achievement of an organization to manage the systems designed according to customs.

From the economic point of view, almost all beneficiaries agree that now with the new electricity service they spend less money on the provision of electricity than they used to spend on traditional energy sources (kerosene, candles, etc.). Apart from that, some of them state they no longer have to breathe smoke like when they used kerosene, burners or candles. Beneficiaries state they have a solid and consolidated organization, although this is not directly reflected at the time of monthly contributions. 
Table 3 shows the qualitative assessment of the changes resulting from the project in the organizational, economic, social and environmental aspects; it shows the percentage of beneficiaries that state the changes have been positive, negative or non significant (no change). The most significant changes occur in the economic area, thanks to a reduction of costs on energy provision, and in the environmental aspects, by decreasing smoke of candles, lighters and kerosene lamps.

\begin{tabular}{|l|c|c|c|c|}
\cline { 2 - 5 } \multicolumn{1}{c|}{} & & positive & negative & no change \\
\hline \multirow{4}{*}{ Turco } & Organizational & $100 \%$ & $0 \%$ & $0 \%$ \\
\cline { 2 - 5 } & Economical & $60 \%$ & $0 \%$ & $40 \%$ \\
\cline { 2 - 5 } & Social & $10 \%$ & $10 \%$ & $80 \%$ \\
\cline { 2 - 5 } & Environmental & $100 \%$ & $0 \%$ & $0 \%$ \\
\hline \multirow{4}{*}{ Challapata } & Organizational & $100 \%$ & $0 \%$ & $0 \%$ \\
\cline { 2 - 5 } & Economical & $100 \%$ & $0 \%$ & $0 \%$ \\
\cline { 2 - 5 } & Social & $0 \%$ & $0 \%$ & $100 \%$ \\
\cline { 2 - 5 } & Environmental & $100 \%$ & $0 \%$ & $0 \%$ \\
\hline
\end{tabular}

Table 3. Assessment of the changes.

The only negative impact found in the evaluation is that people who are not beneficiaries of the project are now in an unequal position and feel they are now in a situation of inferiority. It is noteworthy to remind that only homes with at least one permanent resident throughout the year were electrified, to ensure proper operation and maintenance.

\subsection{Sustainability}

The promoters (Engineers Without Borders, CINER and Mosoj CAUSAY), and the management committees of the projects signed an agreement with the mayors involved in the projects, where the municipalities assumed to take over the sustainability of actions. The management committees are afraid of not being self-sufficient to maintain the systems of electrification (lack of regular payments, technical operator's temporary absence, etc.) and so the mayors involved agreed to give support and to take over the long term sustainability of projects. However, changes in the technical and municipal authorities, bureaucracy, lack of financial resources, lack of continuity in the training of technicians of the municipality and other stakeholders may hinder the fulfilment of commitments.

Moreover, the future of these systems is contingent on the proper use and proper maintenance of each of the equipments. The company that installed the wind systems is committed to maintain and to repair themfor a period of two years. So far, the company repaired the systems when needed but has taken some time, so some beneficiaries have had no electricity during weeks or months.

\subsection{Coherence}

The results of the evaluation confirmed there is a clear coherence between identified problems in the area and goals of the project. The project has successfully overcome one of the main problems identified in the area: lack of electricity and reliance on traditional energy sources (candles, lighters, wood and other fuels). Now beneficiaries say they no longer breathe smoke (of kerosene or candles), and state they spend less money on energy supply. 
In addition, the evaluation confirmed this project is not against any plan, program or policy; on the contrary, it contributes to the government's obligation to provide basic services to the population.

\subsection{Facilities}

The verification of the quality of the facilities is conducted as part of the field work, making home visits to most users of both Turco and Challapata. To check the correct design and installation of the facilities, the standard guidance document IBNORCA Bolivian NB 1056 was used. All components were verified in each household, taking into account the data of the original design. Most equipment was found to be working properly and user feedback was favourable. Only minor problems were detected which were easily solved (low batteries, bearing noises, light poles with vertical offset).

\subsection{Evaluation and analysis}

The rating scales and the weighting of each criterion were discussed and agreed at a meeting between the evaluation team and CINER and Mosoj Causay. This meeting was held before the start of the collection and analysis of information to ensure maximum objectivity. From the analysis of the results of the evaluation and the defined rating scales (1 to 5), each of the components of each criterion was quantified. The resulting score of each component of each indicator is shown in the following table (Table 4).

Figure 4 shows the results of the evaluation according to each criterion. The project achieved an overall weighted evaluation of $89.33 \%$, which corresponds to a qualitative assessment of "functioning under optimal conditions".

\begin{tabular}{|c|c|c|c|c|}
\hline CRITERIA & Total & $\mathrm{N}^{\mathrm{a}}$ & COMPONENT & Value \\
\hline \multirow{4}{*}{ RELEVANCE } & \multirow{4}{*}{4.35} & 1 & Adequacy of the project to local needs expressed & 4.33 \\
\hline & & 2 & Adequacy of the project to local priorities & 3.57 \\
\hline & & 3 & Complement with other actions & 5 \\
\hline & & 4 & Design of the intervention & 4.5 \\
\hline \multirow{3}{*}{ EFFICIENCY } & \multirow{3}{*}{4.50} & 5 & $\begin{array}{l}\text { Analysis of the achievement of individual results from realized } \\
\text { activities }\end{array}$ & 4.17 \\
\hline & & 6 & $\begin{array}{l}\text { Analysis of the relationship between results and invested } \\
\text { resources }\end{array}$ & 4.33 \\
\hline & & 7 & Analysis of management in relation to the results & 5 \\
\hline \multirow{2}{*}{ EFFECTIVENESS } & \multirow{2}{*}{4.67} & 8 & Performance analysis of the Specific Objectives & 4.63 \\
\hline & & 9 & Usefulness and availability of the Specific Objectives & 4.71 \\
\hline \multirow{2}{*}{ IMPACT } & \multirow{2}{*}{4.75} & 10 & Analysis of compliance of the logical framework & 5 \\
\hline & & 11 & Impacts from a broad perspective & 4.5 \\
\hline \multirow{2}{*}{ SUSTAINABILITY } & \multirow{2}{*}{4} & 12 & $\begin{array}{l}\text { Analysis of the possibility that each of the processes and their } \\
\text { positive impacts are sustainable }\end{array}$ & 5 \\
\hline & & 13 & $\begin{array}{l}\text { Factors that facilitate / impede the permanence of the positive } \\
\text { effects and the processes }\end{array}$ & 3 \\
\hline COHERENCE & 5 & 14 & Relation with strategic public sector policies & 5 \\
\hline \multirow{3}{*}{ FACILITIES } & \multirow{3}{*}{4.33} & 15 & The design of the facilities meet the regulation & 4.5 \\
\hline & & 16 & Facilities are in accordance with the design & 4.5 \\
\hline & & 17 & Facilities are operating according to design & 4 \\
\hline
\end{tabular}

Table 4. Evaluation of the external evaluation process. 


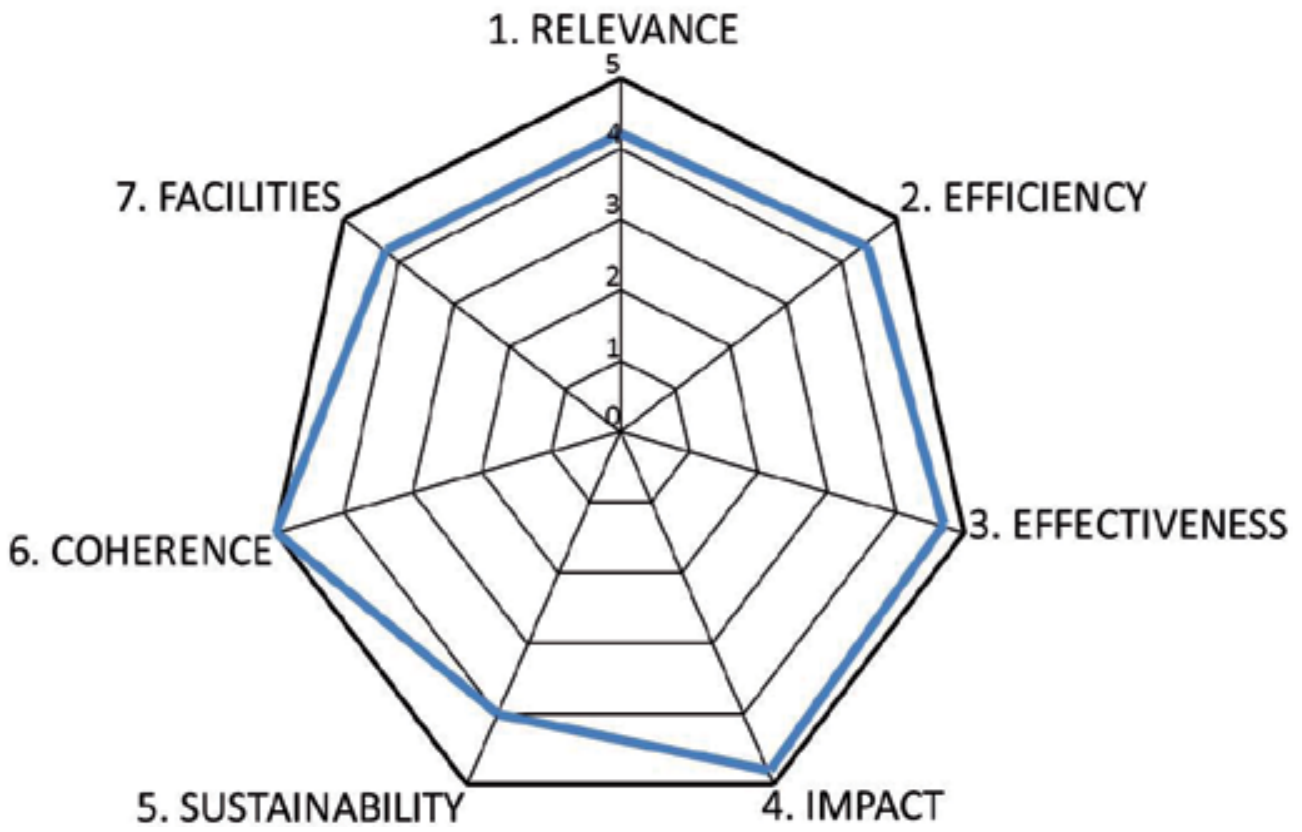

1. Relevance: $4.35 / 5$ (weight: $25 \%$ )

2. Efficiency: $4.50 / 5$ (weight: $10 \%$ )

3. Effectiveness: $4.67 / 5$ (weight: $10 \%$ )

4. Impact: $4.75 / 5$ (weight: $15 \%$ )

5. Sustainability: $4 / 5$ (weight: $15 \%$ )

6. Coherence: $5 / 5$ (weight: $10 \%$ )

7. Facilities: $4.33 / 5$ (weight: $10 \%$ )

Fig. 4. Results from the multicriteria evaluation.

\subsection{Recommendations of use and maintenance}

The following recommendations are deduced from the evaluation and are proposed to proper use and maintenance of systems and to promote long term sustainability:

- To facilitate the sustainability of the project, the management was transferred to the involved municipalities, and should be monitored periodically by these entities. The mayors should support the preventive maintenance plan for wind turbines and should include training for users at least once a year, especially to the young.

- Management committees in coordination with Installation Company must check the level of the batteries and the wind systems performance. The maintenance plan for wind systems must check the status of bearings, the load control system and the verticality of the poles.

- Users must remember that when they buy a radio or TV their power must be appropriate for the wind systems. The maintenance plan should ensure that the light output of focus fulfils the standard NB IBNORCA -1056 and users should paint rooms in white for greater light efficiency.

- Batteries must be in a suitable container for efficient and secure use. The municipal government should provide a battery charger as a backup system for each community. 


\section{Analysis of alternative designs}

Due to the characteristic dispersion of communities, rural electrification projects tend to install individual systems at each point of consumption, as the cases presented in this paper. Alternatively, design of a single point of generation and distribution of electricity with microgrids (Kirubi et al. 2009) has its advantages:

- Flexibility in use: energy generation and storage is shared among several users, thus one or more users can increase their consumption at a specific moment if needed.

- Easier integration of future users: new users may be electrified just extending a wire.

- Robustness against failure: microgrids facilitate feeding users with more than one generator. Thus, in case of failure of a generator, energy supply decreases but no user is completely left without access.

- Cost savings: microgrids facilitate to use more powerful equipment, which are proportionally cheaper.

In particular, the electrification with microgrids in Turco and Challapata would have avoided some of the problems identified in the assessment:

1. Some users were expecting to have more energy availability. The use of microgrid generation facilitates the use of more powerful and proportionally cheaper turbines, so more energy can be generated and supplied with the same investment. Moreover, higher energy supply scenarios can be considered with lower cost increase.

2. People that do not live permanently in the community were not electrified to avoid operation and maintenance problems. In systems with microgrids generation equipment is not installed at each household and, therefore, not living permanently is not a problem because the maintenance is common and not necessarily the responsibility of each user.

3. The lack of supply during breakdowns. In case of breakdown of a generator, no user is completely left without access, so the time taken to repair the system is not that critic.

\subsection{Design models with microgrids}

To study the possible use of microgrids in future projects, the electrification options with microgrids in Turco and Challapata are analysed. Although in both communities most households are scattered, there are small groups of households close to each other that could have been electrified with a microgrid.

To optimize the design of these alternatives a Mixed Integer Linear Programming (PLEM) model (Ferrer-Martí et al., 2011) is used. This model is based on the definition of a set of parameters (which specify the input data of the problem), variables (which define the configuration of the solution) objective function (which defines the standard resolution) and constraints (that specify the set of conditions to be satisfied that the solution is feasible). The solution of this model determines the point of generation and micro design to minimize costs, taking into account the demand, the wind resource and power generation equipment available in the area (cost and technical characteristics).

Next, the parameters, variables, objective function and constraints of this model are briefly introduced.

- Parameters

- Demand: Energy and power consumption of each point and days of autonomy. 
- Generation and accumulation: Turbines with built-in controller (type, cost, maximum operating power, and maximum power generated at one point) and batteries (type, cost, capacity and discharge factor).

- Definition of the network: Distance between points, conductors (types, cost including the infrastructure, resistance and current carrying capacity), rated voltage distribution and voltage drop.

- $\quad$ Equipment: Inverters (type, cost and power) and meters (cost).

- Variables

- Equipment: number of each type of equipment installed at each points.

- Definition of the network: connections between two points, and energy and power flow between the two points.

- Objective function: To minimize the investment cost considering wind turbines, batteries, inverters, meters and conductors.

- Constraints

- Generation and accumulation: Energy and power balances at each point, required energy capacity in the batteries at each point of generation.

- Definition of the microgrid: It establishes the relationship between energy and power flows and the existence of a conductor between two points, compliance of maximum voltage drop and maximum intensity, the structure of microgrid (if any) should be radial.

- Equipment. Inverters are installed at the points of generation; the meters are installed at points of microgrid.

To specifically assess all the advantages of the microgrids, a constraint that forces to form microgrids to feed the households that were close to each other at each community is included.

\subsection{Results of the design of the projects with microgrids}

Next, the data and parameters considered in the generation and study of alternative designs are summarized. In particular, this experiment considers the use of the equipment installed in the real projects and more power equipment for their possible use in microgrids that feed several households.

- $\quad$ Demand

- Two demand scenarios: the first for a basic consumption (energy 140Wh/day, power $100 \mathrm{~W}$ ) and the second to promote the development of productive activities (energy $280 \mathrm{Wh}$ / day, power $200 \mathrm{~W}$ ).

- 2 days of autonomy.

- Generation and accumulation

- 4 types of turbines: Air X, Whisper 100, Whisper 200 and Whisper 500) at a cost of $\$ 1000-\$ 4600$ and 550W-3300W, respectively, by South West Windpower.

- Regulators are incorporated into each type of turbine.

- 3 types of batteries: $\$ 240-325$ and $150-250$ Ah capacity discharge $60 \%$.

- Microgrids

- 3 types of conductors: cost \$4.05- 4.4 per meter.

- $220 \mathrm{~V}$ distribution voltage and a 5\% maximum voltage drop.

- $\quad$ Equipment 
- 1 type of inverter: cost \$255, power 350W.

- 1 type of meter: cost $\$ 50$.

Table 5 shows the obtained results. The table is divided into two columns for each demand scenario and two rows for each municipality. The sub-columns show the obtained results considering: 1) the individual solution (one generation equipment per household); 2) the solution with microgrids with one type of wind turbines (the type used in the real projects, Air $\mathrm{X}$ ) and 3) the solution with microgrids with 4 types of wind turbines (the type used in the real projects, Air X, and 3 more powerful ones). The sub-rows present the investment cost, the difference of the cost of individual generators in the low demand scenario, the total energy, wind turbines used, the microgrids and the number of users in each one and number of individual users.

\begin{tabular}{|c|c|c|c|c|c|c|c|}
\hline & \multicolumn{3}{|c|}{$\begin{array}{l}\text { Low Energy Demand } \\
\text { (140Wh/day; } 100 \mathrm{~W})\end{array}$} & \multicolumn{3}{|c|}{$\begin{array}{l}\text { High Energy Demand } \\
(280 \mathrm{Wh} / \text { day; 200W) }\end{array}$} \\
\hline & & Individual & $\begin{array}{c}\text { Microgrid } \\
(1 \text { w.t. })\end{array}$ & $\begin{array}{c}\text { Microgrid } \\
\text { (4 w.t.) }\end{array}$ & Individual & $\begin{array}{c}\text { Microgrid } \\
\text { (1 w.t.) }\end{array}$ & $\begin{array}{c}\text { Microgrid } \\
\text { (4 w.t.) }\end{array}$ \\
\hline \multirow{6}{*}{ Turco } & Total cost [\$] & 19423 & 17862 & 16862 & 26423 & 26277 & 22777 \\
\hline & $\begin{array}{c}\text { Difference } \\
(\%)\end{array}$ & - & $-8,0 \%$ & $-13,2 \%$ & $36,0 \%$ & $35,3 \%$ & $17,3 \%$ \\
\hline & $\begin{array}{c}\text { Energy } \\
\text { [Wh/day] }\end{array}$ & 4460 & 4234 & 4166 & 6086 & 6124 & 6227 \\
\hline & $\begin{array}{l}\text { Wind } \\
\text { turbine } \\
\text { (type) }\end{array}$ & $13($ Air X) & $12($ Air X) & $\begin{array}{c}8 \text { (Air X) } \\
2 \text { (Whis. } \\
100)\end{array}$ & $20($ Air X) & $20($ Air X) & \begin{tabular}{|c|}
7 (Air X) \\
3 (Whis. \\
$100)$ \\
1 (Whis. \\
200 ) \\
\end{tabular} \\
\hline & $\begin{array}{c}\text { Microgrids } \\
\text { (users) }\end{array}$ & - & $\begin{array}{l}1(4) \\
1(3) \\
2(2) \\
\end{array}$ & $\begin{array}{l}1(4) \\
1(3) \\
2(2) \\
\end{array}$ & - & $\begin{array}{l}1(4) \\
1(3) \\
2(2) \\
\end{array}$ & $\begin{array}{l}1(4) \\
1(3) \\
2(2) \\
\end{array}$ \\
\hline & $\begin{array}{c}\text { Individual } \\
\text { users }\end{array}$ & 13 & 2 & 2 & 13 & 2 & 2 \\
\hline \multirow{6}{*}{ Challapata } & Total cost $[\$]$ & 14447 & 13886 & 13886 & 16447 & 16867 & 15867 \\
\hline & $\begin{array}{l}\text { Difference } \\
(\%)\end{array}$ & - & $-3,9 \%$ & $-3,9 \%$ & $13,8 \%$ & $16,8 \%$ & $9,8 \%$ \\
\hline & $\begin{array}{l}\text { Energy } \\
\text { [Wh/day] }\end{array}$ & 4641 & 3381 & 3381 & 5185 & 5196 & 5161 \\
\hline & $\begin{array}{l}\text { Wind } \\
\text { turbine } \\
\text { (type) }\end{array}$ & $10($ Air X) & $8($ Air X) & $8($ Air X) & $12($ Air X) & $12($ Air X) & $\begin{array}{c}\text { (Air X) } \\
1 \text { (Whis. } \\
100)\end{array}$ \\
\hline & $\begin{array}{c}\text { Microgrids } \\
\text { (users) }\end{array}$ & - & $3(2)$ & $3(2)$ & - & $1(2)$ & $1(2)$ \\
\hline & $\begin{array}{c}\text { Individual } \\
\text { users }\end{array}$ & 9 & 3 & 3 & 9 & 7 & 7 \\
\hline
\end{tabular}

Table 5. Analysis of the electrification solutions of Turco and Challapata with microgrids. 
In Turco, in the low demand scenario, the cost of real implemented project, that installed an individual wind turbine at each household, is $\$ 19423$. The design with microgrids reduces the cost by $8 \%$ when only one type of wind turbine is available ( $\$ 19423$ vs. $\$ 17862)$; the cost reduction is higher $13.2 \%$ when 4 types and more powerful wind turbines are considered (\$19423 vs. \$16862). In both solutions one microgrid of 4 households is formed in Iruni, another of 3 households is formed in Villacollo Norte and 2 microgrids are formed in Villacollo Sur and Huasquiri.

In the high demand scenario in Turco, the cost of electrification solution increases by $36 \%$ when only individual generators are considered (\$19423 vs. \$26423). This increase is significantly reduced to $17.3 \%$ when microgrids and 4 types of wind turbines are considered (\$19423 vs. \$22777); thus, twice energy and power demand only implies a cost increase of $17.3 \%$. The formed microgrids are always the same in all cases.

In Challapata, in the low demand scenario, the cost of real implemented project is $\$ 14447$. The design with microgrids reduces the cost by 3.9\% ( $\$ 14447$ vs. $\$ 13886$ ); 3 microgrids of 2 users each are formed. In the high demand scenario, the cost of electrification solution in Challapata increases by $13.6 \%$ when only individual generators are considered ( $\$ 14447$ vs. \$16447). This increase is reduced to $8.8 \%$ when microgrids and four type of wind turbines are uses (\$14447 vs. \$15867).

\section{Conclusions}

This article aims to describe and evaluate two wind generation projects implemented in Bolivia, in the municipalities of Turco and Challapata, department of Oruro. This multicriteria evaluation was conducted when the systems had been running for one year by an external evaluation team. The results of the evaluation showed that the project has achieved its main objectives giving a weighted mark $89.33 \%$, which corresponds to a qualitative assessment of "functioning under optimal conditions." This confirms that renewable energy is the best choice for access to modern energy in isolated communities.

Among the main strengths of the project $s$ the positive acceptance of the beneficiaries and access to electricity in remote areas must be highlighted. The main weaknesses of the project are the bureaucracy that slows down municipal governments and internal conflicts among beneficiaries. The assessment highlighted limitations in the systems that must be resolved in future projects, for instance, the training should be extensive in time. The biggest risk is long term sustainability if the municipalities do not fulfil their commitments.

Furthermore, alternative designs were analyzed with microgrids to improve some of the drawbacks identified in the assessment: the continuity of supply against breakdowns, supply of electricity to non-permanent residents and the possible increase in energy supply to cover more applications. The results recommend taking advantage of microgrids for projects in future, to feed groups of households, improve the quality of electric service and reduce costs.

\section{Acknowledgments}

This paper was supported by the Spanish MICINN project ENE2010-15509 and co-financed by FEDER, by the Centre for Development Cooperation of the Universitat Politècnica de Catalunya - Barcelona Tech (UPC), by the Agència Catalana de Cooperació al Desenvolupamentand (ACCD) and by the Agencia Española de Cooperación Internacional para el Desarrollo (AECID). 


\section{References}

Chaureya, A., Ranganathana, M. and Mohanty, P. (2004). Electricity access for geographically disadvantaged rural communities - technology and policy insights. Energy Policy, 32, 1693-1705.

Ferrer-Martí, L., Garwood, A., Chiroque, J., Escobar, R., Coello, J, Castro, M. (2010) A Community Small-Scale Wind Generation Project in Peru. Wind Engineering, 34 (3), p 277-288.

Ferrer-Martí, L., Pastor, R., Capó, G.M. and Velo, E., (2011). Optimizing microwind rural electrification projects. A case study in Peru. Journal of Global Optimization, 50 (1), 127-143.

IEA (2009) International Energy Agency: World Energy Outlook

Kanagawa, M. and Nakata, T. (2008). Assessment of access to electricity and the socioeconomic impacts in rural areas of developing countries. Energy Policy, 36 (6), 2016-2029.

Kirubi, C., Jacobson, A., Kammen, D.M. and Mills, A., (2009). Community-Based Electric Micro-Grids Can Contribute to Rural Development: Evidence from Kenya. World Dev., 37 (7), 1208-1221.

Lew, D.J. (2000). Alternatives to coal and candles: wind power in China. Energy Policy, 28, 271-286.

PDM (2007) Municipal Development Program.

Seitz, M. (2006). Patagonia wind aids remote communities, BBC News, 10 February 2006. 


\title{
Taxes Incentives to Promote Res Deployment: The Eu-27 Case
}

\author{
José M. Cansino*, María del P. Pablo-Romero, \\ Rocío Román and Rocío Yñiguez \\ University of Seville, \\ Spain
}

\section{Introduction}

The share of renewable energy source (RES) in gross final energy consumption was $10.3 \%$ in the European Union (EU-27) in 2008; the remaining 89.7\% was covered through the use of conventional fuels such as natural gas or oil products (Eurostat, 2010). The renewable energy share in gross final energy consumption was used for the production of heat $(5.5 \%)$, electricity $(4 \%)$ and transport fuels $(0.8 \%)$.

Deployment of RES contributes to two of the four targets of the EU-27 energy strategy: the need to reduce primary energy dependency and the stress of demand on primary energy resources. In addition, the Green House Gas (GHG) abatement due to a more intensive use of RES contributes to improve the EU-27's target related to climate change, this being the fourth target in its energy strategy.

From a legal point of view, The Green Paper (EC 1996), which was the first attempt of establishing a common policy on renewable energies in the European Union, settled down the goal of duplicating the contribution of RES in the gross domestic consumption in 15 years. From the year 1996 until the present, the European Union has developed an intense ruling activity around the promotion of RES.

An important step forward the construction of the Community framework about harmonized fiscal treatment was the passing of the Directive (EC, 2003/96), that restructures the community regime about taxation over energy products and electricity.

In order to improve on energy efficiency, the most important EU policies for the households sector are the EPBD (EP\&C, 2010), “The Energy Services Directive (ESD)" (EP\&C, 2006) and "The Eco-design Directive" (EP\&C, 2009).

The renewable energy Directive 2009/28/EC covers renewable energy use in three sectors:

1. Gross final consumption of electricity from renewable energy sources;

2. Gross final consumption of energy from renewable sources for heating and cooling $(\mathrm{H}$ $\& \mathrm{C})$; and

3. Final consumption of energy from renewable sources in transport.

IEA (2009) has recently pointed out that part of renewable energies growth is due to strong policy support. Therefore, policy measures to promote RES are becoming an interesting issue in its deployment. 
In November 2010 the Commission presented the new strategy for competitive, sustainable and secure energy (COM 2010/0639). The communication, named "energy 2020", fixes the priorities in the field of energy for the next ten years and the actions that should be performed to save energy, achieve a competitive market, and guarantee the safety of supply, promoting at the same time technological leadership.

Focusing on green electricity, RES for Heating and Cooling and its use in transport, this chapter offers an overview of the main tax incentives that have been implemented to promote their use by the Member States (MSs) of the EU-27. In a general way, along with the reduction of investment costs, tax incentives can also be used to make the energy generated from RES more profitable than that generated by conventional energy sources.

Chapter has been structured as follows. Section 2 analyzes tax incentives to promote green electricity. Section 3 is dedicated to study the same topic in promoting RES for $\mathrm{H}$ \& C. Section 4 focus on the way MSs promote the use of biofuels in transport by using tax incentives. Finally, section 5 includes a political discussion and main conclusions.

In a summarized way, Section 2 provides a comprehensive overview of the main tax incentives used in the EU-27 MSs to promote green electricity. Sixteen MSs use tax incentives to promote green electricity along with other promotion measures as quota obligations and price regulation. Section 3 shows the main tax incentives used to promote RES for H\&C by EU-27 countries up to 2009. Although subsidies is the most widely used instrument to promote RES for $\mathrm{H} \& \mathrm{C}$, twelve MSs have used tax incentives as deductions, exemptions and reduced tax rates. Section 4 analyses the tax incentives that MSs have used to reach the target of a share of $5.75 \%$ in final consumption of energy biofuels in transport in 2010. This is the target fixed by Directive 2009/28/EC. Although green electricity for transport and hydrogen vehicle are included in the Directive 2009/28/EC framework, this chapter focuses on the policy measures, mainly those related with taxes, that have been used to promote the use of biofuels in transport.

\section{Tax incentives to promote green electricity}

This section provides a comprehensive overview of the main tax incentives used in the EU27 MSs to promote green electricity ${ }^{1}$. As stated Cansino et al. (2010), in promoting green electricity, there are probably no "perfect" fiscal incentives that should be widely applied in all situations and countries. These incentives are applied simultaneously with other promotion's measures, specially quota obligations and price regulation.

In UE-27, seventeen MSs have used fiscal incentives to promote green electricity. Mainly designed as tax exemptions, rebates on taxes, tax refunds and by applying lower tax rates on activities promoted. However, not all disposable technologies are always promoted. Table 1 provides an overview of the use of these tax incentives in the EU-27 MSs.

Fiscal incentives in direct taxes are used to promote electricity from RES by seven MSs. Czech Republic, Belgium, France and Luxembourg use the personal income tax as it allows either tax deductions or exemptions depending on the source of income and the capacity installed.

\footnotetext{
${ }^{1}$ In this section, in addition to the country-specific information, we have taken into account the country reports in EREC (2009) titled "Renewable Energy Policy Review", the information obtained from Bundesministerium für Umwelt, Naturschutz und Reaktorsicherheit (2011), the "Taxes in Europe" database published by the European Commission (2011) and the paper of Cansino et al. (2010).
} 
Czech Republic has a total exemption of the tax revenues that the taxpayer obtains coming from the generation of this type of energy. A similar exemption is also contemplated in the corporate tax. In Belgium and in France an exemption is allowed in the personal income tax (on the taxable income) on behalf of the cost of the investment of the system installation PV. In the French case, the exemptions not only cover the cost of the investment in system PV but also in the systems with small capacity which use wind energy, hydraulics and biomass. Luxembourg promotes solar photovoltaic electricity with an exemption from income tax of the sale of electricity generated by this system and whose capacity is small.

\begin{tabular}{|l|c|c|c|c|c|c|c|}
\hline & $\begin{array}{c}\text { Personal } \\
\text { Income } \\
\text { Tax }\end{array}$ & $\begin{array}{c}\text { Corporate } \\
\text { tax }\end{array}$ & $\begin{array}{c}\text { Property } \\
\text { Tax }\end{array}$ & VAT & $\begin{array}{c}\text { Others } \\
\text { Excise Duty } \\
\text { Exemptions }\end{array}$ & CCL & $\begin{array}{c}\text { Other } \\
\text { Taxes }\end{array}$ \\
\hline Belgium & $\checkmark$ & $\checkmark$ & & & & & \\
\hline Czech Rep. & $\checkmark$ & $\checkmark$ & & & & & \\
\hline Denmark & & & & & $\checkmark$ & & \\
\hline Finland & $\checkmark$ & & & $\checkmark$ & & & $\checkmark$ \\
\hline France & & & & & $\checkmark$ & & \\
\hline Germany & & $\checkmark$ & & & & & \\
\hline Greece & & & $\checkmark$ & $\checkmark$ & & & \\
\hline Italy & & & & & & & \\
\hline Luxembourg & $\checkmark$ & & & & & $\checkmark$ \\
\hline Netherlands & & & & & $\checkmark$ & & \\
\hline Poland & & & & $\checkmark$ & & & \\
\hline Portugal & & & & & $\checkmark$ & & \\
\hline Romania & & & & & $\checkmark$ & & \\
\hline Slovakia & & & $\checkmark$ & & & & \\
\hline Spain & & & & & $\checkmark$ & & \\
\hline Sweden & & & & & & $\checkmark$ & \\
\hline $\begin{array}{l}\text { United } \\
\text { Kingdom }\end{array}$ & & & & & & & \\
\hline
\end{tabular}

Source: Cansino et al. (2010)

Table 1. Fiscal incentives to promote green electricity

Belgium, Greece and Spain allow the deduction of a percentage of the investment made in systems that generate green electricity from the net tax base in the corporate tax. In the first two cases, the exemption is allowed by the company that has spent the funds in building the systems that generate green electricity. In Spain, it is allowed a deduction of a percentage of the investment that the company carries out in the installation of systems for the green electricity from the net tax base.

Finally, only Italy and Spain have used property taxes to promote green electricity. In Italy, municipalities may establish rates lower than 4 per 1000 of ICI ('Imposta comunale sugli immobili') for taxpayers who install or have installed a system of renewable energy to produce electricity or heat for domestic use. In Spain, municipalities may reduce the IBI, which is a similar tax to ICI, under specific conditions, up to $50 \%$ of the full share of the tax for real state to promote the establishment of solar energy systems. However, this measure has been used by few municipalities because are borne by them. 
Fiscal incentives in indirect, pigouvian and others taxes are used to promote electricity from RES by twelve MSs. The Value Added Tax is theoretically one of the most suitable indirect tax to promote renewable energies. However, only three MSs have chosen this tax as an instrument to boost green electricity: France, Italy and Portugal.

A cut in the Value Added Tax rate has to follow European guidelines about state helps that favour the environment (EC, 2001) and also has to get the Commission's authorization in order to prevent disproportioned effects over competition and economic growth. France allows a 5.5\% reduction when buying basic products related to improvements, changes and installation in residential buildings that incorporate technology based on solar power, wind power, hydro-electric power and biomass. Italy charges a reduced tax rate on sales and services related to wind and solar power generation. There is also a reduced tax on investments in green electricity distribution networks. Finally, Portugal allows a reduction in buying systems which generate green electricity.

Electric energy excise duty exemption is the most pervasive measure to encourage the use of renewable electricity of all. Actually, six MSs use it: Germany, Denmark, Romania, Slovakia, Sweden and Poland. In general, they use this measure because produces two types of benefits, known as the double dividend (Goulder, 1995). The first is to preserve the environment and the second can be obtained in several ways, as a positive impact on employment levels (De Mooij, 1999). This measure has been also use for reducing the higher prices of production of this type of energy. In that sense, this type of exemption is being usually applied to biofuels sales (Bomb et al., 2007; Van Beers, C et al. 2007). Nevertheless, some EU countries have applied to renewable electricity with the same propose. Fossil fuels and nuclear generations' benefit of a competitive advantage with respect to RES because its lower marginal costs than new renewable technologies and they are able to cope with downward price pressure. Because of that, taxation is important for decreasing most costs of RES sector, by allowing exemptions, reductions and accelerated depreciations (Di Domenico, 2006).

In Germany the law provides exemptions to encourage the use of friendly sources of energy when the electricity is generated exclusively from renewable sources and taken for use from a power grid. In the same sense, Romania has included an exemption from the payments of excises duties for energetic products and electricity when the electricity is generated by RES. is (also) promoted in Slovak Republic renewable energy is promoted through the exemption of the excise duty on electricity. Finally, the new Polish legislation continues to exempt from excise duty electricity from RES.

In the other hand, some countries have introduced electricity excise exemptions for renewable electricity only if they are generated by determinate technology. In Denmark, it is only exempt for excise duty, the electricity produced by wind, waterpower or solar cell systems or in a small plant. In Sweden, the electricity produced in a wind power station is not taxable if it is for own consumption although the electricity surplus might be sold. The exemption value depends on the consumption area. Also, during a transition period all wind energy production has been also entitled a tax reduction (environmental bonus).

Some other tax exemptions are used to promote green electricity. In the United Kingdom, electricity from RES is exempted from the 'Climate Change Levy -CCL-', which can characterize as a typical pigouvian tax. This tax is borne by agents that generate carbon emissions because it pursues to reduce negative externalities which come from human activities (Viladrich, 2004). The CCL was forecast to cut annual emissions by 2.5 million tons by 2010, and forms part of the UK's Climate Change Program. 
The CCL has to be paid by the electricity suppliers, who pass the costs to the industrial and commercial final consumers. To be tax-exempt, is required an authorization which may be given only under some conditions which involve consumers, suppliers and electricity producer. As requirements in the contract enter the electricity consumer and the electricity supplier, an agreement enters the electricity supplier and the electricity producer and some obligation of the electricity producer with the Office of Gas and Electricity Markets.

In Netherlands, electricity from RES is granted by a reduction of the ecotax, if it is produced within and outside the Netherlands but with the condition that has to be supplied to Dutch. All technologies used for the generation of electricity from RES are promoted.

Finally, in Finland, the consumption of electricity from RES is also taxable by the excise duty electricity. Nevertheless all operators of plants generating electricity from RES are entitled to a subsidy by statutory law, in order to offset the tax they must pay, which normally is transferred to the consumer. So, this subsidy is used to reduce the price of renewable energies. The application for the subsidy has to be lodged with the Customs District of the area of the domicile of the power plant and no subsidy is paid when the volume of electricity referred to in the application is small.

\section{Tax incentives to promote RES for H\&C}

This section shows the main tax incentives used to promote RES for H\&C by EU-27 countries up to 2009. Although subsidies is the most widely used instrument to promote RES for H\&C, twelve MSs have used tax incentives as deductions, exemptions and reduced tax rates (Cansino et al., 2011).

In addition to subsidies, RES H\&C are often promoted through a range of tax incentives, although with a lower intensity compared with green electricity and biofuel promotions (Cansino et al., 2011 and Uyterlinde et al., 2003). The main tax incentives used by EU-27 MSs are deductions, exemptions and reduced tax rates. ${ }^{2}$ Table 2 provides an overview of the use of these tax incentives in the EU-27 MSs.

\subsection{Deductions}

There are six MSs that offer different direct tax deductions to encourage the use of RES H\&C (Belgium, Finland, Greece, Italy, The Netherlands and Sweden), as Table 2 shows.

In Belgium, all RES H\&C technologies benefit from a tax deduction from taxable profits. For all RES and CHP installations, companies can receive a tax deduction of $13.5 \%$ for all investments in equipment used to reduce energy consumption. Since January 2003, the Federal Public Service of Belgium offers tax reductions for individuals undertaking energy efficiency and certain renewable energy investments in their homes. In 2009, a tax reduction of $40 \%$ of the investment cost was introduced on personal income tax with a maximum of $2,770 €$ for investment in heat pumps and biomass heating, and 3,600 € for investments in solar boilers. However, for every investment, the taxpayer can only obtain the maximum support for four years.

\footnotetext{
${ }^{2}$ In this section, in addition to the country-specific information, we have taken into account the country reports in EREC (2009) titled "Renewable Energy Policy Review", the Intelligent Energy Europe (2010) report titled "Re-Shape Renewable Energy Country Profile", the EuroACE (2009) report on tax incentives that affect buildings in Europe, the "Taxes in Europe" database published by the European Commission (2011) and the paper of Cansino et al. (2011).
} 


\begin{tabular}{|l|c|c|c|}
\hline & Deductions & Exemptions & Reduced tax rates \\
\hline Austria & & $\checkmark$ & \\
\hline Belgium & $\checkmark$ & & \\
\hline Bulgaria & & $\checkmark$ & \\
\hline Denmark & $\checkmark$ & $\checkmark$ & \\
\hline Finland & & $\checkmark$ & \\
\hline France & & $\checkmark$ & \\
\hline Germany & $\checkmark$ & & \\
\hline Greece & $\checkmark$ & & $\checkmark$ \\
\hline Italy & $\checkmark$ & & \\
\hline The Netherlands & $\checkmark$ & $\checkmark$ & \\
\hline Sweden & & $\checkmark$ & \\
\hline UK & & & \\
\hline
\end{tabular}

Source: (Cansino et al., 2011)

Table 2. Member States that use tax incentives to promote RES H\&C

Finish consumers can also benefit from tax deductions provided the expenses are used to promote the use of more efficient systems and RES. Since 2006, a 60\% household tax deduction has been available to offset labor costs incurred in replacing, upgrading and repairing the heating systems of small residential houses. The maximum amount of the tax deduction per household is 6,000 $€$ (EuroACE, 2009).

Related to Greece, a $20 \%$ deduction is available on personal income tax up to $700 €$, for money spent on the installation of RES, such as solar panel systems, thermal insulation and district heating. In Italy, personal income tax deductions up to a total of $55 \%$ of the investment outlaid on solar thermal systems (and any other energy efficiency investment), spread over ten years, can be obtained. This deduction decreases to $36 \%$ if the national fund set aside for each year is exhausted.

In the case of The Netherlands, in order to stimulate investments in RES, a scheme implemented by Senter Novem and the Dutch Tax Authorities allows Dutch companies that investment in RES (including those related to H\&C) a deduction of $44 \%$ on such investments from their fiscal profit up to a national maximum of $€ 108$ million per year. The investment threshold is 2,200 $€$ and no investment allowance is granted for investments exceeding 113 million $€$ in a tax year. ${ }^{3}$ Among the criteria for the deduction is whether the purchased equipment is on the 'Energy List'. The allowable list of technologies included in the Energy List has varied over the years around an average of 50. The Energy List 2010 contains examples of investments that have proven, in practice, that they meet the International Energy Agency (IEA) criteria. These examples are not exclusive - all investments that meet the energy-performance criteria are eligible for IEA support. However, if investments are not listed among the examples, entrepreneurs will need to prove that they meet the IEA criteria. For example, solar-thermal systems are on this list.

Sweden sponsors innovative programs to promote the use of alternative fuels for home heating. For example, a central furnace that consumes biological fuels if it is used to provide hot water for nearby homes. Oil furnaces have been replaced by boilers that use wood-based

\footnotetext{
${ }^{3}$ A more detailed study of these measures can be found in the report for the RES-H Policy Project by Menkveld and Beurskens (2009).
} 
pellets, thereby dramatically reducing Sweden's dependence on oil for home heating. Among the actual fiscal measures that exist in Sweden to promote the use of alternative fuels, tax rebates for consumers to stimulate market adoption of renewable technologies should be mentioned. This measure is reinforced with a high carbon tax on fossil fuels (by applying the Polluter Pays Principle). According to the EuroACE (2009) report (related to the fiscal incentives that are applied to European buildings), since 2006, households in Sweden benefited from a 30\% tax credit when converting from direct electric heating and oil-based heating to systems based on biomass or heat pumps. Solar heating support was prolonged until 2010.

\subsection{Exemptions}

Seven MSs have implemented tax exemptions to promote RES H\&C (Austria, Bulgaria, Denmark, Finland, Germany, Sweden and UK).

Biomass fuels used for heating are also exempt from fossil fuel taxes in Austria. According to the EuroACE (2009) report, a Building Tax Exemption has been in place in Bulgaria since 2005. From 6 July 2007, the Amendment to the Local Taxes and Fees Act established that the owners of buildings, having obtained a category A certificate issued under the terms of the Energy Efficiency Act and Building Certificate Regulation, are exempt from building tax for a term of 10 years. This exemption starts from the year after the year of issue of the certificate, and is only valid if RES are used in the building's energy consumption. Under the same terms and conditions, buildings with a category B certificate are exempt from building tax for a term of 5 years.

In the case of Denmark, solar heating plants are exempt from energy tax. Meanwhile, in Germany, to promote environment-friendly sources of energy for heating, there is a tax exemption on the energy tax for all solid biofuels used for heating as stated in the Energy Duty Law. In Sweden, bioenergy solid waste and peat are tax-exempt for most energy uses while taxes on fossil fuels have risen.

Finally, in the UK, renewable heat installations commissioned since July 2009 are due to receive a Feed-In Tariff, or the Renewable Heat Incentive of around $0.06 €$ per $\mathrm{kWh}$. This income received by domestic users and other income tax payers will not be taxed.

\subsection{Reduced tax rates}

While the use of reduced tax rates to promote RES is an instrument largely used in RES promotions such as biofuel use (see Del Río and Gual, 2004 and Uyterlinde et al., 2003), only three MSs (France, Italy and the UK) have introduced reduced value-added tax (VAT) rates on components and materials required for eligible heating and cooling systems (EuroACE, 2009).

In France, a reduced VAT of $5.5 \%$ is applied to the supply of heat if this is produced from at least $60 \%$ biomass, geothermal energy from waste, and recovered energy. Consumers in Italy can also benefit from a reduced VAT $(10 \%$ instead of $20 \%)$ in the case of the refurbishment of a house when this includes the installation of solar-thermal systems. Finally, in the UK, a reduced VAT of $5 \%$ is charged on certain energy-saving materials if these are used in non-business buildings or village halls. ${ }^{4}$

Furthermore, in the case of Finland, taxes on heat are zero for RES.

\footnotetext{
${ }^{4}$ The reduced VAT covers installations of solar panels, wind and water turbines; ground-source and airsource heat pumps and micro-CHP; and wood/straw/similar vegetal matter-fuelled boilers.
} 


\section{Promotion of biofuels in transport via tax incentives}

A large variety of biofuel support policies have been in place in MSs, ranging from command and control instruments such as standards and quotas, over economic and fiscal measures such as tax exemptions, to information diffusion ${ }^{5}$. However, from the early $90^{\prime}$ s of the past century there have been two main instruments which were the basis of biofuels supports schemes in EU: those were subsidization to compensate extra costs of biofuels compared to fossils fuels or prescription of a mandatory uptake in the market.

The first option has been usually implemented by tax exemptions schemes and the second one obliges fuel suppliers to achieve a certain biofuel share in their total sales. Any case, in practice both instruments can be used by national authorities of EU at the same time of others promotion measures.

We focus on tax incentives instruments oriented to promote the use of biofuels in transport. Sections develop above include tax incentives to also promote the biofuels use for green electricity generation and for $\mathrm{H} \& \mathrm{C}$ uses.

From Pelkmans et al. (2008) we can conclude that MSs strategies to reach the biofuels targets differ strongly from country to country. This is a result we observe also in the cases of green electricity and $\mathrm{H} \& \mathrm{C}$ exposed above. Some MSs have focused mainly in pure biofuels, while others have stimulated low blending from the beginning.

This section contains an actualized overview in which authors will mention the main tax incentives. It is not intended to give a comprehensive overview.

The use of tax exemptions to promote biofuels in EU is feasible under the conditions settled by the EU Energy Taxation Directive ${ }^{6}$. The most relevant conditions are:

- The tax exemption or reduction must not exceed the amount of taxation payable on the volume of renewable used.

- Changes in the feedstock prices are accounted for in order to avoid overcompensation.

- The exemption or reduction authorized may not be applied for a period of more than six consecutive years, renewable.

But before the EU Energy Taxation Directive came into force, some MSs with a large agricultural sector introduced some tax incentives at the same time at the European Common Agricultural Policy (CAP) reform of 1992. Those were the cases of Germany and France ${ }^{7}$. The fact of having a large agricultural sector with a long tradition and social influence motive those MSs to stimulate the production and use of biofuels. Next, environmental protection was also added as an additional and significant driving force.

The cases of Germany and France were followed in the following years by others MSs as the same time the EU area were expanded. In fact, some MSs add tax incentives to promote biofuels with direct subsidies to farmers who produce feedstock for biofuels uses (i.e. France, Bulgaria, Slovenia, Latvia, Lithuania, Poland and Czech Republic).

\footnotetext{
${ }^{5}$ Wiesenthal et al. (2009) give information about these complementary policies and measures: support to the cultivations of agricultural feedstock production in the framework of the Common Agricultural Policy, capital investment support to biofuel production facilities and biofuel standards to estimulate the wide market introduction of biofuels.

${ }^{6}$ Council Directive 2003/96/EC of 27 October restructuring the Community framework for the taxation of energy products and electricity.

${ }^{7}$ Eastern countries like the Czech Republic also introduced tax exemptions in theses years although wasn't an EU MSs in 1992.
} 
A correct overview of tax measures to support biofuels in transport must divide incentives into three main groups. Firstly tax incentive measures have been implemented as tax exemptions included in national mineral oil tax. Secondly, others taxes on GHG emissions have been also used to implemented these types of measures. Thirdly, some incentives were introduced to reduce taxation on ecological cars and biofuel industry.

Related with the first group of measures and following Pelkmans et al. (2008), since 1993 until 2003, the German fiscal authority determined that pure biofuels were exempted from the national mineral oil tax although mixed biofuel components fall under full taxation like traditional fossil fuels. However, an amendment of the Mineral Oil Tax Act up to 2004 established that not only pure biofuels, but also mixed biofuels were exempted from the excise tax on mineral oils in proportion to the amount of biofuel that they contain. In 2006 the government switched from the tax exemption policy to obligation schemes. The Netherlands authorities have followed a similar path.

Since 1991 pure biodiesel enjoys a full tax exemption in the Austria's mineral tax and since 2007 there is a tax reduction also for gasoline blended with bioethanol. Tax exemption for ethanol is also allowed in Sweden since 1992 but for all of biofuels full tax exemption is only permit for pilot projects since 1995.

The France incentive system is particularly conductive to the development of biofuels. Since 1992 biodiesel enjoys a total exemption from the internal tax on petroleum products (TIPP). In the case of bioethanol incorporated as ETBE in gasoline the exemption is a partial one (80 $\%)$. An interesting tax reform was implemented in France up to 2005. In order to raise the share of biofuels in the market, the French Parliament introduced a general tax on polluting activities (TGAP) for fuel resellers. TGAP is zero if an annual target percentage biofuels is reached ${ }^{8}$.

Joint with France, the Spanish incentive system is particularly conductive to the development of biofuels as they enjoy total exemption from the hydrocarbons tax until 31 December 2012. This special rate is applied to the biofuel volume contained in the mixture.

In 1992 Czech Republic established a zero excessive duty on produced biodiesel. This incentive was valid until 2007 when national government decided to change to a compulsory system (mandatory quotas). Different form Czech Republic, the Poland government maintains the tax exemption introduced in 1993. Incentives also remain valid in the United Kingdom where a duty incentive of 0.30 euro per liter for biodiesel is allowed since July 2002 and for bioethanol since January 2005. Incentives also remain valid in Lithuania (since 2005).

Over the past 4 years, a number of MSs have moved towards obligation or mixed systems to lower the revenue losses. Belgium is a significant case of mixed system where since 2006 exist a quota system for biodiesel (2007 for bioethanol) with tax reduction.

If we considered now taxes on GHG emissions -the second group of tax incentives-, since $2002 \mathrm{CO}_{2}$ neutral fuels are exempted from the Sweden $\mathrm{CO}_{2}$ tax. This is also the case of Denmark.

\footnotetext{
${ }^{8}$ A similar scheme was introduced in Germany since 2006 when the government switched from the tax exemption policy to obligation schemes. Then the Germany authorities introduced penalties in case of non-compliance the annual targets for biofuels consumptions. Penalties for non-compliance were been set rather high (>0.50 euros/litre). As Pelkmans et al. (2008) pointed out this gave a good motivation for fuel distributors to fulfil the obligation.
} 
Finally, a third group of tax incentives involves a heterogeneous set of measures oriented to promote industrial activities (biofuels production and the installation of points of sales for biofuels in traditional gas stations) or to promote ecological cars.

Many MSs as Germany have implemented tax incentive in the corporate tax to biofuels industry and to firms with projects related with biofuels.

Flexible Fuel Vehicles (FFV) have also enjoyed tax incentive in some MSs. In 2007, Spain implemented a reduction in the tax on matriculation of vehicles (Cansino and Ordoñez, 2008). This tax exemption is a total one in Ireland and in the case of electrical cars.

Table 3 summarizes our analysis and gives an overview of the MSs which have implemented tax incentives to promote biofuels in the last years.

\begin{tabular}{|l|c|c|c|c|c|c|}
\hline & $\begin{array}{c}\text { Low } \\
\text { biodiesel } \\
\text { blends (B5) }\end{array}$ & B30 & B100 & $\begin{array}{c}\text { Low ethanol } \\
\text { blends } \\
\text { (E5/ETBE) }\end{array}$ & E85 & PPO \\
\hline Austria & $\checkmark$ & & $\checkmark$ & $\checkmark$ & $\checkmark$ & $\checkmark$ \\
\hline Belgium & $\checkmark$ & & & & $\checkmark$ & $\checkmark$ \\
\hline Bulgaria & $\checkmark$ & & $\checkmark$ & $\checkmark$ & & \\
\hline Cyprus & $\checkmark$ & & $\checkmark$ & $\checkmark$ & & \\
\hline Czech Rep. & $\checkmark$ & $\checkmark$ & & & & \\
\hline Denmark & $\checkmark$ & & & $\checkmark$ & & \\
\hline Estonia & $\checkmark$ & & & $\checkmark$ & & \\
\hline Finland & & & & & & \\
\hline France & $\checkmark$ & $\checkmark$ & & $\checkmark$ & $\checkmark$ & \\
\hline Germany & $\checkmark$ & & $\checkmark$ & $\checkmark$ & $\checkmark$ & $\checkmark$ \\
\hline Greece & $\checkmark$ & & & & & \\
\hline Hungary & $\checkmark$ & & & $\checkmark$ & $\checkmark$ & \\
\hline Ireland & $\checkmark$ & & $\checkmark$ & $\checkmark$ & $\checkmark$ & $\checkmark$ \\
\hline Italy & $\checkmark$ & $\checkmark$ & & & & \\
\hline Latvia & $\checkmark$ & $\checkmark$ & $\checkmark$ & $\checkmark$ & $\checkmark$ & $\checkmark$ \\
\hline Lithuania & $\checkmark$ & & & $\checkmark$ & & \\
\hline Luxembourg & $\checkmark$ & & $\checkmark$ & $\checkmark$ & & $\checkmark$ \\
\hline Malta & $\checkmark$ & & & & & \\
\hline The \\
Netherlands
\end{tabular}

Source: Pelkmans et al. (2008)

Table 3. EU MSs and tax incentives 
As tax exemptions provoke the losses in revenues for governments, it is interesting the case of Belgium. In this country and to overcoming the revenue losses, authorities promoted a simultaneous increase in the fossil fuel tax so as to render the policy budgetneutral.

The use of tax exemptions to promote biofuel has and additional advantage. As Wiesenthal et al. (2009) pointed out; the increasing number of available production pathways with different characteristics in term of GHG emissions, production costs and potentials implies that MSs may employ differentiated biofuel strategies, favoring specific types of biofuels in order to better serve the objectives underlying their biofuel support policy.

However, the use of tax exemptions provokes a revenue loss. This explains that in the last years it is observed a switch from these types of measures to obligation schemes.

\section{Political discussion and main conclusions}

Proliferation of RES is a political question. Many measures can be implemented for it. Among them, tax incentives have been used to promote green electricity, RES for H\&C and biofuels. Table 4 summaries these tax measures. This Table also shows the electricity generated from renewable sources as a percentage of gross electricity consumption, the combined heat and power generation as a percentage of gross electricity generation and the share of renewable energy in fuel consumption of transport in 2006 and the incremental points in 2006-2008.

In general, countries that show high percentages also are those that have implemented tax incentives. However, these data do not allow us to assess specifically the effects of tax incentives as they are not isolated actions but in general all countries use a mix of measures to advance the development of RES. Among these measures, the fiscal measures, the others economic measures and the non economic measures such as advertising campaigns are some of them. Among the economic measures should be highlighted feed in tariffs and financial incentives. Among the non-financial measures include the regulation especially important for buildings and fuel. Therefore, besides presenting the data in Table 4, the specific effects of the measures in each country are discussed below.

After analyzing the energy policies of EU-27 MSs, it can be pointed out that the main tax incentive used to promote green electricity by the MSs is the exemption from the payments of excises duties for electricity when the electricity is generated by RES (Germany, Romania, Slovak Republic, Denmark, Sweden, Poland and Finland). This measure has been basically used for reducing the higher prices of production of this type of energy. With the same aim, tax incentives in CCL are implemented in the United Kingdom, a reduction of the ecotax is implemented in Netherlands and some subsidies are used in Finland to offset the excise duty on electricity. Also, lower tax rates in VAT are applied in three MSs, France, Italy and Portugal. Fiscal incentives in direct tax are applied in personal income tax, corporate tax and in property tax. In direct taxes, Belgium and France have designed these incentives as a deduction on the taxable income, which is calculated as a percentage of investment cost of system installed. While Czech Republic has designed it as a tax exemption of the taxpayers income that come from generate green electricity and Luxembourg as a tax exemption to electricity producers that produce electricity exclusively for their own use. The corporate tax incentives consist mainly in a deduction of the profit obtained (Belgium, Greece and Spain), but in Czech Republic, it consist in a tax exemption of the income obtained from generating green electricity. Finally, it can be said that only Spain and Italy uses fiscal incentives in terms of a tax exemption. 


\begin{tabular}{|c|c|c|c|c|c|c|c|c|c|}
\hline \multirow[t]{2}{*}{ UE-27 } & \multicolumn{3}{|c|}{ Green electricity } & \multicolumn{3}{|c|}{ Heating and Cooling } & \multicolumn{3}{|c|}{ Biofuels } \\
\hline & F.I. & 2006 & $\begin{array}{c}\Delta 2006- \\
2008\end{array}$ & F.I. & 2006 & $\begin{array}{c}\Delta 2006- \\
2008\end{array}$ & F.I. & 2006 & $\begin{array}{c}\Delta 2006- \\
2008\end{array}$ \\
\hline Austria & & 16.1 & -0.8 & $\checkmark$ & 16.1 & -0.8 & $\checkmark$ & 2.2 & 4.9 \\
\hline Belgium & $\checkmark$ & 8.7 & --- & $\checkmark$ & 8.7 & --- & $\checkmark$ & 0.1 & 1.1 \\
\hline Bulgaria & & 6 & 4 & $\checkmark$ & 6 & 4 & $\checkmark$ & 0.2 & 0 \\
\hline Cyprus & & 0.3 & 0 & & 0.3 & 0 & $\checkmark$ & 0 & 2.1 \\
\hline Czech Rep. & $\checkmark$ & 15.1 & -0.9 & & 15.1 & -0.9 & $\checkmark$ & 0.1 & 0.1 \\
\hline Denmark & $\checkmark$ & 40.7 & 5.4 & $\checkmark$ & 40.7 & 5.4 & $\checkmark$ & 0.3 & 0 \\
\hline Estonia & & 10.7 & -2.1 & & 10.7 & -2.1 & $\checkmark$ & 0 & 0 \\
\hline Finland & $\checkmark$ & 34.9 & 0.7 & $\checkmark$ & 34.9 & 0.7 & & 0.4 & 1.8 \\
\hline France & $\checkmark$ & 3.2 & -0.1 & $\checkmark$ & 3.2 & -0.1 & $\checkmark$ & 2 & 3.6 \\
\hline Germany & $\checkmark$ & 12.5 & 0 & $\checkmark$ & 12.5 & 0 & $\checkmark$ & 6.7 & -0.2 \\
\hline Greece & $\checkmark$ & 1.7 & 0.2 & $\checkmark$ & 1.7 & 0.2 & $\checkmark$ & 0.7 & 0.3 \\
\hline Hungary & & 22.4 & -1.3 & & 22.4 & -1.3 & $\checkmark$ & 0.1 & 3.8 \\
\hline Ireland & & 5.6 & 0.6 & & 5.6 & 0.6 & $\checkmark$ & 0.1 & 1.1 \\
\hline Italy & $\checkmark$ & 9.8 & -0.3 & $\checkmark$ & 9.8 & -0.3 & $\checkmark$ & 0.9 & 1.4 \\
\hline Latvia & & 42.6 & -9 & & 42.6 & -9 & $\checkmark$ & 1.1 & -0.2 \\
\hline Lithuania & & 14.3 & -1.6 & & 14.3 & -1.6 & $\checkmark$ & 1.6 & 2.4 \\
\hline Luxembourg & $\checkmark$ & 10.9 & 1 & & 10.9 & 1 & $\checkmark$ & 0 & 2 \\
\hline Malta* & & 0 & 0 & & 0 & 0 & $\checkmark$ & 0 & 0 \\
\hline Netherlands & $\checkmark$ & 29.9 & 3.7 & $\checkmark$ & 29.9 & 3.7 & $\checkmark$ & 0.4 & 2.1 \\
\hline Poland* & $\checkmark$ & 16 & 0.9 & & 16 & 0.9 & $\checkmark$ & 0.9 & 2.4 \\
\hline Portugal & $\checkmark$ & 11.6 & 0.3 & & 11.6 & 0.3 & $\checkmark$ & 1.3 & 1.1 \\
\hline Romania & $\checkmark$ & 18 & -8.4 & & 18 & -8.4 & $\checkmark$ & 0.8 & 2 \\
\hline Slovakia & $\checkmark$ & 27.6 & -3.6 & & 27.6 & -3.6 & $\checkmark$ & 0.5 & 5.8 \\
\hline Slovenia & & 7.4 & -0.7 & & 7.4 & -0.7 & $\checkmark$ & 0.4 & 1.1 \\
\hline Spain & $\checkmark$ & 7.2 & -0.2 & & 7.2 & -0.2 & $\checkmark$ & 0.7 & 1.2 \\
\hline Sweden & $\checkmark$ & 8 & 1.6 & $\checkmark$ & 8 & 1.6 & $\checkmark$ & 4.9 & 1.4 \\
\hline UK & $\checkmark$ & 6.3 & 0.1 & $\checkmark$ & 6.3 & 0.1 & $\checkmark$ & 0.5 & 1.5 \\
\hline
\end{tabular}

Source: Own elaboration.

Table 4. Effects of fiscal incentives to advance RES deployment 
Literature about energy requirements for heating and cooling has largely focused on new building standards. Government interventions in heating and cooling have mainly consisted of establishing construction standards for buildings in an attempt to increase energy efficiency with respect to heating and cooling requirements.

The revision of the energy policies of EU-27 MSs and the government interventions concerning energy use with respect to heating and cooling, make us to conclude that $23 \mathrm{MSs}$ have adopted additional measures to promote the use of RES for heating and cooling. The implementation of such measures corroborates the opinion of those experts who explain that the increased use of RES can only be achieved if it is accompanied by additional support from government authorities.

Twelve MSs have used tax incentives with a dual purpose, to reduce investment costs and to make renewable energy profitable through a decrease in relative prices. In the first case, the use of tax deductions has the advantage of involving ex-post incentives, although they do not lower the hurdle of the initial upfront payment. Some MSs have thus resorted to reducing tax (VAT) rates to overcome this. In the second case, these measures have been relatively successful when they have been accompanied by other measures that tend to increase the price of alternative energy sources.

Finally, if we focus on the tax measures to support the use of biofuels in transport, we can conclude that, until now, subsidies through partial or total exemptions have proven to be the most successful instruments to raise the share of biofuels use for transport, especially when tax incentives are complemented by other measures.

Additionally, the tax exemptions allow steering the market by applying different reduction rates to various types of biofuels by considering its effects on GHG emissions.

However the losses in revenues for governments which have implemented tax exemptions become high with rising market volumes. As a consequence of that over the past 7 years, a number of MSs have moved towards obligation or mixed systems to lower the revenue losses.

The actual economic crisis has forced the MSs to review the incentive measures of RES. All the measures studied are linked to tax restrictions, so that in times of deficit reduction, all these policies may be affected.

\section{Acknowledgement}

The authors acknowledge financial support received by the Andalusian Energy Agency, Fundació Roger Torné and by SEJ 132. They also acknowledge the suggestions made by the participants of the III Workshop on Public Economics and Renewable Energy, University of Seville, April 2011. Authors acknowledge the suggestions made by the reviewers. The usual disclaimer applies.

\section{References}

Bomb, C. McCormick, K. Deurwaarder, E. and S Kaberger, T. 2007. Biofuels for transport in Europe: Lessons from Germany and the UK, Energy Policy 35(4), 2256-2267

Bundesministerium für Umwelt, Naturschutz und Reaktorsicherheit, 2011 Bundesministerium für Umwelt, Naturschutz und Reaktorsicherheit, 2008. Legal sources on the generation of electricity from renewable energy sources. 
(http://www.res-legal.eu/en.html). Bundesministerium für Umwelt, Naturschutz und Reaktorsicherheit Berlin.

Cansino, J.M. and M. Ordoñez. Impuestos Pigouvianos e Incentivos Fiscales para el Fomento de Energías renovables en España: Análisis Panorámico. Actas de la XXXIV Reunión de Estudios Regionales. XXXIV Reunión de Estudios Regionales. Baeza. Asociación Española de Ciencia Regional. 2008, 1-10

Cansino, J. M., Pablo-Romero, M. P., Román, R. and Yñiguez, R. 2010. Tax incentives to promote green electricity: An overview of EU-27 countries. Energy Policy, 38(10), 6000-6008

Cansino, J. M., Pablo-Romero, M. P., Román, R. and Yñiguez, R. 2011. Promoting renewable energy sources for heating and cooling in eu-27 countries. Energy Policy, 39 (6), 3803-3812.

Communication from the Commission to the European Parliament, the Council, the European Economic and Social Committee and the Committee of the Regions (COM/2010/0639 final). Energy 2020. A Strategy for competitive, sustainable and secure energy, Brussels.

Intelligent Energy Europe. 2010. RE-SHAPING Renewable energy policy country profiles. Intelligent Energy Europe. Utrecht, The Netherlands http:/ / www.solarthermalworld.org/node/1157

De Mooij, R. A. 1999. The double dividend of an environmental tax reform, in:. Van den Bergh, J. C. J. M (ed.), Handbook of Environmental Economics, Edward Elgar, Cheltenham.

Del Río P., Gual M., 2004. The promotion of green electricity in Europe: present and future. European Environment 14, 219-234.

Di Domenico, M. 2006. EU Member States tax measures for renewable energy policies development.IEFE-Università Bocconi.

http://favores.die.unipd.it/Downloads/finalReports/wp5/WP_5_EU_Tax_Measu res.pdf

EREC. 2009. Renewable Energy Policy Review, Austria, Belgium, Bulgaria, Cyprus, the Czech Republic, Denmark, Estonia, Finland, France, Germany, Greece, Hungary, Ireland, Italy, Latvia, Lithuania, Luxembourg, Malta, the Netherlands, Poland, Portugal, Romania, Slovakia, Slovenia, Sweden, and the United Kingdom. http://www.erec.org/fileadmin/erec_docs/Projcet_Documents/RES2020/

EuroACE. 2009. Current financial and fiscal incentive programs for sustainable energy in buildings from across Europe. EuroACE. Belgium.

European Commission (EC), 1996. Green Paper on renewable sources of energy of 20 November 1996, COM(1996) 576 final ,Brussels, Belgium.

European Commission (EC), 2001. Communication of 3 February 2001 on Community guidelines on state aid for environmental protection, Brussels, Belgium.

European Council (EC), 2003. Directive 2003/96/EC of 27 October 2003 restructuring the Community framework for the taxation of energy products and electricity, Brussels, Belgium.

European Commission (EC), 2006. Communication from the Commission to the Council and the European Parliament about the Renewable Energy Road Map: Renewable energies in the 21st century. Building a more sustainable future $\operatorname{COM}(2006) 848$ final, Brussels, Belgium. 
European Commission, 2007. Communication from the Commission to the European Council and the European Parliament of 10 January 2007, "An energy policy for Europe" [COM(2007) 1 final - Not published in the Official Journal].

European Commission, 2010. Communication from the Commission to the European Parliament, The Council, The European Economic and Social Committee and The Committee of the Regions of 10 November 2010, "A strategy for competitive, sustainable and secure energy" [COM(2010) 639].

European Commission. 2011. Taxes in Europe. Database.

http:/ / ec.europa.eu/taxation_customs/taxation/gen_info/info_docs/tax_invento ry/index_en.htm

European Parliament resolution with recommendations to the Commission on heating and cooling from renewable sources of energy, OJC 290E, 29.11.2006

European Parliament and the Council (EP\&C), 2002. Directive 2002/91/EC of the European Parliament and of the Council of 16 December 2002 on the energy performance of buildings, Brussels, Belgium.

European Parliament and the Council (EP\&C), 2006. Directive 2006/32/EC of the European Parliament and of the Council of 5 April 2006 on energy end-use efficiency and energy services and repealing Council Directive 93/76/EEC, (ESP). Brussels, Belgium.

European Parliament and the Council (EP\&C), 2009. Directive 2009/28/EC of the European Parliament and of the Council of 23 April 2009 on the promotion of the use of energy from renewable sources and amending and subsequently repealing Directives 2001/77/EC and 2003/30/EC, Brussels, Belgium.

European Parliament and the Council (EP\&C), 2009. Directive 2009/125/EC of the European Parliament and of the Council of 21 October 2009 on establishing a framework for ecodesign requirements for energy-related products, Brussels, Belgium.

European Parliament and the Council (EP\&C), 2010. Directive 2010/30/EC of the European Parliament and of the Council of 19 May 2010 on the indication by labelling and standard product information of the consumption of energy and other resources by energy-related products, Brussels, Belgium

European Parliament and the Council (EP\&C), 2010. Directive 2010/31/EC of the European Parliament and of the Council of 19 May 2010 on the energy performance of buildings (recast), Brussels, Belgium.

http:/ / eur-lex.europa.eu/LexUriServ/LexUriServ.do?uri=OJ:L:2010:153:0013:0035: EN:PDF

Eurostat 2010b. Energy Statistics -quantities-. Available at http://epp.eurostat.ec.europa.eu (last access 05 July, 2010).

Goulder, L.H. 1995. Environmental taxation and the double dividend: A reader's guide. International Tax and Public Finance, 2, 155-182

International Energy Agency (IEA). OECD, 2007. Renewable for heating and cooling. IEA http://www.dekoepel.org/documenten/Renewable_Heating_Cooling_Final_WEB .pdf (last access 3 February, 2011).

Menkveld, M. and Beurskens, L. 2009. Renewable heating and cooling in the Netherlands. Energy Research Centre of the Netherlands 
Pelkmans, L., Govaerts, L. and Kessels, K. 2008. Inventory of biofuel policy measures and their impact on the market. Report of ELOBIO subtasks 2.1-2.2. September.

Uyterlinde M.A., Daniels B.W., De Noord M., De Vries, H.J., De Zoeten-Dartenset C., Skytte K., Meibom P., Lescot D., Hoffman T., Stronzik M., Gual M., del Rio P., Hernández P., 2003. Renewable electricity market developments in the European Union, Final Report of the Admire Rebus Project, ECN-C-03-082. ECN: Pettern, Netherlands.

Van Beers, C., Van den Bergh, J.C., De Moor, A and Oosterhuis, F. 2007. Determining the environmental effects of indirect subsidies: integrated method and application to the Netherlands. Applied Economics, 39, 2465-2482

Viladrich, M. 2004. Las principales aportaciones a la teoría de la regulación medioambiental. Los últimos cuarenta años. Economía Agraria y Recursos Naturales, 4(8), 41-62

Wiesenthal, T, Leduc, G, Christidis, P, Schade, B, Pelkmans, L, Govaerts, L, and Georgopoulos, P. 2009. Biofuel support policies in Europe: Lessons learnt for the long way ahead. Renewable and Sustainable Energy Reviews, 13 (4), 789-800. 


\section{Part 2}

Applications 



\title{
Structural Design of a Dynamic Model of the Battery for State of Charge Estimation
}

\author{
Frédéric Coupan, Ahmed Abbas, Idris Sadli, \\ Isabelle Marie Joseph and Henri Clergeot \\ UMR ESPACE-DEV, Université des Antilles et de la Guyane \\ Guyane Française
}

\section{Introduction}

For a standard interconnected electrical power network, the problem of optimal management of production arises from randomness of users demand. When using renewable energies, an additional critical problem is that the resource itself is random. The difficulty is still more pregnant when dealing with small isolated production networks, in locations where photovoltaic systems or wind generators should be a promising solution. To resolve the difficulties induced by intermittent production or consumption, these systems must make a consistent use of the energy storage. For example, in the case of an individual photovoltaic system, storage is essential to the scale of at least $24 \mathrm{~h}$, in order to overcome the daily fluctuations.

Among the various methods used to store electrical energy, electrochemical batteries constitute the most readily available, with good performance and a reasonable cost (Riffonneau et al.,2008). Renewable Energies are concerned by stationary storage, for which lead acid batteries are a good choice. Despite decades of use and its apparent simplicity, the battery maintains a complex and poorly understood dynamical behavior. Moreover, possible degradation of the battery is largely related to poor control of periods of deep discharge or full load with gassing. For efficient use of this device, a detailed knowledge of operation, and thus a good electrochemical modeling, is essential. Otherwise, it could constitute the most fragile element in a photovoltaic or wind systems because of premature aging resulting in a loss of capacity or a failure risk (Garche et al.,1997).

A lot has been done in the domain of batteries modeling from two opposite ways.

On the one hand, a purely phenomenological approach has been developed by engineers. In particular, very valuable tests are commonly performed using battery cycling with constant charge and discharge currents. In particular, there appears a reduction of the effective capacity when the cycling current increases (Peucker's law (Manwell Jams, 2003)). These results may have direct application for charge monitoring in systems with alternate charging and discharging sequences (for instance traction vehicles); unfortunately, they do not apply to wind turbines or photovoltaic applications subject to random electrical current variations.

On the other hand, extensive physical studies have been made by electrochemists concerning the physics of electrochemical cells. Descriptions of the cell behavior have been 
proposed in terms of equivalent electrical circuits (Bard, 2000). In particular, associated to diffusion phenomenon, the Warburg impedance $\mathrm{Zw}$ has been introduced, involving integration with a non integer order. In Laplace notation (where $p$ denotes the equivalent derivation operator) the Warburg impedance has the form: $Z_{w}=A p^{-1 / 2}$. In a previous communication, we demonstrated that the effective cell capacity reduction described by Peucker's law may be connected to the step response associated to the Warburg impedance (Marie-Joseph et al., 2004).

Anyway, some midway solution must obviously be found between underlying fundamental physics and the need of the engineers for a computationally efficient simplified model.

In this chapter, we discuss the major processes resulting in a voltage drop that occurs during a redox reaction sitting in storage electrochemical. The phenomena of diffusion/storage and activation are identified as the main factors for the voltage drop in the batteries (Esperilla et al.,2007). These phenomena occur when the battery is subjected to an electric current, which is to say when there is mass transport in electrochemical interface; they are called faradic phenomena. Focusing particularly on transport mechanism of carriers in the battery, we observed strong similarities between electrochemical interfaces and PN junction diodes (Coupan et al., 2010). Based on the approximation of the physics of semiconductor PN junction, we propose a physical analysis coupled to experimental investigation.

Along these lines, in this chapter, we introduce a dynamical model of the battery, which explains in terms of a simplified equivalent circuit how the total stored charge is distributed along a cascade of individual elements, with increasing availability time delays. This explains why short cycling makes use only of the closer elements in the chain. It opens the way to a wise design of systems combining short delay storage (for instance supercapacities) and conventional batteries used for long term full range cycling.

\section{Analysis methodology}

At steady state (without current), according to the electrical charges of the reactants in the redox reaction, the chemical potential gradient across the interface may be balanced by an electrical potential gradient. This electric field, integrated across the interface, results in the equilibrium potential given by the Nernst relationship (Marie-Joseph, 2003).

When a current is applied to the electrochemical cell, the electronic flow in the metal terminals corresponds to an ionic flow, in proportion defined by the redox reaction stoechiometry at the electrolyte interface. Corresponding carriers which are present in the electrolyte can then move either under the effect of an electrical potential gradient (migration) or the effect a concentration gradient (diffusion). Occasionally, electrolyte transport by convection may also be of influence (Linden et al., 2001). This movement of carriers causes a change in battery voltage compared to the steady sate potential, called over-potential. Note that it is a nonlinear function of the current, depending not only on the present value of the current but on its past variations: it is termed a dynamical non linear relationship. The phenomena responsible for this over-potential involve a number of different and complex processes that overlap each other: that is to say, the kinetics of electron transfers, mass transfers, but also ohmic effect and other non-faradic effects. In this study, we focus on the phenomena of diffusion/storage and activation.

- The diffusion/storage overvoltage is connected to variation of the ionic concentrations in the electrolyte: average value related to the state of charge, and gradient related variation at the interface in presence of current. However this phenomenon always 
appears in agreement with the Nernst equation. We propose a linearisation by inversion of this relation and a dynamical model drawing from the analogy of diffusion equation with a capacitive transmission line. Diffusion phenomena predominate for response times ranging from $10^{3}$ to $10^{5} \mathrm{~s}$.

- The activation overvoltage may be related to injection of sulfate ions in the oxide film at the surface of electrodes. These constitute solid electrolytes no longer governed by Boltzmann but by Fermi-Dirac statistics. There are strong similarities which the injection of minority carriers in PN junctions. In the literature, this phenomenon is usually described by the semi empirical Butler-Volmer relation. We propose a dynamical model drawn from the charge driven model of PN diodes, with given relaxation time (typically in the order of some $10^{2} \mathrm{~s}$ ).

- Full description of the battery includes conventional circuit modeling of non faradic effects. This is taken into account by an RC "input cell" including plates electrostatic capacitance, Ohmic resistance and the plates double layer capacitances, with typical time constants between $1 \mathrm{~s}$ and 100s. High frequency models may include inductive effects (Blanke et al, 2005).

\section{Input cell and diffusion voltage for lead acid batteries}

\subsection{Input impedance cell}

With a simplified assumption of symmetrical electrochemical impedance for the electrodes (denoted $Z^{\prime} / 2$ ), we can infer equivalent circuit of fig 1-a, $\gamma$ being an inter-plates capacitance, $R$ the electrolyte resistance and $2 C_{0}$ the double layer capacitance of the interface. The corresponding reduced input circuit is given fig 1-b.

Elements of the input cell are easily identified experimentally at small operating currents and high enough frequencies. Due to the activation threshold, impedance $Z^{\prime}$ is quite high at low current, so that the double layer impedance $C_{0}$ dominates for frequencies greater than about $0.1 \mathrm{~Hz}$.

Once the elements of the cell are known, current and voltage may easily be corrected for. In the following, we are interested only in the internal electrochemical impedance $Z$ '.

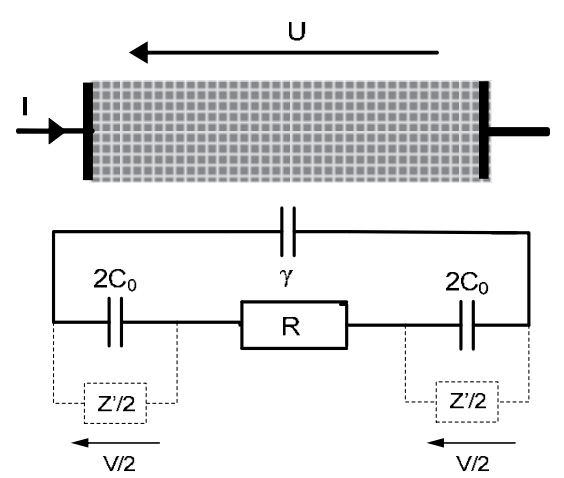

1.a

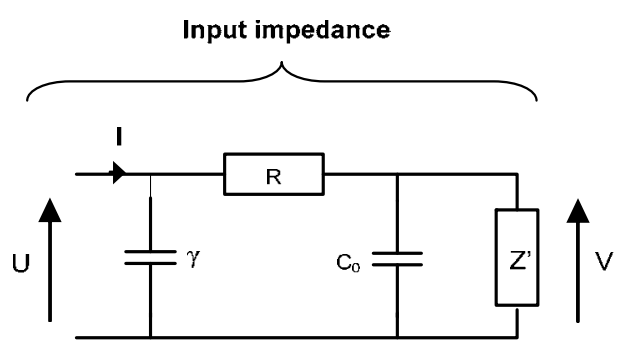

1.b

Fig. 1. Input impedance cell (simplified symmetric plates model) 


\subsection{Diffusion overvoltage}

For the sake of clarity, a good part of the analysis will be carried in the stationary case, corresponding to constant current. We use a one dimensional battery model, the variable being the abscissa $z$ between the negative $(z=0)$ and the positive plate $(z=L)$. Results are then extended with a constant cross section $S$. to the general dynamical case, including time dependency.

\subsubsection{Constant current analysis}

\subsubsection{General presentation}

During the discharge of the lead acid battery, sulfate ions are "swallowed" by both electrodes according to chemical reactions:

Positive electrode:

$$
\mathrm{PbO}_{2}+\mathrm{SO}_{4}^{2-}+4 \mathrm{H}^{+}+2 e^{-}-\stackrel{\text { Discharge }}{\longrightarrow} \mathrm{PbSO}_{4}+2 \mathrm{H}_{2} \mathrm{O}
$$

Negative electrode:

$$
\mathrm{Pb}+\mathrm{SO}_{4}^{2-}-\underline{\text { Discharge }} \stackrel{\longrightarrow}{\longrightarrow} \mathrm{PbSO}_{4}+2 e^{-}
$$

Figure 2 illustrates the transport of ions along axis $\mathrm{Oz}$ associated with the two half-reactions at the electrodes (inter-electrode distance $L$ ):

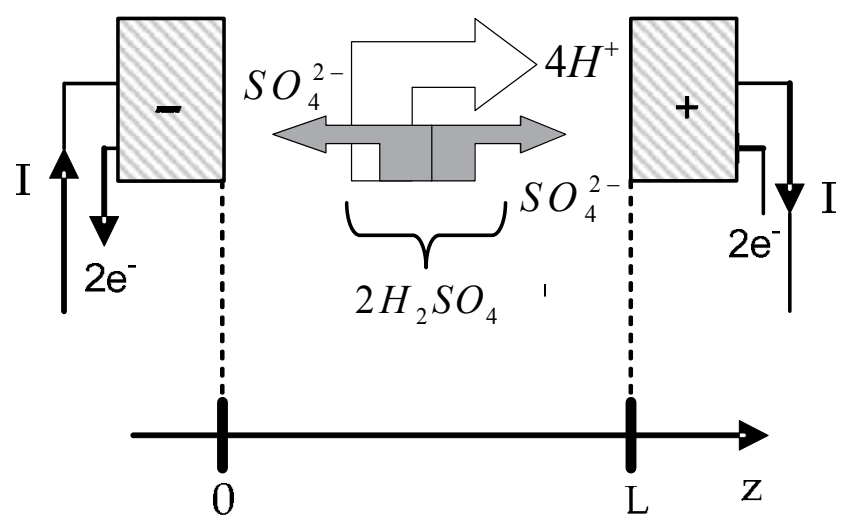

Fig. 2. Battery operation: case of discharge

So, two types of ions are responsible for current transport through the electrolyte. Those are sulfate ions (subscript $S$ ) and hydrogen ions (subscript $H$ ). In terms of currents:

$$
I(z)=I_{H}(z)+I_{S}(z)
$$

Let $\mathrm{S}$ be the section area between the plates (constant for à one dimensional model). The same relation holds in terms of current densities:

$$
J(z)=\frac{I}{S}=J_{H}(z)+J_{S}(z)
$$


In the electrolyte, as can be seen in figure 2, there is an inversion of the sulfate ions flow along the $\mathrm{z}$ axis. More precisely according to the simultaneous equations (2), we obtain the boundary conditions at the electrodes:

$$
\begin{gathered}
\mathrm{I}_{\mathrm{S}}(0)=\mathrm{I} \text { and } \mathrm{I}_{\mathrm{H}}(0)=0 \\
\mathrm{I}_{\mathrm{S}}(\mathrm{L})=-\mathrm{I} \text { and } \mathrm{I}_{\mathrm{H}}(\mathrm{L})=2 \mathrm{I}
\end{gathered}
$$

As it will be seen in section 3.2 the constant current case corresponds to a stationary solution of the dynamical case with $\partial^{2} I / \partial z^{2}=0$, which implies a linear variation of the current between the given limits. The profile of currents $I_{S}(z)$ and $I_{H}(z)$ is then obtained according to Figure 3:

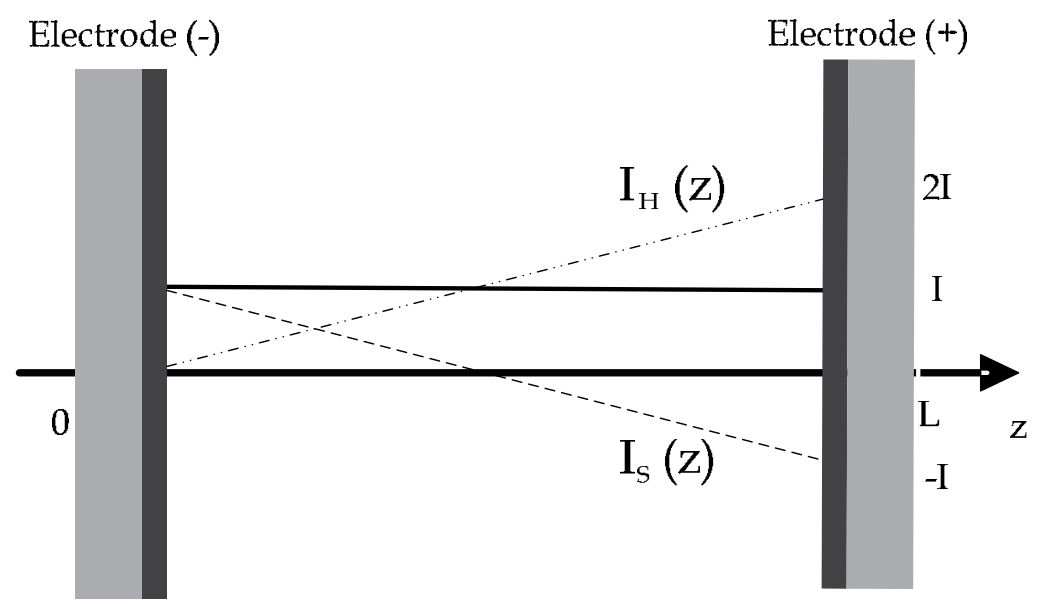

Fig. 3. Linear model of current $\mathrm{I}_{\mathrm{S}}(\mathrm{z})$ et $\mathrm{I}_{\mathrm{H}}(\mathrm{z})$

\section{Main steps in diffusion phenomena analysis}

The mains steps in our analysis will be the following:

a. The total current is equal to the sulfate ion current at the negative electrode (see equation 3.a)

b. Sulfate ion motion is dominated by diffusion (see next section)

c. According to b), we will establish that there is a linear relationship between sulfate concentration and density current (trough linear Partial Derivative Equations)

d. The Nernst cell voltage may be expressed as a non linear function of the sulfate concentration for $\mathrm{z}=0$ (section 3.2.1.3)

As a consequence, for given boundary conditions, from a) and c) we deduce that there exists a relation of linear filtering between the total current $I(t)$ and the sulfate anode concentration $n_{s}(0, t)$.

According to $\mathrm{d}$ ), we find that the cell voltage $V(t)$ may be directly expressed as a (non linear) logarithmic function of this concentration (sect 3.1.3). We propose a linearization of the problem, by the use of an exponential mapping on $V(t)$ : in this way we introduce a "pseudopotential" proportional to the sulfate concentration (sect 3.2.1.3). This pseudo-potential is then related to the current by linear impedance. This impedance may be simplified in terms of a RC network (3.2.2.4). 


\subsubsection{Diffusion fields and currents}

In the electrolyte, the carriers are transported under the influence of an electric field $\mathrm{E}$ and the diffusion field $\xi$, connected to the concentration gradient. For the two types of carrier ( $\mathrm{k}$ : Boltzmann constant; e: charge of one electron):

$$
\begin{aligned}
\xi_{S} & =-\frac{k T}{q_{S}} \frac{1}{n_{S}} \frac{d n_{S}}{d z} \\
\xi_{H} & =-\frac{k T}{q_{H}} \frac{1}{n_{H}} \frac{d n_{H}}{d z}
\end{aligned}
$$

Note that, from the relation: $\mathrm{q}_{\mathrm{S}}=-2 \mathrm{q}_{\mathrm{H}}=-2 \mathrm{e}$, and the neutrality condition, we get the relation between concentrations: $\mathrm{n}_{\mathrm{H}}=2 \mathrm{n}_{\mathrm{S}}$. By substitution in (4), we derive the corresponding relation between the diffusion fields:

$$
\xi_{\mathrm{H}} / \xi_{\mathrm{S}}=\mathrm{q}_{\mathrm{S}} / \mathrm{q}_{\mathrm{H}}=-2
$$

The corresponding expression of the currents, for each type of carrier, is then given by the relation:

$$
\begin{aligned}
& J_{S}=\mu_{S} q_{S} n_{S}\left(E+\xi_{S}\right) \\
& J_{H}=\mu_{H} q_{H} n_{H}\left(E+\xi_{H}\right)
\end{aligned}
$$

In this relation, $J_{H}$ and $J_{S}$ have a similar magnitude (see fig 3 ). The mobility of hydrogen ions being much higher than the sulfate ions, this implies that $E+\xi_{H}$ is very small, so that: $E \approx-\xi_{H}$. From this result and (5), we find that the current densities may be expressed in terms of the diffusion field $\xi_{S}$ alone:

$$
\mathrm{E} \approx-\xi_{\mathrm{H}}=2 \xi_{\mathrm{S}} \mathrm{E}+\xi_{\mathrm{S}} \approx 3 \xi_{\mathrm{S}}
$$

Whence

$$
\mathrm{J}_{\mathrm{S}}=\mu_{\mathrm{s}} \mathrm{q}_{\mathrm{s}} \mathrm{n}_{\mathrm{S}}\left(3 \xi_{\mathrm{s}}\right)
$$

Or, according to (4):

$$
J_{s}(z)=3 \mu_{s} k T\left(\frac{d n_{s}}{d z}\right)
$$

And from (2):

$$
J=J_{s}(0)=3 \mu_{s} k T\left(\frac{d n_{s}}{d z}\right)_{0}
$$

This establishes the step c) of our diffusion analysis exposed in section 3.2.1.1

We may introduce in $(7 b)$ the linear profile of the current, valid in the stationary case. We then derive a parabolic symmetric profile of the concentration of sulfate ions (Fig. 4), with $n_{S}(0)=n_{S}(L)$. 


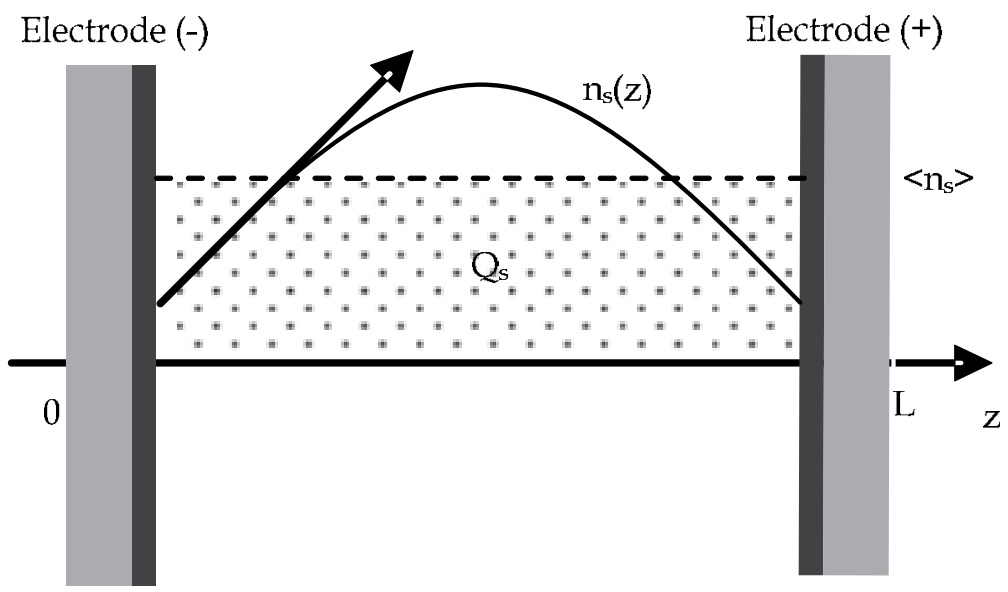

Fig. 4. Concentration profile (Stationary 1D Model)

Let us point out this symmetry property which will generalize for the dynamical case. Following the boundary condition ( $3 a$ and $3 b$ ) we find:

- For currents, the anti symmetry property: $I_{S}(L-z)=-I_{S}(z)$

- $\quad$ For densities, the symmetry property: $\mathrm{n}_{\mathrm{s}}(\mathrm{L}-\mathrm{z})=\mathrm{n}_{\mathrm{s}}(\mathrm{z})$

\subsubsection{Voltage and concentration}

According to the electrochemical model defined above, while applying Nernst's equation (Marie-Joseph, 2003); we obtain the expression of voltage as a function of the limit concentrations in the form:

$$
. V=A_{1}+\frac{k T}{2 e} \ln \left(\frac{n_{S}(0)}{a_{\mathrm{PbSO}_{4}}(0)}\right)+\frac{k T}{2 e} \ln \left(\frac{n_{s}(L) n_{H}(L)^{4}}{a_{\mathrm{PbSO}_{4}}(L)}\right) .
$$

In this relation, we may use the fact that:

- $\quad$ According to the neutrality condition (section 3.2.1.2), $\mathrm{n}_{\mathrm{H}}=2 \mathrm{n}_{\mathrm{S}}$

- $\quad$ Due to the symmetry of concentrations, $\mathrm{n}_{s}(\mathrm{~L})=\mathrm{n}_{\mathrm{s}}(0)$.

- Concerning PbSO4 activity, it is equal to one, unless we are very close to full charge (this will not be considered here).

In such conditions, the expression of battery voltage may be set in the form:

$$
V=A_{2}+\frac{3 k T}{e} \ln \left(n_{s}(0)\right)
$$

Let $\mathrm{n}_{0}$ be a reference sulfate concentration and $\mathrm{E}_{0}$ the corresponding Nernst voltage, then the relation may be written in the form:

$$
\left\{\begin{array}{l}
V=E_{0}+V_{L} \ln \left(\frac{n_{s}(0)}{n_{0}}\right) \\
V_{L}=\frac{3 k T}{e}
\end{array}\right.
$$


This result corresponds to point $d$ ) in introduction (3.2.1.1).

\subsubsection{4 "Linearised" pseudo-voltage using an exponential transformation}

We suggest to introduce a "pseudo-voltage" which is à linear function of the concentration, and which aims to the voltage $V$ when it is close to the reference voltage $E_{0}$, according to figure 5:

$$
\tilde{\mathrm{V}}=\mathrm{E}_{0}+\mathrm{V}_{\mathrm{L}}\left(\frac{n_{\mathrm{S}}-n_{0}}{n_{0}}\right)=\mathrm{E}_{0}-\mathrm{V}_{\mathrm{L}}+\mathrm{V}_{\mathrm{L}}\left(\frac{n_{S}}{n_{0}}\right)
$$

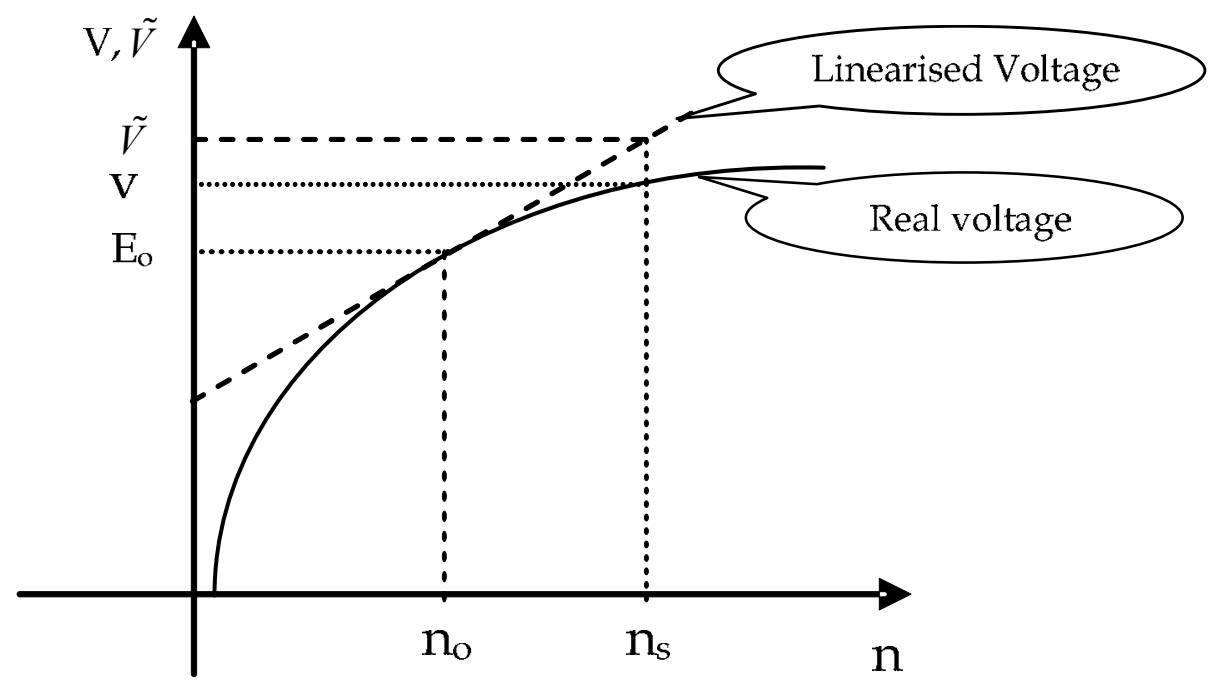

Fig. 5. Linearised Pseudo-voltage

The pseudo voltage may then be obtained by an exponential transformation of the original voltage according to the expression:

$$
\tilde{\mathrm{V}}=\mathrm{E}_{0}+\mathrm{V}_{\mathrm{L}}\left(\exp \left(\frac{V-\mathrm{E}_{0}}{\mathrm{~V}_{\mathrm{L}}}\right)-1\right)=\mathrm{E}_{0} \cdot \mathrm{V}_{\mathrm{L}}+\mathrm{V}_{\mathrm{L}}\left(\exp \left(\frac{V-\mathrm{E}_{0}}{\mathrm{~V}_{\mathrm{L}}}\right)\right)
$$

\subsubsection{Constant current equivalent circuit}

According to figure 4, the limit concentrations (for $z=0$ and $z=L$ ) are easily expressed, and may be related to the total stored charge $Q_{S}$ and the internal current I:

$$
\left\{\begin{array}{l}
\mathrm{n}_{\mathrm{s}}(0)=\mathrm{n}_{\mathrm{s}}(L)=\left\langle\mathrm{n}_{\mathrm{s}}\right\rangle-\frac{L}{6}\left(\frac{\mathrm{dn}_{\mathrm{s}}}{d z}\right)_{0} \\
\mathrm{Q}_{\mathrm{s}}=S L\left\langle\mathrm{n}_{\mathrm{s}}\right\rangle \\
I=\mathrm{I}_{\mathrm{s}}(0)=S J_{\mathrm{s}}(0)=3 S \mu_{\mathrm{s}} k T\left(\frac{\mathrm{dn}_{\mathrm{s}}}{d z}\right)_{0}
\end{array}\right.
$$

According to equations (8) and (11), the voltage may be expressed in terms of the stored charge $Q_{s}$ and the internal current I according to: 


$$
\left\{\begin{array}{l}
\mathrm{V}=\mathrm{E}_{0}+\frac{3 \mathrm{kT}}{\mathrm{q}} \ln \left(\frac{\mathrm{Q}_{\mathrm{S}}-\theta \mathrm{I}}{\mathrm{Q}_{0}}\right) \\
\theta=\frac{L^{2}}{18 \mu_{\mathrm{s}} k T}
\end{array}\right.
$$

Relation (12) may be written in terms on an RC model valid only for constant current charge or discharge in the form:

$$
\tilde{V}=V_{L} \frac{\left(Q_{S}-\theta I\right)}{Q_{0}}=\frac{Q_{S}}{C_{D}}-R_{D} I
$$

With $C_{D}=Q_{0} / V_{L}$ and $R_{D}=\theta / C_{D}$

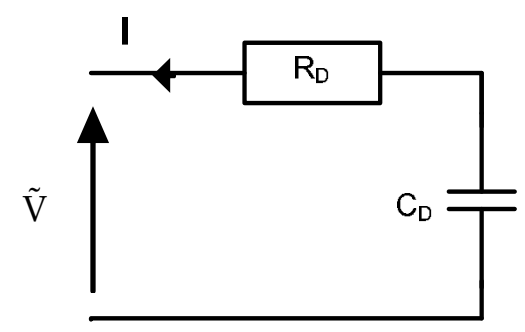

Fig. 6. RC equivalent circuit for constant current (after linearization)

\subsubsection{Dynamical model for time varying current}

\subsubsection{General diffusion equations (one dimension)}

In the general case, current densities and concentrations densities depend both on $\mathrm{z}$ and $\mathrm{t}$. Equation (7) may be written in term of partial derivative:

$$
\frac{\partial n_{S}}{\partial z}=\frac{J_{S}}{3 \mu_{S} k T}
$$

We may add the charge conservation equation:

$$
\frac{\partial \mathrm{J}_{\mathrm{S}}}{\partial \mathrm{z}}=-\frac{\partial \rho}{\partial \mathrm{t}}=2 \mathrm{e} \frac{\partial \mathrm{n}_{\mathrm{s}}}{\partial \mathrm{t}}
$$

These two coupled Partial Derivative Equations define the diffusion process (Lowney et al., 1980).

The driving condition is given by relation:

$$
J_{S}(0, t)=J(t)=\frac{I(t)}{S}
$$

And the bounding condition resulting of the current anti symmetry:

$$
J_{S}(L, t)=-J_{S}(0, t)
$$




\subsubsection{General electrical capacitive line analogy}

In the diffusion equations (14) et (15), making use of relation (9), the sulfate ion density $n_{S}$ may be expressed in terms of the pseudo potential $\tilde{V}$, and the current densities $J$ s may be replaced by currents $I s=S J$ s. We then obtain a couple of joint partial derivative equations between the pseudo voltage $\tilde{V}(z, t)$ and the sulfate current $I s(z, t)$ :

$$
\left\{\begin{array}{l}
\frac{\partial \tilde{\mathrm{V}}_{\mathrm{S}}}{\partial \mathrm{z}}=\frac{\mathrm{V}_{\mathrm{L}}}{\mathrm{n}_{0}} \frac{\partial \mathrm{n}_{\mathrm{S}}}{\partial \mathrm{z}}=\frac{\mathrm{V}_{\mathrm{L}}}{\mathrm{n}_{0} \mu_{\mathrm{S}} k T}\left(\frac{\mathrm{I}_{\mathrm{S}}}{\mathrm{S}}\right) \\
\frac{\partial \mathrm{I}_{\mathrm{S}}}{\partial \mathrm{z}}=S \frac{\partial \mathrm{J}_{\mathrm{S}}}{\partial \mathrm{z}}=2 e S\left(\frac{\mathrm{n}_{0}}{\mathrm{~V}_{\mathrm{L}}} \frac{\partial \tilde{\mathrm{V}}_{\mathrm{S}}}{\partial t}\right)
\end{array}\right.
$$

These are the equations of a capacitive transmission line with linear resistance $\rho$ and linear capacity $\gamma$ as defined below. (Bisquert et al., (2001).

$$
\begin{array}{ll}
\frac{\partial V_{S}}{\partial z}=\rho I_{S} & \rho=\frac{1}{\mu_{S} e S n_{0}} \\
\frac{\partial I_{S}}{\partial z}=\gamma \frac{\partial V_{S}}{\partial t} & \gamma=\frac{2 e n_{0} S}{V_{L}}
\end{array}
$$

Taking in account the symmetry of the concentrations, we obtain an equivalent circuit consisting in a length $\mathrm{L}$ section of transmission line, driven on its ends with symmetric voltages. The current is then 0 in the symmetry plane at $\mathrm{L} / 2$. The input current is the same as for a $\mathrm{L} / 2$ section with open circuit at the end.

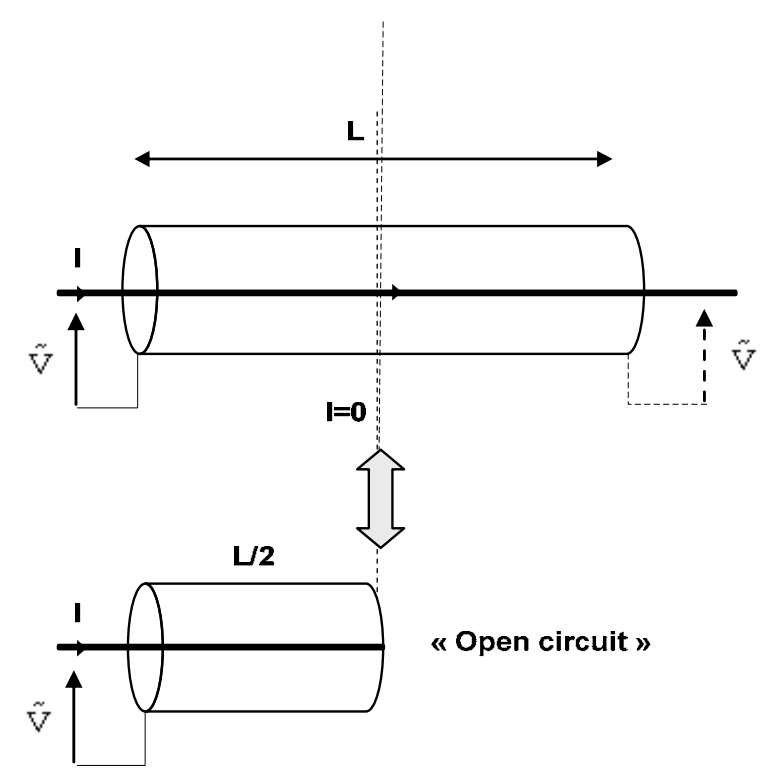

(Open circuit capacitive transmission line of length $\mathrm{L} / 2$ )

Fig. 7. Equivalent electrical circuit for the pseudo-voltage 


\subsubsection{Equivalent impedance solution}

For linear systems, we look for solutions in the form $A \exp (p t)$ for inputs, or $A(z) \exp (p t)$ along the line, $\mathrm{p}$ being any complex constant.

Let:

$$
\left\{\begin{array}{l}
I(z, t)=I(z) \exp (p t) \\
V(z, t)=V(z) \exp (p t)
\end{array}\right.
$$

Then we obtain the simplified set of equations

$$
\left\{\begin{array}{l}
\frac{d V_{S}}{d z}=\rho I_{S} \\
\frac{d I_{S}}{d z}=\gamma p V_{S}
\end{array}\right.
$$

Whence $\frac{\mathrm{d}^{2} \mathrm{I}_{\mathrm{s}}}{\mathrm{dz}^{2}}=\rho \gamma p \mathrm{I}_{\mathrm{s}}$

Let $\rho \gamma=\tau / L^{2}$. Then $-\alpha$ and $\alpha$ be the solutions of :

$$
\alpha^{2}=p \rho \gamma=p \frac{\tau}{L^{2}}
$$

Then solution for Is $(z)$ is a linear combination of $\exp ( \pm \alpha z)$. If we impose $I_{s}(L / 2)=0$, then

$$
I_{S}(z)=\operatorname{Ish}\left(\alpha\left(z-\frac{L}{2}\right)\right)
$$

Whence:

$$
V_{S}(z)=\frac{1}{\alpha} \rho \operatorname{Ich}\left(\alpha\left(z-\frac{L}{2}\right)\right)
$$

We then get the Laplace impedance at the input of the equivalent circuit:

$$
Z(p)=\frac{V_{S}(0)}{I_{S}(0)}=\frac{\rho}{\alpha \operatorname{th}\left(\frac{\alpha L}{2}\right)}
$$

if $|\alpha L|<<1 \quad \operatorname{th}\left(\frac{\alpha L}{2}\right) \approx \frac{\alpha L}{2}$

$$
\left\{\begin{array}{l}
Z(p) \approx \frac{1}{C p} \\
C=\frac{\gamma L}{2}
\end{array}\right.
$$


In case of harmonic excitation $(p=j \omega)$ this corresponds to small frequencies $(\omega \tau<<1)$. The impedance is the global capacity of the line section. In practice for batteries (Karden et al., 2001), this corresponds to very small frequencies $\left(10^{-5} \mathrm{~Hz}\right)$

if $|\alpha L|>>1 \quad \operatorname{th}\left(\frac{\alpha L}{2}\right) \approx 1$

$$
Z(p) \approx \sqrt{\frac{\rho}{\gamma}} p^{-1 / 2}
$$

In case of harmonic excitation $(p=j \omega)$ this corresponds to high enough frequencies $(\omega \tau>>1)$ the impedance is the same as for an infinite line (Linden, D et al., 2001), corresponding to the Warburg impedance.

\subsubsection{Approximation of the Warburg impedance in terms of RC net}

An efficient approximation of a $\mathrm{p}^{-1 / 2}$ transfer function is obtained with alternate poles and zeros in geometric progression. In the same way, concerning Warburg impedances an efficient implementation (Bisquert et al., 2001) is achieved by a set of RC elements in geometric progression with ratio $\mathrm{k}$, as represented in figure 8.

Let $\omega_{0}=1 / R C$. Note that the progression of the characteristic frequencies is in ratio $\mathrm{k}^{2}$.

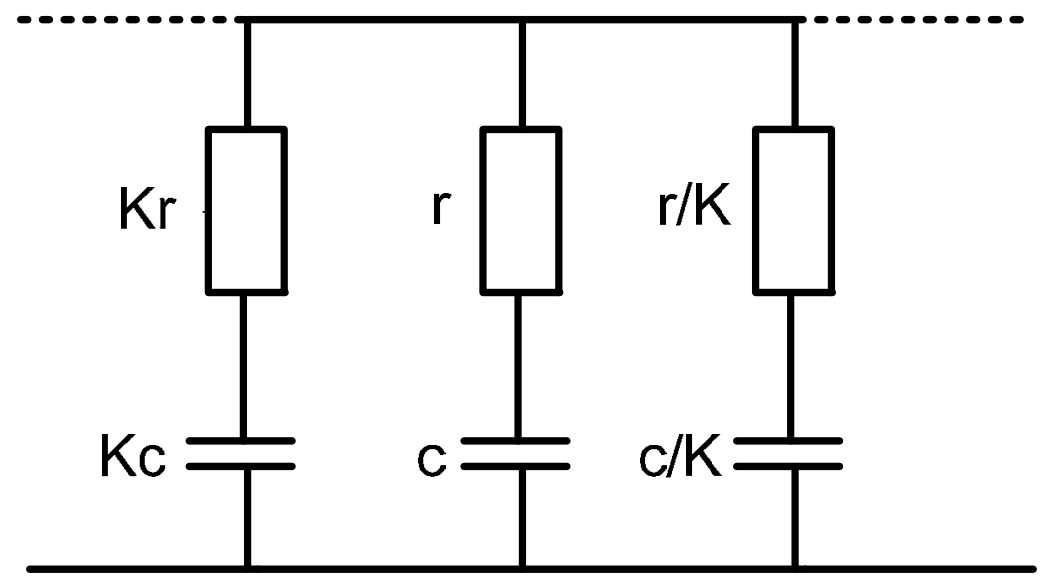

Fig. 8. RC cells in geometric progression

Let $Y(\omega)$ be the admittance of the infinite net. It is readily verified that

- For $\omega=\omega_{0}, Y\left(\omega_{0}\right)$ may be set in the form Sk/(1-j), with real Sk (complex angle exactly $\pi / 4)$

- $\quad \mathrm{Y}\left(\mathrm{k}^{2} \omega_{0}\right)=\mathrm{k} \mathrm{Y}\left(\omega_{0}\right)$ (Translation of one cell in the net)

It can be verified by simulation that the fitting is quite accurate, even for values up to $\mathrm{k}=3$.

\subsubsection{Approximation of a finite line in terms of $\mathrm{RC}$ net}

The simplest approximation would to use a cascade of $\mathrm{N}$ identical RC cells simulating successive elementary sections of line of length $\Delta L=L / 2 N$. with: $r=\rho \Delta L$ and $c=\gamma \Delta L$ 


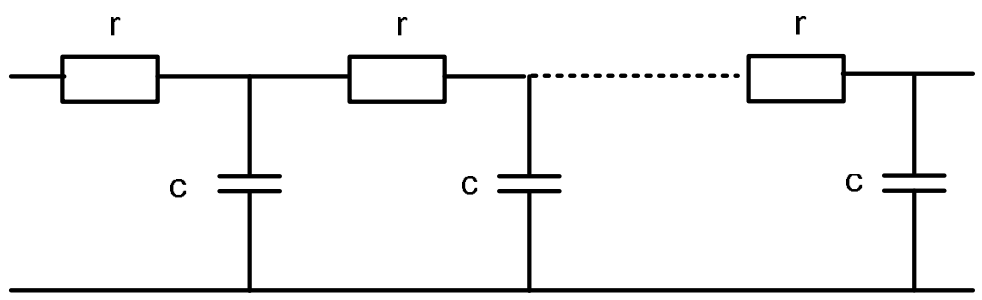

Fig. 9. Elementary approximation by a cascade of identical RC cells

This approximation introduces a high frequency limit equal to the cutoff frequency of the cells $f_{N}=1 / 2 \pi r c$. Drawing from the previous example concerning Warburg impedance, we propose to use $(M+1)$ cascaded sections but with impedance in geometric progression.

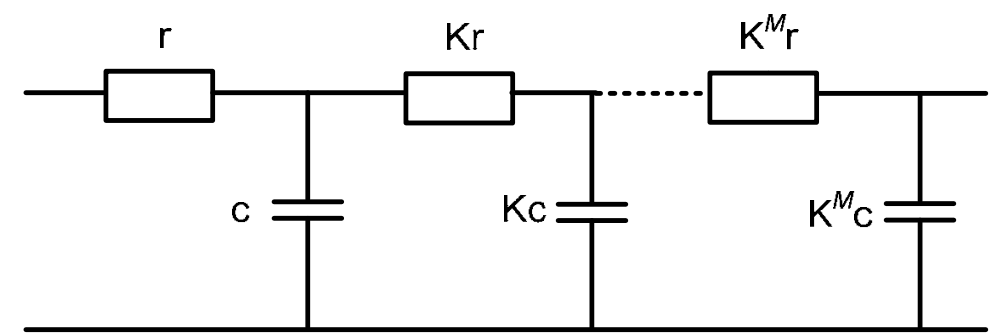

Fig. 10. Approximation by a cascade of RC cells in geometric progression

The total capacity will be equal to the total L/2 line capacity. The frequency limit for the approximation remains given by the first cell cutoff frequency.

For instance for $\mathrm{k}=3$ this may result in a drastic reduction of the number of cells for a given quality of approximation.

\subsubsection{Practical RC model used for experimentations}

In practice, the open circuit line model will be valid only if the entire electrolyte is between the cell plates. In practice this is usually not true. For our batteries, about one half of the electrolyte volume was beside the plates. In such case there is an additional transversal transport of ions, with still longer time constants. This could be accommodated by an additional RC cell connected at the output of the line.

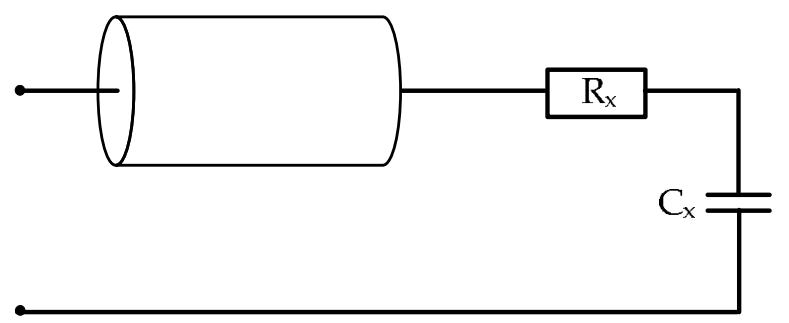

Fig. 11. Transmission line with additional RC cell

Satisfactory preliminary results for model validation were obtained with a much simplified network, with an experimental fitting of the component values (Fig 11). 
We may consider that $\mathrm{c}$ and $\mathrm{c} 1(\mathrm{c}<<\mathrm{c} 1)$ account for the transmission line impedance, while $\mathrm{Cx}, \mathrm{Rx}(\mathrm{Cx}$ in the order of $\mathrm{C} 1$ ) accounts for external electrolyte storage.

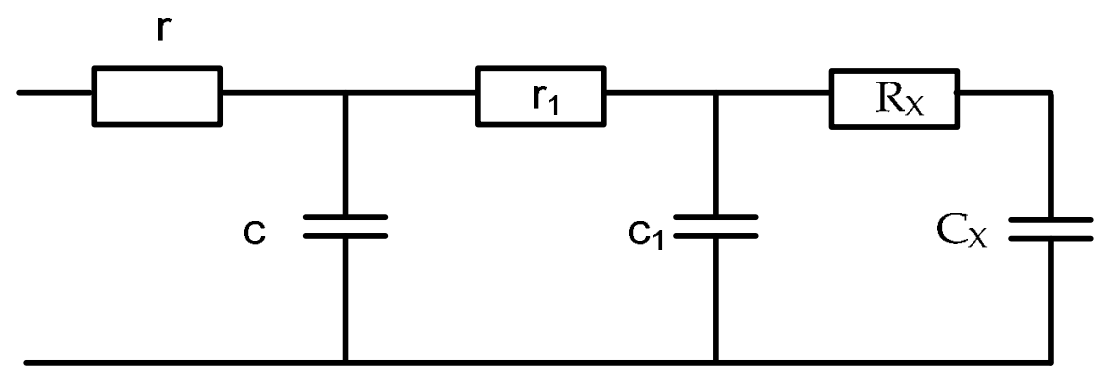

Fig. 12a. Diffusion/storage model -1-

Provided that $C_{D} \ll C_{1}$ connection as a parallel RC cell should not modify drastically the resulting impedance. This model was introduced in order to separate "short term" and "long term" overvoltage variations in the experimental investigation.

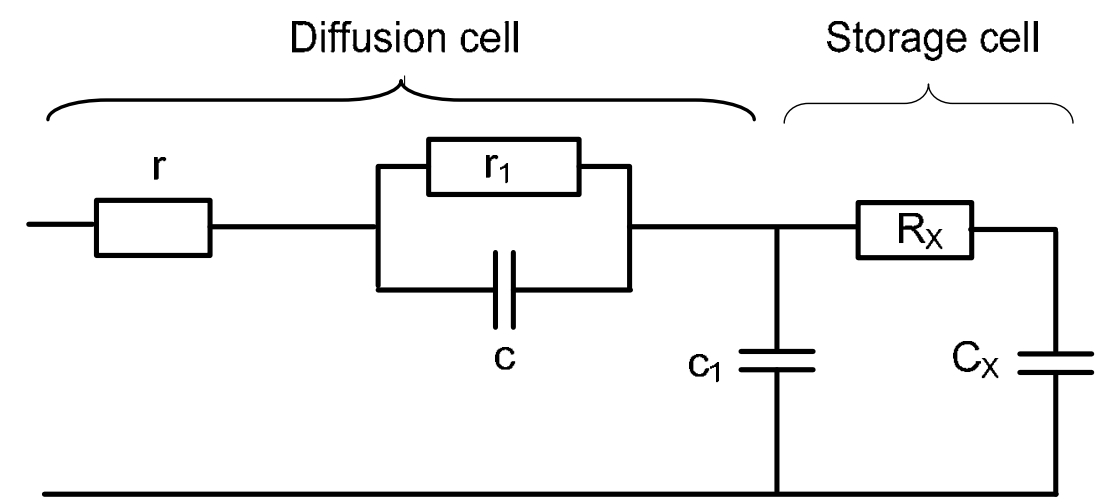

Fig. 12b. Diffusion/Storage model -2-

\section{Activation voltage}

\subsection{Comparison to $\mathrm{PN}$ junction}

A PN junction is formed of two zones respectively doped $\mathrm{N}$ (rich in electrons: donor atoms) and $\mathrm{P}$ (rich in holes: acceptor atoms). When both $\mathrm{N}$ and $\mathrm{P}$ regions are assembled (Fig. 13), the concentration difference between the carriers of the $\mathrm{N}$ and $\mathrm{P}$ will cause a transitory current flow which tends to equalize the concentration of carriers from one region to another. We observe a diffusion of electrons from the $\mathrm{N}$ to the $\mathrm{P}$ region, leaving in the $\mathrm{N}$ region of ionized atoms constituting fixed positive charges. This process is the same for holes in the P region which diffuse to the $\mathrm{N}$ region, leaving behind fixed negative charges. As for electrolytes, it then appears a double layer area (DLA). These charges in turn create an electric field that opposes the diffusion of carriers until an electrical balance is established. 


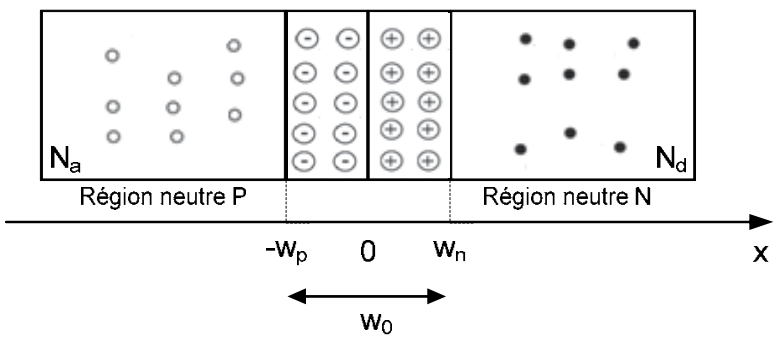

Fig. 13. Representation of a PN junction at thermodynamic equilibrium

The general form of the charge density depends essentially on the doping profile of the junction. In the ideal case (constant doping " $\mathrm{N}_{\mathrm{a}}$ and $\mathrm{N}_{\mathrm{d}}$ "), we can easily deduce the electric field form $\mathrm{E}(\mathrm{x})$ and the potential $\mathrm{V}(\mathrm{x})$ by application of equations of electrostatics (Sari-Ari et al.,2005). In addition, the overall electrical neutrality of the junction imposes the relation:

$$
N_{a} W_{n}=N_{d} W_{p}
$$

with $W_{n}$ and $W_{p}$ corresponding to the limit of DLA on sides $N$ and P respectively (Fig. 13). It may be demonstrated that according to the Boltzmann relationship, the corresponding potential barrier (diffusion potential of the junction) is given by:

$$
V_{0}=U_{T} \ln \left(\frac{N_{a} N_{d}}{n_{i^{2}}}\right), U_{T}=\frac{k T}{e}
$$

where $n_{i}$ represents the intrinsic carrier concentration. On another hand, note that the width of the DLA may be related to the potential barrier (Mathieu H, 1987).

The PN junction out of equilibrium when a potential difference $\mathrm{V}$ is applied across the junction. According to the orientation in figure 14, the polarization will therefore directly reduce the height of the potential barrier which becomes $\left(\mathrm{V}_{0}-\mathrm{V}\right)$ resulting in a decrease in the thickness of the DLA. (Fig. 14)
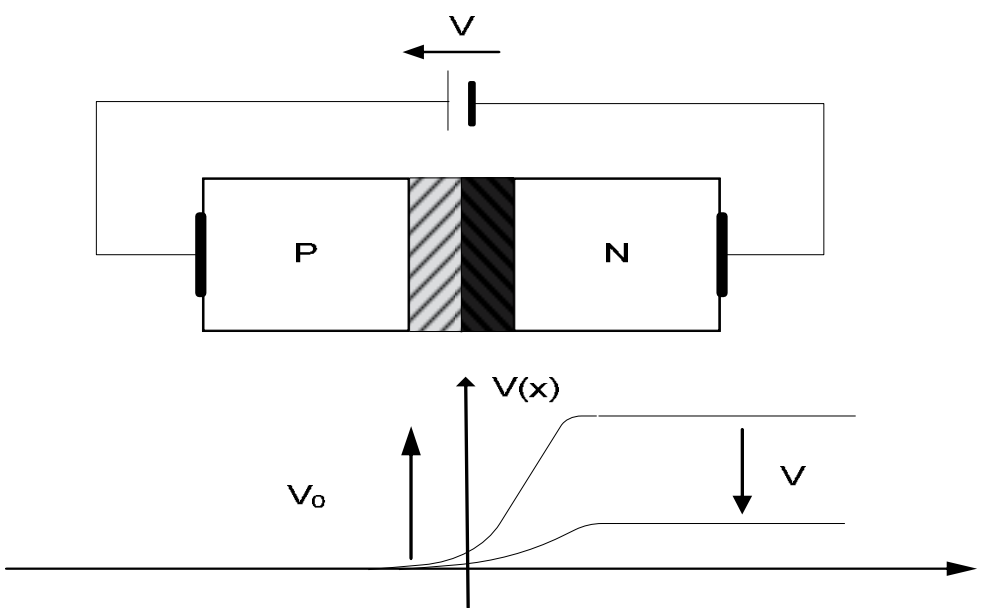

Fig. 14. Representation of a PN junction out of equilibrium thermodynamics 
The decrease in potential barrier allows many electrons of the $\mathrm{N}$ region and holes from the $\mathrm{P}$ region to cross this barrier and appear as carriers in excess on the other side of the DLA. These excess carriers move by diffusion and are consumed by recombination. It is readily seen that the total current across the junction is the sum of the diffusion currents, and that these current may be related to the potential difference $V$ in the form (Mathieu $H, 1987$ ):

$$
J=J_{S}\left(\exp \left(\frac{V}{U_{T}}\right)-1\right)
$$

where Js is called the current of saturation.

On the other hand the diffusion current is fully consumed by recombination with time constant $\tau$, so that the stored charge $Q$ may be expressed as $Q=\tau$ J. This expression will be used for the dynamic model of the diode.

\subsection{Comparison of PN junction and electrochemical interface}

From the analysis of PN junction diodes, following similarities can be cited in relation to electrochemical interfaces (Coupan and al., 2010):

- The electrical neutrality is preserved outside an area of "double layer" formed at the interface electrode / electrolyte.

- In the neutral zone, conduction is predominantly by diffusion.

- The voltage drop located in the double layer zone is connected to limit concentrations of carriers by an exponential law (according to the Nernst's equation in electrochemistry, the Boltzmann law for semi-conductors).

However, significant differences may be identified:

- For the PN junction, it is the concentration ratio that leads to predominant diffusion current for the minority carriers by diffusion. For lead acid battery, it is the mobility ration that explains that $\mathrm{SO}_{4}^{2-}$ ions move almost exclusively by diffusion

- There is no recombination of the carriers in the battery. As a result, in constant current operation the stored charge builds up linearly with time, instead of reaching a limit value proportional to the recombination time.

- The diffusion length is in fact the distance between electrodes, resulting in very long time constants (time constants even longer if one takes into account the migration of ions from outside the plates).

- $\quad$ within the overall "double-layer", additional "activation layers" build up in the presence of current, corresponding to the accumulation of active carries close to the reaction interface.

Based on method for modeling the PN junction, and the comparison seen above, we propose to analyze and model the phenomenon of activation in a lead-acid battery.

\subsection{Phenomenon of non-linear activation}

The activation phenomenon is characterized by an accumulation of reactants at the space charge region. This electrokinetic phenomenon obeys to the Butler-Voltmer: exponential variation of current versus voltage, for direct and reverse polarization (Sokirko Artjom et al., 1995). Dynamical behavior can be introduced using a "charge driven model", familiar for PN junctions, connected to an excess carrier charge $Q$ stored in the activation phenomenon. Bidirectional conduction can be accommodated using two antiparallel diodes. Based on the 
for one single PN junction, the static and dynamic modeling of a diode is given by the current expression:

$$
V_{a} \prod^{\mathrm{I}}\left\{\begin{array}{l}
I_{s t}=J_{s}\left(e^{\left(\frac{V_{a}}{v_{0}}\right)}-1\right. \\
I=\frac{Q(t)}{\tau}+\frac{d Q}{d t}
\end{array}\right)=\frac{Q}{\tau_{0}}
$$

with $Q$ representing an amount of stored charge and a time constant $\tau$ associated.

It is noted that one can easily model the current through the diode with an equivalent model of stored charge; this approach is valid for one current direction and not referring to the battery charge. We must therefore provide a more complete model that can be used in charge or discharge. This analysis therefore reflects a model with two antiparallel diodes. The static and dynamic modeling of the two antiparallel diodes is given by the current expression (simplified symmetric model):

$$
V_{a} \overbrace{1}^{\downarrow} I_{s t}=G\left(V_{a}\right)=J_{s} \operatorname{sh}\left(\frac{V_{a}}{v_{0}}\right)
$$

The static relation corresponds to the Butler Volmer equation (symmetric case). It is completed by the charge driven model:

$$
\left\{\begin{array}{l}
Q=\tau I_{s t}=\tau G\left(V_{a}\right) \\
I=I_{s t}+\frac{d Q}{d t}
\end{array}\right.
$$

After an analysis resulting static (and dynamic) and an experimental validation, we get the model of the phenomenon of activation with a parallel non linear capacitance and conductance circuit (fig.15) whose expressions are given by the following equations:

$$
I_{s t}=G\left(V_{a}\right)=\frac{J_{0}}{v_{0}} \operatorname{sh}\left(\frac{V_{a}}{v_{0}}\right) \text { and } Q\left(V_{a}\right)=\frac{c_{0}}{v_{0}} \operatorname{sh}\left(\frac{V_{a}}{v_{0}}\right)
$$

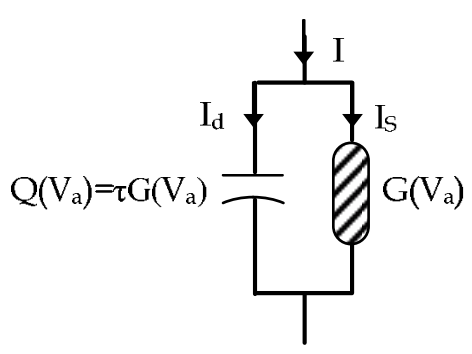

Fig. 15. Activation model : non-linear capacitance and conductance 


\section{Overvoltage model and experimental validation}

By combining models obtained (diffusion phenomena/Storage, activation and input cell) and experimental measurements, we propose a simple and effective model of the battery voltage.

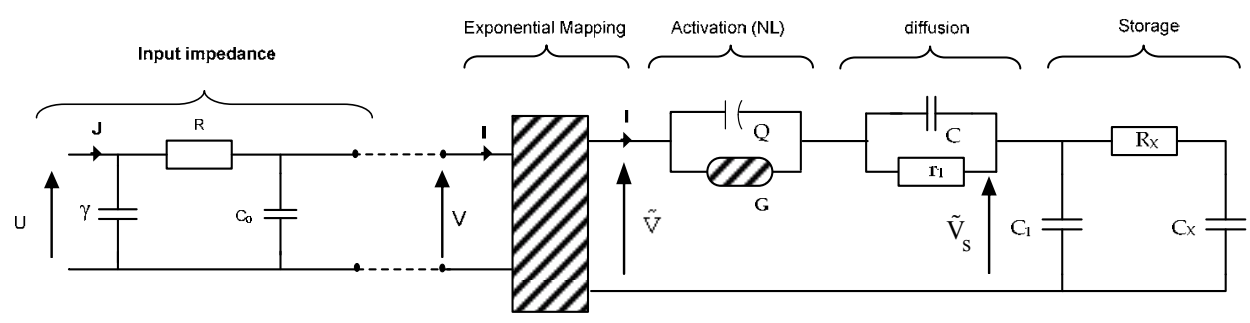

$\left(\mathrm{R} \approx 2.510^{-3} \Omega, \mathrm{\gamma}=400 \mathrm{~F}, \mathrm{C}_{0}=2.310^{4} \mathrm{~F}, \mathrm{c}=3.210^{4} \mathrm{~F}, \mathrm{r}_{1}=2.510^{-3} \Omega, \mathrm{c}_{1}=\mathrm{C}_{\mathrm{x}}=510^{5} \mathrm{~F}, \mathrm{R}_{\mathrm{x}}=0.01 \Omega\right)$

Fig. 16. Overvoltage model of lead acid battery

\subsection{Experimental analysis}

Identification of a linear model may be delicate, but there are a lot of classical well trained methods for this.

For a non linear system, it is difficult to find a general approach.

For most cases, it is possible to separate steady state non linear set point positioning, then local small signal linear investigation.

For battery, the set point should be defined by the state of charge and the operating current. But the fact that when you apply a non zero operating current, the state of charge is no longer fixed. This is an important practical problem, all the more critical as there is a the strong dependence of the activation impedance with respect to the current. The experimental methodology presented is centered on this non linearity topic.

\subsection{Separation on the basis of the time constant}

Our objective is to establish the static value of the activation voltage as a function of current. The problem is that if the current scanning is too slow the variation of the state of charge will corrupt the measure.In such condition we can never reach the static value. Typical results are given in fig 17, compare to charge driven dynamical models as discussed in section 4 .

\subsection{Correction of battery voltage connected to the state of charge}

A first hypothesis is that for slowly varying current the voltage drift is a function of the stored charge $Q$, computed by summation of the current. 3D plots are made as a function of the couple I, Q, with current steps to identify the relaxation time and asymptotic value as representative of the storage voltage or activation steps. (Fig.18) 


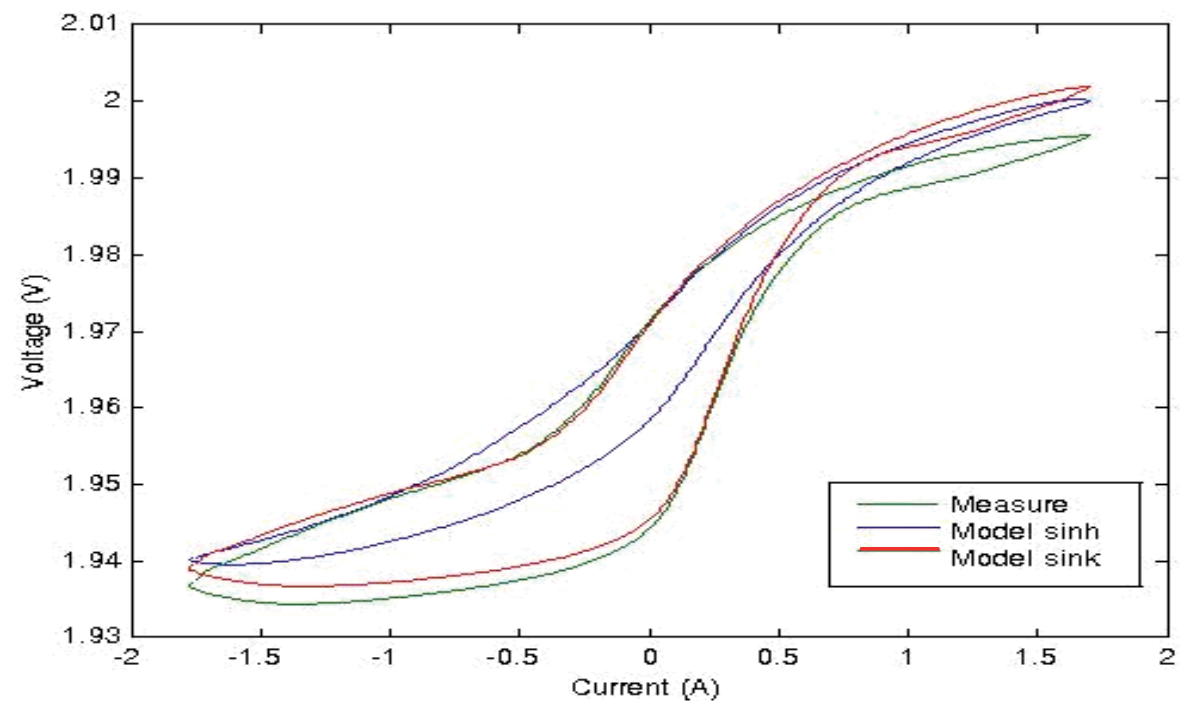

Fig. 17. Experimental analysis and simulation of activation phenomena

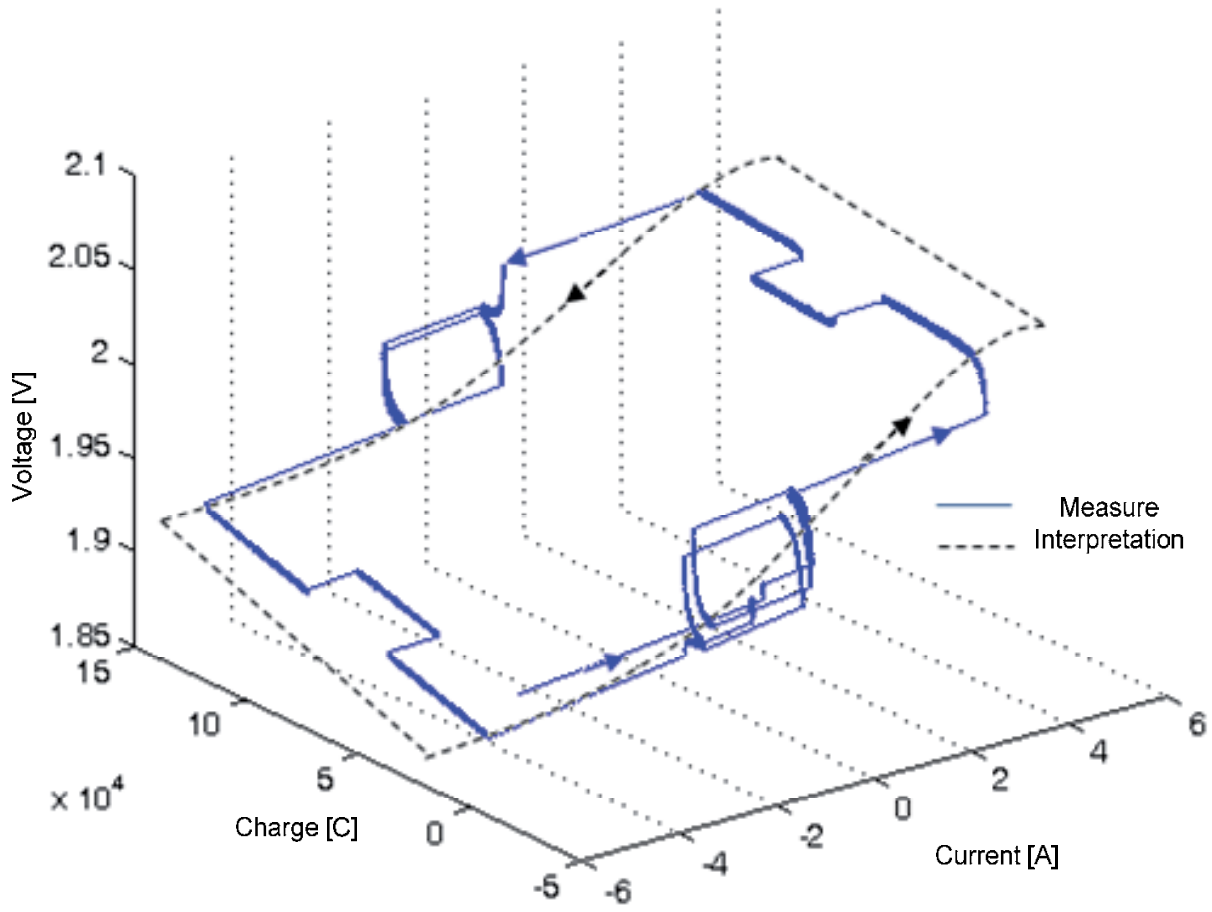

Fig. 18. Highlight of the diffusion and activation process 


\subsection{Improved storage voltage estimation}

Instead of using $\mathrm{Q}$ as a reference for the storage voltage, we use the voltage given by the optimized RC storage net. Again the plot is made for steps between constant values of the current. We can see that between curves corresponding to two given values of the current, there remains a variation of the activation voltage.

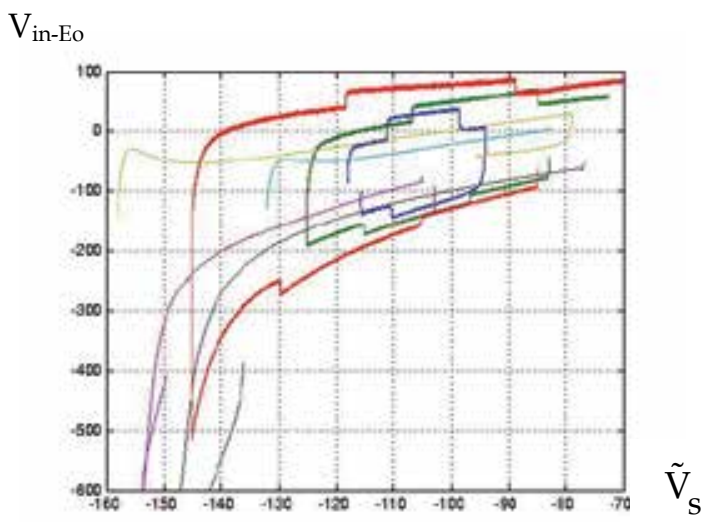

Fig. 19a. General Validation of diffusion/stockage and activation phenomena

\subsection{Effect of the non linear voltage transformation}

The same points are plotted using the pseudo-voltage after exponential transform. We see that now the plot between two given values of the current, which constitutes a good validation of the non linear model.

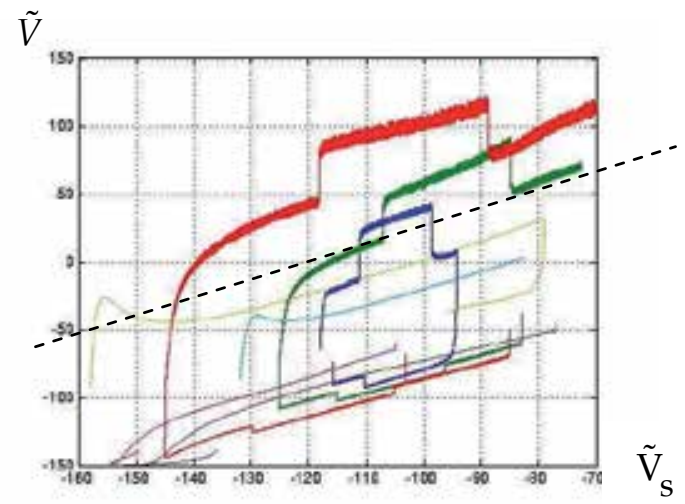

Fig. 19b. Reduction of activation voltage variations by linearisation

\section{Conclusion}

Electrochemical batteries are becoming quite usual components for electrical engineers. One of our purposes was to provide a good understanding for such users, by the way of a short form equivalent circuit.

This equivalent circuit sums up the different steps of a simplified physical analysis. Two most important aspects may be cited: 
- Investigation of nonlinearities

- $\quad$ Efficient lumped model for diffusion

\subsection{Investigation of nonlinearities}

Characterization of dynamical non linear systems is quite complex. Purely phenomenological description may lead to a huge number of parameters for imperfect results.

From our physical analysis, nonlinearities are summarized by two simple elements:

- The exponential mapping of voltage into a "pseudo-voltage" proportional to ionic concentration. Diffusion processes may then be described in terms of linear equivalent impedance

- The activation overvoltage, described in static by Butler Volmer equations, for which we propose a dynamical model drawing from an analogy with semiconductor diodes (charge driven model with given relaxation time)

\subsection{Efficient lumped model for distributed parameters systems}

For non specialists, the "Warburg impedance" may look a very esoteric electrochemical topic. We introduce an analogy with a subject quite trivial for electronic engineers, capacitive transmission lines. Approximation of such distributed parameter device by lumped RC network has been the subject of a lot of papers (Kuhn et al., 2006 and Mauracher et al., 1997). We propose an efficient approximation with RC cells in geometric progression.

\subsection{Possible extensions}

We consider that our analysis constitutes an important contribution to the understanding of battery operation, in particular for electronic engineers. It opens the way for inclusion in efficient control of complex systems, either in the field of power managing or signal processing.

\section{References}

Bard A. (2000). Electrochemical Methods, Fundamental and Applications, 2nd ed., Harris D., (Ed), John Wiley \& Sons, ISBN 0-471-04372-9.

Bisquert, J.,Compte, A. (2001). Theory of the electrochemical impedance of anomalous diffusion,Journal of Electroanalytical Chemistry, vol. 499, pp. 112-120.

Blanke, H., Bohlen, O., Buller S., De Doncker, R.W. Fricke, B., Hammouche, A., Linzen, D., Thele, M., et Sauer ,D.U. (2005), "Impedance measurements on lead-acid batteries for state-of-charge, state-of-health and cranking capability prognosis in electric and hybrid electric vehicles," Journal of Power Sources,vol. 144, pp. 418-425.

Coleman, M.; Chi Kwan Lee; Chunbo Zhu; Hurley, W.G.(2007). State-of-Charge Determination From EMF Voltage Estimation: Using Impedance, Terminal Voltage, and Current for Lead-Acid and Lithium-Ion Batteries, IEEE Transactions on Industrial electronics, Vol. 54, pp. 2550 - 2557.

Coupan F., Sadli I., Marie-Joseph I., Primerose A., Clergeot H.(2010). New Battery dynamic Model: Application to lead-acid battery, The 2nd International conference on computer and automation Engineering. Electrical and energy systems of IEEE volume 5 pp 140-145, Singapore, 26-28 Feb, 2010. 
Esperilla J., Félez J., Romero G., Carretero A.(2007). A model for simulating a lead-acid battery using bond graphs, Simulation Modelling Practice and Theory, vol. 15, pp. 82-97, 2007.

Garche J., Jossen A., Döring H.(1997). The influence of different operating conditions, especially overdischarge, on the lifetime and performance of lead/acid batteries for photovoltaic systems, Journal of Power Sources,vol. 67, pp. 201-212, 1997

Henri Mathieu, Dunod, ISBN 2-10-048633-0 (1987), Physique des semi-conducteurs et composants électroniques.

Karden, E.; De Doncker, R.W.(2001). The non-linear low-frequency impedance of lead/acidbatteries during discharge, charge and float operation, Telecommunications Energy Conference, 2001. INTELEC 2001. Twenty-Third International, pp. 65-72.

Kuhn, E., Forgez, C., Lagonotte, P., Friedrich, G. (2006). Modelling Ni-mH battery using Cauer and Foster structures, Journal of power sources, vol. 158, pp. 1490-1497.

Landolt D.(1993). Corrosion et chimie de surfaces des métaux, Traite des matériaux, Presses Polytechniques et Universitaires Romandes, 1993.

Linden, D. and Reddy, T.B. McGraw-Hill, ISBN 0-07-135978-8 (2001). Handbook of Batteries.

Lowney, J.R.; Larrabee, R.D. (1980). Estimating the state of charge of a battery, IEEE Transactions on Electron Devices, Vol. 27, pp. 1795-1798.

Manwell Jams F., McGowan Jon G. (2003). Lead acid battery storage model for hybrid energy systems, Solar Energy, vol. 50, pp. 399-405, 2003

Marie-Joseph, I., Diagnostic methodology applied to preventive maintenance units of electricity production in isolated sites, PhD Thesis, Université des Antilles et de la Guyane 2003.

Marie-Joseph I., Clergeot H., Oukaour A., Linguet L. (2004). Dynamic model of an electrochemical accumulator, 19th European Photovoltaic Solar Energy Conferenceand Exhibition Proceeding, 2004.

Mauracher, P., Karden, E. (1997). Dynamic modeling of lead/acid batteries using impedance spectroscopy for parameter identification, journal of power sources, vol. 67, pp. 6984.

Riffonneau Y., Barruel F., and Bacha S.(2008). Problématique du stockage associé aux systèmes photovoltaïques connectés au réseau, Rev. Energ. Ren,vol. 11, pp. 407-422, 2008

Sari-Ari I., Benyoucef B., et Chikh-bled B.(2005). Etude de la jonction PN d'un semiconducteur a l'équilibre thermodynamique, Journal of Electron Devices,vol. 5, pp.122-126,

Sokirko Artjom, V., Bark Fritz, H.,(1995). Diffusion-migration transport in a system with butler-volmer kinetics, an exact solution, electrochimica Acta, vol. 40, pp. 19831996. 


\title{
Parameterisation of the Four Half-Day Daylight Situations
}

\author{
Stanislav Darula and Richard Kittler \\ Institute of Construction and Architecture, Slovak Academy of Sciences, Bratislava, \\ Slovakia
}

\section{Introduction}

The International Commission on Illumination (C.I.E) in its Technical Committee TC 3-08 for Daylight initiated in 1983 the so called International Daylight Measurement Programme (IDMP). This programme was officially launched by the CIE President Bodmann (1991) and several CIE IDMP stations were established world-wide and now relatively long-term regular data are available for studies and analysis (Kittler et al., 1992). Although some daily courses served to characterise luminance sky patterns and local daylight climate, there are possible more detail analysis of half-day situations with relation to sunshine duration, cloudiness and turbidity influences parametrised. This chapter tries to show the theoretical basis with documented applications using examples of several parametrised evaluations of measurements taken at the Bratislava and Athens CIE IDMP general stations which can be taken as instructing samples to be imitated using local measured data. The aim is also to show how momentary illuminance values correspond with hourly averages under four different daylight situations and how these half-day situations can be simulated when only monthly relative sunshine duration is available and when monthly or year-round random daylight conditions are needed and could be approximated.

\section{Regular daylight measurements and their possible analysis}

Since the CIE (2003) and ISO (2004) fifteen general homogeneous sky luminance patterns were standardised many CIE IDMP (International Daylight Measurement) stations recording regularly long-term daylight parameters try to evaluate the frequency of typical skies in their localities. Because the general CIE IDMP stations without sky luminance scanners sometimes do not record even zenith luminance $L_{v z}$ simultaneously with diffuse skylight illuminance measurements $D_{v}$ there are missing either sky scans or the classifying parameter $L_{v z} / D_{v}$, which could identify the momentary sky type. Thus, usually are only available data of regularly measured illuminance parameters in one minute steps during daytime, i.e.:

- Global horizontal illuminance by an unshaded detector $G_{v}$,

- Diffuse skylight illuminance on a horizontal sun-shaded detector $D_{v}$,

- Parallel sunbeam illuminance is sometimes measured by a sun tracker with a skyshading cylinder and a detector placed perpendicularly to sunbeam flux $P_{v \perp}$,

- Global vertical illuminances on planes oriented to North $G_{v v N}$, East $G_{v v E}$, South $G_{v v S}$ and West $G_{v v W}$ excluding the ground reflection. 
A clock controling system starting every minute count has to be recorded too either in local clock time LCT or true solar time TST. These regular measurements can serve for the specification of daylight situations during the half-day or to the rough identification of the sky type in any minute, hour or date.

In fact even in absence of the sun tracker the $P_{v \perp}$ illuminance can be derived from $G_{v}$ and $D_{v}$ recordings as

$$
P_{v \perp}=\frac{G_{v}-D_{v}}{\sin \gamma_{s}}=\frac{P_{v}}{\sin \gamma_{s}}[\mathrm{~lx}]
$$

where $P_{v}=P_{v \perp} \sin \gamma_{s}$ is the horizontal illuminance caused by only parallel sunbeams in lx, $\gamma_{s}$ is the momentary solar altitude which can be determined for any station location, date and clock time after:

$$
\sin \gamma_{s}=\sin \varphi \sin \delta-\cos \varphi \cos \delta \cos \left(15^{\circ} H\right) \quad[-] .
$$

The station location is given by the geographical latitude $\varphi$ in deg., while date is specified by solar declination $\delta$ and hour number $H$ during daytime in TST .

Solar declination angle can be calculated for any day number within a year $J$ (i.e. for $1^{\text {st }}$ January $J=1$ and for $31^{\text {st }}$ December $J=365$ ) using different approximate equations (e.g. Kittler \& Mikler, 1986). The simplest is that introduced by Cooper (1969)

$$
\delta=23.45^{\circ} \sin \left[\frac{360^{\circ}}{365}(284+J)\right]\left[^{\circ}\right],
$$

and a more accurate approximation was recommended by EU after Gruter (1981)

$$
\delta=23.45^{\circ} \sin \left[\frac{360^{\circ}}{365}\left(J-80.2^{\circ}\right)+1.92^{\circ} \sin \left(J-280^{\circ}\right)\right]\left[^{\circ}\right] .
$$

Because usually CIE IDMP stations record all measurements in local clock time LCT the value $H$ in TST has to be recalculated without consideration of summer shift time, after

$$
H=L C T+\eta+\frac{\left(\lambda_{z}-\lambda_{L}\right)}{15^{\circ}}[\mathrm{h}]
$$

where $\eta$ is the equation of time in hours approximated after a simpler formula by Pierpoint (1982)

$$
\eta=0.17 \sin [4 \pi(J-80) / 373]-0.129 \sin [2 \pi(J-8) / 355][\mathrm{h}],
$$

or a more accurate formula by Heindl \& Koch (1976)

$$
\begin{aligned}
& \eta=0.008 \cos \frac{360^{\circ} \mathrm{J}}{365}-0.052 \cos 2 \frac{360^{\circ} \mathrm{J}}{365}-0.001 \cos 3 \frac{360^{\circ} \mathrm{J}}{365}- \\
& -0.122 \sin \frac{360^{\circ} \mathrm{J}}{365}-0.157 \sin 2 \frac{360^{\circ} \mathrm{J}}{365}-0.005 \sin 3 \frac{360^{\circ} \mathrm{J}}{365}
\end{aligned}
$$


$\lambda_{z}$ is geographical longitude of the time zone in deg.,

$\lambda_{L}$ - geographical longitude of the location in deg.

The perpendicular parallel sunbeam illuminance at the ground level can be also calculated applying the Bouguer law, i.e.

$$
P_{v \perp}=L S C \in \exp \left(-a_{v} m T_{v}\right)[1 x]
$$

where LSC is the luminous solar constant (Darula et al., 2005), which is the normal extraterrestrial illuminance on the outer border of the atmosphere for the average distance between sun and earth, approximately $L S C=133800$ lx., which is corrected for any date by the ellipticity factor $\in$, which is often approximated by IESNA (1984)

$$
\in=1+0.034 \cos \frac{360^{\circ}}{365}(J-2)[-]
$$

$m$ - relative optical air mass approximated by Kasten \& Young (1989)

$$
m=\frac{1}{\sin \gamma_{s}+0.50572\left(\gamma_{s}+6.07995^{\circ}\right)^{-1.6364}}[-],
$$

$a_{v}$ - luminous extinction coefficient of a clean and dry (Rayleigh) atmosphere after Clear (1982), later published by Navvab et al., (1984)

$$
a_{v}=\frac{0.1}{1+0.0045 m}[-]
$$

or

$$
a_{v}=\frac{1}{9.9+0.043 m}[-]
$$

$T_{v}$ - luminous turbidity factor, which defines the number of clean and dry atmospheres in the direction of sunbeams that reduces relatively its momentary penetration. In fact, if in eq. (8) $P_{v \perp}$ is measured by a sun tracker or $P_{v}$ is derived from measured $G_{v}-D_{v}$ data, then the actual value $T_{v}$ can be determined as

$$
T_{v}=\frac{-\ln \left(P_{v \perp} /(\in L S C)\right)}{a_{v} m}=\frac{\ln \left(E_{v} / P_{v}\right)}{a_{v} m}[-],
$$

where $P_{v}=G_{v}-D_{v}$ and the extraterrestrial horizontal illuminance $E_{v}$ is

$$
E_{v}=\in L S C \sin \gamma_{s}[\mathrm{~lx}] .
$$

Thus, once the momentary illuminance $P_{v \perp}$ or $P_{v}$ is determined the actual sunlight impact on any arbitrary plane can be calculated using the cosine of its incidence angle. However, for the vertical planes oriented either to direct East or West cardinal points this cosine function is simplified to 


$$
P_{v v E}=P_{v v W}=P_{v \perp} \cos \delta \sin \left(15^{\circ}|12-H|\right)[\mathrm{lx}] .
$$

Note, that the East and West oriented vertical planes or fasades are exposed to the morning and afternoon half-day sunlight and skylight effects as measured by global vertical illuminances $G_{v v E}$ or $G_{v v W}$ respectively. So, when the direct sunlight using eq. (15) can be subtracted only diffuse skylight components for these orientations can be determined, i.e. $D_{v v E}$ or $D_{v v W}$.

\section{Four typical half-day situations indicated by illuminance courses}

In the previous paper (Darula \& Kittler, 2004a) from typical half-day illuminance courses were identified four characteristic daylight situations, which need to be explained in more detail:

Situation 1: Absolutely cloudless half-day with relative sunshine duration $s \geq 0.75$ and the parameter of instability $U \leq 8.4$ is almost clear with only few smaller clouds moving over the sky vault. Except these few sunshaded events the clear sky is quite stable and all horizontal illuminance parameters $P_{v}, G_{v}$ and $D_{v}$ follow a fluent increase in level during the morning hours and similar decrease during the afternoon due to solar altitude changes in different seasons.

Examples of selected half-days with situation 1 are using recorded data from the Bratislava CIE IDMP general station $\left(\varphi=48^{\circ} 10^{\prime} \mathrm{N}, \lambda_{\mathrm{L}}=17^{\circ} 05^{\prime} \mathrm{E}\right)$ with the Central European climatic influences, but these should be taken as instructional and illustrative examples characterising typical cases of situation 1. As examples of clear sky mornings in Bratislava, Slovakia, were chosen courses measured during a long summer day on the $20^{\text {th }}$ July 2006 followed by an autumn day on 22nd September 2007, while a short winter day $26^{\text {th }}$ December 2006 represents one of the shortest days and the spring day $8^{\text {th }}$ April 2006 with slight veiling Cirro-Stratus influences is also documented. The measured half-day courses of global horizontal illuminance $G_{v}$ and diffuse sky illuminance $D_{v}$ are documented in Fig. 1. Although the measurement registration is in the local clock time without the summertime shift it is evident that the courses follow the solar altitude changes, i.e. the $\sin \gamma_{s}$ tendency of the extraterrestrial horizontal illuminance after eq. (14). Therefore the efficiency parameters $G_{v} / E_{v}$ and $P_{v} / E_{v}$ should be rather stable and showing a large amount of the extraterrestrially available luminous flux reaching the ground level, therefore these parameters can markedly characterise situation 1 (Fig. 2). The momentary 1-minute measurements except some slight spreads on the April day show a steady rise with the solar altitude which is even better followed by the hourly averages in Fig. 3 with the stepwise rise of $G_{v} / E_{v}$ from 0.45 to 0.75 . In consequence, also the luminous turbidity factors $T_{v}$ follow the stable atmospheric conditions without abrupt changes, except when the sun position is shaded by crossing cloud patches and then can reach higher short time peaks as in Fig. 4 on $8^{\text {th }}$ April 2006. However, due to gradual evaporation during morning the turbidity might fluently rise with the formation of Cirrus or Cirrostartus veiling cloudiness as is shown by the trend of rising hourly average $T_{v}$ values in a small range 1.5 to 3 in Fig. 5. Such rising $T_{v}$ effects can be expected especially in equatorial regions with sometimes gradual cloud formation at noontime and in afternoon hours, which no longer belong to situation 1 . 


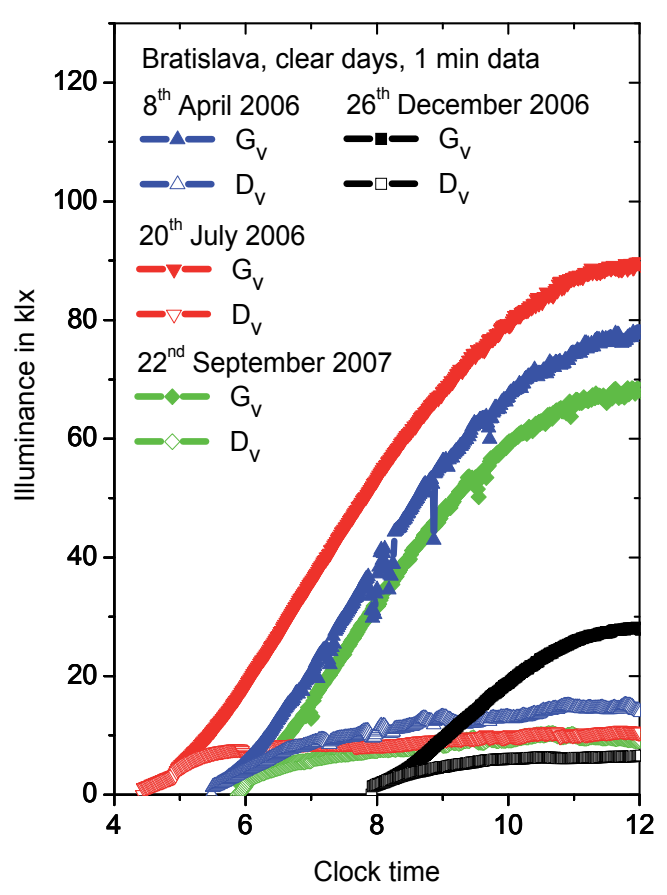

Fig. 1. Illuminance courses during clear morning situations 1

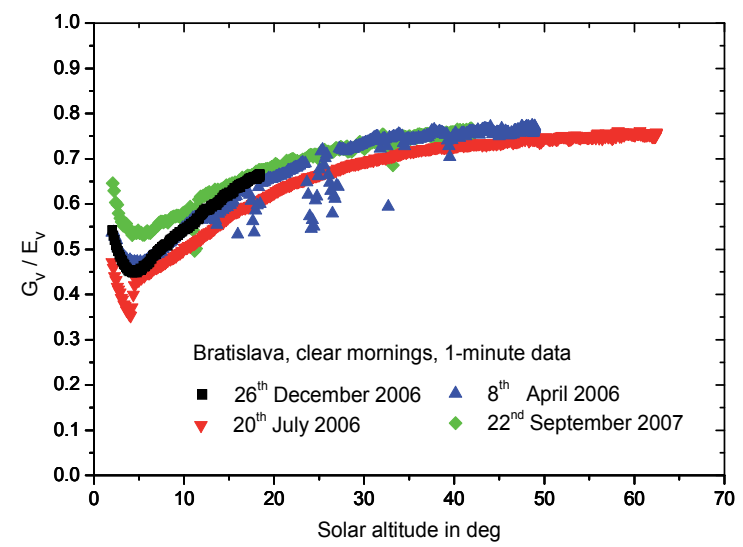

Fig. 2. $G_{v} / E_{v}$ courses under situation 1 after 1-minute measurements 


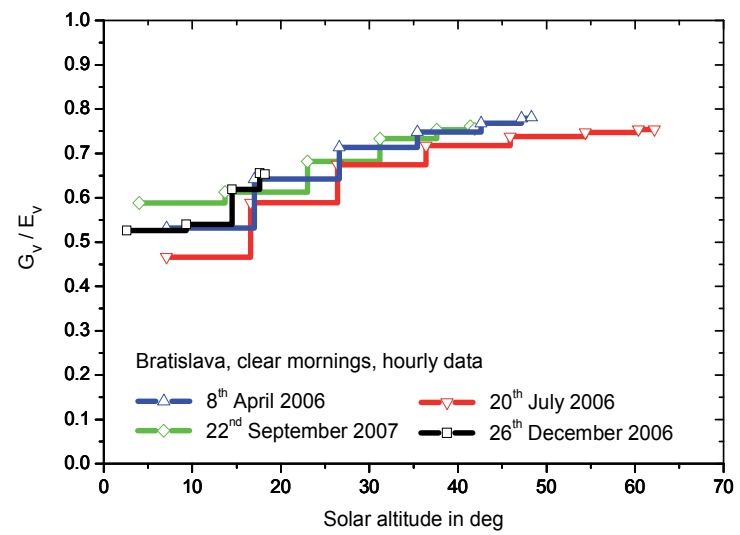

Fig. 3. $G_{v} / E_{v}$ courses under situation 1:after measured hourly averages

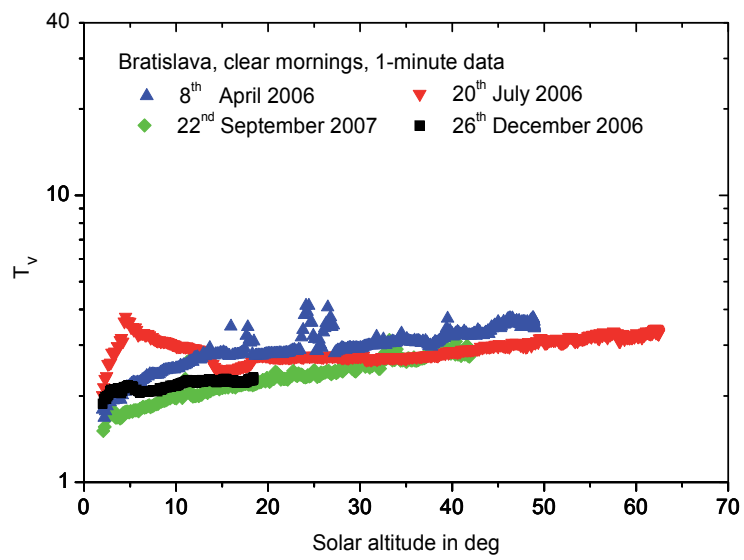

Fig. 4. $T_{v}$ courses under situation 1: after 1-minute measurements

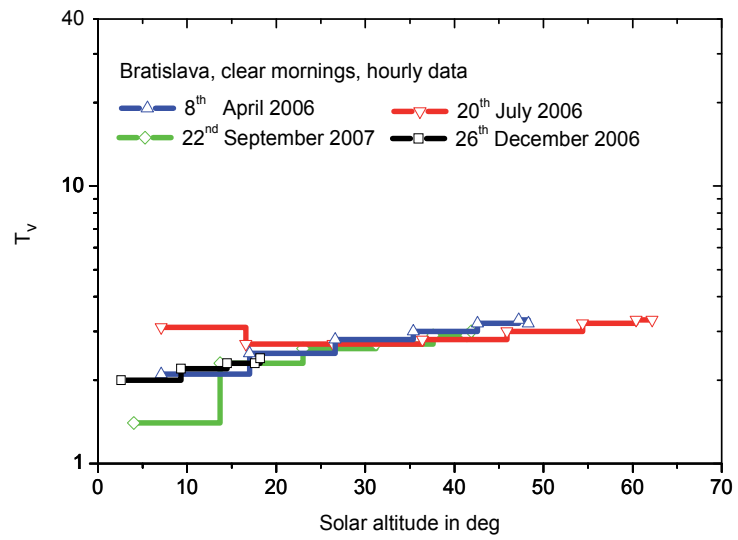

Fig. 5. $T_{v}$ courses under situation 1: after measured hourly averages 
It has to be noted that during sunrise and early morning hours the prevailing daylight is caused by skylight and therefore also on clear days the early $G_{v} / E_{v}$ values are equal or quite close to $D_{v} / E_{v}$ while under higher solar altitude the $P_{v} / E_{v}$ component is rising while $D_{v} / E_{v}$ value fluently decreases after Fig. 6 from roughly 0.5 to 0.1 . The average hourly decrease is slightly distorting this range showing approximately 0.4 to 0.1 respectively (Fig. 7).

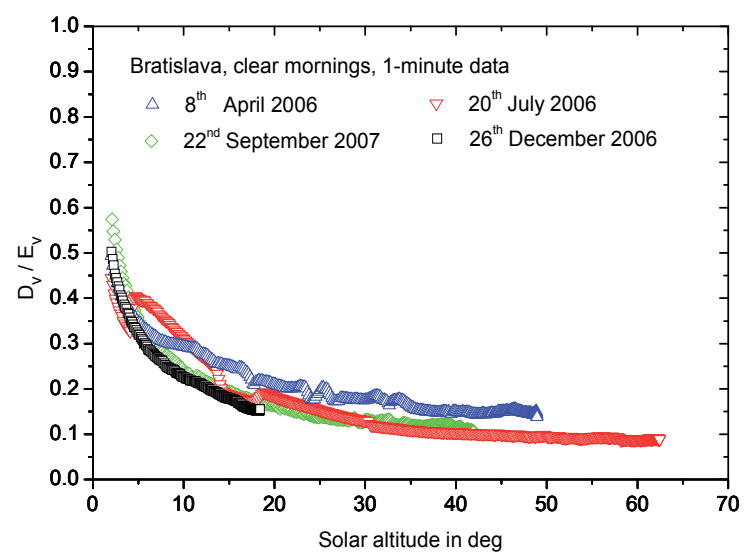

Fig. 6. $D_{v} / E_{v}$ courses under situation 1: after 1-minute measurements

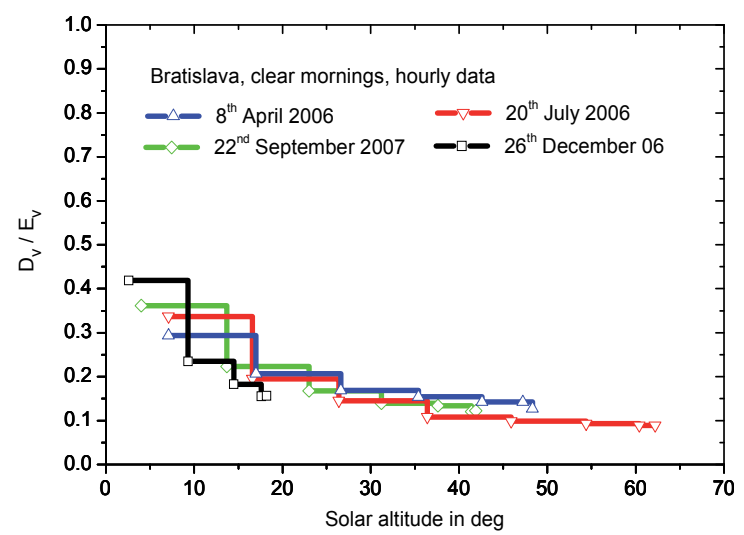

Fig. 7. $D_{v} / E_{v}$ courses under situation 1: after measured hourly averages

If simultaneous measurements of the zenith luminance is recorded under clear sky conditions the classifying parameters $L_{v z} / D_{v}$, can identify the momentary sky type with the fluent rising tendency dependent on the solar altitude. In Fig. 8 this tendency is shown using 1-minute data while in Fig. 9 the same is documented after hourly mean values. Due to rather constant and fluent trends during situation 1 besides the momentary one-minute recordings also hourly averages and appropriate parameters are quite satisfactorily reflecting clear half-days which might reduce the number of data considerably (Darula. \& Kittler, 2005a). 


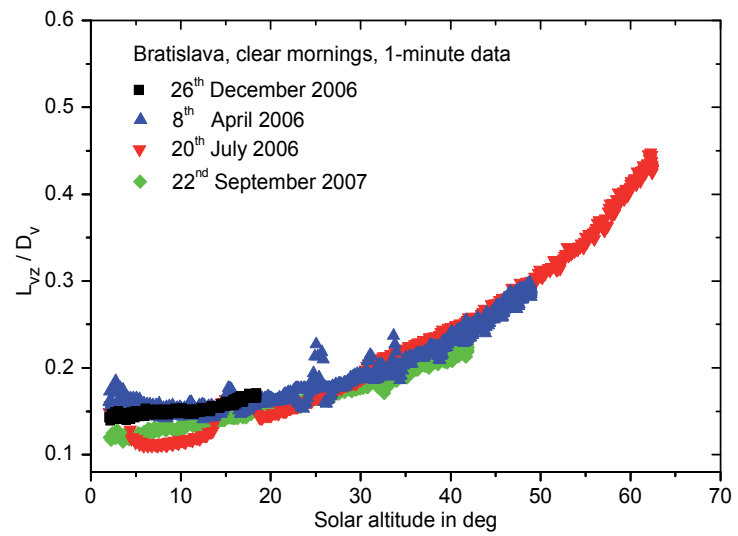

Fig. 8. $L_{v z} / D_{v}$ courses under situation 1: after 1-minute measurements

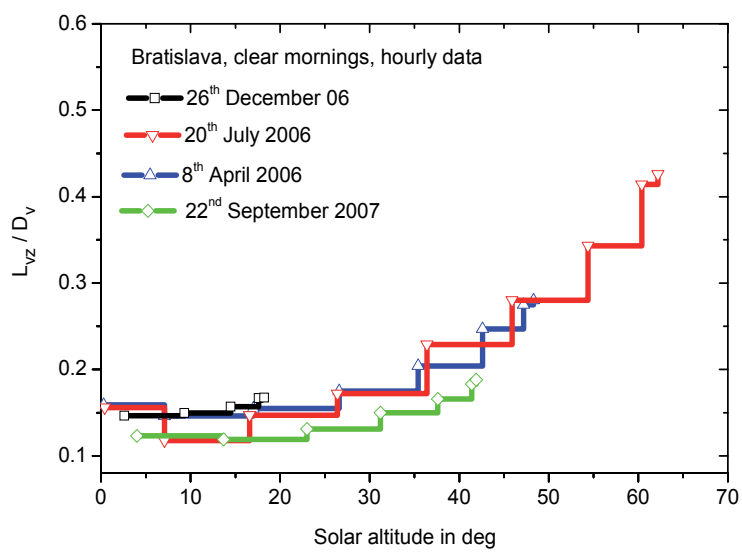

Fig. 9. $L_{v z} / D_{v}$ courses under situation 1: after measured hourly averages

It is evident that the time period close to sunrise is untrustworthy due to an interval when solar altitude is zero and average $G_{v} / E_{v}$ ratios are also reduced due to close to horizon mist or high turbidities. The minute courses are intersected by the hourly level in the point of hourly average solar altitude after Kittler \& Mikler (1986)

where $H_{1}, H_{2}$ are consecutive hours

$$
\gamma_{s H}=\frac{180^{\circ}}{\pi} \arcsin \left[\sin \varphi \sin \delta+\frac{12}{\pi}\left(\sin \frac{\pi H_{1}}{12}-\sin \frac{\pi H_{2}}{12}\right)\right] \cos \varphi \cos \delta \text { [rad], }
$$

Sunrise hour $H_{s r}$ when $\gamma_{s}=0^{\circ}$ is for any location and date defined by

$$
H_{s r}=\frac{1}{15^{\circ}} \arccos (\tan \varphi \tan \delta)[\mathrm{h}],
$$

and due to symmetry around noon the hour of sunset $H_{s s}=24-H_{s r}$ and the astronomically possible sunshine duration $S_{\text {ahd }}$ during a half-day is 


$$
S_{\text {ahd }}=\frac{1}{15^{\circ}} \arccos (-\tan \varphi \tan \delta)[\mathrm{h}] .
$$

This is an normalising amount to calculate relative sunshine duration during the halfday $s_{h d}$ if the true measured sunshine duration in hours $S_{h d}$ is available:

$$
s_{h d}=\frac{S_{h d}}{S_{\text {ahd }}}[-]
$$

In the half-day system relative sunshine duration during the morning half-day is $s_{h d}=s_{m}$ while its afternoon relative duration is $s_{h d}=s_{a}$ either in absolute values or \% respectively.

If regular minute recordings are measured, then $S_{h d}$ can be calculated as the sum of all data after the WMO (1983) and CIE 108 (1994) when the direct irradiance $P_{e \perp} \geq 120 \mathrm{~W} / \mathrm{m}^{2}$ taken in hours or their decimals.

Situation 2: Cloudy half-days with possible foggy short periods are characterised by scarce and lower sunlight influences under a range of relative sunshine durations $(0.03 \leq s \leq 0.75$ and $U \leq 10-6 s)$ and relatively higher diffuse illuminance levels. Such situations are caused by the prevailing area of the sky covered from almost homogeneous presence of clouds layers with different combinations of cloud type, turbidity and cloud cover overlayed in their height positions and movement drifts. Therefore, usually their $G_{v}$ courses are close to $D_{v}$ levels and so are also ratios $G_{v} / E_{v}$ and $D_{v} / E_{v}$ typical for situation 2 .

To document cloudy half-days were chosen from the Bratislava data again seasonally typical cases, i.e. a summer day $3^{\text {rd }}$ June 2007, an autumn day on $5^{\text {th }}$ September 2007, a cloudy winter morning on 20th December 2006 and a spring morning on $5^{\text {th }}$ April 2006. The measured half-day courses of global horizontal illuminance $G_{v}$ and diffuse sky illuminance $D_{v}$ are recorded in local clock time again in Fig. 10. In early morning hours under cloudy conditions $G_{v} / E_{v}$ and $D_{v} / E_{v}$ are almost the same as is not so noticeable from the winter course of illuminances, but evident in Fig. 11 in 1-minute or in Fig. 12 in the hourly alternative compared with Fig. 13 and 14. In this cloudy case the $G_{v} / E_{v}$ and $D_{v} / E_{v}$ values is very high reaching 0.25 to 0.6 level indicating a very bright but sunless winter half-day which is indicated also by the $T_{v}$ lower values compared with all other cloudy samples (in Fig. 15 and 16) as well as in rather horizontal range of $L_{v z} / D_{v}$ parameters in Fig. 17 and especially their averages in Fig. 18 with the data spread within the values 0.2 to 0.38 close to overcast sky (Darula \& Kittler, 2004b).

Due to cloudiness overlays and turbidity changes rather high values of $T_{v}$ factors have to be expected usually dependent on the solar altitude as shown in Fig. 15 or 16. However, within the half-day courses momentary unstable $P_{v}$ can occur, thus there are cases also with higher average relative sunshine durations during the half-day in the range 0.1 to 0.5 , but seldom over 0.5 with lower sunlight intensities, which are usually indicated by smaller peaks within the half-day course. These drab sunlight influences are documented by the small differences between $G_{v} / E_{v}$ and $D_{v} / E_{v}$ values when comparing Fig. 12 and 14 respectively.

Situation 3: Overcast half-days are absolutely without any sunlight and are caused by either dense layers of Stratus or Altostratus cloudiness or inversion fog when the sun 
position is uncertain as it cannot be seen or guessed behind the overall dense clouds. Under such conditions $G_{v}=D_{v}, P_{v}=0$ and average relative sunshine duration during the half-day $s \leq 0.03$. While the $D_{v}$ illuminance levels and the ratio $D_{v} / E_{v}$ are quite low, usually in the range $0.02-0.25$, the ratios $L_{v z} / D_{v}$ are over 0.3 and stable during the half-day, i.e. without any dependence on the solar altitude (Darula \& Kittler, 2004c). Under overcast sky conditions when sunbeam influences are absent the sky luminance patterns in all azimuth directions are uniform, so only gradation luminance distribution can cause the $D_{v}$ illuminance rise from sunrise to noon.

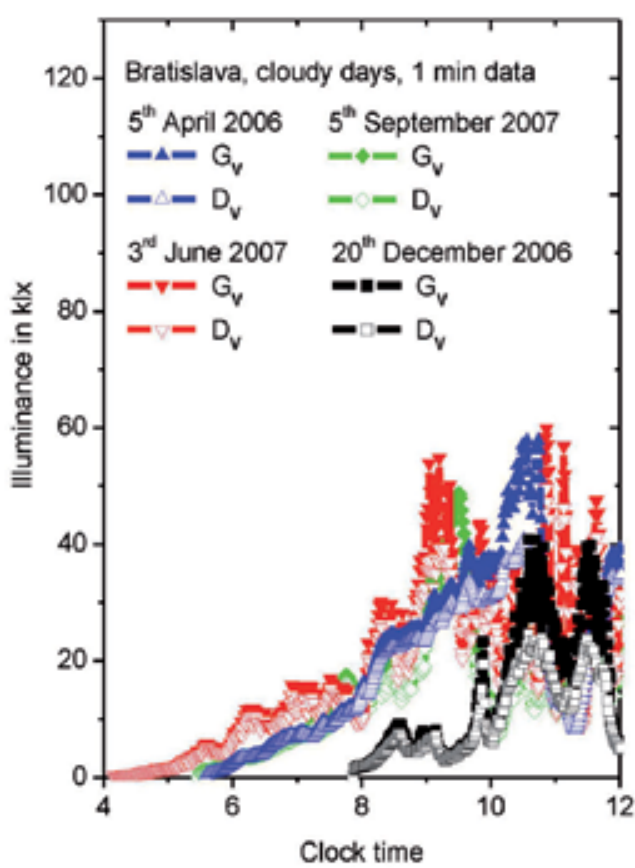

Fig. 10. Illuminance courses during cloudy morning situations 2

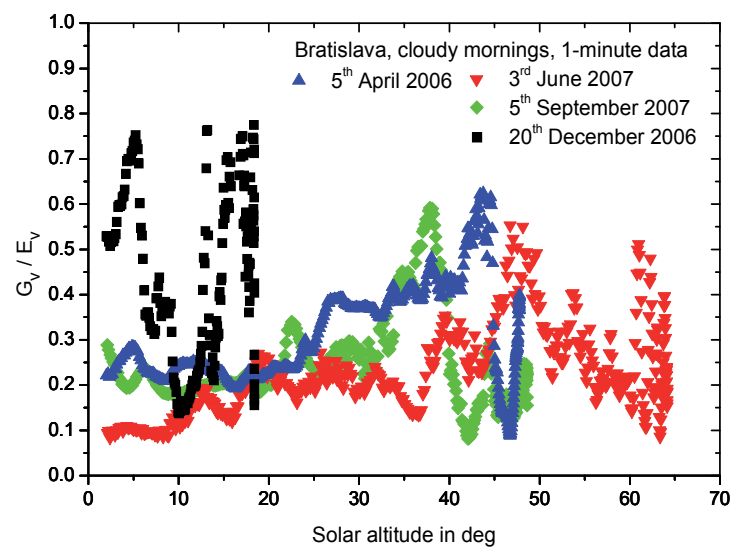

Fig. 11. $G_{v} / E_{v}$ courses under situation 2: after 1-minute measurements 


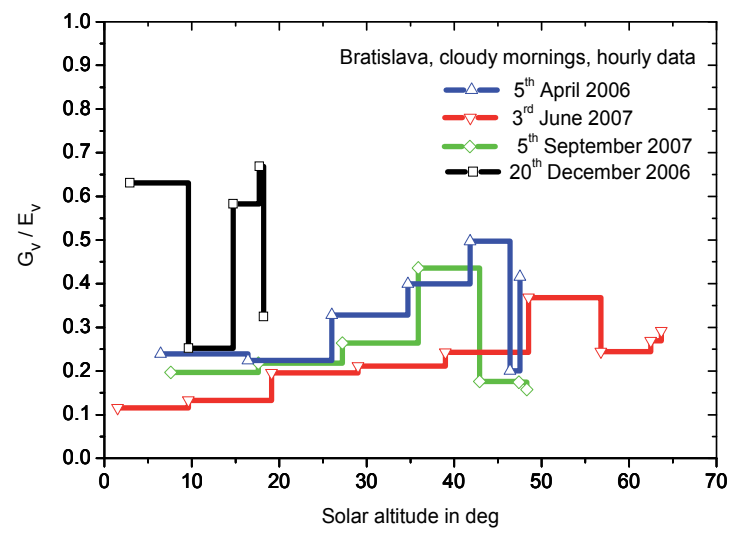

Fig. 12. $G_{v} / E_{v}$ courses under situation 2: after measured hourly averages

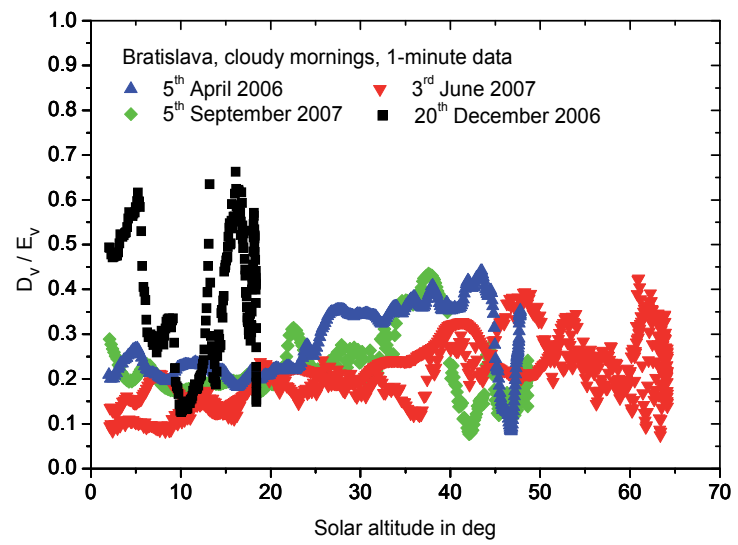

Fig. 13. $D_{v} / E_{v}$ courses under situation 2: after 1-minute measurements

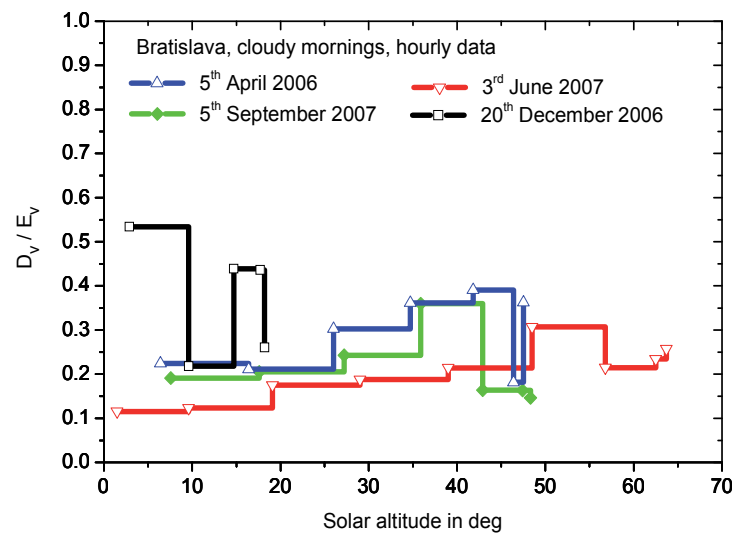

Fig. 14. $D_{v} / E_{v}$ courses under situation 2: after measured hourly averages 


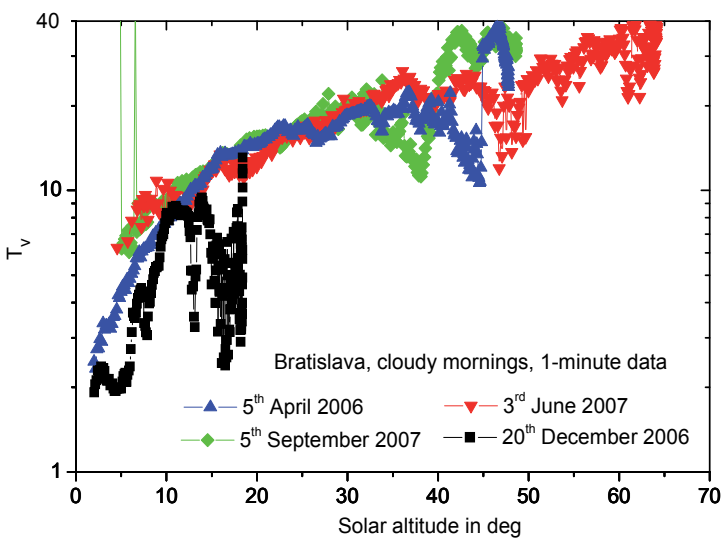

Fig. 15. $T_{v}$ courses under situation 2: after 1-minute measurements

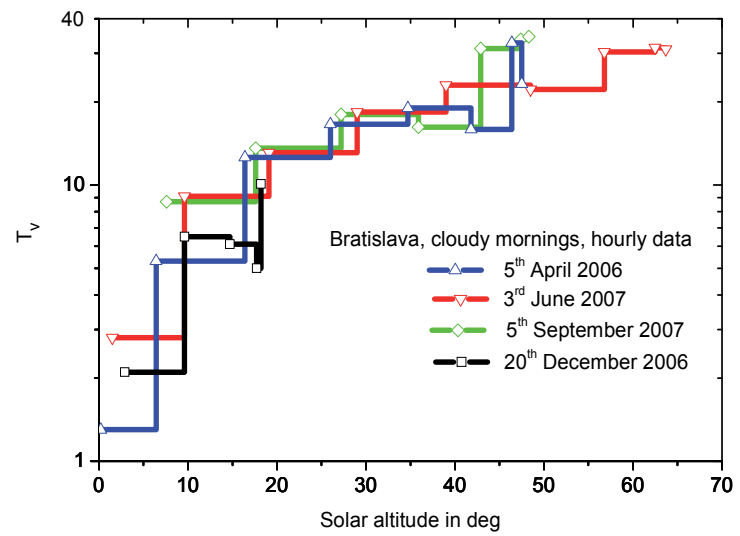

Fig. 16. $T_{v}$ courses under situation 2: after measured hourly averages

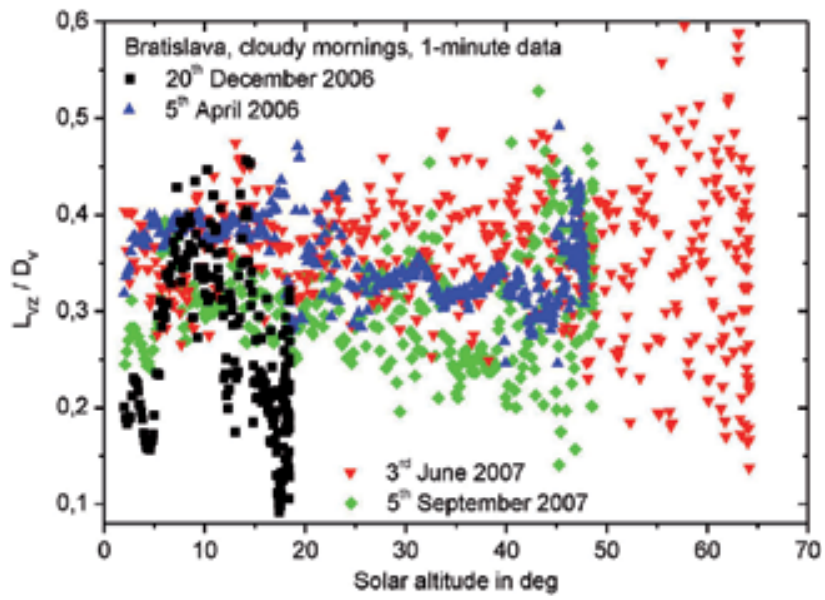

Fig. 17. $L_{v z} / D_{v}$ courses under situation 2: after 1-minute measurements 


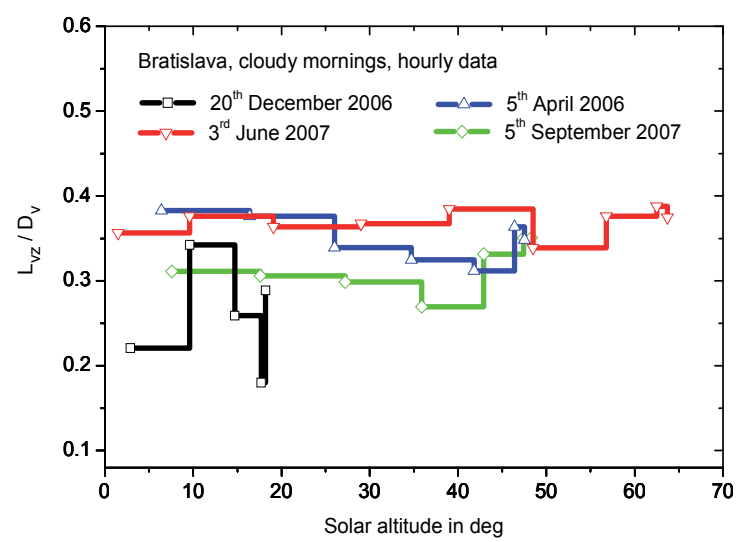

Fig. 18. $L_{v z} / D_{v}$ courses under situation 2:after measured hourly averages

To document overcast half-days by Bratislava recordings again four seasonal examples were chosen, i.e. a winter morning on the $23^{\text {rd }}$ January 2001 and a spring case on $3^{\text {rd }}$ March 2001, an exceptional summer half day on $4^{\text {th }}$ June 2001 and an autumn case on $6^{\text {th }}$ September 2007 . The half-day courses of measured global and diffuse illuminances in 1-minute intervals are in Fig. 19 with the $G_{v} / E_{v}=D_{v} / E_{v}$ analysis in Fig. 20 in 1-minute and in Fig. 21 in hourly alternatives. All four cases document the low and stable efficiency of penetration in the range 0.05-0.2 without any dependence on the solar altitude. The same stable and independent trend shows also the $L_{v z} / D_{v}$ courses in Fig. 22 and 23 within the average range 0.3-0.4.

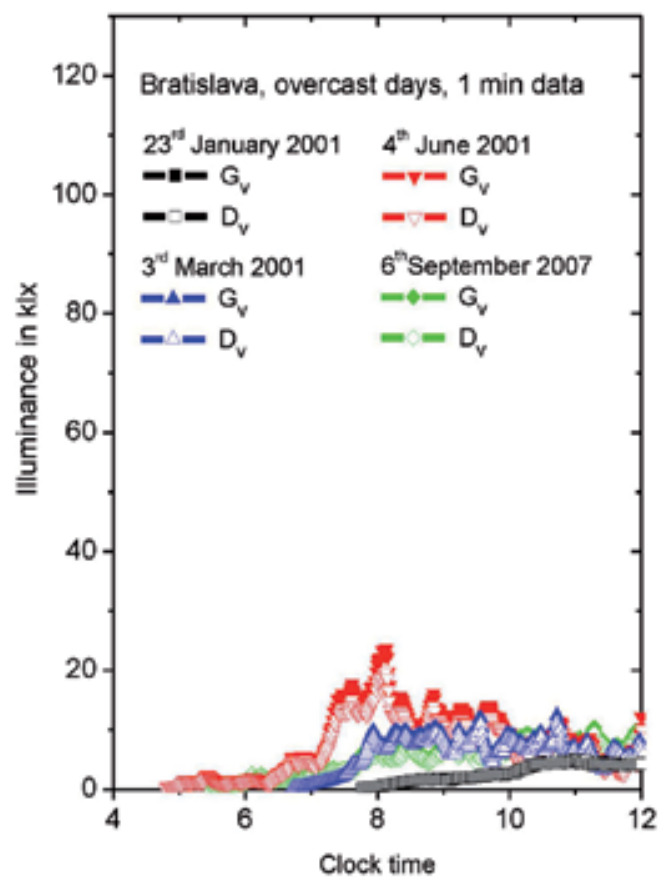

Fig. 19. Illuminance courses during overcast morning situations 3 


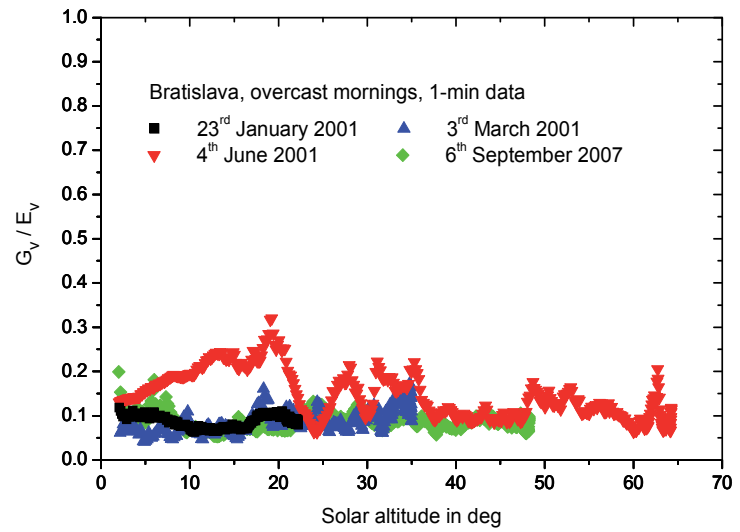

Fig. 20. $G_{v} / E_{v}$ courses under situation 3: after 1-minute measurements

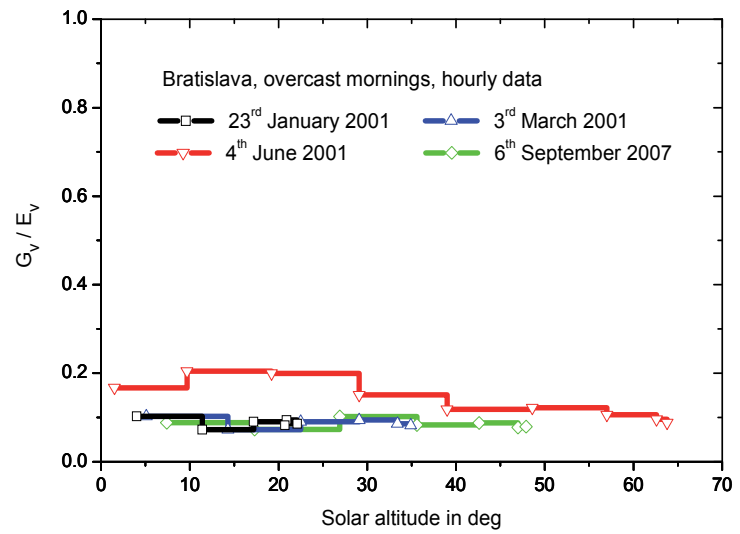

Fig. 21. $G_{v} / E_{v}$ courses under situation 3:after measured hourly averages

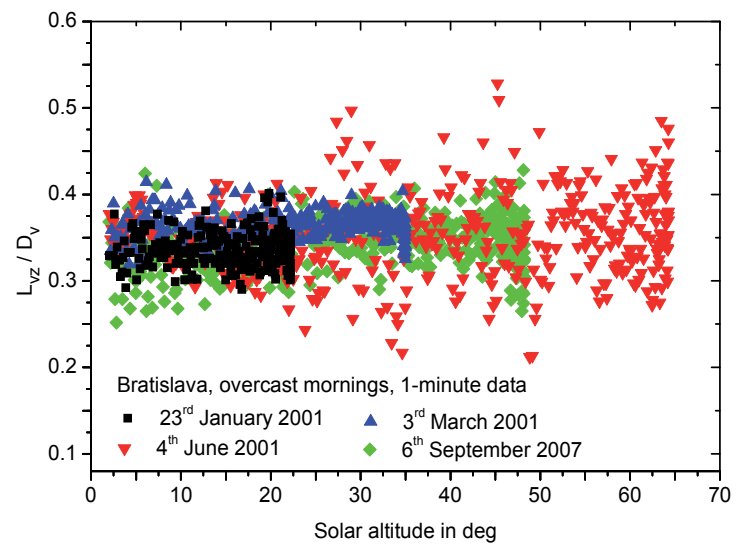

Fig. 22. $L_{v z} / D_{v}$ courses under situation 3: after 1-minute measurements 


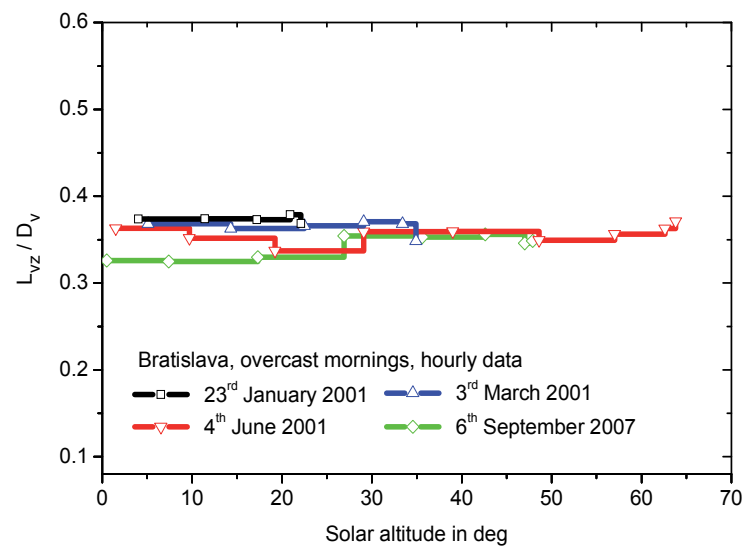

Fig. 23. $L_{v z} / D_{v}$ courses under situation 3: after measured hourly averages

Situation 4: The dynamic courses in horizontal illuminance levels happen during those half-days when the clear sky is covered by smaller cloud patches passing the sun position and shade direct sunlight in many short-term intervals or moments. Thus the overall $G_{v}$ course trends can be usually kept but with many drops of temporary loss or reduction of $P_{v}$ components, which mean dynamic variations between $G_{v}$ and $D_{v}$ levels. Because $D_{v}$ levels are not affected by the $P_{v}$ changes, $L_{v z} / D_{v}$ ratios indicate the sky patterns when the zenith luminance is not influenced by passing clouds significantly. However, dynamic changes are reproduced also in $G_{v} / E_{v}$ and $P_{v} / E_{v}$ courses. In case of dynamic situations it is problematic to use hourly averages which are levelling the momentarily occurring peaks and drops replacing them by an even horizontal line. Thus is also distorted the wide range of $T_{v}$ values that have to be expected in situation 4.

Due to the irregularity and occasional movement of the shading cloud patches there is a multiple number of different cases, so the selection of characteristic courses is very problematic. However, from Bratislava data were selected also four seasonal representatives, i.e. for winter the morning on $12^{\text {th }}$ January 2007, for spring $14^{\text {th }}$ March 2001, for the summer example the course on 29th June 2007 and for the autumn example was chosen the dynamic morning on $26^{\text {th }}$ November 2007. The actual global and diffuse illuminance courses in Fig. 24 document the dynamic changes during the chosen half-days. The same dynamic variations of $G_{v} / E_{v}$ parameters in minute representation are in Fig. 25 while hourly means erase the highest peaks and drops (Fig. 26) considerably. The $D_{v} / E_{v}$ courses are relatively more stable and document the low borderline (Fig. 27 and 28) from which additional sunlight influences the peaks. Similarly to $G_{v} / E_{v}$ also $L_{v z} / D_{v}$ courses are very distorted in hourly averages in Fig. 30 in comparison to 1-minute fluctuating values in Fig. 29, but the former indicate a tendency of the background spring and summer clear skies. However, these background scene is also influenced by gradually increasing turbidity, which is low with lower solar altitude and considerably rising when the sunheight is over 35 degrees (Fig. 31 and 32). 


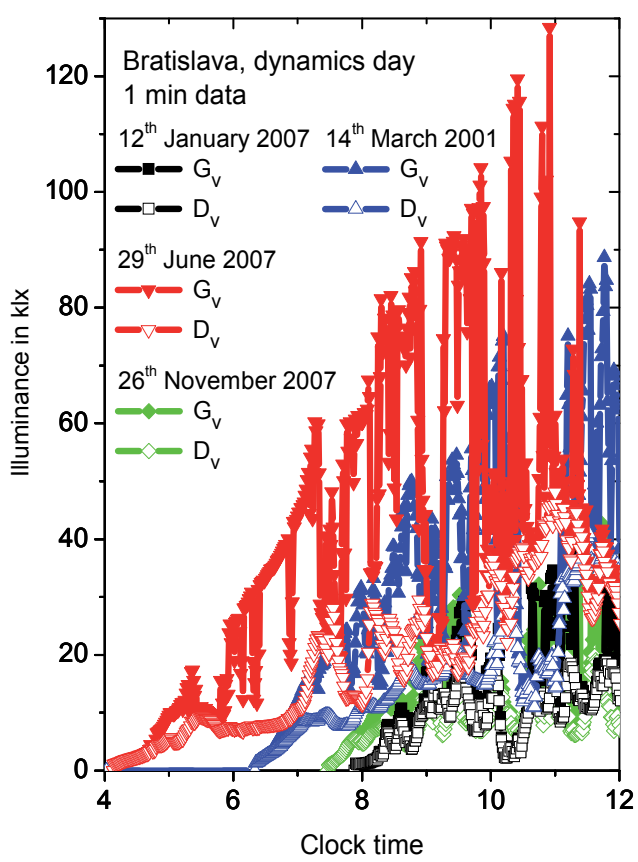

Fig. 24. Illuminance courses during overcast morning situations 4

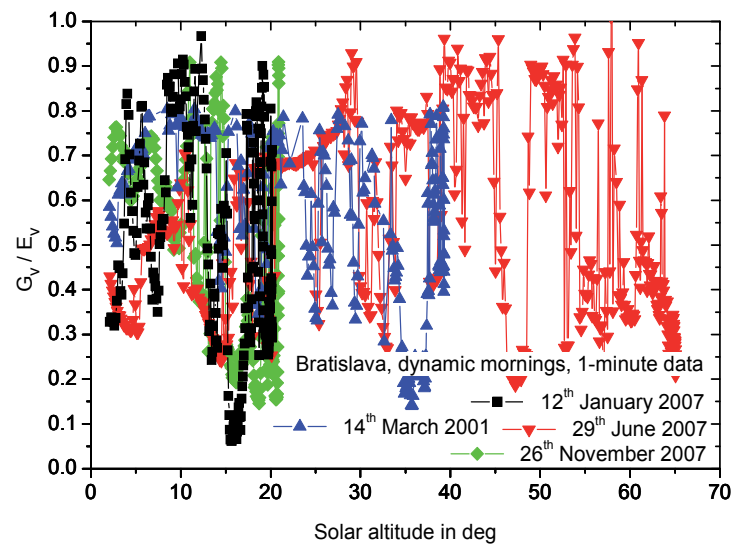

Fig. 25. $G_{v} / E_{v}$ courses under situation 4: after 1-minute measurements 


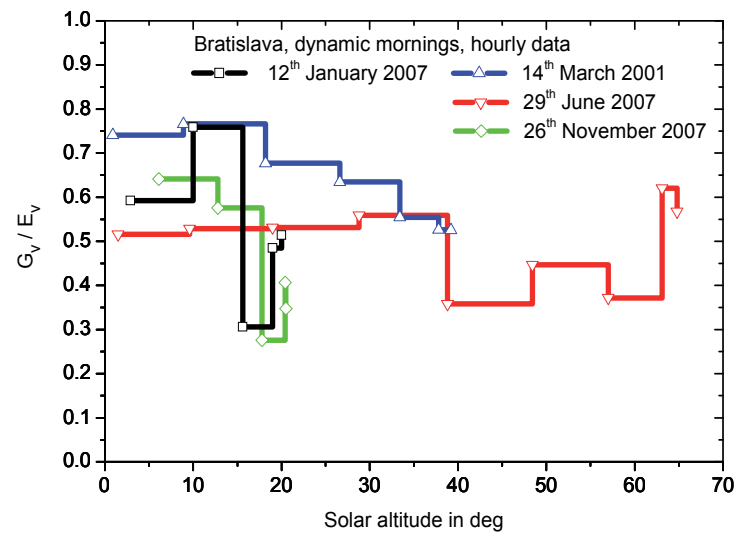

Fig. 26. $G_{v} / E_{v}$ courses under situation 4: after measured hourly averages

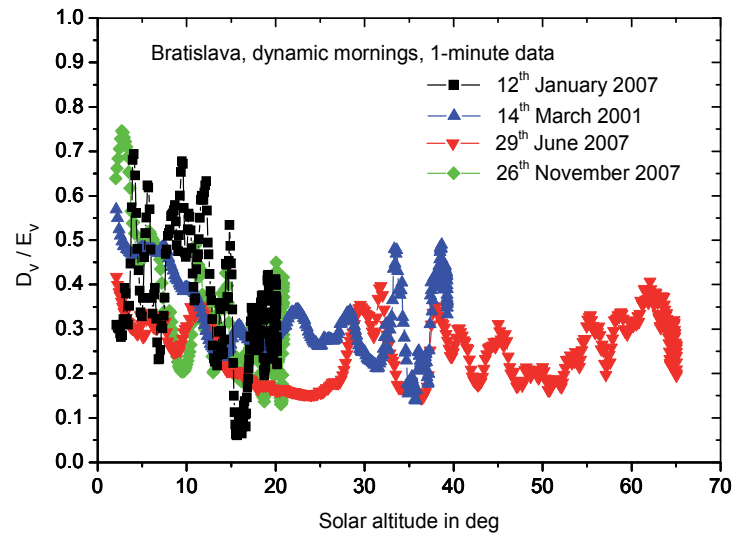

Fig. 27. $D_{v} / E_{v}$ courses under situation 4: after 1-minute measurements

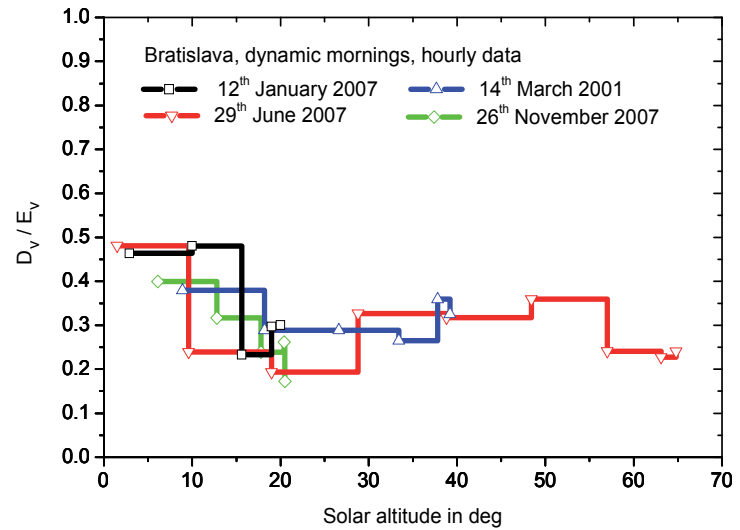

Fig. 28. $D_{v} / E_{v}$ courses under situation 4:after measured hourly averages 


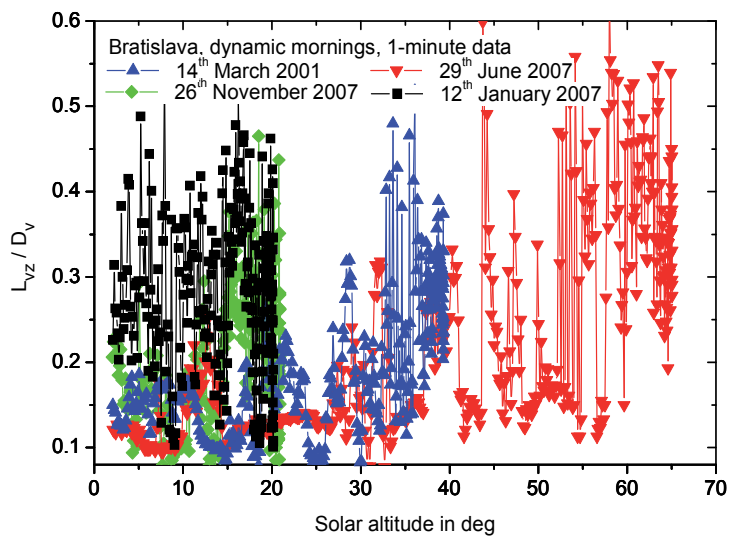

Fig. 29. $L_{v z} / D_{v}$ courses under situation 4: after 1-minute measurements

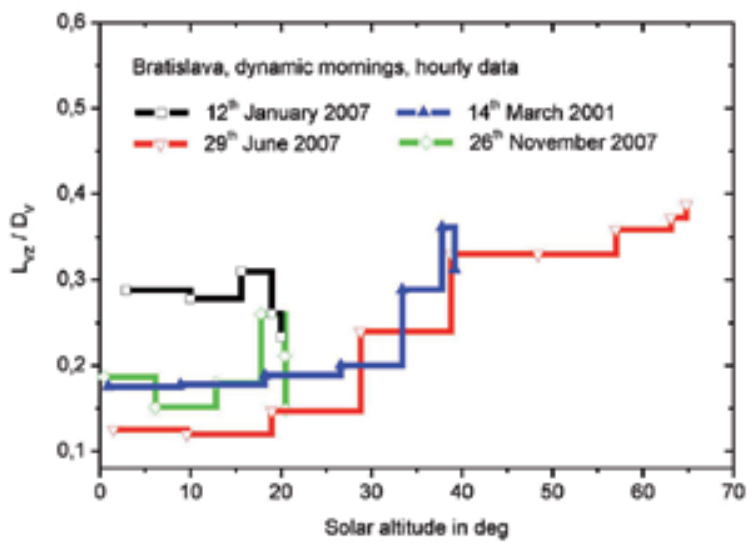

Fig. 30. $L_{v z} / D_{v}$ courses under situation 4 : after measured hourly averages

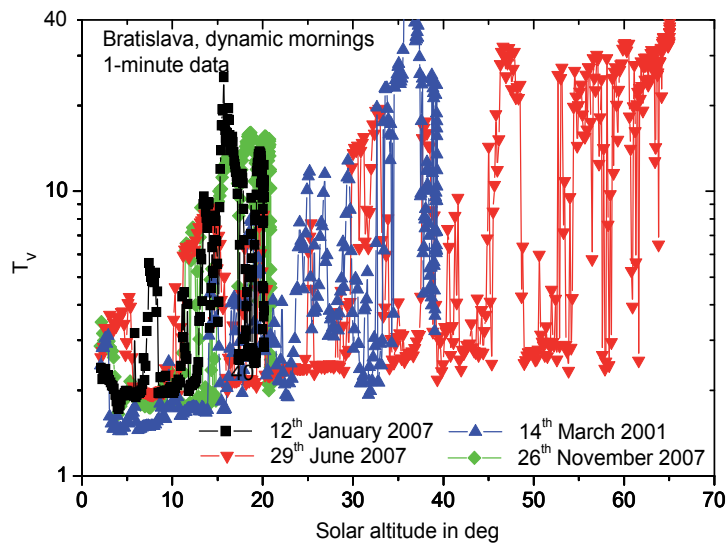

Fig. 31. $T_{v}$ courses under situation 4: after 1-minute measurements 


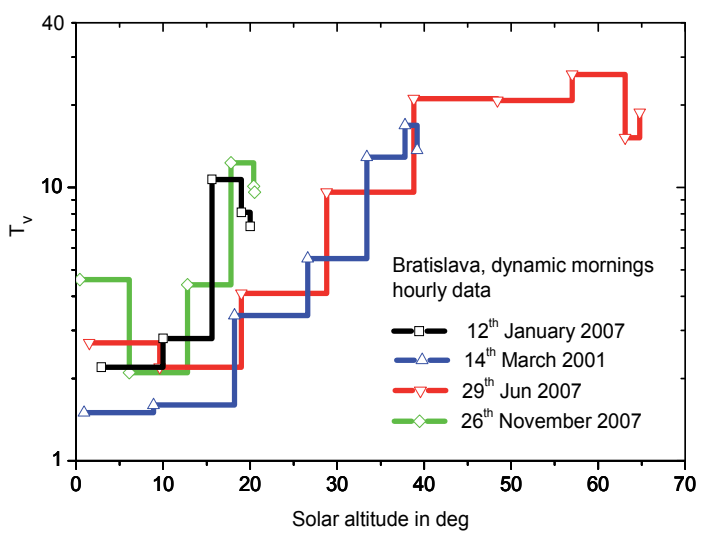

Fig. 32. $T_{v}$ courses under situation 4:after measured hourly averages

\section{Approximate dependence of the four daylight situations on relative sunshine duration}

In the paper by Kittler \& Darula (2002) a P-D-G diagram was published to show Bratislava 5-minute data covering the whole July 1996. From 5315 cases were 3113 with sunshine while 2202 measured cases were without sunshine according to the WMO (1983) classification. The monthly relative sunshine duration after 1-minute recordings was in July 1996 on the average $s=0.52$ with daily changes within the range $0.022-0.946$ which indicates the possibility of half-day situations in all four categories. Due to the averaging distortion it would seem that the prevailing sunny 5-minute intervals 3113/5315 indicate the sunshine duration roughly 0.586 .

The review of daily measured illuminance courses representing July 1996 by 62 half- days can be classified into:

- $\quad$ situation 1 approximately 9 morning courses and 7 in the afternoon half-day,

- $\quad$ situation 2 only 2 morning courses and 2 in the afternoon half-day,

- $\quad$ situation 3 only 2 morning courses and 1 in the afternoon half-day,

- $\quad$ situation 4 the prevailing 18 morning and 21 afternoon half-days.

It is evident that neither the number of sunshine or sunless cases within a month in a P-D-G diagram nor $L_{v z} / D_{v}$ and $G_{v} / E_{v}$ time-averaged ratios are capable to differentiate the halfday situations when data are summarised during a day, a week or month in these mixed groups. Therefore the first step to identify, select or classify the half-day situations is to check the overall courses of $G_{v}$ and $D_{v}$ illuminance trends and levels and their relative efficiencies compared to the momentary extraterrestrial availability levels expressed in $G_{v} / E_{v}$ and $D_{v} / E_{v}$ ratios. Of course the stable or discontinuous sunshine duration follows the changes in $G_{v} / E_{v}$ and the momentary presence of $P_{v} / E_{v}$ ratios indicating the penetration of available extraterrestrial sunshine intensity. These half-day courses roughly characterise also the range of prevailing sky luminance patterns that can be expected and principally belong to the particular half-day situation. While situation 1 and 3 and sometimes even 2 are approximately homogeneous with evenly distributed turbidities and cloudiness cover over the whole sky vault, the situation 4 is characteristic for its unstable dynamic illuminance changes caused by complex layers of different cloud types and 
distribution as well as patch movements. Thus under situation 4 can happen locally many accidental variations between quite low turbidity pockets with white-blue sky background through which direct sunshine temporarily can reach the ground while in other intervals the cloud patches cover and shade the sun beam penetration considerably.

Under homogeneous atmospheric conditions the $L_{v z} / D_{v}$ ratio is quite a safe indicator of the sky luminance pattern, but during the dynamic half-day the zenith luminance as well as the sun position are influenced by passing clouds or cloud patches in several following sequence intervals.

However, for general practice and local characterisation of daylight conditions year-round longterm data are needed and should be locally available. Daylight data are also measured at the CIE IDMP stations or can be taken from the satellite database. In this respect besides global irradiation recorded in short-term variability or hourly averages at ground meteorological stations or recalculated from satellite measurements, only relative sunshine duration in daily or monthly averages have a very long tradition and are evaluated in many stations world-wide.

When inspecting monthly graphs of daily illuminance courses it becomes obvious that especially during winter and summer seasons typical weather patterns last for several days with changes either during night-time or noon. Even during perfectly clear days the symmetry around noon seems to be broken by higher turbidity in afternoon hours caused by water vapour evaporated due to rising air temperature and sunshine. Furthermore, in equatorial climate have to be expected changes in cloud cover at around noon, i.e. frequent mostly clear mornings and hours before noon but rather cloudy afternoons. During the Slovak-Greek cooperation simultaneously collected data at the CIE IDMP stations in Bratislava and Athens could serve to compare four half-day situations occurring in the temperate climate of Central Europe to those in the Mediterranean region (Darula et al., 2004). Available data was gathered during relatively long period 1994-1999.

The whole set of measured data was used to analyse the relation between sunshine duration and daily courses of illuminance. Relative sunshine duration with standard deviation $S D$ for four typical situations were investigated in number with respect to their sequence of occurrence and results are documented in Table 1. Symbol $s$ is relative sunshine duration calculated for the whole day while $s m$ is for the morning period when local clock time was less than 12 o'clock and $s a$ for the afternoon relative sunshine duration when local clock time was from 12 hours to sunset.

Except for the rapid change from overcast to clear all possible changes from morning to afternoon situations were found during the long-term of six years, i.e. 2182 days or 4364 half-days. The average relative sunshine duration corresponds perfectly with the change from the morning situation to the afternoon one respecting the tendency of the following situation change.

Although the half-day characteristics and their sequences in one or few days can form a typical year simulation, within this span any time subdivision can be utilised, i.e. Bratislava 1-minute data or Bratislava and Athens 5-minute average data can serve for analysis and comparison studies of several descriptor interrelations. However, to reach an absolute symmetry in halfdays due to perfect noon time all measured momentary or average values are to be recalculated from local clock time in which these were recorded to true solar time. Of course, it has to be realised that because the daytime span between sunrise and sunset is changing during the year as well as with the local latitude the relative time of a half-day element is not constant. 


\begin{tabular}{|c|c|c|c|c|c|c|c|c|}
\hline \multicolumn{2}{|c|}{ Situation sequence } & \multirow{2}{*}{$\begin{array}{c}\text { Number } \\
\text { of cases }\end{array}$} & \multicolumn{2}{|c|}{$s$} & \multicolumn{2}{c|}{$s m$} & \multicolumn{2}{c|}{$s a$} \\
\hline Morning & Afternoon & Average & $S D$ & Average & $S D$ & Average & $S D$ \\
\hline Clear & Clear & 175 & 0,917 & 0,034 & 0,967 & 0,031 & 0,849 & 0,034 \\
\hline Clear & Cloudy & 87 & 0,796 & 0,091 & 0,944 & 0,054 & 0,586 & 0,131 \\
\hline Clear & Overcast & 4 & 0,506 & 0,027 & 0,868 & 0,032 & 0,003 & 0,004 \\
\hline Clear & Dynamic & 70 & 0,818 & 0,094 & 0,941 & 0,037 & 0,655 & 0,165 \\
\hline Cloudy & Clear & 9 & 0,649 & 0,148 & 0,512 & 0,185 & 0,839 & 0,038 \\
\hline Cloudy & Cloudy & 128 & 0,261 & 0,224 & 0,265 & 0,220 & 0,254 & 0,208 \\
\hline Cloudy & Overcast & 201 & 0,049 & 0,074 & 0,082 & 0,080 & 0,000 & 0,001 \\
\hline Cloudy & Dynamic & 38 & 0,200 & 0,122 & 0,109 & 0,097 & 0,324 & 0,153 \\
\hline Overcast & Clear & 0 & - & - & - & - & - & - \\
\hline Overcast & Cloudy & 53 & 0,056 & 0,055 & 0,003 & 0,003 & 0,134 & 0,108 \\
\hline Overcast & Overcast & 311 & 0,002 & 0,002 & 0,003 & 0,003 & 0,000 & 0,000 \\
\hline Overcast & Dynamic & 34 & 0,096 & 0,065 & 0,004 & 0,003 & 0,219 & 0,128 \\
\hline Dynamic & Clear & 90 & 0,753 & 0,154 & 0,690 & 0,220 & 0,841 & 0,035 \\
\hline Dynamic & Cloudy & 160 & 0,383 & 0,208 & 0,467 & 0,227 & 0,267 & 0,210 \\
\hline Dynamic & Overcast & 72 & 0,149 & 0,140 & 0,257 & 0,201 & 0,001 & 0,002 \\
\hline Dynamic & Dynamic & 750 & 0,504 & 0,219 & 0,536 & 0,252 & 0,462 & 0,205 \\
\hline \multicolumn{2}{|l|}{ Sum of cases } & 2182 & & & & & & \\
\hline
\end{tabular}

Table 1. Statistical parameters of typical courses in Bratislava, 1994 -1999

Anyhow it can be assumed that in simulation programs of a daylight reference year the halfday sequences or changes will allow to model in series of about sixty cases during a specific month either the fluent and gradual or sudden changes in weather or sky types corresponding to the probability of occurrence with its proportionality to monthly averages of relative sunshine duration. At least the mentioned four half-day daylight situations have to be foreseen for modelling the complex sun-sky coexistence with cloudiness patterns in any daylight climate, although typical cases were selected only from measurements collected in Athens and Bratislava. A research report (Darula et al., 2004) contains the detail analysis with proposals of several parameters to identify the four relevant situations from measured half-day illuminance courses and the daily average relative sunshine duration. It is evident that the stable and homogeneous situation 1 and situation 3 can be defined by the $s$ instead of sm and sa. However, the dynamically changing illuminance courses had to be identified and classified or selected to situation 1 , situation 2 or situation 4 by introducing an additional $U$ parameter. Thus

$$
\text { situation }=\left\{\begin{array}{ll}
1 & \text { if } s \geq 0.75 \text { and } U<7, \tau \\
2 & \text { if } s<0.75 \text { and } U<7, \tau \\
3 & \text { if } s<0.01, \tau \\
4 & \text { if } s \geq 0.01 \text { and } U \geq 7, \tau
\end{array}\right. \text {, }
$$

where

$$
U=\ln \left(\frac{1}{n-1} \sum_{i=1}\left|x_{i}-x_{i+1}\right|\right),
$$

and $x_{i}$ and $x_{i+1}$ are consecutive illuminance values in the half-day course. 
Using these classification parameters all four daylight types are interrelated by a fluent course of half-day average $G_{v} / E_{v}$ and $D_{v} / E_{v}$ dependent on the half-day sunshine duration as documented in Fig. 33 and 34 containing all 1994 morning and afternoon data recorded in Bratislava and in Athens first. In the second step a more detail separation of half-day situations dependent on half-day relative sunshine duration was made for morning 1994 data (Fig. 35) and afternoon (Fig. 36) in relation to $G_{v} / E_{v}$ parameter repeated for also $D_{v} / E_{v}$ and $P_{v} / E_{v}$ with the best fit simulation of their dependence on the half-day relative sunshine duration. However, as most frequently are available only monthly relative sunshine durations in meteorological station reports the probability of occurrence of the morning and afternoon halfday situations was sought first for 1994 data (example in Fig. 37 for situation 1) and checked for 1991-2001 data. Thus best fit probability for the monthly redistribution simulation of morning and afternoon situations 1 to 4 were predetermined solely dependent on the monthly relative sunshine duration using curves in Fig. 38 for morning half-days or in Fig. 39 for afternoons (Darula et al., 2004 and Darula \& Kittler, 2005b).

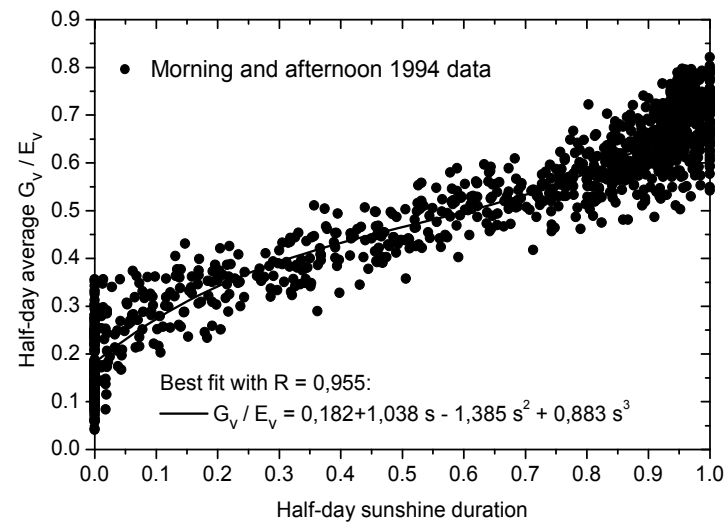

Fig. 33. Morning and afternoon $G_{v} / E_{v}$ data after Bratislava and Athens measurements during 1994

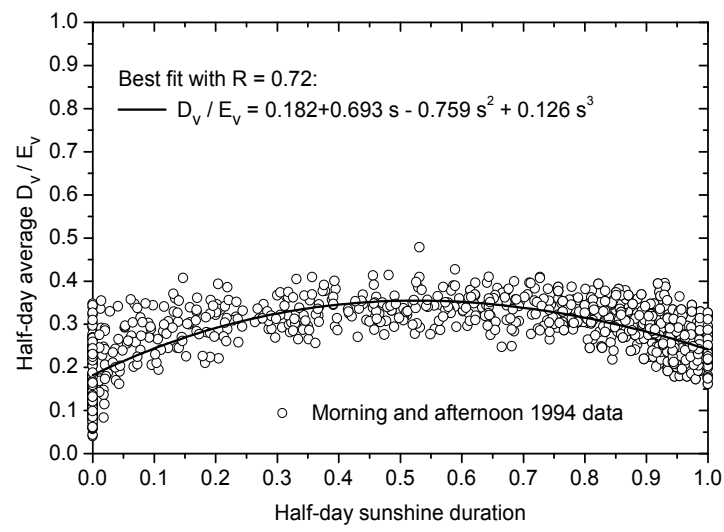

Fig. 34. Morning and afternoon $D_{v} / E_{v}$ data after Bratislava and Athens measurements during 1994 


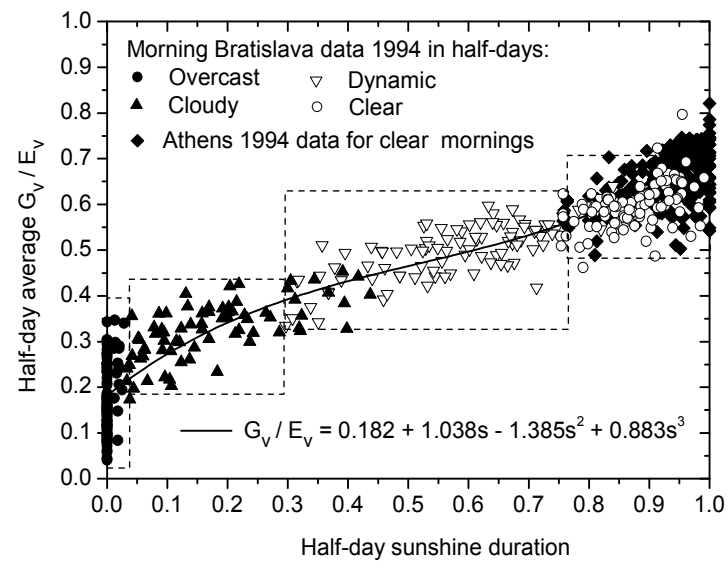

Fig. 35. Morning data for four half-day situations

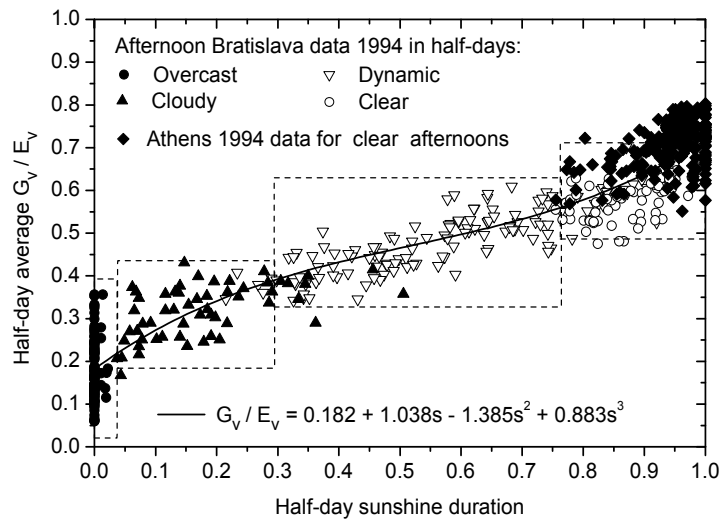

Fig. 36. Afternoon data for four half-day situations

The probability of occurrence of each of the four daylight situations in each month can be approximately estimated

- for morning half-days by:

$$
P m 1=100\left(0.55 s-0.95 s^{2}+1.65 s^{3}\right)[\%],
$$

except if $s>0.93$, then $P m 1=100$

$$
\begin{aligned}
& \text { if } s=0-0.5 \text {, then } P m 2=100 s(1.5-1.85 s)[\%] \\
& \text { if } s=0.5-0.93 \text {, then } P m 2=66.86(0.93-s)[\%], \\
& \text { if } s>0.93 P m 2=0[\%], \\
& P m 3=100(1-s)^{2.47}[\%],
\end{aligned}
$$




$$
P m 4=100-(P m 1+P m 2+P m 3)[\%],
$$

- $\quad$ for the afternoon half-days by:

$$
P a 1=100\left(0.62 s-0.77 s^{2}+1.26 s^{3}\right)[\%],
$$

except if $s>0.97$, then $P a 1=100$

$$
\begin{aligned}
& \text { if } s=0-0.5 \text {, then } P a 2=100 s(1.2-1.6 s)[\%], \\
& \text { if } s=0.5-0.93 \text {, then } P a 2=46.51(0.93-s)[\%], \\
& \text { if } s>0.93 P a 2=0 \quad[\%], \\
& P a 3=100(1-s)^{2.7}[\%], \\
& P a 4=100-(P a 1+P a 2+P a 3)[\%] .
\end{aligned}
$$

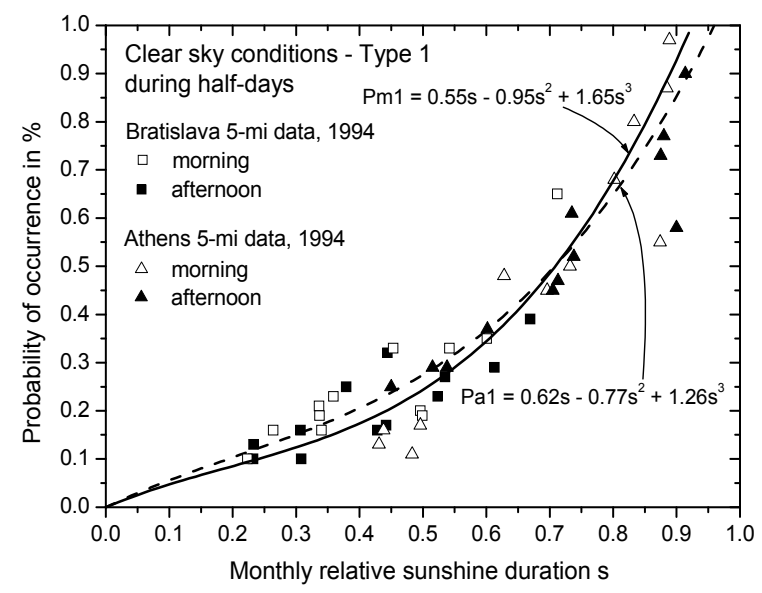

Fig. 37. Relation of clear situation to monthly relative sunshine duration in Bratislava and Athens 


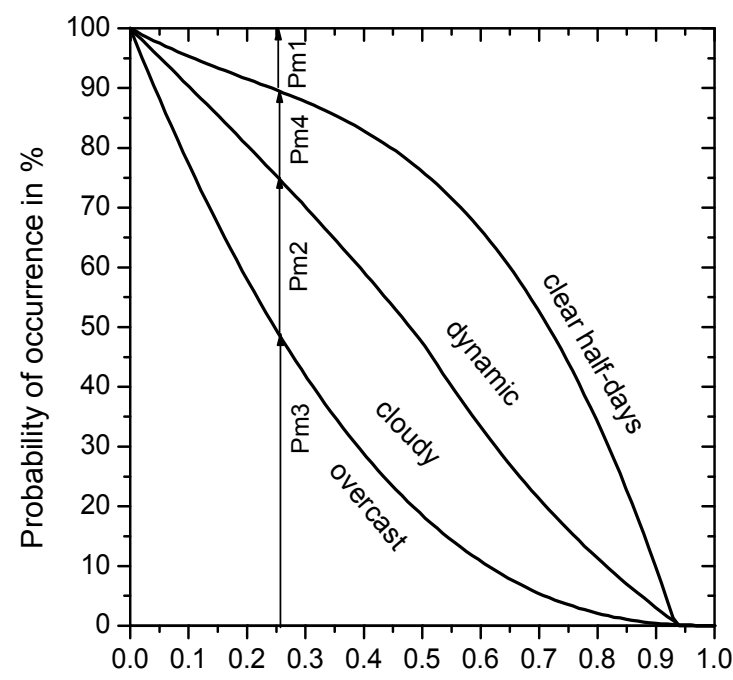

Monthly average relative sunshine duration, $\mathrm{s}$

Fig. 38. Occurrence probability of half-day situations during mornings

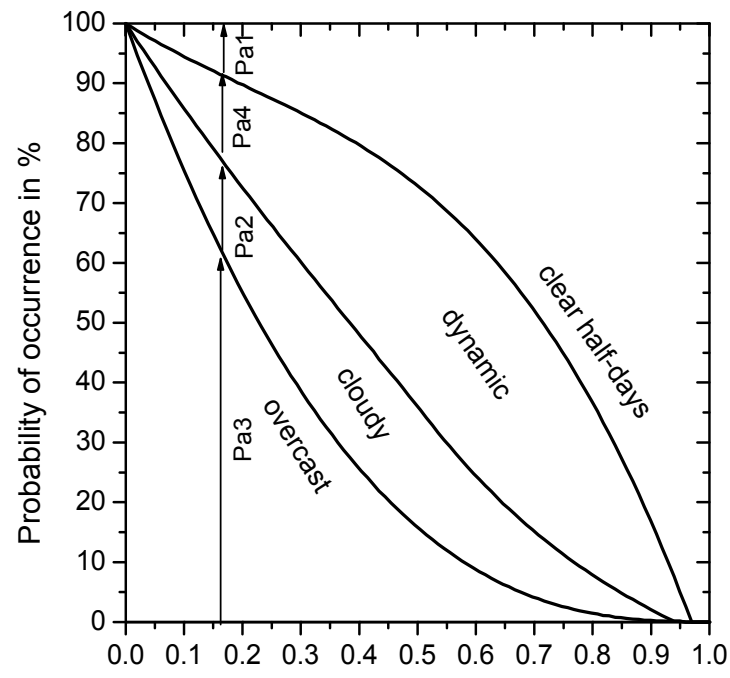

Monthly average relative sunshine duration, $\mathrm{s}$

Fig. 39. Occurrence probability of half-day situations during afternoons

These probabilities of the occurrence of typical four daylight situations were derived from measurements in two different climate zones, i.e. in Bratislava as well as in Athens. So, it can be assumed that the dependence on monthly sunshine durations during morning and afternoon half-days could be valid not only in Central Europe and European Mediterranean regions but also world-wide. 


\section{Approximate redistribution of the four daylight situations in the yearly simulation of their occurrence}

In accordance with the probability study of the four daylight situations in Bratislava morning and afternoon data during 1994-2001 the check was done using Athens data gathered in a five year period 1992-1996 (Darula et al., 2004). Because the calculated probability had to be substituted by a concrete number of days within a particular month, i.e. in integer numbers, these had to correspond with sum of half-days in that actual month. The redistribution into half-days had to dependent also on the overall monthly sunshine duration, so the redistribution model correlating the probability percentage and number of half-day situations had to be found. The best fit final solution is documented for the morning redistribution model with results shown in Fig. 40 as well as for afternoon in Fig. 41 with monthly relative sunshine duration data measured during mornings $s m$ and measured during afternoons $s a$.

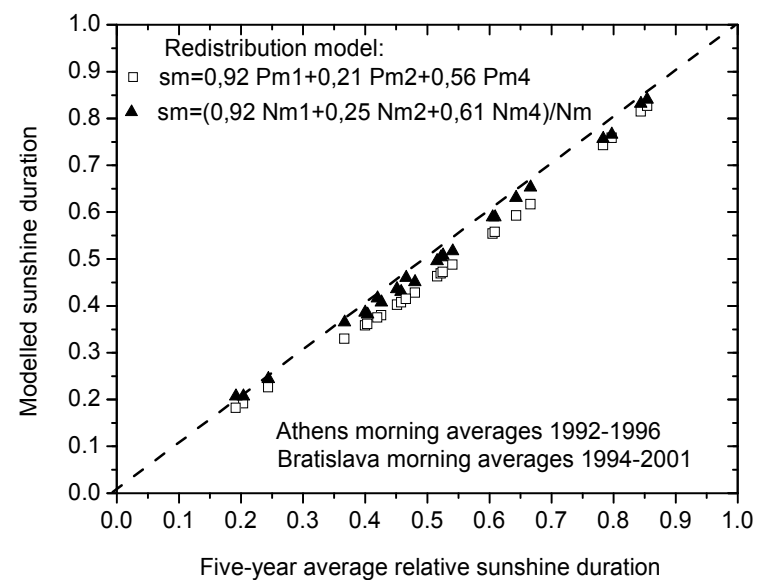

Fig. 40. Redistribution model after Bratislava and Athens morning data

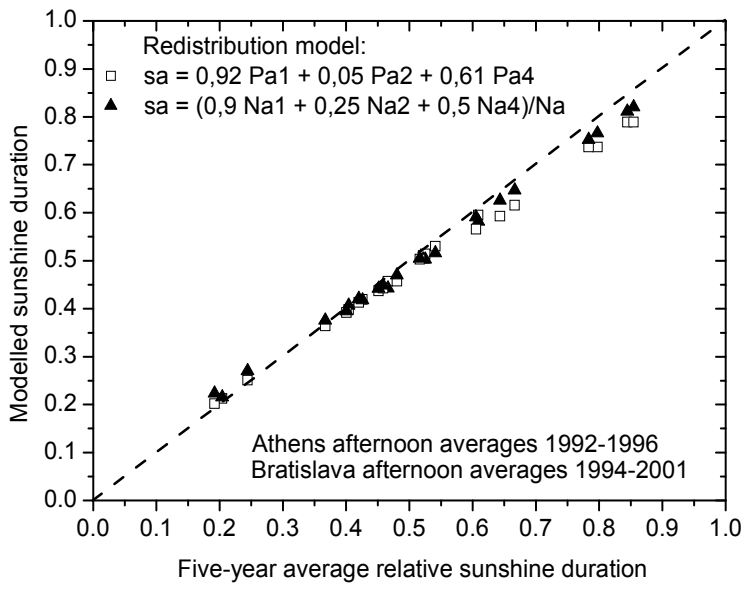

Fig. 41. Similar redistribution for afternoon half-days 
In these figures besides the probability percentage notation $P m 1-P m 4$ and $P a 1-P a 4$ a similar notation for the number of half-days is used $N m 1-N m 4$ and $N a 1-N a 4$ while the overall number of morning half-days in a particular month is $\mathrm{Nm}$ for mornings and $\mathrm{Na}$ for afternoons in Fig. 40 and 41. These document and confirm the redistribution model that approximates the participation of the main three situations on sunlight presence and monthly sunshine duration within the particular half-day assuming that the overcast halfday is absolutely without any sunshine, thus

$$
s m=(0.92 N m 1+0.25 N m 2+0.61 N m 4) / N m,
$$

and

$$
s a=(0.9 \mathrm{Na} 1+0.25 \mathrm{Na} 2+0.5 \mathrm{Na} 4) / \mathrm{Na} .
$$

This redistribution of half-day situations during mornings and afternoons was calculated for Bratislava and Athens data and as examples are shown in Table 2 and 3 only those for morning half-days. Although the verification of these redistributions for other localities is rather complicated it is evident that the ranges of mornings $s m$ and those measured during afternoons $s a$ can be in every month specific too. While during overcast situations the range of $s \leq 0.05$ is relatively small with $G_{v} / E_{v}$ within the spread $0.05-0.35$ (Fig. 35 and 36), the $s$ ranges in dynamic situations are quite large i.e. $0.3-0.76$ while $\mathrm{Gv} / \mathrm{Ev}$ spread is approximately within $0.32-0.61$.

Thus eq. (34) and (35) characterise the redistribution of sm and sa due to four half-day situations simulating Central European and Mediterranean daylight conditions. In other climate regions (like maritime and equatorial) or during rainy (April or May) or during monsoon months more general relations might be valid as

$$
s m=(s m 1 N m 1+s m 2 N m 2+s m 4 N m 4) / N m,
$$

and

$$
s a=(s a 1 N a 1+s a 2 N a 2+s a 4 N a 4) / N a .
$$

Therefore in the application of this redistribution it is recommended to test whether the $s m$ and $s a$ for appropriate situations are within their usual ranges. Approximately this is done by checking sm4 and sa4 ranges after eq. (34) and (35). During dynamic half-days both $s m 4$ and sa 4 should be in the range 0.3 to 0.75 to be related to the rise of $G_{v} / E_{v}$ from 0.35 to 0.6 respectively.

For an example of such a check can be taken the ten-year (1995-2004) average of relative sunshine duration in Prague, which is for May $s=0.502$. In the book by Darula et al., (2009) after percentage probabilities the number of four half-day situations was determined (on p. 64, Tab. 5.4.1) as follows:

$N m 1=8, N m 2=9, N m 3=6$ and $N m 4=8$ with the full number of morning half-days in May $\mathrm{Nm}=31$;

So, after eq. (34)

$$
s m 4=\frac{s m N m-(0.92 N m 1+0.25 N m 2)}{N m 4}=\frac{31(0.502)-[(0.92) 8+(0.25) 9]}{8}=0.744
$$




\begin{tabular}{|c|c|c|c|c|c|c|c|c|c|c|c|}
\hline Month & $\mathrm{s}$ & $\mathrm{Pm} 1$ & $\mathrm{Nm} 1$ & $\mathrm{Pm} 2$ & $\mathrm{Nm} 2$ & $\mathrm{Pm} 3$ & $\mathrm{Nm} 3$ & $\mathrm{Pm} 4$ & $\mathrm{Nm} 4$ & $\mathrm{Nm}$ & $\mathrm{sm}$ \\
\hline 1 & 0,204 & 8,67 & 3 & 22,90 & 7 & 56,92 & 18 & 11,51 & 3 & 31 & 0,207 \\
\hline 2 & 0,404 & 17,59 & 5 & 30,41 & 9 & 27,85 & 8 & 24,15 & 6 & 28 & 0,382 \\
\hline 3 & 0,367 & 15,55 & 5 & 30,13 & 9 & 32,32 & 10 & 22,00 & 7 & 31 & 0,365 \\
\hline 4 & 0,466 & 21,70 & 7 & 29,73 & 9 & 21,23 & 6 & 27,34 & 8 & 30 & 0,460 \\
\hline 5 & 0,541 & 28,08 & 9 & 26,01 & 8 & 14,61 & 5 & 31,30 & 9 & 31 & 0,517 \\
\hline 6 & 0,522 & 26,29 & 8 & 27,28 & 8 & 16,15 & 5 & 30,28 & 9 & 30 & 0,504 \\
\hline 7 & 0,525 & 26,57 & 8 & 27,08 & 8 & 15,90 & 5 & 30,45 & 10 & 31 & 0,508 \\
\hline 8 & 0,609 & 35,53 & 11 & 21,46 & 7 & 9,83 & 3 & 33,18 & 10 & 31 & 0,589 \\
\hline 9 & 0,426 & 18,95 & 6 & 30,33 & 9 & 25,38 & 8 & 25,35 & 7 & 30 & 0,408 \\
\hline 10 & 0,420 & 18,57 & 6 & 30,37 & 9 & 26,04 & 8 & 25,03 & 8 & 31 & 0,416 \\
\hline 11 & 0,244 & 10,16 & 3 & 25,59 & 8 & 50,11 & 15 & 14,14 & 4 & 30 & 0,244 \\
\hline 12 & 0,192 & 8,23 & 3 & 21,98 & 7 & 59,06 & 18 & 10,73 & 3 & 31 & 0,207 \\
\hline
\end{tabular}

Table 2. Redistribution of half-day situations according to Bratislava morning 8 - year data related to monthly average relative sunshine duration

\begin{tabular}{|c|c|c|c|c|c|c|c|c|c|c|c|}
\hline Month & $\mathrm{s}$ & $\mathrm{Pm} 1$ & $\mathrm{Nm} 1$ & $\mathrm{Pm} 2$ & $\mathrm{Nm} 2$ & $\mathrm{Pm} 3$ & $\mathrm{Nm} 3$ & $\mathrm{Pm} 4$ & $\mathrm{Nm} 4$ & $\mathrm{Nm}$ & $\mathrm{sm}$ \\
\hline 1 & 0,451 & 20,62 & 6 & 30,02 & 9 & 22,74 & 7 & 26,62 & 9 & 31 & 0,436 \\
\hline 2 & 0,480 & 22,76 & 6 & 29,38 & 8 & 19,89 & 6 & 27,98 & 8 & 28 & 0,451 \\
\hline 3 & 0,516 & 25,75 & 8 & 27,68 & 9 & 16,66 & 5 & 29,91 & 9 & 31 & 0,496 \\
\hline 4 & 0,643 & 39,95 & 12 & 19,19 & 6 & 7,85 & 2 & 33,00 & 10 & 30 & 0,631 \\
\hline 5 & 0,666 & 43,23 & 13 & 17,65 & 5 & 6,66 & 2 & 32,45 & 11 & 31 & 0,653 \\
\hline 6 & 0,797 & 67,02 & 20 & 8,89 & 3 & 1,95 & 1 & 22,14 & 6 & 30 & 0,766 \\
\hline 7 & 0,844 & 77,95 & 24 & 5,75 & 2 & 1,02 & 0 & 15,29 & 5 & 31 & 0,832 \\
\hline 8 & 0,854 & 80,45 & 25 & 5,08 & 2 & 0,86 & 0 & 13,60 & 4 & 31 & 0,841 \\
\hline 9 & 0,783 & 64,03 & 19 & 9,83 & 3 & 2,30 & 1 & 23,85 & 7 & 30 & 0,757 \\
\hline 10 & 0,605 & 35,04 & 11 & 21,73 & 7 & 10,08 & 3 & 33,15 & 10 & 31 & 0,589 \\
\hline 11 & 0,458 & 21,11 & 6 & 29,89 & 9 & 22,03 & 7 & 26,96 & 8 & 30 & 0,430 \\
\hline 12 & 0,400 & 17,36 & 5 & 30,40 & 9 & 28,32 & 9 & 23,92 & 8 & 31 & 0,386 \\
\hline
\end{tabular}

Table 3. Redistribution of half-day situations according to Athens morning 5 - year data related to monthly average relative sunshine duration 
which means that $s m 4=0.744$ falls to the upper range 0.75 , but $s m 2=0.25$ is suspect due to probably more sunshine intervals in May. Under such conditions probably $s m 4=0.61$ as in eq. (34) and in May sm2 is higher:

$$
\operatorname{sm} 2=\frac{31(0.502)-[(0.92) 8+(0.61) 8]}{9}=0.369 .
$$

Similarly a November check can be done using $s=0.195$ for Prague with $N m 1=3$, $N m 2=7, N m 3=18$ and $N m 4=2$ with the full number of morning half-days in November $\mathrm{Nm}=30$ where after eq. (34) is

$$
s m 4=\frac{s m N m-(0.92 N m 1+0.25 N m 2)}{N m 4}=\frac{30(0.195)-[(0.92) 3+(0.25) 7]}{2}=0.67
$$

which suites the dynamic range and is quite close to the assumed $\operatorname{sm} 4=0.61$.

In accordance with the already approximated monthly averaged values $G_{v} / E_{v}$ in Fig. 33, 35 and 36 as well as $D_{v} / E_{v}$ in Fig. 34 can be simulated also roughly half-day illuminance courses as

$$
G_{v}=\frac{G_{v}}{E_{v}}\left(L S C \in \sin \gamma_{s}\right)[1 x]
$$

where

$$
G_{v} / E_{v}=0.182+1.038 s-1.385 s^{2}+0.883 s^{3}[-]
$$

and

$$
D_{v}=\frac{D_{v}}{E_{v}}\left(L S C \in \sin \gamma_{s}\right)[1 x]
$$

where

$$
D_{v} / E_{v}=0.182+0.693 s-0.759 s^{2}+0.126 s^{3}[-] .
$$

It is evident that the course distribution of illuminances is caused by the sine of the solar angle with either the momentary sine value for the moment or for the chosen time interval. This sine of the solar altitude $\gamma_{s}$ after eq. (2) for any hour number $H$ during daytime in TST can be used. For a short time period a straight-line interpolation can be applied when $H=\left(H_{1}+H_{2}\right) / 2$ or a value after eq. (16) is more precise.

A further possible step to specify the site and situation dependent illuminance stimulated a study that would show the relation of the four situations on typical sky patterns or ISO (2004)/CIE (2003) standard general skies if possible. Originally these standards were derived with the specification of indicatrix and gradation function in Kittler (1995) and finally recommended for standardisation in Kittler et al., (1997).

After a detail number of 5-minute measured cases in Bratislava specifying every year within the five year 1994 - 1998 span all four daylight situations were analysed with the following results:

1. under situation 1 were present

- during mornings over $75 \%$ of clear sky types 11,12 and 13 with the prevailing $32.55 \%$ of sky type 12 , 
- during afternoons over $76 \%$ sky types 10, 11 and 12 with the prevailing $34.48 \%$ of sky type 12 ,

2. under situation 2 were occurring

- during mornings almost $50 \%$ of cloudy sky types 2, 3 and 4 with the prevailing $18 \%$ of sky type 3,

- $\quad$ during afternoons over $46 \%$ sky types 2, 3 and 4 with the prevailing almost $17 \%$ of sky type 3,

3. under situation 3 were present

- during mornings almost $72 \%$ of overcast sky types 1, 2, and 3 with the prevailing almost $27 \%$ of sky type 2 ,

- during afternoons over $70 \%$ sky types 1, 2, and 3 with the prevailing almost $27 \%$ of sky type 2,

4. under sitation 4 were very changeable sky patterns, but the most present were

- during mornings almost $40 \%$ sky types 11,12 and 13 with the prevailing over $15 \%$ of sky type 12 ,

- during afternoons almost $38 \%$ sky types 11, 12 and 13 with the prevailing almost $15 \%$ of sky type 12.

This sky type prevalence (Darula \& Kittler, 2008a) was in coherence considerably also with the seasonal frequency of dominant sky types found in the seasonal distribution (Kitttler et al., 2001) with prevailing overcast skies in type 2 and 3 and clear sky types 12 and 11 in Bratislava, while in Athens the highest frequency of clear polluted sky type 13 was documented, while uniform cloudy skies 5 and 6 were the most often occurring in dull seasons. Of course, the seasonal changes in occurrence frequency of clear and overcast skies is linked with relative sunshine duration and therefore with the number of half-days in any locality. However, it is interesting that in any daylight climate there exists a number of (Lambert) overcast sky type 5 with uniform luminance sky patterns, e.g. in Bratislava five year long-term these represented $12.6 \%$ whithin cloudy situation 2 during morning halfdays and over $14 \%$ during afternoons whithin overcast situation 3 these were represented by morning $8.08 \%$ and afternoon $7.74 \%$ presence.

More and further measurements in different locations are expected to demonstrate the sitespecific and short-term variability of illuminance levels (as recently was shown for irradiance by Perez et al., 2011). Due to dynamic situations it is important to evaluate shortterm (momentary 1 or 5-minute regular measurements) because estimations of using hourly insolation data from satellite-based sources can be problematic and less accurate when subhourly variability is uncertain and especially if irradiance data are recalculated via luminous efficacy into illuminances (Darula \& Kittler, 2008b). Therefore long-term regular measurements in absolute illuminance values are so important to have site-specific fundamental data with the possibility to derive also half-day situations. When modelling year-round situation frequencies it is also important to randomly distribute also some sequential ocurrence of specific situations (Darula \& Kittler 2002) which can occur several half-days or even days after each other as is documented in Table 4 and 5. Of course, one situation can last during the whole day, i.e. the morning situation is the same in the afternoon, but quite frequent are also changes from clear to dynamic or cloudy to dynamic and vice versa especially in summer as shown in Table 4 . In winter are typical lasting same situations except dynamic in two adjacent days, while in summer all consecutive days with the same situation are quite often except overcast. 


\begin{tabular}{|c|c|c|c|c|c|c|c|}
\hline \multicolumn{2}{|c|}{ Situation sequence } & \multicolumn{2}{c|}{ Winter } & \multicolumn{2}{c|}{ Summer } & \multicolumn{2}{c|}{ Spring and autumn } \\
\hline Morning & Afternoon & $\begin{array}{c}\text { Number } \\
\text { of cases }\end{array}$ & $\%$ & $\begin{array}{c}\text { Number } \\
\text { of cases }\end{array}$ & $\%$ & $\begin{array}{c}\text { Number } \\
\text { of cases }\end{array}$ & $\%$ \\
\hline Clear & Clear & 44 & 10,35 & 55 & 12,20 & 52 & 11,38 \\
\hline Cloudy & Cloudy & 82 & 19,29 & 56 & 12,42 & 81 & 17,72 \\
\hline Overcast & Overcast & 55 & 12,94 & 1 & 0,22 & 11 & 2,41 \\
\hline Dynamic & Dynamic & 29 & 6,82 & 56 & 12,42 & 62 & 13,57 \\
\hline Clear & Cloudy & 13 & 3,06 & 20 & 4,44 & 13 & 2,85 \\
\hline Clear & Overcast & 2 & 0,47 & 0 & 0,00 & 0 & 0,00 \\
\hline Clear & Dynamic & 30 & 7,06 & 109 & 24,17 & 65 & 14,22 \\
\hline Cloudy & Clear & 15 & 3,53 & 6 & 1,33 & 12 & 2,63 \\
\hline Cloudy & Overcast & 18 & 4,24 & 2 & 0,44 & 4 & 0,88 \\
\hline Cloudy & Dynamic & 55 & 12,94 & 75 & 16,63 & 70 & 15,32 \\
\hline Overcast & Clear & 0 & 0,00 & 0 & 0,00 & 0 & 0,00 \\
\hline Overcast & Cloudy & 28 & 6,59 & 0 & 0,00 & 3 & 0,66 \\
\hline Overcast & Dynamic & 5 & 1,18 & 0 & 0,00 & 3 & 0,66 \\
\hline Dynamic & Clear & 23 & 5,41 & 31 & 6,87 & 36 & 7,88 \\
\hline Dynamic & Cloudy & 25 & 5,88 & 40 & 8,87 & 45 & 9,85 \\
\hline Dynamic & Overcast & 1 & 0,24 & 0 & 0,00 & 0 & 0,00 \\
\hline \multicolumn{2}{|c|}{ Sum of cases } & 425 & 100 & 451 & 100 & 457 & 100 \\
\hline
\end{tabular}

Table 4. Occurrence of daylight situations with typical sequences in one whole day

\begin{tabular}{|c|c|r|r|r|r|r|r|}
\hline Situation sequence & \multicolumn{2}{|c|}{ Winter } & \multicolumn{2}{|c|}{ Summer } & \multicolumn{2}{c|}{ Spring and autumn } \\
\hline Morning & Afternoon & $\begin{array}{c}\text { Number } \\
\text { of cases }\end{array}$ & $\%$ & $\begin{array}{c}\text { Number } \\
\text { of cases }\end{array}$ & $\%$ & $\begin{array}{c}\text { Number } \\
\text { of cases }\end{array}$ & \multicolumn{1}{c|}{$\%$} \\
\hline Clear & Clear & 13 & 13,27 & 18 & 21,95 & 20 & 19,05 \\
\hline Cloudy & Cloudy & 39 & 39,80 & 14 & 17,07 & 26 & 24,76 \\
\hline Overcast & Overcast & 24 & 24,49 & 0 & 0,00 & 3 & 2,86 \\
\hline Dynamic & Dynamic & 3 & 3,06 & 14 & 17,07 & 18 & 17,14 \\
\hline Clear & Cloudy & 0 & 0,00 & 2 & 2,44 & 0 & 0,00 \\
\hline Clear & Overcast & 0 & 0,00 & 0 & 0,00 & 0 & 0,00 \\
\hline Clear & Dynamic & 3 & 3,06 & 13 & 15,85 & 14 & 13,33 \\
\hline Cloudy & Clear & 3 & 3,06 & 0 & 0,00 & 0 & 0,00 \\
\hline Cloudy & Overcast & 1 & 1,02 & 0 & 0,00 & 0 & 0,00 \\
\hline Cloudy & Dynamic & 7 & 7,14 & 10 & 12,20 & 15 & 14,29 \\
\hline Overcast & Clear & 0 & 0,00 & 0 & 0,00 & 0 & 0,00 \\
\hline Overcast & Cloudy & 2 & 2,04 & 0 & 0,00 & 1 & 0,95 \\
\hline Overcast & Dynamic & 0 & 0,00 & 0 & 0,00 & 0 & 0,00 \\
\hline Dynamic & Clear & 1 & 1,02 & 3 & 3,66 & 2 & 1,91 \\
\hline Dynamic & Cloudy & 2 & 2,04 & 8 & 9,76 & 6 & 5,71 \\
\hline Dynamic & Overcast & 0 & 0,00 & 0 & 0,00 & 0 & 0,00 \\
\hline \multicolumn{2}{|c|}{ Sum of cases } & 98 & 100 & 82 & 100 & 105 & 100 \\
\hline
\end{tabular}

Table 5. Repetition of four half-day situations in conscutive two days 


\section{Conclusions}

Architectural and building science tries to gather and apply available human knowledge for the complex, aesthetic and functional creation of sophisticated habitable and healthy spaces with best environmental qualities encompassing shelter for human live, relaxation and work activities. Of course, the urban and structural objects with different interior spaces in their architectural plans and building forms have to respect natural conditions in various geographical locations, topography, local life stile and culture with trials for optimal solutions according to requirements concerning human health and prosperity, investor tendencies, investment and maintenance costs. To satisfy a complex sum of conditions, needs, codes and standards summarised by inhabitants, investors and national institutions leads to relatively simple and realistic criteria with a reasonable and experience-based background including simplified scientifically sound knowledge.

In case of utilising insolation and daylight conditions the traditional daylight science and technology is facing novel approaches and more real enhancements. In this sense are questionable also some older daylight criteria that were still recently used since the first calculation simplifications derived in the $18^{\text {th }}$ Century. The Daylight Factor, Sky factor and Sky Component of the Daylight Factor used as basic criteria in various standards assume the existence of the unit uniform sky luminance after Lambert (1760). Although such Lambert uniform skies exist world-wide these do not represent typical sky luminance patterns in any site-specific conditions especially in subtropical, tropical and equatorial regions where mostly clear sky luminance distributions prevail that cause skylight illuminance conditions added frequently by sunlight.

This study tries to show and document that site-dependent daylight illuminance levels and their changes have to be expected in short-term, half-day, monthly or yearly variations in a realistic range under four typical half-daily situations. These situations can be classified with respect to relevant parameters which are dependent on extraterrestrially available illuminance reduced by atmospheric optical depth and air mass, turbidity and cloudiness conditions in site-specific variability. For practical purposes the probability of occurrence frequency of a particular half-day situation is related to the half-day or monthly relative sunshine duration which in absence of special measurements is available from many meteorological records world-wide. These monthly relative sunshine duration data can serve to estimate the local number of morning and afternoon half-day situations in any month and model their year-round expectance. Following this aim all data and figures after Bratislava and Athens CIE IDMP regular measurements can be considered as examples documenting the parameterisation and applicability of the four half-day situation system.

Current saving energy policies are also directed towards utilising renewable energy and in this respect also daylighting can serve to reduce electricity consumption in artificial illumination of interiors. A more precise determination of half-day illumination levels within year-round balance of supplementary electric lighting will enable to control it more effectively. Thus, daylight as natural source can be applied for interior illumination respecting local sunlight and skylight availability.

\section{Acknowledgement}

This chapter was written and partially supported under the Slovak grant project APVV0177-10 using daylight measurements recorded by the Bratislava CIE IDMP gathered and evaluated under the Slovak VEGA grant 2/0029/11. 


\section{References}

Bodmann, H.W. (1991). Opening of the CIE Conference by the President, Proceedings of 22nd Session CIE, Vol.2, p. 3

Clear, R. (1982). Calculation of turbiidity and direct sun illuminances. Memo to Daylighting Group. LBL, Berkeley

CIE - Commission Internationale de l'Éclairage (1994). Guide to recommended practice of daylight measurement. CIE Publ. 108, CB CIE, Vienna, Austria

CIE - Commission Internationale de l'Éclairage (2003). Spatial distribution of daylight - CIE Standard General Sky, CIE Standard S 011/E:2003, CB CIE Vienna, Austria

Cooper, P.I. (1969). The absorption of radiation in solar stills. Solar Energy, Vol.12, No.3, pp.333-346

Darula, S. \& Kittler, R. (2002) Sekvencie situácií dennej osvetlenosti v Bratislava. (In Slovak, Sequences of daylight situations in Bratislava). Proceedings of the $5^{\text {th }}$ Intern. Conf. Light, pp. 20-24, Brno

Darula, S. \& Kittler, R. (2004a). Sunshine duration and daily courses of illuminances in Bratislava. International Journal of Climatology, Vol.24, No.14, pp.1777-1783

Darula, S. \& Kittler, R. (2004b). New trends in daylight theory based on the new ISO/CIE Sky Standard: 2. Typology of cloudy skies and their zenith luminance. Building Research Journal, Vol.52, No.4, pp.245-255

Darula, S. \& Kittler, R. (2004c). New trends in daylight theory based on the new ISO/CIE Sky Standard: 1. Zenith luminance on overcast skies. Building Research Journal, Vol.52, No.3, pp.181-197

Darula, S.; Kittler, R.; Kambezidis, H.D. \& Bartzokas, A. (2004). Generation of a Daylight Reference Year for Greece and Slovakia. Final Report GR-SK 004/01. Available from ICA SAS, Bratislava.

Darula, S. \& Kittler, R. (2005a). New trends in daylight theory based on the new ISO/CIE Sky Standard: 3. Zenith luminance formula verified by measurement data under cloudless skies. Building Research Journal, Vol.53, No.1, pp.9-31

Darula, S. \& Kittler, R. (2005b). Monthly sunshine duration as a thrustworthy basis to predict annual daylight profiles. Proceedings of the Lux Europa Session, Berlin, pp. 141-143

Darula, S.; Kittler, R. \& Gueymard, Ch. (2005). Reference luminous solar constant and solar luminance for illuminance calculations. Solar Energy, Vol.79, No.5, pp.559-565

Darula, S. \& Kittler, R. (2008a). Occurrence of standard skies during typical daytime halfdays. Renewable Energy, Vol.33, pp.491-500

Darula, S. \& Kittler, R. (2008b). Uncertainties of luminous efficacy under various skies. Proceedings Intern. Conf. Lighting Engineering, Ljubljana, pp.315-322

Darula, S., Kittler, R., Kocifaj, M., Plch, J., Mohelniková, J. \& Vajkaj, F. (2009). Osvětlování světlovody. (In Chech, Illumination by light guides). Grada Publ., Prague

Gruter, J.W. (1981). Radiation nomenclature, definitions, symbols, units and related quantities. Commision of the Europ. Communities, Brussels

Heindl, W. \& Koch, H.A. (1976). Die Berechnung von Sonneneinstrahlungsimtensitäten für wärmetechnische Untersuchungen im Bauwesen. Gesundheits Ing., Vol. 97, No, 12, pp. 301-314 
IESNA - Illuminating Engineering Society of North America (1984). Calculation Procedures Committee Recommended practice for the calculation of daylight availability. Journal of IESNA, Vol. 13, No. 4, pp.381-392, 1984

ISO - International Standardisation Organisation (2004). Spatial distribution of daylight - CIE Standard General Sky, ISO Standard 2004: 15409

Kasten, F. \& Young, A.T. (1989). Revised optical air mass tables and approximation formula. Applied Optics, Vol.28, No.22, pp.4735-4738

Kittler, R. \& Mikler, J. (1986). Základy využívania slnečného žiarenia. (In Slovak. Basis of the utilization of solar radiation.) Veda Publ., Bratislava

Kittler, R.; Hayman, S.; Ruck, N. \& Julian, W. (1992). Daylight measurement data: Methods of evaluation and representation. Lighting Research and Technology, Vol.24, No.4, pp.173-187

Kittler, R. (1995). The general relationship between sky luminance patterns and exterior illuminance levels. Proceedings of 23rd Session CIE, Vol.1, pp.217-218

Kittler, R.; Darula, S. \& Perez, R. (1997). A new generation of sky standards. Proceedings of Lux Europa Conference, Amsterdam, pp.359-373

Kittler, R.; Darula, S.; Kambezidis, H.D. \& Bartzokas, A. (2001). Daylight climate specification based on Athens and Bratislava data. Proceedings of the Lux Europa 2001 Conf., pp. 442-449, Reykjavik, Iceland

Kittler, R. \& Darula, S. (2002). Parametric definition of the daylight climate. Renewable Energy, Vol.26, pp.177-187

Lambert, J.H. (1760). Photometria sive de mensura et gradibus luminis, colorum et umbrae. Augsburg, German translation by Anding, E.: Lamberts Fotometrie. Klett Publ., Leipzig (1892), English translation and notes by DiLaura, D.L.: Photometry, or on the measure and gradation of light, colors and shade. Publ.IESNA, N.Y. (2001)

Navvab, M.; Karayel, M.; Ne'eman, E. \& Selkowitz, S. (1984). Analysis of atmospheric turbidity for daylight calculations. Energy and Buildings, Vol.6, No.3, pp.293-303

Perez, R.; Kivalov, S.; Schlemmer, J.; Hemker Jr., K. \& Hoff, T. (2011) Parametrisation of sitespecific short-term irradiance variability. Solar Energy, Vol.85, No.7, pp.1343-1353

Pierpoint, W. (1982). Recommended practice for the calculation of daylight availability. Draft US IES Daylight Guide

WMO - World Meteorological Organization (1983). Guide to meteorological instruments and methods of observation, $5^{\text {th }}$ edition, No.8, pp. 9.53-9.55, World Meteorological Organization, Geneva 


\title{
Energetic Willow (Salix viminalis) - Unconventional Applications
}

\author{
Andrzej Olejniczak, Aleksandra Cyganiuk, \\ Anna Kucińska and Jerzy P. Łukaszewicz \\ Faculty of Chemistry, Nicholas Copernicus University \\ Poland
}

\section{Introduction}

Salix viminalis (Common Osier, Basket Willow, Energetic Willow) is a plant belonging to the SRWC group (Short Rotation Woody Crops) (Borjesson et al., 1994; Christersson \& Sennerby-Forsse, 1994). Such a qualification points out possible applications resulting from a fast growth and annual yield of biomass. The woody stems of Salix viminalis can be cut frequently and serve as burnable biomass. Therefore Salix viminalis wood is often called a "green fuel". In general, willows (genus Salix) are popular plants since more than 400 species occur in Nature (including Salix viminalis). Particularly, Northern Hemisphere is a natural region for different willow species bearing sometimes traditional and very unique names like Sageleaf Willow, Goat Willow, Pussy Willow, Coastal Plain Willow, Kimura, Grey Willow, Sand Dune Willow, Furry Willow, Heartleaf Willow, Del Norte Willow, American Willow, Drummond's Willow, Eastwood's Willow, Mountain Willow, Sierra Willow etc. The variety of willow species partly results from ease of hybrid formation by cross-fertile of particular Salix genotypes in a natural process and/or by planned cultivation. Table 1 contains systematic botanic classification of willows.

\begin{tabular}{|l|l|}
\hline Kingdom & Plantae \\
\hline Order & Malpighiales \\
\hline Family & Salicaceae \\
\hline Tribe & Salicaceae \\
\hline Genus & Salix \\
\hline
\end{tabular}

Table 1. Botanic classification.

The differences between Salix species also consists in the morphology of willows i. e. scrubs and trees naturally occur. In practice moist soils and mild climate conditions suits perfectly the demands of willows. 


\section{Salix viminalis - Conventional applications}

\subsection{Energetic utilization}

In the recent decades among all Salix genotypes particularly Salix viminalis gained most attention as a agriculturally cultivated plant due to its application as a green fuel. Several positive and negative aspects of such an application are summarized in table 2.

\begin{tabular}{|c|c|}
\hline Positive arguments & Negative arguments \\
\hline $\begin{array}{l}\text { High fertility and yield } \\
\text { High environmental tolerance } \\
\text { Long exploitation of plantations } \\
\text { Low labor consumption and advantageous } \\
\text { year schedule on labor demand during } \\
\text { cultivation } \\
\text { Improvement of local economy } \\
\text { Reduction of unemployment } \\
\text { Diversification of energy resources } \\
\text { Low capital consumption during vegetation } \\
\text { High energetic effectiveness } \\
\text { Reduced consumption of conventional fuels } \\
\text { Environment friendly biomass utilization for } \\
\text { energetic purposes } \\
\text { Exploitation of lie fallows } \\
\text { Efficient assimilation of heavy metals } \\
\text { Possible cultivation on soils unusable for } \\
\text { other crops } \\
\text { Possible reclamation of deteriorated lands } \\
\text { Constant price increase of fossil fuels } \\
\text { Increase of ecological awareness of the } \\
\text { society } \\
\text { Financial support from EU and local } \\
\text { institutions }\end{array}$ & $\begin{array}{l}\text { High cost of plantation lodging } \\
\text { Lost of financial fluency due to high cost of } \\
\text { the preliminary stage of undertaking } \\
\text { Difficult prediction of investment return } \\
\text { Lack of integrated bio-energy consumer } \\
\text { market } \\
\text { High transportation cost from plantation } \\
\text { Necessity of fast utilization after harvesting } \\
\text { Better cost efficiency of coal originated } \\
\text { energy } \\
\text { Energy overproduction } \\
\text { High cost of biomass agglomerate } \\
\text { fabrication } \\
\text { High volume of biomass } \\
\text { High nitrogen content in fresh harvested } \\
\text { biomass } \\
\text { High moisture content in fresh harvested } \\
\text { biomass } \\
\text { Threats resulting form monoculture } \\
\text { cultivation on large agriculture areas } \\
\text { Unexpected weather and climate changes } \\
\text { Damages caused by diseases and pests }\end{array}$ \\
\hline
\end{tabular}

Table 2. Selected positive and negative aspects of energetic willow (Salix viminalis) cultivation. Particular points in the table selected from the original content. Cited and translated after (Zabrocki \& Ignacek, 2008).

Many of the above mentioned arguments result in fact from economic, social and political background. Thus, the cultivation of Salix viminalis may definitely find numerous supporters but also opponents. However, positive features of Salix viminalis cultivation must be kept in mind since they may help to solve some critical environmental and social issues. In some countries the cultivation and usage of Energetic Willow is at very limited level (Poland). Some sources claim (Bio-energia, 2008) that overall Salix viminalis cultivation area does not exceed 6000 hectares. The share of Salix viminalis wood burned as a fuel in the total mass of burnable fuels is only ca. $2 \%$ high. The situation has not changed significantly in the last period despite of competitive energetic (table 3) and economic (table 4) parameters of the fuel. 


\begin{tabular}{|c|c|}
\hline Fuel & Heat of combustion [GJ/1000 kg] \\
\hline LPG & ca. 45 \\
\hline Fuel oil (light fraction) & ca. 42 \\
\hline Fuel oil (heavy fraction) & ca. 40 \\
\hline Black coal & ca. 27 \\
\hline Coke & ca. 25 \\
\hline Dry wood (incl. Energetic Willow) & ca. 19 \\
\hline Dry straw & ca. 15 \\
\hline
\end{tabular}

Table 3. Heat of combustion of selected fuels. The content of the table selected from the original material and translated (Iso-Tech, 2011).

\begin{tabular}{|c|c|c|c|c|}
\hline \multirow[b]{2}{*}{ Plant } & \multirow[b]{2}{*}{ Plantation no. } & \multirow{2}{*}{$\begin{array}{l}\text { Harvest } \\
\text { frequency* }\end{array}$} & \multicolumn{2}{|c|}{ Dry biomass price } \\
\hline & & & $\begin{array}{c}\text { Netto } \\
{\left[\mathrm{PLN}^{* *} / 1000 \mathrm{~kg}\right]}\end{array}$ & $\begin{array}{c}\text { Brutto } \\
{\left[\text { PLN }^{* *} / 1000 \mathrm{~kg}\right]}\end{array}$ \\
\hline \multirow{3}{*}{$\begin{array}{l}\text { Energetic } \\
\text { Willow }\end{array}$} & \multirow{3}{*}{8} & 1 & 367 & 491 \\
\hline & & 2 & 333 & 458 \\
\hline & & 3 & 253 & 356 \\
\hline \multirow{3}{*}{$\begin{array}{l}\text { Energetic } \\
\text { Willow }\end{array}$} & \multirow{3}{*}{9} & 1 & 346 & 447 \\
\hline & & 2 & 335 & 444 \\
\hline & & 3 & 247 & 337 \\
\hline
\end{tabular}

${ }^{*}$ Harvest frequency: 1 - each year, 2 - every 2 years, 3 - every 3 years

**PLN - currency of Poland, 1 EUR $=4$ PLN

Source: http://www.bio-energia.pl/

Table 4. Dry biomass prices in Poland. The content of the table selected from the original source and translated (Bio-energia, 2008).

Thus, $1000 \mathrm{~kg}$ of dry Salix viminalis wood offers amount of energy comparable to $700 \mathrm{~kg}$ of black coal of good quality. However, black coal mining is evidently associated with serious irreversible environmental damages what becomes more and more important issue nowadays. This is a next argument for increasing of biomass production and usage for energetic purposes. Energetic utilization of other plants from SRWC group like Plantanus occidentalis, Liquidambar styraciflua, Pennisetum purpureum, Erianthus arundenaceum, Panicum virgatum, Ricinus communis, Hibiscus cannabinnis, Populus deltoids, Pinus elliottii, Eucalypytus amplifolis, Eucalyptus grandis, or Pinus taeda is a much more rare case in the world scale and particularly in Europe where climate conditions are often the main limiting factor. In Europe, Salix viminalis wood seen as renewable source of "green fuel" has a one important competitor i. e. dry straw. Straw is a side product (ca. 20 billion $\mathrm{kg}$ per annum in Poland) of grains cultivation i. e. one of the most frequent agricultural activities (Gradziuk, 1999).

\subsection{Environment protection - Phytoremediation}

Phytoremediation of soil and waters is a task of numerous research projects and technological undertakings. Such attempts base on an unique feature of Salix viminalis i. e. the ability to effective uptake, deactivation and accumulation of relatively high amounts of 
heavy metals without loosing its vitality. The efficiency of metal ion accumulation is extraordinarily high if compared to other plants and microorganisms. Therefore Salix viminalis is often called "hyper-accumulator". This point let to state that Salix viminalis is an unique plant among other energetic plants which mainly offer only a high growth rate and mass production but are poor metal ion accumulators.

Memon et al., 2001 citing other authors stated that retention of heavy metals may be accounted to one the below mentioned technologies (Salt et al., 1995; Pilon-Smits \& Pilon, 2000):

1. Phytoextraction, in which metal-accumulating plants are used to transport and concentrate metals from soil into the harvestable parts of roots and above-ground shoots (Brown et al., 1994; Kumar et al., 1995).

2. Rhizofiltration, in which plant roots absorb, precipitate and concentrate toxic metals from polluted effluents (Smith \& Bradshaw, 1979); Dushenkov et al., 1995).

3. Phytostabilization, in which heavy metal tolerant plants are used to reduce the mobility of heavy metals, thereby reducing the risk of further environmental degradation by leaching into the ground water or by airborne spread (Smith \& Bradshaw, 1979; Kumar et al., 1995).

4. Plant assisted bioremediation, in which plant roots in conjunction with their rhizopheric microorganisms are used to remediate soils contaminated with organics (Walton \& Anderson, 1992; Anderson et al., 1993).

In the case of Salix viminalis the process of metal ion accumulation proceeds through a root system and ion transport involving vascular tissues in stems and differentiated distribution in the whole plant body. Permeation of ions into roots is a typical way of efficient metal ion collection by Salix viminalis. This a basis for practical utilization of Salix viminalis for purification of various matrixes (soli, water, etc.) being in contact with roots of the plant. Planting of Salix viminalis on metal contaminated soils and/or bringing the plant in contact with contaminated waters lead to slow but constant removal of the metal impurities and finally remediation of soil and waters.

According to Baker \& Walker, 1990 plants may follow three pathways when they grow on metal contaminated soils.

1. Metal excluders: aerial parts of these plants are free from metal contamination despite of high concentration of them in the soil and in the roots.

2. Metal indicators: such plants accumulate metals in their aerial parts and the concentration of metals depends on the metal content in the soil.

3. Accumulators and hyperaccumulators: These plants concentrate metals in their aerial part but the metal content in the tissues exceeds metal content in the soil. A plant capable to accumulate more than $0.1 \%$ of $\mathrm{Ni}, \mathrm{Co}, \mathrm{Cu}, \mathrm{Cr}$ or $\mathrm{Pb}$ or $1 \%$ of $\mathrm{Zn}$ (despite of differences in metal content in the soil) in its leaves (dry mass) is called a hyperaccumulator. Salix viminalis, according to our earlier studies, may be accounted to the accumulators / hyperaccumulators category. Figs 1 and 2 present (Łukaszewicz et al., 2009) some of our results on the concentration of selected metal ions $\left(\mathrm{Zn}^{2+}, \mathrm{Cu}^{2+}\right.$, $\mathrm{Cr}^{3+}$ ) in different parts of Salix viminalis rods after a certain time of contact with water solutions of the ions.

Table 5 shows that example heavy metal ions $\left(\mathrm{Cu}^{2+}\right)$ penetrate all important parts of Salix viminalis. The ion penetration and the resulting copper accumulation increase with increasing concentration of $\mathrm{Cu}^{2+}$ in an artificial soil. Plants were incubated in complete 
Knop's medium (Reski \& Abel, 1985) containing copper salt at 0, 0.5, 1.0, 1.5, 2.0, 2.5, 3.0 $\mathrm{mM}$ stabilized with quartz sand in hydroponic pots. It is also visible that roots and rods (stems) i. e. plant parts responsible for metal ion transportation accumulate copper ions more intensively that new shots and leaves. The latter parts are rather a final location of metal ions and do not participate significantly in the ion transportation. Table 5 informs about biometric changes of the plants exposed to $\mathrm{Cu}^{2+}$ infiltration. The plants were still living but shots, leaves and roots underwent a gradual degradation consisting in reduction of mass and/or dimensions. Table 6 (Mleczek et al., 2009) considers the dependence between the kind of metal ion and its accumulation in different tissues. No strict correlation is visible except general tendency to intensive accumulation of cadmium and chromium.

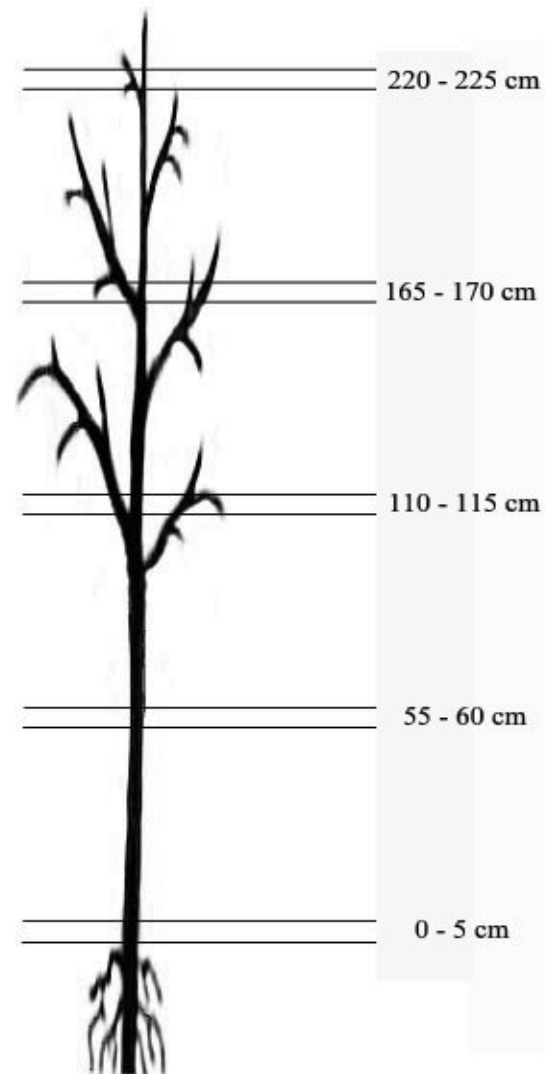

Fig. 1. Sampling wood material from Salix viminalis species planted in metal ions solutions. (Eukaszewicz et al., 2009). 


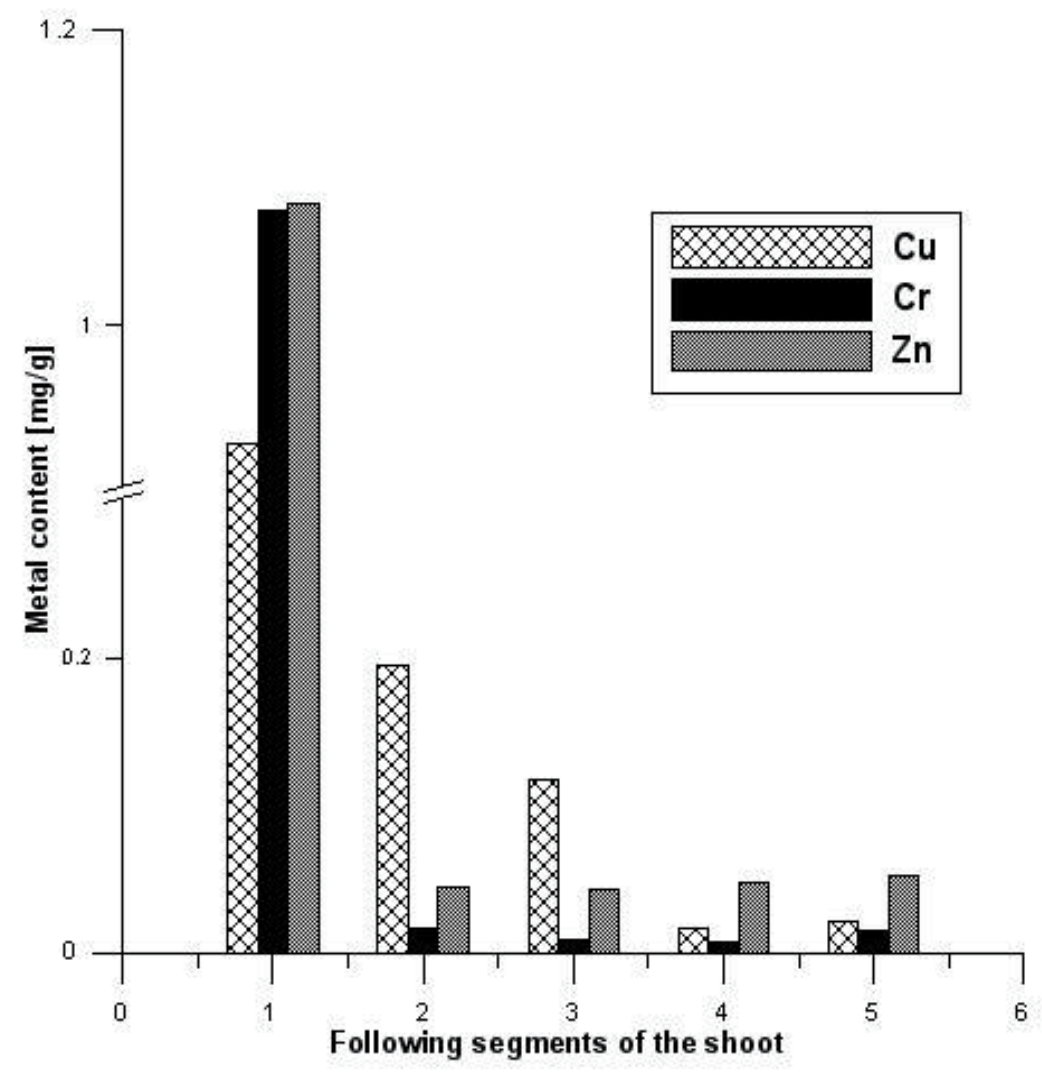

Fig. 2. Metal content in following segments of shoots (distance from rhizosphere: $1.1-5 \mathrm{~cm}$; $2.55-60 \mathrm{~cm} ; 3.110-115 \mathrm{~cm} ; 4.165-170 \mathrm{~cm} ; 5.220-225 \mathrm{~cm}$ ). (Łukaszewicz et al., 2009).

During the experiment young shoots of Salix viminalis after defoliation were put into vessels with water and left until fresh leaves and root sprouted. Selected plants were moved to glass vessels filled with $\mathrm{Cu}, \mathrm{Cr}$ and $\mathrm{Zn}$ salts solutions (0.01 M each). Additionally, chelation agent i. e. EDTA in water solution was added in the amount calculated basing on the assumption that EDTA was capable to form bichelates. According to some authors (Blaylock et al., 1997) plants should be more tolerant to chelated metal ions since after complexation their toxicity is lower. However, there is no common agreement about the positive influence of chelation on the metal ion uptake by Salix viminalis. After 7 days the plants were taken form the vessels and appropriate parts of stems (wood samples) were cut and subjected to elemental analysis (fig. 2). It is visible that metal ions enter the aerial part of Salix viminalis but the concentration of metals depends on the height above the ground level. Some studies point out differentiated distribution of metal ions in roots, stem, leaves etc. Tables 5 and 6 present such a kind of data (Gąsecka et al., 2010). 


\begin{tabular}{|c|c|c|c|c|c|c|c|c|c|}
\hline $\begin{array}{c}\mathrm{Cu} \\
\text { addition } \\
{[\mathrm{mM} /} \\
\mathrm{dm} 3\end{array}$ & \multicolumn{3}{|c|}{$\begin{array}{c}\mathrm{C} \text { accumulation (dry weight) } \\
{[\mathrm{mg} / \mathrm{kg}]}\end{array}$} & $\begin{array}{c}\text { Leaves } \\
\text { length } \\
{[\mathrm{cm}]}\end{array}$ & $\begin{array}{c}\text { Total } \\
\text { leaves } \\
\text { surface } \\
{\left[\mathrm{cm}^{2}\right]}\end{array}$ & $\begin{array}{c}\text { Shoots } \\
\text { length } \\
{[\mathrm{cm}]}\end{array}$ & $\begin{array}{c}\text { Roots } \\
\text { length } \\
{[\mathrm{cm}]}\end{array}$ & $\begin{array}{c}\text { Roots } \\
\text { biomass } \\
{[\mathrm{g}]}\end{array}$ \\
\hline 0 & 0.22 & 0.28 & 0.48 & 1.47 & 6.58 & 194.9 & 9.69 & 9.76 & 11.57 \\
\hline 0.5 & 0.84 & 1.69 & 3.27 & 3.89 & 4.24 & 182.0 & 8.91 & 6.18 & 3.39 \\
\hline 1.0 & 1.65 & 2.46 & 5.38 & 5.25 & 3.97 & 181.3 & 8.77 & 5.69 & 2.66 \\
\hline 1.5 & 2.79 & 2.93 & 8.84 & 6.37 & 3.71 & 179.0 & 8.13 & 4.36 & 2.37 \\
\hline 2.0 & 3.46 & 3.56 & 10.61 & 7.44 & 3.65 & 174.7 & 7.47 & 4.34 & 1.84 \\
\hline 2.5 & 4.22 & 3.90 & 13.51 & 8.17 & 3.42 & 174.6 & 7.55 & 3.99 & 1.82 \\
\hline 3.0 & 4.30 & 4.69 & 15.38 & 9.46 & 3.41 & 171.8 & 5.93 & 3.82 & 0.82 \\
\hline
\end{tabular}

Table 5. Copper accumulation in Salix viminalis L. organs and biomass parameters for subsequent levels of copper addition to the growing medium - mean values $(n=3)$. Selected data cited after (Gąsecka et al., 2010).

\begin{tabular}{|c|c|c|c|c|c|c|c|}
\hline Tissue & \multicolumn{6}{|c|}{ Decreasing metal accumulation abilities of tissues (from left to Wright) } \\
\hline Root & $\mathrm{Zn}$ & $\mathrm{Cd}$ & $\mathrm{Pb}$ & $\mathrm{Cu}$ & $\mathrm{Co}$ & $\mathrm{Cr}$ & $\mathrm{Ni}$ \\
\hline Bark & $\mathrm{Cu}$ & $\mathrm{Cd}$ & $\mathrm{Zn}$ & $\mathrm{Co}$ & $\mathrm{Pb}$ & $\mathrm{Cr}$ & $\mathrm{Ni}$ \\
\hline Leaf & $\mathrm{Ni}$ & $\mathrm{Cr}$ & $\mathrm{Co}$ & $\mathrm{Zn}$ & $\mathrm{Pb}$ & $\mathrm{Cu}$ & $\mathrm{Cd}$ \\
\hline Petioles & $\mathrm{Cd}$ & $\mathrm{Cr}$ & $\mathrm{Zn}$ & $\mathrm{Cu}$ & $\mathrm{Pb}$ & $\mathrm{Ni}$ & $\mathrm{Co}$ \\
\hline Shoot $(0.1 \mathrm{~m})$ & $\mathrm{Cu}$ & $\mathrm{Cr}$ & $\mathrm{Zn}$ & $\mathrm{Cd}$ & $\mathrm{Pb}$ & $\mathrm{Ni}$ & $\mathrm{Co}$ \\
\hline Shoot $(1 \mathrm{~m})$ & $\mathrm{Cd}$ & $\mathrm{Cr}$ & $\mathrm{Cu}$ & $\mathrm{Pb}$ & $\mathrm{Ni}$ & $\mathrm{Zn}$ & $\mathrm{Co}$ \\
\hline
\end{tabular}

Table 6. Heavy metal accumulation in different tissues of Salix materials. The table content cited after (Mleczek et al. 2009) with no changes. 
High metal ion accumulation is not an exclusive feature of Salix viminalis. Other Salix genotypes may exhibit high accumulation capacities towards different heavy metal ions (table 7) with particular emphasis on $\mathrm{Zn}^{2+}$ accumulation (Mleczek et al., 2010).

\begin{tabular}{|l|c|c|c|c|c|c|c|c|}
\hline \multirow{2}{*}{ Salix genotype } & \multicolumn{7}{|c|}{ Metal kontent in Salix genotypes [mg / kg] (dry mass) } \\
\cline { 2 - 9 } & & $\mathrm{Cd}$ & $\mathrm{Co}$ & $\mathrm{Cr}$ & $\mathrm{Cu}$ & $\mathrm{Ni}$ & $\mathrm{Pb}$ & Zn \\
\hline Salix purpurea var. & before & 0.86 & 0.134 & 0.67 & 6.54 & 3.05 & 1.93 & 65.72 \\
Angustifilia Kerner & after & 1.48 & 0.218 & 0.94 & 7.88 & 8.45 & 2.15 & 70.02 \\
\hline Salix purpurea L. & before & 1.64 & 0.112 & 0.99 & 5.72 & 3.08 & 5.62 & 91.46 \\
Nigra longifolia & after & 1.75 & 0.240 & 1.27 & 6.73 & 9.28 & 6.07 & 96.34 \\
pendula & & & & & & & & \\
\hline Salix purpurea $L$. & before & 2.19 & 0.050 & 2.29 & 7.94 & 4.66 & 2.16 & 57.19 \\
Green Dicks & after & 2.47 & 0.098 & 2.51 & 7.98 & 7.49 & 2.51 & 60.86 \\
\hline Salix purpurea L. & before & 1.77 & 0.058 & 1.91 & 7.01 & 4.18 & 1.11 & 58.33 \\
Uralensis & after & 2.42 & 0.122 & 2.32 & 7.49 & 4.86 & 1.39 & 60.65 \\
\hline Salix alba L. & before & 1.58 & 0.050 & 2.21 & 4.22 & 4.25 & 1.47 & 97.48 \\
Kanon & after & 1.87 & 0.095 & 3.04 & 6.47 & 8.44 & 1.53 & 103.21 \\
\hline Salix purpurea var. & before & 1.87 & 0.054 & 0.55 & 8.12 & 3.74 & 1.93 & 94.28 \\
Schultze Schultze & after & 2.03 & 0.124 & 1.02 & 11.51 & 5.46 & 2.29 & 98.33 \\
\hline Salix fragilis L. & before & 0.89 & 0.057 & 2.02 & 9.35 & 3.51 & 0.97 & 81.48 \\
Kanon & after & 1.06 & 0.129 & 2.47 & 10.87 & 7.75 & 1.27 & 84.79 \\
\hline Salix petiolaria & before & 1.21 & 0.093 & 3.16 & 5.24 & 2.28 & 2.05 & 62.49 \\
Rigida & after & 1.58 & 0.174 & 3.78 & 8.89 & 5.46 & 2.40 & 68.92 \\
\hline Salix purpurea & before & 1.57 & 0.026 & 1.61 & 7.13 & 1.97 & 2.88 & 91.37 \\
233 & after & 1.82 & 0.049 & 2.32 & 10.37 & 3.24 & 3.11 & 98.45 \\
\hline Salix nigra Marsch & before & 0.61 & 0.036 & 0.59 & 8.26 & 6.42 & 1.42 & 102.47 \\
& after & 0.78 & 0.048 & 1.33 & 10.19 & 8.45 & 1.76 & 112.27 \\
\hline Salix japonica & before & 1.51 & 0.069 & 2.74 & 6.79 & 3.68 & 2.07 & 84.25 \\
& after & 1.97 & 0.151 & 3.54 & 8.31 & 7.58 & 2.30 & 89.55 \\
\hline Salix purpurea & before & 0.47 & 0.037 & 2.07 & 4.71 & 1.19 & 1.41 & 37.91 \\
Utilissima & after & 0.92 & 0.059 & 3.18 & 6.95 & 2.73 & 1.76 & 44.51 \\
\hline
\end{tabular}

Table 7. Concentration of heavy metals in young shoots of 12 Salix genotypes before and after experiment (hydroponic estimation of heavy metal accumulation). Table cited after (Mleczek et al., 2010) with no changes.

Mechanism of heavy metal intrusion, transportation, deactivation and accumulation has been investigated intensively over many years (Shah \& Nongkynrih, 2007; Memon et al., 2001; Lasat, 2001, Clemens, 2006). Fig. 3 illustrates the complex nature of the processes. Shah \& Nongkynrih, 2007 recall several basic mechanism of metal ion assimilation among which chelating plays a crucial role. Many substances (chelators) occurring in plant cells contain typical chelating (ligand) atoms like oxygen, nitrogen and sulfur ones. Chelators contribute to metal ion detoxification. Other functional compounds called chaperones specifically deliver metal ions to organelles and metalrequiring. The principal metal chelators in plants are phytochelatins, metallothioneins, organic acids and amino acids. Shah \& Nongkynrih, 2007 after some other authors state that phytochelatins are small metal-binding peptides which formation involves glutathione, homoglutathione, hydroxymethyl-glutathione or gammaglutamylcysteine. Metallothioneins are low molecular mass cysteine (cys)-rich proteins, that 
bind metal ions in metal-thiolate clusters. Over 50 metallothioneins has been identified so far in plants. Organic acids and amino acids because of $\mathrm{N}$ and $\mathrm{O}$ content may chelate intensively various metal ions. Shah \& Nongkynrih, 2007 claim that "citrate, malate, and oxalate have been implicated in a range of processes, including differential metal tolerance, metal transport through xylem and vacuolar metal sequestration". Salicylic acid and its derivatives which are definitely present in Salix viminalis tissues, has been also identified as chelating agent in some plants. For Salix viminalis naturally high concentration of the latter species is probably the key factor providing hyperaccumulating properties of the plant.

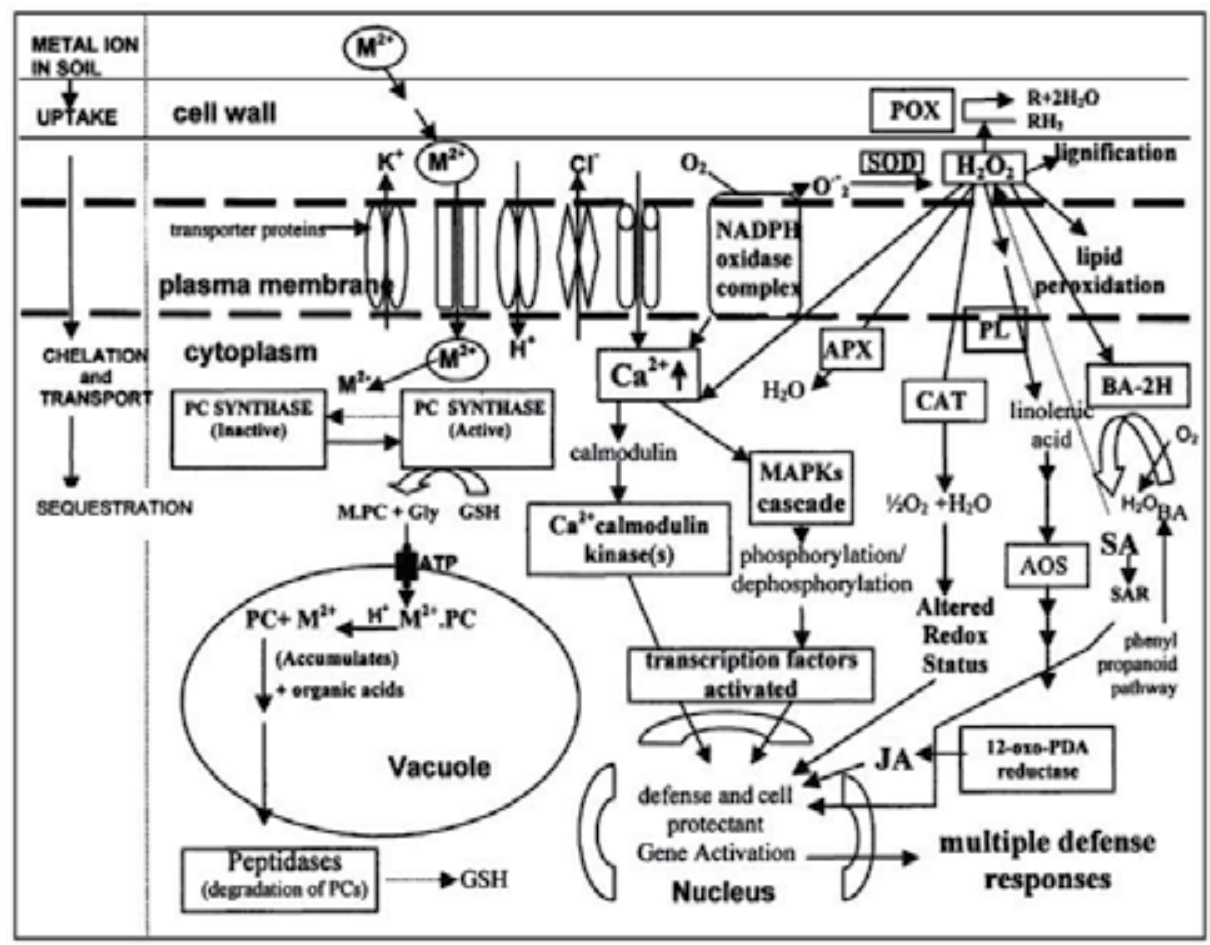

Fig. 3. A model of the mechanisms that occur in plant cell upon exposure to metals: metal ion uptake, chelation, transport, sequestration, signalling and signal transduction. The diagram shows the uptake of metal ions by $\mathrm{K}+$ efflux and transporter proteins, their sequestration by formation of PCs by enzyme PC synthase and GSH in vacuoles, the subsequent degradation of PC-peptides by peptidases to release GSH, the generation of ROI species, the contribution of $\mathrm{Ca}^{2+}$ towards activation of $\mathrm{Ca}^{2+} /$ calmodulin kinase(s) and MAP kinase(s) cascade leading to defense gene activation in nucleus, the effect of ROI on natural plant defense pathways like octadecanoid pathway (JA) and phenyl propanoid pathway (SA) biosynthesis that lead to defense and cell protectant gene activation is also included to correlate the induced metal stress defense with natural plant defense mechanism. AOS - allene oxide synthase; APX ascorbate peroxidase; BA - benzoic acid; BA-2H - benzoic acid 2-hydroxylase; CAT - catalase; GSH - glutathione; JA - jasmonic acid; $\mathrm{M}^{2+}$ - metal ions; MAPK - mitogen activated protein kinase; 12-oxo PDA reductase - 12-oxo-cis-10,15-phytodienoic acid reductase; PC phyochelatin; PL - phospholipase; POX - peroxidase; SA - salicylic acid; SOD - superoxide dismutase. The figure and the caption cited with no changes after Shah \& Nongkynrih, 2007. 
Memon et al., claim that the application of biological metal-accumulators and metalhyperaccumulators for purification of soils and waters has several positive features like "low cost, generation of a recyclable metal-rich plant residue, applicability to a range of toxic metals and radionuclides, minimal environmental disturbance, elimination of secondary air or water-borne wastes, and public acceptance". The latter statement applies in full to Salix viminalis, too. Table 8 proves that $\mathrm{Cd}$ removal from soil is extraordinarily high $(217 \mathrm{~g} / \mathrm{ha})$ if compared to other phytoaccumulators tested in the study (Porębska \& Ostrowska, 1999). Also the concentration of the metal in dry Salix viminalis wood was very high $(22.1 \mathrm{mg} / \mathrm{kg})$ exceeding values found in our study Łukaszewicz et al., 2009.

\begin{tabular}{|c|c|c|c|}
\hline Plant & $\begin{array}{c}\text { Biomass } \\
{[\mathrm{t} / \mathrm{ha}]}\end{array}$ & $\begin{array}{c}\text { Metal content } \\
{[\mathrm{mg} / \mathrm{kg}]} \\
\text { (dry weight })\end{array}$ & $\begin{array}{c}\text { Metal removal } \\
{[\mathrm{g} / \mathrm{ha}]}\end{array}$ \\
\hline Thlaspi caerulescens & 2.93 & 12.1 & 35 \\
\hline Alyssum murale & 1.32 & 33.7 & 217 \\
\hline Salix viminalis & 10.00 & 22.1 & 47 \\
\hline Potato - tuber & 14.77 & 3.2 & 2 \\
\hline Barley - straw & 4.95 & 2.4 & 4 \\
\hline Barley - grain & 3.14 & 0.70 & 1.14 \\
\hline White clover & 3.52 & & 43 \\
\hline
\end{tabular}

Table 8. Estimated removal of $\mathrm{Cd}$ with the biomass. Selected data cited and translated after Porębska \& Ostrowska, 2009.

\section{Unconventional application of Salix viminalis}

\subsection{Fabrication of adsorbents and catalysts}

The above described proved efficiency in metal ion accumulation by Salix viminalis led to a novel concept of non-energetic use of the plant. In some earlier studies (Łukaszewicz \& Wesołowski, 2008) authors have discovered that thermal treatment (oxygen free conditions) of dry Salix viminalis wood yields charcoals of a very original and potentially useful pore structure. Usually a two step procedure was applied:

- 1 hour long preliminary carbonization in an inert gas atmosphere at $600{ }^{\circ} \mathrm{C}$,

- 1 hour long secondary carbonization in an inert gas atmosphere at a desired temperature ranging from 600 to $900{ }^{\circ} \mathrm{C}$.

The pore structure of such obtained charcoals is characteristic because of a very narrow pore size distribution function (PSD) i. e. only pores of not differentiated dimensions contribute to the total pore volume (figs 4, 5 and 6). The calculated dimensions of pores let to call such fabricated charcoals "nanoporous Carbon Molecular Sieves" (CMS). 


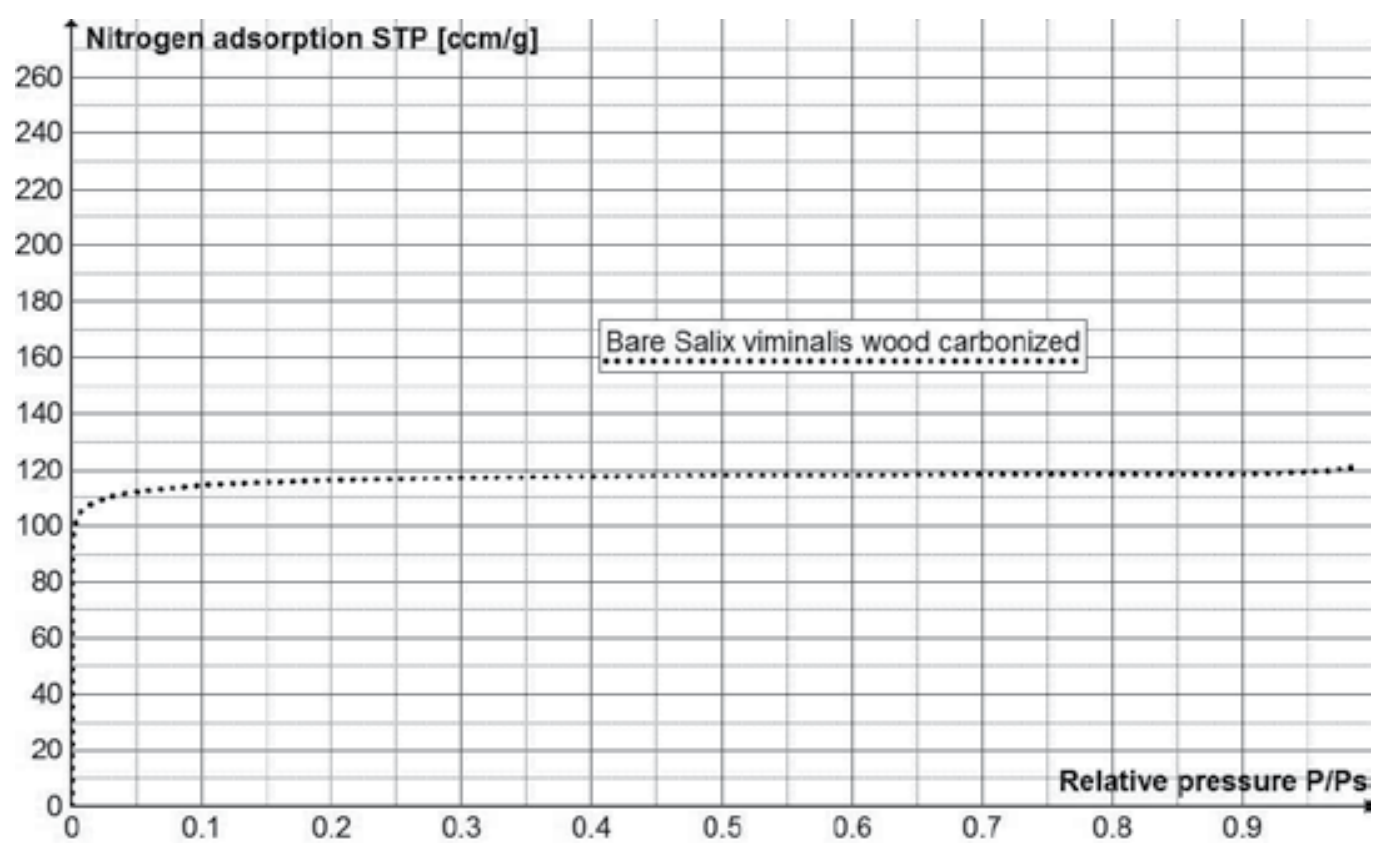

Fig. 4. Nitrogen adsorption isotherm at $-196{ }^{\circ} \mathrm{C}$ for bare Salix viminalis wood finally carbonized at $700{ }^{\circ} \mathrm{C}$. I type isotherm characteristic for the presence of nanopores.

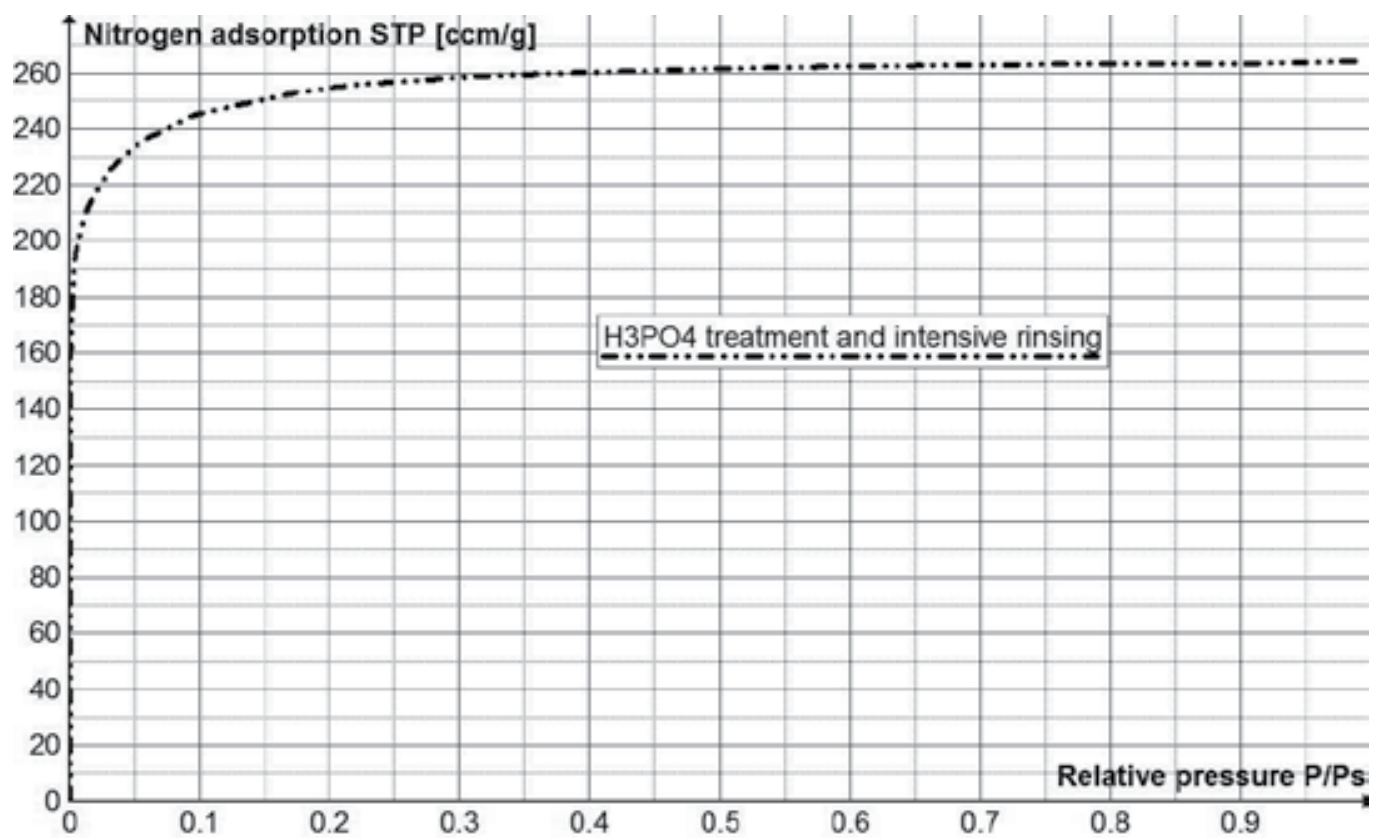

Fig. 5. Nitrogen adsorption isotherm at $-196^{\circ} \mathrm{C}$ for activated Salix viminalis wood (phosphoric acid treatment) finally carbonized at $700^{\circ} \mathrm{C}$. I type isotherm characteristic for the presence of nanopores. 


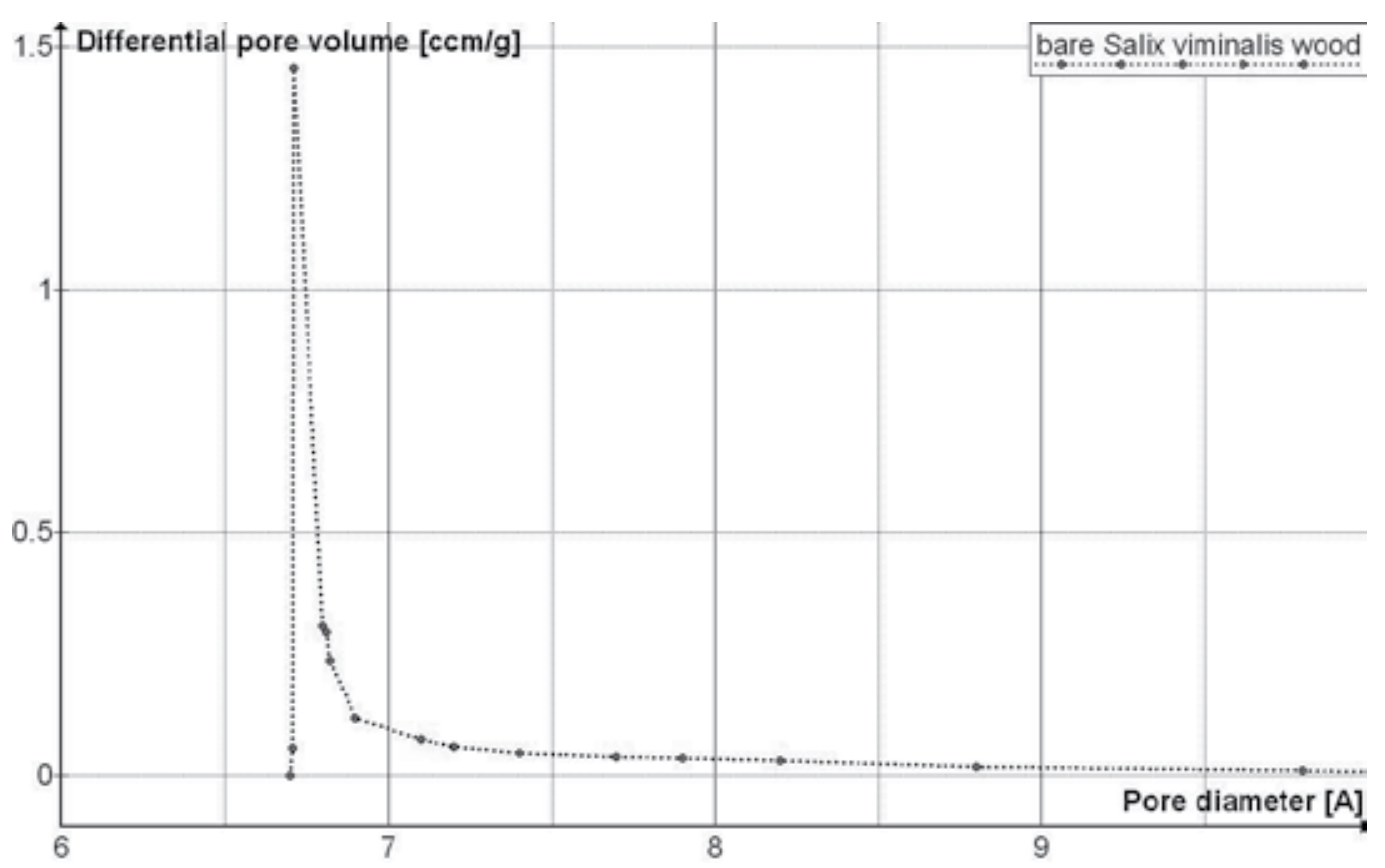

Fig. 6. Pore size distribution function (PSD) determined from low temperature $\left(-196^{\circ} \mathrm{C}\right)$ nitrogen adsorption data by means of Hortvath-Kawazoe method (Horvath \& Kawazoe, 1983).

The Salix viminalis originated CMSs proved their sieving properties in gas mixture separation to single components in chromatographic conditions (Gorska, 2009). For example table 9 contains separation coefficients determined for $\mathrm{N}_{2} / \mathrm{CH}_{4}$ binary gas mixture over two example Salix viminalis originated CMSs of similar surface area. The separation is of industrial importance since natural gas resources are often contaminated by nitrogen which high content may reduce commercial value of methane. The values are dramatically bigger than 1 at all investigated temperatures i. e. 30, 40,50, 60 and $70{ }^{\circ} \mathrm{C}$. It is to emphasize that separation is very efficient at highest temperature of $70{ }^{\circ} \mathrm{C}$. It is particularly important regarding a potential application of such carbons as and adsorbing bed in a PSA (Pressure Swing Adsorption) installation. In the PSA method, the first step consists in the compression of a gas mixture to be separated in the adsorbing chamber (filled with CMS). Gas compression is an exothermal process leading to the warming of gases and carbon adsorbent what is an undesired phenomenon since separation at high temperature is generally much worse since PSA separation of air is very temperature sensitive (Japan EnviroChemicals Ltd., 2011). 
The described fabrication of CMSs does not exploit both unique features of Salix viminalis i. e. the unique ability of Salix viminalis biomass transformation into a CMS and the Salix viminalis ability to heavy metal ion accumulation. Both feature were exploited in the case of a series of hybrid carbon-metal oxide catalysts obtained according to the fabrication procedure proposed recently by Łukaszewicz et al., 2007. The novelty of the method consists in the exploitation of natural phenomenon of metal ion transportation in living plants for the introduction of a metal-based catalytic phase. Metal ions, after introduction to transport-responsible tissues in a living plant (Salix viminalis), are transported to the plant cells. The process was efficient since Salix viminalis was highly tolerant to the presence of heavy metal ions in its body. Freshly cut ca. $20 \mathrm{~cm}$ longs sections of a stem (rootless) of Salix viminalis were immersed (vertical alignment) in a water solution containing equimolar quantities of $\mathrm{La}\left(\mathrm{NO}_{3}\right)_{3}$ and $\mathrm{Mn}\left(\mathrm{NO}_{3}\right)_{2}$ (example concentrations: $0.001 \mathrm{M}, 0.01 \mathrm{M}, 0.1 \mathrm{M})$. The stems were fresh enough to preserve intensive metal ion transport resulting in a gradual rise of the solution along the treated stems. A contrast dye was added to the solutions in some experiments to provide eye observation of the capillary rise of solutions along the treated stems. One the other hand, the length of stems was short enough to avoid differentiated distribution of metal ions in the stem what might be expected regarding some former tests (see figs 1 and 2). After the contact with $\mathrm{La}^{3+}$ and $\mathrm{Mn}^{2+}$ ion solutions, the metal saturated stems were dried, diminished and carbonized $\left(600-800{ }^{\circ} \mathrm{C}\right.$, a two-step procedure) in an inert gas atmosphere $\left(\mathrm{N}_{2}\right)$. The first carbonization let to expel volatile species and to transform the wood (lignin-cellulose matrix) into carbon matrix (CMS resembling), consisting mainly of $\mathrm{C}, \mathrm{O}, \mathrm{N}$ and $\mathrm{H}$ atoms (Gorska, 2009). The next heat treatment $\left(1 \mathrm{~h}, \mathrm{~N}_{2}\right.$ flow) at the temperature of $800{ }^{\circ} \mathrm{C}$ did not destroy already developed pore structure (preliminary carbonization) and, what is the most important, it enabled the transformation of introduced metal ions into the corresponding metal clusters. XPS and XRD analysis (Cyganiuk et al., 2010) proved that a complex oxide $\mathrm{LaMnO}_{3}$ was synthesized from introduced ions. SEM and HRTEM investigations proved that the provskite-type oxide is present in such obtained samples in form of inorganic nano-crystallites suspended in carbon matrix, which in general was an amorphous material with few graphite nano-crystallites (figs 7 an 8).

\begin{tabular}{|c|c|c|c|c|}
\cline { 2 - 5 } \multicolumn{1}{c|}{} & \multicolumn{2}{c|}{ Carbon $1\left[\mathrm{~S}_{\mathrm{BET}}=312 \pm 9.5 \mathrm{~m}^{2} / \mathrm{g}\right]$} & \multicolumn{2}{c|}{ Carbon $2\left[\mathrm{~S}_{\mathrm{BET}}=358 \pm 10.94 \mathrm{~m}^{2} / \mathrm{g}\right]$} \\
\hline Temp $\left[{ }^{\circ} \mathrm{C}\right]$ & $\mathrm{Rs}$ & $\pm \Delta \mathrm{Rs}$ & $\mathrm{Rs}$ & $\pm \Delta \mathrm{Rs}$ \\
\hline 70 & 3.64 & 0.31 & 4.80 & 0.75 \\
\hline 60 & 3.55 & 0.24 & 4.71 & 0.26 \\
\hline 50 & 3.74 & 0.62 & 4.91 & 0.19 \\
\hline 40 & 3.83 & 0.53 & 5.25 & 3.52 \\
\hline 30 & 4.17 & 0.34 & 5.87 & 0.01 \\
\hline
\end{tabular}

Table 9. Separation factors determined the separation of $\mathrm{N}_{2} / \mathrm{CH}_{4}$ binary gas mixtures. Separating medium - Salix viminalis originated carbons. Specific surface area $S_{\mathrm{BET}}$ determined by BET method from low temperature $\left(-196{ }^{\circ} \mathrm{C}\right)$ nitrogen adsorption. Calculated from data collected by Gorska, 2009. 


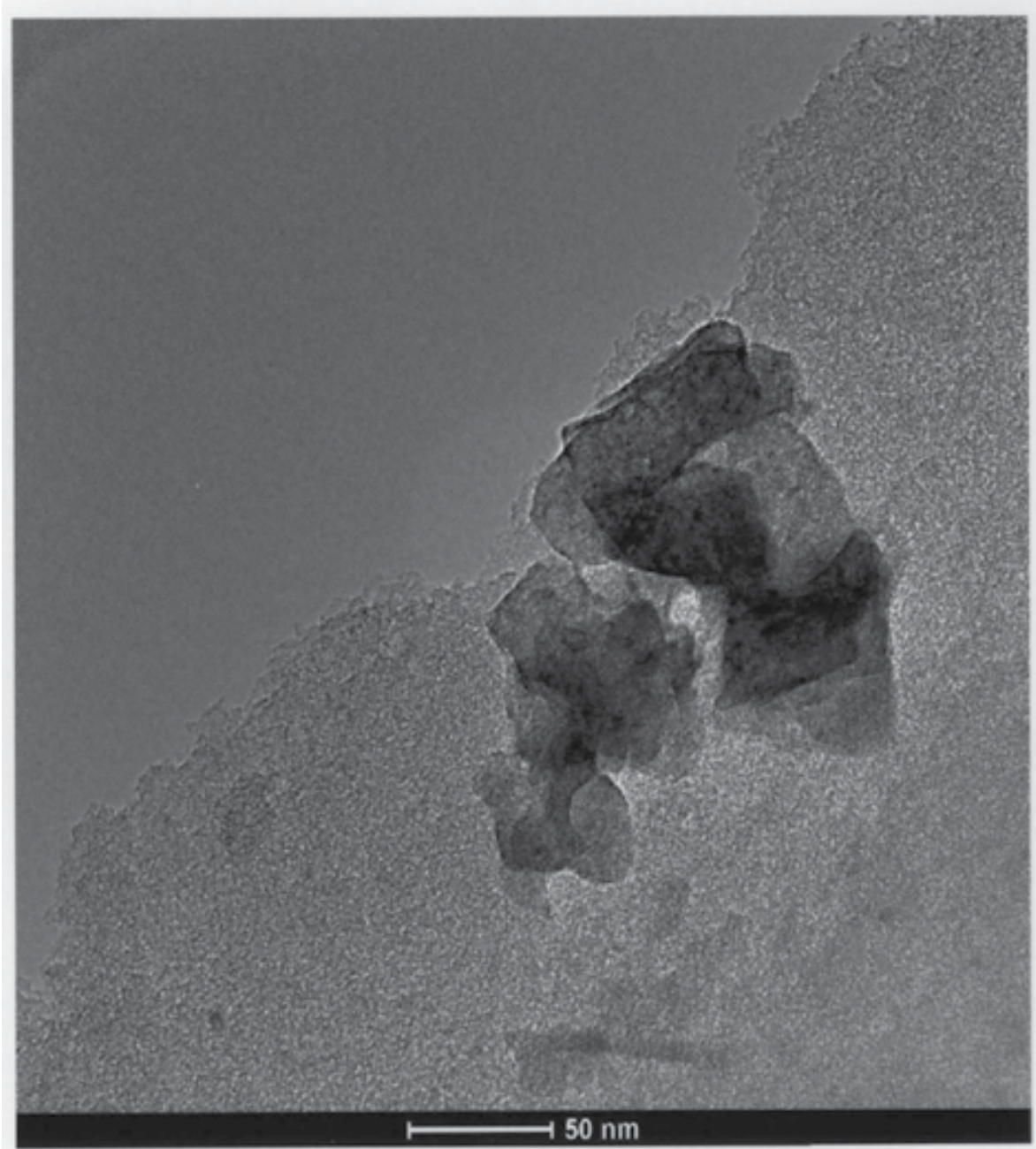

Fig. 7. HRTEM image of a $\mathrm{LaMnO}_{3}$ crystallite embedded in the carbon matrix. 


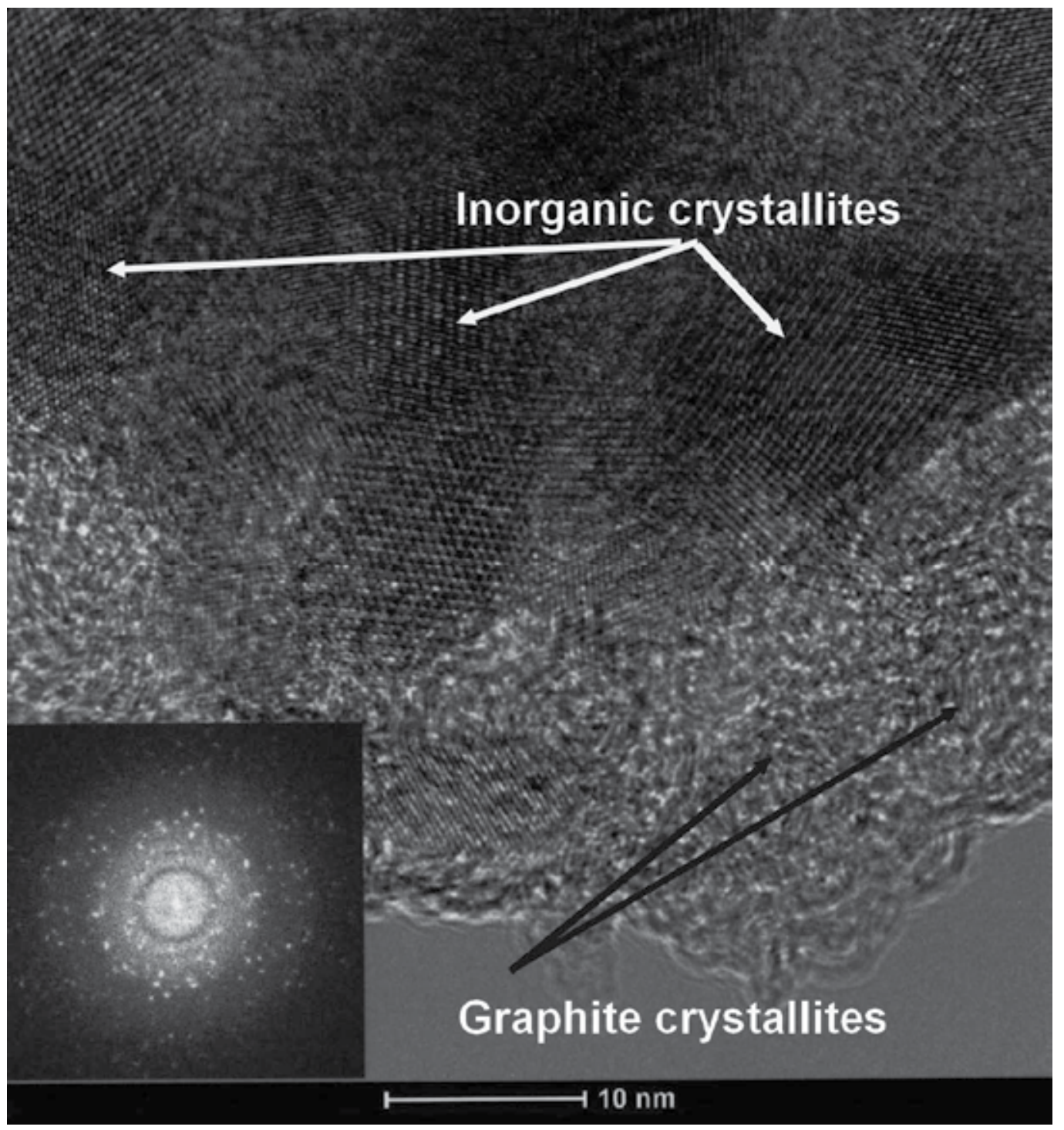

Fig. 8. HRTEM image of a $\mathrm{LaMnO}_{3}$ crystallite embedded in the carbon matrix. Crystalline domains (graphite crystallites) visible in the amorphous carbon matrix. 

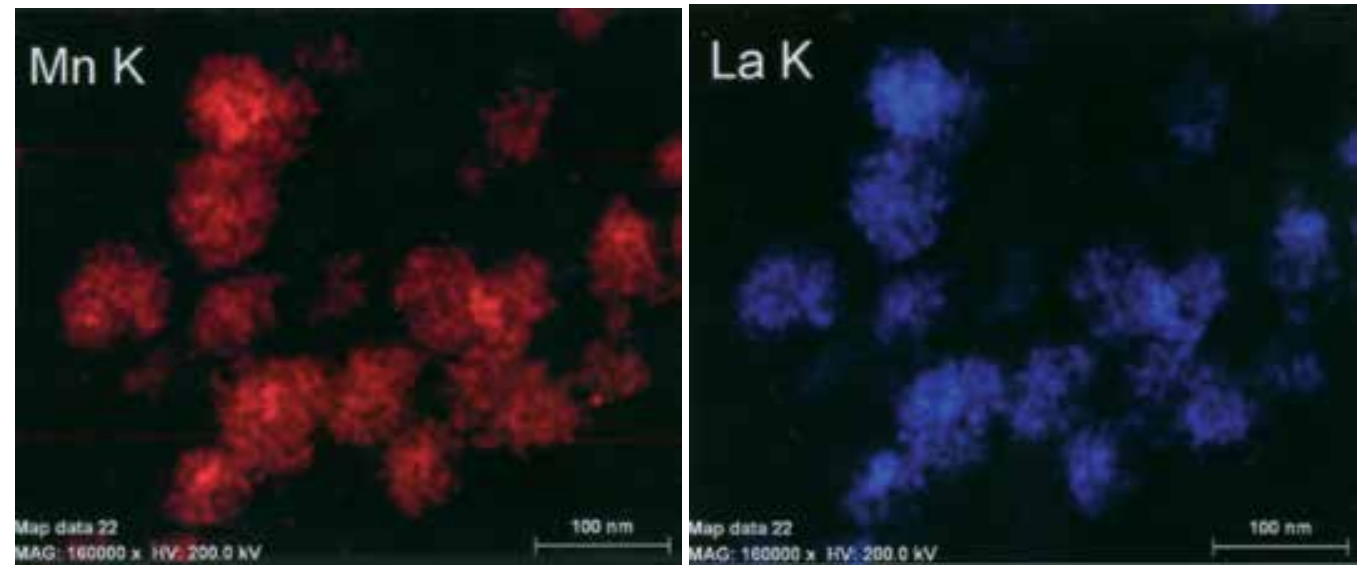

Fig. 9. Identical distribution of $\mathrm{Mn}$ (left) and $\mathrm{La}$ (right) atoms in hybrid $\mathrm{C} / \mathrm{LaMnO}_{3}$ catalyst.
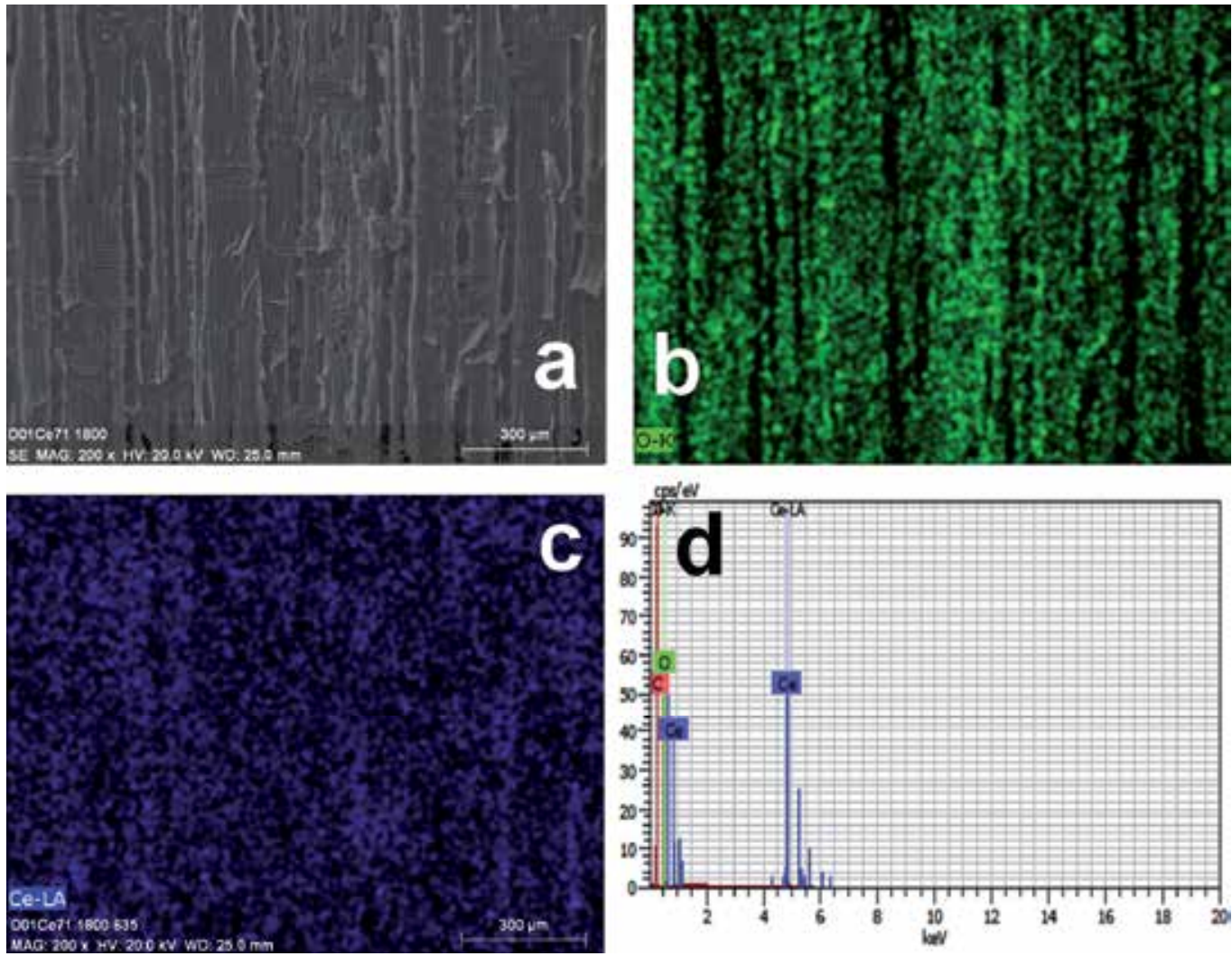

Fig. 10. SEM and SEM-EDS/EDX analysis of hybrid C/Ce catalysts obtained from Salix viminalis: a - SEM micrograph, $\mathrm{b}$-distribution of oxygen atoms determined by SEMEDS/EDX, c - distribution of cerium atoms determined by SEM-EDS/EDX, d - elemental analysis of the hybrid material. 

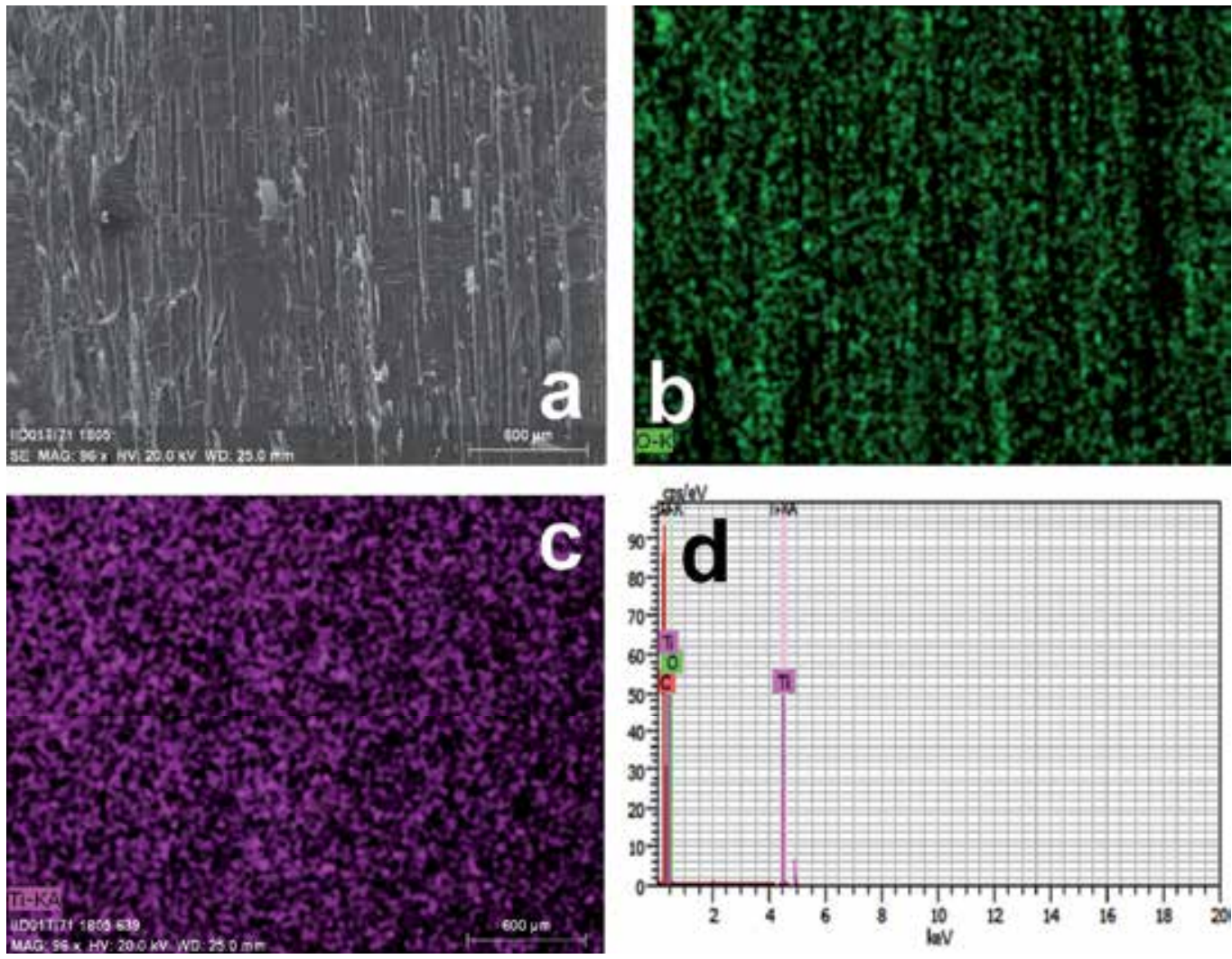

Fig. 11. SEM and SEM-EDS/EDX analysis of hybrid C/Ti catalysts obtained from Salix viminalis: a - SEM micrograph, $\mathrm{b}$-distribution of oxygen atoms determined by SEMEDS/EDX, c - distribution of titanium atoms determined by SEM-EDS/EDX, d - elemental analysis of the hybrid material.

Such obtained hybrid materials were tested as catalysts for n-butanol conversion to a 4heptanone according to the reaction:

\section{$2 \mathrm{RCH}_{2} \mathrm{OH} \rightarrow 2 \mathrm{RCHO} \rightarrow \mathrm{RCOR}$}

The catalysts exhibited very good catalytic performance despite very low concentration of the active component i. e. a perovskite-type oxide $\mathrm{LaMnO}_{3}$ (atomic content below 1\%). The noticed high activity i. e. yield and selectivity (Cyganiuk et al., 2010) resulted from very high dispersion of the active phase understood as:

- $\quad$ - reduced size of $\mathrm{LaMnO}_{3}$ crystallites (10-100 nm),

- $\quad$ - uniform distribution of both metals in the carbon matrix (fig. 9).

Similarly, titanium and cerium based hybrid materials were obtained by exploitation of metal ion transportation in living parts of Salix viminalis (ca. $20 \mathrm{~cm}$ long stem sections). Figs 10 and 11 depict uniform distribution of $\mathrm{Ce}$ and $\mathrm{Ti}$ atoms in a carbon matrixes. Their occurrence is accompanied by oxygen atoms however the latter are a usual constituent of carbon matrixes and can not be exclusively associated with $\mathrm{Ce}$ and $\mathrm{Ti}$ in the form of metal oxides. Elemental analysis data definitely prove (figs 10 and 11 ) that $\mathrm{Ce}$ and $\mathrm{Ti}$ are present in investigated hybrid 
samples and their presence result only from the performed fabrication procedure. The elements are relatively rare and have not been found in the samples of non-impregnated but carbonized Salix viminalis wood. Also in this case the atomic content of the metals is very low $i$. e. definitely below $1 \%$ despite of the concentration of impregnating solution. Thus, the proposed exploitation of metal ion transport in living parts of Salix viminalis ensures rather low level of impregnation but of very high dispersion. The Ti and Ce containing hybrid materials were tested as catalysts, too. Both materials despite of the same properties of carbon component of them, exhibited dramatically different catalytic activity:

- Ti/C hybrids towards dehyration of n-alcohols (n-butanol conversion to butane, ca. $55 \%$ selectivity at $460{ }^{\circ} \mathrm{C}$ ),

- $\quad \mathrm{Ce} / \mathrm{C}$ hybrids towards ketonization of n-alcohols (n-butanol conversion to heptanone-4, ca. $75 \%$ selectivity at $460^{\circ} \mathrm{C}$ ).

The differences must by attributed to different catalytic properties of the active components of the hybrid materials i. e. to Ce and Ti derivatives (mixed oxides) which presence was proved by XRD, XPS and HRTEM measurements.

In summary, the proposed hybrid catalysts fabrication method is basing on two important and exclusive features of Salix viminalis:

- $\quad$ high vitality preserving some living functions like metal ion transportation in fragments of a complete plant (single rod cut into $20 \mathrm{~cm}$ long pieces),

- $\quad$ high tolerance of still living parts of Salix viminalis to heavy metal ions which enter the plant structure. We assume that toxic influence of the heavy metal ions is considerably reduced in the plant cells otherwise transportation of metal ions could be severely disrupted and finally terminated. During impregnation in most Salix viminalis samples (sections of rod) no visible morphological changes were observed and the $20 \mathrm{~cm}$ long sections retained their original olive-green color characteristic for its bark. Visible bulge and shrinkage did not occur.

The originality of the above presented concept let to submit patent applications (Łukaszewicz et al., 2006; Łukaszewicz et al., 2007).

\subsection{Dry distillation of Salix viminalis wood}

Fabrication of charcoals from Salix viminalis consists in the a heat treatment of the biomass in oxygen free conditions. In fact this process can be also called dry distillation $\mathrm{w}$ wood. However, usually distillation is run aiming at the collection of volatile products which evolve during heat treatment. Looking at charcoal fabrication (described above) from such a point view authors has decided to cool down (liquefaction) volatiles leaving heating zone of stove along with the stream of inert gas (nitrogen) passing through the stove. The condensate in form of a dark brown viscous liquid was collected in a glass beaker and subsequently subjected to several analysis. We assumed that the condensate is a mixture of numerous organic compound as in the case of wood tar obtained by dry distillation of other sorts of wood i. e. pine (Egenberg et al., 2002).

At the beginning we assumed that the collected tar must contain phenols and polyphenols which are created during thermolysis of lignin (de Wild et al., 2010). Salix viminalis wood contains ca. 20-24 \% (by weight) of lignin in dry mass of wood (Mleczek et al., 2010). The distillate called biooil was subjected to some separation measures like extraction to isolate several fractions containing polyphenols. Polyphenols are a precious group of compounds mainly because of their antioxidant properties. 


\subsection{Polyphenols and other antioxidants}

Free radicals play important role in the functioning of human organism (Grajek, 2007). However, their presence may be the reason of oxidative stress. The stress often results from disrupted balance between peroxidants and antioxidants in an organism. It is proven that high activity of free radicals and prolonged influence of oxidative stress are responsible for pathogenesis of nearly 100 diseases (Wolski, 2007) including Alzheimer and Parkinson diseases (Bartosz, 2008; Fitak \& Grzegorczyk-Jaźwińska, 1999). During ageing oxidative damages in cells become more frequent with parallel reduction the activity of antioxidative enzymes. The situation becomes worse due to UV irradiation, environmental pollution, permanent mental stress and bad nutrition habits. Oxygen being the base of human existence is mainly available in it triplet form $\mathrm{O}_{2}{ }^{* *}$. The electron configuration results in moderate chemical activity in contrast to other forms like $\left(\mathrm{O}_{2}{ }^{*}\right)^{-}, \mathrm{HO}_{2}{ }^{*}$ and $\mathrm{OH}^{*}$. The latter form is considered as the most reactive. Proper enzymes ensure control over $98-99 \%$ of all oxygen in a human body. However, the remaining amount of oxygen may undergo transformation (Fenton reaction, Haber-Weiss reaction) into the most reactive forms i. e. oxygen derivatives being free radicals. Daily up to 10 thousand DNA oxygen-related damages occur in a human body. The damages may be repaired by some specific enzymes but the introduction of antioxidants should reduce the threat. Therefore everyday diet has to be supplemented by natural antioxidants. Antioxidation properties of polyphenols may involve the three general mechanisms:

- direct expunge of reactive form of oxygen and nitrogen by two possible pathways: Single Electron Transfer (SET) or Hydrogen Atom Transfer (HAT). In such processes a polyphenol molecule transforms into a phenoxyl radical which after reaction with a next oxygen radical stabilizes as chinone like structure (fig. 12)

- chalation of transition metal ions (particularly copper and iron) which participate in the reactions leading to the formation of reactive radicals like the Fenton reaction involving $\mathrm{Fe}^{2+}$ ions and yielding dangerous hydroxyl radical $\mathrm{OH}$,

- $\quad$ increasing of concentration of endogenous antioxidants and/or inhibition of enzymes stimulating the formation of free radicals.

Such positive chemical features of polyphenols turns peoples attention towards intensive search for sources of them and the development of methods of polyphenols separation from their natural matrixes for further enrichment of some products like pharmaceuticals, food, cosmetics etc. This way of thinking involves investigations on appropriate plants i. e. candidates for a subsequent chemical treatment like polyphenol extraction. According to some extended studies (Makowska-Wąs \& Janeczko, 2004) polyphenols occur in many plants and plant originated products like herbs, needles of coniferous plants, algae, green tea leaves, eucalyptus wood, byproducts of olive, wine, yeast production. It is obvious that chemical exploitation of one source plant yields a limited number of polyphenols and search for other polyphenols needs a selection and a proper treatment of another source plants. It has to be stated that the polyphenol content in source plants is very differentiated but also very low. Table 10 informs about the antioxidant activity determined for $100 \mathrm{~g}$ of example fruits and vegetables. The highest activity is noticed for pure vitamins and synthetic antioxidants. However, the mentioned products owe their antioxidative activity not only due to the presence of polyphenols since other type of antioxidants may be present, too. 

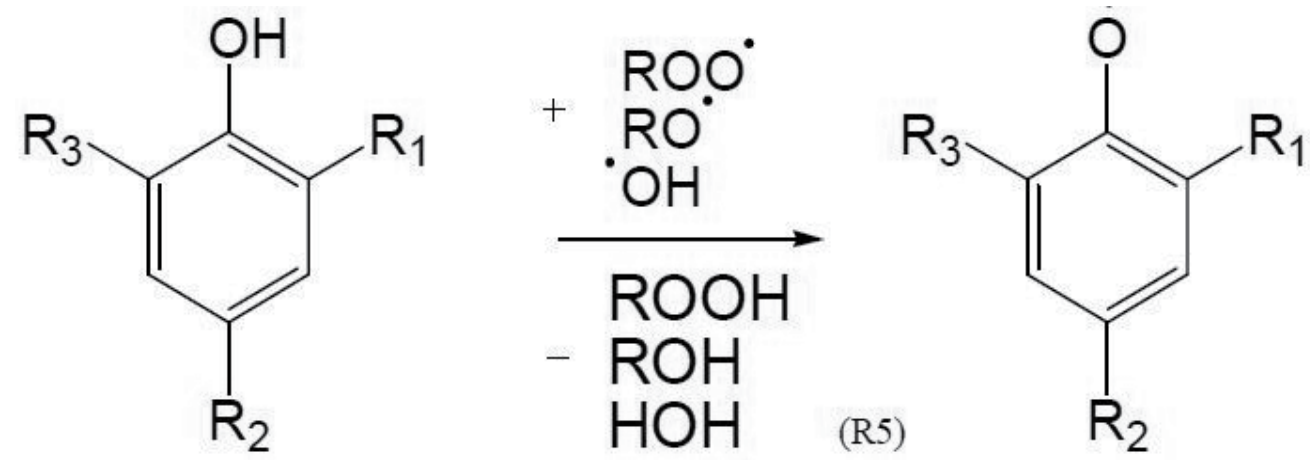

(R5)

(R6)
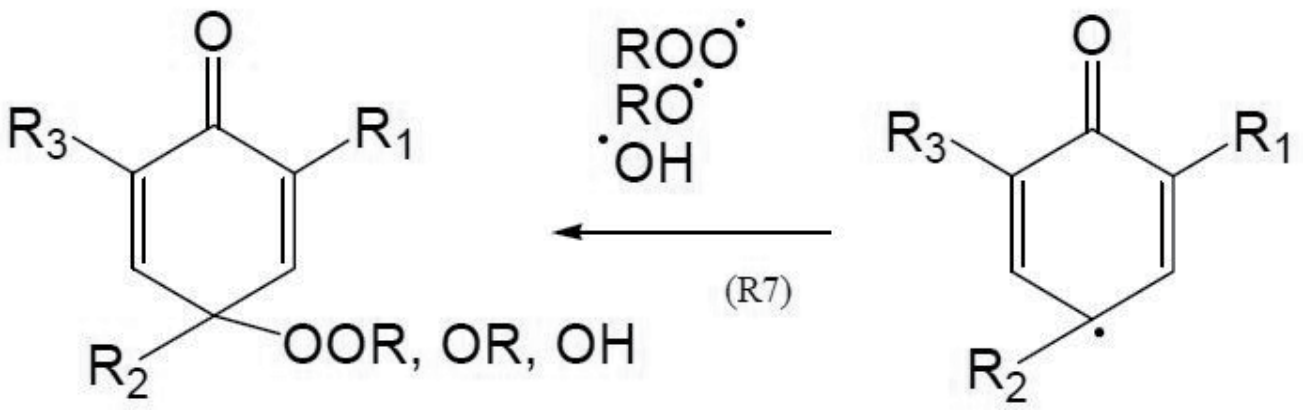

Fig. 12. Oxygen based free radical reaction with a polyphenol.

Obviously the above list is not closed and other natural and synthetic products may be addend and therefore search for other effective products is fully justified. Authors attention has turned towards chemical processing of some easily accessible and renewal resources. Our primary idea was to involve chemical processing not limited to the separation of already existing polyphenols (a passive approach) but also on treatments that transform original matter of low polyphenol content into a new product of high polyphenol concentration (active approach). Such a concept focused our attention on Salix viminalis again due to its inexpensiveness, renewal cultivation and high content of lignin which thermal treatment releases polyphenols. As the matter of fact Salix viminalis as a living plant contains some amounts of different polypneols like flavonoides (flavanols, flavones, flavonones, flawonone dimers, chalcones), phenolic acids, lignans, catechin and its derivatives as well as tannins (procyanidins, prodelfinidins) being derivatives of flavan-3-ols. Particular Salix species differ much regarding the total content of polypheneols (Nyman \& Julkunen-Tiitto, 2005) and their type (Landucci et al., 2003).

For example Salix caprea contains variety of flavonoids and the lack of lignans (Pohjamo et al., 2002). Contrastly, for Salix viminalis characteristic are relatively low concentrations of flavonoids (Harborne \& Baxter, 1999), moderate concentrations of lignans (Pohjamo et al., 2003) and high concentrations of tannins (Nikitina \& Orazov, 2001). 


\begin{tabular}{|c|c|}
\hline Food produkt & $\begin{array}{c}\text { Antioxidant activity } \\
{[\mathrm{TE} / 100 \mathrm{~g}]}\end{array}$ \\
\hline Red Grapes & 1350 \\
\hline Red Cabbage & 1000 \\
\hline Broccoli Flowers & 500 \\
\hline Spinach & 500 \\
\hline Green Grapes & 400 \\
\hline Tomato & 300 \\
\hline Green Beans & 175 \\
\hline Green Cabbage & 150 \\
\hline Lima Beans & 1055 \\
\hline Red Beans & 11459 \\
\hline Blueberries & 3300 \\
\hline Raisins & 5900 \\
\hline Wheat Bran & 4620 \\
\hline Wheat Flour (refined) & 600 \\
\hline Substance & $\begin{array}{c}\text { Antioxidant activity } \\
\text { [TE/100 g] }\end{array}$ \\
\hline Ascorbate & 442000 \\
\hline Trilox & 400000 \\
\hline Witamin E & 201000 \\
\hline BHT & 395000 \\
\hline TE - TRILOX Equivalent & TRILOX \\
\hline
\end{tabular}

Table 10. Antioxidant activity of selected food products, vitamins and synthetic antioxidants. Selected points cited after (Prakash et al., 2010). 
The concentration of polyphenols in Salix viminalis depends also on the season of the year. $t$ maximal concentration of flavonoids is reached during blossom while tannins concentration is highest in Autumn (Nikitina \& Orazov, 2001). Long exposure of Salix viminalis to sunshine (UV radiation) additionally increases the content of compounds capable to neutralization of free radicals (flavonoids, phenolic acids, proantocyanidynes) and reduces the content of salicylic acid and its derivatives (Tegelberg \& Julkunen-Titto, 2001). Thus, a proper cultivation of Salix viminalis and well planned collection of polyphenols by extractive methods may result in a better efficiency of the whole attempt. However, as mentioned earlier, the total contents of polyphenols is relatively low and therefore the mass of isolated antioxidants in relation to the mass of raw material is dramatically low. Thus, the contemporary chemical technology should not only rely on the Nature's productivity but also search for more effective methods of polyphenols fabrication instead of collection. The heat-treatment of Salix vimanlis wood yields three basic products (charcoal, biooil, biogas) but yield of each depends on heating rate as depicted in fig. 13).

As mentioned biooil formation is a result of lignin pyrolysis. Lignin is biopolymer (fig. 14) consisting of some characteristic units i. e. p-cumarol alcohol, coniferyl alcohol, synapine alcohol (fig. 15.) bonded by various organic bridges. Thus, the bonds may break at different point yielding a huge number of organic compounds including polyphenols. Volatile products evolve during heat-treatment with unequal intensity (fig. 16). The most intensive collection of liquid condensate is possible in the temperature range of $260-380^{\circ} \mathrm{C}$ ).

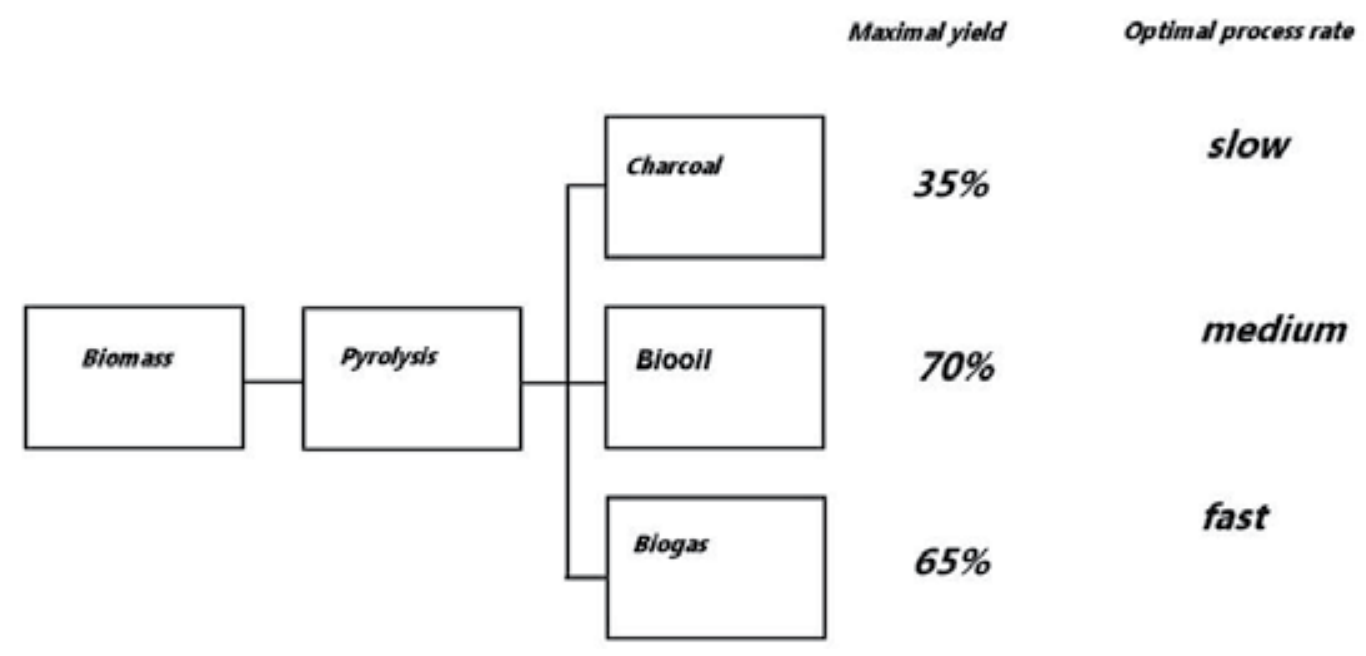

Fig. 13. Typical products of biomass pyrolysis. The influence of process conditions (heating rate, temperature) on yield of particular products. 


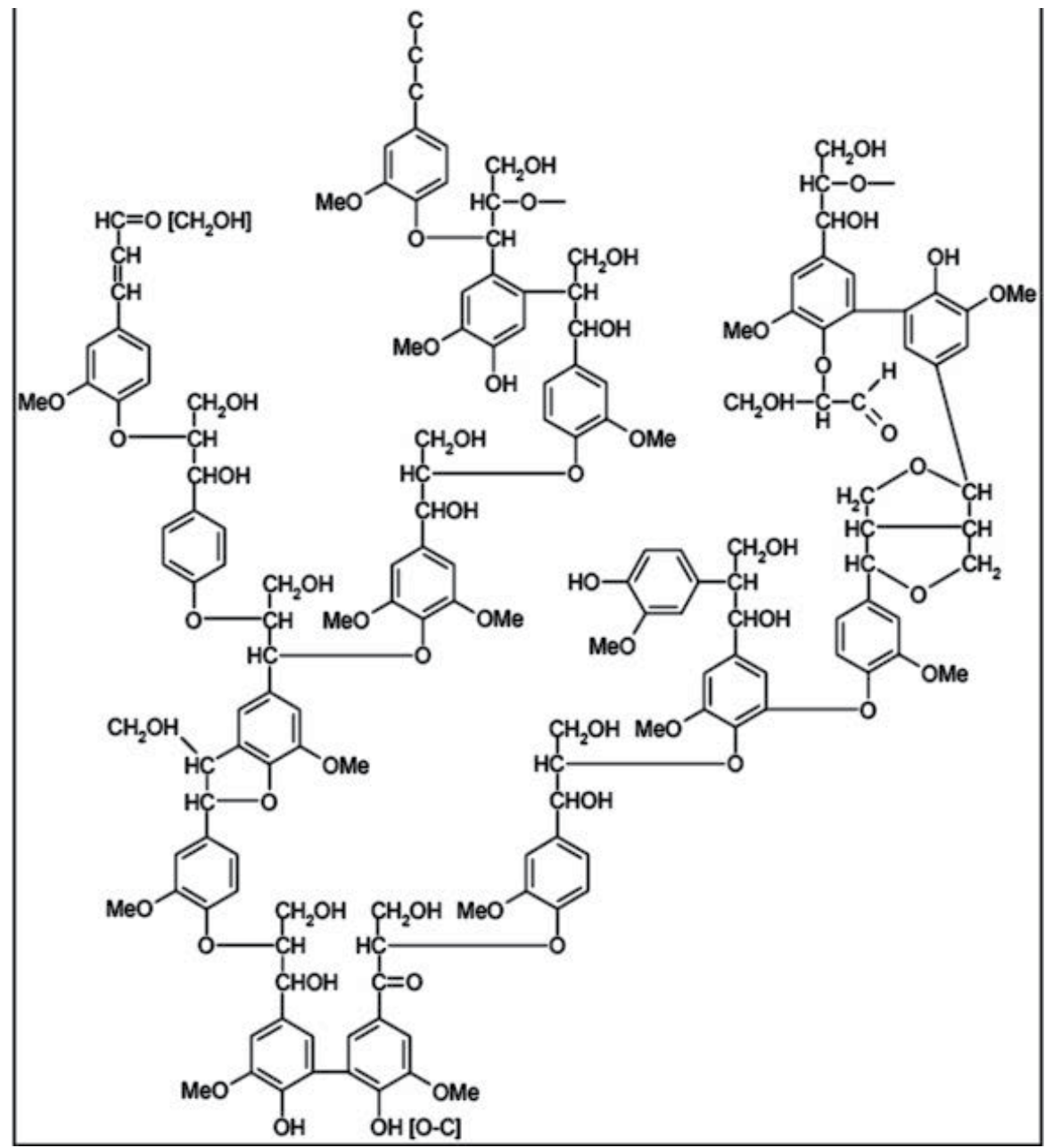

Fig. 14. Pattern structure of lignin.<smiles>[R]c1ccc(O)cc1</smiles>

A<smiles>[R]c1ccc(O)c(OC)c1</smiles>

B<smiles>[R]c1cc(OC)c(O)c(OC)c1</smiles>

C

$\mathrm{R}=-\mathrm{H},-\mathrm{CH}_{3},-\mathrm{C}_{2} \mathrm{H}_{3},-\mathrm{C}_{2} \mathrm{H}_{5},-\mathrm{C}_{3} \mathrm{H}_{5},-\mathrm{C}_{3} \mathrm{H}_{7},-\mathrm{COCH}_{3},-\mathrm{C}_{3} \mathrm{H}_{4} \mathrm{OH},-\mathrm{CHO}$

Fig. 15. Structures of three phenolic alcohols being monomers in lignin: A - p-cumarol alcohol, B - coniferyl alcohol, C - synapine alcohol. 


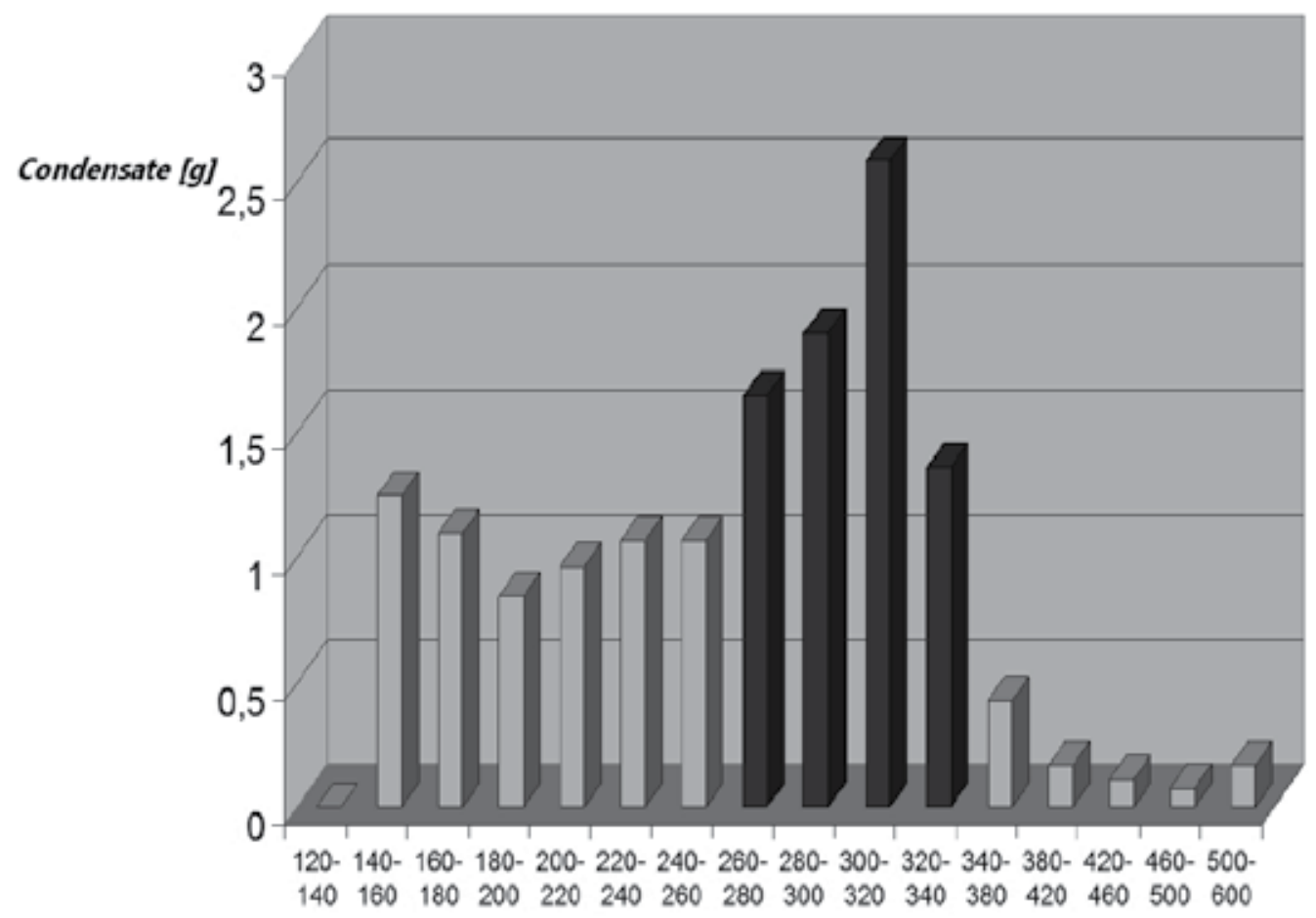

Temperature [deg C]

Fig. 16. The intensity of liquid condensate yield (biooil) at different temperatures.

The such collected fraction was considered as a raw biooil subsequently subjected to separation (extraction, chromatography) procedures and chemical characterization. Several instrumental methods were applied: gas chromatography GC-MS (Autosystem XL - MS Turbomass), nuclear magnetic resonance ${ }^{1} \mathrm{H}$ and ${ }^{13} \mathrm{C}$ NMR (700 MHz Bruker Avance) and infrared spectroscopy FT-IR (Perkin Elmer Spectrum 2000). Additionally the isolated fractions were tested as antioxidants according to ASTM 4871 standard (www.astm.org/Standards/D5770.htm, 2011). The latter procedure consists in the oxidation of a standard substance DBS (dibuthyl sebacate) in liquid phase at relatively severe conditions $\left(150{ }^{\circ} \mathrm{C}\right.$, constant flow of air $\left.100 \mathrm{~cm}^{3} / \mathrm{min}\right)$. The oxidation may proceed in the presence $(1000 \mathrm{ppm})$ of different protective antioxidants including separated fractions of raw biooil of Salix viminalis origin (dry distillation) and some commercially distributed antioxidants like BHT (2,6-di-tert-buthyl-p-cresol, buthyl hydroxy toluene, buthylated hydroxy toluene). BHT is widely used for the protection and stabilization of cosmetics and food products. The most promising results were achieved so far for two extracts called A and $\mathrm{B}$ (ethyl ether and dichloromethane extracts respectively).

The results of a complex analysis (GC-MS, NMR, FTIR, UV-VIS) of both extracts confirm that:

- each extract contains ca. 50 different compounds which may exhibit antioxidative properties, 
- most of the potential antioxidats are in fact derivatives of three organic structures (cumarol alcohol, coniferyl alcohol, synapine alcohol) which are claimed to be units of a the biopolymer occurring in Salix viminalis wood i. e. lignin (see text above); the compounds are released from the wood sample due to thermolysis of the biopolymer lignin,

- the extract B contains more furan derivatives while the extract A contains more oxygen heterocyclic compounds.

The determination of the composition of the two preliminary extracts $\mathrm{A}$ and $\mathrm{B}$ has a certain chemical value but more important is to confirm if the extract theoretically consisting of antioxidant species can exhibit efficient antioxidant activity, what is the main motivation for this research. The absence of such activity could question the whole research attempt which from early beginning was focused on a practical aspects i. e. on the applicability of all products of the dry Salix viminalis wood pyrolysis. The preliminary hypothesis was confirmed by the performed controlled oxidation tests (fig. 17). It is visible that the addition of $1000 \mathrm{ppm}$ of a commercial antioxidant i. e. BHT protects the test substance DBS for ca. 50 hours. After this time one observes increasing concentration of some oxidation products in the reaction chamber. In the same experimental conditions pure DBS undergoes instant oxidation without any significant protection time. The addition of the biooil extract $B$ in the same proportion of $1000 \mathrm{ppm}$ extends threefold the protection time. Thus, DBS was protected nearly for one week despite sever experimental conditions. It has to be stated that the protection times for much lower temperatures like room temperature must by very long.

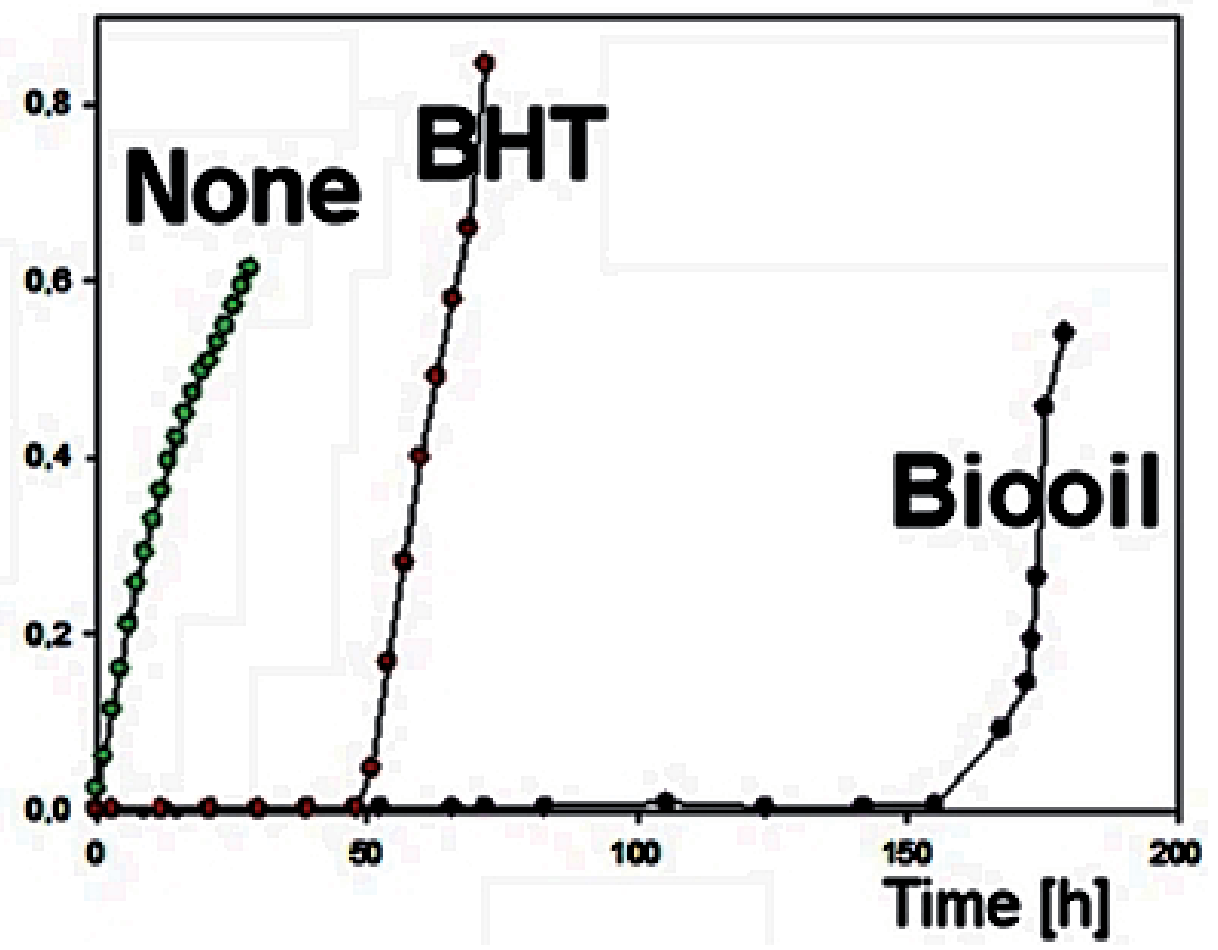

Fig. 17. Restraining of DBS oxidation by means of extract B and BHT. 


\section{Summary}

The performer research program prove that Salix viminalis is a precious raw material for chemical treatment and it could not be seen only as a fuel for energetic utilization. Its practical value increases regarding that it is easily accessible as agriculture product. It grows fast with a good yield. Salix viminalis cultivation has a positive influence on the environment since their high mass productivity per hectare is definitely associated with $\mathrm{CO}_{2}$ absorption from the atmosphere. The proposed elaboration method is nearly complete since all major products of the wood thermolysis i. e. solid (active carbon of CMS properties) and liquid (biooil containing antioxidants) may find a wide application in practice.

\section{References}

Anderson T.A., Guthrie E.A., Walton B.T. (1993). Bioremediation. Environ. Sci. Technol., 27, (13), pp. (2630-2636), ISSN:0013-936X.

Baker A.J.M., Walker P.L. (1990). Ecophysiology of metal uptake by tolerant plants, heavy metal tolerance in Plants. In: Evolutionary Aspects. Shaw A.J., pp (155-177), ISBN:184405-143-9, CRC Press, Boca Raton.

Bartosz G. (2008). Druga twarz tlenu (II). Państwowe Wydawnictwo Naukowe, ISBN 97883-01-13847- 9, Warsaw.

Bio-energia. (2008). www.bio-energia.pl.

Blaylock M.J., Slat D.E., Dushenkov S., Zakharova O., Gussman C., Kapulnik Y., Ensley B.D., Raskin I. (1997). Enhanced accumulation of $\mathrm{Pb}$ in Indian mustard by soil applied chelating agents. Environ. Sci. Technol., 31 (3), pp. (860-865), ISSN: 0013-936X.

Borjesson P., Gustavsson L., Christersson L., Linder S. (1997). Future production and utilization of biomass in Sweden: Potentials and $\mathrm{CO}_{2}$ mitigation. Biomass Bioenerg., 13, (6), pp. (399-412), ISSN: 0961-9534.

Brown S.L., Chaney R.L., Angle J.S., Baker A.J.M. (1994). Phytoremediation potential of Thlaspi caerulescens and bladder campion for zincand cadmium-contaminated soil. J. Environ. Qual., 23, (6), pp. (1151-1157), ISSN: 0047-2425.

Christersson L., Sennerby-Forsse. (1994). The swedish programme for intensive short rotation forests. Biomass Bioenerg., 6, (1-2), pp. (145-149), ISSN: 0961-9534.

Clemens S. (2006). Toxic metal accumulation, responses to exposure and mechanisms of tolerance in plants. Biochimie, 88, (11), pp. (1707-1719), ISSN: 0300-9084.

Cyganiuk A., Klimkiewicz R., Olejniczak A., Łukaszewicz J.P. (2010). Biotechnological fabrication of LaMnO3-carbon catalyst for n-butanol conversion to ketones. Carbon, 48, (1), pp. (99-106), ISSN 0008-6223.

Dushenkov V., Kumar P.B.A.N., Motto H., Raskin I. (1995). Rhizofilteration the use of plants to remove heavy metals from aqueous streams. Environ. Sci. Technol., 29, (5), pp. (1239-1245), . ISSN:0013-936X.

Egenberg I.M, Aasen J.A.B., Holtekjølen A.K., Lundanes E. (2002). Characterisation of traditionally kiln produced pine tar by gas chromatography-mass spectrometry. J. Anal. Appl. Pyrolysis, 62, (1), pp. 143-155, ISSN: 0165-2370.

Fitak E., Grzegorczyk-Jaźwińska A. (1999). Wolne rodniki i ich aktywność w układach biologicznych. Nowa Stomatologia, 3, pp. (27-30), ISSN: 1426-6911.

Gąsecka M., Mleczek M., Magdziak Z., Drzewiecka K., Goliński P., Chadzinikolau T. Physiological and Morphological Changes in Salix viminalis as a Result of Plant 
Exposure to Copper. Proc. 15th ICHMET, ISBN: 9788392898658, pp. (350-353), Gdańsk, September 2010.

Górska O.M. (2009). Wybrane surowce naturalne jako potencjalne źródło do otrzymywania materiałów węglowych o właściwościach sitowo-molekularnych. Master thesis. Wydział Chemii UMK, Torun.

Gradziuk P. (1999). Możliwości wykorzystania surowców pochodzenia rolniczego na cele energetyczne. Rocz. Nauk. Stow. Ekonom. Roln. Agrobiz., 1, (3), pp. (233-238).

Grajek W. (2007). Przeciwutleniacze w żywności. Aspekty zdrowotne technologiczne molekularne i analityczne (I). Wydawnictwa Nukowo-Techniczne, ISBN: 97883204-32770, Warsaw.

Harborne J.B., Baxter H. (1999). The handbook of natural flavonoids (I). Willey, ISBN: 0-47195893-X, Chichester.

Horvath G., Kawazoe K. (1983). Method for the calculation of effective pore size distribution in molecular sieve carbon. J. Chem. Eng. Jpn., 16, (8), pp. (470-475), ISSN: 0021-9592.

Iso-Tech. (2011). www.biomasa.org.

Japan EnviroChemicals Ltd. (2011). www.jechem.co.jp/shirasagi_e/tech/psa.html.

Kumar P.B.A.N., Dushenkov V., Motto H., Raskin I. (1995). Phytoextractionthe use of plants to remove heavy metals from soils. Environ. Sci. Technol., 29, (5), pp. (1232-1238), ISSN:0013-936X.

Landucci L., Ralph S., Hirth K. Characterization and reactions of a Salix extractive with a unique ring system. Proceedings of 12th Int. Symp. Wood Pulping Chem., vol. III, pp. (199-202). Madison, June 2003.

Łukaszewicz J P., Arcimowicz A., Klemp-Dyczek B. (2006). Sposób wytwarzania węglowych sit molekularnych. Patent application P 380164, Polish Patent Office.

Łukaszewicz J.P., Wesołowski R., Arcimowicz A. (2007). Metoda otrzymywania węglowych sit molekularnych wzbogaconych w nanokrystality tlenków metali zwłaszcza do budowy elektrod w urządzeniach elektrochemicznych. Patent application P 384122, Polsih Patent Office.

Łukaszewicz J.P., Wesołowski R. (2008). Fabrication of Molecular-Sieve-Type Carbons from Salix viminalis. Microporous and Mesoporous Mater., 111, (1-3), pp. (723-726), ISSN: 1387-1811.

Łukaszewicz J.P., Wesołowski R., Cyganiuk A. (2009). Enrichment of Salix viminalis wood in metal Ions by means of phytoextraction. Pol. J. Environ. Stud., 18, (3), pp. (507511), ISSN: 1230-1485.

Makowska-Wąs J., Janeczko Z. (2004). Bioavailability of plant polyphenols, Postępy Fitoterapii, 3/2004, pp. (126-137), ISSN: 1509-8699.

Memon A.R., Aktoprakligul D., Zdemur A., Vertiil A. (2001). Heavy Metal Accumulation and Detoxification Mechanisms in Plants. Turk. J. Bot., 25, (3), pp. (111-121), ISSN: 1300-008X.

Lasat M.M. (2002). Phytoextraction of toxic metals: a review of biological mechanisms. J. Environ. Qual., 31(1), pp. (109-120), ISSN: ISSN: 0047-2425.

Mleczek M., Magdziak Z., Rissmann I., Goliński P. (2009). Effect of different soil conditions on selected heavy metal accumulation by Salix viminalis tissues, J. Environ. Sci. Health Part A, 44, (14), pp. (1609-1616), ISSN: 1093-4529.

Mleczek M., Kaczmarek Z., Magdziak Z. Goliński P. (2010). Hydroponic estimation of heavy metal accumulation by different genotypes of Salix. J. Environ. Sci. Health Part A, 45, (5), pp. (569-578), ISSN: 1093-4529. 
Nikitina V.S., Orazov O.E. (2001). The dynamics of total flavonoids in leaves and tannides in the bark of branches in heterosexual specimens of Salix triandra L. and S. acutifolia Willd. Rastitelnye Resursy, 37, (1), pp. (65-72), ISSN: 0033-9946.

Nyman T., Julkunen-Tiitto R. (2005). Chemical variation within and among six northern willow species. Phytochem., 66, (24), pp. (2836-2843), ISSN: 0031-9422.

Pilon-Smits E, Pilon M (2000). Breeding mercury-breathing plants for environmental cleanup. Trends in Plant Sci., 5, (6), pp. (235-236), ISSN: 1360-1385.

Pohjamo S.P, Willfor S., Reunanen M., Hemming J., Holmbom B. (2002). Bioactive phenolic substances in fast-growing tree species. Abo Akademi. Laboratoriet for Skogsprodukternas Kemi, B1-02.

Pohjamo S.P., Hemming J.E., Willfor S.M., Reunanen M.H.T., Holmbom B.R. (2003). Phenolic extractives in Salix caprea wood and knots. Phytochem., 63, (2), pp. (165169), ISSN: 0031-9422.

Porębska G., Ostrowska A. (1999). Heavy Metal Accumulation in Wild Plants: Implications for phytoremediation. Pol. J. Environ. Stud., 8, (6), pp. (433-442), ISSN: ISSN: 12301485.

Prakash A., Rigelhof F., Miller E. (2011). Medallion Laboratories. Analytical Progress. www.medallionlabs.com/Downloads/Antiox_acti_.pdf.

Reski R., Abel, W.O. (1985) Induction of budding on chloronemata and caulonemata of the moss, Physcomitrella patens, using isopentenyladenine. Planta, 165, (3), pp. (354358), ISSN: 0021-9258.

Salt D.E., Blaylock M., Kumar P.B.A.N., Dushenkov S., Ensley B.D., Chet I., Raskin I. (1995). Phytoremediation: A novel strategy for the removal of toxic metals from the environment using plants. Nature Biotechnol., 13, (5), pp. (468-474), ISSN: 10870156.

Shah K., Nongkynrih J.M. (2006). Metal hyperaccumulation and bioremediation, Biol. Plantarum, 51, (4), pp. 618-634, ISSN: 0006-3134.

Smith R.A.H., Bradshaw A.D. (1979). The use of metal tolerant plant populations for the reclamation of metalliferous wastes. J. Appl. Ecol., 16, (2), pp. (595-612), ISSN: 13652664.

Tegelberg R., Julkunen-Titto R. (2001). Quantitative changes in secondary metabolites of dark-leaved willow (Salix myrsinifolia) exposed to enhanced ultraviolet-B radiation. Physiol. Plant, 113, (4), pp. (541-547), ISSN: 0031-9317.

Walton B.T., Anderson T.A. (1992). Plant-microbe treatment systems for toxic waste. Current Opinion in Biotechnology, 3, (3), pp. (267-270), ISSN: 0958-1669.

de Wild P.J., van der Laan R.R., Wilberink R.W.A. Thermolysis of lignin for value-added products. ftp://ftp.ecn.nl/pub/www/library/report/2010/110071.pdf. Presented at 15th Meeting of the International Humic Substances Society, Tenerife, June-July 2010.

Wolski T., Kalisz O., Gerkowicz M., Morawski M. (2007). The role and the significance of antioxidants in medicine with particular respect to eye disorders. Postępy Fitoterapii, 2, pp. (82-90), ISSN: 1509-8699.

Zabrocki R., G. Ignacek G. (2008). Wykorzystanie wierzby energetycznej w gospodarce rolnej. Roczniki Naukowe Stowarzyszenia Ekonomistów Rolnictwa i Agrobiznesu. 9, (3), pp. ( 234-238), ISSN: 1508-3535. 


\title{
Biomass Energy Conversion
}

\author{
Sergio Canzana Capareda \\ Texas AEM University \\ USA
}

\section{Introduction}

The use of biomass as a source of energy varies in different countries and depends in part on the country's level of development. In many developing countries, biomass provides most of the basic energy needs, mostly as fuelwood, animal wastes or crop residues while in developed countries only a fraction of their energy requirement comes from agriculture and agro-industrial wastes. In the United States for example, biomass conversion amounts to about 3.25\% of the energy supply (EIA, 2002 and Haq, 2002) while in Bhutan, the share of biomass energy in total energy use accounts for about $87 \%$ (Victor, and Victor, 2002).

Biomass resources could play a significant role in meeting the future energy requirements. However, the approach in their utilization should be carefully analyzed in view of diverse cultural, socio-economic and technological factors in a given locality. Agricultural and agro-industrial wastes can provide an inexpensive source of energy and effective low sulphur fuel. It could be processed into other fuels thereby reducing environmental hazards (e.g. biomass from sewage). Also, there is relative ease with which it could be gathered and generated. However, the conversion of light energy into biomass by plants is relatively of small percentage and there is relatively low concentration of biomass per unit area of land and water. The additional land for biomass production is getting scarce, and the high moisture content of fresh biomass makes collection and transport expensive. Thus, biomass energy conversion could be relatively inefficient. Moreover, extensive utilization of these resources may compete with the demand for these as food. These are some of the issues concerning the extensive utilization of biomass resources.

In view of the depleting forest and agricultural resources for energy use, attention should be focused on new and emerging technologies for their efficient conversion. There are a number of sources of energy for both rural or agricultural and urban or industrial residues. There is a need to diversify the traditional resources for energy to meet the demands. These include, among others: (1) planting high energy value crops, fast growing trees, sugar and starchy crops, aquatic plants, oil and hydrocarbon crops, and (2) getting energy from municipal sewage and solid wastes. Some common properties of biomass resources will be reviewed to gain perspective of biomass as a source of energy compared with traditional fossil fuel sources.

The primary advantage in the use of biomass as an energy resource is that it is a renewable feedstock and does not contribute to global warming. 


\section{Biomass properties and characterization}

The important biomass properties include the following: (a) heating value, (b) proximate analysis and (c) ultimate analysis. Any biomass conversion process begins with knowing its energy content in units of $\mathrm{MJ} / \mathrm{kg}$ and compared with traditional resources like coal. Further, biomass resources may be describe based on its proximate analysis whereby its moisture content (MC) is reported, followed by the volatile combustible matter (VCM) contents, fixed carbon (FC) and ash. Finally, the ultimate analysis is important to illustrate the biomass composition in relation to the top five elements it contains as follows: (a) carbon (C), (b) hydrogen $(\mathrm{H})$ (c) oxygen $(\mathrm{O})$, (d) nitrogen $(\mathrm{N})$ and (e) sulphur (S) content. Other characterization would include describing its compositional contents such as lignin, cellulose and hemi-celluloses, carbohydrates and fat contents.

When biomass is converted thermally in the presence of excess amounts of air, (i.e. combustion) the total energy released in the form of heat is termed its heating value or calorific value. The heating value of biomass is reported in units of $\mathrm{kJ} / \mathrm{kg}$. Gasoline used as fuel for running internal combustion engines has a reported heating value of about 47 $\mathrm{MJ} / \mathrm{kg}$ and diesel has heating value of about $45 \mathrm{MJ} / \mathrm{kg}$. Biomass on the other hand may have heating values ranging from $15-25 \mathrm{MJ} / \mathrm{kg}$.

\subsection{Heating value and ultimate analysis of biomass}

Heating value of biomass is usually measured using a bomb calorimeter. Table 1 shows the ultimate analyses and heating value of some fossil fuels and common biomass. In the absence of equipment for measuring heating values of biomass, two most common equations are used. These are the Dulong equation (Gupta and Manhas, 2008) and the Boie equation (Annamalai, et al., 1987) shown in equations (1) and (2).

\begin{tabular}{|c|c|c|c|c|c|c|c|}
\hline \multirow[t]{2}{*}{ Material } & \multicolumn{6}{|c|}{ Elements (\% dry weight) } & $\begin{array}{c}\text { Heating } \\
\text { Values }\end{array}$ \\
\hline & $\mathrm{C}$ & $\mathrm{H}$ & $\mathrm{N}$ & $S$ & $\mathrm{O}$ & Ash & $\mathrm{MJ} / \mathrm{kg}$ \\
\hline Pittsburgh seam coal & 75.5 & 5.0 & 1.2 & 3.1 & 4.9 & 10.3 & 31.7 \\
\hline Utah coal & 77.9 & 6.0 & 1.5 & 0.6 & 9.9 & 4.1 & 32.9 \\
\hline Wyoming Elkol coal & 71.5 & 5.3 & 1.2 & 0.9 & 16.9 & 4.2 & 29.5 \\
\hline Lignite & 64.0 & 4.2 & 0.9 & 1.3 & 19.2 & 10.4 & 24.9 \\
\hline Charcoal & 80.3 & 3.1 & 0.2 & 0.0 & 13.0 & 3.4 & 57.4 \\
\hline Douglas fir & 52.3 & 6.3 & 0.1 & 0.0 & 40.5 & 0.8 & 21.3 \\
\hline Pine bark & 52.3 & 5.8 & 0.2 & 0.0 & 38.8 & 2.9 & 20.4 \\
\hline Redwood & 53.5 & 5.9 & 0.1 & 0.0 & 40.3 & 0.2 & 21.0 \\
\hline Rice hulls & 38.5 & 5.7 & 0.5 & 0.0 & 39.8 & 15.5 & 15.4 \\
\hline Rice straw & 39.2 & 5.1 & 0.6 & 0.1 & 35.8 & 19.2 & 15.2 \\
\hline Sawdust & 49.7 & 6.2 & 0.7 & 0.2 & 42.5 & 0.7 & 20.0 \\
\hline Paper & 43.4 & 5.8 & 0.3 & 0.2 & 44.3 & 6.0 & 17.6 \\
\hline Feedlot manure (fresh) & 45.4 & 5.4 & 1.0 & 0.3 & 32.0 & 15.9 & 17.4 \\
\hline Municipal solid waste & 47.6 & 6.0 & 1.2 & 0.3 & 32.9 & 12.0 & 19.9 \\
\hline Corn cobs & 46.2 & 7.6 & 1.2 & 0.3 & 42.3 & 2.4 & 26.3 \\
\hline Sorghum stalks & 40.0 & 5.2 & 1.4 & 0.2 & 40.7 & 12.5 & 15.4 \\
\hline Cotton gin trash (CGT) & 42.0 & 5.4 & 1.4 & 0.0 & 36.7 & 14.5 & 15.5 \\
\hline
\end{tabular}

Table 1. Ultimate analysis data and heating values for selected solid and biomass fuels (from LePori and Soltes, 1985, with permission). 
The Dulong equation is given by the following equation (1),

$$
\mathrm{HV}(\mathrm{kJ} / \mathrm{kg})=33,823^{*} \mathrm{C}+144,250 *(\mathrm{H}-\mathrm{O} / 8)+9,419^{*} \mathrm{~S}
$$

where $\mathrm{C}, \mathrm{H}, \mathrm{O}, \mathrm{N}$ and $\mathrm{S}$ are the elemental mass fractions in the material.

Example. From the ultimate analysis data shown in Table 1, estimate the heating value in $\mathrm{MJ} / \mathrm{kg}$ of douglas fir.

Solution.

1. Substituting the mass fractions of the elements into the equation, we have

$$
\mathrm{HV}(\mathrm{kJ} / \mathrm{kg})=33,823^{*}(0.523)+144,250(0.063-((0.405) / 8))+9,419^{*}(0)
$$

2. Thus, the heating value is calculated as

$$
\mathrm{HV}(\mathrm{kJ} / \mathrm{kg})=17,689+1,785+0=19,474 \mathrm{~kJ} / \mathrm{kg}(19.5 \mathrm{MJ} / \mathrm{kg}) \text {. }
$$

Note that the heating value from the table is given as $21.3 \mathrm{MJ} / \mathrm{kg}$, an $8.45 \%$ difference. The Dulong equation is valid when the oxygen content of the biomass is less than $10 \%$. In this example, the oxygen content of douglas fir is $40.5 \%$ and way above $10 \%$, hence a large difference.

The Boie equation is given by the following equation (2),

$$
\mathrm{HV}(\mathrm{kJ} / \mathrm{kg})=35,160 * \mathrm{C}+116,225 * \mathrm{H}-11,090 * \mathrm{O}+6,280 * \mathrm{~N}+10,465 * \mathrm{~S}
$$

where $\mathrm{C}, \mathrm{H}, \mathrm{O}, \mathrm{N}$ and $\mathrm{S}$ are the elemental mass fractions in the material.

\subsection{Proximate analysis of biomass}

The proximate analysis is a good indicator of biomass quality for further conversion and processing. Proximate analysis is important for thermal conversion processes since the process require relatively dry biomass (normally less than $10 \%$ moisture). If gaseous combustible fuel from biomass is to be produced, the feedstock with the highest volatile matter content is ideal to use. For slagging and fouling issues, the feedstock with the lowest ash content is an excellent choice. The fixed carbon is used to relate the heating value of the product and coproducts. Table 2 shows some proximate analysis data for some biomass resources.

\begin{tabular}{|l|c|c|c|c|c|c|c|}
\hline \multirow{2}{*}{ Material } & \multicolumn{4}{c|}{$\begin{array}{c}\text { Proximate Analysis } \\
\text { (\% weight, wet basis) }\end{array}$} & \multicolumn{3}{c|}{$\begin{array}{c}\text { Proximate Analysis } \\
\text { (\% weight, dry basis) }\end{array}$} \\
\cline { 2 - 8 } & MC & VCM & FC & Ash & VCM & FC & Ash \\
\hline $\begin{array}{l}\text { Corn cob } \\
\text { (Stout, 1985) }\end{array}$ & 15.0 & 76.60 & 7.00 & 1.40 & 90.12 & 8.23 & 1.65 \\
\hline Stover (Stout, 1985) & 35.0 & 54.60 & 7.15 & 3.25 & 84.00 & 11.00 & 5.00 \\
\hline CGT & 9.01 & 64.78 & 14.36 & 11.85 & 71.20 & 15.78 & 13.02 \\
\hline Switchgrass & 10.31 & 73.24 & 13.01 & 3.44 & 81.67 & 14.51 & 3.82 \\
\hline Sorghum & 22.11 & 55.62 & 11.25 & 11.02 & 71.40 & 14.45 & 14.15 \\
\hline Woodchips & 21.05 & 67.46 & 10.07 & 1.42 & 85.44 & 12.76 & 1.80 \\
\hline
\end{tabular}

Table 2. Proximate analysis data for selected biomass.

\section{Biomass conversion processes}

The development of conversion technologies for the utilization of biomass resources for energy is growing at a fast pace. Most developing countries find it hard to catch up because 
the level of technology is beyond their manpower as well as their manufacturing and technological capability. Added to this is the unavailability of local materials and parts for the fabrication of these conversion units. Figure 1 shows the different methods for converting biomass into convenient fuel. Biomass conversion into heat energy is still the most efficient process but not all of energy requirement is in the form of heat. Biomass resources need to be converted into chemical, electrical or mechanical energy in order to have widespread use. These take the form of solid fuel like charcoal, liquid fuel like ethanol or gaseous fuel like methane. These fuels can be used in a wide range of energy conversion devices to satisfy the diverse energy needs. In general, conversion technologies for biomass utilization may either be based on bio-chemical or thermo-chemical conversion processes. Each process will be described separately.

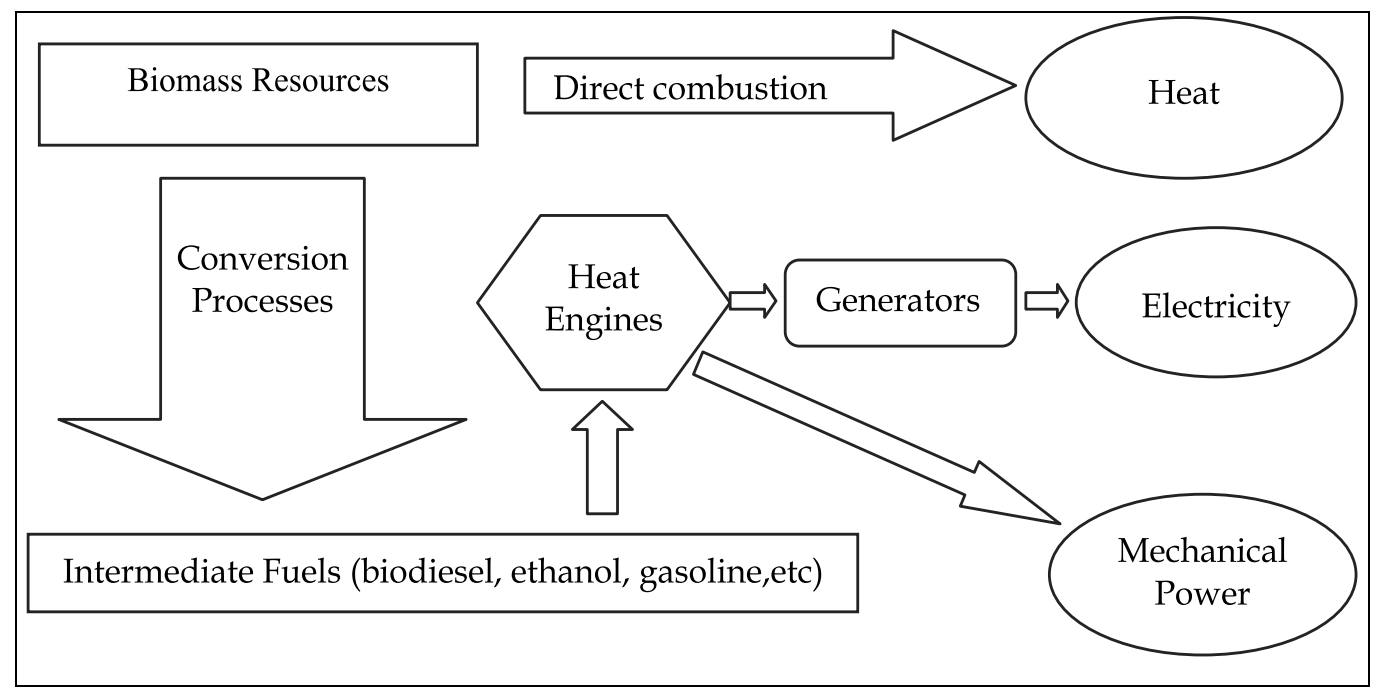

Fig. 1. Methods of using biomass for energy.

\subsection{Bio-chemical conversion processes}

The two most important biochemical conversion processes are the anaerobic digestion and fermentation processes.

\subsubsection{Anaerobic digestion}

Anaerobic digestion is the treatment of biomass with naturally occurring microorganisms in the absence of air (oxygen) to produce a combustible gaseous fuel comprising primarily of methane $\left(\mathrm{CH}_{4}\right)$ and carbon dioxide $\left(\mathrm{CO}_{2}\right)$ and traces of other gases such as nitrogen $\left(\mathrm{N}_{2}\right)$ and hydrogen sulphide $\left(\mathrm{H}_{2} \mathrm{~S}\right)$. The gaseous mixtures is commonly termed "biogas". Virtually all nitrogen $(\mathrm{N})$, phosphorus $(\mathrm{P})$ and potassium $(\mathrm{K})$ remain in the digested biomass.

The entire process takes place in three basic steps as shown in Figure 2. The first step is the conversion of complex organic solids into soluble compounds by enzymatic hydrolysis. The soluble organic material formed is then converted into mainly short-chain acids and alcohols during the acidogenesis step. In the methanogenesis step, the products of the second step are converted into gases by different species of strictly anaerobic bacteria. The percentage of methane in the final mixture has been reported to vary between 50 to $80 \%$. A 
typical mixture consists of $65 \%$ methane and $35 \% \mathrm{CO}_{2}$ with traces of other gases. The methane producing bacteria (called methanogenic bacteria) generally require a $\mathrm{pH}$ range for growth of 6.4 to 7.2. The acid producing bacteria can withstand low $\mathrm{pH}$. In doing their work, the acid producing bacteria lower the $\mathrm{pH}$ and accumulate acids and salts of organic acids. If the methane-forming organisms do not rapidly convert these products, the conditions become adverse to methane formers. This is why the first type of reactors developed for conversion of biomass wastes into methane have long retention times seeking equilibrium between acid and methane formers.

Municipal wastes and livestock manures are the most suitable materials for anaerobic digestion. In the US, numerous landfill facilities now recover methane and use it for power generation. Aquatic biomass such as water hyacinth or micro-algae can be digested and may become valuable sources of energy in the future. Anaerobic digestion of organic wastes may constitute an effective device for pollution control with simultaneous energy generation and nutrient conservation. A major advantage of anaerobic digestion is that it utilizes biomass with high water contents of as high as $99 \%$. Another advantage is the availability of conversion systems in smaller units. Also the residue has fertilizer value and can be used in crop production. The primary disadvantage of anaerobic digestion of diluted wastes is the large quantity of sludge that must be disposed of after the digestion process including the wastewater and the cost of biogas storage. In cold climates, a significant fraction of the gas produced may be used to maintain the reactor operating temperature. Otherwise, microorganisms that thrive on lower or moderate temperatures should be used.

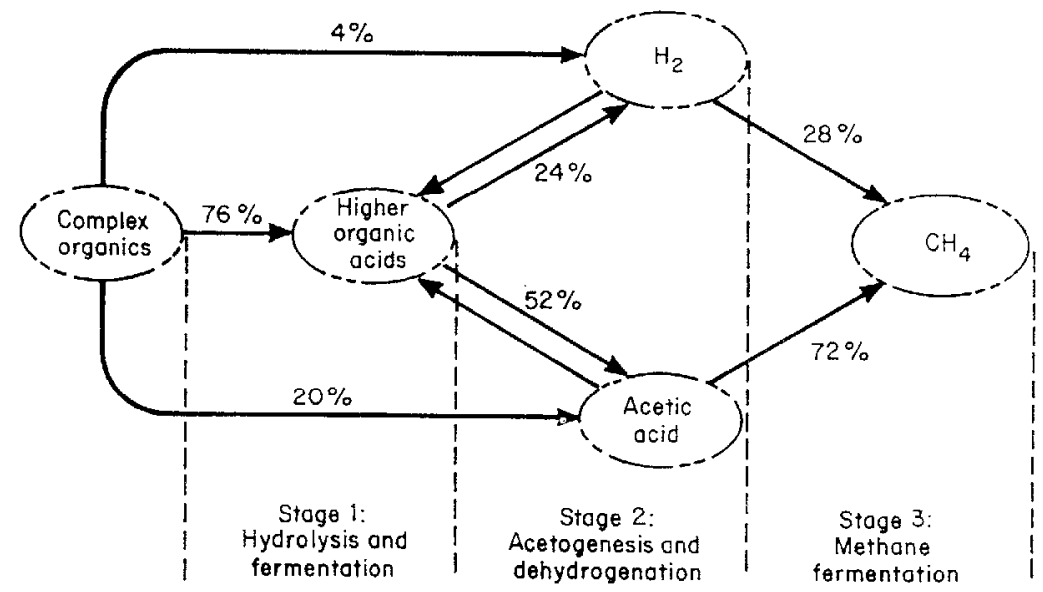

(Source: American Chemical Society)

Fig. 2. Steps in anaerobic digestion process with energy flow represented as \% chemical oxygen demand (COD).

\subsubsection{The first generation biogas reactors}

Three main types of biogas facilities have been successfully developed in Asia for widespread biogas production in households and industrial use. These are the "Chinese Digester" of fixed dome type, the "Indian Gobar Gas Plant" of floating gas holder type and the rectangular commercial size biogas digesters developed in Taiwan. These are what we may call the first generation biogas reactors. Shown in Figure 3 is the common Chinese digester design. These 
designs have eliminated the use of a floating gas holder and incorporated local materials for construction (brick or concrete). Biogas is pressurized in the dome and can be easily used for cooking and lighting. Figure 4 shows the "Indian Gobar Gas Plant" with floating gas holder.

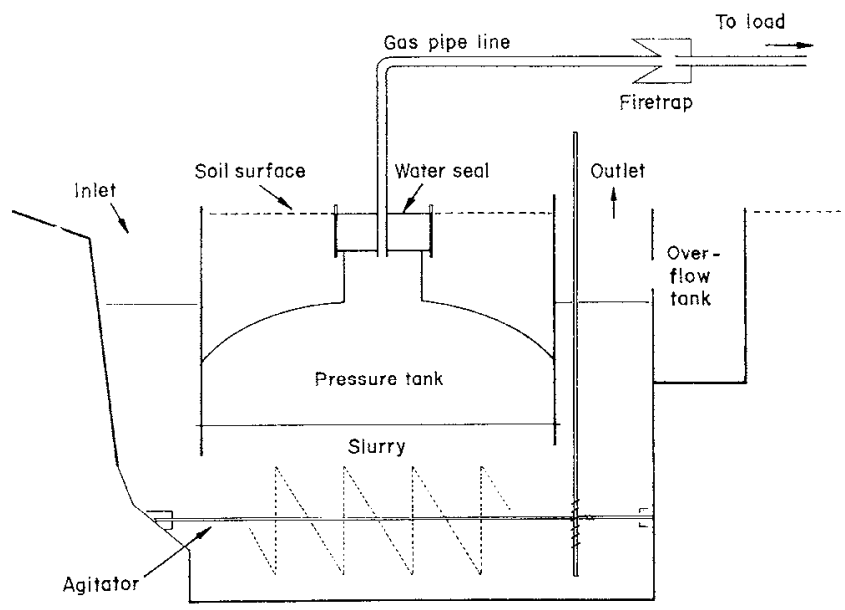

Fig. 3. The "Chinese Digester" of the dome type.

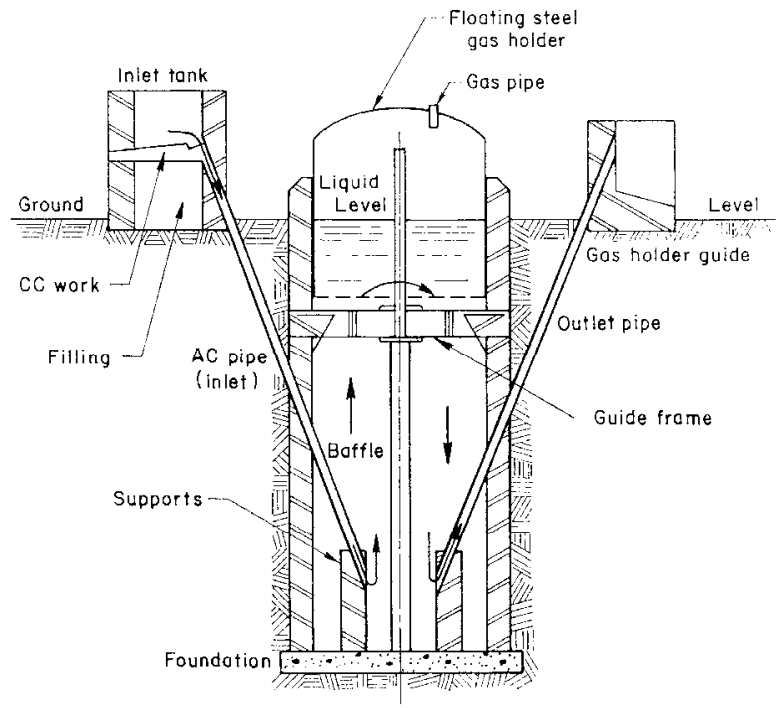

Fig. 4. The "Indian Gobar Gas Plant" schematic showing cross-sectional design.

The Indian design uses concrete inlet and outlet tanks and reactor. The steel cover acts as the floating gasholder. These digesters have no pumps, motors, mixing devices or other moving parts and digestion takes place at ambient temperature. As fresh material is added each day, digested slurry is displaced through an outlet pipe. The digesters contain a baffle in the center which ensures proper utilization of the entire digester volume and prevents short circuiting of fresh biomass material to the outlet pipe. 
Figure 5 is an example of a rectangular biogas digester used in commercial swine facilities in Taiwan. Similar reactors have been built and used in the Philippines for commercial swine facilities (Maramba, 1978). The gas holder is designed and constructed separately.

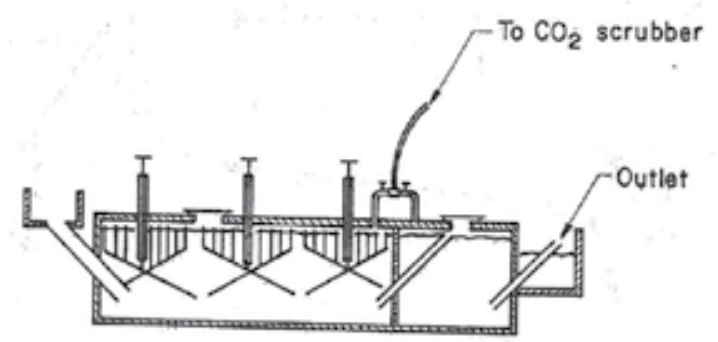

Fig. 5. The Taiwan rectangular digester design with a separate gas holder.

While the above designs have been operated successfully, the reactors are still considered World War II technologies. The main disadvantage is the long retention times of between 30 to 60 days. Thus, for large scale units, they require larger reactor volumes which make the initial cost and area requirements quite high. Their main advantage is the fact that these units have less maintenance and operational costs and they are less prone to breakdowns due to variations in the quantity and quality of feed. They are resistant to shock loadings and minimal process parameters are monitored for efficient operation. The only operating procedure made is the daily mixing of the slurry.

\subsubsection{The second generation biogas digesters}

There are now new technologies which we may call the second generation biogas digesters. These high rate bio-reactors were originally designed for low strength liquid wastes but the progress has been remarkable and most units can now be used for even the high strength wastes with high quantities of suspended solids like those of livestock manure.

Callander, et al., (1983), have made an extensive review of the development of the high rate digester technology. The improvements of such digesters can be largely attributed to better understanding of the microbiology of the methane production process. The most popular high rate anaerobic digesters originated from many conventional wastewater treatment plants that utilizes the anaerobic contact process (Figure 6) followed by the anaerobic clarigester. Perhaps the design that has caused widespread attention is the development of the upflow anaerobic sludge blanket (UASB) developed in Netherlands (Letingga, et al., 1980). Many commercial high rate digesters are now based on this design. Other reactors include the anaerobic filters (Young, et. al., 1969), the expanded bed fixed film reactor, and the stationary fixed film reactor.

As researchers began to understand the microbiology of the processes, they began to realize the varied nature and characteristics of the microorganisms used in the conversion. Thus recent designs call for the separation of two types of microorganisms in the reactors. Some new reactors are designed whereby acid forming bacteria are separated from the methane producing bacteria. With this design, the acid formers are now independent from the methane formers and therefore each group of microorganisms can do its job without harming the population of the other types of microorganisms.

The retention times have been reduced for most of the high rate biogas digesters and thus reducing the size of the digesters. However, there are corresponding need for a modest 
laboratory for microbial analysis, system $\mathrm{pH}$ control and monitoring of other parameters such as buffering capacity, solids retention times, alkalinity and the like.

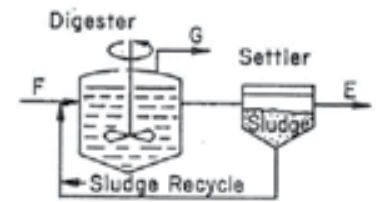

ANAEROBIC CONTACT PROCESS
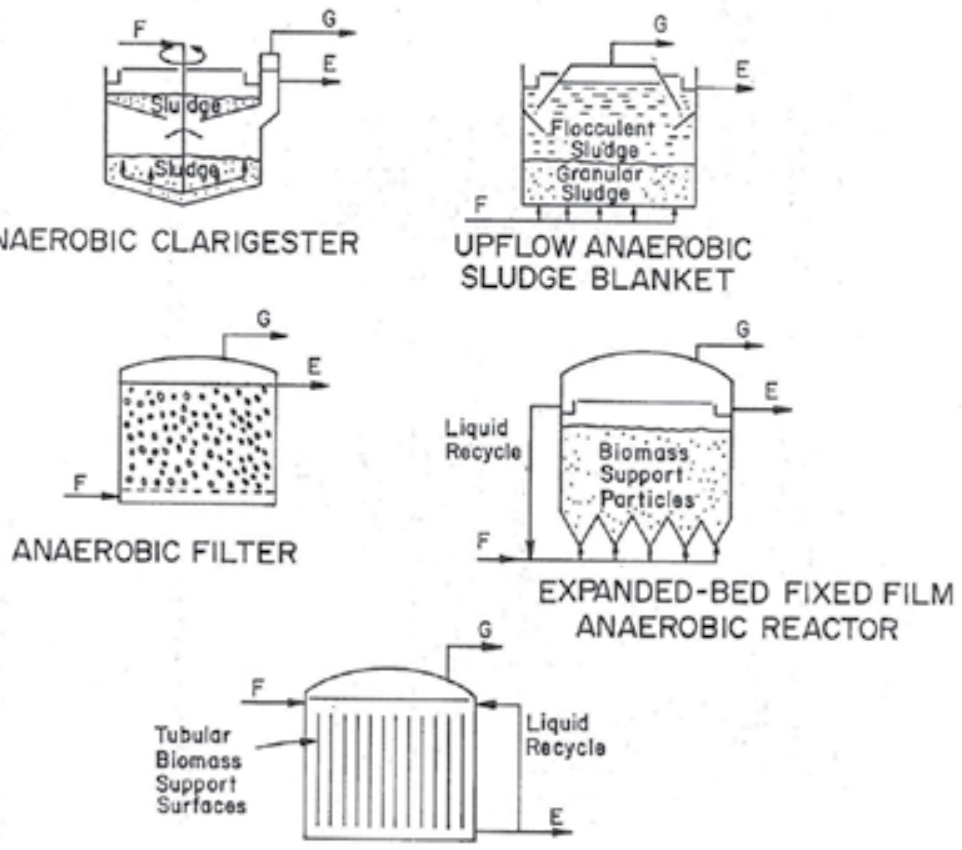

STATIONARY FIXED-FILM REACTOR

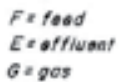

Fig. 6. Some examples of second generation biogas digesters.

\subsubsection{Ethanol fermentation}

Ethyl alcohol can be produced from a variety of sugar containing materials by fermentation with yeasts. Strains of Saccharomyces cerevisiae are usually selected to carry on the fermentation that converts glucose $\left(\mathrm{C}_{6} \mathrm{H}_{12} \mathrm{O}_{6}\right)$ into ethyl alcohol $\left(\mathrm{C}_{2} \mathrm{H}_{5} \mathrm{OH}\right)$ and carbon dioxide $\left(\mathrm{CO}_{2}\right)$. In the batch process the substrate is diluted to a sugar content of about $20 \%$ by weight, acidified to ph $4-5,8-10 \%$, the liquid is distilled, fractionated and rectified. One gallon of alcohol (3.79 liters, $21257 \mathrm{kcal})$ is obtained from 2.5 gallons of cane molasses or the equivalent of $5.85 \mathrm{~kg}$ of sugar $(21,842 \mathrm{kcal})$. So there is almost no energy loss in the fermentation process.

When a starchy material, such a corn, grain sorghum or barley, is used as substrate, the starch must be converted into fermentable sugars before yeast fermentation. The 
decomposition of large organic molecules requires the catalytic action of certain enzymes also produced by microorganisms. The most popular microbe is the Aspegillus niger.

Crops mentioned as potential substrate for the production of alcohol include sugarcane, sorghum, cassava, and sugar beets. The two main by-products of then fermentation are $\mathrm{CO}_{2}$ and the spent materials, which will contain the non-fermentable fraction of the substrate, the non-fermented sugars and the yeast cells. The two most important reasons for the high costs for ethanol production are: the batch nature of the process and the end-product (ethanol) inhibition of the yeast.

Continuous fermentation has been found successful on a laboratory scale. One way of avoiding end product inhibition is operation under vacuum so that ethanol is removed as it is formed. More researches are underway. Figure 7 shows a schematic diagram for the production of high percent ethanol from cassava (NRC, 1983).

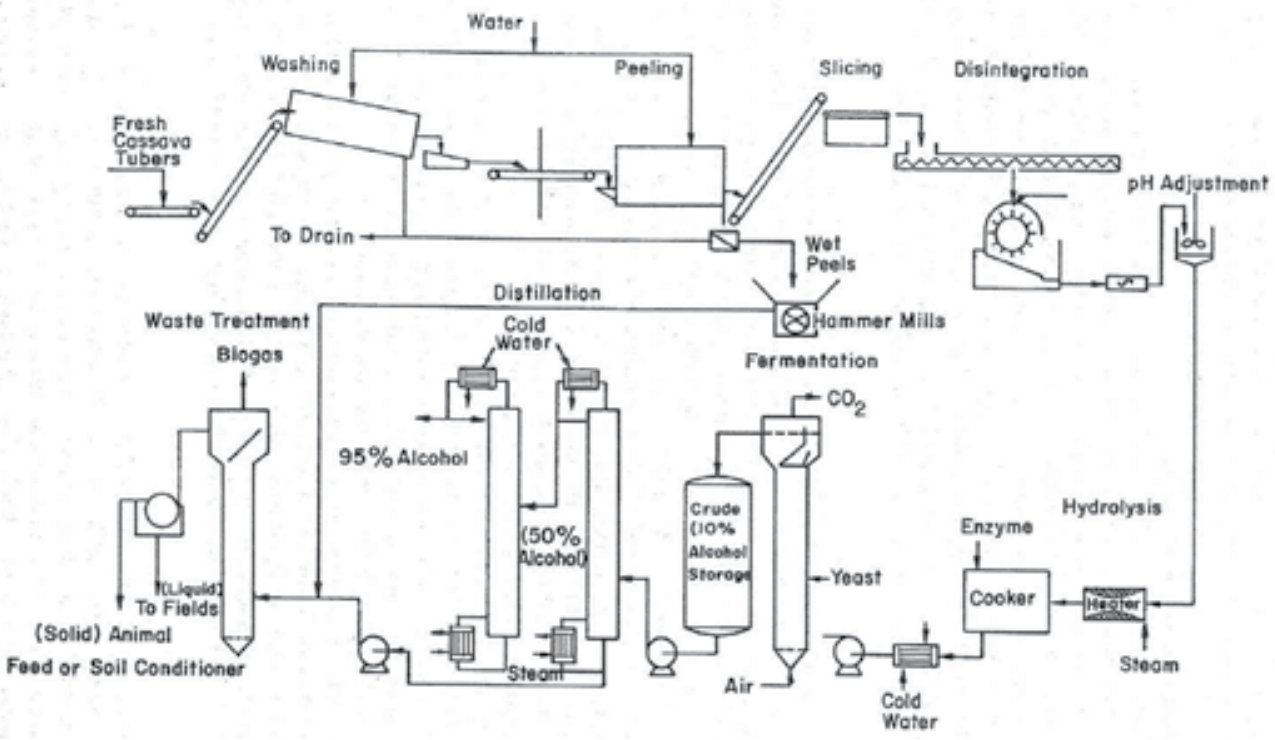

Fig. 7. Schematic of ethanol production from cassava.

If the feedstock is high in cellulosic components, these must be hydrolyzed also by a different sets of enzymes to break down the long chain cellulose structure into shorter chain compounds. In our laboratory facilities, we made use of enzymes produced by Trichoderma reesi. Commercially, genetically modified $T$. reesi may be sourced from Genencor International (Palo Alto, California, USA).

\subsection{Thermo-chemical conversion processes}

Biomass wastes can be easily converted into other forms of energy at high temperatures, They break down to form smaller and less complex molecules both liquid and gaseous including some solid products. Combustion represents a complete oxidation to carbon dioxide $\left(\mathrm{CO}_{2}\right)$ and water $\left(\mathrm{H}_{2} \mathrm{O}\right)$. By controlling the process using a combination of temperature, pressures and various catalysts, and through limiting the oxygen supply, partial breakdown can be achieved to yield a variety of useful fuels. The main thermochemical conversion approaches are as follows: pyrolysis/charcoal production, gasification 
and combustion. The advantages of thermo-chemical conversion processes include the following:
a. Rapid completion of reactions
b. Large volume reduction of biomass
c. Range of liquid, solid and gaseous products are produced
d. Some processes do not require additional heat to complete the process

\subsubsection{Pyrolysis}

Pyrolysis or destructive distillation is an irreversible chemical change caused by the action of heat in the absence of oxygen. Pyrolysis of biomass leads to gases, liquids and solid residues. The important components of pyrolysis gas in most cases are hydrogen, carbon monoxide, carbon dioxide, methane and lesser quantities of other hydrocarbons $\left(\mathrm{C}_{2} \mathrm{H}_{4}\right.$, $\mathrm{C}_{2} \mathrm{H}_{6}$, etc.). The liquid consists of methanol, acetic acid, acetone, water and tar. The solid residue consists of carbon and ash. Thus pyrolysis can be used to convert biomass into valuable chemicals and industrial feedstock.

In a typical pyrolysis process the feed material goes through the following operations: (a) primary shredding (b) drying the shredded material (c) removal of organics (d) further shredding to fine size (e) pyrolysis (f) cooling of the products to condense the liquids and (g) storage of the products.

Different types of pyrolytic reactors include vertical shaft reactors, horizontal beds. Among these, the simplest and generally cheapest is the vertical shaft type. Fluidized bed reactors are relatively a recent development. Figure 8 shows a rotary kiln pyrolysis reactor. The unit is cylindrical, slightly inclined and rotates slowly which causes the biomass to move through the kiln to the discharge end.

Numerous technologies have now been developed for the production of bio-oil and char using the pyrolysis process, Many of the reactors developed are improvements on the traditional reactors used in rural areas of developing countries that include simple pit kilns or drum type reactors. The energy efficiency of charcoal production using these methods is only the order of $17-29 \%$ while theoretically, efficiencies as high as $40 \%$ could be achieved.

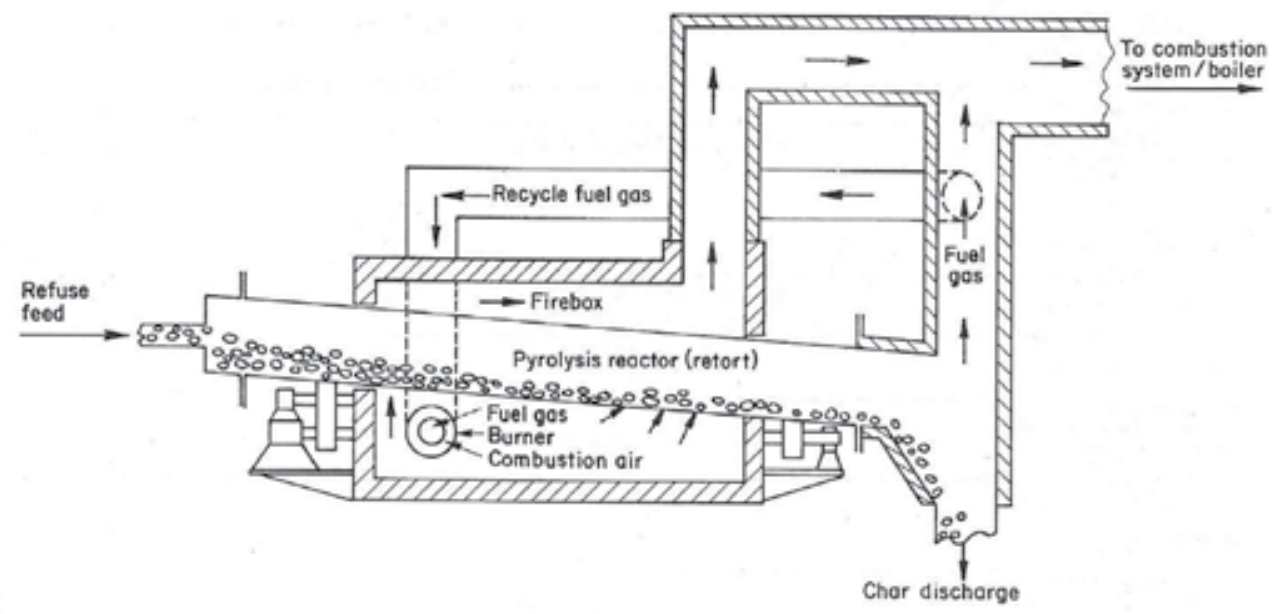

Fig. 8. Schematic of the rotary kiln pyrolysis reactor. 


\subsubsection{Gasification}

Gasification is the thermo-chemical process of converting biomass waste into a low medium energy gas utilizing sub-stoichiometric amounts of oxidant (Coovattanachai, 1991). The simplest form of gasification is air gasification in which biomass is subjected to partial combustion with a limited supply of air. Air gasifiers are simple, cheap and reliable. Their chief drawback is that the gas produced is diluted with nitrogen and hence has low calorific value. The gas produced is uneconomical to distribute; it must be used on-site for process heat. In oxygen gasification, pure oxygen is used so that the gas produced is of high energy content. The chief disadvantage of oxygen gasification is that it requires an oxygen plant and thus increases the total cost of gasification. The schematic diagram of the processes occurring is a gasifier is shown in Figure 9 including the temperature profile at each important step in the process.
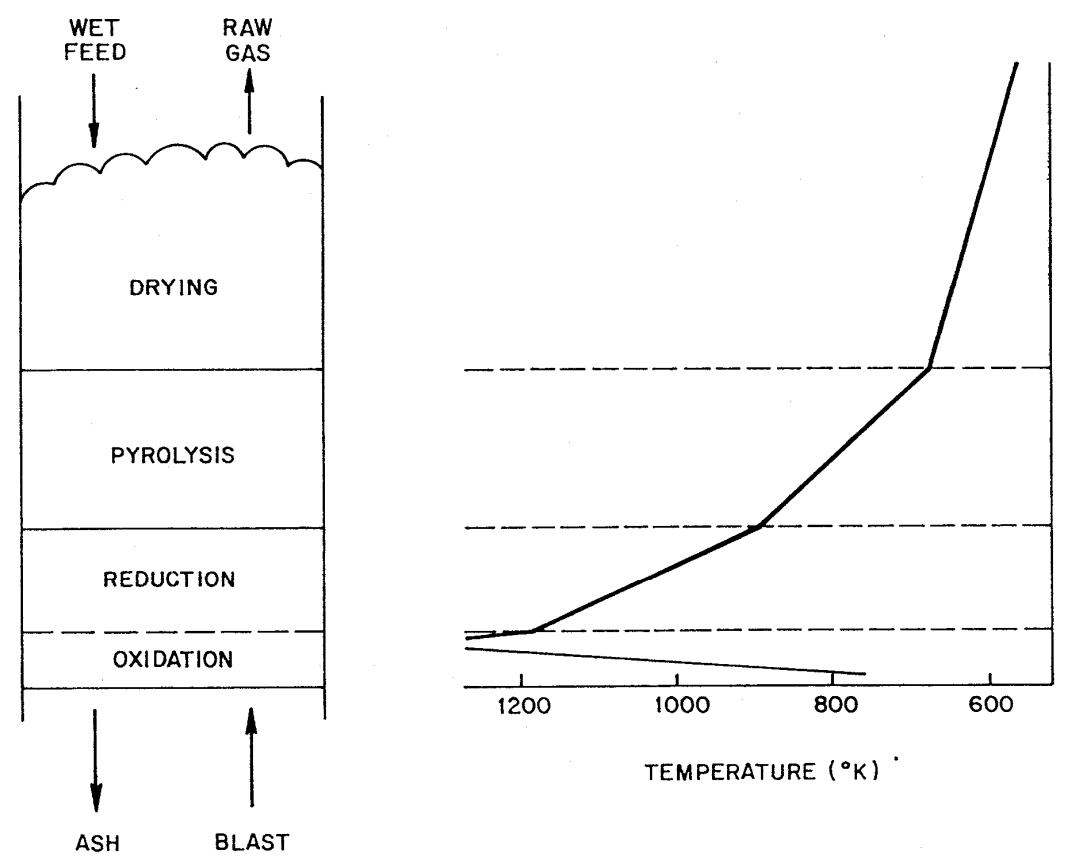

Fig. 9. Schematic diagram of processes occurring in a gasifier and the temperature profile.

The simplest air gasifier is the updraft gasifier shown in Figure 10. Air is introduced at the bottom of the bed of biomass near the hearth zone. The gas produced is usually at a low temperature. The sensible heat of the gas is used to dry and preheat the biomass before it reaches the reduction zone. Products from the distillation and drying zones consist mainly of water vapor, tar and oil vapors and are not passed through the hot bed. They therefore leave the reactor uncracked and will later condense at temperatures between $125^{\circ} \mathrm{C}-400^{\circ} \mathrm{C}$.

Because the tar vapors leaving an updraft gas producer seriously interfere with the operation of internal combustion engines, the downdraft gasifiers (Barret, et. al., 1985) are more extensively used. The air is introduced into a downward flowing bed of solid fuel and the gas outlet is at the bottom as shown in Figure 11. The tarry oils and vapors given off in 
the distillation zone are cracked and reduced to non-condensible gaseous products while passing through the oxidation (hearth) zone. Downdraft gasifiers have a reduced crosssectional area above which the air is introduced. The throat ensures a homogeneous layer of hot carbon through which the distillation gases must pass.

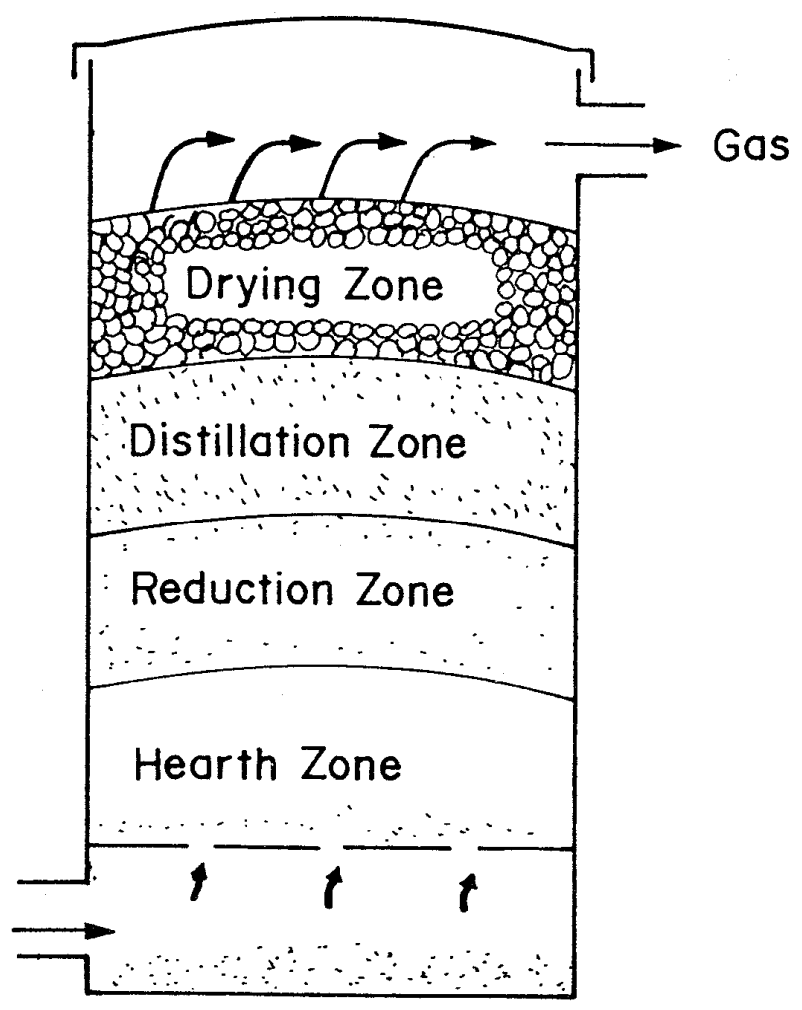

Ash Zone

Fig. 10. Schematic diagram of an updraft gasifier.

The crossdraft gasifier is also a fixed bed gasifier where the feed material could be moved by gravity while the flow of air is at an angle against the feed flow. The usual flow of air is perpendicular to the flow of biomass. They have almost the same performance as the updraft and downdraft gasifiers.

A fluidized bed gasifier (LePori and Soltes, 1985) consists of a fluidized bed of inert particles in which biomass is fed. The gas stream generally carries with it the char particles out of the bed. These particles are separated from the gas by means of cyclones. Fluidized beds can gasify much higher amounts of biomass area per unit of time compared to the other types of gasifiers. The precise composition of the gas from the gasifiers depends on the type of biomass used, the temperature and rate of reaction. Typically, if wood is used as the feed, the gas composition is shown in Table 3. The heat content is about $5500 \mathrm{~kJ} / \mathrm{m}^{3}$. The synthesis gas quality for the Texas A\&M University fluidized bed gasifier is shown in Table 4 (Lepori, 1985). A schematic of a fluidized bed gasifier is shown in Figure 12. 


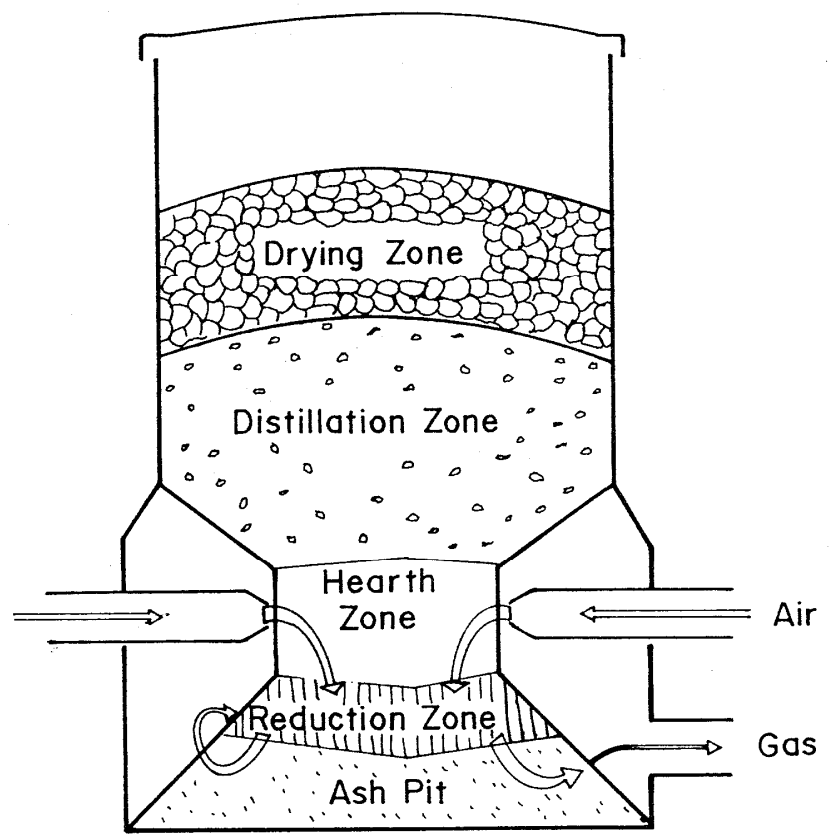

Fig. 11. Schematic diagram of a downdraft draft gasifier.

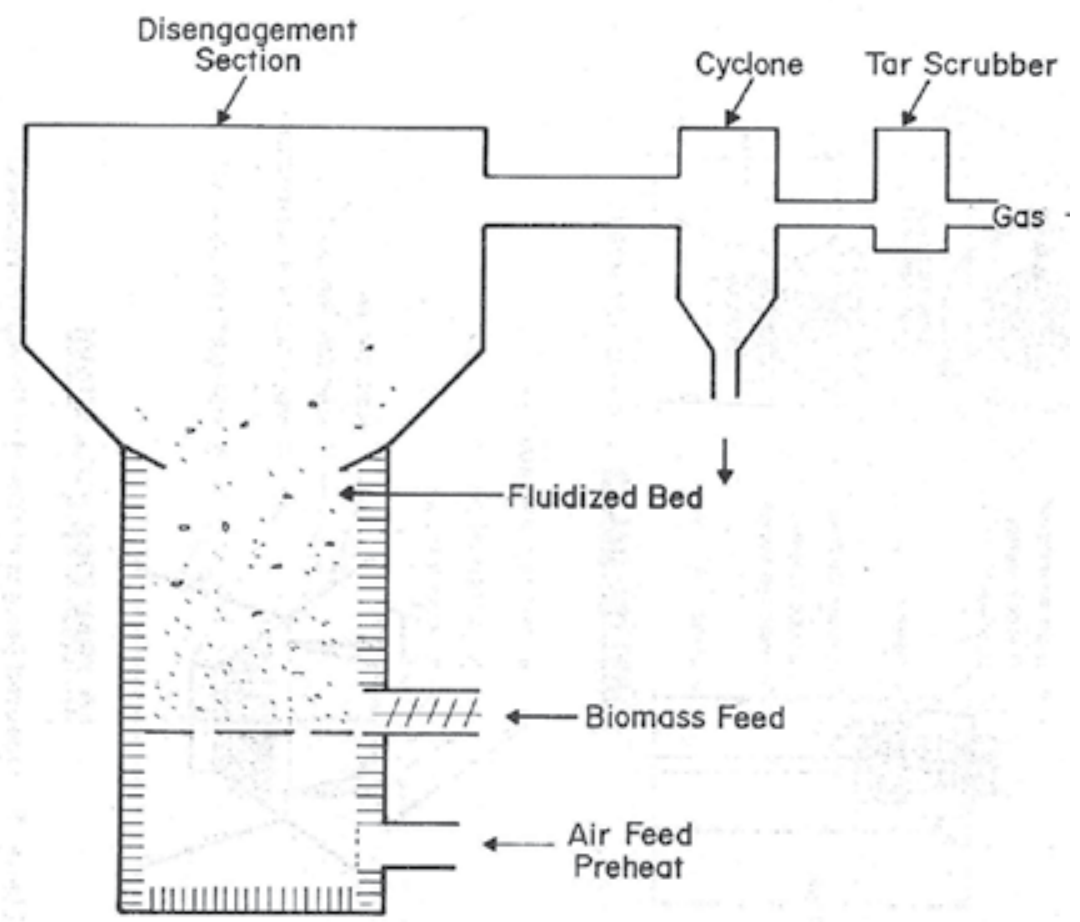

Fig. 12. Schematic diagram of a fluidized bed gasifier. 


\begin{tabular}{|ll|c|}
\hline \multicolumn{2}{|l|}{ Type of Gas } & Percent Composition \\
\hline 1. & Carbon dioxide $\left(\mathrm{CO}_{2}\right)$ & $10 \%$ \\
\hline 2. & Carbon monoxide $(\mathrm{CO})$ & $20-22 \%$ \\
\hline 3. & Hydrogen $\left(\mathrm{H}_{2}\right)$ & $12-15 \%$ \\
\hline 4. & Methane $\left(\mathrm{CH}_{4}\right)$ & $2-3 \%$ \\
\hline 5. & Nitrogen $\left(\mathrm{N}_{2}\right)$ & $50-53 \%$ \\
\hline
\end{tabular}

Table 3. Typical gas composition of a fluidized bed gasifier using wood as feedstock.

\begin{tabular}{|ll|c|}
\hline Type of Gas & Percent Composition \\
\hline 1. & Carbon dioxide $\left(\mathrm{CO}_{2}\right)$ & $18.25 \%$ \\
\hline 2. & Carbon monoxide $(\mathrm{CO})$ & $13.44 \%$ \\
\hline 3. & Hydrogen $\left(\mathrm{H}_{2}\right)$ & $14.68 \%$ \\
\hline 4. & Methane $\left(\mathrm{CH}_{4}\right)$ & $3.21 \%$ \\
\hline 5. & Nitrogen $\left(\mathrm{N}_{2}\right)$ & $47.31 \%$ \\
\hline 6. & Ethylene $\left(\mathrm{C}_{2} \mathrm{H}_{4}\right)$ & $1.83 \%$ \\
\hline 7. & Ethane $\left(\mathrm{C}_{2} \mathrm{H}_{6}\right)$ & $0.36 \%$ \\
\hline
\end{tabular}

Table 4. Typical gas composition of the TAMU fluidized bed gasifier.

\subsubsection{Biomass combustion}

One of the most common methods of biomass conversion is by direct combustion or burning. The simplest units include numerous cookstoves already developed in rural areas of developing countries. Much improved and continuous flow designs include the SpreaderStoker system (similar to that shown in Figure 13) used in many refuse derived fuels (RDF) facility for converting solid wastes, and the fluidized bed combustion units (similar to that shown in Figure 12). The number component parts of this system is listed below:

1. Refuse charging hopper

2. Refuse charging throat

3. Charging ram

4. Grates

5. Roller bearings

6. Hydraulic power cylinders and control valves

7. Vertical drop-off

8. Overfire air jets

9. Combustion air

10. Automatic sifting removal system

In a spreader-stoker system, the fuel is introduced into the firebox above a grate. Smaller particles will tend to burn in suspension and larger pieces will fall onto the grate. Most units, if properly designed, can handle biomass with moisture content as high as $50-55 \%$. Moisture contained in the fuel is driven off partially when the fuel is in suspension and partially on the grate. The feed system should provide an even thin layer of fuel on the grate.

In a fluidized bed combustor (FBC), the fuel particle burns in a fluidized bed of inert particles utilizing oxygen from the air. Advantages of fluidized bed combustion include: (1) high heat transfer rate, (2) increased combustion intensity compared to conventional combustors and, (3) 
absence of fouling and deposits on heat transfer surfaces. The schematic diagram of a fluidized bed combustor is similar to that of a fluidized bed gasifier. The only difference is the use of excess air for combustion processes and starved air for gasification processes.

So far FBC has been used mostly for coals. A number of wastes, e.g. wastes from coal mining and municipal wastes, are also sometimes incinerated in fluidized beds. It has been suggested that certain quick-maturing varieties of wood could be combusted in fluidized beds for generation of steam. There is indeed a global search for suitable varieties of wood for this purpose and $\mathrm{FBC}$ is likely to play an important role in supplying energy requirements in certain countries in the future.

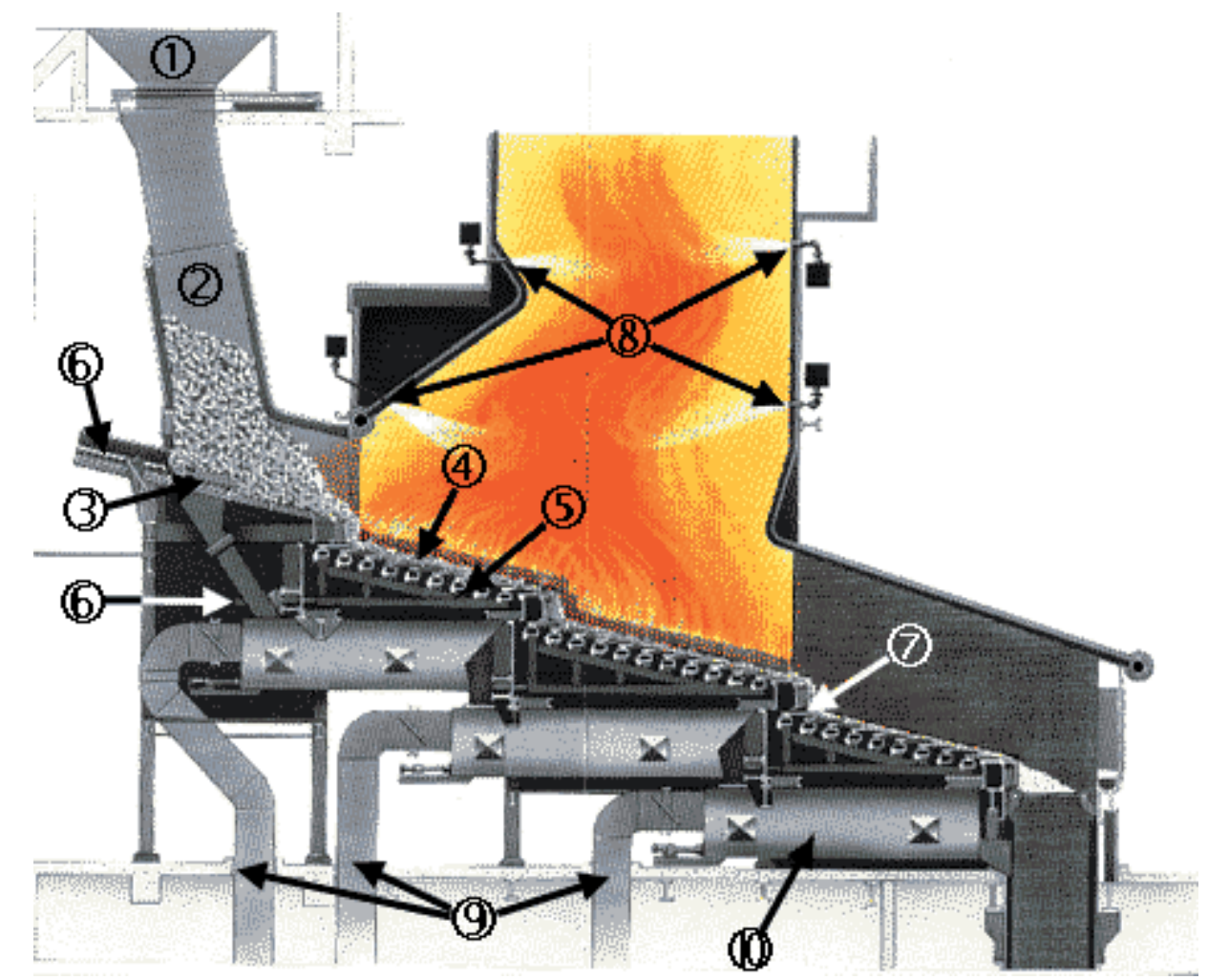

Fig. 13. Schematic diagram of a reciprocating grate combustor (Courtesy of Detroit Reciprogate Stocker).

Granular biomass fuels, e.g. paddy husk and chips of wood up to $2 \mathrm{~cm} \times 2 \mathrm{~cm} \times 2 \mathrm{~cm}$ in size have been successfully combusted in fluidized beds of sand particles. Conventional combustion of paddy husk is slow and inefficient. Nearly complete combustion and high combustion intensities of paddy husk can be achieved in a fluidized bed combustor. The same combustor can also be used for burning wood. Combustion intensities up to about 500 $\mathrm{Kg} / \mathrm{hr}-\mathrm{m}^{2}$ have been achieved in fluidized bed combustors using biomass fuels.

A number of thermo-chemical conversion processes exist for converting biomass into liquid fuels. These can be crudely divided into direct liquefaction and indirect liquefaction (in which the biomass is gasified as a preliminary step) processes. While all these techniques are relatively sophisticated and will generally be suitable for large scale conversion facilities, 
they do represent an important energy option for the future because the heavy premium that liquid fuels carry.

The steam produced from heat of combustion of biomass may power a steam turbine to produce electricity. However, because of the high ash contents of most biomass resources, direct combustion of these biomass resources is not practical and efficient due to slagging and fouling problems. Because of these problems, some biomass with high ash are often mixed with low ash biomass such as coal, also termed co-firing.

\subsubsection{Biomass co-firing}

Co-firing refers to mixing biomass and fossil fuels in conventional power plants. Significant reductions in sulfur dioxide $\left(\mathrm{SO}_{2}-\right.$ an air pollutant released when coal is burned) emissions are achieved using co-firing systems in power plants that use coal as input fuel. Small-scale studies at Texas A\&M University show that co-firing of manure with coal may also reduce nitrogen oxides (NOx- contribute to air pollution) emissions from coal (Carlin, 2009). Manure contains ammonia $\left(\mathrm{NH}_{3}\right)$. Upon co-firing manure and coal, $\mathrm{NH}_{3}$ is released from manure and combines with NOx to produce harmless $\mathrm{N}$ and water.

Biomass co-firing has the potential to cut emissions from coal powered plants without significantly increasing the cost of infrasructure investments (Neville, 2011). Research shows that when implemented at relatively low biomass-to-coal ratios, energy consuption, solid waste generation and emissions are all reduced. However, mixing biomass and coal (especially manure) does create some challenges that must be address.

There are three types of co-firing systems adopted around the world as follows:

a. Direct co-firing

b. Indirect co-firing, and

c. Separate biomass co-firing.

Direct co-firing is the simplest of the three and the most common option especially if the biomass have very similar characteristics with coal. In this process, more than one type of fuel is injected into the furnace at the same time. Indirect co-firing involves converting the biomass into gaseous form before firing. The last type has a separate boiler for the co-fired fuel.

It was reported that the carbon life cycle and energy balance when co-firing $15 \%$ biomass with coal is carbon neutral or better (Eisenstat, et al., 2009). In this research, carbon emissions are reduced by $18 \%$.

\section{Conclusion}

From the above discussions we observe a rapid development of technologies for the conversion of biomass into heat energy and fuels. Countries should take advantage of these rapidly developing technologies. However, as more conversion technologies are developed, the biomass resource base may be the next constraint. Thus, methods to diversify the biomass resource base have to be made in conjunction with the use of emerging technologies for conversion. The sources of biomass have to be broadened from the traditional crop residues, livestock manure and fuel wood to culturing energy crops such as aquatic biomass (e.g. algae) while recovering the energy from municipal solid wastes and sewage.

Attempt has to be made to make use of more efficient equipment and technologies for energy utilization. In anaerobic digestion for example, many countries are still utilizing age old first generation anaerobic reactors while high rate biogas reactors are already gaining 
popularity. In the implementation of new and emerging technologies, lessons learned from past experiences must be taken into consideration. Many of these technologies require highly qualified and skilful manpower, more advanced monitoring techniques and equipment and materials that many developing countries may not have. The government of each country should have an active role to support the developing of such technologies including massive information campaign and training and improvement of local expertise in the use of advanced materials and process equipment for biomass conversion into energy and fuels.

Finally, to reverse the trend in the depletion of agriculture and forestry resources, massive reforestation program must be made together with developing technologies for harvesting, pre-processing and storage of biomass. This should be implemented together with infrastructure development for efficient transport of biomass to where it is needed or develop technologies that will be brought to where biomass resources are abundant.

\section{References}

Annamalai, K, J. M. Sweeten and S. C. Ramalingam. 1987. Estimation of Gross heating Values of Biomass Fuels. Transactions of the ASAE, American Society of Agricultural Engineers, Vol. 30(4): 1205-1208.

Barret, J.R., R.B. Jacko and C.B. Richey. 1985. Downdraft Channel Gasifier Furnace for Biomass Fuels. Transactions of the ASAE, American Society of Agricultural Engineers. Vol. (32): 592-598. St. Joseph, MI.

Callander, I.J. and J.P. Barford. 1983. Recent Advances in Anaerobic Digestion Technology. Proc. Biochem. 18(4):24-30 and 37.

Carlin, N. T. 2009. Optimum Usage and Economic Feasibility of Animal Manure-Based Biomass in Combustion Systems. Ph.D. Dissertation, Department of Mechanical Engineering, Texas A\&M University, College Station, Texas.

Coovattanachai, N. 1991. Gasification of Husk for Small Scale Power Generation. RERIC International Energy Journal. 13(1):1-17.

Eisenstat, L., A. Weinstein and S. Wellner. 2009. Biomass Co-firing: Another Way to Clean Your Coal. Power Vol. 153 Issue 7, 68-71 (July 2009).

Energy Information Administration. 2002. Annual Energy Outlook. DOE/EIA-0383 (2002). Washington, DC. USA.

Gupta, S. C. and P. Manhas. 2008. Percentage Generation and Estimated Energy Content of Municipal Solid Waste at Commercial Area of Janipur, Jammu. Environmental Conservation Journal 9(1): 27-31.

Haq, Zia. 2002. Biomass for Electricity Generation. EIA, US Department of Energy, 1000 Independence Ave., SW, Washington, DC. USA.

LePori, W.A. 1985. Thermo-chemical Conversion of Biomass Using Fluidized Bed Technology. ASAE Paper No. 85-3701, ASAE, St. Joseph, MI 49085.

LePori, W. A. and E. J. Soltes. 1985. Thermochemical Conversion for Energy and Fuel. In : Biomass Energy : A Monograph. E. A. Hiler and B. A. Stout : Editors. Texas A\&M University Press, College Station, Texas, USA.

Lettinga, G., A.F.M. Van Velsen, S.W. Homba, W. de Zeeuw, and A. Klapwijk. 1980. Use of the Upflow Sludge Blanket (USB) Reactor Concept for Biological Wastewater Treatment, Especially for Anaerobic Treatment. Biotech and Bioengineering. 22:699734. 
Maramba, F.D. Sr. 1978. Biogas and Waste Recycling. Regal Printing Company, Manila Philippines.

National Research Council (NRC) of America. 1983. Alcohol Fuels: Options for Developing Countries. 1983. Report of an Ad Hoc Panel of the Advisory Committee on Technology Innovation, Board on Science and Technology for Internal Development, Office of Internal Affairs, National Research Council. National Academy Press, Washington, D.C.

Neville, A. 2011. Biomass Co-firing: A Promising New Generation Option. Power, Volume 155 (4): 52-56 (April 2011).

Stout, B. A. 1984. Energy Use and Management in Agriculture. Breton Publishers. North Scituate, Massachusetts.

Victor, N. M. and D. G. Victor. 2002. Macro Patterns in the Use of Traditional Biomass Fuels. Report on Stanford/TERI Workshop on "Rural Energy Transitions" held in New Delhi, India on November 5-7, 2002. Stanford University, Palo Alto, California, USA.

Young, J.C. and P.L. McCarty. 1969. The Anaerobic Filter for Waste Treatment. JWPCF. 41:r 160. 


\title{
Air Gasification of Malaysia Agricultural Waste in a Fluidized Bed Gasifier: Hydrogen Production Performance
}

\author{
Wan Azlina Wan Ab Karim Ghani1,2, Reza A. Moghadam ${ }^{1}$ and \\ Mohamad Amran Mohd Salleh ${ }^{1,2}$ \\ ${ }^{1}$ Department of Chemical and Environmental Engineering, \\ The Universiti Putra Malaysia, Serdang, Selangor, \\ ${ }^{2}$ Green Engineering and Sustainable Technology Lab, Institute of Advanced \\ Technology(ITMA), Universiti Putra Malaysia, Serdang, Selangor, \\ Malaysia
}

\section{Introduction}

Recently, biomass gasification technology to produce hydrogen-rich fuel gas is highly interesting possibilities for biomass utilization as sustainable energy (McKendry, 2002). Hydrogen production from biomass gasification has many advantages as secondary renewable energy source as it is the universe's most abundant element, clean fuel has the potential to serve as renewable gaseous and liquid fuel for transportation vehicles. As a fuel, hydrogen is considered to be very clean as it releases no carbon or sulfur emissions upon combustion. The energy contained in hydrogen on a mass basis $(120 \mathrm{MJ} / \mathrm{kg})$ is much higher than coal $(35 \mathrm{MJ} / \mathrm{kg})$, gasoline $(47 \mathrm{MJ} / \mathrm{kg})$ and natural gas $(49.9 \mathrm{MJ} / \mathrm{kg})$. Additionally, the most important advantage for all the living beings is that when it is burned, hydrogen produces non toxic exhaust emissions. Clearly, the emissions from hydrogen combustion contain no carbon monoxide $(\mathrm{CO})$, carbon dioxide $\left(\mathrm{CO}_{2}\right)$ and unburned hydrocarbons (Veziroglu et al., 2005). Using biomass as an energy source can reduce the greenhouse gas emission that causes global warming which is a negative effect of using fossil fuels as an energy source.

In Malaysia, more than 2 million tonnes of agricultural wastes are produced annually and potentially an attractive feedstock for producing energy as the usage contributes little or no net carbon dioxide to the atmosphere. Major agricultural products are oil palms, sawlogs, paddy and tropical fruits. The palm oil sector is the biggest producer and hence the major contributor to the agricutural residues generation in Malaysia. The oil-palm solid wastes (including shell, fibre and Empty Fruit Bunch (EFB)) are abandoned materials produced during palm oil milling process. For every ton of oil-palm fruit bunch being fed to the palmoil refining process, about 0.07 tons of palm shell, 0.146 tons of palm fiber and 0.2 tons of EFB are produced as the solid wastes. Bagasse which is the matted cellulose fibre residue from sugar cane that has been processed in a sugar mill were produced about $3 \times 10^{5} \mathrm{~T}$ per year in 1999. Despite the decreasing acreage, coconut still plays an important role in the 
socio-economic position of the Malaysian rural population that involves 80,000 households. About $63 \%$ of coconut production, coconut fronds and shells represent the largest amount as residues (about 8\%) (Ninth Malaysia Plan 2006-2010). Table 1 summarize the estimations of the current and potential selected agicultural wastes (biomass) utilizations in annual energy productivity in Malaysia.

Thermo-chemical conversion processes, including gasification, pyrolysis and combustion have been proven the best available technology to convert these renewable materials into valuables fuel (hydrogen) and fine chemical feedstock. However gasification process offers technologically more attractive and useful options for medium and large scale applications due to presence of non-oxidation conditions and lower green house gases emission. Fluidized bed gasifier is proven to be a versatile technology capable of burning practically any wastes combination with low emissions. The significant advantages of fluidized bed gasifier over conventional gasifiers include their compact furnaces, simple designs, effective gasification of wide variety of fuels, relatively uniform temperatures and ability to reduce emissions of carbon dioxide, nitrogen oxides and sulfur dioxides.

\begin{tabular}{|c|c|c|c|c|c|}
\hline $\begin{array}{c}\text { Crops/ } \\
\text { Activities }\end{array}$ & $\begin{array}{c}\text { Energy } \\
\text { productivity } \\
\text { (boe/ha/year) }\end{array}$ & $\begin{array}{r}\text { Curren } \\
\text { Amount Us } \\
\text { Pur }\end{array}$ & $\begin{array}{l}\text { nual } \\
\text { r Energy }\end{array}$ & $\begin{array}{c}\text { Current Annu } \\
\text { Potential of } \\
\text { Biomass (mil }\end{array}$ & $\begin{array}{l}\text { Energy } \\
\text { ilised } \\
n \text { boe) }\end{array}$ \\
\hline Oil Palms & 88.7 & $\begin{array}{c}\text { Fruit shells } \\
\text { Fruit fibres } \\
\text { Effluents }\end{array}$ & $\begin{array}{c}23.609 \\
13.630 \\
0.022\end{array}$ & $\begin{array}{c}\text { Pruned fronds } \\
\text { EFB } \\
\text { Effluents } \\
\text { Replanting } \\
\text { wastes }\end{array}$ & $\begin{array}{c}77.665 \\
11.444 \\
2.928 \\
12.94\end{array}$ \\
\hline $\begin{array}{c}\text { Rubber } \\
\text { trees }\end{array}$ & 29.5 & Wood & 4.967 & $\begin{array}{c}\text { Wood } \\
\text { Effluents }\end{array}$ & $\begin{array}{l}3.707 \\
0.210\end{array}$ \\
\hline $\begin{array}{l}\text { Paddy } \\
\text { plants }\end{array}$ & 11.54 & & & $\begin{array}{l}\text { Rice husks } \\
\text { Rice straws }\end{array}$ & $\begin{array}{l}1.025 \\
2.541\end{array}$ \\
\hline $\begin{array}{l}\text { Coconut } \\
\text { trees }\end{array}$ & 28.21 & $\begin{array}{l}\text { Fronds } \\
\text { Shells }\end{array}$ & $\begin{array}{l}1.578 \\
0.785\end{array}$ & Fronds & 0.164 \\
\hline Cocoa trees & 80.33 & N.A. & N.A. & $\begin{array}{c}\text { Pruning } \\
\text { wastes } \\
\text { Pod husks } \\
\text { Replanting } \\
\text { wastes }\end{array}$ & $\begin{array}{c}16.850 \\
0.085 \\
0.630\end{array}$ \\
\hline Sugarcane & 54.9 & Bagasse & 0.421 & $\begin{array}{l}\text { Leaves and } \\
\text { tops }\end{array}$ & 0.298 \\
\hline Logging & - & - & & Residues & 19.060 \\
\hline $\begin{array}{c}\text { Timber } \\
\text { processing }\end{array}$ & - & $\begin{array}{c}\text { Sawdust \& } \\
\text { waste }\end{array}$ & 3.733 & $\begin{array}{c}\text { Tree bark and } \\
\text { sawdust }\end{array}$ & 1.0 \\
\hline
\end{tabular}

Table 1. Estimates of the energy productivity and biomass production and utilization (Ninth Malaysia Plan 2006-2010) 


\subsection{Hydrogen fuel}

Technology development for conversion of waste feedstock to hydrogen has an economical potential. Depletion of fossil fuel source such as oil, gas and coal is going to become the biggest problem in the near future. Therefore, hydrogen fuel from the biomass waste is the best supersede for fossil fuels. Hydrogen is not widely used today but it has a great potential as an energy carrier such as fuel cell that can be applied to power cars and factories and also for home usages in the future. In comparison with fossil fuels, $9.5 \mathrm{~kg}$ of hydrogen produce energy equivalent to that produced by $25 \mathrm{~kg}$ of gasoline (Mirza et al., 2009).

Hydrogen has the highest energy content of any common fuel by weight (about three times more than gasoline). Hydrogen is an odorless, tasteless, colorless and non-poisonous gas. It is a renewable resource found in all growing things. Hydrogen is an important raw material for chemical, petroleum and agro-based industries. The demand for hydrogen in the hydrotreating and hydrocracking of crude petroleum is steadily increasing (Min et al., 2005). Hydrogen is catalytically combined with various intermediate processing streams and is used in conjunction with catalytic cracking operations to convert heavy and unsaturated compounds to lighter and more stable compounds. Large quantities of hydrogen were used to purify gases such as argon that contain trace amounts of oxygen. Furthermore, in the food and beverages industry, hydrogen was used for hydrogenation of unsaturated fatty acids in animal and vegetable oils, to produce solid fat and other food products. While in manufacturing of semi conducting layers in integrated circuits, hydrogen were used as a carrier gas. The pharmaceutical industries use hydrogen to make vitamins and other pharmaceutical products. Hydrogen is mixed with inert gases to obtain a reducing atmosphere that is required for many applications in the metallurgical industry such as heat treating steel and welding (Delgado et al., 1997 and Dupont et al., 2008).

In 2005, the overall U.S. hydrogen market is estimated at $\$ 798.1$ million and it is expected to rise to $\$ 1,605.3$ million for U.S. and $\$ 740$ million for European in 2010 (Keizai, 2005). However, hydrogen production is not enough to uphold this value. The hydrogen technology had been intensively studied to find a variety of hydrogen source with different treatment processes because hydrogen has great potential as an environmentally clean energy fuel and as a way to reduce reliance on imported energy sources. In Asian region, the biomass from agriculture sector is the largest source of hydrogen production. Many experts predict that hydrogen will eventually power tomorrow's industries and thereby may replace coal, oil and natural gas. However, it will not happen until a strong framework of hydrogen production, storage, transport and delivery is developed.

\subsection{Biomass gasification}

According to Xiao et al. (2007), it is generally reported by different authors that the process of biomass gasification occurs through main three steps. At the first step in the initial heating and pyrolysis, biomass is converted to gas, char and tar. Homogeneous gas-phase reaction resulted in higher production of gaseous. High bed temperature during this phase allowed further cracking of tar and char to gases. Second step is tar-cracking step that favours high temperature reactions and more light hydrocarbons gases such as Hydrogen $\left(\mathrm{H}_{2}\right)$, carbon monoxide $(\mathrm{CO})$, carbon dioxide $\left(\mathrm{CO}_{2}\right)$ and methane $\left(\mathrm{CH}_{4}\right)$. Third step is char gasification step that is enhanced by the boudouard reaction.

The gasification mechanism of biomass particles might be described by the following reactions: 


$$
\text { Biomass } \rightarrow \text { Gas+ Tars }+ \text { Char }
$$

The Combustion reactions:

$$
\begin{gathered}
\mathrm{C}+1 / 2 \mathrm{O}_{2} \rightarrow \mathrm{CO}-111 \mathrm{MJ} / \mathrm{Kmol} \\
\mathrm{CO}+1 / 2 \mathrm{O}_{2} \rightarrow \mathrm{CO}_{2}-283 \mathrm{MJ} / \mathrm{Kmol} \\
\mathrm{H}_{2}+1 / 2 \mathrm{O}_{2} \rightarrow \mathrm{H}_{2} \mathrm{O}-242 \mathrm{MJ} / \mathrm{Kmol}
\end{gathered}
$$

The Boudouard reaction:

$$
\mathrm{C}+\mathrm{CO}_{2} \rightleftarrows 2 \mathrm{CO}+172 \mathrm{MJ} / \mathrm{Kmol}
$$

The Water gas reaction:

$$
\mathrm{C}+\mathrm{H}_{2} \mathrm{O} \rightleftarrows \mathrm{CO}+\mathrm{H}_{2}+131 \mathrm{MJ} / \mathrm{Kmol}
$$

The Methanation reaction:

$$
\mathrm{C}+2 \mathrm{H}_{2} \rightleftarrows \mathrm{CH}_{4}-75 \mathrm{MJ} / \mathrm{Kmol}
$$

The Water gas shift (CO shift) reaction:

$$
\mathrm{CO}+\mathrm{H}_{2} \mathrm{O} \rightleftarrows \mathrm{CO}_{2}+\mathrm{H}_{2}-41 \mathrm{MJ} / \mathrm{Kmol}
$$

The gasification performance for optimized gas producer quality (yield, composition, production of $\mathrm{CO}, \mathrm{H}_{2}, \mathrm{CO}_{2}$ and $\mathrm{CH}_{4}$ and energy content) depends upon feedstock origin, gasifier design and operating parameters such as temperatures, static bed height, fluidizing velocity, equivalence ratio, oxidants, catalyst and others which are summarized in Table 2.

In summary, most of performed researches have explored the effect of different gasifying agent (air or steam) and applied different types of catalysts on gasification or pyrolysis process. Temperature and equivalence ratio of biomass with fuel (either air or steam) is the most significant parameter to contribute to the hydrogen production. However, less emphasis has been given to experimental investigation on the optimization of pyrolysis and gasification processes integration for the conversion of low value biomass into hydrogen and value-added products, which is the focus of this paper.

\section{Materials and experimental}

\subsection{Raw materials}

Three types of agricultural residues were investigated in this research namely palm kernel shell, coconut shell and bagasse as they are abundantly available in the agriculture sector in Malaysia. The samples were open air dried for 2 to 3 days to remove moisture and to ease crushing. Both of these samples were pulverized into powder and were sieved into specific particle size of $(0.1-0.3 \mathrm{~mm})$. Sieving was accomplished by shaking the ground biomass samples in a Endecotts Shaker Model (EFL2 MK3) for 30 minutes and dried in a vacuum oven at $80^{\circ} \mathrm{C}$ overnight and were kept in a tightly screw cap bottle. Table 3 summarized fuel properties investigated in this research. 


\begin{tabular}{|c|c|c|c|c|}
\hline & $\begin{array}{c}\text { Raw } \\
\text { materials }\end{array}$ & Gasifier design & Gasification performance & References \\
\hline 1 & $\begin{array}{l}\text { Wood } \\
\text { sawdust }\end{array}$ & $\begin{array}{l}\text { Integrated } \\
\text { gasifier }\end{array}$ & $\begin{array}{l}\text { Efficiencies: }>87.1 \% \\
\mathrm{LHV} \text { : of } 5000 \mathrm{~kJ} / \mathrm{Nm}^{3} \text {. }\end{array}$ & $\begin{array}{l}\text { Cao et al. } \\
(2006)\end{array}$ \\
\hline 2 & $\begin{array}{l}\text { Pine wood } \\
\text { block }\end{array}$ & $\begin{array}{l}\text { down draft } \\
\text { gasifier }\end{array}$ & $\begin{array}{l}\text { Fuel gas yield: } \\
(0.82-0.94) \mathrm{Nm} 3 / \mathrm{kg} \text { biomass, } \\
\text { Hydrogen yield: } \\
(21.18-35.39) \mathrm{g} / \mathrm{kg} \text { biomass } \\
\mathrm{LHV}:(4.76-5.44) \mathrm{MJ} / \mathrm{Nm}^{3}\end{array}$ & $\begin{array}{l}\text { Pengmei } \\
\text { et al. } \\
(2007)\end{array}$ \\
\hline 3 & $\begin{array}{l}\text { Hazelnut } \\
\text { shell }\end{array}$ & $\begin{array}{l}\text { applied air-blown } \\
\text { gasification }\end{array}$ & $\begin{array}{l}\text { Hydrogen yield: } \\
24 \mathrm{~g} / \mathrm{kg} \text { hazelnut shells. }\end{array}$ & $\begin{array}{l}\text { Midilli et } \\
\text { al. (2001) }\end{array}$ \\
\hline 4 & Biomass & two-step process & $\begin{array}{l}\text { Hydrogen content : } 60 \% \\
\text { Hydrogen yield : } 65 \mathrm{~g} / \mathrm{kg} \\
\text { biomass }\end{array}$ & $\begin{array}{l}\text { Zhao et al. } \\
\text { (2010) }\end{array}$ \\
\hline 5 & Palm kernel & $\begin{array}{l}\text { Fluidized bed } \\
\text { gasifier }\end{array}$ & $\begin{array}{l}\text { Hydrogen yield : } 67 \mathrm{~mol} \% \\
\mathrm{LHV}: 1.482 \text { - } 5578 \mathrm{MJ} / \mathrm{Nm}^{3}\end{array}$ & $\begin{array}{l}\text { Wan } \mathrm{Ab} \\
\text { Karim } \\
\text { Ghani et } \\
\text { al.,(2009) }\end{array}$ \\
\hline 6 & Biomass & $\begin{array}{l}\text { downdraft } \\
\text { gasifier }\end{array}$ & $\begin{array}{l}\mathrm{LHV}: 9.55 \mathrm{MJ} / \mathrm{Nm}^{3} \\
\mathrm{H} 2 \text { yield }: 52.19-63.31 \%\end{array}$ & $\begin{array}{l}\text { LV et al. } \\
(2007)\end{array}$ \\
\hline 7 & $\begin{array}{l}\text { Woody } \\
\text { biomass }\end{array}$ & Fixed bed & $\begin{array}{l}\text { The product gas composition: } \\
\text { a)cellulose : } 35.5 \% \mathrm{~mol} \mathrm{CO}, 27 \% \\
\text { mol } \mathrm{CO}_{2} \text { and } 28.7 \% \mathrm{~mol} \mathrm{H}_{2} \text {. } \\
\text { b) Xylan and lignin were } \\
\text { approximately } 25 \% \mathrm{~mol} \mathrm{CO}_{3} 36 \% \\
\mathrm{~mol} \mathrm{CO}_{2} \text { and } 32 \% \mathrm{~mol} \mathrm{H}_{2} \text {. }\end{array}$ & $\begin{array}{l}\text { Hanaoka } \\
\text { et al. } \\
(2005)\end{array}$ \\
\hline 8 & Biomass & Fixed bed & $\begin{array}{l}\text { H2 concentration: } \\
\text { air- } 59 \% \text { mol } \\
\text { steam }-87 \% \\
\text { (increasing trend from } 600 \text { to } \\
1050 \mathrm{~K} \text { ) }\end{array}$ & $\begin{array}{l}\text { Florin and } \\
\text { Harris } \\
(2007)\end{array}$ \\
\hline 9 & Biomass & updraft gasifier & $\begin{array}{l}\mathrm{H} 2 \text { composition: } 22.3 \mathrm{~mol} \% \text { (air) } \\
\text { and } 83 \% \mathrm{~mol} \% \text { (steam) }\end{array}$ & $\begin{array}{l}\text { Lucas et } \\
\text { al. (2004) }\end{array}$ \\
\hline 10 & Biomass & $\begin{array}{l}\text { catalytic fluidized } \\
\text { bed }\end{array}$ & $\begin{array}{l}\text { Hydrogen yield: } 28.7 \% \\
\text { Conversion efficiencies } 79 \% \text {. }\end{array}$ & $\begin{array}{l}\text { Miccio et } \\
\text { al. (2009) }\end{array}$ \\
\hline
\end{tabular}

Table 2. Selected review on biomass gasification performance for hydrogen production. 


\begin{tabular}{|c|c|c|c|}
\hline & $\begin{array}{c}\text { Palm } \\
\text { Kernel shell }\end{array}$ & $\begin{array}{c}\text { Coconut } \\
\text { shell }\end{array}$ & Bagasse \\
\hline \multicolumn{4}{|l|}{$\begin{array}{l}\text { Proximate Analysis } \\
\text { (wt } \% \text { wet basis) }\end{array}$} \\
\hline Volatile matter & 30.53 & 51.10 & 43 \\
\hline Fixed carbon & 48.5 & 26.4 & 32.40 \\
\hline Ash & 8.97 & 12.50 & 10.20 \\
\hline Moisture & 12 & 10 & 14.40 \\
\hline \multicolumn{4}{|l|}{$\begin{array}{l}\text { Ultimate Analysis } \\
\text { (wt } \% \text { dry basis) }\end{array}$} \\
\hline Hydrogen & 5.52 & 5.40 & 5.30 \\
\hline Carbon & 51.63 & 50.20 & 43.80 \\
\hline Oxygen & 40.91 & 43.40 & 47.10 \\
\hline Nitrogen & 1.89 & 1.46 & 1.20 \\
\hline Sulfur & 0.05 & 0.06 & 0.03 \\
\hline Cellulose & 20.80 & 28.60 & 30 \\
\hline Hemicellulose & 22.70 & 28.60 & 23 \\
\hline Lignin & 50.70 & 24.40 & 22 \\
\hline $\begin{array}{l}\text { Bulk Density }\left(\mathrm{kg} / \mathrm{m}^{3}\right) \\
\text { HHV }(\mathrm{MJ} / \mathrm{kg})\end{array}$ & $\begin{array}{c}733 \\
24.97\end{array}$ & $\begin{array}{c}661 \\
21.50\end{array}$ & $\begin{array}{c}111 \\
16.70\end{array}$ \\
\hline
\end{tabular}

Table 3. Proximate and Ultimate Analysis of Feedstock Sample

\subsection{Experimental set up and procedures}

The schematic diagram of the experimental facility used in this study is shown in Figure 1. The reactor was made of stainless steel pipe and the total high of reactor is $850 \mathrm{~mm}$ with an internal diameter of $50 \mathrm{~mm}$, directly heated via electrical furnace equipped with Temperatures Indicator Controller (TIC) and thermocouples that those installed in two different zones of reactor, screw feeder, condenser, gas cleaning, gas drying and sampling section, gas chromatograph (GC). 


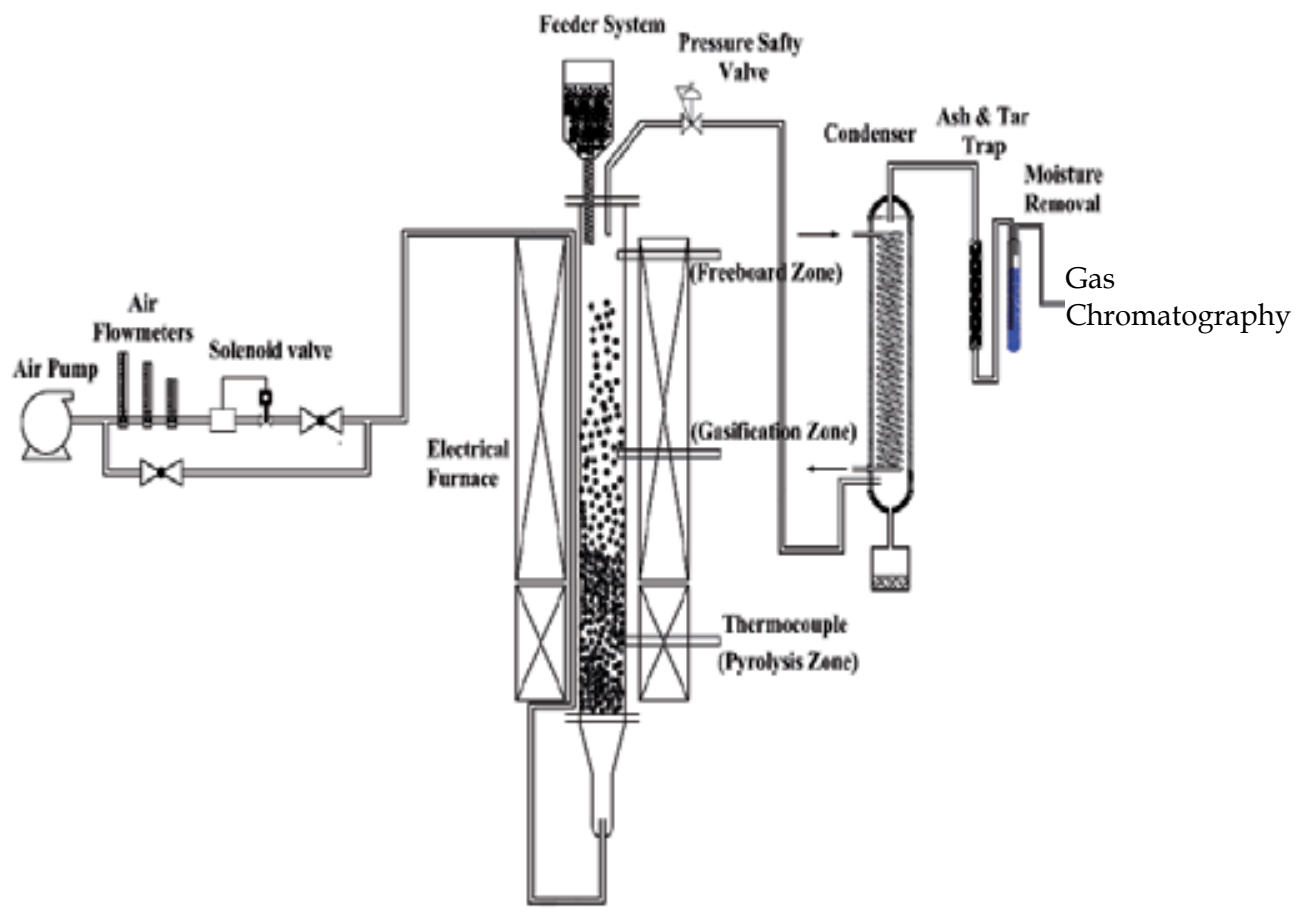

Fig. 1. Schematics diagram of biomass air gasification in fluidized bed reactor

Prior each experiment, the reactor was charged with $20 \mathrm{~g}$ of silica beads as the bed material to obtain a better temperature distribution, to stabilize the fluidization and to prevention coking inside the reactor. The solenoid valve (S.V) was turned on and a pre-heated air flow passed through the bed and the reactor when the temperatures in the bed (pyrolysis zone) and in the gasification zone reached the desired temperature. The feeder was turned on once the temperatures of these two parts stabilized. Typically, each test took about 20 to 25 minutes to stabilize and measurements were taken at intervals of 2 minutes. During each experiment, the air stream and the biomass feedstock were introduced from bottom and top of the gasifier, respectively. The clean gas was then sent to a water cooler to separate the condensed and un-condensed tars and steam. Sampling gas bags were employed to collect the product gas leaving the cooler for off line gas analysis.

\section{Results and discussion}

The gasification performance mainly will be evaluated based on the gas production quality (hydrogen yield and carbon conversion efficiency) and quantity (gas composition). Furthermore, the ash and oil yield will also be determined and quantified.

\subsection{Effect of gasification temperature}

The product yields (hydrogen, ash and oil) and detail gas composition of studied biomass at different gasification temperature are summarized in Table 4 and Figure 2, respectively. In this study, reactor temperature is increase from 700 to $1100{ }^{\circ} \mathrm{C}$ in $50^{\circ} \mathrm{C}$ and at constant feeding rate $(0.78 \mathrm{~kg} / \mathrm{h})$ and equivalence ratio(ER) $(0.26)$. 


\begin{tabular}{|c|c|c|c|c|c|c|c|}
\hline $\begin{array}{l}\text { Reactor } \\
\text { Temperature }\left({ }^{\circ} \mathrm{C}\right)\end{array}$ & 750 & 800 & 850 & 900 & 950 & 1000 & 1100 \\
\hline \multicolumn{8}{|l|}{ a) Palm kernel shell } \\
\hline Hydrogen yield & 14.08 & 16.8 & 22.88 & 23.44 & 26.7 & 28.56 & 31.04 \\
\hline \multicolumn{8}{|l|}{$\begin{array}{l}\text { ( } \mathrm{g} \mathrm{H}_{2} / \mathrm{kg} \text { biomass, } \\
\text { wet basis) }\end{array}$} \\
\hline LHV (MJ/kgNm³) & 25.776 & 29.964 & 25.451 & 24.954 & 24.439 & 21.3 & 18.3 \\
\hline $\operatorname{Ash}(w / w)$ & 0.174 & 0.158 & 0.142 & 0.136 & 0.12 & 0.114 & 0.1 \\
\hline Oil $(w / w)$ & 0.1 & 0.13 & 0.164 & 0.144 & 0.29 & 0.16 & 0.1 \\
\hline \multicolumn{8}{|l|}{ b) Coconut shell } \\
\hline Hydrogen yield & 18.93 & 19.8 & 20.64 & 22.37 & 23.7 & 25 & 25.44 \\
\hline \multicolumn{8}{|l|}{$\begin{array}{l}\text { ( } \mathrm{g} \mathrm{H}_{2} / \mathrm{kg} \text { biomass, } \\
\text { wet basis) }\end{array}$} \\
\hline LHV (MJ/kgNm³) & 24.68 & 26.328 & 25.872 & 25.489 & 23.274 & 20.936 & 20.247 \\
\hline $\operatorname{Ash}(w / w)$ & 0.183 & 0.167 & 0.156 & 0.132 & 0.128 & 0.122 & 0.114 \\
\hline Oil $(w / w)$ & 0.06 & 0.078 & 0.11 & 0.11 & 0.12 & 0.07 & 0.05 \\
\hline \multicolumn{8}{|l|}{ c) Bagasse } \\
\hline Hydrogen yield & 11.6 & 13.1 & 13.47 & 17.44 & 19 & 21.4 & 23 \\
\hline \multicolumn{8}{|l|}{$\begin{array}{l}\text { ( } \mathrm{g} \mathrm{H}_{2} / \mathrm{kg} \text { biomass, } \\
\text { wet basis) }\end{array}$} \\
\hline LHV (MJ/kgNm³) & 23.245 & 26.74 & 26.224 & 25.674 & 25.152 & 24.53 & 21.653 \\
\hline $\operatorname{Ash}(w / w)$ & 0.178 & 0.143 & 0.122 & 0.1 & 0.092 & 0.088 & 0.083 \\
\hline $\operatorname{Oil}(w / w)$ & 0.052 & 0.052 & 0.064 & 0.084 & 0.072 & 0.052 & 0.03 \\
\hline
\end{tabular}

Table 4. Summary of results for effect of gasification temperature on hydrogen production

In general, higher temperature favoured production gas as compared to ash and oil. Hydrogen yield increased as the temperature increased from 750 to $1000^{\circ} \mathrm{C}$ with the value of 14 to $31 \mathrm{~mol} \%, 18$ to $25.44 \mathrm{~mol} \%$ and 11 to $23 \mathrm{~mol} \%$ for palm kernel shell, coconut shell and bagasse, respectively. Palm kernel shell gave the highest $\mathrm{H}_{2}$ compared to other samples due to the highest lignin content in their structure (Worasuwanarak et. al., 2007 and Dawson and Boopathy, 2008). Meanwhile, the product gas low heating value (LHV) showed a maximum value, 30, 23, 23 and $27 \mathrm{MJ} / \mathrm{KgNm}^{3}$ for palm kernel, coconut shell and bagasse, respectively. Ash and oil products yield ranging $0.10-0.29 \%$ and $0.02-0.29 \%$, respectively. These phenomena would be due to various reasons namely (i) higher production of gases in initial pyrolysis step whose rate is faster at higher temperature (Franco et al., 2003); (ii) higher gas production caused by endothermic char gasification reactions, which are favored at high temperature in pyrolysis zone, (iii) elevated temperature in gasification zone is favourable for tar and heavy hydrocarbons cracking that result to higher gas production (Tavasoli et al., 2009). 


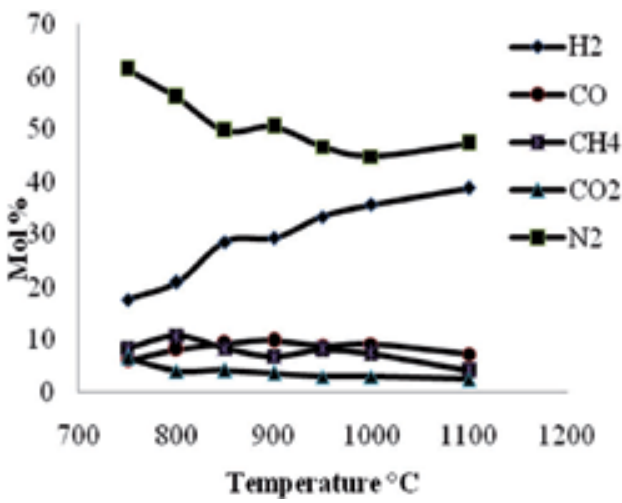

(a)

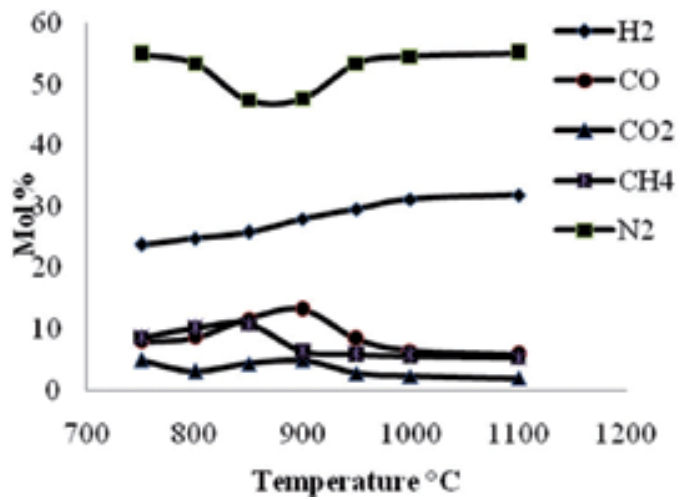

(b)

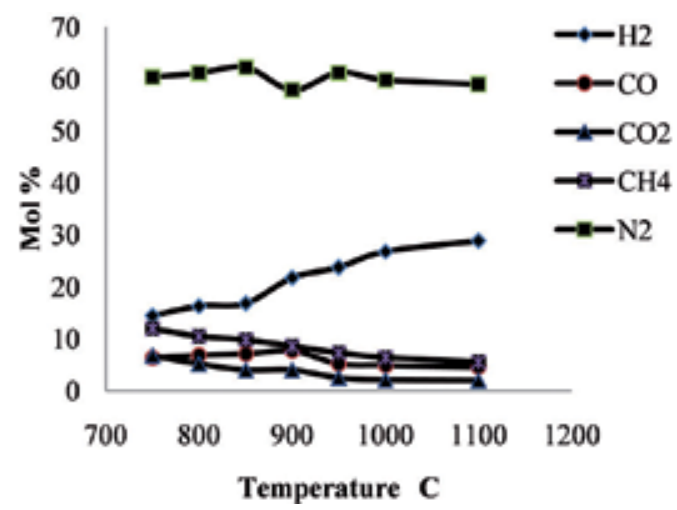

(c)

Fig. 2. Comparison gas composition for (a) palm kernel shell, (b) coconut shell and (c) bagasse at different temperature

Figure 2 illustrates that hydrogen mol fraction significantly increased while the content of other produced gas particularly methane $\left(\mathrm{CH}_{4}\right)$ showed an opposite trend for all studied samples. This is in accordance with Le Chatelier's principle; higher temperatures favour the reactants in exothermic reactions and favour the products in endothermic reactions. The $\mathrm{H}_{2}$ formation is favoured by increasing of the gasification temperature, which could be due to the combination effect of exothermal character of water-gas shift reaction (Eqn. 8) which occur and predominate between $500-600^{\circ} \mathrm{C}$ and the water-gas reaction (Eqn. 6) which becomes significant at the temperature from 1000 to $1100^{\circ} \mathrm{C}$ and upward (Midilli et. al., 2001). The water shift reaction occurred in any gasification process due to the presence of water inside of fuel and water vapour in side of air. Water vapour and carbon dioxide promote hydrogen production in biomass gasification process (Cao et. al, 2006). Furthermore, increasing of gasification temperature also increases thermal cracking of tar and heavy hydrocarbons into gaseous components (Babu, 1995). At the same time, the gas production also increased due to cracking of liquid fraction developed in this range of temperature $\left(300-500^{\circ} \mathrm{C}\right)$. These observations are in accordance with Encinar et al. (1996), Fagbemi et al. (2001), Zanzi et al. (2002) and Chen et al. (2003) where they found that the pyrolysis temperature below $600^{\circ} \mathrm{C}$ should be favoured for overall hydrogen production. 
On the contrary, different trend were observed for other produced gaseous. Methane $\left(\mathrm{CH}_{4}\right)$ increased to $0.7 \%, 10.8 \%$ and $9.83 \%$ for palm kernel shell, coconut shell and bagasse, respectively when temperature rises from $750^{\circ} \mathrm{C}$ to $850^{\circ} \mathrm{C}$ but decreased gradually with temperature decreases. This can be explained as contribution of methanation reaction (Eqn. 7) during the gasification process. This was an expected result because as explained above most $\mathrm{H}_{2}$ production reactions are endothermic and content of $\mathrm{CH}_{4}$ decreases because temperature strengthens steam methane reforming reaction (McKendry, 2002, Lucas et al., 2004) and Pengmei et al., 2007). Furthermore, increasing of temperature contributes to decreases in $\mathrm{CO}_{2}$ but increased $\mathrm{CO}$. The content of $\mathrm{CO}$ was mainly determined by Bourdouard reaction (Eqn. 5) where the boudouard reaction only produces $\mathrm{CO}$ at high temperature around $800-900^{\circ} \mathrm{C}$ (Encinar et al., 2001 and Mathieu and Dubuisson, 2002). Moreover, Tavasoli at el. (2009) reported that decreasing the concentration of $\mathrm{CH}_{4}$ and heavy hydrocarbons with increasing of the rise in temperature in gasification process results in higher conversion of biomass and exhausting of major energy that is the reason for decline in value of LHV, because produced gases contain less quantities of $\mathrm{CH}_{4}$ due to contribution in stem reforming reaction.

\subsection{Effect of equivalence ratio (ER)}

The Equivalence Ratio (ER) varied from 0.23 to 0.27 through changing airflow rate at three constant temperatures $\left(900^{\circ} \mathrm{C}, 950^{\circ} \mathrm{C}\right.$ and $\left.1000^{\circ} \mathrm{C}\right)$ at constant feeding rate $(0.78 \mathrm{~kg} / \mathrm{hr})$ to find the optimum condition for hydrogen production. Table 5 summarize the obtained results and shows that the maximum molar fraction of hydrogen at $1000^{\circ} \mathrm{C}$ reached to (44.6\% at ER: 0.23$),(36.65 \%$ at ER: 0.23$)$ and (36.38\% at ER: 0.22$)$ for palm kernel shell, coconut shell and bagasse, respectively.

\begin{tabular}{|l|c|c|c|c|c|}
\hline Equivalence Ratio (ER) & 0.23 & 0.24 & 0.25 & 0.26 & 0.27 \\
\hline a) palm kernel shell & 20.48 & 22 & 26 & 23.44 & 20 \\
\hline i) $900^{\circ} \mathrm{C}$ & 25.28 & 30.2 & 27.44 & 26.7 & 21.6 \\
\hline ii) $950^{\circ} \mathrm{C}$ & 35.68 & 32.24 & 30.1 & 28.6 & 24.65 \\
\hline iii) $1000^{\circ} \mathrm{C}$ & 23.5 & 25.4 & 24.9 & 22.37 & 19.4 \\
\hline b) $\operatorname{coconut}^{\prime}$ shell & 27.8 & 26.6 & 25.4 & 23.7 & 20.6 \\
\hline i) $900^{\circ} \mathrm{C}$ & 29.32 & 28.9 & 26.8 & 25 & 21.05 \\
\hline ii) $950^{\circ} \mathrm{C}$ & \multicolumn{5}{|l}{} \\
\hline iii) $1000^{\circ} \mathrm{C}$ & 22 & 23 & 24.52 & 22.26 & 19.86 \\
\hline c) $\mathrm{Bagasse}$ & 21.9 & 28.1 & 26.8 & 23.72 & 21 \\
\hline i) $900^{\circ} \mathrm{C}$ & 23.7 & 29.1 & 27.74 & 25.22 & 23.1 \\
\hline ii) $950^{\circ} \mathrm{C}$ &
\end{tabular}

Table 5. Summary of results for effect of equivalence ratio on hydrogen yield $(\mathrm{gH} 2 / \mathrm{kg}$ biomass 
Figure 3 shows the gas composition for palm kernel shell gasification (selected sample for optimization study) at different temperature. Hydrogen yield were observed to increase first and decreased as ER increased. The obtained results are in accordance with other researchers where they found that increasing temperature in air gasification contributed to increasing of the hydrogen release (Midilli et al., 2001; Gonzalez et al., 2008; Lucas et al., 2004). In addition, they observed that increasing of the flow rate of air will decrease hydrocarbon contents due to partial combustion which subsequently contributed to decrease in tar and gaseous hydrocarbons. However, high flow rate of air will decrease the lower heating value (LHV) of the gasification gas (Pinto et al., 2003 and Lv et al., 2004). This phenomenon can be discussed by the following explanations.

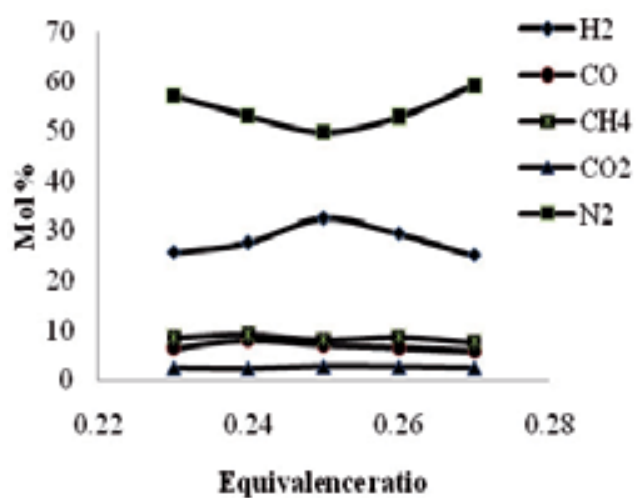

(a)

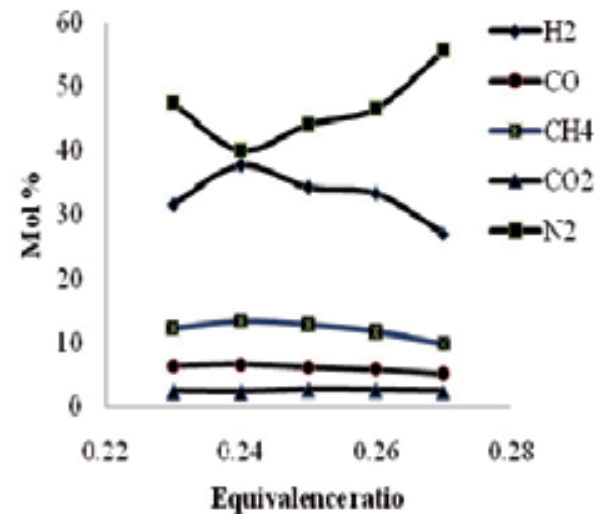

(b)

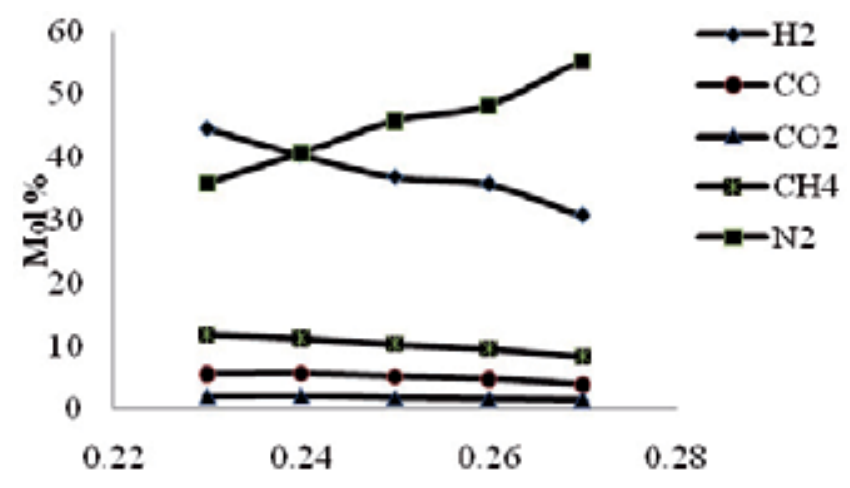

Equivalenceratio

(c)

Fig. 3. Comparison gas composition at temperature (a) $900^{\circ} \mathrm{C}$ (b) $950^{\circ} \mathrm{C}$ and (c) $1000^{\circ} \mathrm{C}$ in different ER at optimized condition of palm kernel shell gasification

At highest temperature $1000^{\circ} \mathrm{C}$, low ER was suitable with compare to $900^{\circ} \mathrm{C}$ and $850^{\circ} \mathrm{C}$. At low ER the combustion reactions in Eqn. 2 was dominated when compared to the combustion reaction in Eqn. 3 because of lack of oxygen. This is further verified by Wan Ab karim Ghani et. al. (2009) and Pengmei et. al. (2004) that explained that ER not only represents the oxygen quantity introduced to the reactor but also affects the gasification 
temperature under the condition of auto thermal operation. Higher equivalence ratio caused gas quality to degrade because of more oxidization reaction. In addition, the usage of air as oxidants contributed to higher ER which introduced large percentage of nitrogen into the system and diluted the combustible constituents in fuel gas (Pengmei et. al., 2007). On other hand, small ER will cause of lower oxygen be available for complete the gasification reactions which is not favourable for process. Therefore the gas composition is affected by the two contradictory factors of ER.

\subsection{Effect of feeding rate}

Various feeding rate ranging from 0.20 to $1.21 \mathrm{~kg} / \mathrm{hr}$ were tested for palm kernel shell to determine the time required for complete reactions of gasification of biomass and suitable feeding rate of reactor by considering of value of reactor and minimum fluidization velocity of biomass particles. Figure 4 shows that with increasing of the feeding rate, the hydrogen yield increased and reached to the maximum value of $29.1 \%$. It was found that higher feeding rates did not have great influence neither on net gas production nor on the hydrogen yield. This is explained by the fact that the higher feeding rate attributed to less residence time per volume air which will caused less oxygen be in contact with the biomass particles (W.A.W.A.K. Ghani et. al., 2009). Thus, decreasing of temperature at pyrolysis and consequently gasification process will be occurred and hence the biomass samples will remain raw or partially gasified.

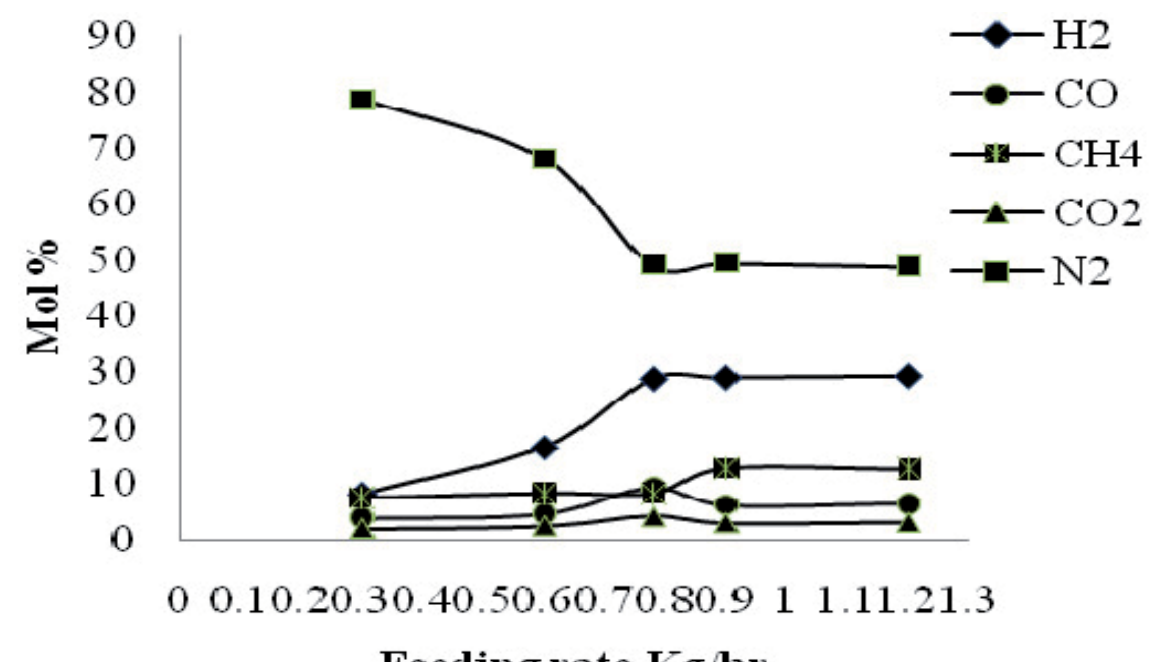

Feeding rate $\mathbf{K g} / \mathbf{h r}$

Fig. 4. Effect of feeding rate on gas composition at optimized condition of palm kernel shell gasification

\subsection{Effect of biomass particle size}

Figure 5 illustrates the hydrogen production performance for palm kernel shell at difference particle size $(0.1,2$ and $5 \mathrm{~mm})$. It was observed that with decreasing the particles size, the produced hydrogen and hydrogen yield decreased with the maximum value of $22.2 \%$ which belong to the smallest particle size. Lv et al. (2004) reported that pyrolysis process of small particles mainly controlled by reaction kinetics. Thus, as the size of biomass particles 
increase, the production gas resultant inside the particles is more difficult to diffuse out and process is mainly controlled by gas diffusion. On other hand, larger particles are not only difficult to be entrained by fluidizing gas, but also produce fewer smaller particles after gasification reaction. This results in a reduction in fine particle entrainment, and hence decreases the amount of volatile matter and unburned char (Leung et al., 2003).
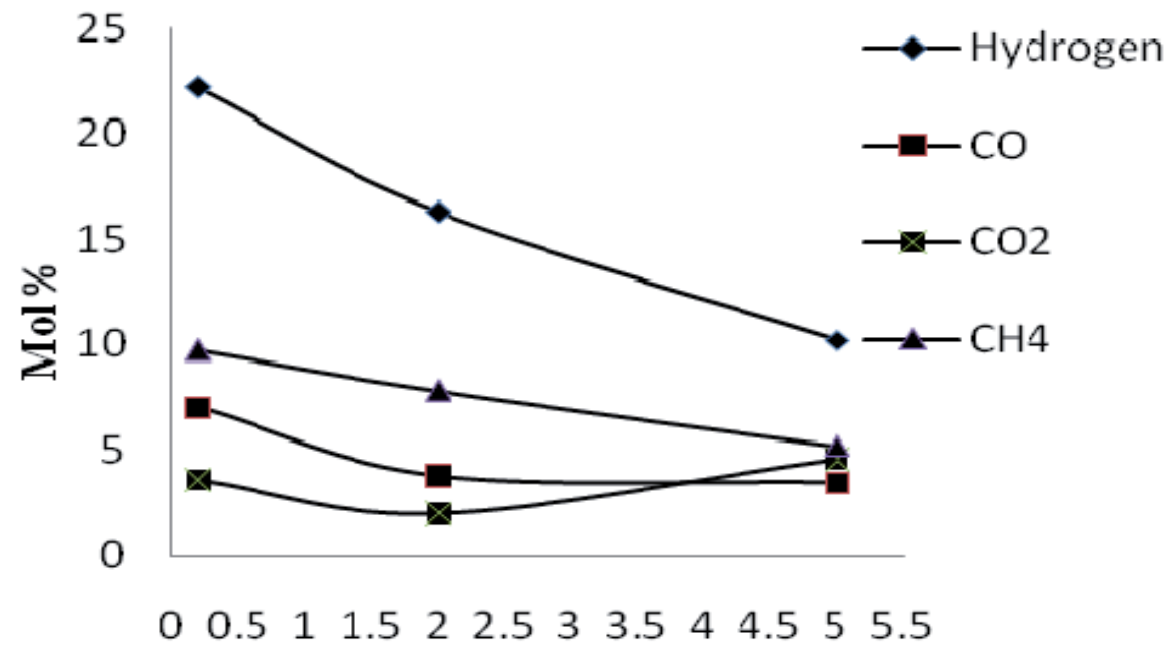

Particle size (mm)

Fig. 5. Effect of particle size on gas composition at optimized condition of palm kernel shell gasification

\subsection{Carbon conversion efficiency}

The carbon conversion efficiency in this study were calculated based on the below equation (Eqn. 9).

$$
\text { Carbon conversion efficiency }=(a / b) \times 100 \%
$$

Where:

$\mathrm{a}=$ Total reacted carbon in the system $(\mathrm{kg})$

$\mathrm{b}=$ Total carbon fed to the system $(\mathrm{kg})$.

In this study, the maximum carbon conversion efficiency reached up to $(89 \%),(88.6 \%)$ and $(94.5 \%)$ for palm kernel shell, coconut shell and bagasse, respectively at $1100^{\circ} \mathrm{C}$ under the air/biomass ratio $\left(1.12 \mathrm{Nm}^{3} / \mathrm{Kg}\right)$. These variations were observed as resulted from the biomass properties (see Table 2). As expected bagasse with the lowest carbon content and lowest density should be burned completely under given fluidizing velocity. As for other samples, the unburned carbon out of the gasifier might attributed by the sort residence time of biomass particles to further react either with $\mathrm{O}_{2}$ and $\mathrm{CO}_{2}$ and $\mathrm{H}_{2} \mathrm{O}$ at the same fluidizing conditions. This phenomenon is explained by Cao et al. (2006) that the carbon conversion also has relation with air/biomass ratio where they founded the maximum carbon conversion occurs at air/biomass ratio about $2.5 \mathrm{Nm}^{3} / \mathrm{kg}$. They reported that carbon conversion increased rapidly with increasing of the air/biomass ratio and decreased gradually with further air/biomass ratio increased. This is due to the fact that higher gas 
velocity had contributed to longer residence time for carbon to complete the reaction with $\mathrm{O}_{2}$ or with $\mathrm{CO}, \mathrm{CO}_{2}$ and $\mathrm{H}_{2} \mathrm{O}$ and consequently decreasing in the carbon conversion efficiency.

\section{Conclusion}

Air gasification of agricultural wastes was successfully performed in a lab scale fluidized bed gasifier, producing producer gas mainly hydrogen which could replaced fossil fuel in the near future. Among the gasification parameters tested, the gasification temperature and equivalence ratio appeared to have the most pronounced effect on the hydrogen performance. Hydrogen production is favoured by an increasing temperature and hydrogen yield is enhanced as the water gas shift reaction goes to the completion with reducing of $\mathrm{CO}$ and $\mathrm{CO} 2$ in the product gas. The influence of equivalence ratio on the performance of a gasifier could be regarded as the effect of reactor temperature as the reactor was found to be ER dependent. As a higher equivalence (ER) had complex effects on tests results and there existed an optimal value for this factor, which was different according to different operating parameters. The feeding rate and biomass particle size would only show minor effect during the gasification process. In view of laboratory scale, the optimum conditions for hydrogen production in air gasification for studied biomass feedstock can be summarised as the following; a) temperature of gasification zone $\left(950-1000^{\circ} \mathrm{C}\right)$; b) Equivalence ratio 0.23 and c) feeding rate at $0.70 \mathrm{~kg} / \mathrm{hr}$ and d) Particle size $(1-3 \mathrm{~mm})$. The obtained results deduced to the conclusion that agricultural wastes are potential candidate for hydrogen production as an alternative renewable energy source and partially reduced the landfill problems of agricultural residues.

\section{Acknowledgment}

This work is financially supported by a Science Fund Grant by the Ministry of Science, Technology and Innovation (MOSTI) of Malaysia (03-01-04-SF0530).

\section{References}

Babu S. P. (1995). Thermal gasification of biomass technology developments. Biomass and Bioenergy, Vol.9, No. 1-5 (1995), pp. 271-285, ISSN 09619534.

Cao Y., Wang Y., Riley J.T., Pan W.P. (2006). A novel biomass air gasification process for producing tar-free higher heating value fuel gas. Fuel Processing Technology, Vol.87, pp. 343-353, ISSN 037838320.

Chatterjee, P.K., A.B. Datta and K.M. Kundu (1995). Fluidized Bed Gasification of Coal. The Canadian Journal of Chemical Engineering, Vol. 73, pp. 204-210, ISSN 00084034.

Chen G., Andries J., Luo Z., Spliethoff H. (2003). Biomass pyrolysis/gasification for product gas production: the overall investigation of parametric effects. Energy Conversion and Management.; Vol. 44, No. 11 (July 2003), pp. 1875-1884, ISSN 01968904.

Dawson L. and Boopathy R. (2008). Cellulosic ethanol production from sugarcane bagasse without enzymatic saccharification. Bioresources Technology, Vol.3, (January 2008), pp. 452-460, ISSN 09608524. 
Delgado, J., Aznar, M. P. (1997). Biomass gasification with steam in fluidized bed: effectiveness of $\mathrm{CaO}, \mathrm{MgO}$ and $\mathrm{CaO}-\mathrm{MgO}$ for hot raw gas cleaning. Industrial and Engineering Chemistry Research, Vol.36, (Dec. 1997), pp. 1535-1543, ISSN 08885885.

Dupont C., Commandre J-M., Gauthier P. (2008). Biomass pyrolysis experiments in an analytical entrained flow reactor between $1073 \mathrm{~K}$ and $1273 \mathrm{~K}$, Fuel, Vol.87, No. 7 (June 2008), pp. 1155-1164, ISSN 00162361.

Encinar J.M., Gonzalez J.F., Rodriguez J.J., Ramiro M.J. (2001). Catalysed and uncatalysed steam gasification of eucalyptus char: influence of variables and kinetic study. Fuel, Vol.80, No. 11 (November 2001), pp. 2025-2036, ISSN 00162361.

Enciner J.M., Beltran F.J., Bernalte A., Biro A., Gonzalez J.F. (1996). Pyrolysis of two agricultural residues: olive and grape bagasse. Influence of particle size and temperature. Biomass and Bioenergy, Vol.11, No. 5 (1996), pp. 397-409, ISSN 09619534.

Fagbemi L., Khezami L., Capart L. (2001). Pyrolysis products from different biomasses: application to the thermal cracking of tar. Applied Energy, Vol.69, No. 4 (August 2001), pp. 293-306, ISSN 03603199.

Florin N. H. and Harris A.T. (2007). Hydrogen production from biomass coupled with carbon dioxide capture: the implications of thermodynamic equilibrium. International Journal of Hydrogen Energy, Vol.32, No. 32 (December 2007), pp. 41194134, ISSN 03603199.

Gonzalez J.F., Roman S., Bragado D., Calderon M. (2008). Investigation on the reactions influencing biomass air and air/steam gasification for hydrogen production. Fuel Processing Technology, Vol.89, No. 8 (May 2008), pp. 764-772, ISSN 037838320.

Hanaoka T., Inoue S., Uno S., Ogi T., Minowa T. (2005). Effect of woody biomass components on air-steam gasification. Biomass and Bioenergy, Vol.28, No. 1 (January 2005), pp. 69-76. ISSN 09619534.

Kunii D. and Levenspiel O. (1990).Entrainment of Solids from Fluidized Beds I. Hold-Up of Solids in the Freeboard II. Operation of Fast Fluidized Beds. Powder Technology, Vol.61, No. 2 (May 1990), pp. 193-206, ISSN00325910.

Leung D.Y.C., Wang C.L. (2003). Fluidized bed gasification of waste tire powders. Fuel Processing Technology, Vol.84, No. 1 (November 2003), pp. 175-196, ISSN 037838320.

Lv P., Yuan Z., Wu C., Ma L., Chen Y., Tsubaki N. (2007). Bio-syngas production from biomass catalytic gasification. Energy Conversion and Management, Vol.48, No. 4 (April 2007), pp. 1132-1139, ISSN 01968904.

Lv P.M., Xiong, Z.H., Chang J., Chen, Y., Zhu, J.X. (2004). An experimental study on biomass air-steam gasification in a fluidized bed. Bioresource Technology, Vol.95, No. 2 (November 2004), pp. 95-101, ISSN 09608524.

Midilli A., Dogru M., Howarth C.R. and Ayhan T. (2001). Hydrogen production from hazelnut shell by applying air-blown downdraft gasification technique. International Journal of Hydrogen Energy, Vol. 26, No. 1 (January 2001), pp. 29-37. ISSN 03603199.

Mirza U.K., Ahmad N., HarijanK., Majeed T. (2009). A vision for hydrogen economy in Pakistan. Renewable and Sustainable Energy Reviews. Vol.13, No. 6-7 (August September 2009), pp. 1111-1115, ISSN 13640321.

Ninth Malaysia Plan 2006-2010, Economic Planning Unit, Prime Minister's Department, Malaysia. 27.6.2011, http://www.parlimen.gov.my/news/eng-ucapan_rmk9.pdf 
Pengmei Lv, Zhenhong Y., Longlong M.(2007). Hydrogen-rich gas production from biomass air and oxygen/steam gasification in a downdraft gasifier. Renewable Energy, Vol 32, No. 13 (October 2007), pp. 2173-2185, ISSN 09601481.

Pinto Filomena, Franco Carlos, Rui Neto Andre, Tavares C., Dias M., Gulyurtlu I., Cabrita I. (2003). Effect of experimental conditions on co-gasification of coal, biomass and plastics wastes with air/steam mixtures in a fluidized bed system. Fuel, Vol.82, No. 15-17 (October - December 2003), pp. 1967-1976, ISSN 00162361.

Ramirez J. J., Martinez J. D., Petro S. L. (2007). Basic design of a fluidized bed gasifier for rice husk on pilot scale. Latin American Applied Research, Vol.37, pp. 299-306, ISSN 03270793.

Tavasoli Ahmad, Ahangari Masoumeh G., Soni Chirayu, Dalai Ajay K. (2009). Production of hydrogen and syngas via gasification of the corn and wheat dry distiller grains (DDGS) in a fixed-bed micro reactor. Fuel Processing Technology, Vol.90, No. 4 (April 2009), pp. 472-482, ISSN 03783820.

Wan Ab Karim Ghani, W. A; Moghadam, R.; Salleh, M.; Alias, A. (2009). Air Gasification of Agricultural Waste in a Fluidized Bed Gasifier: Hydrogen Production Performance. Energies, Vol.2, No. 2 (May 2009), pp. 258-268, ISSN 19961073.

W.A.W.A.K, Ghani, A.B. Alias, R.M. Savory and K.R. Cliffe (2009). Co-combustion of Agricultural Waste with Coal in a $10 \mathrm{~kW}$ Fluidised Bed Combustor, Journal of Waste Management, Vol.29, No.2 (February 2009), pp. 767-773, ISSN 0956035X.

Worasuwannarak N., Sonobe T., Tanthapanichakoon, W. (2007). Pyrolysis behaviors of rice straw, rice husk, and corncob by TG-MS technique. Journal of Analytical and Applied Pyrolysis. Vol.78, No. 2 (March 2007), pp. 265-271, ISSN 01652370.

Xiao R., Jin B., Zhou H., Zhong Z., Zhang M. (2007). Air gasification of polypropylene plastic waste in fluidized bed gasifier Energy Conversion Management, Vol.48, No. 3 (March 2007), pp. 778-786, ISSN 01968904.

Zanzi R., Sjostrom K., Bjornbom E. (2002). Rapid pyrolysis of agricultural residues at high temperature. Biomass and Bioenergy, Vol.23, No. 5 (Novemver 2002), pp. 357-366, ISSN09619534. 


\title{
Extraction and Optimization of Oil from Moringa Oleifera Seed as an Alternative Feedstock for the Production of Biodiesel
}

\author{
A.S. Abdulkareem ${ }^{1}$, H. Uthman ${ }^{2}$, A.S. Afolabi ${ }^{1}$ and O.L. Awenebe ${ }^{3}$ \\ ${ }^{1}$ Department of Civil and Chemical Engineering, College of Science, Engineering and \\ Technology, University of South Africa, Johannesburg, \\ ${ }^{2}$ Membrane Research Unit (MRU), Block L-01, Universiti Teknologi Malaysia (UTM), \\ International Campus, Jalan Semarak, 54100 WP, Kuala Lampur \\ ${ }^{3}$ Department of Chemical Engineering, School of Engineering and Engineering \\ Technology, Federal University of Technology, Minna, \\ ${ }^{1}$ South Africa \\ ${ }^{2}$ Malaysia \\ ${ }^{3}$ Niger State Nigeria
}

\section{Introduction}

Energy production for industrial and domestic purpose has primarily been based upon the combustion of fossil fuels, such as oil and coal and it has been reported that these resources are finite and pose significant environmental impact from their combustion (Carraretto et al., 2004; Abdulkareem \& Odigure, 2002; Odigure \& Abdulkareem, 2001). It has been predicted that coal will be a viable energy resource for 90-200years, while the world oil supply is reaching its peak due to over dependence on oil consumption (Odigure et al., 2003). This was blame on the inability of energy sector to balance the oil supply with the increasing demand by various sectors including domestic consumption (Abdulkareem, 2005). Like any other commodity, fossil fuel price is also influence by shortage or oversupply and it has been reported that the change in demand as well as supply by the OPEC and non OPEC nations will greatly affects the price of the oil for many years (Abdulkareem, 2005). In other to meet up with the energy demand worldwide, government and oil sector embarks on the programme of new oil discoveries, and it has been reported that searching for new oil is a loss to the companies. For instance, about ten major oil companies spent $\$ 8$ billion on searching for new oil; results of their search only produce commercial discoveries of oil worth approximately $\$ 4$ billion. Consequently, the oil companies now consider searching for new oil not economical and unable to replace their rapidly depleting resources (Abdulkareem \& Odigure, 2006; Abdulkareem \& Odigure, 2010; Ahmmad et al., 2011; Udaeta et al., 2007). Apart from the price instability of the fossil fuel which is the major sources of energy, environmental pollution is also a major problem emanated from over dependence on fossil fuel. Combustion of fossil fuel is harmful to human health and the environment, and there is an increasing campaign for cleaner burning 
fuel in order to safeguard the environment and protect man from the inhalation of genotoxic substances (Perez-Roa et al., 2006; Adeniyi et al., 2007; Abdulkareem et al., 2010). For instance, the exhaust from petroleum products, especially diesel is known to be toxic and carcinogenous in nature, since they contain polycyclic aromatic hydrocarbons (Ahmmad et al., 2011). Though, there is no energy source that is completely environmentally safe, hence it is important to use the available energy sources wisely to minimize environmental hazard and optimize the efficiency with which it is produced (Bernard \& Wolfgang, 2009; Abdulkareem et al., 2011). The environmental impacts of using fossil fuel and other nonrenewable fuels, such as coal and uranium, present a major obstacle to the continued use of such resources to meet our energy needs. The conventional petroleum-based fuels such as gasoline or diesel, as well as natural gas and coal, all contain carbon. When these fuels are burnt, their carbon recombines with oxygen from the air to form carbon dioxide which is the primary greenhouse gas that causes global warming. In the same vein, combustion of fossil fuels at the high temperature and pressures reached inside an internal combustion engine (what powers most vehicles) or in an electric power plant produces other toxic emissions (Abdulkareem et al., 2011). Carbon monoxide, oxides of nitrogen, oxides of sulphur, volatile organic chemicals, and fine particles are all components of air pollution attributable to the refining and combustion of fossil fuels. When released into the atmosphere, many of these compounds cause acid rain or react with sunlight to create ground level smog. Vast ecosystem damage, increase lung disease and cancer are the ultimate price inhabitant pay for consuming these fossil fuels (Abdulkareem \& Odigure, 2006). The concern for price instability due to over dependence on the fossil and increasingly awareness on the environmental impact of combustion of fossil fuel have called for the alternative source of energy and proper utilization of existing energy sources. Biofuel which is described as the natural and renewable domestic fuel are now considered promising and economical alternative and sustainable energy sources (Shireen \& Debabrate, 2008; Khunrong et al., 2011; Eevere et al., 2011). Biodiesel made from vegetable oil, has been reported to burns clearly, which result in a significant reduction for the types of pollutants that contribute to smog and global warming. Some of the advantages of the biodiesel over the fossil fuel diesel include cost of production, it has been reported that once the technology of biofuel is readily available, the cost of biofuel will be much less than that of fossil fuel (Ahmmad et al., 2011; Durosoy et al., 2011). This was blame on the fact that increases in word population will lead to an increment in demand for oil which will results in increase in price beyond the expectation level (Nashawi et al., 2010). While fossil fuel is described as limited resources since it is produce from a specific material, biofuel can be manufactured from a variety of material (Vera \& Langlois, 2007). Other problem associated with fossil fuel is the nonbiodegradability; the situation that makes it difficult to clean when spillage is experienced. While the biofuel are easily biodegradable and safer to handle than the fossil fuel, this makes spill of biofuel to be less hazardous and less expensive to clean up. Biodiesel also had a high flash point which makes it less explosive at moderate temperature, hence biodiesel is safer to transport and store (Hamamci et al., 2011). There is also wide spread of efforts to investigate an economical additives that can be blended with biodiesel to enhace its application in a colder climates which is the major detractor at moment. On the suitability of the biodiesel in a diesel engine, it has been reported that the first diesel engine which was invented by Rudolf Diesel in 1892, was originally designed to run on unrefined biodiesel.This provide an indiaction that diesel engine can easily adapt to biofuel with little 
modification (Agarwal and Das, 2001). Biodiesel is therefore, produced by the process known as transesterification, which is a chemical reaction for conversion of oil to biodiesel (El-Sabagh et al., 2011; Adeniyi et al., 2007). In this process the oil is chemically reacted with alcohol like methanol or ethanol in the presence of catalyst like sodium hydroxide or potasium hydroxide. After the chemical reaction, various components of the oil break down to form new compounds known as triglycerides. The triglycerides are converted into alkyl esters, which is the chemical name of biodiesel. If methanol is used in the chemical reaction, methyl esters are formed, while when ethanol is used, ethyl esters are formed. Both of these compounds are biodiesel fuels with different chemical combination (Silas, 2008). While the glycerin, that has been separated during transesterification process is released as a byproduct of the chemical reaction. Glycerin will either sink to the bottom of reaction vessel or come to the surface depending on its phase. It can be easily separated by the centrifuges. This whole process is called transesterification. The feedstock (oil) therefore play a major role in the production of biodiesel (Ayhan, 2008).

Biodiesel as an alternative sources of energy, can be produced from biological or biomass material including corn, cellulose, sugar cane, edible oils such as vegetable oil, soybean, palm oil etc. Biodiesel Fuel can also be produced from a variety of non edible oil including rapeseed, mustard flax, sunflower, canola, hemp, Jatropha and waste vegetable oils (Aghan, 2005; Adeniyi et al., 2007; Helwani et al., 2009; Hossain and Boyce, 2009; Abdulkareem et al., 2010). This fuel sources are said to reduce engine wear and produce less harmful emissions. In different part of the world, depending on availability, biodiesel has been produced from different plants. This was first done as an academic exercise, but today commercialization of this production process and product is on-going. For instance Freedman et al, (1984) reported the use of fish oil, soy oil, rape seed oil, cotton seed oil, sun flower, safflower, peanut and line seed oil for the production of methyl esters. According to Barminas et al, (2001) categories of suitable agricultural products for bio-fuel production include seeds, nuts, fruits, leaves, and root and stem etc. It has also been reported that algae farming provide yields 4-5 times more biodiesel per acre than crops like soybeans, but the technology of producing biodiesel from algae is very expensive hence the possibility of achieving commercialization of biodiesel from algae might not happen any moment soon. The European standard specification EN 14214 in 2004, therefore defined biodiesel as fatty acid methyl esters (FAME) from any kind of feedstock (Canakci, 2007; Chhetri et al., 2008; Refaat et al., 2008). Therefore, from an economic point of view; the production of biodiesel is very feedstock sensitive. The cost of biodiesel has been estimated based on assumption regarding production volume, feedstock and chemical technology (Canakci and van Gerpen, 2001; Zhang et al., 2003b; Kulkarni and Dalai, 2006) and feedstock cost comprises a very substantial portion of overall biodiesel cost. Though, the production from various feed stocks had been investigated, however, each of the feedstock has its own problems. For instance, the production of biofuel from waste oil has been described to be economical and readily available, however the inherent difficulties of processing and gathering remain the major factor that militate against its usage as a feedstock in the production of biodiesel (Whang et al 2003(a\&b)). Edible sources like soybeans, sunflower seeds and cotton seeds etc. which are easily available and can be gathered and processed easily need to be closely monitored and controlled in other not to create larger global problems of deforestation, hunger and poverty while trying to solve the problem of energy crises. Critics of biofuel fear that the uses of food (edible oil) as a feed feedstock in the production of biodiesel could result into food crisis. It has been reported that to produce 5\% of the total diesel consumption in United State of America 
from biodiesel, will require approximately $60 \%$ of the crop produced in United State, the action consider being unethical by the critics. Despite the wide acceptance of biofuel as alternative energy source to supplement or replace fossil fuel. The latest research and development in the production of biodiesel is aimed at producing the biofuel from non edible oil like Jatropha Curcas, sunflower etc. Employing non edible oil as a feedstock in the production of biodiesel will actually help in solving the strain relationship between the energy sectors and critics of production of biodiesel from edible oil which was considered unethical. This present study is therefore focus on the optimization of extraction of oil from moringa oleifera seed kernel which is non edible oil especially in Nigeria where it is abundantly available, as an alternative feedstock in the production of biodiesel. Moringa Oleifera (Zogale) seed kernel contains about $45 \%$ oil by weight. The oil can be use for cosmetic making, lubrication and consumption. Beside its industrial use as a fine lubricant, the fatty acid profile of the oil with its high content of oleic acid make it an oil with potential for further industrial application (Michelle, 1994). Moringa oleifera seeds are available in abudant in Minna and utilizing the oil from the seed to produced biodiesel will not constituite any enviromental hazard.

\subsection{War of energy and food security}

Food security refers to the availability of food and one's access to it, a household is therefore, considered food-secure when its occupants do not live in hunger or fear of starvation. According to FAO, 2008, food security exists when all people, at all times, have physical, social and economic access to sufficient, safe and nutritious food to meet their dietary needs and food preferences for an active and healthy life. Hence, the stages of food insecurity range from food secure situations to full-scale famine. Generally, the food insecurity can be categorized as either chronic or transitory. In chronic food insecurity situation, the societies exposed to a high degree of vulnerability to famine and hunger. The situation is similar to undernourishment and is related to poverty, which is existing mainly in poor countries (Ayalew, 1988). Many countries experience perpetual food shortages and distribution problems, which resulted in chronic and often widespread hunger amongst significant numbers of people. Worldwide around 852 million people are chronically hungry due to extreme poverty, while up to 2 billion people lack food security intermittently due to varying degrees of poverty (FAO, 2003). According to CNN report (2009), six million children die of hunger every year - 17,000 every day. It has been reported that as of late 2007, export restrictions and panic buying, US Dollar depreciation, (HM Government, 2010) increased farming for use in biofuel (Smith and Edwards, 2011), world oil prices at more than $\$ 100$ a barrel (The Monitor's view, 2008), global population growth, (Randerson, 2008) climate change (Vidal, 2007), loss of agricultural land to residential and industrial development (Dancy, 2008) and growing consumer demand in China and India (Walt, 2008) are claimed to have pushed up the price of grains (Brown, 2008). The issue of food security is therefore a complex objective pursued with shelter, safety, health and self-esteem in a world where individual households, face diverse complex and different livelihood opportunities (Smit et al., 1993). Hence, the proper understanding of food security requires explicit recognition of complexity and diversity, and that it necessarily privileges the subjective perceptions of the food insecure themselves (World Bank, 1986).

Energy security is a term used to describe an association between national security and the availability of natural resources for energy consumption. Though, access to cheap energy has become essential to the functioning of modern economies, however, the uneven 
distribution of energy supplies among countries has led to significant vulnerabilities. It has been reported that energy security resulted into the political instability of several energy producing countries, the manipulation of energy supplies, the competition over energy sources, attacks on supply infrastructure, as well as accidents, natural disasters, the funding to foreign dictators, rising terrorism, and dominant countries reliance to the foreign oil supply (Wesley, 2007). The world wide over dependence on the oil and the peaking limits of oil production, it is obvious that economics and societies will begin to feel the decline in the resources that we have dependent upon. Hence, the issue of energy security has become one of the leading issues in the world today as oil and other resources have become as vital to the world's people. The looming end of the era of cheap oil is going to put the energy security of most industrialized countries in jeopardy and the same is true in the case of food since many of the imports which are not sustainable even at this very moment, may become far too expensive to afford. It is therefore, important that both of these issues are extremely serious and need to be dealt with and addressed immediately.

Food security is probably on a more serious level than energy security even though both have to be considered side by side. The high prices of food today are mostly driven by elevating demand due to rapid population growth among other conventional factors such as urbanization and industrialization, economic growth and food consumption, and land use changes and water scarcity (Khan et al., 2009). Today there are almost 219,000 additional people to feed at the global table every night, this unfortunate scenario is the consequenc of the current competition between food and energy. Most developed nations are now converting food products into energy sources, for instance, the United States is now converting massive quantities of grains into fuel for cars, even with increasing grain consumption. This massive capacity to convert grain into fuel means that the price of grain is now tied to the price of oil. The same phenomenon is also happening in Brazil, where distills ethanol from sugar cane, ranks second in production after the United States, while the European Union's goal of getting 10 percent of its transport energy from renewable, mostly biofuel, by 2020 is also diverting land from food crops (Eaves and Eaves, 2007).

\subsection{Application of optimization in solvent extraction}

Principles of optimization find applications in the fields of science, engineering, and business. Optimization is therefore concerned with selecting the best among the entire set by efficient quantitative methods (Onifade, 2002). It has been reported that the recent development in chemical and process engineering industry has undergone significant changes during the past few years due to the increased cost of energy, increasingly stringent environmental regulations, and global competition in product pricing and quality (Onifade, 2002). One of the most important engineering tools for addressing these issues is optimization of the technique involved. Effective optimization techniques are now available in software for personal computers, a capability that did not exist some years ago. To achieve effective application of optimization in the chemical and process industries, there is the need for proper understanding of both the theory and application by engineers and scientists who find optimization as the decision making process which is the exasperating and difficult. In this present study, optimization technique is employ to determine the best conditions at which oil can be extracted from moringa oleifera seed by solvent extraction method. 
The process of solvent extraction of oil, includes diffusion of a solvent into oil-bearing cells of vegetable oil seeds resulting in a solution of the oil in solvent. Various solvents can be used for extraction. However, after extensive research and consideration of various factors, such as commercial economics, edibility of the various products obtained from extraction, physical properties of the solvent especially its low boiling point, volatility, toxicity, viscosity etc. Hence, the selection of the equipment for an extraction process is influenced by the factors, which are responsible for limiting the extraction rate. Thus if the diffusion of the solute through the pores of the residual solid is the controlling factors, the material should be of small size so that the distance the solute has to travel is small. On the other hand, if the diffusion of the solute from the surface of the particle to the bulk of the solution is the controlling factor, then a high degree of agitation is required for optimum leaching of the seed, thus particle size, temperature, agitation and solvent are the major factors influencing solvent extraction techniques. These factors are therefore combined during experimental design which resulted into what is described as factorial experimental design for the purpose of optimizing the process and to investigate the interaction between the various factors that influence the rate of extraction.

The method of factorial experimental design forces data to be orthogonal which allows one to determine the relative importance of each input variable and thus to develop a parametric model that includes only the most important variables and effects. It also represents efficient method of experimentation to determine the best operating condition for each variable factor that influences the process. In factorial experimental design, experiments are systematically planned and conducted in such a way that all the variable factors are changed simultaneously rather than one at a time, for the purpose of reducing the number of experiments. Due to the orthogonal nature of a factorial design method, statistical tests are effective in discriminating among the effects of different natural variations such as the unit operations, operators, batches and other environmental factors. The standard factorial design therefore requires $2 \mathrm{k}$ tests, where $\mathrm{k}$ represents the number of input variables to be investigated. It is also important for the user of factorial design to decide the extent to which each of the variable input should be changed from its original value. To take this decision, the user needs to take into account the sensitivity of the process response to a change in a given input variable, as well as the typical operating range of the process. The experimental design range should therefore be chosen in other to avoid the possibility of the response of the resulting measurements not to generate errors that are far greater than the typical real values. To achieve this in experimental factorial design, variance (ANOVA) or regression analysis can be use to analyzed the experimental results effectively, which is relatively easy to determine the major effect of a variable factor. The factorial design therefore,becomes an important tool in the solvent extraction techniques.

\section{Moringa oleifera}

Moringa oleifera popularly called Zogale in the northern part of Nigeria is the most widely cultivated variety of the genus Moringa and belong to the family of Moringaceae. Moringa oleifera is a nutritious vegetable tree with a variety of potential uses. The moringa oleifera tree shown in Figure 2.1 is slender with drooping branch that grows to approximately $10 \mathrm{~m}$ in height. To maintain the pod and leaves within the arms reach, the tree is normally cut to one meter or less. 


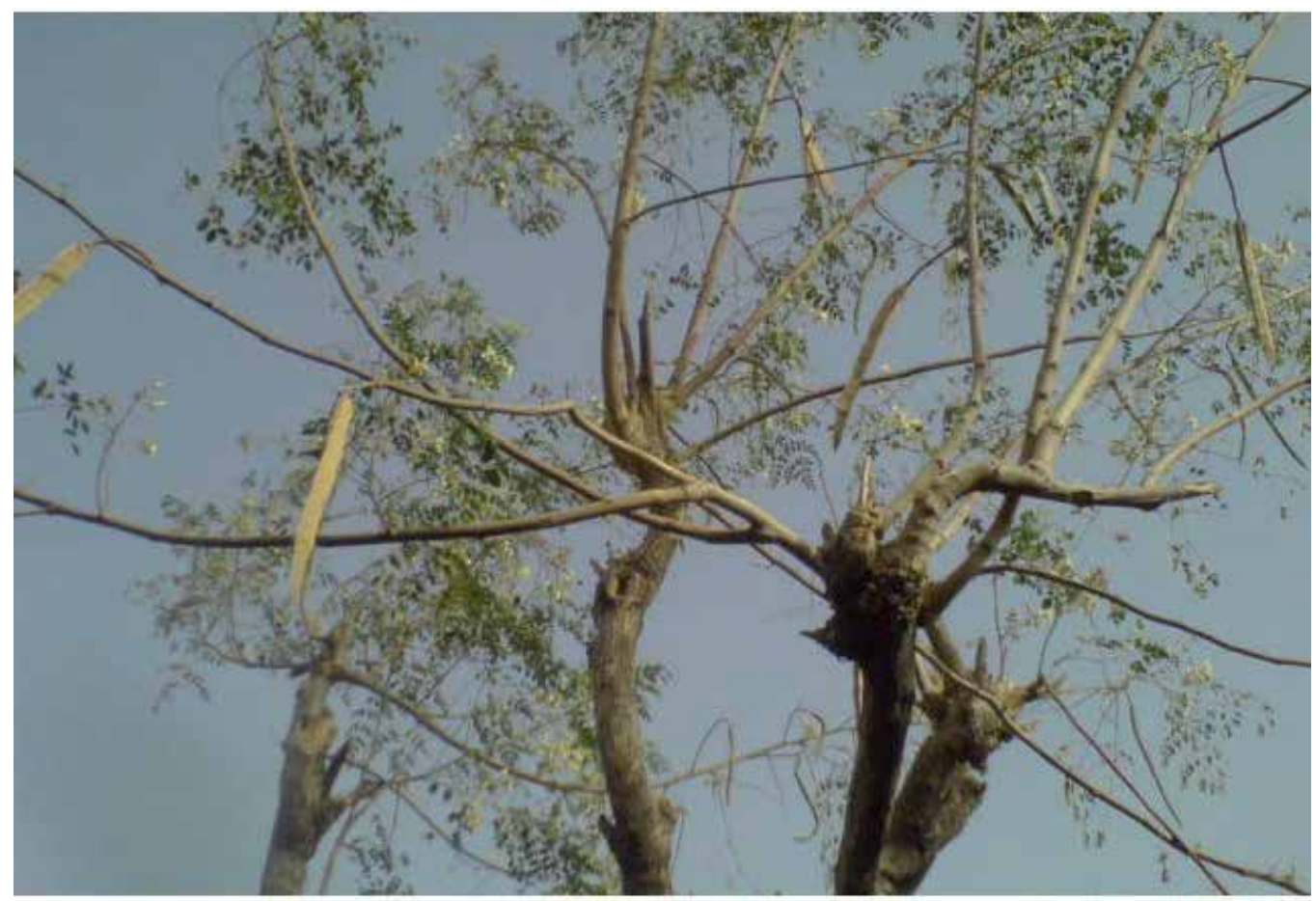

Fig. 2.1. Moringa oleifera tree

The Moringa tree grows mainly in semi-arid tropical and subtropical areas, but grows best in dry sandy soil; it tolerates poor soil, including coastal areas. It is a fast-growing, drought-resistant tree that is native to the southern foothills of the Himalayas, and possibly Africa and the Middle East. The tree has its origin from the Southern Indian State of Tamilnadu. Today, it is widely cultivated in Africa, Central and South America, Sri Lanka, India, Mexico, Malaysia and the Philippines. It grows up to $4 \mathrm{~m}$ in height and develops to flowering and fruiting within one year of its cultivation. Moringa oleifera is considered as one of the world's most useful trees, this is because almost every part of the tree can be used for food, or has some other beneficial property. Hence it is commonly called the 'Wonder Tree'. In the tropics, it is used as foliage for livestock. The immature green pods, called "drumsticks" are probably the most valued and widely used part of the tree. They are commonly consumed in India, and are generally prepared in a similar fashion to green beans and have a slight asparagus taste (Rajangam et al, 2000).

The Moringa seeds (Figure 2.2) yield $38-45 \%$ edible oil (called Ben oil, from the high concentration of Behenic acid contained in the oil) that can be used in cooking, cosmetics and lubrication. Unfortunately, the oil from moringa oleifera seed is not popular edible oil in Nigeria; hence extraction of oil for the purpose of biodiesel production will not pose any food shortage threat which is a major factor against the production of biodiesel from vegetable oil. 

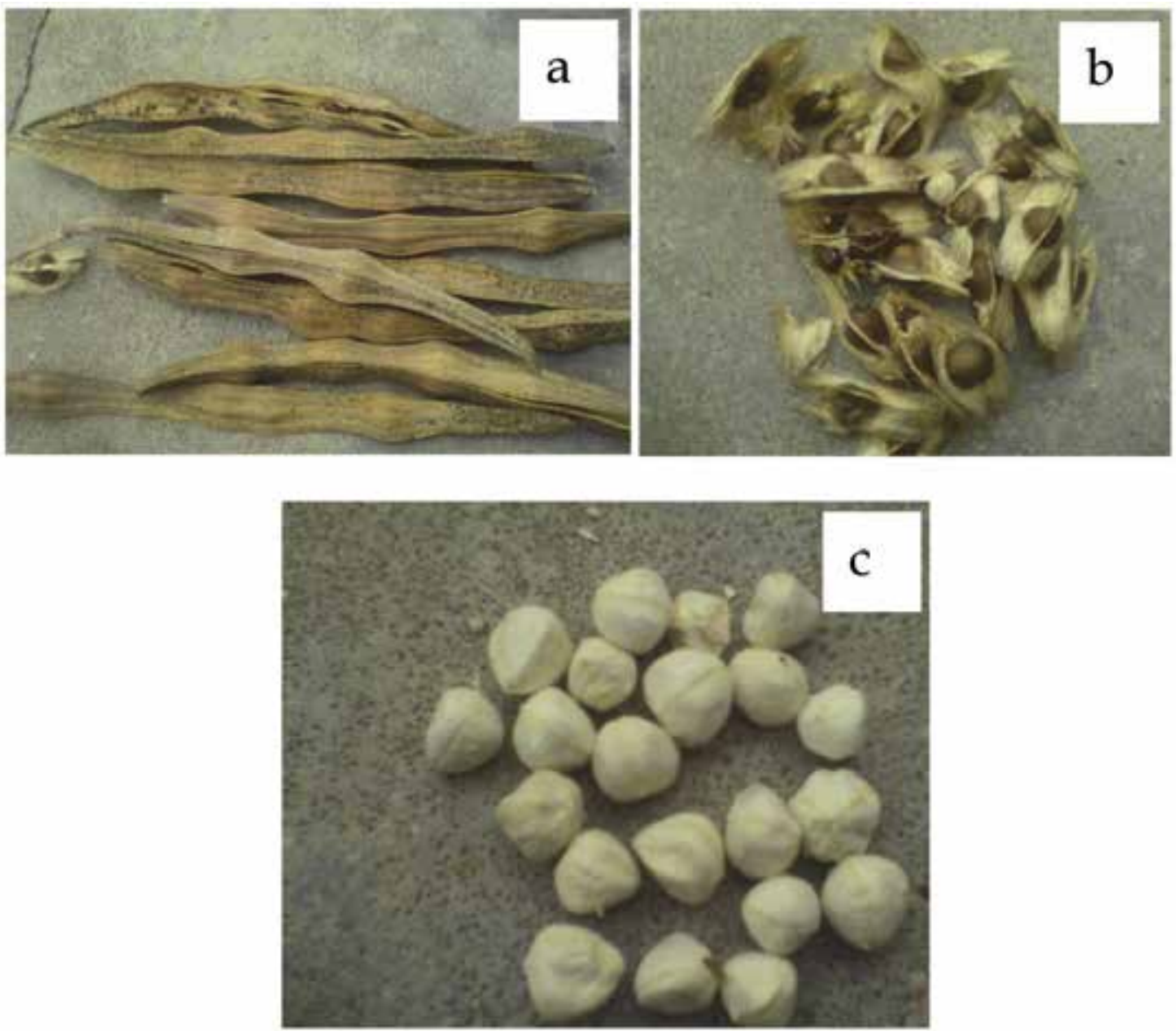

Fig. 2.2. Moringa oleifera (a) Dried pods (b) Seed kernel with husks (c) seed kernel without husk

The refined oil is clear, odourless and resists rancidity like any other botanical oil. The seed cake remaining after the oil extraction can be used as fertilizer or as flocculants to treat turbid water. The leaves are highly nutritious, being a significant source of beta-carotene, Vitamin C, protein, iron and potassium; it is consumed mostly among the Hausas in Northern Nigeria. In addition to being used fresh as a substitute for spinach, the leaves are commonly dried and processed into powder and used in soups and sauces.

\section{Methodology}

\subsection{Material and equipment}

This study focus on the extraction of oil from moringa oleifera seed by means of solvent extraction and production of bio-ethanol from rice husk using alkali as the hydrolising agent and zymomonas for fermentation. The entire chemicals used in this study are of analytical grade (98-99.5\%). They include hexane, ethanol, iodine, sodium hydroxide, calcium oxide, potasium iodide and potasium hydroxide. The equipments used are mortar and pestle, sieve, electronic weighing balance, thimble, measuring cylinder, stop watch, $\mathrm{pH}$ meter, 
electric oven and distillation column. The moringa oleifera seeds and rice husk used in this study were collected in Bosso Estate, Minna, Niger State, Nigeria.

\subsection{The $2^{k}$ factorial experimental design}

When several factors are of interest in an experiment a factorial method of analysis is used in order to study the effect of individual factor and its interaction with other factors to economize the experimental resources (Azeez, 2005;Zhang and Huang, 2011; Wang et al., 2011). In this study, three factors namely temperature, particle size and resident time are of interest while agitation was kept constant. This gives rise to three-factor factorial experiment; the factors are tested at high and low levels. When three factors are tested at two levels as applicable in this study, it is denoted by $2^{3}$ factorial; thus there exist eight $\left(2^{3}\right)$ treatment combinations as shown in Table 3.1. The table indicates how the individual effect and interactions are calculated. It was assumed that $\mathrm{A}, \mathrm{B}$ and $\mathrm{C}$ are the fixed factors where there are ' $a$ ' levels of $A$, ' $b$ ' levels of $B$ and ' $c$ ' levels of $C$ arranged in the factorial experiment. Generally there will be abc.....n total observations if there are $\mathrm{n}$ replicates of the complete experiment. The analysis variance is shown in Table 3.2.

\begin{tabular}{|c|c|c|c|c|c|c|c|c|}
\hline $\begin{array}{c}\text { Treatment } \\
\text { combination }\end{array}$ & \multicolumn{7}{|c|}{ Factorial Effect } \\
\hline I & I & A & B & C & AB & AC & BC & ABC \\
\hline A & + & - & - & - & + & + & + & - \\
\hline $\mathrm{B}$ & + & + & - & - & - & - & + & + \\
\hline $\mathrm{Ab}$ & + & - & + & - & - & + & - & + \\
\hline $\mathrm{C}$ & + & - & - & + & + & - & - & + \\
\hline $\mathrm{Ac}$ & + & + & - & + & - & + & - & - \\
\hline $\mathrm{Bc}$ & + & - & + & + & - & - & + & - \\
\hline $\mathrm{Abc}$ & + & + & + & + & + & + & + & + \\
\hline
\end{tabular}

Table 3.1. Design matrix for a $2^{3}$ Factorial Design

Consider a three factors experiment, with underlying model as shown in Equation1, before the model equation can be fitted, it is important to conduct some statistical tests such as Gtest, T-test and F-test, which involves calculation of these statistical parameters with the aid of certain formulae shown in Equations 2-4 and compare them with those given in the statistical tables. G-test is used to check if the output has the maximum accuracy of replication. T-test is used to check the significance of regression coefficient, and F-test is used to test for the adequacy of the model. Equations 2-4 represent the formulae to calculate G-test, T-test and F-test respectively. 


\begin{tabular}{|c|c|c|c|c|c|}
\hline $\begin{array}{c}\text { Sources } \\
\text { of } \\
\text { Variation }\end{array}$ & $\begin{array}{l}\text { Sum of } \\
\text { Squares }\end{array}$ & $\begin{array}{l}\text { Degree of } \\
\text { Freedom }\end{array}$ & $\begin{array}{l}\text { Mean } \\
\text { Square }\end{array}$ & Expected Mean Squares & $\mathrm{F}_{\mathrm{o}}$ \\
\hline A & $\mathrm{SS}_{\mathrm{A}}$ & $(a-1)$ & $\mathrm{MS}_{\mathrm{A}}$ & $\delta^{2}+\left(b c n \sum \tau^{2}{ }_{i}\right) /(a-1)$ & $\mathrm{MS}_{\mathrm{A}} / \mathrm{MS}_{\mathrm{E}}$ \\
\hline B & $\mathrm{SS}_{\mathrm{B}}$ & (b-1) & $\mathrm{MS}_{\mathrm{B}}$ & $\delta^{2}+\left(\operatorname{can} \Sigma \beta^{2}{ }_{j}\right) /(b-1)$ & $\mathrm{MS}_{\mathrm{B}} / \mathrm{MS}_{\mathrm{E}}$ \\
\hline $\mathrm{C}$ & $\mathrm{SS}_{\mathrm{C}}$ & $(\mathrm{c}-1)$ & $\mathrm{MS}_{\mathrm{C}}$ & $\delta^{2}+\left(\operatorname{abn} \Sigma \gamma^{2} \mathrm{k}\right) /(\mathrm{c}-1)$ & $\mathrm{MS}_{\mathrm{C}} / \mathrm{MS}_{\mathrm{E}}$ \\
\hline $\mathrm{AB}$ & $\mathrm{SS}_{\mathrm{AB}}$ & $(a-1)(b-1)$ & $\mathrm{MS}_{\mathrm{AB}}$ & $\delta^{2}+\left(\operatorname{cn} \Sigma \Sigma(\tau \beta)^{2}{ }{ }^{i j}\right) /(a-1)(b-1)$ & $\mathrm{MS}_{\mathrm{AB}} / \mathrm{MS}_{\mathrm{E}}$ \\
\hline $\mathrm{AC}$ & $\mathrm{SS}_{\mathrm{AC}}$ & $(a-1)(c-1)$ & $\mathrm{MS}_{\mathrm{AC}}$ & $\delta^{2}+\left(\mathrm{bn} \Sigma \Sigma(\mathrm{\tau} \gamma)^{2}{ }_{\mathrm{ik}}\right) /(\mathrm{a}-1)(\mathrm{c}-1)$ & $\mathrm{MS}_{\mathrm{AC}} / \mathrm{MS}_{\mathrm{E}}$ \\
\hline $\mathrm{BC}$ & $\mathrm{SS}_{\mathrm{BC}}$ & $(b-1)(c-1)$ & $\mathrm{MS}_{\mathrm{BC}}$ & $\delta^{2}+\left(\operatorname{an} \Sigma \Sigma(\beta \gamma)^{2}{ }_{j k}\right) /(b-1)(c-1)$ & $\mathrm{MS}_{\mathrm{BC}} / \mathrm{MS}_{\mathrm{E}}$ \\
\hline $\mathrm{ABC}$ & $\mathrm{SS}_{\mathrm{ABC}}$ & $(a-1)(b-1)(c-1)$ & $\mathrm{MS}_{\mathrm{ABC}}$ & $\begin{array}{c}\delta^{2}+\left(\mathrm{n} \sum \sum \sum(\tau \beta \gamma)^{2}{ }{ }_{\mathrm{jk}}\right) /(\mathrm{a}-1) \\
(\mathrm{b}-1)(\mathrm{c}-1)\end{array}$ & $\mathrm{MS}_{\mathrm{ABC}} / \mathrm{MS}_{\mathrm{E}}$ \\
\hline Error & $\mathrm{SS}_{\mathrm{E}}$ & $a b c(n-1)$ & $\mathrm{MS}_{\mathrm{E}}$ & $\delta^{2}$ & \\
\hline Total & $\mathrm{SS}_{\mathrm{T}}$ & & & & \\
\hline
\end{tabular}

Table 3.2. Variance (ANOVA) analysis

$$
Y_{\mathrm{ijkl}}=\mu+\tau_{\mathrm{i}}+\beta_{\mathrm{j}}+\gamma_{\mathrm{k}}+(\tau \beta)_{\mathrm{ij}}+(\tau \gamma)_{\mathrm{ik}}+(\beta \gamma)_{\mathrm{jk}}+(\tau \beta \mathrm{v})_{\mathrm{ijk}}+E_{\mathrm{ijk}}
$$

$\mathrm{i}=1,2,---\mathrm{a}$

$\mathrm{j}=1,2,---\mathrm{b}$

$\mathrm{k}=1,2,---\mathrm{c}$

$1=1,2,---n$

Where $\mu$ is the overall mean effect,

$\tau_{i}$ is the effect of the ith level of factor $A$

$\beta_{\mathrm{j}}$ is the effect of $\mathrm{jth}$ level of factor $B$

$\gamma_{\mathrm{k}}$ is the effect of $\mathrm{kth}$ level of factor $C$

$(\tau \beta)_{i j}$ is the effect of the interaction between $A$ and $C$

$(\beta \gamma)_{\text {ik }}$ is the effect of the interaction between $B$ and $C$

$(\tau \beta \mathrm{v})_{\mathrm{ijk}}$ is the effect of the interaction between $\mathrm{A}, \mathrm{B}$ and $\mathrm{C}$

$\mathrm{E}_{\mathrm{ijkl}}$ is the random error component having a normal distribution with zero and variance $\delta^{2}$

$$
\begin{gathered}
\mathrm{G}_{- \text {cal }}=\frac{\mathrm{Su}_{\text {max }}^{2}}{\sum \mathrm{Su}^{2}} \\
\mathrm{~T}_{- \text {cal }}=\frac{\left|\mathrm{b}_{\mathrm{j}}\right|}{\mathrm{Sb}} \\
\mathrm{Sb}=\frac{\sqrt{\left(\mathrm{Su}^{2}\right)}}{\sqrt{(\mathrm{N} \cdot \mathrm{r})}} \\
F_{-c a l}=\frac{S_{a}^{2} d}{S u^{2}} \\
\mathrm{~S}_{\mathrm{a}}^{2} \mathrm{~d}=\frac{\mathrm{r}}{\mathrm{N}-\lambda} \sum\left(\mathrm{Y}-\mathrm{Y}_{\mathrm{cal}}\right)^{2} \\
\mathrm{Su}^{2}=\frac{1}{\mathrm{r}-1} \sum\left(\mathrm{Y}_{\mathrm{r}}-\mathrm{Y}_{\mathrm{i}}\right)
\end{gathered}
$$


Where

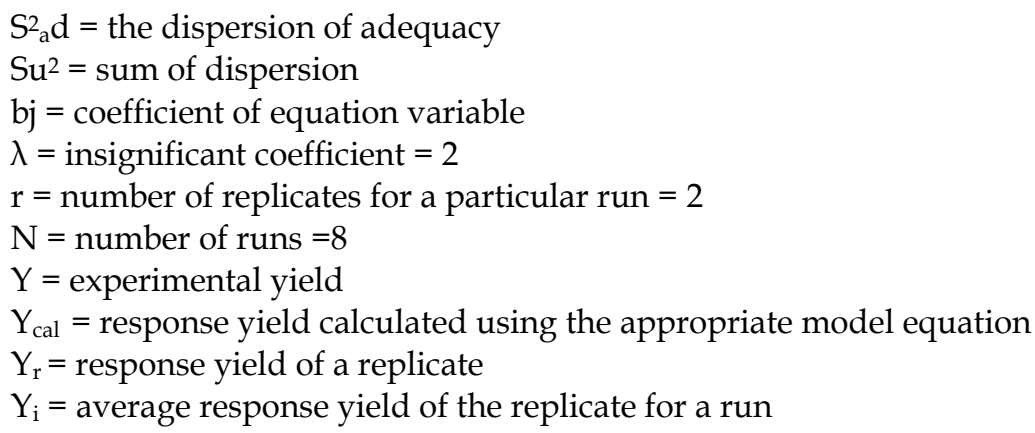

\subsection{Production of bio-ethanol from rice husk}

Prior to the production of bio-ethanol, the rice was treated to confirm the presence of starch. Paddy rice was milled sieved and the residue was collected and weighed. $2 \mathrm{~cm}^{3}$ of sample was measured from the bulk sample and transferred into the test tube. Potassium iodide reagent was then added drop wise into the sample in the test tube and stirred until colour was changed from yellow to black, which confirm the presence of starch. $500 \mathrm{~g}$ of the husk was collected and soaked in $750 \mathrm{~cm}^{3}$ of water for a period of 24 hours after which it was filtered with the aid of a filter cloth, $600 \mathrm{~cm}^{3}$ of the filtrate was collected and made up to $1000 \mathrm{~cm}^{3}$ with boiled water, the mixture was stirred continuously to avoid formation of lumps, it was then allowed to cool and on cooling, a thick-jelly mass was formed, gelatinized mixture was then poured into a $2000 \mathrm{~cm}^{3}$ flask for hydrolysis. $200 \mathrm{~cm}^{3}$ of $0.5 \mathrm{~m}$ potassium hydroxide was added to the sample and immersed in the water bath for hydrolysis and the temperature was maintained at $75^{\circ} \mathrm{C}$ for 60 minutes. $100 \mathrm{~cm}^{3}$ of $50 \%$ ethanoic acid was then added to serve as a terminator of the hydrolysis reaction after which the mixture was set aside to cool. $4 \mathrm{~cm}^{3}$ of hydrolyzed sample, , few drops of Fehling's solution was added in a conical flask and heated, colour change was observed and recorded, sample changes to brick red precipitate, which confirm the presence of simple sugars.

\subsubsection{Fermentation of hydrolysed rice husk}

Zymomonas mobilis "Local strain" was isolated from palm wine using standard solid medium. Media constituents include $5.0 \mathrm{~g}$ of yeast extract, $20 \mathrm{~g}$ of agar and $1000 \mathrm{~cm}^{3}$ of distilled water with $\mathrm{pH}$ 6.8. Medium was treated with actidione (cycloheximide) to inhibit Zymomonas mobilis growth before autoclaving at $121^{\circ} \mathrm{C}$ for 15 minutes. Zymomonas mobilis was then inoculated into the medium and incubated an aerobically at $3{ }^{\circ} \mathrm{C}$ for 24 hours. Working close to the flame (creating aseptic environment), Zymomonas mobilis was introduced into the conical flask containing the substrate, the flask were then shaken (agitation process) and the mouths of the conical flasks were flamed before corking back and incubating at room temperature, they were shaken at various intervals in order to produce a homogenous paste and even distribution of the organisms in the substrates. After fermentation process, the substrates were then filtered using filter cloth and collected in a conical flask, in order to separate the desired product (the filtrate) from the residue. The filtrates were then distilled at $78.3^{\circ} \mathrm{C}$ using alcohol distillation apparatus, round bottom flask containing the filtrate was placed in the heating mantle and the mouth fixed to the condenser, a beaker for distillate collection was placed at the end of the set up, rubber pipes 
or hose were connected to the condenser to supply water from the tap for cooling the condenser to supply water from the tap for cooling the condenser and letting out water out of the condenser simultaneously. Temperature on the heating mantle was set to the standard temperature for the production of ethanol which is $78.3^{\circ} \mathrm{C}$, as the filtrate was heated, the vapour rose and entered into the condenser, tap water was passed into and out of the condenser using the rubber pipes and this condenses the vapor from the heated filtrate, condensed vapour was collected into the beaker at the other end of the distillation set up as the distillate (bio-ethanol), this process was repeated for other samples. The distillate was further purified by the use of calcium oxide (lime), a basic oxide, when added to the ethanol, absorbed the water to form calcium hydroxide, an alkaline solution; calcium hydroxide formed was separated from ethanol by further distillation which leaves absolute ethanol. One $\mathrm{cm}^{3}$ of alcohol was treated with iodine and sodium hydroxide, the colour change was observed and recorded, yellow precipitate was formed, which confirm that ethanol is present. The produced bio-ethanol was characterized to determine the density, flash point, pour point.

\section{Results and discussion of results}

\subsection{Results and statistical analysis of experimental results}

Tables 4.1 and 4.2 present the results on the extraction of oil from moringa oleifera seed with hexane and ethanol as the solvent respectively at different temperature, particle size and resident time. Results obtained as presented indicate that there are thirty two experimental runs with two replicates each for sixteen samples. It can be seen from the results that the extraction time, temperature, particle size and type of extraction solvent affects the rate of extraction of oil from oleifera moringa seed. Ethanol plays a major role in the production of biodiesel from oil, achieve a suistainable production of biodiesel therefore, it is important to employ a cheap and suistanable method of ethanol production. In this work the production of bioethanol from agricultural waste (rice waste) was also conducted and the results obtained are presented in Tables 4.3 and 4.4 .

Results presented reveals that at the extraction conditions combination with all samples at low levels, the oil yield was $37.78 \%$ and $37.35 \%$ for the replicate using n-hexane. Ethanol yielded $19.90 \%$ and $20.25 \%$ for the replicate. While For treatment combination where the temperature was high $(65 \circ \mathrm{C})$ while particle size and extraction time were low $(500 \mu \mathrm{m}$ and 6 hr respectively) n-hexane yielded $38.58 \%$ and $38.37 \%$ for the replicate. Ethanol at a high temperature of $75^{\circ} \mathrm{C}$ and particle size $(500 \mu \mathrm{m}$ and extraction time of $6 \mathrm{hrs}$ yielded $20.82 \%$ and $21.23 \%$ for the replicate. Similarly For treatment combination where the temperature was low $\left(55^{\circ} \mathrm{C}\right)$ while particle size high $(710 \mu \mathrm{m})$ and extraction time low $(6 \mathrm{hr}) \mathrm{n}$-hexane yielded $43.17 \%$ and $43.26 \%$ for the replicate. Ethanol at a low temperature of $65^{\circ} \mathrm{C}$, particle size high $(710 \mu \mathrm{m})$ and extraction time low (6hrs) yielded $38.71 \%$ and $38.65 \%$ for the replicate. While for extraction combination where the temperature was $\left(55^{\circ} \mathrm{C}\right)$ and particle size $(500 \mu \mathrm{m})$ are low, extraction time was high (7hrs) n-hexane yielded $42.22 \%$ and $41.98 \%$ for the replicate. Ethanol at a low temperature and particle size $\left(65^{\circ} \mathrm{C}\right.$ and $500 \mu \mathrm{m}$ respectively) and extraction time high (7hrs) yielded $22.16 \%$ and $21.96 \%$ for the replicate. Also for the extraction conditions combination where the temperature and particle size were high $\left(65^{\circ} \mathrm{C}\right.$ and $710 \mu \mathrm{m}$ respectively) and extraction time were low (6hr) n-hexane yielded $43.01 \%$ and $42.95 \%$ for the replicate. Ethanol at a high temperature and particle size of $\left(75^{\circ} \mathrm{C}\right.$ and $710 \mu \mathrm{m}$ respectively) and low extraction time of 6 hrs yielded $35.32 \%$ and $35.68 \%$ for the replicate. Results 
presented also shows that, for the extraction combination where the temperature was high $\left(65^{\circ} \mathrm{C}\right)$, low particle size $(500 \mu \mathrm{m})$ and high extraction time $(7 \mathrm{hrs})$ n-hexane yielded $42.81 \%$ and $42.25 \%$ for the replicate. Ethanol at a high temperature of $75^{\circ} \mathrm{C}$, low particle size $(500 \mu \mathrm{m})$ and high extraction time of $7 \mathrm{hrs}$ yielded $26.67 \%$ and $26.14 \%$ for the replicate. It could be observed from the Tables of result that, for treatment combination where the temperature was low $\left(55^{\circ} \mathrm{C}\right)$ while particle size and extraction time were high $(710 \mu \mathrm{m}$ and 7 hrs respectively) n-hexane yielded $41.38 \%$ and $41.35 \%$ for the replicate. Ethanol at a low temperature of $65^{\circ} \mathrm{C}$, high particle size and extraction time $(710 \mu \mathrm{m}$ and $7 \mathrm{hrs}$ respectively) yielded $28.84 \%$ and $28.24 \%$ for the replicate. Finally, for extraction condition combination where all the parameters are high temperature $\left(65^{\circ} \mathrm{C}\right)$, particle size and extraction time were (710 $\mu \mathrm{m}$ and $7 \mathrm{hr}$ respectively) n-hexane yielded $42.03 \%$ and $42.52 \%$ for the replicate. Ethanol at a high temperature of $75^{\circ} \mathrm{C}$, particle size and extraction time $(710 \mu \mathrm{m}$ and $7 \mathrm{hrs}$ respectively) yielded $24.75 \%$ and $25.03 \%$ for the replicate

\begin{tabular}{|c|c|c|c|c|c|}
\hline $\mathrm{S} / \mathrm{N}$ & $\begin{array}{l}\text { wt of oil } \\
\text { extracted } \\
\text { (g) }\end{array}$ & $\begin{array}{l}\% \text { wt of oil } \\
\text { extracted }\end{array}$ & $\begin{array}{c}\text { Temp } \\
\left({ }^{\circ} \mathrm{C}\right)\end{array}$ & $\begin{array}{l}\text { Particle Size } \\
\qquad(\mu \mathrm{m})\end{array}$ & $\begin{array}{l}\text { Resident Time } \\
(\mathrm{hr})\end{array}$ \\
\hline \multicolumn{6}{|c|}{ Solvent $=$ Hexane } \\
\hline 1 & 4.22 & 42.03 & 65 & 710 & 7 \\
\hline 2 & 4.15 & 41.38 & 55 & 710 & 7 \\
\hline 3 & 4.23 & 42.22 & 55 & 500 & 7 \\
\hline 4 & 4.29 & 42.81 & 65 & 500 & 7 \\
\hline 5 & 3.87 & 38.58 & 65 & 500 & 6 \\
\hline 6 & 3.79 & 37.78 & 55 & 500 & 6 \\
\hline 7 & 4.31 & 43.01 & 65 & 710 & 6 \\
\hline 8 & 4.33 & 43.17 & 55 & 710 & 6 \\
\hline \multicolumn{6}{|c|}{ Solvent $=$ Ethanol } \\
\hline 1 & 2.48 & 24.75 & 75 & 710 & 7 \\
\hline 2 & 3.76 & 28.84 & 65 & 710 & 7 \\
\hline 3 & 2.22 & 22.16 & 65 & 500 & 7 \\
\hline 4 & 2.67 & 26.67 & 75 & 500 & 7 \\
\hline 5 & 2.09 & 20.82 & 75 & 500 & 6 \\
\hline 6 & 2.00 & 19.90 & 65 & 500 & 6 \\
\hline 7 & 3.55 & 35.32 & 75 & 710 & 6 \\
\hline 8 & 3.89 & 38.71 & 65 & 710 & 6 \\
\hline
\end{tabular}

Table 4.1. Oil yield at various conditions from the first run with hexane and ethanol as the solvent 


\begin{tabular}{|c|c|c|c|c|c|}
\hline $\mathrm{S} / \mathrm{N}$ & $\begin{array}{l}\text { wt of oil } \\
\text { extracted } \\
\text { (g) }\end{array}$ & $\begin{array}{l}\% \text { wt of oil } \\
\text { extracted }\end{array}$ & $\begin{array}{c}\text { Temp } \\
\left({ }^{\circ} \mathrm{C}\right)\end{array}$ & $\begin{array}{l}\text { Particle Size } \\
\qquad(\mu \mathrm{m})\end{array}$ & $\begin{array}{l}\text { Resident Time } \\
(\mathrm{hr})\end{array}$ \\
\hline \multicolumn{6}{|c|}{ Solvent = Hexane } \\
\hline 1 & 4.27 & 42.52 & 65 & 710 & 7 \\
\hline 2 & 4.14 & 41.35 & 55 & 710 & 7 \\
\hline 3 & 4.21 & 41.98 & 55 & 500 & 7 \\
\hline 4 & 4.23 & 42.25 & 65 & 500 & 7 \\
\hline 5 & 3.83 & 38.15 & 65 & 500 & 6 \\
\hline 6 & 3.70 & 36.92 & 55 & 500 & 6 \\
\hline 7 & 4.30 & 42.95 & 65 & 710 & 6 \\
\hline 8 & 4.34 & 43.26 & 55 & 710 & 6 \\
\hline \multicolumn{6}{|c|}{ Solvent $=$ Ethanol } \\
\hline 1 & 2.57 & 25.65 & 75 & 710 & 7 \\
\hline 2 & 3.71 & 27.05 & 65 & 710 & 7 \\
\hline 3 & 2.35 & 23.45 & 65 & 500 & 7 \\
\hline 4 & 2.77 & 27.65 & 75 & 500 & 7 \\
\hline 5 & 2.18 & 21.74 & 75 & 500 & 6 \\
\hline 6 & 2.44 & 20.34 & 65 & 500 & 6 \\
\hline 7 & 3.45 & 34.28 & 75 & 710 & 6 \\
\hline 8 & 3.92 & 38.96 & 65 & 710 & 6 \\
\hline
\end{tabular}

Table 4.2. Oil yield at various conditions from the second run with hexane and ethanol as the solvent

\begin{tabular}{|c|c|c|c|}
\hline Substrate & $\begin{array}{c}\text { Volume of hydrolysate } \\
\left(\mathrm{cm}^{3}\right)\end{array}$ & $\begin{array}{c}\text { Volume of ethanol } \\
(\mathrm{cm} 3)\end{array}$ & $\begin{array}{c}\text { \% Ethanol } \\
\text { concentration }\end{array}$ \\
\hline \multirow{3}{*}{ Rice husk } & 350 & 25 & 7.143 \\
\cline { 2 - 4 } & 300 & 35 & 11.667 \\
\cline { 2 - 4 } & 250 & 37.5 & 14.880 \\
\cline { 2 - 4 } & 150 & 43 & 28.667 \\
\hline
\end{tabular}

Table 4.3. Ethanol production using Zymomonas mobilis from distillation process

\begin{tabular}{|c|c|c|}
\hline Properties & Commercial grade ethanol & $\begin{array}{c}\text { Bio-ethanol produced } \\
\text { from rice husk }\end{array}$ \\
\hline Appearance & Clear, colourless liquid & Clear, colourless liquid \\
\hline Boiling point $\left({ }^{\circ} \mathrm{C}\right)$ & 78.15 & 78.3 \\
\hline Density $\left(\mathrm{g} / \mathrm{cm}^{3}\right)$ & 0.789 & 0.787 \\
\hline Viscosity & 1.20 & 1.34 \\
\hline Flammability & Flammable & Flammable \\
\hline Flash point $\left({ }^{\circ} \mathrm{C}\right)$ & 13 & 14.5 \\
\hline Refractive index & $1.3614-1.3618$ & 1.3626 \\
\hline
\end{tabular}

Table 4.4. Properties of produced ethanol compared to commercial ethanol 


\subsubsection{Statistical analysis of experimental results}

Statistical analyses were conducted with the aim of developing a model to represent the relationship between the factors investigated and the yield of oil from the moringa oleifera seeds with hexane and ethanol as the extraction solvent. Table 4.4 shows an estimation of upper and lower levels of the three factors (temperature, particle size and time). While Tables 4.5 and 4.6 indicates factorial experimental design results with n-hexane and ethanol as the extraction solvent respectively.

The average effect of a factor which is described as the change in response produced by a change in the level of factor response produced by a change in the level of factor averaged over the levels of other factors. This has been calculated and subsequently tabulated in Table 4.7 for n-hexane and ethanol.

\begin{tabular}{|c|c|c|c|c|c|}
\hline $\begin{array}{c}\text { Level of } \\
\text { Factor }\end{array}$ & Code & \multicolumn{2}{|c|}{$\begin{array}{c}\text { A } \\
\text { Temperature } \\
(\mathrm{o})\end{array}$} & $\begin{array}{c}\text { B } \\
\text { Particle } \\
\text { Size } \\
(\mu \mathrm{m})\end{array}$ & $\begin{array}{c}\text { C } \\
\text { Time (hrs) }\end{array}$ \\
\hline & & Hexane & Ethanol & & \\
\hline High level & +1 & 65 & 75 & 710 & 7 \\
\hline Low level & -1 & 55 & 65 & 500 & 6 \\
\hline
\end{tabular}

Table 4.4. Factors and their coded levels

\begin{tabular}{|c|c|c|c|c|c|}
\hline \multicolumn{2}{|c|}{$\begin{array}{c}\text { Treatment } \\
\text { combination }\end{array}$} & Design factor & \multirow[t]{2}{*}{ First yield $Y_{1}$} & \multirow[t]{2}{*}{ Second yield $Y_{2}$} & \multirow[t]{2}{*}{$\begin{array}{c}\text { Average yield } \\
\mathrm{Y}_{\mathrm{av}} \\
\end{array}$} \\
\hline Run & & $\begin{array}{lll}A & B & C\end{array}$ & & & \\
\hline 1 & I & $\begin{array}{lll}-1 & -1 & -1\end{array}$ & 37.78 & 36.92 & 37.35 \\
\hline 2 & $\mathrm{~A}$ & $\begin{array}{lll}+1 & -1 & -1 \\
\end{array}$ & 38.58 & 38.15 & 38.37 \\
\hline 3 & B & $\begin{array}{lll}-1 & +1 & -1\end{array}$ & 43.17 & 43.26 & 43.22 \\
\hline 4 & $\mathrm{C}$ & $\begin{array}{lll}-1 & -1 & +1\end{array}$ & 42.22 & 41.98 & 42.10 \\
\hline 5 & $\mathrm{Ab}$ & $\begin{array}{lll}+1 & +1 & -1\end{array}$ & 43.01 & 42.95 & 42.98 \\
\hline 6 & Ac & $\begin{array}{lll}+1 & -1 & +1 \\
\end{array}$ & 42.81 & 42.25 & 42.53 \\
\hline 7 & $\mathrm{Bc}$ & $\begin{array}{lll}-1 & +1 & +1\end{array}$ & 41.38 & 41.35 & 41.37 \\
\hline 8 & $\mathrm{Abc}$ & $\begin{array}{lll}+1 & +1 & +1\end{array}$ & 42.03 & 42.52 & 42.28 \\
\hline
\end{tabular}

Table 4.5. $2^{3}$ Factorial experimental design results using n-hexane as extraction solvent

\begin{tabular}{|c|c|c|c|c|c|}
\hline \multicolumn{2}{|c|}{$\begin{array}{c}\text { Treatment } \\
\text { combination }\end{array}$} & Design factor & \multirow[t]{2}{*}{ First yield $Y_{1}$} & \multirow[t]{2}{*}{ Second yield $\mathrm{Y}_{2}$} & \multirow[t]{2}{*}{$\begin{array}{c}\text { Average yield } \\
\mathrm{Y}_{\mathrm{av}} \\
\end{array}$} \\
\hline Run & & $\begin{array}{lll}A & B & C\end{array}$ & & & \\
\hline 1 & I & $\begin{array}{lll}-1 & -1 & -1\end{array}$ & 19.90 & 20.25 & 20.08 \\
\hline 2 & $\mathrm{~A}$ & $\begin{array}{lll}+1 & -1 & -1\end{array}$ & 20.82 & 21.25 & 21.04 \\
\hline 3 & B & $\begin{array}{lll}-1 & +1 & -1\end{array}$ & 38.71 & 38.65 & 38.65 \\
\hline 4 & $\mathrm{C}$ & $\begin{array}{lll}-1 & -1 & +1\end{array}$ & 22.16 & 21.96 & 22.06 \\
\hline 5 & $\mathrm{Ab}$ & $+1+1 \quad-1$ & 35.32 & 35.68 & 35.50 \\
\hline 6 & Ac & $\begin{array}{lll}+1 & -1 & +1\end{array}$ & 26.67 & 26.14 & 26.41 \\
\hline 7 & $\mathrm{BC}$ & $\begin{array}{lll}-1 & +1 & +1\end{array}$ & 28.84 & 28.24 & 28.54 \\
\hline 8 & $\mathrm{Abc}$ & $+1+1+1$ & 24.75 & 25.03 & 24.89 \\
\hline
\end{tabular}

Table 4.6. $2^{3}$ Factorial experimental design results using ethanol as extraction solvent 


\begin{tabular}{|c|c|c|}
\hline Factors and interactions & Main effects (n- hexane) & Main effects (Ethanol) \\
\hline $\mathrm{A}$ & 0.5300 & -0.3813 \\
\hline $\mathrm{B}$ & 2.4975 & 9.5213 \\
\hline $\mathrm{C}$ & 1.5900 & -3.3488 \\
\hline $\mathrm{Ab}$ & -0.1925 & -3.0338 \\
\hline $\mathrm{Ac}$ & 0.1400 & 0.7288 \\
\hline $\mathrm{Bc}$ & -2.8675 & -7.0263 \\
\hline $\mathrm{Abc}$ & 0.4325 & -0.8750 \\
\hline
\end{tabular}

Table 4.7. Effects and interactions for solvent extraction of oil using n-hexane and ethanol

Variance (ANOVA) analysis, which enables one to examine the magnitude and direction of the factors' effect and determine which variable are likely to be important was also conducted and the results are presented in Table 4.8 and 4.9 respectively for n-hexane and methanol as the extraction solvent. Variance analysis also helps to determine the statistical significance of the regression coefficients $\left(\beta_{i}\right)$. The level of significance was assumed to be $5 \%(\alpha=0.05)$, which implies that there are about five chances in hundred that reject the hypothesis when it should be accepted: i.e. 95\% confidence that right decision is made. Therefore the critical value for each of the F-ratio $\mathrm{F}\{\mathrm{a}$, dfr, abc(n -1) \}i.e. $\mathrm{F}(0.05,1,8$ is equal to 5.32 from statistical table is equal to 5.32 from statistical table. The F-ratios were compared with this critical value (5.32) and the null hypothesis using Fcal $>F(0.05,1,8)=5.32$. The magnitude of the effects when n-Hexane was used as the extraction solvent indicates that particle size (factor $B$ ) is dominant and has a high significant followed by the extraction time (factor $\mathrm{C}$ ) and the effect of factor A, extraction temperature which is relatively low.

\begin{tabular}{|c|c|c|c|c|c|}
\hline $\begin{array}{c}\text { Sources of } \\
\text { variation }\end{array}$ & $\begin{array}{c}\text { Sum of } \\
\text { square }\end{array}$ & $\begin{array}{c}\text { Degree of } \\
\text { freedom }\end{array}$ & Mean square & $\begin{array}{c}\text { Expected } \\
\text { mean square }\end{array}$ & $\mathrm{F}_{\mathrm{o}}$ \\
\hline $\mathrm{A}$ & 1.1236 & 1 & 1.1236 & 39.5575 & 2.2940 \\
\hline $\mathrm{B}$ & 22.5150 & 1 & 22.5150 & 41.4025 & 45.9677 \\
\hline $\mathrm{C}$ & 10.1124 & 1 & 10.1124 & 40.6175 & 20.6460 \\
\hline $\mathrm{Ab}$ & 0.1482 & 1 & 0.1482 & 41.9325 & 0.3026 \\
\hline $\mathrm{Ac}$ & 0.0784 & 1 & 0.0784 & 41.1475 & 0.1601 \\
\hline $\mathrm{Bc}$ & 32.8902 & 1 & 32.8902 & 42.9925 & 67.1503 \\
\hline $\mathrm{Abc}$ & 0.7482 & 1 & 0.7482 & 43.5225 & 1.5276 \\
\hline Error & 3.9182 & 8 & 0.4898 & & \\
\hline Total & & 15 & & & \\
\hline
\end{tabular}

Table 4.8. Analysis of variance (ANOVA) for the solvent extraction of oil using n-hexane

The magnitude of the effects when ethanol was used as the extraction solvent, clearly shows that particle size (factor $\mathrm{B}$ ) is dominant and has a high significant followed by the interaction of factor A, extraction temperature and factor C, extraction time and the effect of factor A, extraction temperature which is relatively low. Presented in Tables 4.10 and 4.11 are the basic statistical test on the yield of oil from the moringa oleifera seed with n-hexane and ethanol as the extraction solvent respectively. While Table 4.12 present the statistical calculated values of $\mathrm{G}$ and $\mathrm{F}$ test. 
Extraction and Optimization of Oil from

\begin{tabular}{|c|c|c|c|c|c|}
\hline $\begin{array}{c}\text { Sources of } \\
\text { variation }\end{array}$ & $\begin{array}{c}\text { Sum of } \\
\text { square }\end{array}$ & $\begin{array}{c}\text { Degree of } \\
\text { freedom }\end{array}$ & Mean square & $\begin{array}{c}\text { Expected } \\
\text { mean square }\end{array}$ & $\mathrm{F}_{\mathrm{o}}$ \\
\hline $\mathrm{A}$ & 0.5814 & 1 & 0.5814 & 22.9526 & 1.0561 \\
\hline $\mathrm{B}$ & 362.6206 & 1 & 362.6206 & 21.8374 & 658.9508 \\
\hline $\mathrm{C}$ & 44.8578 & 1 & 44.8578 & 32.4602 & 81.5152 \\
\hline $\mathrm{Ab}$ & 36.9372 & 1 & 36.9372 & 22.2200 & 67.1219 \\
\hline $\mathrm{Ac}$ & 2.1246 & 1 & 2.1246 & 31.3450 & 3.8608 \\
\hline $\mathrm{Bc}$ & 197.4756 & 1 & 197.4756 & 22.5700 & 358.8508 \\
\hline $\mathrm{Abc}$ & 3.0625 & 1 & 3.0625 & 32.4602 & 5.5681 \\
\hline Error & 0.5814 & 8 & 0.5503 & 32.0776 & \\
\hline Total & & 15 & & & \\
\hline
\end{tabular}

Table 4.9. Analysis of variance (ANOVA) for the solvent extraction of oil using ethanol

\begin{tabular}{|c|c|c|c|c|c|c|c|c|}
\hline & $\mathrm{Y}_{\mathrm{r} 1}$ & $\mathrm{Y}_{\mathrm{r} 2}$ & $\mathrm{Y}_{\mathrm{T}}$ & $\mathrm{Y}_{\mathrm{av}}$ & $\mathrm{Y}_{\mathrm{cal}}$ & $\left(\mathrm{Y}_{\mathrm{r} 1}-\mathrm{Y}_{\mathrm{cal}}\right)^{2}$ & $\left(\mathrm{Y}_{\mathrm{r} 2}-\mathrm{Y}_{\mathrm{av}}\right)^{2}$ & $\left(\mathrm{Y}_{\mathrm{r} 1}-\mathrm{Y}_{\mathrm{av}}\right)^{2}$ \\
\hline 1 & 42.03 & 42.52 & 84.55 & 42.28 & 39.03 & 9.0000 & 0.0576 & 0.0625 \\
\hline 2 & 41.38 & 41.35 & 82.73 & 41.37 & 39.56 & 3.3124 & 0.0004 & 0.0001 \\
\hline 3 & 42.22 & 41.98 & 84.20 & 42.10 & 41.40 & 0.6724 & 0.0144 & 0.0144 \\
\hline 4 & 42.81 & 42.25 & 85.06 & 42.53 & 40.62 & 4.7961 & 0.0784 & 0.3136 \\
\hline 5 & 38.58 & 38.15 & 76.73 & 38.37 & 41.93 & 11.2200 & 0.0484 & 0.0441 \\
\hline 6 & 37.78 & 36.92 & 74.70 & 37.35 & 41.15 & 11.3600 & 0.1849 & 0.1849 \\
\hline 7 & 43.01 & 42.95 & 85.96 & 42.98 & 42.99 & 0.0004 & 0.0009 & 0.0009 \\
\hline 8 & 43.17 & 43.26 & 86.43 & 43.22 & 43.52 & 0.0081 & 0.0016 & 0.0025 \\
\hline$\Sigma$ & & & & & & 40.3694 & 0.3866 & 0.6230 \\
\hline
\end{tabular}

Table 4.10. Basic statistical test (n-Hexane)

\begin{tabular}{|c|c|c|c|c|c|c|c|c|}
\hline & $\mathrm{Y}_{\mathrm{r} 1}$ & $\mathrm{Y}_{\mathrm{r} 2}$ & $\mathrm{Y}_{\mathrm{T}}$ & $\mathrm{Y}_{\mathrm{av}}$ & $\mathrm{Y}_{\mathrm{cal}}$ & $\left(\mathrm{Y}_{\mathrm{r} 1}-\mathrm{Y}_{\mathrm{cal}}\right)^{2}$ & $\left(\mathrm{Y}_{\mathrm{r} 2}-\mathrm{Y}_{\mathrm{av}}\right)^{2}$ & $\left(\mathrm{Y}_{\mathrm{r} 1}-\mathrm{Y}_{\mathrm{av}}\right)^{2}$ \\
\hline 1 & 24.75 & 25.65 & 50.40 & 25.20 & 22.95 & 3.2400 & 0.2025 & 0.2025 \\
\hline 2 & 28.84 & 27.05 & 55.89 & 27.95 & 21.84 & 49.0000 & 0.8100 & 0.7921 \\
\hline 3 & 22.16 & 23.45 & 45.62 & 22.81 & 32.46 & 106.0900 & 0.4096 & 0.4225 \\
\hline 4 & 26.67 & 27.65 & 54.32 & 27.16 & 22.22 & 19.80000 & 0.2401 & 0.2401 \\
\hline 5 & 20.85 & 21.74 & 42.56 & 21.28 & 31.35 & 0.8454 & 0.2116 & 0.2116 \\
\hline 6 & 19.90 & 20.34 & 40.24 & 20.12 & 22.57 & 7.1289 & 0.0484 & 0.0484 \\
\hline 7 & 35.32 & 34.28 & 69.60 & 34.80 & 32.46 & 8.1796 & 0.2704 & 0.2704 \\
\hline 8 & 38.71 & 38.96 & 77.67 & 38.84 & 32.08 & 43.9569 & 0.0144 & 0.0169 \\
\hline$\Sigma$ & & & & & & 238.24 & 2.2070 & 2.2405 \\
\hline
\end{tabular}

Table 4.11. Basic statistical test (Ethanol)

\begin{tabular}{|c|c|c|c|}
\hline Test & From Statistical Table & \multicolumn{2}{|c|}{ Calculated } \\
\hline & & n-Hexane & Ethanol \\
\hline G-test & 0.6800 & 0.6171 & 0.5003 \\
\hline F-test & & 34.8073 & 35.9825 \\
\hline
\end{tabular}

Table 4.12. Statistical calculated values for G-test and F-test 
Based on the statistical analysis of experimental results, the regression model for the $2^{3}$ design analysis is therefore given by Equation 5, i.e.

$$
Y=a_{0}+a_{1} x_{1}+a_{2} x_{2}+a_{3} x_{3}+a_{12} x_{1} x_{2}+a_{13} x_{1} x_{3}+a_{23} x_{2} x_{3}+a_{123} x_{1} x_{2} x_{3}
$$

The Residual for $2^{3}$ designs for the yield of oil from moringa oleifera seed kernel using $n$ Hexane can now be obtained by considering only the three largest effects, which are B, C and A. Equation 5 therefore reduced to;

$$
\begin{gathered}
Y=a_{0}+a_{1} x_{1}+a_{2} x_{2}+a_{3} x_{3} \\
a_{0}=\frac{1}{8} \sum\left(Y_{i}\right) \\
a_{j}=\frac{1}{8} \sum\left(Y_{i} S_{i}\right)
\end{gathered}
$$

Where $a_{j}$ is the coefficient of factor $j$ and $S_{i}$ is the sign of eight factor combinations from the design matrix table. Thus

$$
\mathrm{Y}=41.275+0.265 \mathrm{X}_{1}+1.1875 \mathrm{X}_{2}+0.795 \mathrm{X}_{3}
$$

Similarly, the residual for $2^{3}$ designs for the yield of oil from moringa oleifera seed with ethanol as the extraction solvent can be obtained by considering only the three largest main effects, which are B, AC and A. The regression equation can therefore reduced to

$$
Y=a_{o}+a_{1} x_{1}+a_{2} x_{2}+a_{13} x_{1} x_{3}
$$

Thus

$$
\mathrm{Y}=27.1488-0.1913 \mathrm{X}_{1}+4.7538 \mathrm{X}_{2}+0.3663 \mathrm{X}_{1} \mathrm{X}_{3}
$$

\subsection{Discussion of results}

The world is presently on the brinks of an environmental disaster owing to the build-up of harmful materials from the use of fossil oil as base oil for lubricants. Coupled with the prediction that the fossil oil will ultimately run out sometime in the future, there is therefore, the urgent need to source for replaceable and environmentally friendly base oil for lubricants. Biodiesels which is the product of transesterification of vegetables oil is considered as perfect alternative and sustainable energy sources, due to less emission and availability. The Promotion of Biomass faces an increasing rate of awareness, research and adoption. One way of increasing the adoption rate is to promote the utilization of the product from plants such as the leaves, fruits, stem, flowers and the roots of the trees. Presently, the alternative way of utilizing the fruit is to extract oil from the seeds, most of which are edible oil which is a source of concern. Despite the wide acceptance of biofuel as alternative energy to supplement or replace the fossil fuel, it will be wise to recognise the consequences of the new technology on the society. For instance, the production of biodiesel from edible oil could result in pressure on farmers, consequence of which is food shortage and environmental problem as a result of deforestation. Hence the need to produce the biodiesel from non-edible oil or from the sources that are not sources of production of edible 
oil such as oil from moringa oleifera seed which is the focus of this study. In order to depend fully on less expensive materials for the production of biodiesel, this study also investigates production bio-ethanol from rice husk. The results of the effects of various parameters, such as extraction time, particle size, temperatures and types of extraction solvents influence the rate extraction of oil from moringa oleifera. In this study, effect of extraction on the yield of oil from moringa oleifera seed was investigated using n-hexane and ethanol as the extraction solvent. It has been reported that the entrainer chosen has to be a good selective solvent with sufficient low viscosity for it to circulate freely. A relatively pure solvent will initially increase the extraction rate, but as the extraction proceeds, the concentration of solute will increase and the extraction rate will progressively decrease, firstly because the concentration gradient will reduce and secondly, the solvent will generally become more viscous and thereby decreases its penetration power.

The results of analysis yield a model equation presented in Equation 7, which was not only used to obtain the effect of one factor on the other but also their interaction. From the analysis it was discovered that when $\mathrm{n}$-hexane was used as the extraction solvent, the effect of factor B (particle size), has the highest magnitude of 2.4975 followed by the effect of factor $\mathrm{C}$ (extraction time) with a magnitude of 1.5900 , the effect of factor $\mathrm{A}$, extraction temperature is relatively low with a magnitude value of 0.5300 . A “- "in a $2^{\mathrm{k}}$ model equation implies an inverse proportionality, while " + " implies a direct proportionality. This means that the extraction temperature, $X_{1}$, the particle size $X_{2}$ and the extraction time $X_{3}$ are all directly proportional to the oil yield (Averill and Kelton, 1996 and Onifade, 2001). Results obtained on the effect of extraction temperature on the yield of oil as expected indicate that rate of extraction of oil from moringa oleifera seed is increases with increase in temperature. Increase in temperature positively affects the diffusivity of the solvent into the inner part of the seed and consequently aid the solubility of the oil in the solvent which increase the rate of extraction of oil from the seed. Though results obtained shows that increase in temperature favoured the extortion of oil, care must be taken not to exceed the limit, which is the boiling point of the solvent n-hexane. Exceeding the boiling temperature of the solvent could result into the evaporation of the solvent consequence of which is the quick usage of the solvent, which is not economical. Also investigated in this research is the effect of particle size on the rate of extraction of oil from the seed and from the model equation, the result reveal that the oil yield is directly proportional to the particle size i.e. oil yield increases with a increase in the particle size. It has been reported that the size of particle could influence the extraction rate and the yield of oil in a number of ways. For instance, the smaller the size of the particle the higher the interfacial area between the solid and the solvent, the higher the rate of transfer of the solute (oil), and the smaller the distance the solute must be diffused within the solid particle, hence the higher the rate of extraction of oil. It is therefore desirable that the range of the particle size should be small so that each particle will require approximately the same time of extraction. It is therefore important that particles size are well selected not to exist a critical particle size at which oil yield will no longer be optimum. Since above the optimum particle size, there will be a reduction in the surface area of the oil molecules exposed to the solvent for dissolution. The effect of time on the extraction of oil from moringa oleifera seed was studied using n-hexane as the solvent. Results obtained as presented in Table 4.1 and the statistical model (Equation 7) indicates that the oil yield has a direct proportion effect with the extraction time. This means that increasing the extraction time will bring about a high yield of oil, however, there is the need to optimized extraction time to save cost of production of oil from the seed. This is 
because higher extraction time above the optimum time cannot yield oil more than the maximum oil content in the seed kernel.

With ethanol as extraction solvent, the effect of factor B (particle size) has the highest dominance of 9.5213. The interaction of factor $\mathrm{AC}$, temperature and extraction time has an effect of 0.7288 , while temperature has the least effect of -0.3813 . The $2^{3}$ factorial analyses, give a model equation (Equation 8). From the statistical model, it can be seen that the extraction temperature, $X_{1}$, is inversely proportional to the oil yield, the particle size $X_{2}$ and the extraction time $X_{3}$ are all directly proportional to the oil yield. The inverse proportion effect of temperature on the extraction of oil from moringa oleifera seed is an indication that a range of $65-70^{\circ} \mathrm{C}$ is adequate to give a better yield of oil. Above this temperature range, the effect of temperature on the oil yield is negative. Thus a reduction in the extraction temperature from the maximum will result in an increase in the yield of oil. Results obtained also shows that the oil yield is directly proportional to the particle size. Hence the effect of particle size on oil yield increases with an increase in the particle size this is because greater surface area of the oil molecules exposed to solvent for dissolution. In the same vein, increase in the extraction time leads to increase in the yield of from moringa oleifera seed with ethanol as the solvent.

Production of ethanol from starch or sugar based feedstock is among man's earliest ventures into value added processing, while the basic steps remain the same, the process has been considerably refined in recent years, leading to a very efficient process. Bio-ethanol is an alcohol made by fermenting sugar components of biomass (Bailey and Ollis, 1986; Elba and Antenieta, 1996). Apart from food and pharmaceutical uses, bio-ethanol is finding alternative uses as motor fuel and fuel additive, ethanol as motor fuel is preferred to fossil fuel in that, it is environmentally friendly, comes from a renewable source and has a higher performance in engine (Eurasia, 2009).It can be mass-produced by fermentation of sugars or by hydration of ethylene from petroleum and other sources (Eurasia, 2009). Hence the need to produce bio-ethanol from relatively inexpensive and readily available raw materials like rice husks. In this study, rice husks were used to produce ethanol through hydrolysis and fermentation with Zymomonas mobilis. In the process of fermentation, the organism fermented the substrate (rice husk) to produce ethanol, Zymomonas mobilis possesses alcohol dehydrogenase (ADH) and pyruvate decarboxylase (PDC) which is key enzymes in ethanol fermentation from organic substrate as stated by Gunasegaram and Chandra (1998). Results obtained of bio-ethanol from rice husks as presented in Table 4.3 indicates that the volume of bio-ethanol is influence by the volume of hydrolysate. The maximum volume of bio-ethanol produced was $43 \mathrm{~cm}^{3}$ from $150 \mathrm{~cm}^{3}$ of hydrolysate, while $25 \mathrm{~cm}^{3}$ of bio-ethanol was produced from $350 \mathrm{~cm}^{3}$ of the hydrolysate. The high yield of bio-ethanol from rice husk may be due to high carbohydrates contents of rice husk or the high ethanol tolerance of Zymomonas mobilis and the presence of alcohol dehydrogenase in Zymomonas mobilis which appears to facilitate ethanol formation even at high ethanol concentration. Presented in Table 4.2 are the properties of oil, such as viscosity, refractive index, density and flash point of the bio-ethanol produced from rice husk, which compared favorably with those of the commercially available methanol. The slight variation between the values of properties of bio-ethanol and that of the commercially available methanol can be attributed the sources of production and experimental methods employed. It can therefore be inferred that the bioethanol produced from rice husk cab be used as an alternative feedstock for the production of biodiesel base on the properties of bio-ethanol presented in table 4.2. 


\section{Conclusion}

The need for alternative sources of energy other than fossil fuel gained momentum recently, and biofuel is considered perfect alternative sources of energy that is sustainable and reliable. However, the possibility of producing biofuel in commercial quantities is not certain; this is blame on the consequence effects of producing the biofuel from vegetable oil, as this can lead to food shortage. To achieve commercial availability of biofuel, it is therefore important to produce biofuel from non-edible oil or from the sources that are not popular sources of edible oil. To achieve commercial realisation of biodiesel production, this work focuses on the extraction and optimization of oil from moringa oleifera seed as an alternative feedstock for the production of biodiesel. Analysis of results indicates that when n-hexane was employed as the extraction solvent, the effect of particle size has the highest effect with magnitude of 2.50, followed by the extraction temperature with magnitude of 1.59 , while the effects of extraction time was the lowest with the magnitude value of 0.53 . With ethanol as the extraction solvent, particle size also has the highest dominance of 9.52, while the interaction of temperature and time has an effect of 0.73 , while the extraction temperature was -0.3813 . Based on these results it can be deduce that for an appreciable yield of oil to be achieved with ethanol as the solvent, the particle size and interaction of temperature and time are the factors which have high significance. Results obtained from the production of bio-ethanol from husk indicate that, it is possible to produced bio-ethanol from rice husk, which is also a major a feedstock in the production of biodiesel.

\section{Acknowledgment}

National research foundation (NRF), South Africa (Grant BS 123456) and Faculty of Science, Engineering and Technology are highly appreciated for their support. Federal University of Technology, Minna, Nigeria is also appreciated.

\section{References}

Abdulakreem, A. S \& Odigure, J.O. (2002). Radiative Heat Evaluation from Gas Flaring By Computer Simulation. Journal of Association for the advancement of Modelling and simulation in enterprises, Lyon France. Vol.71, No 2, pp 19 - 35, ISSN 0761 2516.

Abdulkareem, A. S. (2005). Evaluation of ground level concentration of pollutant due to gas flaring by computer simulation: A case study of Niger - Delta area of Nigeria. Leonardo Electronic Journal of Practices and Technologies, Technical University of Cluj - Napoca Romania. Issue 6, pp 29 - 42, ISSN 1583 - 1078.

Abdulkareem, A. S.(2005). Urban Air Pollution Evaluation by Computer Simulation: A Case study of Petroleum Refining Company, Nigeria. Leonardo Journal of Science Technical University of Cluj - Napoca Romania. Issue 6, pp 17 - 28, ISSN: 1583 0233.

Abdulkareem, A.S \& Odigure, J.O. (2006). Deterministic Model for Noise Dispersion from gas Flaring: A case study of Niger - Delta area of Nigeria. Journal of Chemical and Biochemical Engineering, Croatia Q 20, No 2, pp 139 - 146, ISSN 0352 - 9568. 
Abdulkareem, A.S. \& Odigure. J.O. (2010): Economic Benefit of Natural Gas Utilization in Nigeria: A case study of Food Processing Industry. Journal of Energy Source Part B, Vol 5 Pp 106-114.

Abdulkareem, A.S.; Idibie, C.A.; Afolabi, A.S.; Pienaar, H.C.vZ. \& Iyuke S.E. (2010): Kinetics of sulphonation of polystyrene butadiene rubber in sulphuric acid medium. Journal of International Review of Chemical Engineering, vol. 2, No7, pp 832-839, ISSN 2035-1755

Abdulkareem, A.S.; Odigure, J.O. \& Kuranga. M.B. (2010). Production and Characterization of Bio-Fuel from Coconut oil. Journal of Energy Source Part A, vol. 32, pp 106-114, ISSN 1556-7230.

Adeniyi, O.D.; Kovo, A.S.; Abdulkareem. A.S \& Chukwudozie. C. (2007): Ethanol Fuel Production from Cassava as a Substitute for Gasoline. Journal of Dispersion and Technology, vol. 28, No4, pp 501-504, ISSN 0193-2691.

Agarwal. A.K \& Das. L.M. (2001). Biodiesel development and characterization for use as a fuel in compression ignition engines. Journal of Engineering Gas Turbines Power, vol 123, pp 440-447, ISSN 0022-0825

Aghan D. (2005). Biodiesel production from vegetable oils via catalytic and non catalytic supercritical methanol tranestarification methods. Journal of Progress in energy and combustion, vol 31, pp 406-487., ISSN 0360-1285

Ahmad, M.; Samuel, S.; Zafari, M.; Khan, M.A.; Tariq. M.; Ali. S. \& Sultana. S. (2011). Physicochemical characterization of eco-friendly rice bran oil biodiesel. Journal of Energy, Part A, vol. 33, pp 1386-1397, ISSN 1556-7230.

Ahmmad, M.; Ullah, K.; Khan, M.A.; Ali, S.; Zafari, M. \& Sultana. S. (2011). Quantitative and qualitative anaysis of sesame oil biodiesel. Journal of Energy Sources, Part A, vol. 33, pp 1239-1249, ISSN 1556-7230.

Ahmmad, M.; Ullah, K.; Khan, M.A.; Zafari, M.; Tariq, M.; Ali, S. \& Sultana. S. (2011). Physico chemical analysis of hemp biodiesel: A Promising non edible new sources for bioenergy. Journal of Energy Sources, Part A, vol. 33, pp 1365-1374, ISSN 15567230.

Arjun,B. C.; Martin, S.T,; Suzanne,M. B.; Chris. W.\& Rafiqul Islam. M. (2008).Non-Edible Plant Oils as New Sources for Biodiesel Production. International Journal of Molecular Science, Vol 9 No 2, pp 169-180

Ayalew, M. (1988) Famine early warning system. Paper presented for the National Disaster Prevention and Preparedness Conference, Addis Ababa, Ethiopia, Mimeo.

Ayhan. D. (2008). Importance of biomass energy sources for Turkey. Journal of Energy policy, vol. 36, pp 834-842, ISSN 0301-4215

Azeez. O.S. (2005). Production od dextrins from cassava starch. Leornado Journal of Sciences, issue 7, pp 9-16, ISSN 1583-0233.

Barminas J. T., Maina H. M., Tahir S., Kubmarawa D., Tsware K., (2001), A preliminary investigation into the biofuel characteristics of tigernut (cyperus esculentus), Bioresour. Technol., Vol 79, p p. 87-89. ISSN 0960-8524

Berends, K. (2007): Engineering and construction projects for oil and gas processing: Contracting, uncertainty and the economic information. Journal of Energy Policy, vol. 35, pp 4260-4270., ISSN 0301-4215 
Bernard, E.; Beater, L.; Boucher, C. \& Stencil. B.A. (2007). Continuous flow preparation of biodiesel using microwave heating. Journal of Energy \&Fuel, vol 21(3), pp 17771781.

Bernard, M.E.R. \& Wolfgang, F.H. (2009). New sulfunic acid ion-exchange resins for the preesterification of different oils and fats with high content of free free fatty acide. Journal of Applied Catalysis A: General, vol 362, pp 47-5, ISSN 0926-860X.

Brown, L. R (2008) World facing huge new challenge on food front: Business-as-Usual not a viable option Earth Policy Institute. April 16, 2008

Canakci, M. (2007): The potential of restaurant waste lipids as biodiesel feed stocks. Journal of Bioresource Technology, Vol 98, pp.183-190, ISSN 0960-8524

Carraretto, C.; Macor, A. \& Mirandola, A. (2004). Biodiesel as alternative fuel: Experimental analysis and energetic evaluation. Journal of Energy, pp 2195-2211, ISSN 0360-5442

CNN (2009) Hunger kills 17,000 kids daily Part of complete coverage on Environment and Going green.

Dalai A.K \& Kulkarni, M.G. (2006), Waste cooking oil-an economical source for biodiesel: A review. Journal of Industrial \& Engineering Chemistry Research, vol, 45, pp 29012913.

Dancy, J. (2008) Global food shortages could 'continue for decades' commodities /agricultural commodities. The Market Oracle. February 22, 2008.

Durosoy, I.; Turker, M. F.; Keles, S. \& Kaygusuz, K. (2011). Sustainable agriculture and the production of biomass for energy use. Journal of Energy Sources, Part A, 33, 938947, ISSN 1567-7230.

Eaves, J. and Eaves, S. (2007) Renewable corn-ethanol and energy security. Energy Policy Vol. 5 , pp 5958-5963

Eevera, T.; Balamurughan, P.; and Chittibabu .S. (2011). Characterization of groudnut oil based biodiesel to assess the feasibility for power generation. Journal of Energy Sources, Part A, vol. 33, pp 1354-1364, ISSN 1556-7230.

El-Sabagh, S.M.; Keera, S.T. \& Tama, A.R. (2011). The characterization of biodiesel fuel from waste frying oil. Journal of Energy Source, Part A, vol. 33m pp 401-409, ISSN 15567230 .

FAO (2008) An introduction to the basic concept of foof security. FAO Food Security Programme, pp 1 - 3

Freedman B, Pryde EH, Mounts TL (1984). Variables affecting the yields of fatty esters from transesterified vegetable oils, J. Am. Oil Chem. Soc, Vol 61, pp 1638-1643.

Hamamci, C.; Saydut, A.; Tonbul, Y.; Kaya, C. \& Kafadari, A.B (2011). Biodiesel production via transestarification from safflower (Carthemustinctorious $L$ ) seed oil. Journal of Energy Sources Part A, vol 33, pp 512-520, ISSN 1556-7230.

Helwani, Z.; Othman, M. R,; Aziz, N.; Fernando, W. J. N.\& Kim. J.(2009). Technologies for production of biodiesel focusing on green catalytic techniques: A review. Journal of Fuel Processing Technology, vol 90, pp502-1514, ISSN 0378-3820

HM Government (2010): The 2007/08 Agricultural price spikes: causes and policy implications. National Food Policy Capacity Strengthening Programme. FPMU Documentation Center. p 123 
Hossain, A.B \& Boyce, A.N. (2009). Biodiesel production from waste sunflower cooking oil as an environmental recycling process and renewable energy. Bulgarian. Journal of Agricultural Science, vol 15(4), pp 312-317.

Hossain, M. Janaiah, A. and Otsuka, K. (2005) Is the productivity impact of the Green Revolution in rice vanishing? Economic and Political Weekly (31 December), pp $5595-9600$.

Khan, S. Khan, M. A. Hanjra, M. A. and Mu, J. (2009) Pathway to reduce the environmental footprints of water and energy inputs in food production. Food Policy Vol. 34, pp 141-149

Khunrong, T.; Punsuvon, A.; Vaithanomisate, P. \& Pomchaitawand. C. (2011). Production of ethanol from from pulp obtained by steam explosion pretreatment of oil palm trunk. Journal Energy Sources, Part A, vol 33, pp 221-228, ISSN 1556-7230.

Mathews, J. (2007). Seven steps to curb global warmimg . Journal of Energy Policy, vol 35, pp 4247-4259, ISSN 0301-4215

Mustafa Canakci, M \& Gerpen. J (2001) A Pilot Plant to Produce Biodiesel from High Free Fatty Acid Feedstocks. Presented at ASAE Annual conference Meeting. Sacramento Convention Center, Sacramento, California, USA July 30-August 1, 2001

Nashawi, S.I.; Malallah, A. \& Al-Bisharah, M. (2010). Forecasting world crude oil production using multicyclic Hubert model. Journal of Energy \& Fuels, vol 24, pp 1788-1800,

Odigure, J. O \& Abdulkareem, A. S. (2001). Modelling of Pollutant's migration from gas flaring: A case study of Niger - Delta area of Nigeria. Journal of Association for the advancement of Modelling and simulation in enterprises, Lyon France. Vol.62, No 3, p 57 - 68, ISSN 0761 - 2524.

Odigure, J. O.; Abdulkareem, A.S. \& O.D Adeniyi, O.D (2003). Computer simulation of soil temperature due to heat radiation from gas flaring. Association for the advancement of Modelling and simulation in enterprises, Lyon France. Vol. 72, No 6, pp 1 - 10, ISSN $1259-5969$.

Perez-Roa, A.; Castro, J.; Jarquera, H.; Perez-Correa, J.R.; \& Vesovic, V. (2006): Air poluution modelling in an urban area: Coeeficient by means of an artificial neural networks approach. Journal of Atmospheric Envorment, vol 40, pp 109-125, 1352-2310

Randerson, J (2008) Food crisis will take hold before climate change. The Guardian. $p 17$ Friday 7 March 2008.

Refaat, A. A. (2010). Different techniques for the production of biodiesel from waste vegetable oil. Int. Journal of Environmental Technology, vol 7 (1), pp 183-213.

Refaat, A.A.; El Sheltawy, S.T. \& Sadek, K.U. (2008). Optimum reaction time, performance and exhaust emissions of biodiesel Produced by microwave irradiation. International Journal of Environmental Science and Technology. Vol 5 No3, pp 315322, ISSN: 1735-1472

Shao, H. \& Chu. L. (2008). Resources evaluation of typical energy plants and possible functional zone planning in China. Journal of Biomass and Bioenergy, vol.32, pp 283-288, ISSN 0961-9534.

Shireen, M.K. \& Debabrata. D. (2008). Biohydrogen as a renewable energy source - prospect and potentials. International Journal of Hydrogen Energy, vol. 33, pp 258-263, ISSN 0360-3199. 
Smith K. and Edwards R. (2011) 2008 - The year of global food crisis. Herald Scotland, Sunday Herald

Smith, M., Pointing J. and Maxwell, S. (1992) Household food security, concept and definisitions: An annotated bibliography, Development Biliography No 8. Institute of Development Studies Uncertainty of Sussex, Brighton.

The Monitor's View (2008) The global grain bubble. The Christian Science Monitor

Turapan,S.; Yotkamchornkun, C. \& Nuithitikul, K. (2010). Esterification of free fatty acids in crude palm oil with sulphated zirconia: Effect of calcinations temperature. Journal of world academy of science, engineering and technology, vol 65, pp 520-524.

Udaeta, M.E.M,; Burani, G.E.; Maure. J.O.A. \& Olive. R.C. (2007): Economic of secondary energy from GTL ragarding natural gas reservoirs of Bolivia. Journal of Energy Policy, vol 35, pp 4095-4106, ISSN 0301-4215.

USDA (2009) Food Security in the United States: Measuring Household Food Security. Economics of Food, Farming, Natural Resources and Rural America

Utgikar, V.P. \& Scott, J.P. (2006). Energy forecasting, productions, reality and analysis of cause of error. Journal of Energy Policy, vol. 34, pp 3087-3092. ISSN 0301-4215

Vera, I.\& Langlois, L. (2007). Energy indicators for sustainable development. Journal of Energy, vol.32, pp 875-882, ISSN 0360-5442

Vidal, J. (2007) Global food crisis looms as climate change and fuel shortages bite. The Guardian, Saturday 3 November 2007, p 27.

Walt, V. (2008) The World's growing food-price crisis. Wednesday, February 27, 2008. Time in partnership with CNN.

Wang, M.; Wang, J.; Tan. J.X.; Sun, J.F \& Mou, J. L (2011). Optimization of ethanol fermentation from sweet sorghum juice using response surface methodology. Journal of Energy Part A, vol.33, pp 1139-1146, ISSN 1556-7230.

Wang, Y.; Ou, S.; Pengzhah, F. \& Zhang. Z. (2007). Preparation of biodiesel from waste cooking oil via two-step catalysed process: Journal of Energy conversion and management, vol 48, pp 184-188, ISSN 0196-8904

Wesley, M (2007) Energy and Australia's security. Australian Strategic Policy Institute. ISBN 9781921302169.

World Bank (1986) Poverty and hundger; Issues and options for food security in developing countries. World bank Policy Study, Washington, DC.

Xiaoling, M \& Qingyu,W. (2006). Biodiesel production from heterotrophic microalgal oil. Journal of Bioresource Technology, vol, 97 , pp841-846, ISSN 0960-8524

Yuan, W.; Hansen, A.C. \& Zhang. Q. (2005): Vapour pressure and normal boiling point productions for pure methyl esters and biodiesel fuel. Journal of Fuel, pp 933-9550, ISSN 0016-2361

Zhang, X. W. \& Huang. W. (2011). Optimization of the traesterifcation reaction from cotton seed oil using a statistical approach. Journal of Energy Sources, Part A, 33, pp 11071116, ISSN 1556-7230.

Zhang, Y.; Dube, M.A.; Mclean, D.D. \& Katis. M. (2003). Biodiesel production from waste cooking oil: 1 Process design and technological assessment: Journal of Bioresources technology, vol 89, pp 1-16, ISSN 0960-8524 
Zhang, Y.; Dube, M.A.; Mclean, D.D. \& Katis. M: E. (2003). Biodiesel production from waste cooking oil: 2 Economic assessment and sensitivity analyses. Journal of Bioresources technology, vol 90, pp 229-240, ISSN 0960-8524. 


\title{
Tall Wheatgrass Cultivar Szarvasi-1 (Elymus elongatus subsp. ponticus cv. Szarvasi-1) as a Potential Energy Crop for Semi-Arid Lands of Eastern Europe
}

\author{
Sándor Csete et al.* \\ University of Pécs \\ Hungary
}

\section{Introduction}

By 2020, proportion of renewable energy sources should be around 20 per cent of the total energy consumption in the European Union, according to the new treaty signed by European leaders in 2009. This vast amount of renewable energy can be sourced from hydroelectric, geothermal, wind, solar power and, of course, from biofuels. To achieve this ambitious target, new technologies must be invented to exploit energy from the abiotic source of renewables and new energy plant species should be developed and produced, serving as source for solid, liquid biofuels and for biogas production. The most intensively studied and used bioenergy crops include miscanthus, reed canary grass, willows and poplars. We already have considerable knowledge about these energy plants from their taxonomical relations to their detailed crop technologies. In this chapter, we introduce a novel energy plant that has been cultivated for more than a century in many parts of the world for numerous purposes (e.g. land remediation, erosion control, forage), but its potential for energy production has not yet been realized. Tall wheatgrass, a new energy crop (Elymus elongatus subsp. ponticus cv. Szarvasi-1) has recently been introduced to cultivation in Hungary to provide biomass for solid biofuel energy production. The cultivar was developed in Hungary. The main goal of our research was to investigate the performance of Szarvasi-1 energy grass under different growing conditions (e.g. soil types, nutrition supply). We focused on the ecological background, biomass yield, weed composition, morphology, ecophysiology and the genetics of the plant.

\footnotetext{
"Szilvia Stranczinger1', Bálint Szalontai ${ }^{1}$, Ágnes Farkas'1, Róbert W. Pál1 , Éva Salamon-Albert ${ }^{1}$, Marianna Kocsis' ${ }^{1}$ Péter Tóvári³, Tibor Vojtela³ , József Dezső'1, Ilona Walcz'

Zsolt Janowszky², János Janowszky² and Attila Borhidi ${ }^{1}$

1 University of Pécs, Hungary

${ }^{2}$ Hungaro-Grass Kft, Hungary

${ }^{3}$ Hungarian Institute of Agricultural Engineering, Hungary
} 


\section{Description}

\subsection{Origin and distribution}

Tall wheatgrass is a Pontic-Mediterranean grass species. Its distribution ranges along the Mediterranean Basin from the Black Sea to the Iberian Peninsula. This vast area is covered by two, morphologically very different subspecies. The shorter and more fragile E. elongatus (Host) Runemark subsp. elongatus occurs in the western basin of the Pontus-Mediterranean area, while the taller and more robust E. elongatus (Host) Runemark subsp. ponticus (Podp.) Melderis occupies the Eastern Mediterranean Basin. The latter is also native to Hungary, reaching the north-westernmost part of its distribution in this area (Tutin et al., 1980).

Szarvasi-1 energy grass was bred as an intra-specific hybrid of drought-tolerant and robust E. elongatus subsp. ponticus populations from Hungary and from different pontic areas (Janowsky \& Janowszky, 2007). The 10-year-long breeding process was conducted in Szarvas (East Hungary) but more recently the new breed has been involved in extensive crop management studies in different parts of the country. The Szarvasi- 1 tall wheatgrass cultivar was officially recognized by the Hungarian Central Agricultural Office in 2004.

\subsection{Taxonomy and nomenclature of Elymus elongatus}

Classification and nomenclature of wheatgrass species has been the subject of much taxonomic debate (Assadi \& Runemark, 1995; Mizianty et al., 1999; Murphy \& Jones, 1999). Consequently, representatives of this genus are known by several scientific and vernacular names. Synonyms of Elymus elongatus (Host) Runemark (tall wheatgrass) include: Agropyron elongatum (Host) Beauv., Elytrigia elongata (Host) Nevski, E. pontica (Podp.) Holub, Elymus varnensis (Velen.) Runemark, Lophopyrum elongatum (Host) A. Löve and Thinopyrum ponticum (Podp.) Liu \& Wang.

\subsection{Genetic diversity of energy grass cultivar Szarvasi-1}

Besides studying the agronomical features of Szarvasi-1, it was important to reveal its genetic background, in order to ascertain its taxonomic position in the system of grasses (focusing on the Triticeae tribe), to assess genetic similarities among the closely related Agropyron and Elymus genera and to establish genetic relationships among native Hungarian populations of E. elongatus (the hypothesised ancestor of Szarvasi-1) and the cultivar.

As a first step the genetic background of Szarvasi-1 and its relatives was studied by RAPD (Randomly Amplified Polymorphic DNA) technique, which allowed the random study of the whole genome with no prior knowledge required. RAPDs can produce a large set of markers, which can be used for the evaluation of both between- and within-species genetic variation, more rapidly and easily than isozymes and microsatellites (Guadagnuolo et al., 2001). To determine the exact taxonomic position of the cultivar among its relatives, specific primers for sequencing specific DNA regions were used. The sequences were compared and phylogenetically analysed. Our results indicated a potential risk of gene flow, which is a possible disadvantage of planting Szarvasi-1 energy grass on large scale.

\subsubsection{Interspecific study}

The interspecific variation of three Elymus and an Agropyron species together with the Szarvasi-1 cultivar was screened with 61 RAPD primers (Table 1.). The most informative 16 
primers were retained, due to their ability to produce polymorphic, unambiguous and stable RAPD markers. Various banding patterns were revealed by different primers, but only polymorphic fragments of high intensity and moderate size (between 100 and $3000 \mathrm{bp}$ ) were used. About $98 \%$ (131 bands) of the total number of bands (136) were polymorphic. Though the high number of polymorphic bands allows the easy differentiation of analyzed samples using RAPD markers, it gives poor information regarding the relationships among the studied taxa.

\begin{tabular}{|c|c|c|}
\hline Genus & Species & Synonyms \\
\hline Agropyron Gaertner & cristatum (L.) Gaertner & Eremopyrum cristatum (L.) Willk. \\
\hline \multirow{3}{*}{$\begin{array}{l}\text { Elymus L. } \\
\text { (Roegneria Koch, } \\
\text { Elytrigia Desv., } \\
\text { Clinelymus (Griseb.) } \\
\text { Nevski) }\end{array}$} & elongatus (Host)Runemark & $\begin{array}{l}\text { Triticum elongatum Host } \\
\text { Agropyron elongatum (Host) Beauv. }\end{array}$ \\
\hline & repens (L.) Gould & $\begin{array}{l}\text { Triticum repens L. } \\
\text { Agropyron repens (L.) Beauv } \\
\text { Elytrigia repens (L.) Nevski }\end{array}$ \\
\hline & hispidus (Opiz) Melderis & $\begin{array}{l}\text { Agropyron hispidum Opiz } \\
\text { Agropyron intermedium (Host) Beauv. }\end{array}$ \\
\hline
\end{tabular}

Table 1. Hungarian Agropyron and Elymus taxa used in the interspecies study

Sequence analysis was performed for two DNA regions: the rpoA gene of the plastid genome including partial sequences of petD and rps11 genes, which was successfully applied by Gitta Petersen and Ole Seberg (1997) to study the Triticeae tribe; and the intergenic spacers (ITS) of the rDNA, an extensively used marker in molecular phylogeny. These analyses resolved the exact taxonomic position of Szarvasi-1. Plant materials were collected from field and identified carefully using morphological characters. Total DNA was extracted from leaves, the targeted DNA loci were amplified in polymerase chain reactions (PCR) and sequenced. New DNA sequence data were deposited to GenBank. Cladistic analyses were performed with PAUP* 4.0 software (Swofford, 2001) on Windows XP, using maximum parsimony, supplemented with additional public sequence data referring to the tribe. Bromus inermis was used as an outgroup. The analysis comprised 32 sequences representing 21 of the 24 monogenomic genera of the Triticeae. In the case of the rpoA data, the final matrix contained 1385 characters, of which 1276 (92\%) were constant, $84(6 \%)$ variable but uninformative and $25(1.8 \%)$ informative. The analysis resulted in a 129-step-long parsimonious tree (Fig. 1.A) (consistency index including all characters $=0.9225$, consistency index excluding uninformative characters $=0.7368$, retention index $=0.9048$ ). However, the results were based on only a small number of phylogenetically informative characters $(1.8 \%)$ - concentrated mostly in the non-coding spacer regions. Therefore the study was completed by the analysis based on the nuclear ribosomal internal transcribed spacers (ITS) (Fig. 1.B). In the latter case the final matrix included 596 characters: 459 (77\%) were constant, 53 (8.9\%) variable but uninformative and $83(13.4 \%)$ informative (tree length = 214 steps long, consistency index including all characters $=0.7617$, consistency index excluding uninformative characters $=0.6731$, retention index $=0.7475)$. In both cases, four sequences - E. elongatus, E. elongatus subsp. ponticus cv. Szarvasi-1, E. hispidus, and A. cristatum - were newly determined.

The phylogenetic relationships inferred from molecular data of both the rpoA gene and ITS regions supported the separation of the studied Elymus taxa from A. cristatum - formerly 
also declared an Elymus species. All of the studied Elymus taxa form a well supported clade within Pseudoroegneria, Lophopyrum, and Festucopsis, corresponding with the results of Sha et al. (2010). Interestingly, the Hungarian A. cristatum is located far from the Danish accession of the species on the rpoA based phylogenetic tree. However, the rpoA sequence of E.hispidus and the ITS sequence of E. repens are very similar to those of the Szarvasi-1, suggesting the possibility of unwanted hybridization.

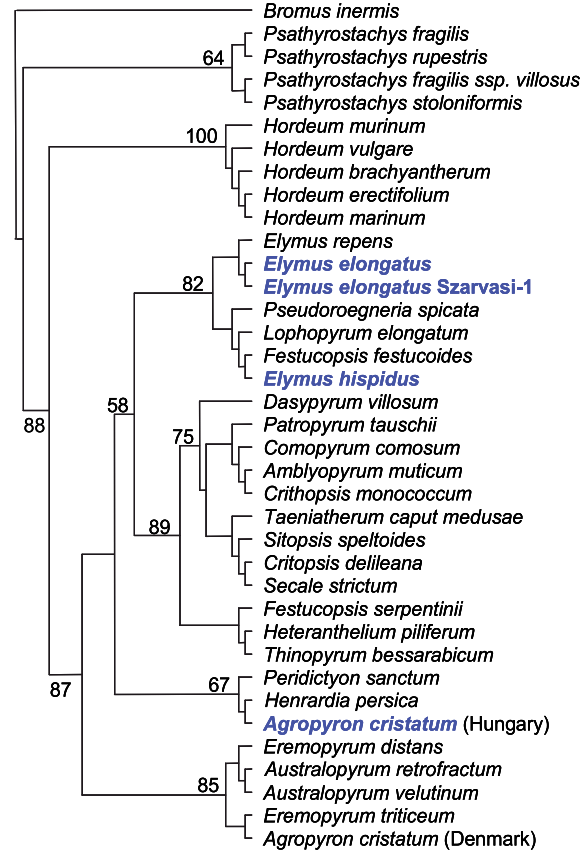

A.

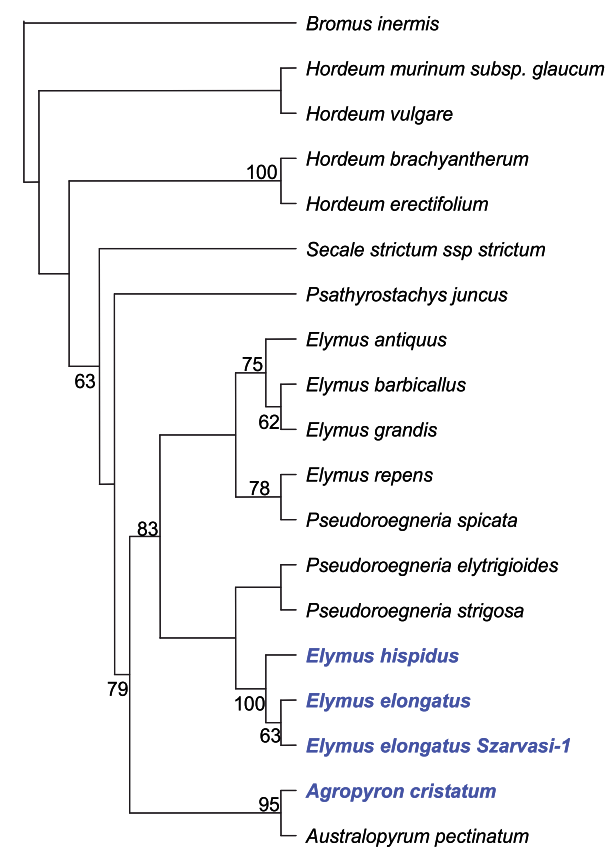

B.

Fig. 1. Strict consensus tree based on phylogenetic analysis A: of the rpoA gene B: of the ITS sequence data. Numbers above and below branches indicate bootstrap support.

\subsubsection{Interpopulational studies}

The interpopulation study compared 15 individuals from each population of E. elongatus and the Szarvasi-1 cultivar by RAPD markers. The samples originated from four different locations in Hungary: Hortobágy, Kunadacs, Tiszaalpár and Szarvasi-1 from Görcsöny. The method can be a valuable tool for populational studies (Reisch et al., 2003), though it has often been criticized for low reproducibility; in order to avoid this phenomenon, highly constant conditions were used and all reactions were repeated at least twice. The samples were screened with a total of 80 arbitrary 10-mer primers, out of which only 30 informative primers were retained. The total number of analyzed bands was 373. The percentage of polymorphic bands was $41.3 \%$ (154 bands). The RAPD data were used for calculation of pairwise genetic distances using the Simple matching coefficient. The distance matrix was used for cluster analysis using UPGMA (unweighted pair-group method with arithmetic averages). A dendrogram was generated using SYN-TAX 5.0 (Podani, 1993).

Consistent with other results (Díaz et al., 2000; Nieto-Lopez et al., 2000), RAPD analysis discriminated the studied populations. The samples from Kunadacs constituted the most 
homogenous population, the samples differed from each other by only $0.8 \%$. The most heterogeneous population seemed to be the population of Hortobágy with $3.8 \%$ difference among individuals. According to the present state of our knowledge of the genetic relationships of Szarvasi-1 and other studied Hungarian tall wheatgrass populations we can claim that there is no genetic difference between the genotype of the Szarvasi- 1 cultivar and that of the population of Hortobágy. This result suggests that the genetic material of the populations from pontic areas involved in the breeding process could disappear during the process. The ability to differentiate the tested populations by RAPD bands suggested that this technique may provide a rapid and inexpensive method for the identification of the three Elymus populations in Hungary and can be used to monitor the possible changes of energy grass genotype by outcrossing different, closely related Elymus taxa during their utilization.

\subsection{Morphology and anatomy of Elymus elongatus subsp. ponticus and Szarvasi-1 energy grass}

Elymus species are caespitose or rhizomatous perennials. The roots of E. elongatus are fibrous (Fig. 2.), and can reach lengths of $3.5 \mathrm{~m}$. E. elongatus can grow to a height of $50-200 \mathrm{~cm}$ (Melderis, 1980; Barkworth, 2011), while Szarvasi-1 energy grass can reach 180-220 cm under optimal growing conditions. From the wheatgrass species that are native to Hungary, three members of the genus Elymus and a closely related Agropyron species were picked for morphological comparison with Szarvasi-1 energy grass (Fig. 3.), taking into consideration both their vegetative (Table 2.) and reproductive features (Table 3.).

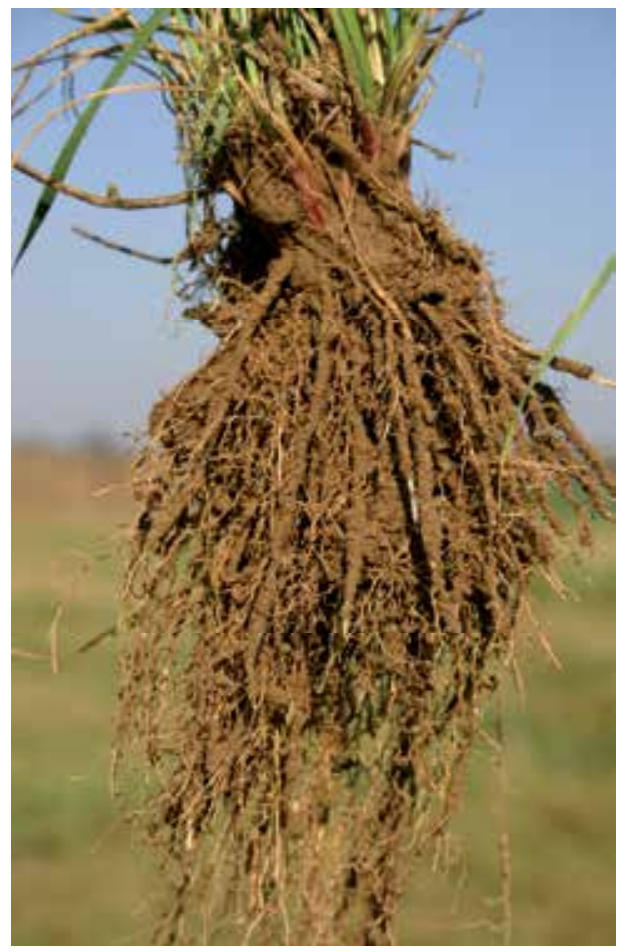

Fig. 2. Fibrous root system of Szarvasi-1 energy grass (photo: Róbert W. Pál) 


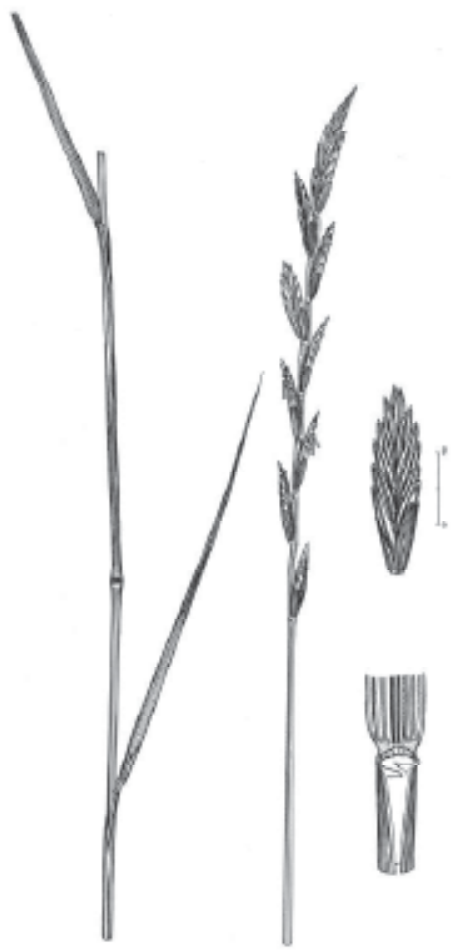

Fig. 3. Stem, leaf, inflorescence and spikelet of Szarvasi-1 energy grass (drawing: Emőke Oláh)

\begin{tabular}{|c|c|c|c|c|c|}
\hline \multirow{2}{*}{$\begin{array}{c}\text { Taxon / } \\
\text { Character }\end{array}$} & Root system & $\begin{array}{c}\text { Stem } \\
\text { height } \\
\text { (cm) }\end{array}$ & leaf blade & ligule & auricle \\
\cline { 4 - 6 } A. pectiniforme & fibrous & $25-60$ & $\begin{array}{c}\text { adaxial side with } \\
\text { trichomes }\end{array}$ & $\begin{array}{c}\text { membranous, } \\
\text { truncate }\end{array}$ & - \\
\hline E. repens & rhizomatous & $40-120$ & dense venation & $\begin{array}{c}\text { membranous, } \\
\text { truncate }\end{array}$ & long \\
\hline E. hispidus & rhizomatous & $40-150$ & $\begin{array}{c}\text { long, sparse } \\
\text { trichomes on } \\
\text { adaxial side }\end{array}$ & $\begin{array}{c}\text { membranous, } \\
\text { truncate }\end{array}$ & medium \\
\hline E. elongatus & fibrous & $50-200$ & $\begin{array}{c}\text { prominent } \\
\text { venation, surface } \\
\text { and margin bearing } \\
\text { spinules }\end{array}$ & $\begin{array}{c}\text { membranous, } \\
\text { dentate }\end{array}$ & medium \\
\hline Szarvasi-1 & fibrous & $50-220$ & $\begin{array}{c}\text { prominent } \\
\text { venation, surface } \\
\text { and margin bearing } \\
\text { spinules }\end{array}$ & $\begin{array}{c}\text { membranous, } \\
\text { dentate }\end{array}$ & long \\
\hline
\end{tabular}

Table 2. Vegetative features of wheatgrass (Elymus and Agropyron) taxa (data are based on our own observations and some literature references, see Melderis, 1980 and Barkworth, 2011) 
The stems of E. elongatus are robust and glabrous (Melderis, 1980). Our comparative histological studies, conducted on E. hispidus, E. elongatus and Szarvasi-1 energy grass, revealed that in Szarvasi-1 the epidermis of the stem is sclerenchymatous (Fig. 4.), covered with a thick cuticle, which suggests drought tolerance of the cultivar. Stomatal guard cells are in level with the epidermal cells (mesomorphic position), both in the stem (Fig. 4.) and the surrounding leaf sheath, which is typical in plants that require a moderate water supply. In the internodes collateral closed vascular bundles are arranged in two rings, embedded in the sclerenchymatous hypodermis and parenchyma. In the outermost cortical region of the culm in Szarvasi-1, clorenchyma alternates with sclerenchyma, or a continuous sclerenchymatous ring is formed. Third order vascular bundles are located in the hypodermis, while first and second order bundles can be found toward the centre of the stem (Fig. 5.). Vascular bundles are supported by a sclerenchymatous sheath and/or bundle cap, the latter often establishing direct contact with the hypodermal sclerenchymatous fascicles in the case of the outer vascular bundles.

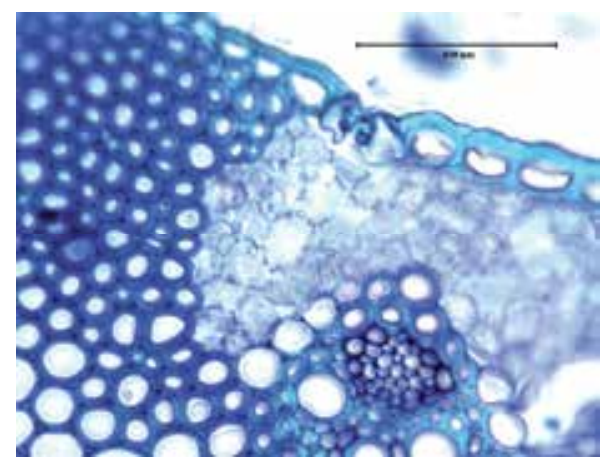

Fig. 4. Sclerenchymatous epidermis with mesomorphic stoma in the stem of Szarvasi-1 (photo: Ágnes Farkas)

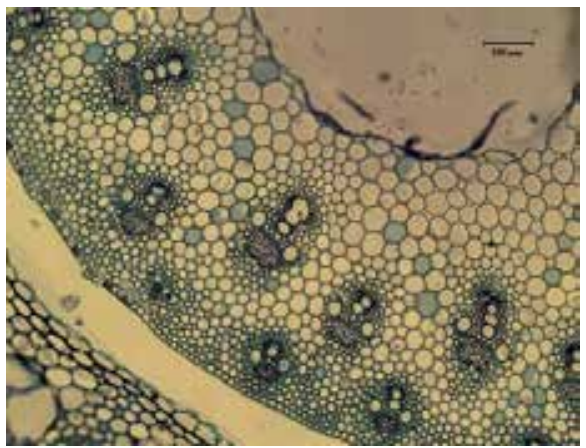

Fig. 5. Vascular bundles of varying size in the stem of Szarvasi-1 energy grass (photo: Ágnes Farkas)

In the nodes of Elymus species, the bundles located in the outer region possess a welldeveloped sclerenchymatous bundle cap, which is kernel-shaped in E. elongatus (Fig. 6.) and ovate in E. hispidus. The phloem consists of sieve tubes and companion cells; the xylem comprises two large tracheas, tracheids and xylem parenchyma, accompanied by a 
rexigenous intercellular space. The walls of vessels and tracheids are strengthened by annular or spiral thickening (Fig. 7.).

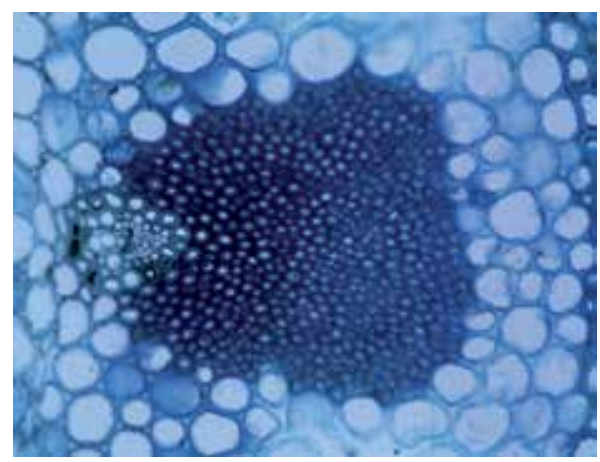

Fig. 6. Bundle cap in the stem of Szarvasi-1 (photo: Ágnes Farkas)

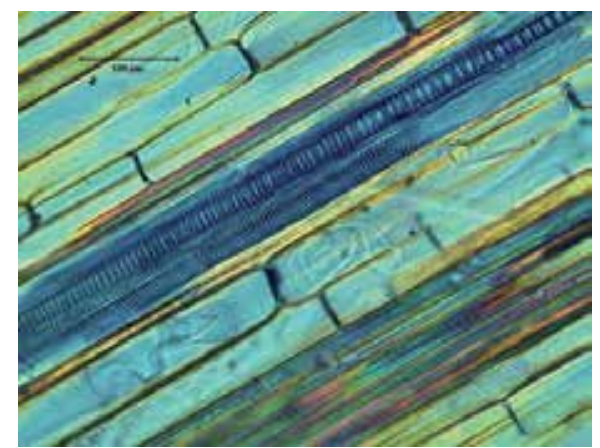

Fig. 7. Vessels with annular and spiral thickening in the stem of Szarvasi-1 (photo: Ágnes Farkas)

The leaves of Elymus species are flat or more or less convolute (Melderis, 1980). In E. elongatus they are convolute, however, in Szarvasi-1 this feature is not typical. The leaf blade is grey-green in E. elongatus, as opposed to the blue-grey colour of E. hispidus (Melderis, 1980). The leaf blade of E. elongatus is $2.5-5 \mathrm{~mm}$ wide, prominently and closely veined. Similarly to E. hispidus, one margin of the leaf sheath can bear trichomes in E. elongatus as well; sparse spinules, and sometimes also short setae can be observed on the surface and the edge of the leaf (Melderis, 1980). The ligule is short and membranous; the presence and length of the auricle varies with Elymus species (Table 2.) (Häfliger \& Scholz, 1980; Melderis, 1980; Barkworth, 2011).

The leaf epidermis in Szarvasi-1 is mostly sclerenchymatized, with thickened cell walls and a thick layer of cuticle, all of which highlight drought tolerance of the energy grass. In the intercostal region of the adaxial epidermis, a group of large bulliform cells can frequently be observed, which play a role in rolling up the leaf blade in the case of drought, thereby reducing transpiration. Both the adaxial and abaxial epidermis may contain stomata, however, they are more frequent on the abaxial side. Most stomatal guard cells are at the level of epidermal cells (mesomorphic position), however, in some cases guard cells may rise above the epidermis (hygromorphic position), or the stoma can become slightly sunken 
(xeromorphic position), when guard cells reach the bottom half of epidermal cells. Nonglandular trichomes (bristles) are present in large numbers (Fig. 8.), especially on the adaxial side of the leaf, enhancing the drought-tolerance of the plant by reducing water loss. The two epidermal layers sandwich a chlorenchymatous, homogenous mesophyll layer, consisting of spongy parenchyma. In Szarvasi-1 energy grass the basal leaf blade is strongly wavy in transverse section, due to the ridges formed by the longitudinally running veins that correspond to collateral closed bundles, arranged in a characteristic pattern formed by the alternation of smaller and larger bundles (Fig. 9.). The vascular bundles are surrounded by an inner sclerenchymatous and an outer parenchymatous bundle sheath. Bundles of first order are accompanied by hypodermal sclerenchyma. In both E. elongatus and Szarvasi-1 the sclerenchymatous bundle cap is more developed than in E. hispidus. In E. elongatus cell wall thickening also reaches a higher level in the sclerenchymatous tissues. In the adaxial part of the primary bundles we can often see rexigenous intercellular spaces, containing the broken elements of the protoxylem.

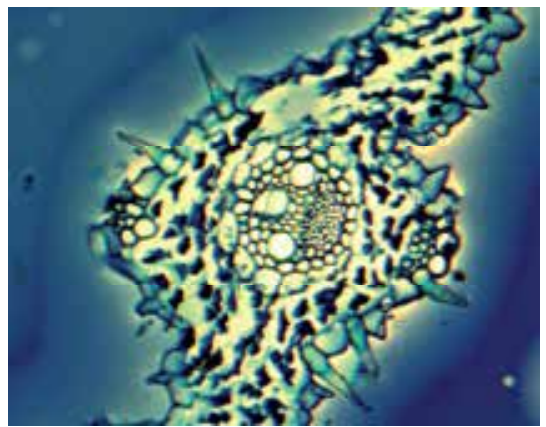

Fig. 8. Non-glandular trichomes on the leaf of Szarvasi-1 (photo: Ágnes Farkas)

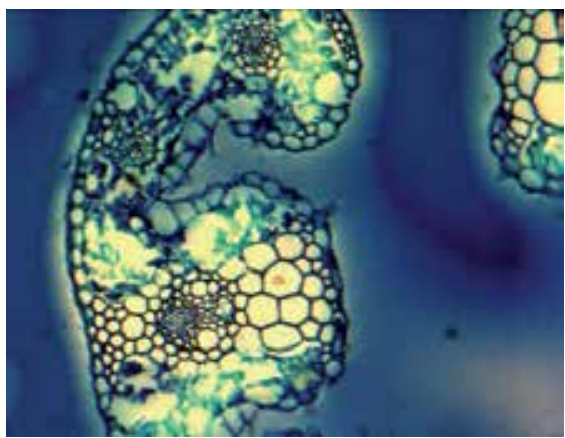

Fig. 9. Vascular bundles in the leaf of Szarvasi-1 (photo: Ágnes Farkas)

The inflorescence is an erect spike, which is long and slender in each wheatgrass species, except for A. pectiniforme, where it is short and dense, with numerous, overlapping spikelets. In E. elongatus the rachis is nearly flat on the side facing the spikelets, usually spinose-ciliate on the main angles (Melderis, 1980). Compared to E. repens, the spikelets are less overlapping and more loosely arranged in E. elongatus, sitting close to the rachis, and strongly compressed laterally; the rachilla is strigulose. The spikelet consists of varying numbers of florets in each species (Table 3.). 


\begin{tabular}{|c|c|c|c|c|}
\hline $\begin{array}{c}\text { Taxon / } \\
\text { Character }\end{array}$ & $\begin{array}{c}\text { Number of } \\
\text { florets/spikelet }\end{array}$ & Glume & Lemma & Palea \\
\hline A. pectiniforme & $4-8$ & $\begin{array}{c}\text { abruptly } \\
\text { narrowing }\end{array}$ & short-awned & $\begin{array}{l}\text { keel with short } \\
\text { trichomes }\end{array}$ \\
\hline E. repens & $4-8$ & acute, tapering & acute & \\
\hline E. hispidus & $4-8$ & truncate & obtuse or acute & $\begin{array}{l}\text { keel with short } \\
\text { trichomes }\end{array}$ \\
\hline E. elongatus & $5-11$ & truncate, glabrous & obtuse, awnless & two-keeled \\
\hline Szarvasi-1 & $7-15$ & truncate & obtuse, awnless & two-keeled \\
\hline
\end{tabular}

Table 3. Reproductive features of wheatgrass (Elymus and Agropyron) taxa

The glumes of Elymus species are indurate-coriaceous, obtuse or truncate, with 1-11 veins, possessing a short awn or no awn at all. The glume can reach half or two thirds of the spikelet in A. pectiniforme, two thirds of the spikelet in E. repens, and one third of the spikelet in E. hispidus, E. elongatus and Szarvasi-1 (Fig. 3.). The glumes are 1-3-veined in $A$. pectiniforme, and 3-7-veined in the other taxa. The lemma of E. elongatus is obtuse, glabrous, unawned and 5-veined; the palea is two-keeled (Melderis, 1980; Barkworth, 2011). Similarly to other representatives of the Poaceae family, the stigma is feather-like in the Elymus genus, where stigmatic secretion is absent even in the mature stage of the stigma, and the receptive surface is discontinuous (Heslop-Harrison \& Shivanna, 1977). The fruit is a caryopsis.

The evaluated anatomical features allow the differentiation of E. elongatus and Szarvasi-1 energy grass from the other investigated members of the Agropyron-Elymus complex. Szarvasi-1 shows several anatomical traits that enhance drought tolerance, such as a sclerenchymatized epidermis covered by a thick cuticle and dense coverage by nonglandular hairs. On the other hand, the mesomorphic position of stoma guard cells is characteristic of an intermediate water requirement. This dual nature of the habitat tolerance of Elymus elongatus cv. Szarvasi-1 has to be taken into account when the new cropfields of this energy grass are planned.

\section{Ecological requirements}

\subsection{Habitat preferences}

Szarvasi-1 energy grass prefers soil conditions similar to common cereals in terms of soil texture, nutrient and water content. However, on lighter soils (e.g. sandy, sandy-silt) it develops faster compared to medium or heavy soils. On sand and sandy soils it can develop seeds in the first year (after spring sowing) and reaches its maximal photosynthetic assimilation one phenophase earlier. The natural habitats of this indigenous plant mainly occur in the central part of Hungary, where the largest sandy areas are located, but it also has an exceptionally natural population on a more clay type soil in a salty marsh.

Considering only the habitats of the natural populations, tall wheatgrass seems to prefer rather alkaline soils where the $\mathrm{pH}$ is between 6.5 and 10 . However, optimal growing potential and biomass production can be linked to a narrower $\mathrm{pH}$ range of 7.5-9. This means that energy grass, in spite of its alkaline origin, can show a more pronounced biomass production in a near neutral soil $\mathrm{pH}$, similarly to the most common cereal cultivations. Slightly acidic soils do not hinder good biomass production, but soil $\mathrm{pH}$ below 5.5 negatively affects the yield. 
The life span of Szarvasi-1 energy grass cultivation can be 10-15 years long, but the temporal change of biomass production during this time has not yet been monitored sufficiently. We have only one complete data series monitoring the yields of an energy grass field on solonec alkaline soil for more than 10 years. According to this study it takes two years for energy grass cultivation to reach maximal biomass production, which can then be maintained for at least 7 years. At around the tenth year energy grass cultivation starts decrease in yearly biomass production. In semi-arid climates without a ground water table serving as water source for cultivation the durability of the energy grass crops can be much shorter.

The flood tolerance of energy grass is relatively good, especially when the cultivation is at least two or three years old and the tussocks of the individuals are well developed. However, in the first year, the short and weak stems of the juveniles cannot tolerate permanent water cover and die out. Hence, the cultivated energy grass stand opens, the density of the stems declines and the establishment of the grass cultivation remains incomplete. In such a condition, weeds can gain multiple chances to invade and to establish. High salt concentrations of the soil can be tolerated by Szarvasi-1 energy grass, but only in wet habitats, where a several weeks long seasonal high water table can occur every year. Because of the high salt resistance, Szarvasi-1 energy grass can be used as salt-tolerant forage and can play an important role in the recycling of saline drainage waters for irrigation.

Since Elymus elongatus subsp. ponticus is a native species of the continental and subcontinental climate in Eastern Europe, it tolerates well the summer high temperatures exceeding daily means of even $30-35^{\circ} \mathrm{C}$, and can also resist cold winter days when the temperature sinks below $-35^{\circ} \mathrm{C}$.

\subsection{Gas exchange behaviour}

Tall wheatgrass is classified as $C_{3}$ plant with cool season characteristics and seasonally different water use efficiency in moderately saline habitats (Bleby et al., 1997; Johnson, 1991). Several cultivars have previously been developed based on adaptability to different environmental conditions in Europe and Asia, but not from ecophysiological perspective. Szarvasi-1 energy grass was developed from a native population of tall wheatgrass (Elymus elongatus subsp. ponticus) that was adapted to slightly salty habitats. Therefore it was expected that E. elongatus cv. Szarvasi-1 will be a good candidate for biomass crop status because it produces large amounts of organic matter with relatively broad tolerance spectra and a high adaptability to different environments. Here we review the current knowledge on environmental gas exchange responses of Szarvasi-1 energy grass under greenhouse and field conditions to different environmental parameters such as temperature, light, air humidity and carbon-dioxide.

We used the following photosynthetic parameters: assimilation as the measure of carbondioxide fixation, transpiration as the measure of water loss and photosynthetic water use efficiency as the ratio of carbon-dioxide input to water output. All of these parameters depend on stomatal regulation and the abiotic environment. In this section capacities and threshold limits of Szarvasi-1 energy grass gas exchange performance will be presented for a better knowledge of its abiotic environmental requirements (Fig. 10.). To define and to compare gas exchange capacities, growing pots were installed using three soil types (sandy soil, Alfisol-Mollisol, Aquic Mollisol) in the Botanic Garden of the University of Pécs with permanent irrigation. In addition, field experiments were established on three soil types (Alfisol, Alfisol-Mollisol, Aquic Mollisol) in South 
Hungary, under natural climatic conditions without any irrigation or fertilization. To evaluate threshold values of gas exchange parameters under different environmental regime, steady state and instantaneous field measurements by IRGA methods were executed.

Among investigated abiotic environmental parameters photon flux density and air humidity turned out to have an essential role in gas exchange performance and regulation (SalamonAlbert \& Molnár, 2009, 2010). Under non-stressed soil water conditions (P2, P3, P5) carbon fixation was the most favourable at the beginning of the growing period described by the assimilation capacity and light efficiency regulated by the air humidity (Fig. 10.A). After seasonal precipitation deficiency in late summer (P4), causing a decline in soil water content, hard reduction was detected in water use efficiency because of strong decrease in assimilation capacity and light efficiency, retaining a regular level of transpiration (Fig. 10.B,C). Effect of climatic air drought was significant for stomatal conductance, going shattered in seasonal response by a greater effectiveness to transpiration (Fig. 10.D). As for the other experimental soil types, overall and seasonal assimilation capacity and light efficiency was a little bit lower on Alfisol-Mollisol and significantly depressed on Aquic Mollisol.
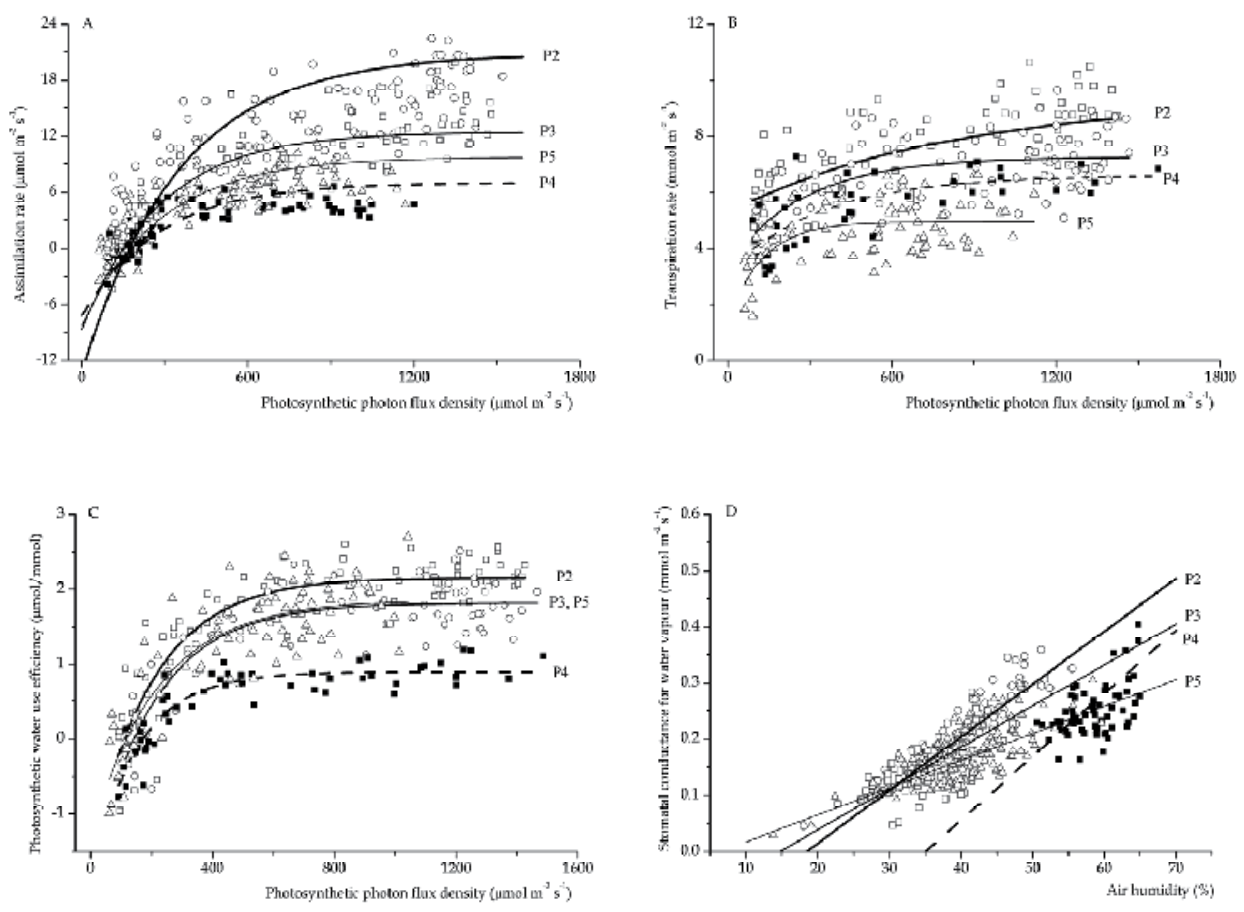

Fig. 10. A) assimilation, B) transpiration, C) photosynthetic water use efficiency as a function of light and D) stomatal conductance for water vapour as a function of air humidity, derived from field measurement (instantaneous data, alfisol, unpublished). Fitted curves $p<0.01$, P2P5 the vegetative phenophases. 
The assimilation and its capacity as the highest net photosynthetic rate in cultivated and natural $C_{3}$ grasses vary greatly from slight to medium values $\left(20-40 \mu \mathrm{mol} \mathrm{m}^{-2} \mathrm{sec}^{-1}\right)$ and in the case of $\mathrm{C}_{4}$ crops from medium to high $\left(30-70 \mu \mathrm{mol} \mathrm{m} \mathrm{m}^{-2} \mathrm{sec}^{-1}\right)$ values under natural carbon-dioxide conditions, saturated light intensity, optimal temperature and adequate water supply (Larcher, 2003). Comparing Szarvasi-1 energy grass to other grasses or crop species, it has a low-medium assimilation capacity among $C_{3}$ species with a range of 10.3 $19.2 \mu \mathrm{mol} \mathrm{m}{ }^{-2} \mathrm{sec}^{-1}$ in greenhouse, and $10.6-20.3 \mu \mathrm{mol} \mathrm{m}^{-2} \mathrm{sec}^{-1}$ under field conditions. Optimal water use efficiency was measured under moderate light intensity (500-1100 $\mu \mathrm{mol}$ $\mathrm{m}^{-2} \mathrm{sec}^{-1}$ ) on all of the studied soil types under greenhouse conditions, while the maximum value was observed on sandy soil in spring $(3.73 \mu \mathrm{mol} / \mathrm{mmol})$. Time and phase shifting in plant growth, poor seasonal rates of assimilation and low water use efficiency detected on Aquic Mollisol under both irrigated and climatic drought conditions underline the negative effect of high clay content of soils on the optimal biomass production of energy grass crops. This is presumably due to insufficient water and nutrient availability.

Under non-stressed environmental conditions, optimum gas exchange in Szarvasi-1 energy grass occurred at the beginning of development in early or late spring, depending on irrigation and soil type. Climatic drought has a strong effect on gas exchange performance through the regulation of stomatal conductance, both for carbon-dioxide and water vapour. According to the studied ecophysiological parameters, Szarvasi-1 energy grass could be beneficial as an energy crop in mesic habitats with lighter soils.

\section{Propagation}

Szarvasi-1 energy grass is propagated by seed. Since E. elongatus ssp. ponticus has evolved in regions of Europe that have long and severe winters, it germinates relatively late in the spring and by the time it develops its tussocks it is mid summer. This is why the suggested sowing time is in autumn, in the middle of September. Its germination needs no special circumstances. A period of only 7 consecutive days with approx. 16 hours dark each day and $18-20{ }^{\circ} \mathrm{C}$ air temperatures can maximize the germination success, up to $90 \%$. In different conditions the proportion of germinating seeds can vary between 52 and $90 \%$. Seedlings die rapidly without proper humidity conditions, but too much watering or a high water table are also poorly tolerated by Szarvasi-1 energy grass seedlings and juveniles. Similarly, strong competition of weeds can dramatically reduce seedling survival. The plant gets in full flower by the middle of June. The energy grass seeds belong to the transient seed bank-type, where the longevity of the seeds is shorter than a year. Hence, the seed bank of Szarvasi-1 energy grass fields contains seeds with the same age with no overlapping generations.

\section{Crop management and production}

The recommended sowing time is between the $1^{\text {st }}$ and $20^{\text {th }}$ of September. The soil must be prepared similarly to any other cereals (e.g. wheat, barley etc). The seeds should be sown at the depth of $2-2.5 \mathrm{~cm}$ with the sowing distance of $12-15 \mathrm{~cm}$. The seed quantity for a hectare land is approx. $40 \mathrm{~kg}$. The seedlings emerge in 14-18 days. Weed management is necessary in this phase of the development of energy grass plantations to avoid the weed species strengthening at the expense of energy grass individuals. In the early spring rolling on the plantation can be important to mitigate the negative effects of winter frost on the root 
system. The first cut can be made in the Central European climate at the beginning of July when the plantation is in full flower. The later the cut takes place the lower the water content is in the biomass as it is shown in Fig. 11. The water content of the biomass is highest in fresh plant material in spring (approx. $80 \%$ ), but during the process of ripening it decreases to $50 \%$ resulting in a higher dry material ratio. Although the highest biomass weight for a unit area can be measured in late spring, the highest dry material weight can be achieved just in the late summer when the seeds are already ripe. The fresh biomass weight reaches its peak with the appearance of the inflorescence, however the high water content decreases its value as solid biofuel. In early August when seeds are ripening plant biomass has a moderately smaller fresh weight but with the highest dry material content. Thereafter, during the autumn (this is not depicted in the figure), dry biomass weight decreases more intensively than water content indicating some loss in dry material content, too.

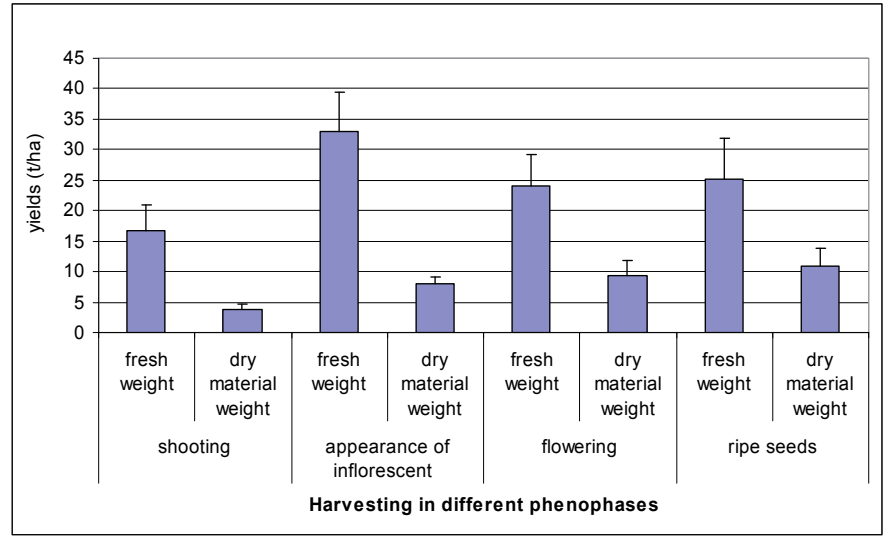

Fig. 11. Changes in fresh and dry weight of yields during a growing season on solonec meadow soil type (mean and SD)

Three or 5 days of full sunshine can reduce the water content of Szarvasi-1 energy grass hay to $9-12 \%$ when it is ready to be baled. In this dry condition the bales can be stored for a long time without a chance of rotting. Later, during the autumn a second mow can be made in October resulting in a lower quantity of biomass with higher content of protein content. The second harvest can be used as forage for cattle or can be grazed in situ.

Soil type has a considerable effect on biomass yields. In the same macroclimatic condition the average weight of the harvested biomass for a unit land can be as much as two times higher thanks to different water and nutrient availability as well as physical soil properties such as texture and compactness of the used soil. An example of this is shown in Fig. 12.

Three soil types were chosen to represent the effect of soil on the yields of energy grass plantations. Alfisol, Alfisol-Mollisol and Aquic Mollisol comprise about $50 \%$ of the cropfields of the South Transdanubian region in South Hungary. The highest yield in fresh as well as dry matter was achieved on Alfisol-Mollisol soil that contained moderate clay fraction and hence it bears a well balanced water and nutrient household. The Aquic Mollisol site was under the control of a relatively high ground water table, particularly in the spring, hindering the early development of the plantation. On the other hand, the high ground water table could serve as a good water source later in the summer, so the overall yield became high enough similarly to that on Alfisol-Mollisol. The relatively higher water content of the biomass produced on Aquic 
Mollisol, likely due to the better water availability, can be seen in Fig. 12. as a relatively high difference between the weight of the fresh and the dry matter. The lowest yield was measured on the Alfisol experimental site. Here, both the water and the nutrient supply was under the control of the high clay content of the soil which resulted in a relatively high dry matter content but an extremely low total biomass yield.

Temporal variability of biomass production of energy grass Szarvasi-1 was also studied in a three-year-long field experiment (2004-2007) in the South Transdanubian region (Hungary). According to our results, the main source of variability was the amount of precipitation. Particularly on the sites with low water table, biomass production decreased with up to $50 \%$ of the average biomass quantity in the year of extreme low precipitation. We measured 6 tons of dry matter per a hectare in 2007 instead of 12 tons of dry biomass yield in a better year (2006). Phenotypic plasticity of Szarvasi-1 energy grass cultivations can therefore be regarded as not very high, resulting in considerable variability of biomass yields in different years.

An extended fertilization experiment was conducted in two different environments in terms of climate and soil types in south-eastern and in south-western Hungary at a distance of 250 $\mathrm{km}$ from each other, in order to find the optimal nutrient supply of Szarvasi-1 energy grass crop (Fig. 13.). As our results suggested, the demand of energy grass for fertilization depends mainly on the soil types.

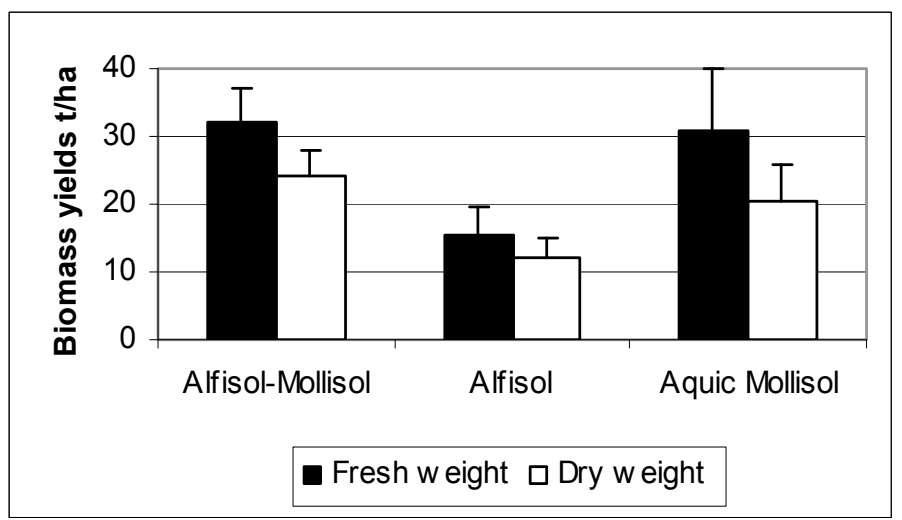

Fig. 12. Biomass yields in 2006 on three study sites near Bóly on different soil types (South Hungary) 


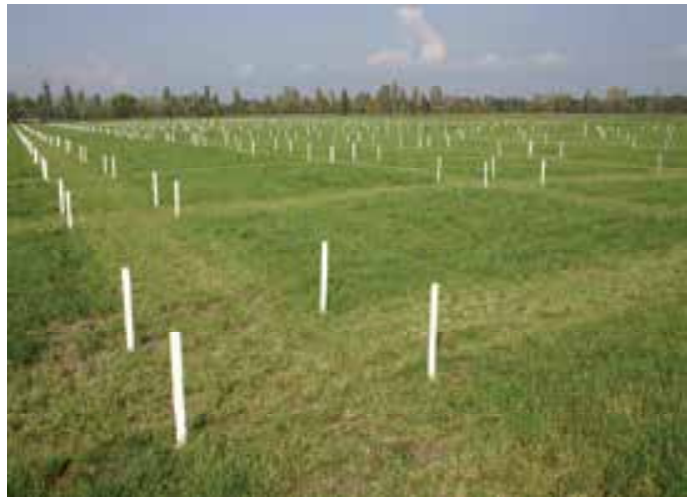

Fig. 13. Experimental fields near Szarvas (Southeast Hungary) to find optimal fertilizer management type (photo: Róbert W. Pál)

The response of biomass production to nitrogen is relatively high, already $60 \mathrm{~kg} \mathrm{~N} / \mathrm{ha}$ can double the dry biomass matter as can be seen in Fig. 14. Until this dose, increasing amounts of nitrogen contribute to increasing biomass production in a linear relationship. Higher doses than $60 \mathrm{~kg} /$ ha nitrogen by itself does not increase the biomass production further due to the lack of other major nutrients, such as potassium and phosphorus. Adding these to the experiment in different doses we have found that biomass production can be increased a further $50 \%$ until it reaches 13 tons dry matter per hectare. The best ratio of the three major nutrients was shown to be 1:1:1 or 3:2:2 to maximize biomass yield of energy grass.

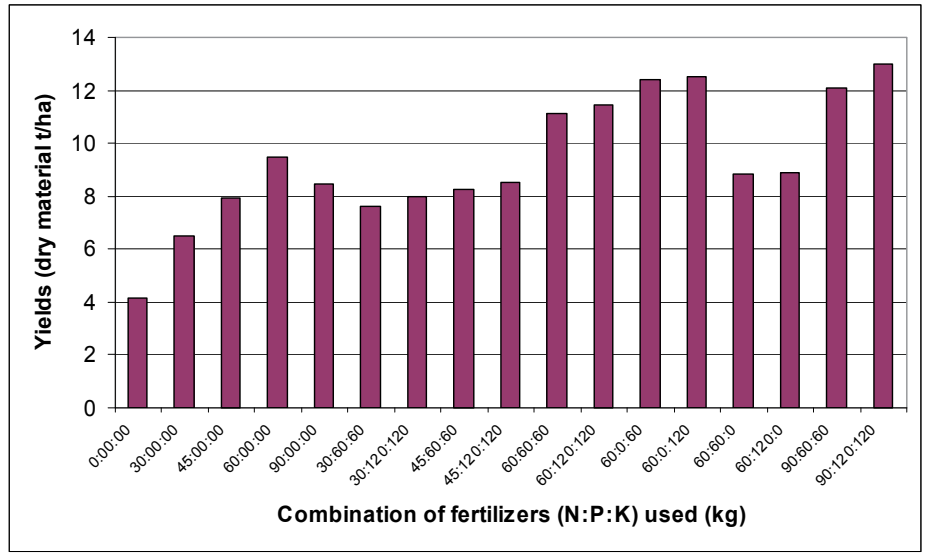

Fig. 14. Biomass yields from fertilizer study near Szarvas (solonec meadow soil)

Nitrogen played an important role in biomass production increasing biomass weight in any phenophases, while potassium and phosphorus were shown to be important only in the early phenophases (spring and flowering period and the beginning of the flowering time, respectively).

The maximum dry matter production of Szarvasi-1 energy grass crop was shown to be dependent on soil types and water supply. In our experiments 13 tons per hectare dry matter derived from solonec meadow soil, while in better soil conditions we got 20-25 tons dry matter per hectare. High and low levels of the average groundwater table can also decrease biomass 
yield substantially. Too high water table can prevent the energy grass crop forming closed and well established stands, while too low water table (less then $4 \mathrm{~m}$ in depth) can limit biomass production during the dry season in summer. As a consequence, the optimal water table level is estimated to be between 1 and 3 meters in depth in the course of the whole growing period.

In conclusion, we can claim that depending on the soil type, nutrient availability and precipitation, Szarvasi-1 energy grass crop can produce 10-25 dry matter/ha biomass a year, but this value cannot reach 5 tons in the case of soils with a high clay content and low precipitation. One harvest in the middle of August can achieve these biomass yields while in the rest of the year an additional $30-40 \mathrm{~cm}$ high second growth can be obtained. Beneficial choice of location for the establishment of Szarvasi-1 energy grass fields can result in considerably higher biomass yields increasing the competitive ability of this new biomass cultivation against conventional arable crops.

\section{Plant protection}

\subsection{Weeds}

\subsubsection{Weed composition of Szarvasi-1 fields}

Knowledge of weed assemblies is extremely important for an effective weed management in all arable cultures. Therefore introducing new crops to large scale cultivation requires comprehensive preliminary investigations. In this chapter the characteristic species composition as well as abundances of weeds on Szarvasi-1 energy grass fields were determined and were compared to other arable crop cultures. Weed-crop competition was also studied in different soil conditions. The analyses were made on the basis of 22 energy grass, 60 cereal, 60 row crop and 15 alfalfa plots that were $4 \times 4 \mathrm{~m}$ in size. A detailed study on this topic was published by Pál \& Csete (2008).

\subsubsection{Relation of weed species composition in energy grass to other arable cultures}

Comparing the weed composition of energy grass fields to other cultures on landscape and field level in terms of an ordination diagram showed a distinctive separation from cereals and row crops (Fig. 15.). A partial overlapping was detected with alfalfa fields, suggesting a similar species composition to this perennial crop.

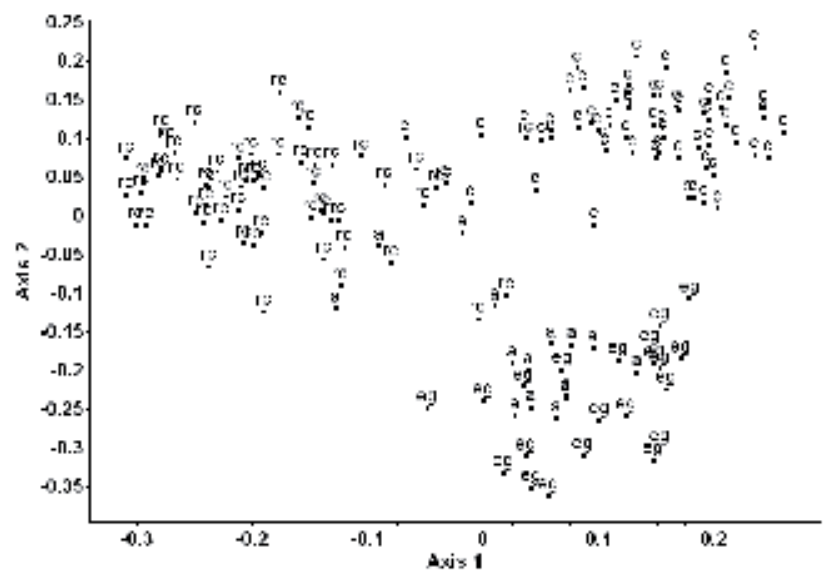

Fig. 15. Scatter diagram of the weed composition of different crops (eg = energy grass, $\mathrm{a}=$ alfalfa, $\mathrm{rc}=$ row $\mathrm{crops}, \mathrm{c}=$ cereals $)(\mathrm{PCoA}$, Jaccard similarity index $)$ 
Regarding the life form distribution of the weeds in the different cultures, energy grass fields resembled annual crops the most, considering all life form categories. However, geophytes were more representative, while therophytes were less common. In alfalfa, a higher proportion of geophytes and hemicryptophytes were found, while therophytes were even more underrepresented than in energy grass fields. Considering the observed life form distribution of the characteristic weed community of each crop, energy grass took an intermediate position between annual crops and the perennial alfalfa.

The characteristic species composition of the different cultures is shown in Table 4. There was only one species (Convolvulus arvensis) which could be regarded as uniformly common in every culture. There were 12 species characterizing the cereals, six the row crops, two in case of alfalfa and only one (Bromus japonicus) in case of energy grass. Bromus japonicus as a problematic weed was already present from the first year of sowing, and despite its annual life form, it has been continuously present and infesting the fields. On the other hand, energy grass fields are often characterized by a lack or a decreased importance of several serious weed species which are quite dominant in other arable crops: Amaranthus spp., Ambrosia artemisiifolia, Apera spica-venti, Artemisia vulgaris, Cirsium arvense, Echinochloa crusgalli, and Galium aparine.

\begin{tabular}{lcccc}
\hline Differential species & $\begin{array}{c}\text { Cereals } \\
\mathrm{n}=60\end{array}$ & $\begin{array}{c}\text { Row crops } \\
\mathrm{n}=60\end{array}$ & $\begin{array}{c}\text { Alfalfa } \\
\mathrm{n}=15\end{array}$ & $\begin{array}{c}\text { Energy } \\
\text { grass n=22 }\end{array}$ \\
\hline Cirsium arvense & 81.7 & 48.3 & 6.7 & 31.8 \\
Capsella bursa-pastoris & 73.3 & 10 & - & 22.7 \\
Papaver rhoeas & 73.3 & - & - & - \\
Artemisia vulgaris & 70 & 35 & 26.7 & 4.5 \\
Consolida regalis & 58.3 & 1.7 & - & 9.1 \\
Stellaria media & 58.3 & 10 & 6.7 & - \\
Veronica persica & 53.3 & 13.3 & 6.7 & - \\
Galium aparine & 48.3 & 3.3 & - & 4.5 \\
Apera spica-venti & 35 & - & - & - \\
Bromus sterilis & 30 & - & - & - \\
Viola arvensis & 30 & - & - & - \\
Veronica polita & 28.3 & - & - & - \\
Setaria pumila & 40 & 86.7 & 13.3 & - \\
Echinochloa crus-galli & 36.7 & 81.7 & 26.7 & - \\
Amaranthus chlorostachys & 1.7 & 50 & 13.3 & - \\
Digitaria sanguinalis & 1.7 & 46.7 & 13.3 & - \\
Persicaria maculosa & 10 & 45 & - & - \\
Solanum nigrum & 11.7 & 41.7 & 6.7 & - \\
Taraxacum officinale & 40 & 13.3 & 93.3 & 22.7 \\
Lolium perenne & 45 & 16.7 & 93.3 & - \\
Bromus japonicus & 10 & - & - & 81.8 \\
\hline Frequent species & & & & \\
\hline Convolvulus arvensis & 98.3 & 88.3 & 66.7 & 68.2 \\
Ambrosia artemisiifolia & 98.3 & 88.3 & 40 & 13.6 \\
Chenopodium album & 76.7 & 75 & 33.3 & 13.6 \\
\hline Table 4. Frequencies of the & & & & \\
\hline
\end{tabular}

Table 4. Frequencies of the weed species in different crops 


\subsubsection{Temporal variation of weed cover and species number}

Our results suggested that energy grass cultures are able to develop properly established, nearly weedless stands with an average crop cover that increased from 77.5 to $90 \%$ during a 4 year period. Furthermore, a quick leaf-litter accumulation was observed during this time reaching an average ground cover of leaf-litter of as much as $55 \%$. This can contribute to a significantly low weed cover. The average species number declined from 16.5 to 4.8 and the average ground cover decreased from 62.5 to $2 \%$. This dynamic process is depicted in an example from an experimental site from the South of Hungary on three different soil types (Fig. 16.).

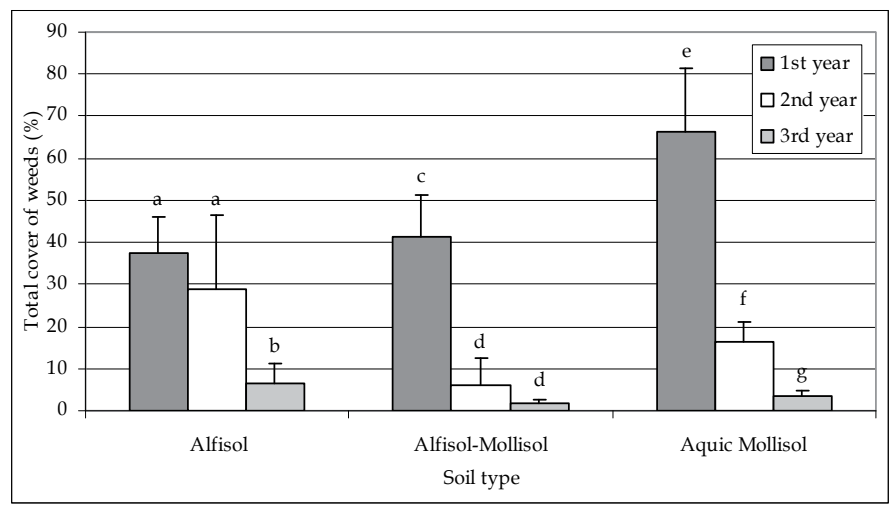

Fig. 16. Changes in total weed cover during three years on three different soil types.

Different letters indicate significant differences at $\mathrm{P}<0.05$; (mean, standard deviation); ( $\mathrm{t}$ test)

\subsubsection{Competitive ability of energy grass on weeds}

The competitive ability of energy grass crop can be demonstrated using experimental plot data. A strong linear relationship was found between the biomass production and the logarithmic values of total weed cover suggesting a high competitive ability of the crop. With less then $10 \mathrm{t} /$ ha of biomass dry yield the cover of weeds exceeded $50 \%$, while at 15 $\mathrm{t} / \mathrm{ha}$ the value decreased to $20-25 \%$ and to $2-5 \%$ at $20 \mathrm{t} / \mathrm{ha}$.

Elymus elongatus is a rare, native plant species in Hungary; therefore its agricultural production is much more favourable than other exotic biomass grasses (e.g. Miscanthus $\times$ giganteus, Sorghum bicolor). Since its stands require a certain weed control only in the year of establishment, chemical input into the environment decreases significantly compared to other intensive cultures. Under favourable conditions, energy grass can entirely close its canopy and exclude more weed species or considerably decrease their cover by the third year of cultivation. This remarkable competitive ability of a crop is appreciated by farmers as it decreases the demand of herbicide use as well as the costs of the agricultural production.

\subsection{Fungi}

Studies on the pests of Szarvasi-1 energy grass are in progress in Hungary, but it is already clear that the plant is sensitive to many of the most common fungal infections typical for cereals. At our experimental sites the most important fungal infection was mildew (Blumeria 
graminis). Szarvasi-1 energy grass proved to be sensitive to mildew particularly on those sites where intensive growth of the plant occurred due to optimal nutrient and water availability. The mildew infection can cause severe damage on the leaf structure of the plant resulting in total devastation of whole patches. Proper chemical plant protection is needed to avoid significant biomass production loss. Infection of mildew was mediated by old hay bales deposited along the edge of energy grass fields, so the prompt collection and transportation of bales can contribute to lowering the chance of energy grass fields being reinfected. According to our results, chemical protection of energy grass fields must be taken into account similarly to that in the case of any other traditional agricultural crops.

\section{Ecological hazard}

Ecological invasion of neophyte plant and animal taxa has now become one of the most feared sources of natural habitat degradation according to many nationwide and international surveys (e.g. Molnár et al., 2008) The most frequent method of neophyte introduction is their agricultural use through which their large-scale distribution and successful establishment are intensively supported by human activities. Suggesting new plant taxa to be involved in agricultural production bears the hazard of suggesting a new potential invasive plant too. Hence thorough investigation and consideration must be taken before introducing any new agricultural crop, especially a new biomass plant.

Elymus elongatus is a rare, native plant species to Hungary; consequently its Szarvasi-1 cultivar is much more favourable for agricultural production in Hungary than other exotic biomass grasses. Szarvasi-1 carries genetic material that is derived from only indigenous populations of E. elongatus in Hungary. Hence the cultivar can be regarded as an indigenous taxon, so its potential as an ecological hazard in terms of invasivity is low. Since Szarvasi-1 energy grass has a transient seedbank type (i.e. its seeds lose their viability in a year), its cropfields can be transformed into any other crop without the problem of resprouting.

High competitive ability as well as fast growth dynamics are the main characters of Szarvasi-1 energy grass when it manages to establish itself completely. As our experiments suggested, weed species can outcompete Szarvasi-1 energy grass individuals if there is only incomplete sprouting and the development of tillers are slow. In this case, the stands of Szarvasi-1 energy grass crop remain open, and weeds can gain a significant advantage in growing and spreading. This is why we expect Szarvasi-1 energy grass not to be able to invade intact natural or semi-natural habitats, not even in the close vicinity of energy grass fields from where the seeds can escape in large quantities. Energy grass can germinate only in anthropogenic habitats where continuous and intensive disturbance takes place (e.g. field margins, dirt roads and banks following man-made canals). Since energy grass cannot spread vegetatively (i.e. with rhizomes), it will not become such a hazardous invasive species as for instance Solidago gigantea or Reynoutria japonica, at least not in its native habitat, in Eastern Europe.

For the rest of the world, it is worth being cautious. From Australia and the US the aggressive spread of energy grass has been reported (e.g. Cox, 2001; Walsh, 2008), where the plant formed homogeneous, closed stands outcompeting all the native elements of the local vegetation. Although this happened only in very close environments to the lands recultivated by Elymus elongatus (e.g. steep slopes and bank of canals), this might indicate the possibilities of its invasive spreading, particularly in those countries where natural specialist herbivores, as well as pathogenic agents of Elymus elongatus are missing. 


\section{Utilization}

The moisture content of the energy grass at harvest can highly influence the possibilities for storage, processing and utilization. Appropriate logistic and storage conditions can be provided by harvesting at the optimal time and the use of bales. In this manner the processing, chopping and direct energetic utilization of low moisture content of the baled fuel can be solved easily. High moisture content causes quality loss and negatively affects the processability and energetic characteristics of the material.

The application forms of energy grass used as fuel are:

- bale

- chips/chaff

- pellet

The physical and some of the energetic characteristics of the listed fuel forms are different. The characteristics are summarized in Table 5.

\begin{tabular}{|l|c|c|c|c|}
\hline \multicolumn{5}{|c|}{ Energy grass (abs. dry condition)* (Governing standards: MSZ EN 14961:2005) } \\
\hline & Unit & Bale & Chips/Chaff & Pellet \\
\hline Carbon & $\%$ & 46.594 & 44.938 & 45.815 \\
\hline Hydrogen & $\%$ & 3.487 & 4.322 & 3.733 \\
\hline Nitrogen & $\%$ & 0.988 & 1.151 & 1.26 \\
\hline Sulphur & $\%$ & 0.214 & 0.258 & 0.234 \\
\hline Oxygen & $\%$ & 44.156 & 44.636 & 42.551 \\
\hline Chlorine & $\%$ & 0.211 & 0.115 & 0.385 \\
\hline Ash & $\%$ & 4.35 & 4.58 & 6.02 \\
\hline Density & $\mathrm{kg} / \mathrm{dm}^{3}$ & $0.110-0.140$ & - & $1.114-1.225$ \\
\hline $\begin{array}{l}\text { Abrasion } \\
\text { index }\end{array}$ & $\%$ & - & - & 97.7 \\
\hline $\begin{array}{l}\text { Caloric } \\
\text { Value }\end{array}$ & $\mathrm{MJ} / \mathrm{kg}$ & 17.983 & 17.597 & 17.645 \\
\hline
\end{tabular}

* values were determined based on the average of several measurements

Table 5. The physical and some of the energetic characteristics of the listed fuel assortment

Data show that independently of its form the energy grass has high ash content. It is necessary to mention however that based on technological and laboratorial investigations we have found that the high ash content is mainly caused by external physical contaminants. This can be significantly reduced e.g. by training the operators in maintaining technological discipline and by using the appropriate harvest-, loading-, and storing processes of the raw material. The elemental compositions of the investigated fuels are also different from the ligneous fuels. Chlorine and sulphur content were investigated by CHNS analysis which shows several times higher values compared to premium quality fuels (according to standards). This factor must be considered for energetic utilization. Herbaceous fuels (such as the energy grass) have low ash melting point, which greatly restricts their energetic utilization. The results, which clearly show the change in amount of ash sample plotted against temperature for ligneous and herbaceous fuels, are summarized in Fig. 17. Based on the results of the measurements it can be stated that the ash melting point of the energy grass is $690^{\circ} \mathrm{C}$, while the ash melting point of the mixed wood-pellet is $1080^{\circ} \mathrm{C}$. 


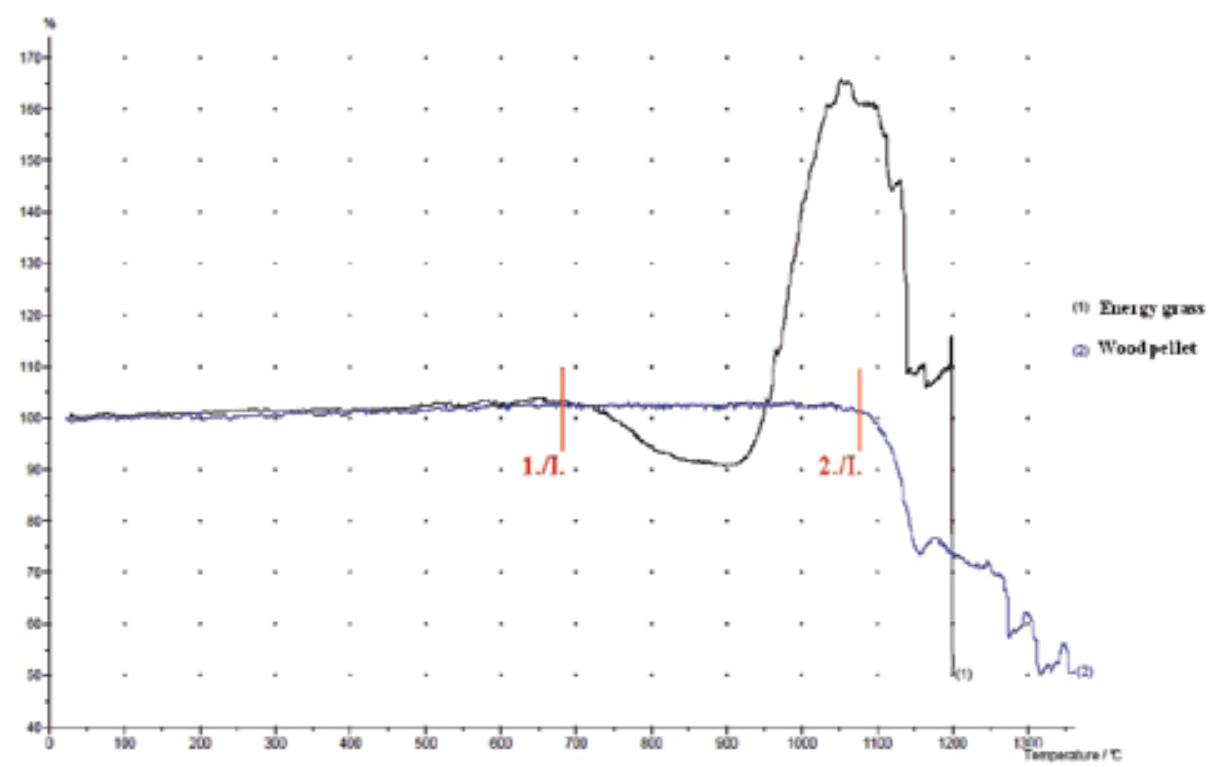

Fig. 17. Ash melting diagram of fuels

The high alkali content, which was adsorbed during the lifetime of the plant, causes the low ash melting point of the energy grass. This causes combustion problems because the ash melting occurs in the operating temperature of boiler. The material can melt and sick onto the surface of the structure elements of the boiler, and this will lead to interior depositions and permanent damage. To solve this problem, new boiler and grate types were developed. The part of the combustion chamber where the fuel burns in solid phase cannot reach high enough temperatures for the ash melting. Continuous movement of the fuel also helps to avoid scorification and interior depositions. Boiler technology was developed so that the fuel is moving on a moving grate in the boiler while the volatile component of the fuel is gasified between $150^{\circ} \mathrm{C}$ and $400^{\circ} \mathrm{C}$. The charred roughage falls off the grate to the ash pit before the fuel would be able to reach the critical melting temperature (Fig. 17.). The volatile component is burnt in the second part of the boiler (the so-called post-combustor) where the temperature of the combustion chamber is approx. $800-900^{\circ} \mathrm{C}$. The problem of ash melting was solved and sufficient burnout of the combustion gas was also ensured by this new technical solution. Based on this operating principle there are many structural solutions and performances available on the market.

The boilers, which are suitable for energetic utilization of the energy grass, can be ranked into three different groups based on their performance levels.

- $\quad$ low power equipment with pellet fuel $(\leq 50 \mathrm{~kW})$

- $\quad$ medium power equipment with pellet fuel $(50-300 \mathrm{~kW})$

- $\quad$ heat and power plant equipment with chips or bale fuel (0.3 - $5 \mathrm{MW})$

Due to their structure and size the low power equipments are mainly operated with pellet fuel. These automatic systems are suitable for the combustion of energy grass pellets with appropriate efficiency and low emission. The size of the boiler and the manufacturing cost are greatly increased by the necessary moving grate. These equipments are more robust than the prevalent wood-pellet boilers. Medium power equipments are primarily used in communal and social facilities, which are mainly operated using pellets. They are 
equipped with "travelling grates" which have a ladder-like structure and consist of more segments. There is another grate, so-called "crawler grate", which was named after its appearance because it resembles a looped ribbon stick. The heat and power plant boiler designs have several solutions. Utilization of the energy grass in coal power-plants was carried out with co-firing which can solve the problem of ash melting. During the combustion of herbaceous fuels higher solid emissions can be measured which mainly deposit in the boiler and exhaust with the flue gas. The efficiency is highly damaged by deposition on the heat transfer surfaces, and depending on the composition it can result in corrosive effects in the boiler. In order to prevent this, mechanical or pneumatic equipment should be installed with a dust separator, which cleans automatically the flue duct.

Parallel with this solution it is necessary to reduce the load of solid components of the flue gas, the equipment is usually mounted with cyclone, which allays larger floating particles from flue gas. Electrostatic filter may also be assessed, which significantly reduces the emission of solid component from boilers.

Another possible method for the energetic utilization of energy grass is the so-called pyrolytic procedure where the fuel is fumigated in a multistage process in an oxygen-low environment. The resultant "grass-gas" will be burnt directly or after a cleaning procedure it will be suitable for use in gas engines for electricity production. Because of the high capital costs these technologies are primarily economical in the case of using high-performance equipment. As a conclusion, it can be stated that problems concerning the use of the herbaceous fuels - including energy grass - in low-and high-performance boilers, directly, or with co-firing technique have been solved. The conditions of the application are determined by the logistic aspects and the current production costs. In the current boiler engineering, considering technical, energetic, environmental and economic aspects, the herbaceous fuels and their boilers may play an important role in the medium power-level market of energy systems.

\section{Conclusion}

A new energy crop (Elymus elongatus subsp. ponticus cv. Szarvasi-1, tall wheatgrass) has recently been introduced to cultivation in Hungary to provide biomass for solid biofuel energy production. The cultivar was developed in Hungary from a native population of $E$. elongatus subsp. ponticus for agronomic and energetic purposes. The main goal of our research was to investigate the performance of Szarvasi-1 energy grass under different growing conditions (e.g. soil types, nutrition supply). We focused on the ecological background, biomass yield, weed composition, morphology, ecophysiology and the genetics of the plant.

The biomass yield of Szarvasi-1 energy grass depends mainly on the presence of macronutrients, soil texture and water availability of fields. Under typical soil nutrient conditions, precipitation has a considerable effect on biomass yield. Average yield of Szarvasi-1 energy grass is as much as 10-15 $\mathrm{t} \mathrm{DM} \mathrm{ha}^{-1}$ with great spatial and temporal variation depending on weather and habitat conditions. As part of an intensive agricultural management, the use of fertilizers can be a good solution when soil nutrients are inadequate. Nitrogen plays an important role in increasing biomass in any phenophases of Szarvasi-1 in the course of annual growth (Fig. 18.). 


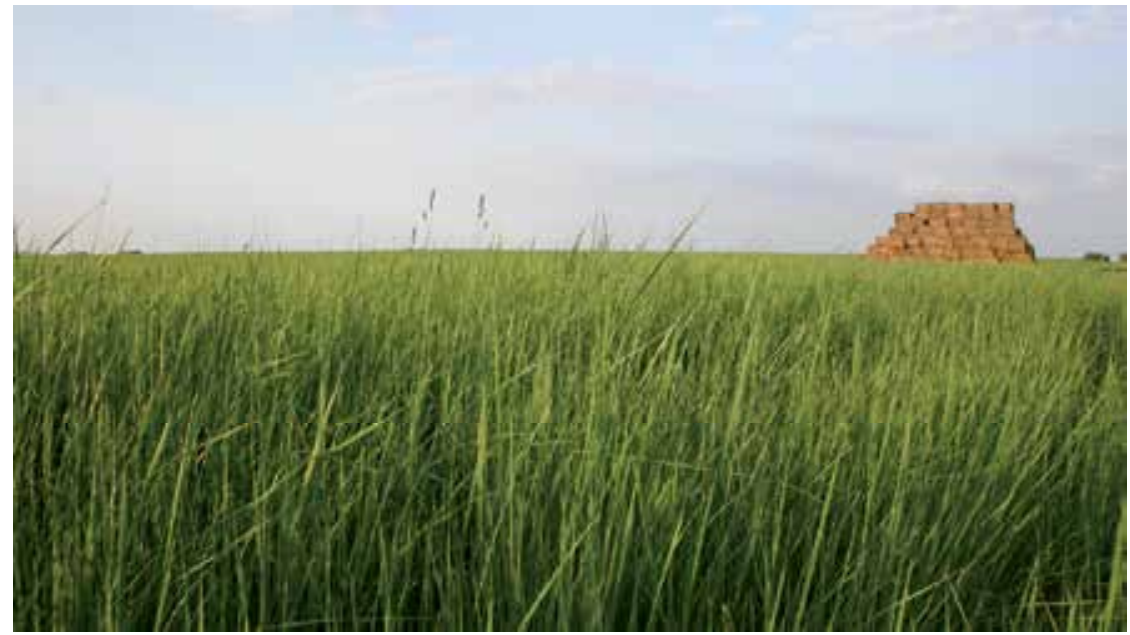

Fig. 18. Energy grass field in Baranya county (photo: Róbert W. Pál)

Quantitative analyses of the plant material of Szarvasi-1 were conducted to describe the chemical profile of the biofuel. Ash and energy content were determined by combustion experiments in laboratory while the dynamics of firing were studied in different experimental furnaces. We developed best practices for combusting Szarvasi-1 biofuel.

Dry matter content of Szarvasi-1 is highly influenced by the morphological features of the vegetative organs. The occurrence and proportion of mechanical and vascular tissues were investigated in the leaves and culms of Szarvasi-1 in various experimental settings for two years. Having examined the effect of different soil types on the anatomical characteristics of the culm and the leaves, we determined the most favourable habitat types of this energy plant to achieve the highest biomass yields with the greatest dry matter content.

Ecophysiological regulation and the threshold limits of gas exchange parameters (assimilation, transpiration, water use efficiency, stomatal conductance) of Szarvasi-1 were also investigated. For abiotic environmental variables, air humidity and light had the most significant effect on gas exchange parameters. Assimilation curves and some characteristic values (e.g. light compensation and efficiency, assimilation capacity) were different at the beginning of the growing period on all studied soil types. These parameters characteristically declined under water-limited environmental conditions. Water limitation had a slightly positive effect on water use efficiency. Ecophysiological conclusions, drawn from gas exchange analyses, can be utilized for planning biological and agronomical aspects to achieve higher biomass production, in accordance with the abiotic environmental regime.

The typical weed composition and abundance in energy grass fields were compared to other arable crop cultures. Weed-crop competition was also investigated in different soil conditions. The weed composition of energy grass fields is more similar to perennial cultures like alfalfa than to other annual ones (cereals, row crops). Although no herbicide treatment was carried out, percent cover of Szarvasi-1 energy grass increased significantly year by year with decreasing weed cover and species number. By the second year, the average weed cover dropped from the first year's value of $48 \%$ to $17 \%$ and in the third year it did not exceed $4 \%$. Different soil types had different effect on the temporal variation of weed composition. 
In order to maintain a standard quality of Szarvasi-1 as an energy crop, it was essential to clarify its genetic characteristics. RAPD-based DNA fingerprinting revealed a low level of genetic variability among samples of the cultivar. In addition, a comparative analysis of three native Hungarian Elymus elongatus populations and Szarvasi-1 cultivar confirmed their genetic identity, having found no specific marker characteristic only for the latter. Ecological risk of unwanted gene exchange among close taxonomic relatives may be rather low but not impossible according to our results.

Moderate phenotypic plasticity, enormous capability to suppress weeds, high potential to produce biomass even among drier climatic conditions and a relatively high energy and moderate ash content suggest that tall wheatgrass cultivar Szarvasi-1 has great potential as a herbaceous energy plant for arid or semi-arid lands in Eastern Europe.

\section{Acknowledgement}

Our research and publication were financially supported by NKFP 3A/061/2004 and TÁMOP-4.2.2/B-10/1-2010-0029. Special thanks should be given to John Michael Lynch and Emily Rauschert for the thorough linguistic corrections of our manuscript.

\section{References}

Assadi, M. \& Runemark, H. (1995). Hybridization, genomic constitution and generic delimitation in Elymus sl (Poaceae, Triticeae). Plant Systematics and Evolution Vol. 194, No. 3-4, (September 1995), pp. 189-205, ISSN 0378-2697

Barkworth, M. (2011). Thinopyrum ponticum (Podp.) Z.W. Liu \& R.R.-C. Wang, In: Thinopyrum Á. Löve, 8 June 2011, Available from:

$<$ http:// herbarium.usu.edu/webmanual/info2.asp?name=Thinopyrum_ponticum

Bleby, T.M.; Avcote, M.; Kennett-Smith, A.K.; Walker, G.P. \& Schachtman, R.P. (1997). Seasonal water use characteristics of tall wheatgrass (Agropyron elongatum (Host) Beauv.) in a saline environment. Plant Cell and Environment Vol. 20, No. 11, (November 1997), pp. 1361-1371, ISSN 0140-7791

Cox, G.W. (2001). An inventory and analysis of the alien plant flora of New Mexico. The New Mexico Botanist, Vol. 17, (January 2001), pp. 1-8.

Díaz, O.; Sun, G. L.; Salomon, B. \& Bothmer, R. (2000). Levels and distribution of allozyme and RAPD variation in populations of Elymus fibrosus (Poaceae). Genetic Resource and Crop Evololution, Vol. 47, No. 1, (February 2000), pp. 11-24, ISSN 0925-9864

Guadagnuolo, R.; Bianchi, D. S. \& Felber, F. (2001). Specific genetic markers for wheat, spelt, and four wild relatives: comparison of isozymes, RAPDs, and wheat microsatellites. Genome, Vol. 44, No. 4, (July 2001), pp. 610-621, ISSN 0831-2796

Häfliger, E. \& Scholz, H. (1980). Grass Weeds. Vol. 2. CIBA-GEIGY Ltd. Basel, Switzerland

Heslop-Harrison, Y. \& Shivanna, K.R. (1977). The Receptive Surface of the Angiosperm Stigma. Annals of Botany Vol. 41, (November 1977), pp. 1233-1258, ISSN 0305-7364

Janowszky, J. \& Janowszky, Zs. (2007). A Szarvasi-1 energiafú fajta - egy új növénye a mezőgazdaságnak és az iparnak (Szarvasi-1 energy grass - a novel crop for the agriculture and industry) In: Tasi, J. A magyar gyepgazdálkodás 50 éve Gödöllő, Szt. István Egyetem ISBN 978-963-9483-77-4 pp. 89-92

Johnson, R.C. (1991). Salinity resistance, water relations, and salt content of crested and tall wheatgrass accessions. Crop Science Vol. 31, (n.d.), pp. 730-734, ISSN 0011-183X 
Larcher, W. (2003). Physiological Plant Ecology. Ecophysiology and stress physiology of Functional Groups. Springer-Verlag, ISBN 3-540-43516-6, Berlin Heidelberg New York

Melderis, A. (1980). Elymus L., In: Flora Europaea, Vol. 5. Alismataceae to Orchidaceae (Monocotyledones), Tutin, T.G.; Heywood, V.H.; Burges, N.A.; Moore, D.M.; Valentine, D.H.; Walters, S.M. \& Webb, D.A., (Eds.), pp. 192-199, Cambridge University Press, ISBN-13: 9780521153706, Cambridge, England

Mizianty, M.; Frey, L. \& Szczepaniak, M. (1999). The Agropyron-Elymus complex (Poaceae) in Poland: nomenclatural problems. Fragmenta Floristica et Geobotanica Vol. 44, No. 1, (n.d.), pp. 3-33, ISSN 1640-629X

Molnár, Zs.; Bölöni, J. \& Horváth, F. (2008). Threatening factors encountered: Actual endangerment of the Hungarian (semi-) natural habitats. Acta Botanica Hungarica Vol. 50(Suppl.), (n.d.), pp. 199-217. ISSN 0236-6495

Murphy, M.A. \& Jones, C.E. (1999). Observations on the genus Elymus (Poaceae: Triticeae) in Australia. Australian Systematic Botany Vol. 12, No. 4 , (n.d.), pp. 593-604, ISSN 1030-1887

Nieto-López, R. M.; Casanova, C. \& Soler, C. (2000). Analysis of the genetic diversity of wild, Spanish populations of the species Elymus caninus (L.) Linnaeus and Elymus hispanicus (Boiss.) Talavera by PCR-based markers and endosperm proteins. Agronomie, Vol. 20, No. 8, (December 2000), pp. 893-905 ISSN 0249-5627

Pál R. \& Csete S. (2008). Comparative analysis of the weed composition of a new energy crop (Elymus elongatus subsp. ponticus [Podp.] Melderis cv. Szarvasi-1) in Hungary. Journal of Plant Diseases and Protection, Vol.21, (March 2008), pp. 215-220, ISSN 1861-4051

Petersen, G. \& Seberg, O. (1997). Phylogenetic Analysis of the Triticeae (Poaceae) Based on rpoA Sequence Data. Molecular Phylogenetics and Evolution, Vol. 7, No. 2, (April 1997), pp. 217-230, ISSN 1055-7903

Podani, J. (1993). SYN-TAX 5.0: Computer programs for multivariate data analysis in ecology and systematics. Abstracta Botanica, Vol. 17, Part 4 , (n.d.), pp. 289-302, ISSN 0133-6215

Reisch, C.; Poschlod, P. \& Wingender, R. (2003). Genetic differentiation among populations of Sesleria albicans Kit. ex Schultes (Poaceae) from ecologically different habitats in central Europe. Heredity, Vol. 91, No. 5, (November 2003), pp. 519-527, ISSN 0018-067X

Salamon-Albert É. \& Molnár H. (2009). CO2 gas exchange parameters as the measure of biomass production of the Hungarian energy grass. Proceedings of International Symposium on Nutrient Management and Nutrient Demand of Energy Plants July 6-8, 2009 Corvinus University Budapest, Hungary.

Salamon-Albert É. \& Molnár H. (2010). Environment regulated ecophysiological responses of a tall wheatgrass cultivar. Novenytermeles Vol. 59., No. 1., (n.d.), pp. 393-396, ISSN 2060-8543

Sha, 1., Fan, X., Yang, R., Kang, H., Ding, C., Zhang, L., Zheng, Y. \& Zhou, Y. (2010). Phylogenetic relationships between Hystrix and its closely related genera (Triticeae; Poaceae) based on nuclear Acc1, DMC1 and chloroplast trnL-F sequences. Molecular Phylogenetics and Evolution, Vol. 54, No. 2, (February 2010), pp. 327-335, ISSN 1055-7903

Swofford, D. L. (2001). PAUP*. Phylogenetic Analysis Using Parsimony (*and Other Methods) Version 4. Sinauer Associates, Sunderland, Massachusetts

Tutin, T.G.; Heywoog, V.H.; Burges, N.A.; Moore, D.M.; Valentine, D.H.; Walters, S.M. \& Webb, D.A. (1980). Flora Europaea Vol. 5 Alismataceae to Orchidaceae (Monocotyledones), Cambridge University Press, ISBN 978-052-1201-08-7, Cambridge, UK

Walsh, N.G. (2008). A new species of Poa (Poaceae) from the Victorian Basalt Plain. Muelleria, Vol. 6, No. 2, (July 2008), pp. 17-20, ISSN 0077-1813 


\title{
Analysis of Time Dependent Valuation of Emission Factors from the Electricity Sector
}

\author{
C. Gordon and Alan Fung \\ Ryerson University \\ Canada
}

\section{Introduction}

In recent years, energy consumption and associated Greenhouse Gas (GHG) emissions and their potential effects on the global climate change have been increasing. Climate change and global warming has been the subject of intensive investigation provincially, nationally, and internationally for a number of years. While the complexity of the global climate change remains difficult to predict, it is important to develop a system to measure the amount of GHG released into the environment. Thus, the purpose of this chapter is to demonstrate how several methods can accurately estimate the true GHG emission reduction potential from renewable technologies and help achieve the goals set out by the Kyoto Protocol reducing fuel consumption and related GHG emissions, promoting decentralization of electricity supply, and encouraging the use of renewable energy technologies.

There are several methods in estimating emission factors from facilities: direct measurement, mass balance, and engineering estimates. Direct measurement involves continuous emission monitoring throughout a given period. Mass balance methods involve the application of conservation equations to a facility, process, or piece of equipment. Emissions are determined from input/output differences as well as from the accumulation and depletion of substances. The engineering method involves the use of engineering principles and knowledge of chemical and physical processes (EnvCan, 2006). In Guler (2008) the method used to estimate emission factors considers only the total amount of fuel and electricity produced from power plants. The previous methodology does not take into consideration the offset cyclical relationship, daily and yearly, between electricity generated by renewable technologies. It should be noted that none of the methods mentioned above include seasonal/daily adjustments to annual emission factors. Specifically, the proposed research would include analyzing existing methods in calculating emission factors and attempt to estimate new emission factors based on the hourly electricity demand for the Province of Ontario.

In this Chapter, several GHG emission factor methodology was discussed and compared to newly developed monthly emission factors in order to realize the true $\mathrm{CO}_{2}$ reduction potential for small scale renewable energy technologies. The hourly greenhouse gas emission factors based on hour-by-hour demand of electricity in Ontario, and the average Greenhouse Gas Intensity Factor $\left(\mathrm{GHGIF}_{\mathrm{A}}\right)$ are estimated by creating a series of emission factors and their corresponding profiles that can be easily incorporated into simulation 
software (Gordon \& Fung, 2009). The use of regionally specific climate-modeled factors, such as those identified, allowed for a more accurate representation of the benefits associated with GHG reducing technologies, such as photovoltaic, wind, etc. This chapter will demonstrate that using Time Dependent Valuation (TDV) emission factors provide an upper limit while using hourly emission factors provide a lower limit. These factors based on hour-by-hour electricity demand data for the Province of Ontario will provide renewable technology researchers with the tools necessary to make informative decisions concerning the selection of renewable technologies.

\section{Traditional methodologies to estimate GHG emission factors from the electricity generation sector}

There are two main methods to estimate pollutant and GHG emission Factors from the electricity generation sector: 1) direct measurement or 2) estimation. Direct measurement is considered to be the most accurate since it uses real-time data from the generation sector. However, these data are not readily available and historically, GHG emissions have been estimated from fossil fuel and process-related activities. Estimation is the method used by several countries when preparing their national GHG inventories (ICPP, 1997). In the past, GHG emissions from the electricity generation sector were calculated using the Average GHG Intensity Factor $\left(\mathrm{GHGIF}_{\mathrm{A}}\right)$ (Guler et al., 2008). The $\mathrm{GHGIF}_{\mathrm{A}}$ is the amount of GHG emissions per $\mathrm{kWh}$ electricity produced. This method assumes that the reduction in electricity demand is uniformly distributed amongst all types of electricity generation. For example, the GHGIF A estimated in 1993 was $136 \mathrm{~g} / \mathrm{kWh}$ for the Province of Ontario. Table 1 shows the GHGIFA values for the years 2004, 2005, and 2006 for the Province of Ontario from the electricity generation sector (EnvCan, 2006).

\begin{tabular}{|c|c|c|}
\hline \multicolumn{3}{|c|}{ Annual GHGIF $\left(\mathrm{g}\right.$ of $\left.\mathrm{CO}_{2} / \mathbf{k W h}\right)$} \\
\hline $\mathbf{2 0 0 4}$ & $\mathbf{2 0 0 5}$ & $\mathbf{2 0 0 6}$ \\
\hline 200 & 221 & 189 \\
\hline
\end{tabular}

Table 1. Annual Emission Factors

The combustion of fossil fuels produces several major greenhouse gases. The amount of emissions from $\mathrm{CO}_{2}, \mathrm{CH}_{4}, \mathrm{SO}_{2}, \mathrm{NO}$, and $\mathrm{N}_{2} \mathrm{O}$ varies from one fuel to another, and they are calculated using emission factors. These emission factors are commonly expressed in tons of $\mathrm{CO}_{2}$ per MWh or grams per kWh of electricity produced (Gordon \& Fung, 2009).

\section{Accuracy of GHG emission factors}

It is necessary to develop methodology to accurately estimate GHG emissions from the electricity generation sector in order to facilitate the implementation of awareness programmes and renewable technologies which are supported with information on current energy usage. It should be noted that the time of use of electricity is related to GHG emissions generated throughout the day (MacCracken, 2006). Therefore, prior to implementing these programmes and renewable technologies, it is necessary to have an accurate model for emission and electricity estimation.

The Province of Ontario has a very unique mix of electricity production technologies. Hydro and nuclear technologies are generally considered to be base load power (IESO, 2006), since 
they both operate at constant load and fossil generating plants are typically used to handle fluctuations in electricity demand throughout the day. The $\mathrm{GHGIF}_{\mathrm{A}}$ estimate is based on the generation mix for the Province of Ontario (nuclear, hydro, coal, etc.) and is not adequate to account for most of the GHG emissions from the electricity generation sector, which mainly come from fossil generating stations. Therefore, in order to estimate and phase out fossil completely, a different emission factor needs to be developed. In response to this, a second intensity factor $\left(\mathrm{GHGIF}_{\mathrm{M}}\right)$ was developed. The $\mathrm{GHGIF}_{\mathrm{M}}$ intensity factor was calculated by dividing the net fossil fuel plant electricity production by the total equivalent $\mathrm{CO}_{2}$ emissions. The value estimated for 1993 was 903.7 t/GWh (Guler et al., 2008). This emission factor assumes that all electricity consumption is provided by fossil plants. This would be beneficial if trying to replace all fossil plants with renewable technologies. However, both of the methodologies neglect to show hourly changes in emission factors.

\section{GHG emission factor methodologies}

Renewable technologies (solar and wind) have become an accepted form of generating electricity and heat in the Province of Ontario. There are many advantages in using solar and wind energy such as taking advantage of an abundant source of free energy (sun and wind), as well as being an effective method in reducing GHG emissions. However, the electricity produced by a renewable technology, such as a photovoltaic (PV), or micro-wind turbine and the availability of solar and wind energy, changes throughout the day. Therefore, an hourly GHG emission factor is needed to truly understand the impact that renewable technologies have on emissions since there is a divergence between when electricity can be generated and when it is required.

Some of these renewable technologies that are being used in the residential and commercial sectors include photovoltaic, micro-wind turbines, ground source heat pumps, and advance solar thermal technologies. Continuous improvement of these technolgies have promoted the development of hybrid homes. The combination of several of these technologies together will result in end-use energy savings and GHG emission reductions. However, prior to implementing any of these technologies, it is necessary to have an accurate estimation of the true reduction potential of GHG emission factors in order to have a clear understanding of the saving potentials associated with renewable technologies.

Currently, Environment Canada uses fuel consumption data from the electricity sector in order to estimate emissions. However, this method can be simplistic and time consuming as well as difficult to use due to the unavailability of certain types of data. Moreover, this method only provides an annual average emission factor which does not reflect the cyclic behaviour of emission factors throughout the day. In 2005, Time Dependent Valuation (TDV) was introduced as a viable method to provide the aformentioned data (MacCracken, 2006). This method was adopted by California as an energy efficient standard for residential and non-residential buildings. Time dependent valuation views energy demand differently depending on the time of use (MacCracken, 2006). California has been able to determine the societal impacts of time of use energy consumption. As a result, this method of analysis would allow for a more accurate representation of the potential reduction of GHGs by using renewable technologies.

This following sections will discuss existing emission factor methodolgy and introduce monthly TDV emission factor methodology. 


\subsection{Hourly GHG emission factors}

Different emission factors have been developed in the past: hourly, seasonal, and seasonal time dependent emission factors (Gordon \& Fung, 2009). This chapter will introduce monthly TDV emission factors and compare them to existing emission factors. GHG emissions from the electricity generation industry have been calculated using the Average GHG Intensity Factor $\left(\mathrm{GHGIF}_{\mathrm{A}}\right)($ Guler et al., 2008). This value represents the amount of GHG emissions produced as a result of generating one kWh of electricity. The GHGIF for 2004, 2005, and 2006 were estimated using the methodology mentioned above in conjunction with the electricity output information from Gordon \& Fung (2009). It should be noted that the emission factor for $\mathrm{CO}_{2}$ does not take into consideration $\mathrm{CH}_{4}$ and $\mathrm{N}_{2} \mathrm{O}$ since these are considered to represent negligible amounts in comparison to $\mathrm{CO}_{2}, \mathrm{SO}_{2}$, and $\mathrm{NO}$ (Gordon \& Fung, 2009). This section will only focus on $\mathrm{CO}_{2}$ emissions since the majority of pollutants are in this form and the purpose of this chapter is to demonstrate emission factor methodology.

The GHG emissions due to coal fired and natural gas plants were determined using Equation 1 (Gordon \& Fung, 2009).

$$
\mathrm{HCO}_{2}=(\mathrm{HECOAL})(\mathrm{i})+(\mathrm{HEOTHER})(\mathrm{j})
$$

Where,

$\mathrm{HCO}_{2}=$ Hourly $\mathrm{CO}_{2}$ production $(\mathrm{kg})$

HECOAL = Hourly Electricity generated by Coal plants

HEOTHER = Hourly Electricity generated by Other (natural gas, etc.)

$\mathrm{i}=\mathrm{CO}_{2}$ emission factor (OPG, 2006)

$\mathrm{j}=$ Environment Canada natural gas emission factor (Environment Canada, 2006)

Currently, there is a hourly greenhouse gas emission factor $\left(\mathrm{NHGHGIF}_{\mathrm{A}}\right)$ model which is based on the hour-by-hour demand of electricity in Ontario from nuclear, fossil, hydro, natural gas and wind (Gordon \& Fung, 2009). The NHGHGIF $\mathrm{A}$ was calculated by dividing the hour-byhour emissions from $\mathrm{CO}_{2}$ by the hour-by-hour total electricity generated from the different sources (Gordon \& Fung, 2009). It should be noted that the new greenhouse gas intensity factor $\left(\mathrm{NGHGIF}_{\mathrm{A}}\right)$ was estimated by taking the average of the hourly emission factors for each season.

The NGHGIF A was determined using Equations 2 and 3 (Gordon \& Fung, 2009).

$$
\begin{gathered}
\text { NHGHGIF }_{\mathrm{A}}=\frac{\mathrm{HCO}_{2}}{\text { HEGTOTAL }} \\
\mathrm{NGHGIF}_{\mathrm{A}}=\sum_{\mathrm{i}=1}^{8760} \frac{\mathrm{NHGHGIF}_{\mathrm{Ai}}}{8760}
\end{gathered}
$$

Where,

NHGHGIF $_{\mathrm{A}}=$ New Hourly Greenhouse Gas Intensity Factor $\left(\mathrm{g} \mathrm{CO}_{2} / \mathrm{kWh}\right)$

$\mathrm{NGHGIF}_{\mathrm{A}}=$ New Greenhouse Gas Intensity Factor $\left(\mathrm{g} \mathrm{CO}_{2} / \mathrm{kWh}\right)$

$\mathrm{HCO}_{2}=$ Hourly $\mathrm{CO}_{2}$ production $(\mathrm{g})$

HEGTOTAL= Hourly Electricity Generated Total $(\mathrm{kWh})$

$\mathrm{i}=$ hour

The values obtained for the $\mathrm{NGHGIF}_{\mathrm{A}}$ were compared for the years 2004, 2005, and 2006 (Gordon \& Fung, 2009). 


\subsection{Seasonal time dependent valuation emission factors}

Currently, there are several TDV profiles (annual and seasonal) for greenhouse gases for the Province of Ontario in the public domain (Gordon \& Fung, 2009). As discussed in Gordon \& Fung (2009), the hourly GHG emissions data has been compiled to developed different types (annual and seasonal) of emission factors. The latter has shown that emission factors vary with electricity demand (MacCracken, 2006). It has also been observed that shape and magnitude of GHGIF profiles varies with time of day, year, climate, and geographical location (Gordon \& Fung, 2009). Hourly emission data does exist from the power generating sector, but is not publicly available. Therefore, rather than using a single annual GHGIF value for the entire year, seasonal GHGIF profiles based on the electricity demand for the Province of Ontario were developed by Gordon \& Fung (2009).

The approach detailed below was used in order to provide a better method to properly estimate greenhouse gases within the Province of Ontario. Hourly electricity consumption data from the IESO and hourly GHG emission factors estimated in the previous section were used to determine Seasonal TDV emission factor profiles for the years 2004, 2005, and 2006. These profiles were calculated using Equation 4 (Gordon \& Fung, 2009).

$$
\text { Seasonal TDV NGHGIF }=\frac{\sum_{\mathrm{i}=1}^{\mathrm{N}} \mathrm{NGHGIF}_{\mathrm{A}}\left(\mathrm{h}_{\mathrm{j}}\right)}{\mathrm{N}}
$$

Where,

Seasonal TDV $\mathrm{NGHGIF}_{\mathrm{A}}=$ Seasonal Time Dependent Valuation New Greenhouse Gas Intensity Factor $\left(\mathrm{g} \mathrm{CO}_{2} / \mathrm{kWh}\right)$

$\mathrm{N}=$ number of days in the season

$\mathrm{i}=$ day number

$\mathrm{j}=$ hour number

The hourly and averaged values obtained for the seasonal TDV NGHGIF were compared for the years 2004, 2005, and 2006.

\subsection{Monthly time dependent valuation emission factors}

Currently, there are several TDV profiles (annual and seasonal) for greenhouse gases for the Province of Ontario in the public domain (Gordon \& Fung, 2009). However, monthly GHG emission factors are not available. Therefore, this section will provide renewable technology professionals with monthly TDV profiles for estimating emissions.

The approach detailed below was used in order to provide a better method to properly estimate greenhouse gases within the Province of Ontario. Hourly electricity consumption data from the IESO and hourly GHG emission factors estimated in Section 4.1 were used to determine monthly TDV NGHGIF profiles for the years 2004, 2005, and 2006. These profiles were calculated using Equation 5 for each hour in a day.

$$
\text { Monthly TDV NGHGIF }=\frac{\sum_{\mathrm{i}=1}^{\mathrm{N}} \mathrm{NGHGIF}_{\mathrm{A}}\left(\mathrm{h}_{\mathrm{j}}\right)}{\mathrm{N}}
$$


Where,

Monthly TDV NGHGIF A Monthly Time Dependent Valuation New Greenhouse Gas Intensity Factor $\left(\mathrm{g} \mathrm{CO}_{2} / \mathrm{kWh}\right)$

$\mathrm{N}=$ number of days in the month

$\mathrm{i}=$ day number

$j=$ hour number

The hourly and average values obtained for the monthly TDV NGHGIF $_{\mathrm{A}}$ were compared for the years 2004, 2005, and 2006.

\section{Test case scenario}

The following test case provides an example on how the different GHG emission factors can be used to demonstrate the cyclic behaviour of emission factors througout the day, month, season, and year. In addtion, the test cases also show the beneficial attributes associated with renewable technologies.

Transient System Simulation Tool (TRANSYS) building energy simulation software can be used to perform highly complex thermal analysis, HVAC analysis and electrical power flow simulations.

Tse et al. (2008) performed simulations, using TRANSYS, which included the use of PV on the computational model for a townhouse that would be built in the Annex area in Toronto.

TRANSYS was used to simulate and help optimize the performance of the home, as well as the different systems that would be implemented. The systems that were analyzed consist of a solar domestic hot water system, a photovoltaic system $(6.25 \mathrm{~kW})$, and a ground source heat pump. Hourly annual simulations were run to demonstrate the potential electricity contribution and emission savings from PV. This data has been utilized in combination with the hourly, seasonal and monthly TDV emission factors discussed in the previous sections to estimate the reduction potential of GHG emissions by the use of PV technology.

\section{Results}

\subsection{Hourly GHG emission factors}

The results for the $\mathrm{NGHGIF}_{\mathrm{A}}$ for the years 2004, 2005, and 2006 are shown in Table 2 (Gordon \& Fung, 2009).

\begin{tabular}{|c|c|c|c|}
\hline \multirow{2}{*}{ Season } & \multicolumn{3}{|c|}{$\mathrm{NGHGIF}_{\mathrm{A}}\left(\mathrm{g}\right.$ of $\left.\mathrm{CO}_{2} / \mathrm{kWh}\right)$} \\
\hline & 2004 & 2005 & 2006 \\
\hline Annual & 208 & 221 & 189 \\
\hline Winter & 248 & 231 & 196 \\
\hline Spring & 164 & 205 & 164 \\
\hline Summer & 174 & 241 & 214 \\
\hline Fall & 244 & 205 & 190 \\
\hline
\end{tabular}

Table 2. Hourly annual and seasonal average GHG emission factors

Table 2 shows a large variance between emission factors throughout the year and from year to year. Clearly, the use of hourly data is necessary to accurately estimate the GHG reduction potential from renewable technologies. 


\subsection{Annual time dependent valuation emission factors}

Table A-1 in Appendix A shows the annual TDV emission factors (Gordon \& Fung, 2009). It can be observed that emissions throughout the day vary considerably. It should be noted that the maximum TDV values for the years 2004, 2005, and 2006 occurred at 1 p.m.

Table 3 shows the annual average TDV GHG emission factors. These values were obtained by using the annual TDV GHG emission factors in Table A-1 in Appendix A.

\begin{tabular}{|c|c|c|c|}
\hline \multirow{2}{*}{} & \multicolumn{3}{|c|}{$\mathbf{N G H G I F}_{\mathbf{A}}$ (g of $\left.\mathrm{CO}_{2} / \mathbf{k W h}\right)$} \\
\cline { 2 - 4 } & $\mathbf{2 0 0 4}$ & $\mathbf{2 0 0 5}$ & $\mathbf{2 0 0 6}$ \\
\hline Annual & 224.2 & 237.3 & 207.2 \\
\hline
\end{tabular}

Table 3. Annual average TDV GHG emission factors

\subsection{Seasonal time dependent valuation emission factors}

Seasonal TDV emission factors were also developed for the years 2004, 2005, and 2006 (Gordon \& Fung, 2009) as shown in Table 4. Table A-2 and A-3 in Appendix A show the seasonal TDV emission factor profiles for 2004, 2005, and 2006. The following can be observed from Table 4:

- For the year 2004 - the highest emission factors were in the fall (afternoons) and winter (early mornings).

- For the years 2005 and 2006 the highest emission factor was observed in the summer.

\begin{tabular}{|c|c|c|c|}
\hline \multirow{2}{*}{ Season } & \multicolumn{3}{|c|}{$\mathbf{N G H G I F}_{\mathbf{A}} \mathbf{( g}$ of $\left.\mathbf{C O}_{2} / \mathbf{k W h}\right)$} \\
\cline { 2 - 4 } & $\mathbf{2 0 0 4}$ & $\mathbf{2 0 0 5}$ & $\mathbf{2 0 0 6}$ \\
\hline Winter & 264.7 & 246.4 & 213.4 \\
\hline Spring & 182.0 & 221.5 & 179.9 \\
\hline Summer & 190.1 & 256.6 & 229.5 \\
\hline Fall & 259.8 & 224.8 & 206.1 \\
\hline
\end{tabular}

Table 4. seasonal average TDV GHG emission factors

\subsection{Monthly time dependent valuation emission factors}

Monthly TDV emission factors were developed for the years 2004, 2005, and 2006 as shown in Table 5. Table A-4 in Appendix A shows the monthly TDV emission factor profiles for 2004, 2005, and 2006. The following can be observed from Table 4:

- For the year 2004 - the highest and lowest emission factor was observed in January and May, respectively.

- For the year 2005 - the highest and lowest emission factor was observed in August and May, respectively.

- For the year 2005 - the highest and lowest emission factor was observed in July and April, respectively.

This section discussed the different types of existing and new GHG emission factors for the years 2004, 2005, and 2006. The hourly emission factor proved to be the most accurate and monthly TDV were more accurate than using the seasonal average value.

However, it is the user's responsability to select the appropiate emission factor depending on the type of analysis conducted. In certain cases it might be more practical to employ seasonal, time dependent valuation (seasonal or monthly), or annual average emission factors to estimate $\mathrm{CO}_{2}$ emissions without sacrificing much accuracy. 


\begin{tabular}{|c|c|c|c|}
\hline \multirow{2}{*}{ Season } & \multicolumn{3}{|c|}{$\mathrm{NGHGIF}_{\mathrm{A}}\left(\mathrm{g}\right.$ of $\left.\mathrm{CO}_{2} / \mathrm{kWh}\right)$} \\
\hline & 2004 & 2005 & 2006 \\
\hline January & 284.3 & 242.2 & 215.1 \\
\hline February & 259.3 & 228.9 & 198.8 \\
\hline March & 214.5 & 230.4 & 180.8 \\
\hline April & 171.3 & 209.6 & 125.5 \\
\hline May & 144.0 & 183.2 & 164.8 \\
\hline June & 156.0 & 238.7 & 216.9 \\
\hline July & 166.4 & 236.8 & 233.9 \\
\hline August & 179.4 & 245.4 & 205.3 \\
\hline September & 210.9 & 222.1 & 188.0 \\
\hline October & 265.0 & 206.0 & 193.6 \\
\hline November & 242.4 & 192.9 & 191.1 \\
\hline December & 199.9 & 214.3 & 155.4 \\
\hline
\end{tabular}

Table 5. Monthly TDV average GHG emission factors

\subsection{Test case study}

The electricity generated by the PV simulations performed for 2005 is illustrated in Figure 1 (Tse et al., 2008). It can be observed that PV electricity generation was the highest during the summer.

Table 6 shows the total electric power generated by PV for year 2005 using the test case townhouse located in the Annex part of Toronto (Tse et al., 2008).

\begin{tabular}{|c|}
\hline Photovoltaic \\
\hline Electricity Generated $(\mathrm{kWh})$ \\
\hline 7767 \\
\hline
\end{tabular}

Table 6. Total electricity generated by PV for test case study

Figure 1 shows the total monthly electric power generated by the PV system for the year 2005. Electricity generation was the highest during July and throughout the summer. 


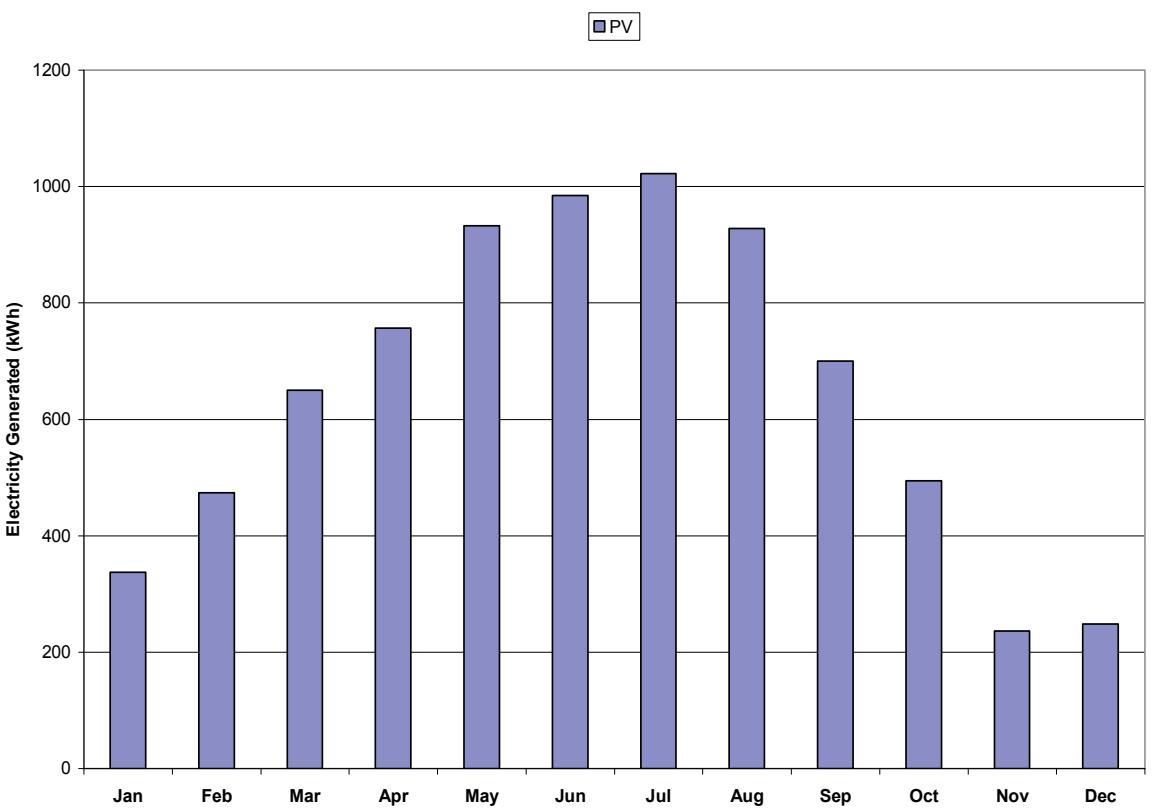

Fig. 1. Monthly electricity generated by PV for test-case study

In order to calculate the $\mathrm{CO}_{2}$ emission reduction potential by PV, the hourly electricity data was multiplied by the different emission factors as defined in Equations 6, 7, 8, 9 (Gordon \& Fung, 2009), and 10.

$$
\mathrm{GHG}_{\mathrm{el}, \mathrm{HNGHGIF}_{\mathrm{A}}}=\sum\left[\left(\text { Generated }_{\mathrm{el}, \text { hourly }}\right)\left(\mathrm{NHGHGIF}_{\mathrm{A}}\right)\right]
$$

Where,

$\mathrm{GHG}_{\mathrm{el}, \mathrm{HNGHGIF}}=$ Annual GHG emission reduction using the new hourly emission factor (g of $\mathrm{CO}_{2}$ )

Generated $_{\mathrm{el} \text {,hourly }}=$ Hourly electricity generated by renewable technology for test case house (kWh)

$\mathrm{NHGHGIF}_{\mathrm{A}}=$ New Hourly Greenhouse Gas Intensity Factor $\left(\mathrm{g} \mathrm{CO}_{2} / \mathrm{kWh}\right)$

$$
\mathrm{GHG}_{\mathrm{el}, \mathrm{SANGHGIF}_{\mathrm{A}}}=\sum\left[\left(\text { Generated }_{\text {el, hourly }}\right)\left(\mathrm{SANGHGIF}_{\mathrm{A}}\right)\right]
$$

Where,

$\mathrm{GHG}_{\mathrm{el}, \mathrm{SANGHGIF}_{\mathrm{A}}}=$ Annual GHG emission reductions using the seasonal average emission factor ( $\mathrm{g}$ of $\mathrm{CO}_{2}$ )

Generated $_{\mathrm{el} \text {,hourly }}=$ Hourly electricity generated by renewable technology for test case house $(\mathrm{kWh})$

SANGHGIF $_{\mathrm{A}}=$ Seasonal Average New Greenhouse Gas Intensity Factor $\left(\mathrm{g} \mathrm{CO}_{2} / \mathrm{kWh}\right)$

$$
\mathrm{GHG}_{\mathrm{el}, \mathrm{AANGHGIF}_{\mathrm{A}}}=\sum\left[\left(\text { Generated }_{\mathrm{el}, \text { hourly }}\right)\left(\mathrm{AANGHGIF}_{\mathrm{A}}\right)\right]
$$


Where,

$\mathrm{GHG}_{\mathrm{el}, \mathrm{AANGHGIF}}=$ Annual GHG emission reductions using the annual average emission factor ( $\mathrm{g}$ of $\mathrm{CO}_{2}$ )

Generated $_{\mathrm{el} \text {,hourly }}=$ Hourly electricity generated by renewable technology for test case house $(\mathrm{kWh})$

AANGHGIF $_{\mathrm{A}}=$ Annual Average New Greenhouse Gas Intensity Factor $\left(\mathrm{g} \mathrm{CO}_{2} / \mathrm{kWh}\right)$

$$
\mathrm{GHG}_{\text {el, } \text { TDVNGHGIF }_{\mathrm{A}}}=\sum\left[\left(\text { Generated }_{\text {el, hourly }}\right)\left(\text { TDVNGHGIF }_{\mathrm{A}}\right)\right]
$$

Where,

$\mathrm{GHG}_{\mathrm{el}, \mathrm{TDVNGHGIF}_{\mathrm{A}}}=$ Annual GHG emission reductions using the seasonal time dependent valuation new greenhouse gas intensity factor $\left(\mathrm{g} \mathrm{CO}_{2} / \mathrm{kWh}\right)$

Generated $_{\mathrm{el} \text {,hourly }}=$ Hourly electricity generated by renewable technology for test case house (kWh)

TDVNGHGIF $_{\mathrm{A}}=$ Seasonal Time Dependent Valuation New Greenhouse Gas Intensity Factor $\left(\mathrm{g} \mathrm{CO}_{2} / \mathrm{kWh}\right)$

$$
\mathrm{GHG}_{\mathrm{el}, \mathrm{TDVNGHGIF}_{\mathrm{A}}}=\sum\left[\left(\text { Generated }_{\mathrm{el} \text {, hourly }}\right)\left(\text { TDVNGHGIF }_{\mathrm{A}}\right)\right]
$$

Where,

$\mathrm{GHG}_{\mathrm{el}, \mathrm{TDVNGHGIF}_{\mathrm{A}}}=$ Annual GHG emission reductions using the monthly time dependent valuation new greenhouse gas intensity factor $\left(\mathrm{g} \mathrm{CO}_{2} / \mathrm{kWh}\right)$

Generated $_{\mathrm{el} \text {,hourly }}=$ Hourly electricity generated by renewable technology for test case house (kWh)

TDVNGHGIF $_{\mathrm{A}}=$ Monthly Time Dependent Valuation New Greenhouse Gas Intensity Factor $\left(\mathrm{g} \mathrm{CO}_{2} / \mathrm{kWh}\right)$

Table 7 summarizes the total emission reduction results from PV by using the different emission factors. The upper and lower limits of $\mathrm{CO}_{2}$ reductions were obtained by using the seasonal TDV and annual average emission factors, respectively. It should be noted that the new monthly TDV emission factors resulted in an emission reduction potential very close to that of using hourly emission factors.

\begin{tabular}{|c|c|c|}
\hline Emission Factor Type & $\begin{array}{c}\text { Emission Reduction } \\
\text { Potential (kg of } \mathbf{C O}_{\mathbf{2}} \text { ) }\end{array}$ & \% Difference \\
\hline Hourly & 1856 & -6.97 \\
\hline Seasonal Average & 1727 & -7.54 \\
\hline Annual Average & 1716 & 6.36 \\
\hline Seasonal TDV & 1974 & -0.12 \\
\hline Monthly TDV & 1854 & \\
\hline
\end{tabular}

Table 7. Emission reduction potential comparison for test case study 
The total monthly emission reduction potential by PV is shown in Figure 2. During June and July the emission reductions were the highest and in November, the lowest.

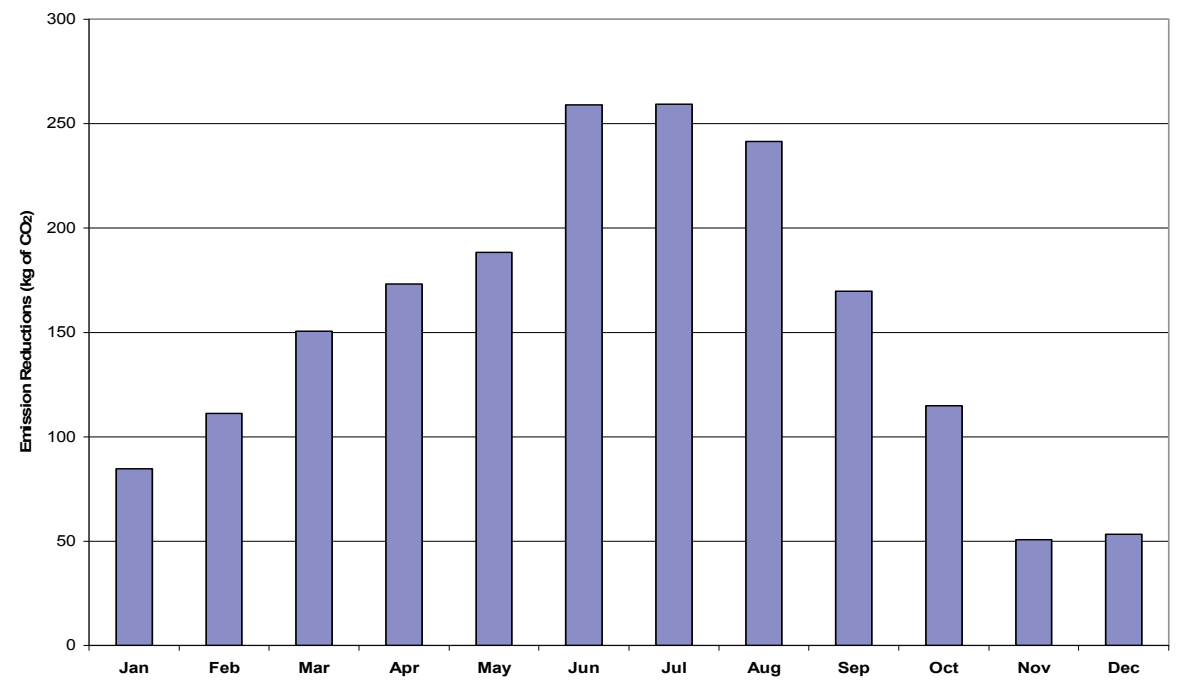

Fig. 2. Monthly emission reductions for PV test case study

\section{Conclusion}

Several emission factors were developed for the years 2004, 2005, and 2006. The hourly emission factor proved to be the most accurate. In addition, depending on the type of analysis conducted it might be practical but not as accurate to employ seasonal, time dependent valuation, or annual averages emission factors to estimate $\mathrm{CO}_{2}$ emissions. It was observed that TDV and seasonal average emission factors were more accurate than using the annual average value. It should also be mentioned, that monthly TDV emission factors proved to be as accurate as using hourly values. The use of hourly emission factors to accurately estimate the potential reduction of renewable technologies should be incorporated in all renewable technology assesments.

\section{Recommendations}

This chapter discussed the use of hourly, seasonal, monthly and annual emission factors in order to demonstrate the daily fluctuations from the electricity generation sector. In the future, peak, weekly and marginal emission factors could be developed in order to increase the accuracy of emission estimations. In addition, emission factors could be updated every year in order to allign with current renewable technology analysis models and electricity generation mix. 
9. Appendix A

\begin{tabular}{|c|c|c|c|}
\hline \multicolumn{4}{|c|}{ Annual } \\
\hline \multicolumn{4}{|c|}{ TDV NGHGIF $_{\text {A }}(\mathrm{g}$ of $\mathrm{CO} 2 / \mathrm{kWh})$} \\
\hline Hour & 2004 & 2005 & 2006 \\
\hline 1 & 185.9 & 219.7 & 181.2 \\
\hline 2 & 179.2 & 213.3 & 170.5 \\
\hline 3 & 173.6 & 206.2 & 161.5 \\
\hline 4 & 171.6 & 203.9 & 159.4 \\
\hline 5 & 177.1 & 209.1 & 167.9 \\
\hline 6 & 192.5 & 216.8 & 178.3 \\
\hline 7 & 210.7 & 223.7 & 191.5 \\
\hline 8 & 227.8 & 236.7 & 209.1 \\
\hline 9 & 237.0 & 244.2 & 218.3 \\
\hline 10 & 243.6 & 248.5 & 223.1 \\
\hline 11 & 248.1 & 251.5 & 227.3 \\
\hline 12 & 251.1 & 253.6 & 229.5 \\
\hline 13 & 253.0 & 255.6 & 229.9 \\
\hline 14 & 252.0 & 255.2 & 228.7 \\
\hline 15 & 249.7 & 252.9 & 225.4 \\
\hline 16 & 248.4 & 249.3 & 223.3 \\
\hline 17 & 247.8 & 248.3 & 223.7 \\
\hline 18 & 246.5 & 249.6 & 224.9 \\
\hline 19 & 244.3 & 248.6 & 225.5 \\
\hline 20 & 246.6 & 249.0 & 228.1 \\
\hline 21 & 246.9 & 252.1 & 228.0 \\
\hline 22 & 236.4 & 247.3 & 219.5 \\
\hline 23 & 215.2 & 235.0 & 207.0 \\
\hline 24 & 195.0 & 226.0 & 191.4 \\
\hline
\end{tabular}

Table A-1. Annual TDV emission factor comparison for 2004-2006 


\begin{tabular}{|c|c|c|c|c|c|c|c|}
\hline \multicolumn{4}{|c|}{ Winter } & \multicolumn{4}{|c|}{ Spring } \\
\hline \multicolumn{4}{|c|}{ TDV NGHGIF $_{A}(\mathrm{~g}$ of CO $2 / \mathrm{kWh})$} & \multicolumn{4}{|c|}{ TDV NGHGIF $_{\mathrm{A}}(\mathrm{g}$ of $\mathrm{CO} 2 / \mathrm{kWh})$} \\
\hline Hour & 2004 & 2005 & 2006 & Hour & 2004 & 2005 & 2006 \\
\hline 1 & 254.9 & 241.8 & 200.7 & 1 & 133.3 & 192.3 & 147.0 \\
\hline 2 & 254.8 & 234.8 & 191.4 & 2 & 129.1 & 188.5 & 138.9 \\
\hline 3 & 252.9 & 229.3 & 183.1 & 3 & 126.6 & 180.0 & 132.9 \\
\hline 4 & 250.9 & 226.8 & 179.8 & 4 & 125.6 & 179.0 & 130.8 \\
\hline 5 & 252.4 & 227.5 & 183.8 & 5 & 130.7 & 186.8 & 140.2 \\
\hline 6 & 255.3 & 231.9 & 186.5 & 6 & 148.2 & 201.2 & 153.0 \\
\hline 7 & 258.8 & 234.7 & 196.6 & 7 & 171.0 & 213.2 & 171.3 \\
\hline 8 & 262.5 & 240.9 & 208.5 & 8 & 192.4 & 228.5 & 189.7 \\
\hline 9 & 265.6 & 247.1 & 216.3 & 9 & 203.0 & 234.2 & 194.5 \\
\hline 10 & 266.8 & 250.5 & 219.7 & 10 & 208.7 & 237.0 & 198.7 \\
\hline 11 & 268.8 & 253.1 & 225.7 & 11 & 213.2 & 239.8 & 202.8 \\
\hline 12 & 270.9 & 254.8 & 228.5 & 12 & 214.8 & 241.8 & 204.5 \\
\hline 13 & 272.8 & 256.5 & 229.0 & 13 & 215.5 & 244.3 & 204.4 \\
\hline 14 & 272.8 & 256.5 & 227.8 & 14 & 215.2 & 244.1 & 203.4 \\
\hline 15 & 271.3 & 252.8 & 224.8 & 15 & 212.3 & 242.0 & 201.3 \\
\hline 16 & 268.8 & 246.5 & 219.2 & 16 & 212.4 & 240.8 & 200.7 \\
\hline 17 & 268.6 & 244.9 & 218.8 & 17 & 212.4 & 240.5 & 201.1 \\
\hline 18 & 270.9 & 250.3 & 224.4 & 18 & 205.0 & 234.4 & 195.9 \\
\hline 19 & 274.6 & 257.5 & 233.3 & 19 & 198.5 & 224.8 & 190.5 \\
\hline 20 & 273.4 & 258.5 & 235.3 & 20 & 204.2 & 228.6 & 198.7 \\
\hline 21 & 273.3 & 260.1 & 234.2 & 21 & 206.5 & 238.3 & 203.1 \\
\hline 22 & 271.4 & 259.2 & 229.1 & 22 & 190.3 & 231.9 & 187.3 \\
\hline 23 & 265.4 & 253.5 & 217.6 & 23 & 161.5 & 218.2 & 170.4 \\
\hline 24 & 255.3 & 243.3 & 207.8 & 24 & 138.8 & 206.0 & 155.6 \\
\hline
\end{tabular}

Table A-2. Seasonal TDV GHG Emission Factors for Winter and Spring 


\begin{tabular}{|c|c|c|c|c|c|c|c|}
\hline \multicolumn{4}{|c|}{ Summer } & \multicolumn{4}{|c|}{ Fall } \\
\hline \multicolumn{4}{|c|}{ TDV NGHGIFA (g of CO2/kWh) } & \multicolumn{4}{|c|}{ TDV NGHGIFA (g of CO2/kWh) } \\
\hline Hour & 2004 & 2005 & 2006 & Hour & 2004 & 2005 & 2006 \\
\hline 1 & 129.4 & 244.9 & 199.8 & 1 & 226.1 & 199.9 & 177.2 \\
\hline 2 & 119.8 & 236.6 & 186.5 & 2 & 213.2 & 193.4 & 165.1 \\
\hline 3 & 112.5 & 227.6 & 175.2 & 3 & 202.5 & 187.9 & 154.8 \\
\hline 4 & 109.9 & 224.1 & 173.2 & 4 & 200.2 & 185.7 & 153.8 \\
\hline 5 & 114.3 & 225.6 & 181.9 & 5 & 210.9 & 196.5 & 165.8 \\
\hline 6 & 134.7 & 229.1 & 189.5 & 6 & 231.7 & 205.0 & 184.0 \\
\hline 7 & 159.5 & 232.4 & 202.1 & 7 & 253.4 & 214.3 & 196.0 \\
\hline 8 & 187.5 & 251.1 & 227.3 & 8 & 268.7 & 226.4 & 211.0 \\
\hline 9 & 205.0 & 262.4 & 243.1 & 9 & 274.5 & 233.2 & 219.4 \\
\hline 10 & 220.1 & 268.1 & 250.7 & 10 & 278.8 & 238.4 & 223.4 \\
\hline 11 & 228.3 & 270.4 & 254.0 & 11 & 282.2 & 242.6 & 226.6 \\
\hline 12 & 234.5 & 273.4 & 256.3 & 12 & 284.2 & 244.4 & 228.5 \\
\hline 13 & 237.8 & 276.7 & 256.3 & 13 & 285.7 & 245.0 & 230.0 \\
\hline 14 & 236.6 & 276.4 & 254.6 & 14 & 283.5 & 243.8 & 229.1 \\
\hline 15 & 234.1 & 275.3 & 251.0 & 15 & 281.3 & 241.3 & 224.5 \\
\hline 16 & 234.7 & 273.5 & 251.3 & 16 & 277.4 & 236.3 & 221.8 \\
\hline 17 & 234.4 & 272.4 & 252.9 & 17 & 275.9 & 235.4 & 221.8 \\
\hline 18 & 228.5 & 272.1 & 252.0 & 18 & 281.7 & 241.4 & 227.3 \\
\hline 19 & 218.7 & 267.5 & 248.3 & 19 & 285.5 & 244.4 & 229.8 \\
\hline 20 & 223.3 & 267.3 & 251.3 & 20 & 285.4 & 241.8 & 227.1 \\
\hline 21 & 226.3 & 269.8 & 252.6 & 21 & 281.5 & 240.2 & 222.2 \\
\hline 22 & 209.7 & 264.3 & 245.7 & 22 & 274.0 & 233.9 & 216.1 \\
\hline 23 & 176.2 & 249.8 & 236.9 & 23 & 257.9 & 218.4 & 202.9 \\
\hline 24 & 146.7 & 248.7 & 214.9 & 24 & 239.2 & 206.1 & 187.5 \\
\hline
\end{tabular}

Table A-3. Seasonal TDV GHG Emission Factors for Summer and Fall 


\begin{tabular}{|c|c|c|c|c|c|c|c|}
\hline \multicolumn{4}{|c|}{ January } & \multicolumn{4}{|c|}{ February } \\
\hline \multicolumn{4}{|c|}{ TDV NGHGIFA (g of CO2/kWh) } & \multicolumn{4}{|c|}{ TDV NGHGIF $_{\text {A }}(\mathrm{g}$ of $\mathrm{CO} 2 / \mathrm{kWh})$} \\
\hline Hour & 2004 & 2005 & 2006 & Hour & 2004 & 2005 & 2006 \\
\hline 1 & 282.1 & 229.9 & 195.4 & 1 & 254.4 & 221.2 & 183.0 \\
\hline 2 & 288.0 & 226.7 & 184.4 & 2 & 251.0 & 210.6 & 174.1 \\
\hline 3 & 286.6 & 224.6 & 174.3 & 3 & 248.6 & 203.0 & 168.0 \\
\hline 4 & 285.0 & 221.4 & 169.0 & 4 & 245.2 & 201.2 & 165.5 \\
\hline 5 & 283.9 & 221.2 & 172.5 & 5 & 252.0 & 203.9 & 169.8 \\
\hline 6 & 283.1 & 222.6 & 177.0 & 6 & 256.5 & 212.1 & 173.6 \\
\hline 7 & 279.3 & 223.0 & 190.0 & 7 & 258.5 & 220.0 & 184.0 \\
\hline 8 & 278.0 & 231.9 & 210.2 & 8 & 260.3 & 228.9 & 196.5 \\
\hline 9 & 280.2 & 241.9 & 221.7 & 9 & 263.7 & 234.0 & 203.7 \\
\hline 10 & 280.1 & 244.0 & 222.7 & 10 & 264.0 & 236.1 & 207.3 \\
\hline 11 & 280.5 & 248.4 & 228.0 & 11 & 264.7 & 238.4 & 214.9 \\
\hline 12 & 282.2 & 251.1 & 232.1 & 12 & 264.6 & 238.5 & 216.3 \\
\hline 13 & 285.4 & 253.7 & 233.7 & 13 & 266.6 & 241.0 & 215.2 \\
\hline 14 & 286.5 & 256.6 & 235.2 & 14 & 268.1 & 239.9 & 213.4 \\
\hline 15 & 287.0 & 251.7 & 233.9 & 15 & 265.6 & 236.0 & 209.5 \\
\hline 16 & 285.8 & 246.0 & 224.5 & 16 & 260.5 & 230.3 & 206.3 \\
\hline 17 & 283.3 & 245.4 & 224.5 & 17 & 258.3 & 228.4 & 205.0 \\
\hline 18 & 284.5 & 251.8 & 233.5 & 18 & 257.9 & 231.6 & 205.4 \\
\hline 19 & 289.6 & 258.7 & 244.5 & 19 & 262.6 & 240.9 & 219.0 \\
\hline 20 & 287.5 & 257.2 & 241.6 & 20 & 264.6 & 246.0 & 223.2 \\
\hline 21 & 287.9 & 258.7 & 240.7 & 21 & 265.2 & 246.5 & 220.7 \\
\hline 22 & 287.7 & 256.9 & 236.7 & 22 & 264.2 & 244.6 & 213.9 \\
\hline 23 & 286.4 & 249.9 & 227.9 & 23 & 257.5 & 238.6 & 195.6 \\
\hline 24 & 281.4 & 238.9 & 208.7 & 24 & 248.1 & 222.3 & 187.1 \\
\hline \multicolumn{4}{|c|}{ March } & \multicolumn{4}{|c|}{ April } \\
\hline \multicolumn{4}{|c|}{ TDV NGHGIF $_{\text {A }}(\mathrm{g}$ of CO2/kWh) } & \multicolumn{4}{|c|}{ TDV NGHGIF $_{\text {( }}(\mathrm{g}$ of $\mathrm{CO} 2 / \mathrm{kWh})$} \\
\hline Hour & 2004 & 2005 & 2006 & Hour & 2004 & 2005 & 2006 \\
\hline 1 & 191.2 & 228.4 & 172.8 & 1 & 116.9 & 177.5 & 79.7 \\
\hline 2 & 189.0 & 223.7 & 164.0 & 2 & 115.1 & 175.7 & 74.9 \\
\hline 3 & 187.4 & 217.9 & 153.9 & 3 & 114.6 & 167.2 & 73.7 \\
\hline 4 & 185.6 & 215.7 & 150.9 & 4 & 115.6 & 167.9 & 76.1 \\
\hline 5 & 184.9 & 218.5 & 155.3 & 5 & 124.2 & 176.9 & 82.3 \\
\hline 6 & 192.3 & 225.1 & 158.6 & 6 & 147.0 & 197.9 & 99.0 \\
\hline 7 & 205.3 & 227.6 & 170.8 & 7 & 168.2 & 207.5 & 121.3 \\
\hline 8 & 218.1 & 227.8 & 179.1 & 8 & 188.0 & 219.8 & 138.7 \\
\hline 9 & 224.8 & 233.2 & 185.2 & 9 & 196.1 & 224.8 & 144.1 \\
\hline 10 & 225.1 & 235.3 & 188.7 & 10 & 201.3 & 229.1 & 151.5 \\
\hline 11 & 227.2 & 236.3 & 192.2 & 11 & 204.2 & 230.6 & 155.4 \\
\hline 12 & 230.4 & 239.7 & 193.6 & 12 & 204.1 & 230.7 & 157.4 \\
\hline 13 & 230.2 & 241.5 & 194.1 & 13 & 204.5 & 232.4 & 155.7 \\
\hline 14 & 231.8 & 240.3 & 193.4 & 14 & 203.8 & 230.9 & 153.3 \\
\hline 15 & 229.0 & 237.5 & 193.2 & 15 & 201.8 & 229.9 & 149.3 \\
\hline 16 & 228.5 & 233.3 & 189.2 & 16 & 199.9 & 231.1 & 148.0 \\
\hline 17 & 228.2 & 231.5 & 187.9 & 17 & 197.9 & 229.9 & 146.4 \\
\hline 18 & 225.8 & 229.9 & 185.2 & 18 & 189.2 & 221.8 & 139.5 \\
\hline 19 & 225.4 & 226.2 & 183.8 & 19 & 183.2 & 211.1 & 134.5 \\
\hline 20 & 228.9 & 229.9 & 196.4 & 20 & 196.0 & 219.0 & 150.9 \\
\hline 21 & 229.1 & 232.8 & 198.1 & 21 & 198.1 & 227.1 & 155.8 \\
\hline 22 & 223.2 & 235.2 & 193.4 & 22 & 176.1 & 213.8 & 129.5 \\
\hline 23 & 210.3 & 232.1 & 182.6 & 23 & 145.9 & 197.9 & 105.1 \\
\hline 24 & 195.7 & 230.3 & 176.9 & 24 & 120.4 & 180.0 & 89.4 \\
\hline
\end{tabular}

Table A-4. Monthly TDV GHG Emission Factors for the years 2004, 2005, and 2006 


\begin{tabular}{|c|c|c|c|c|c|c|c|}
\hline \multicolumn{4}{|c|}{ May } & \multicolumn{4}{|c|}{ June } \\
\hline \multicolumn{4}{|c|}{ TDV NGHGIF $_{\text {A }}(\mathrm{g}$ of $\mathrm{CO} 2 / \mathrm{kWh})$} & \multicolumn{4}{|c|}{ TDV NGHGIFA (g of CO2/kWh) } \\
\hline Hour & 2004 & 2005 & 2006 & Hour & 2004 & 2005 & 2006 \\
\hline 1 & 87.4 & 147.5 & 129.1 & 1 & 106.4 & 215.9 & 194.7 \\
\hline 2 & 80.3 & 143.0 & 123.9 & 2 & 102.3 & 208.1 & 181.1 \\
\hline 3 & 78.8 & 134.0 & 117.5 & 3 & 94.5 & 197.4 & 169.5 \\
\hline 4 & 78.1 & 135.9 & 115.5 & 4 & 91.3 & 191.1 & 161.9 \\
\hline 5 & 83.8 & 146.6 & 130.6 & 5 & 93.5 & 194.7 & 168.9 \\
\hline 6 & 101.9 & 163.8 & 142.3 & 6 & 110.6 & 199.7 & 180.1 \\
\hline 7 & 132.0 & 175.9 & 158.1 & 7 & 134.9 & 216.6 & 201.0 \\
\hline 8 & 156.6 & 192.7 & 176.8 & 8 & 158.2 & 241.7 & 223.1 \\
\hline 9 & 168.1 & 197.1 & 180.4 & 9 & 173.1 & 251.5 & 227.5 \\
\hline 10 & 175.3 & 199.1 & 181.8 & 10 & 184.3 & 254.4 & 231.6 \\
\hline 11 & 180.8 & 202.9 & 185.2 & 11 & 190.5 & 257.7 & 235.8 \\
\hline 12 & 180.9 & 206.4 & 187.3 & 12 & 196.1 & 259.4 & 238.7 \\
\hline 13 & 182.1 & 209.0 & 188.0 & 13 & 198.2 & 261.1 & 239.0 \\
\hline 14 & 181.4 & 209.4 & 186.4 & 14 & 196.9 & 259.9 & 238.7 \\
\hline 15 & 178.7 & 208.2 & 184.2 & 15 & 193.6 & 257.3 & 237.1 \\
\hline 16 & 180.7 & 204.4 & 184.5 & 16 & 194.3 & 256.6 & 239.2 \\
\hline 17 & 180.8 & 203.6 & 187.1 & 17 & 193.9 & 256.6 & 241.7 \\
\hline 18 & 172.8 & 194.8 & 182.7 & 18 & 184.6 & 255.1 & 236.1 \\
\hline 19 & 164.8 & 185.5 & 178.2 & 19 & 175.6 & 250.0 & 230.5 \\
\hline 20 & 168.1 & 187.8 & 183.1 & 20 & 174.7 & 251.1 & 232.1 \\
\hline 21 & 170.5 & 201.4 & 186.0 & 21 & 177.6 & 259.1 & 236.3 \\
\hline 22 & 152.0 & 196.7 & 171.9 & 22 & 169.5 & 256.3 & 230.5 \\
\hline 23 & 120.8 & 181.8 & 154.6 & 23 & 137.7 & 241.7 & 224.1 \\
\hline 24 & 99.5 & 169.5 & 140.5 & 24 & 112.9 & 236.3 & 206.5 \\
\hline \multicolumn{4}{|c|}{ July } & \multicolumn{4}{|c|}{ August } \\
\hline \multicolumn{4}{|c|}{ TDV NGHGIF $_{\text {A }}(\mathrm{g}$ of $\mathrm{CO} 2 / \mathrm{kWh})$} & \multicolumn{4}{|c|}{ TDV NGHGIF $_{\mathrm{A}}(\mathrm{g}$ of $\mathrm{CO} 2 / \mathrm{kWh})$} \\
\hline Hour & 2004 & 2005 & 2006 & Hour & 2004 & 2005 & 2006 \\
\hline 1 & 108.1 & 227.5 & 213.4 & 1 & 123.7 & 236.7 & 174.9 \\
\hline 2 & 98.2 & 216.4 & 200.6 & 2 & 113.7 & 230.3 & 158.5 \\
\hline 3 & 92.8 & 207.3 & 188.6 & 3 & 106.1 & 220.2 & 146.9 \\
\hline 4 & 91.4 & 203.8 & 183.7 & 4 & 101.6 & 217.2 & 145.7 \\
\hline 5 & 96.7 & 203.2 & 187.5 & 5 & 103.7 & 219.0 & 156.9 \\
\hline 6 & 111.3 & 202.4 & 186.1 & 6 & 125.3 & 221.8 & 163.9 \\
\hline 7 & 131.4 & 204.0 & 197.0 & 7 & 146.6 & 221.5 & 173.8 \\
\hline 8 & 157.4 & 228.6 & 225.1 & 8 & 177.9 & 239.2 & 201.5 \\
\hline 9 & 175.8 & 244.3 & 243.1 & 9 & 195.5 & 247.5 & 218.4 \\
\hline 10 & 191.4 & 251.0 & 252.4 & 10 & 209.2 & 253.8 & 227.6 \\
\hline 11 & 201.6 & 251.0 & 257.0 & 11 & 216.3 & 257.3 & 230.3 \\
\hline 12 & 207.4 & 251.8 & 260.0 & 12 & 223.2 & 260.5 & 232.7 \\
\hline 13 & 212.0 & 255.7 & 260.3 & 13 & 226.9 & 264.1 & 233.5 \\
\hline 14 & 210.6 & 257.2 & 258.8 & 14 & 225.4 & 264.1 & 233.3 \\
\hline 15 & 209.1 & 256.2 & 255.6 & 15 & 221.9 & 262.0 & 229.2 \\
\hline 16 & 209.0 & 255.5 & 252.3 & 16 & 220.4 & 260.7 & 230.7 \\
\hline 17 & 210.3 & 255.5 & 252.5 & 17 & 218.8 & 259.2 & 233.2 \\
\hline 18 & 205.7 & 254.5 & 253.6 & 18 & 212.3 & 260.5 & 232.2 \\
\hline 19 & 196.0 & 251.2 & 250.3 & 19 & 201.2 & 255.7 & 228.8 \\
\hline 20 & 194.1 & 246.3 & 249.4 & 20 & 208.6 & 254.6 & 228.7 \\
\hline 21 & 199.4 & 248.3 & 253.0 & 21 & 219.5 & 261.2 & 232.5 \\
\hline 22 & 193.5 & 248.7 & 252.8 & 22 & 201.8 & 251.8 & 220.6 \\
\hline 23 & 159.8 & 235.0 & 248.2 & 23 & 167.3 & 232.4 & 209.7 \\
\hline 24 & 130.3 & 228.5 & 232.4 & 24 & 139.1 & 238.0 & 184.5 \\
\hline
\end{tabular}

Table A-4. (Continued) 


\begin{tabular}{|c|c|c|c|c|c|c|c|}
\hline \multicolumn{4}{|c|}{ September } & \multicolumn{4}{|c|}{ October } \\
\hline \multicolumn{4}{|c|}{ TDV NGHGIF $_{A}(\mathrm{~g}$ of $\mathrm{CO} 2 / \mathrm{kWh})$} & \multicolumn{4}{|c|}{ TDV NGHGIF $_{A}(\mathrm{~g}$ of $\mathrm{CO} 2 / \mathrm{kWh})$} \\
\hline Hour & 2004 & 2005 & 2006 & Hour & 2004 & 2005 & 2006 \\
\hline 1 & 137.1 & 195.8 & 138.8 & 1 & 207.5 & 159.8 & 144.3 \\
\hline 2 & 125.9 & 190.5 & 127.7 & 2 & 192.9 & 149.6 & 136.0 \\
\hline 3 & 116.4 & 184.4 & 118.3 & 3 & 182.2 & 142.8 & 127.4 \\
\hline 4 & 117.4 & 182.9 & 120.8 & 4 & 185.0 & 143.9 & 131.5 \\
\hline 5 & 129.8 & 191.0 & 138.8 & 5 & 205.8 & 165.5 & 154.0 \\
\hline 6 & 162.9 & 202.9 & 164.1 & 6 & 241.3 & 187.5 & 175.2 \\
\hline 7 & 199.0 & 212.5 & 183.0 & 7 & 274.1 & 203.7 & 189.4 \\
\hline 8 & 221.9 & 224.8 & 201.7 & 8 & 290.1 & 216.6 & 203.0 \\
\hline 9 & 229.7 & 232.4 & 215.0 & 9 & 290.6 & 223.7 & 210.3 \\
\hline 10 & 243.3 & 234.8 & 220.1 & 10 & 295.2 & 228.1 & 217.1 \\
\hline 11 & 250.6 & 238.4 & 222.1 & 11 & 298.7 & 232.1 & 221.7 \\
\hline 12 & 255.9 & 243.5 & 222.5 & 12 & 300.3 & 235.1 & 223.1 \\
\hline 13 & 257.0 & 245.6 & 222.0 & 13 & 303.1 & 234.4 & 222.5 \\
\hline 14 & 257.5 & 244.6 & 216.8 & 14 & 300.9 & 234.1 & 222.2 \\
\hline 15 & 255.8 & 245.0 & 212.9 & 15 & 296.7 & 233.6 & 220.3 \\
\hline 16 & 259.2 & 240.4 & 213.7 & 16 & 295.3 & 235.0 & 220.9 \\
\hline 17 & 260.5 & 239.0 & 214.2 & 17 & 294.9 & 233.9 & 219.1 \\
\hline 18 & 255.1 & 237.1 & 211.0 & 18 & 291.3 & 228.6 & 215.3 \\
\hline 19 & 248.3 & 231.7 & 209.0 & 19 & 294.0 & 228.9 & 219.0 \\
\hline 20 & 261.5 & 238.1 & 217.9 & 20 & 293.6 & 228.3 & 217.4 \\
\hline 21 & 251.5 & 235.1 & 209.2 & 21 & 286.7 & 224.2 & 209.9 \\
\hline 22 & 221.1 & 222.8 & 191.9 & 22 & 271.9 & 213.5 & 199.9 \\
\hline 23 & 187.7 & 212.2 & 172.8 & 23 & 244.6 & 189.7 & 185.0 \\
\hline 24 & 157.7 & 203.8 & 148.7 & 24 & 222.8 & 170.9 & 161.4 \\
\hline \multicolumn{4}{|c|}{ November } & \multicolumn{4}{|c|}{ December } \\
\hline \multicolumn{4}{|c|}{ TDV NGHGIF $_{A}(\mathrm{~g}$ of $\mathrm{CO} 2 / \mathrm{kWh})$} & \multicolumn{4}{|c|}{ TDV NGHGIF $_{\text {( }}(\mathrm{g}$ of $\mathrm{CO} 2 / \mathrm{kWh})$} \\
\hline Hour & 2004 & 2005 & 2006 & Hour & 2004 & 2005 & 2006 \\
\hline 1 & 232.7 & 175.2 & 176.0 & 1 & 192.7 & 218.3 & 141.8 \\
\hline 2 & 218.2 & 166.8 & 159.5 & 2 & 180.7 & 214.3 & 130.9 \\
\hline 3 & 205.8 & 160.7 & 148.2 & 3 & 171.5 & 210.8 & 122.6 \\
\hline 4 & 197.8 & 153.9 & 144.6 & 4 & 163.7 & 208.8 & 116.8 \\
\hline 5 & 200.6 & 156.0 & 148.3 & 5 & 164.8 & 213.3 & 118.3 \\
\hline 6 & 210.4 & 159.0 & 164.2 & 6 & 170.8 & 206.7 & 127.0 \\
\hline 7 & 223.4 & 172.8 & 173.6 & 7 & 180.8 & 199.6 & 134.5 \\
\hline 8 & 238.6 & 191.3 & 192.1 & 8 & 192.4 & 200.4 & 147.1 \\
\hline 9 & 248.8 & 197.9 & 201.4 & 9 & 201.9 & 207.1 & 156.3 \\
\hline 10 & 252.4 & 207.0 & 204.8 & 10 & 208.0 & 211.3 & 159.1 \\
\hline 11 & 254.8 & 213.3 & 207.8 & 11 & 211.7 & 215.8 & 163.8 \\
\hline 12 & 256.8 & 213.3 & 209.3 & 12 & 213.7 & 218.4 & 170.2 \\
\hline 13 & 258.7 & 214.5 & 211.9 & 13 & 214.8 & 219.7 & 171.9 \\
\hline 14 & 254.7 & 211.9 & 211.4 & 14 & 214.5 & 217.7 & 170.6 \\
\hline 15 & 257.0 & 206.6 & 205.6 & 15 & 209.7 & 213.7 & 164.5 \\
\hline 16 & 250.2 & 196.6 & 200.8 & 16 & 199.6 & 207.3 & 160.3 \\
\hline 17 & 246.3 & 197.0 & 199.9 & 17 & 197.7 & 206.4 & 164.8 \\
\hline 18 & 260.6 & 212.3 & 211.2 & 18 & 215.9 & 224.2 & 183.6 \\
\hline 19 & 266.6 & 219.4 & 213.0 & 19 & 222.8 & 227.2 & 185.3 \\
\hline 20 & 264.3 & 213.1 & 209.3 & 20 & 219.7 & 221.3 & 179.5 \\
\hline 21 & 262.9 & 212.8 & 207.3 & 21 & 220.4 & 222.5 & 176.9 \\
\hline 22 & 261.6 & 207.6 & 204.4 & 22 & 219.5 & 223.0 & 174.9 \\
\hline 23 & 255.0 & 191.3 & 195.4 & 23 & 213.2 & 218.2 & 161.8 \\
\hline 24 & 239.7 & 179.4 & 187.5 & 24 & 197.0 & 216.9 & 148.0 \\
\hline
\end{tabular}

Table A-4. (Continued) 


\section{References}

Environment Canada. (2006). Canada's National Greenhouse Gas Inventory, Retrieved from<http://www.ec.gc.ca/pdb/ghg/inventory_report/2006_report/ta9_7_eng.cfm>

Gordon, C., Fung, A.S. (2009). Hourly Emission Factors from the Electricity Generation Sector - A Tool for Analyzing the Impact of Renewable Technologies in Ontario. Canadian Society of Mechanical Engineers (CSME), Vol. 33, No. 1, (March, 2009), pp.105-118.

Guler, B., Ugursal, V.I., Fung, A.S, and Aydinalp, M. (2008). Technoeconomic Evaluation of Energy Efficiency Upgrade Retrofits on the Energy Consumption and Greenhouse Gas Emissions in the Canadian Housing Stock. International Journal of Environmental Technology and Management (IJETM), Vol. 9, No. 4, (2008), pp.434-444.

Intergovernmental Panel on Climate Change (IPCC). (1997). National Greenhouse Gas Inventory, Retrieved from

<http://www.ipcc.ch/publications_and_data/publications_and_data_reports. shtml >

MacCracken, M. (2006). California's Title 24 \& Cool Storage. ASHRAE Journal Vol. 48, (2006).

Ontario Power Generation. (2006). Sustainable Development Report (2004, 2005, 2006), Retrieved from< http://www.opg.com/safety/sustainable/index.asp >

Tse H., Fung A., Siddiqui O., Rad F. (2008). Simulation and Analysis of a Net-Zero Energy Townhome in Toronto, Proceedings of 3rd SBRN and SESCI 33rd Joint Conference, Fredericton, August and 2008. 


\title{
Photovoltaic Conversion: Outlook at the Crossroads Between Technological Challenges and Eco-Strategic Issues
}

\author{
Bouchra Bakhiyi ${ }^{1}$ and Joseph Zayed ${ }^{1,2}$ \\ ${ }^{1}$ Department of Environmental and Occupational Health, \\ Faculty of Medicine, University of Montreal \\ 2Institut de Recherche Robert-Sauvé en Santé et en Sécurité du Travail (IRSST),
}

Canada

\section{Introduction}

Photovoltaic (PV) conversion or the production of electricity directly through the use of solar energy (Fig. 1) is undoubtedly a promising source of renewable energy despite the negligible position it still holds in the global energy landscape, namely barely $0.2 \%$ of the global electricity produced in 2010 (European Photovoltaic Industry Association [EPIA], 2011a; British petroleum Global [BPG], 2011).

In fact, it is difficult not to take its breathtaking growth into consideration since the production of PV electricity increased from 1 TWh in 1999 to 50 TWh $(40 \mathrm{GW})$ in 2010, for an annual increase of 36\% with a spectacular leap of 50\% between 2009 and 2010 (Observ'ER, 2010; EPIA, 2011; BPG, 2011). Various hypotheses predict a global capacity between $131 \mathrm{GW}$ and 196 GW in 2015 (EPIA, 2011). In comparison, from 1999 to 2009, wind energy increased $29 \%$ whereas fossil energy only grew 3.7\% (Observ'ER, 2010).

Therefore, it is not surprising that the term "solar revolution" was already in use in the field of renewable energy as of 2006 (Bradford, 2006). However, although PV conversion is a credible and preferred candidate as a safe source of energy in the highly probable context of mixed energy and sustainable development, it remains marginal and there are legitimate questions concerning its development, which is still in the very early stages, particularly with respect to performance, production costs and competitiveness. It should be noted that fossil energies still satisfy $80 \%$ of the global demand for electricity (Observ'ER, 2010).

The purpose of this chapter is to assess both the performance of PV conversion, in economic and energetic terms, in a favourable global market and the intense research into the use of innovative technologies to improve performance. These assessments require an excursion into the life cycle of PV systems from the synthesis of semi-conductors to the use of the electricity generated, the storage of the energy and finally on to the dismantling and recycling of facilities.

The development of PV systems, from the design to the end of their life, is accompanied by environmental, health and safety concerns related to the expansive use of potentially toxic 
materials. Logically, the assessment of the life cycle of PV systems will raise concerns about their compatibility with the global approach of sustainable development in terms of ecological footprint, economic profitability and social acceptability. Social acceptability is even more fundamental in terms of the sustainability since the user should adopt a less traditional energy approach. Will solar energy, which is perceived as the future of renewable energies, be able to challenge of meeting the essential concepts of clean and green energy?

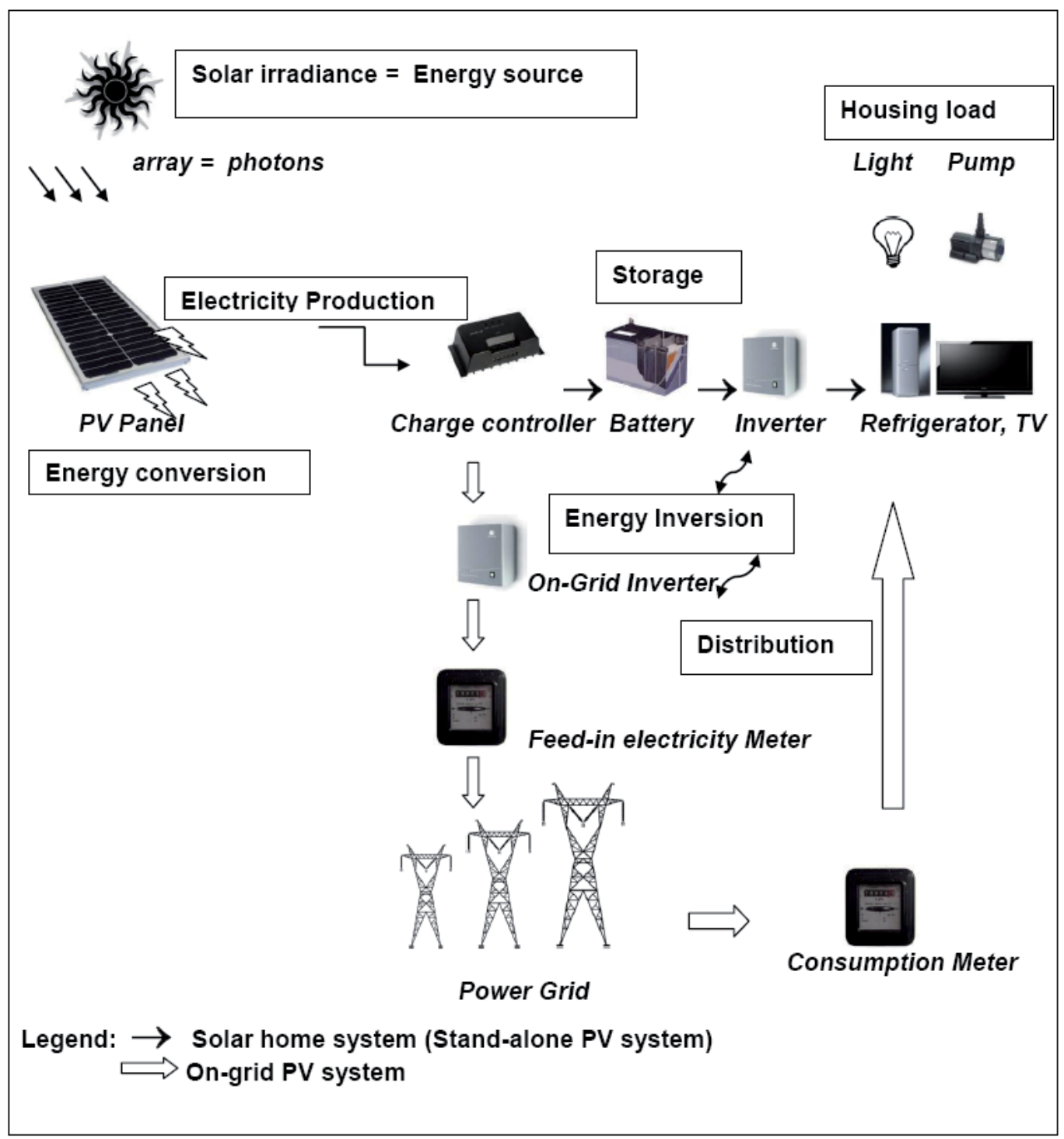

Fig. 1. Diagram of Photovoltaic Conversion and Practical applications 


\section{Genesis and context of solar energy use}

Although the history of solar energy dates back to the earliest days of humanity, its evolution has been extremely slow and laborious, swinging between euphoria, aborted attempts, total disinterest and re-birth. The first time this resource was used in prehistoric times, namely when the rays of the sun were captured and used to kindle flames, apparently took place in Mesopotamia, in the Arabic desert.

The ancient Greeks were the first to describe the famous "burning mirrors" or solar reflectors, the ancestors of parabolic mirrors, created with silver, copper or brass, which were used to light the Olympic flame (Butti \& Perlin, 1980). In addition, solar energy was used by the ancient Greeks in a passive form which had a major impact on the architecture of homes since, even in that distant time, deforestation was an issue, resulting in a shortage of charcoal as a result of the unchecked use of this fuel for heating and cooking.

The Roman Empire quickly adopted similar architectural habits since the Romans were also suffering from an over-consumption of charcoal. Outrageous taxes were even imposed for the domestic use of wood (Butti \& Perlin, 1980). In 1515, Leonardo da Vinci attempted to build a giant mirror, a primitive solar concentrator, intended to transform the rays of the sun into heat for commercial purposes (Butti \& Perlin, 1980; Lhomme, 2004). It would only be during the Industrial Revolution of the 19th century that the solar energy pioneers would emerge in a universe suddenly filled with scientific and technological effervescence in order to improve energy performance and eliminate dependency on wood and charcoal. However, these efforts, while praiseworthy and ingenious, were only partially successful.

One of the most brilliant and prolific of these pioneers was Augustin Mouchot, the French inventor of the first solar engine in 1880. Despite his scientific fervour and his obvious desire to demonstrate the potential of solar energy, he failed to draw France into the Solar Age (Butti \& Perlin, 1980). William Adams improved on Mouchot's prototype by installing a group of mirrors to boil the water to a faster way and doing his utmost to demonstrate the great potential of solar energy for the British Empire (Bradford, 2006). John Ericsson, invented the "caloric" engine in 1833, which used hot air as the operating fluid; this air was provided by a solar engine, thereby limiting energy losses (Butti \& Perlin, 1980; Bradford, 2006). These pioneers provided the basis of thermodynamic solar energy, by transforming the rays of the sun into energy.

In 1839, Edmond Becquerel first observed the PV reaction, which involves the creation of a spontaneous electrical current when a chain of conductive elements was lit. The first solar batteries, ancestors of modern solar cells, used selenium and were developed in 1883 by Charles Fritts. At that time, they had an efficiency of 0.2\% (Lhomne, 2004). In 1921, Albert Einstein explained the PV effect that earned him the Nobel Prize in physics. According to history, Einstein considered the description of the PV effect of greater value than the theory of relativity (Bradford, 2006).

Between 1900 and 1915, the first efforts were made to market thermodynamic solar energy. Aubrey Eneas built and sold two immense machines to be used as boilers; they were equipped with more than 1700 individual mirrors generating 2.5 steam horsepower. Unfortunately, a major storm and hailstorm overpowered his inventions and forced him to abandon any idea of pursuing this line of research as he concluded that his projects were not economically viable (Butti \& Perlin, 1980; Bradford, 2006). In 1912, Frank Shuman, one of the greatest visionaries in matters of solar energy, built a plant in Egypt that was strangely similar to modern solar power plants. Unfortunately, it was destroyed during the battles 
that took place in Northern Africa during World War I. Moreover, the advent of fossil fuels, with more affordable costs and better performances, ruined all efforts for the economic existence of solar energy for close to 50 years.

In 1954, the idea of solar energy was revitalized as a result of the efforts of Gerald Pearson, Calvin Fuller and Daryl Chapin, three researchers who developed the first silicon solar cells with an initial efficiency of $6 \%$ which soon increased to $14 \%$ (Singh, 1998). The first commercial applications started in 1958 but these cells were essentially used for space applications. Even though the terrestrial use of solar energy was slow, the scientists and the public were enthusiastic (Goetzberger \& Hoffman, 2005; Bradford, 2006; Krauter, 2006).

The development of solar PV systems was strongly influenced at the outset by the price of fossil fuels. Thus, the oil crisis of the 1970s and the sudden increase in the price of oil revealed the precariousness of fossil energy resources and encouraged the solar industry. As a result, the Solar Energies Research Institute was created in the USA and the first subsidies were granted, injecting three billion dollars. In 1979, solar panels were installed on the roofs of the White House, a gesture considered highly symbolic (Bradford, 2006). Thermodynamic solar energy, however, declined in the 1970s and 1980s, for the benefit of by PV energy (Vaille, 2009). At that time, the USA accounted for $80 \%$ of the solar market. However, when the price of oil once again declined in the 1980s and the early 1990s, the enthusiasm for solar energy dropped and the solar panels were removed from the White House. Nevertheless, research into PV technologies continued, but was less sustained (Bradford, 2006).

During the 1990s, the world became aware of the need to revise energy policies based on sustainable development and concerns about climate change. Obviously, these issues involved the consideration of the level of energy consumption as well as the environmental consequences (such as greenhouse gas emissions, GHG) and the precariousness of fossil resources (Bradford, 2006). Thus, more attention was paid to PV solar resources.

This time, Europe took the lead in this industry which was predestined to flourish. Thus, of the $40 \mathrm{GW}$ of solar electricity generated in 2010, $30 \mathrm{GW}$ were generated by the European Union, of which $17 \mathrm{GW}$ were produced by Germany. For the same year, Japan and the United States trailed behind with 3.6 GW and 2.5 GW respectively (EPIA, 2011).

The applications of PV are incredibly diverse at present, ranging from small to large, including solar calculators, irrigation pumps, the heating of single-family homes, and solar facilities (roofs, facades, etc.) connected to the power grid (Labouret \& Villoz, 2009; Bradford, 2006). PV systems are interesting because they can also be installed in zones that are completely devoid of electrical networks or energy infrastructures, particularly in certain developing countries where the isolated segments intended for rural electrification are experiencing a veritable boom (Singh, 1998). Current applications and future projections differ by region since socio-economic concerns are dissimilar. Thus, in the developed countries, future visions focus on the large-scale integration of PV energy in the urban environment. The idea of a city as a gigantic PV power plant is germinating in peoples' minds as they wait for a large-scale study on the potential environmental and social impacts (Gaidon et al., 2009). In the developing countries, PV energy provides added value and is becoming a symbol of progress and openness to the world, outside the outlying rural zones that could enjoy the benefits (Singh, 1998). 


\section{Solar radiation: Geophysical considerations and energy potential}

Located nearly 150 million $\mathrm{km}$ from Earth, the Sun is a huge nuclear power plant - the oldest in the history of mankind - and has a capacity of 25 million $\mathrm{kW} / \mathrm{h}$ per gram of hydrogen, its main component. The nuclear fusion of one $\mathrm{kg}$ of hydrogen releases an energy value of 8.3 million tons oil equivalent (Lhomme, 2004). Since the sun accounts for some two billion tons of material, over $90 \%$ being hydrogen of which it uses 600 million tons per second, the energy produced is unimaginable. In fact, it produces $4 \mathrm{x}$ $10^{17} \mathrm{GW}$, or the equivalent of 400 million billion nuclear power plants! The Earth receives only a tiny fraction of this energy (Centre National de Recherche Scientifique, n.d.; Lhomme, 2004).

The major characteristics of sun energy, despite a certain ubiquity, are a large regional disparity and more or less marked by seasonal imbalance. For instance, the average energy received by Europe is $1,200 \mathrm{kWh} / \mathrm{m}^{2} / \mathrm{y}$ vs 1,800 to $2,300 \mathrm{kWh} / \mathrm{m}^{2} / \mathrm{y}$ in the Middle East (EPIA/Greenpeace, 2011). Latitude, exposure and altitude are parameters that influence the overall daily and seasonal radiation. Tropical regions corresponding to 25-30 degrees latitude are sunnier compared to European countries above the 45-degree parallel.

Climatologists have long endeavoured to assess the solar energy of a given area as thoroughly as possible and even be able to predict the evolution. Statistics on solar radiation were therefore compiled from data collected to input into valuable databases (EPIA/Greenpeace, 2011). Assembling data of a given region based on different criteria is strategic for the design and dimensioning of PV systems, especially their orientations and inclinations (Labouret \& Villoz, 2009).

Characterization of increasingly sophisticated global solar energy resources is a sign of PVs' promising potential. Thus the calculations by the International Energy Agency (US IEA) lead to surprising conclusions. Installing PV systems on only $4 \%$ of the area of the world's driest deserts would likely be able to provide all of humanity's primary energy needs (EPIA/Greenpeace, 2011).

\section{Technological aspects from solar energy to photovoltaic electricity}

The PV effect consists in the direct conversion of solar energy into electricity (Fig.1). Three interdependent and successive physical phenomena are involved: a) the optical absorption of light rays, b) the transfer of the energy from the photons to the electrons in the form of potential energy; c) the collection of the electrons excited in this manner so that they recover their initial energy. The ideal converter is still the semi-conductor, since both the conductivity and the collection method are both sufficient and efficient. However, there are two major obstacles with respect to PV conversion. The first one is related to the photons and electrons. In fact, not all the photons are absorbed and not all of the excited electrons are collected. This impacts the energy performance of a semi-conductor, one of the key parameters for the PV industry. In practical terms, the performance of a solar cell is the maximum power produced, expressed in Watts-peak (Wp) and the higher the Wp is, the better the performance of the cell is (Goetzberger \& Hoffman, 2005 ; Labouret \& Villoz, 2009). The other major obstacle is the price of the solar module. Development of the technologies and the PV materials is continuing while the two goals are to increase energy performance and reduce the cost of the Wp beneath the symbolic threshold of $\$ 1 \mathrm{US} / \mathrm{Wp}$ (Krauter, 2006; Xakalashe \& Tangstad, 2011). 
The material currently used preponderantly in the design of PV cells is silicon, which is abundant in nature, accounting for $90 \%$ of the global market for the production of the modules. More than $80 \%$ of the silicon used is in crystalline form with an energy performance between $14 \%$ and $22 \%$ for a solar cell, compared to $12 \%-19 \%$ once assembled in modules (Labouret \& Villoz, 2009; EPIA/Greenpeace, 2011; Xakalashe \& Tangstad, 2011).

There are currently three generations of photovoltaic cells. Those referred to as the first generation are made of crystalline silicon. The cells are provided in plates or wafers and have to be made from very pure silicon, using a manufacturing process that is still very onerous (Goetzberger \& Hoffman, 2005; Labouret \& Villoz, 2009; Jaeger-Waldau, 2010). The price of the solar module based on first generation cells is estimated at close to $\$ 2 \mathrm{US} / \mathrm{Wp}$ (Xakalashe \& Tangstad, 2011; SolarServer, 2011).

The second-generation solar cells, so-called thin layer cells, require less material and should cost less to design. Their development is more and more promising since their market share grew from $5 \%$ in 2005 to $16 \%-20 \%$ in 2009 . Their production capacity, estimated at about 10 GW in 2010, could grow to 20 GW in 2012 and 70GW in 2015 (Jaeger-Waldau, 2010). The thin-layer solar cells include, first and foremost, amorphous silicon, with a very uncompetitive performance of between $4 \%$ and $8 \%$ although the price per $\mathrm{Wp}$ is advantageous, approximately \$1.3 US in 2011 (EPIA/Greenpeace, 2011; SolarServer, June 2011). The second generation also includes other polycrystalline thin-layer films, particularly those based on cadmium telluride (CdTe), copper indium selenide (CIS) and its alloy copper indium gallium selenide (CIGS). The average performance of the CdTe cells is between $8 \%$ and $10 \%$. The price per Wp was $\$ 0.81$ US in the first quarter of 2010 and at the end of the same year, CdTe modules contributed to the production of almost $14 \%$ of the PV solar electricity generated by thin-layer cells (Jaeger-Waldau, 2010).

In theory, the CIS and CIGs cells have the highest performance for thin-layer cells, which is estimated at $20 \%$ in laboratory tests. However, the modules installed yield only $7 \%$ to $12 \%$. Nevertheless, this technology is in the early stages of development and the manufacturing process is still complex, particularly since indium is a material that is in high demand in the flat screen (LCD) industry, which makes its use in PV systems problematic (Labouret \& Villoz, 2009; EPIA/Greenpeace, 2011).

The objective set for the third generation cells is in the vicinity of $30 \%$ and these cells rely on innovative technologies. This group includes primarily: a) multi-junction cells with a thin layer of silicon or gallium arsenide combined with a solar concentrator, b) organic polymer cells or poly-electrochemical cells, also called Grätzel cells; c) thermophotovoltaic cells, primarily with an indium arsenide base (EPIA/Greenpeace, 2011). The multi-junctions, equipped with solar concentrators with a factor of up to 1000 , are by far the most performing, with a record performance of 35.8\% announced in 2009 . However, the applications remain limited since they are confined to the space and military fields (Chataing, 2009; Guillemoles, 2010). While the performances of the organic cells are lower, from $8 \%$ to $12 \%$, interest in such cells and particularly the Grätzel cells is growing since the production costs are constantly declining with an interesting price outlook estimated at \$0.73 dollars US (0.5 Euros) per Wc in 2020 (Chabreuil, 2010; EPIA/Greenpeace, 2011).

One of the emerging technologies in the field of PVs is nanotechnology, which uses nanocrystalline particles or quantum dots, which would significantly increase the efficiency of the conversion compared to conventional semi-conductors (Nozik et al., 2010). Current 
research is focussing on the use of hybrid organic-inorganic cells with a great deal of load mobility that uses cadmium selenide as the inorganic material (Freitas et al., 2010).

\section{Practical applications}

The solar modules consist of cells assembled in series, encapsulated between supports made of tempered glass, a special Tedlar ${ }^{\circledR}$ type plastic or "solar" resin, and then framed. In order to amplify their power, the modules may be grouped in voltaic panels or even voltaic fields with power output ranging from $1 \mathrm{kWp}$ (kilowatt peak) to more than $100 \mathrm{kWp}$ (Antony et al., 2010).

The two types of PV systems in use are autonomous (off-grid system) systems and those connected to the public electrical network (on-grid system); they differ in terms of their finality and the nature of their components. The electricity produced by the autonomous systems is consumed on site whereas that generated by facilities connected to the network is intended to fully or partially supply that network (Labouret \& Villoz, 2009; Antony et al., 2010).

Moreover, there is a hybrid system, an intermediary and emerging form of the PV market that allows connection to another source of energy. Efforts to combine sources of energy are continuing particularly as a complementary source of energy although this type of system remains complex, laborious and onerous (Goetzberger \& Hoffman, 2005; Labouret \& Villoz, 2009).

There are many applications for autonomous systems such as internal market for solar gadgets (calculators, clocks, etc.), solar home systems and water pumps. These systems are still a preferred solution for developing countries where more than two billion people are not connected to an electrical network and have no hope of being connected to one someday (Goetzberger \& Hoffman, 2005; Labouret \& Villoz, 2009). Nevertheless, despite their appeal as sources of energy and their potential for development, these systems are still the source of major concerns requiring intense consideration so as to ensure both their sustainability and their wide-scale generalization in developing countries.

In this case, it would be possible to enhance their tangible added value in the global energy landscape. First, apart from the internal market and "sun-related" applications such as pumping or ventilation, the autonomous systems would have to include judicious storage batteries in order to accumulate excess electricity, but these batteries are problematic. The financing for the autonomous generators is the first negative element since, even if only $20 \%-30 \%$ of the initial investments are for storage, the reduced lifespan of the batteries (batteries have to be replaced every 2,5 or 10 years) results in a final cost that could amount to $70 \%$ of the total costs (Labouret \& Villoz, 2009).

It is a fact that the positive development of individual solar systems in the developing countries is having pernicious effects since that easier access to electricity could lead to an increase in the acquisition of electrical appliances and, consequently, to the overuse of batteries, thereby reducing their lifespan (Goetzberger \& Hoffman, 2005). Moreover, the scarcity of training on autonomous systems, aggravated by the high rate of illiteracy in the developing countries, could result in difficulties in maintaining the batteries which, obviously, influences their durability. Thus, the integration of batteries, although essential for autonomous systems, will have an impact on their costs, already high (\$500 to \$1500 US), thereby handicapping, to a certain extent, their generalization in terms of rural electrification in developing countries (Goetzberger \& Hoffman, 2005; Labouret \& Villoz, 2009). 
The other issue with respect to autonomous systems concerns the nature of the batteries, which are essentially lead-based. The lead battery has two disadvantages: the most particular concern is the potential effect on public health and safety and its impact on the environment, mainly resulting from the presence of lead, a toxic heavy metal. Concerns are not only to the manufacture and handling of this type of battery but also to end-of-life recycling (Vest, 2002).

\section{Energy and economic performances}

It is possible to evaluate the competitiveness of PV systems in terms of economic and energy performances. The prominent economic parameters are the global cost of the PV systems and the price of the solar energy generated while energy profitability is estimated in terms of the Energy Pay-Back Time [EPBT] as well as the Energy Return Factor [ERF].

Two realities affect the photovoltaic market: a) growth has been spectacular in just a few years and $b$ ) the price of the energy produced remains the most expensive (Aladjidi \& Rolland, 2010). Thus, when a price per Wp is announced, it only reflects the price of the solar unit when it leaves the plant. The overall cost of the PV solar energy includes an entire series of parameters, such as the cost of the initial investment, the operating lifespan of the system, the energy performance during operation, the cost of maintenance and whether or not storage batteries are integrated (Goetzberger \& Hoffman; PVResources, 2011).

The crucial parameter that will condition price fluctuations is certainly the maturity of the market, even more than the type of application for which the photovoltaic system is used. Thus, countries such as Germany and Spain are considered, as a result of their precocious commitment to the development of solar energy, the driving forces behind the growth of the PV market (Labouret \& Villoz, 2009).

The cost of the initial investment, depending on the power desired, includes several elements, in particular the retail price of the unit and the various components of the system, the feasibility study, planning, and the cost of installing the equipment. The various components vary according to the type of system. Those connected to the network, in residential segments on rooftops or facades or in solar fields, require more assembly structures, a cabling system and eventually grounding work (EPIA/Greenpeace, 2011). On the other hand, in addition to storage batteries, autonomous systems include load controllers which, although they represent only $5 \%$ of the initial investment, are essential for protecting the systems against solar overloads and discharges (Labouret \& Villoz, 2009).

In 2009, the price of PV installations varied from 3.5 to 5 Euros/Wp for $1 \mathrm{Kw}$ of power with projections of 0.7-0.9 Euro/Wp in 2030 and even 0.56 Euro/Wp in 2050 (PVResources, 2011; EPIA/Greenpeace, 2011). The price of the photovoltaic unit is the most important factor in determining the cost of the initial investment. It is still rather high and is currently estimated at between $40 \%$ and $60 \%$ of the total cost, depending on the technology used, although it has decreased significantly over the past five years (EPIA/Greenpeace, 2011).

Since silicon dominates the PV market, the retail price of the units made using crystalline silicon reflects fluctuations in the price of the raw material, which is closely related with the production capacities of the industry. The spectacular overproduction of silicon noted in 2009, particularly as a result of the opening of an Asian PV market, although it destabilized the supply and demand through the multiplication of the number of independent producers, helped to remove the spectre of a silicon shortage (EPIA, 2011). 
In addition to readjusting the silicon market as a condition for stability requiring the consolidation of firms, the real issue with respect to reducing the price of the units involves improving the manufacturing process through automation. Thus, major efforts should be made to improve refining capacity, reduce the thickness of silicon wafers and increase conversion performances through an equitable manufacturing process that respects specific standards (Aladjidi \& Rolland, 2010; EPIA/Greenpeace, 2011).

Although there are still good days ahead for silicon, the development of various emerging technologies in the field of photovoltaics would necessarily have a most beneficial effect since they would either use less silicon, as in the case of amorphous or micro-crystalline cells, or they would use innovative materials other than silicon (Aladjidi \& Rolland, 2010).

The lifespan of the PV systems is a key parameter not only for the assessment of the overall cost of the systems but also for estimating the EPBT and ERF. Most of the manufacturers of PV units provide performance guarantees, namely a life span between 20 and 25 years at $80 \%$ of the minimum nominal power for both crystalline and cadmium telluride units, while stating that this average would be a minimum estimate and not a definitive value since it would be estimated at 40 years in 2020 (Labouret \& Villoz, 2009; EPIA/Greenpeace, 2011).

The improvement in lifespan is both technological and technical in nature since it is closely related to the stability of the PV systems in use elsewhere, which are negatively impacted by a deterioration process that affects both the solar units, despite the encapsulation of the cells, and the support frame. This degradation can result from the aging of the semiconductors, the delamination or loss of adhesiveness between the solar cells and from the intrusion of humidity. The fragility of the systems has a major impact on the energy performance during operation. However, only few studies were done on the estimation of losses, while a decrease in performance of $1 \%-2 \%$ per year was observed for some systems (Goetzberger \& Hoffman, 2005).

The cost of maintenance, including the ongoing control of the performance and the appearance of the systems as well as their cleaning, remains low and is estimated to be between 0.01 and 0.1 Euro/kWh (PVResources, 2011). However, integrating storage batteries in the autonomous systems, which are characterized by a decrease in lifespan of a factor of 2 for every 10 degrees Celsius as a result of corrosion, leads to a long-term increase in the cost of the investment as seen earlier (Labouret \& Villoz, 2009).

The average price of the solar electricity generated depends, among other things, on the initial installation costs and the rate of sunshine and is estimated at $0.22 \mathrm{Euro} / \mathrm{kWh}$ in Europe and remains, despite a significant decrease of $40 \%$ between 2007 and 2009, less competitive than the electricity generated using fossil fuels, which is evaluated between 0.09 and 0.27 Euro/kWh (EPIA/Greenpeace, 2011). However, there is no shortage of programs intended to make PV systems profitable, such as investment contributions (subsidy, green loan), tax benefits (reduction, exoneration) and direct pricing support, including the compensatory redemption rate systems in place in several European Union countries, particularly Germany and Italy (Goetzberger \& Hoffman, 2005).

Germany was the first country to implement a law giving priority to renewable energy and has been a powerful driving force behind the development of PV programs. This law, and others which have been based on it, establishes the right to inject solar energy into the public network and to be reimbursed per PV kWh (EPIA/GREENPEACE, 2011; PVResources, 2011). 
Photovoltaics consume necessarily energy throughout a system's life cycle, i.e. during the manufacturing of modules, their installation and, at the end of their useful life, disassembly and recycling. The energy balance is defined by two common parameters: the EPBT, meaning the time required for PV energy to repay its energy debt, and the ERF or how many times the consumed energy is reproduced. These two parameters are determined by the rate off sunshine, the purpose and design of the PV system, and the type of technology (International Energy Agency-Photovoltaic Power Systems Program [IEA-PVPS], 2006; EPIA/Greenpeace, 2011).

The energy balance is closely related to the lifespan of the systems. A 2006 study gives an EPBT of between 1.6 and 3.3 years for systems installed on roofs and 2.7 to 4.7 years for those integrated into facades. The ERF, estimated for a business life of 30 years, is between 8 and 18 for roofs and from 5.4 to 10 for facades (IEA-PVPS, 2006). Data collected in 2009 for systems integrated into roofs in southern Europe indicate an EPBT of nearly 1.75 years for systems that use silicon cells, except for silicon ribbon, which is estimated at just over one year. Thin film technologies remain effective with nearly 0.7 years for cadmium telluride systems (EPIA/Greenpeace, 2011), which was adjusted to 0.7 to 1.1 years by the Held team from Germany (Held \& Ilg, 2011).

Preliminary results related to commercial applications for solar concentrators present an EPBT of 0.8 to 1.9 years (Wild-Scholten et al., 2010). It appears that the silicon wafer industry is highly energy intensive and that the development of thin-film technologies, which require few materials, would be more compatible with an energy gain reducing the EPBT, maximizing the ERF and consequently optimizing the energy efficiency (Wild-Scholten et al., 2010; EPIA/Greenpeace, 2011).

However, a low EPBT does not always equate low energy efficiency and this finding makes perfect sense when applied to autonomous systems, which are of great use in developing countries. These systems are somewhat not considered in these calculations since few studies reinforce this reality, except one with an EPBT of 3.5 to 6 years due to the presence of storage batteries that must be regularly renewed and excess energy during periods of strong sunlight (Kaldellis et al., 2010).

These energy assessment calculations include the end-of-life recycling of systems. Although the first large-scale PV applications were installed in the 1990s, increasing growth of the market will require that more systems be disassembled and recycled. Once disassembled, in terms of waste to be treated, PV modules represent about 2,300 $\mathrm{t}$ in 2007, over 7,500 $\mathrm{t}$ in 2011 and a forecast of $132,000 \mathrm{t}$ in 2030 considering average annual growth of $17 \%$. Silicon modules currently represent over $80 \%$ of this waste. But if trends in thin film and emerging technologies continue, by 2030 they could account for over $65 \%$ of waste generated (Sander et al., 2007).

The era of waste collection and recycling PVs is still in its infancy despite voluntary measures in the PV industry (PVCycle, 2011) and the ongoing search for more efficient recycling techniques, both energy and economic, for all types of modules (Radziemskai et al., 2010). The recent integration of PV in the Waste Electrical and Electronic Equipment (WEEE) directive (Council of European Commission, 2011a) is only a first step and a strong legislative framework underpinned by sustained efforts is required in order to structure PV waste management, generalize the most competitive recycling processes for all system components, including batteries, and make them applicable to the extent of PV installations worldwide (PVCycle, 2011). 


\section{Life cycle of photovoltaic systems and ecological footprint}

As a result of the accelerated growth of the PV industry, a rigorous assessment of the environmental impacts of the systems has become necessary, conducted through a life cycle assessment (LCA) integrating all of the manufacturing, operating, collection and waste recycles. The LCA is an orderly process that analyzes the input/output impact of the PV industry from the "cradle to grave", with the inputs referring to the materials and energy consumed and the outputs illustrated by greenhouse gas (GHG) type emissions and solid and liquid waste.

A form of environmental management that is as exhaustive as possible, the LCA is a series of tools and techniques for which the ultimate objective, beyond the descriptive and quantitative aspect of the environmental profile, is to reinforce the sustained effort to limit the environmental impacts in a context of sustainable development (Fthenakis et al., 2005a; IEA-PVPS, 2011). The key factor that will determine the pertinence and the credibility of the LCA will be the voluntary and transparent cooperation of the manufacturers with respect to the accurate and full disclosure of the various inputs/outputs (Fthenakis et al., 2005a; Stoppato, 2008; IEA-PVPS, 2009; Ecoinvent , 2010; IEA-PVPS, 2011).

In addition to the energy considerations previously illustrated by the calculation of the EPBT and the ERF, the parameter most frequently estimated for the LCA assessment is the ecological footprint describing and quantifying the entire greenhouse gases (GHG) released during the lifespan of the PV system and expressed in carbon dioxide equivalents per $\mathrm{kWh}$. The environmental gain expected by the reduction of GHG related to the operation of PV electricity has also to be taking into account. These two assessments are always determined in comparison with the emissions attributed to fossil energies (Fthenakis et al., 2005a; IEAPVPS, 2011).

The estimate of the GHG attributed to PV systems is an increasingly complex exercise since it includes criteria that are as diversified as the technology used, the choice of manufacturing processes and the type of energies consumed, the techniques for assembling the cells and units, the power generated, the transportation of raw materials and the finished product, the components required for the installation of the units (Balance Of System/BOS) as well as the recycling processes. The BOS will, in turn, depend on the applications, the dimensions, the orientations and, above all, the location selected (Krauter \& Rüther, 2004; Stoppato, 2008; Fthenakis \& Kim, 2011; Reich et al., 2011).

A major distinction is acknowledged between indirect emissions, which concern the overall energy, electricity included, needed to manufacture the units, and the direct emissions, which concern all of the chemical compounds, raw materials included, that are involved in the manufacturing process and are a potential source of GHG (Reich et al., 2011). It is essential to point out that the GHG emission estimates for PV systems are not absolute since they are subject to a certain number of constraints, particularly the quality of the information provided by the manufacturers involved throughout the life cycle. Thus, the estimates are subject to future revisions as are the EPBT and ERF calculations (Reich et al., 2011; Held \& Ilg, 2011).

With respect to the direct emissions of the silicon industry, three critical phases are identified: the development of metallurgical-grade silicon from silica, its transformation into solar-grade silicon and the development of a structure and framework in the form of panels. While the production of metallurgical-grade silicon requires the consumption of roughly 14 $\mathrm{kWh}$ per $\mathrm{kg}$ of metallurgical-grade silicon whole releasing 3 tons of $\mathrm{CO}_{2}$ equivalents for one 
ton of metallurgical-grade silicon, the solar-grade silicon stage is by far the most energy consuming, with $150 \mathrm{kWh}$ per $\mathrm{kg}$ obtained (Miquel, 2009) or $1190 \mathrm{MJ} /$ panel $\left(0.65 \mathrm{~m}^{2}\right)$ (Stoppato, 2008).

Assembling the panels with an aluminum frame also consumes energy, ranging between 53 and $245 \mathrm{kWh}$ with emissions varying between 15 and $19 \mathrm{~kg} \mathrm{CO}$-eq, all per $\mathrm{kg}$ of aluminum consumed (Krauter \& Rüther, 2004). Overall, the estimation of GHG emissions for silicon panel manufacturing is variable as shown in table 1.

The silicon technologies release also GHG directly, with the primary sources being the raw material itself, the various fluoride compounds involved in the manufacturing process as well as the incineration of the plastic used to encapsulate the solar cells, one of the common processes in the recycling of plastic materials. According to the estimates, the emission is virtually negligible, about $0.16 \mathrm{~g} \mathrm{CO}_{2}-\mathrm{eq} / \mathrm{kWh}$ for the raw material, whereas the incineration of plastic would be a source of $1.1 \mathrm{~g}$ (Reich et al., 2011).

\begin{tabular}{r|l}
\hline $\begin{array}{r}\text { Emission estimates } \\
(\mathrm{g} \mathrm{CO} \text {-eq/kWh })\end{array}$ & Reference \\
\hline $15-25$ & EPIA/Greenpeace, 2011 \\
$30-45$ & Fthenakis \& Alsema, 2006; Fthenakis et al., 2008 \\
$43-73$ & Weisser, 2007; Miquel, 2009 \\
$148-187$ & Stoppato, 2008 \\
\hline
\end{tabular}

Table 1. GHG emissions for silicon panel according to different authors

The fluoride compounds remain the Achilles heel of silicon cells since they have an even higher Global Warming Potential (GWP). $\mathrm{CO}_{2}$, methane and the nitrogen oxides have GWPs of 1,23 and 296. There are also issues with respect to $\mathrm{CF}_{4}$ (carbon tetrafluoride), $\mathrm{SF}_{6}$ (sulphur hexafluoride), $\mathrm{C}_{2} \mathrm{~F}_{6}$ (hexafluoroethane) and above all $\mathrm{NF}_{3}$ (nitrogen trifluoride) for which the GWPs range from 7,400 to more than 17,000 (Fthenakis et al., 2010; Miquel, 2009). Despite this fact, these fluoride compounds, excluding $\mathrm{SF}_{6}$, are not included in the Kyoto protocol whereas $\mathrm{NF}_{3}$ is considered to be the gas with a significant environmental impact (Prather \& $\mathrm{Hsu}, 2008)$.

Concerning the thin layer technology and, more specifically, the cadmium telluride (CdTe) technology, the small amount of data available relies on a certain number of parameters such as the geographic location of the facility, the conditions at the site of the installation and, certainly, the type of databases used. The information about the recycling procedures has a particular impact on the calculation, as for all of the technologies, but the recycling process is in the experimental stage since the CdTe market is still relatively young (Held \& Ilg, 2011). From 18 to $20 \mathrm{~g} \mathrm{CO}$-eq/kWh (Fthenakis \& Kim, 2005; Fthenakis, 2009) the estimates are currently being revised slightly upwards (Held \& Ilg, 2011).

The autonomous PV systems include, in their calculations, the emissions generated by the storage batteries and eventually those caused by the diesel generators integrated in most of the hybrid systems. Taking into account the $1.26 \mathrm{~kg} \mathrm{CO}$-eq released per $\mathrm{kg}$ of batteries produced, the cost of transportation and maintenance, and based on an operating life of more than 20 years, the individual systems, namely solar home systems (SHS), with a power of $15 \mathrm{Wp}$ release an average of $160 \mathrm{~kg} \mathrm{CO}$-eq whereas SHS with a power of $50 \mathrm{Wp}$ release $650 \mathrm{~kg}$ (Posorski et al., 2003). 
Notwithstanding this disparate data, the GHG emissions of PV systems are well below those of fossil energies as summarised in table 2 . The overall production of electricity, all energy sources combined, generates an average of $600 \mathrm{~g} \mathrm{CO}_{2}-\mathrm{eq} / \mathrm{kWh}$, although this varies between countries (Stoppato, 2008; EPIA/Greenpeace, 2011).

\begin{tabular}{l|c|l}
\hline \multicolumn{1}{c|}{ Energy system } & Average emission & \multicolumn{1}{c}{ Reference } \\
\hline PV Systems & $15-187$ & See references in Table 1 \\
Coal & $800-1280$ & $\begin{array}{l}\text { Dones et al., 2003; Weisser, } \\
\text { 2007; Evans; 2010 } \\
\text { Oil }\end{array}$ \\
& $519-1200$ & $\begin{array}{l}\text { Dones et al., 2003; Weisser, } \\
\text { 2007; Evans; 2010 } \\
\text { Natural Gas }\end{array}$ \\
& $360-991$ & $\begin{array}{l}\text { Dones et al., 2003; } \\
\text { Jaramillo et al., 2007; } \\
\text { Weisser, 2007; Evans; 2010 }\end{array}$ \\
\hline
\end{tabular}

Table 2. GHG emissions ( $\mathrm{g} \mathrm{CO}_{2}$-eq/ $\mathrm{kWh}$ ) resulting from different energy systems

Moreover, the ecological footprint may be evaluated in terms of environmental gains resulting from the expected reduction in GHG caused by the use of PV systems. Based on the principle that, once installed, the systems (with the exception of the diesel generators and the transportation of maintenance services) do not emit GHG, it is possible to calculate how many $\mathrm{CO}_{2}$-eq will be saved throughout their lifespan. Scenarios have been developed to extrapolate this reduction with a forecast of $0.6 \mathrm{~kg} \mathrm{CO}$-eq/ $\mathrm{kWh}$ on average saved by the extension of the systems connected to the network and taking into account emissions (optimistic) of 12-25 $\mathrm{g} \mathrm{CO}_{2}$-eq/ $\mathrm{kWh}$. Almost 4 billion tons of $\mathrm{CO}_{2}$-eq could be saved by 2050 (EPIA/Greenpeace, 2011).

As for the autonomous systems, $70 \%$ would experience a reduction of more than $200 \mathrm{~kg}$ of $\mathrm{CO}_{2}$-eq per year, namely 6 tons of $\mathrm{CO}_{2}$-eq and 8.9 tons of $\mathrm{CO}_{2}$-eq for 15 and $50 \mathrm{Wp}$ systems respectively with a lifespan of more than 20 years (Posorski et al., 2003). The projections go even further, considering that the implementation of PV plants in developing countries, combined with a generalization of systems connected to the network in order to supplement the hybrid systems and reduce emissions related to the transfer of technology from the supplier country to the consumer country would be even more beneficial in ecological terms with more than 26 tons of $\mathrm{CO}_{2}$-eq/ $\mathrm{kWh}$ saved per site implemented (Krauter, 2006).

\section{Potential health effects}

The photovoltaic industry, with its ambitious goal to provide clean electricity, paradoxically uses materials and/or manufacturing processes that are not free from inherent potential health and safety effects. The sector is therefore facing a dual objective: increase energy efficiency and reduce or even abandon processes that use potentially toxic compounds. 
Health concerns date back to the 1960s (Neff, 1979) and many frameworks have been developed since. The integration of PV panels into the European Waste Electrical and Electronic Equipment directive also shows awareness of PV systems potential toxic waste, which is classified as electronic waste (Silicon Valley Toxics Coalition [SVTC], 2009; Council of the European Union, 2011a). Legal frameworks such as the European REACH directive (Registration, Evaluation, Authorisation and Restriction of Chemicals) have lent support to the trend. As a whole and regardless of the technology, potential risks are a reality that must be addressed thoroughly, without invoking the environmental benefits to delay the risk assessments and possible adoption of mitigation measures.

The solar-grade silicon industry involves potential risks primarily during the manufacturing phase. However, mining of quartz or sand, precursors of metallurgical-grade silicon, also presents various risks mainly due to chronic exposure to crystalline silica dust, causing diseases of respiratory and urinary systems, arthritis, scleroderma and even lung cancer (International Agency for Research on Cancer [IARC], 1998; Yassin et al., 2005).

Developing solar-grade silicon from metallurgical-grade silicon through the Siemens process, which is still the most common in the sector despite the existence of other nonstandardized techniques (Miquel, 2009), releases chlorosilanes especially silane gas and silane tetrachloride $\left(\mathrm{SiCl}_{4}\right)$. Silane gas is extremely explosive, which is potentially dangerous both for workers and the community surrounding manufacturing sites. Fatal explosions have been reported in Germany (1976), Taiwan (2005) and India (2007) (Ngai, 2010).

As for $\mathrm{SiCl}_{4}$, it is a potent eye and lung irritant that can also affect the central nervous system. It reacts with water and can lead to skin burns and no carcinogenicity or reproductive toxicity studies have been performed so far (Right To Know, 2010). This same gas is the cause of various irritative symptoms observed in the residents of a Chinese village in the Henan province, some 50 meters from a polycrystalline silicon cell plant (Cha, 2008). Cutting solar-grade silicon ingots into plates exposes workers to silica dust (kurf) that can induce breathing problems due to overexposure despite the use of protective masks (Yassin et al., 2005). Other non specific chemicals are also involved in the manufacturing process including sodium hydroxide, sulphuric acid or hydrofluoric acid, and pose potential risks to workers.

It is therefore important for the following two priorities to be applied in order to adjust the accelerated development of the market: a) review the manufacturing processes for emission-reducing technology (abatement technologies), b) carry out or complete the appropriate risk analyses of all potentially toxic compounds with great transparency from manufacturers.

In terms of potential risks to public health, thin film technologies are no exception. The risks are still poorly documented for copper indium selenide and its alloy copper indium gallium selenide but two compounds that are particularly irritating to eyes and lungs are still being handled, namely hydrogen selenide and selenium dioxide (Agency for Toxic Substances and Diseases Registry [ATSDR], 2003). Indium is also problematic as it can induce various diseases including lung cancer and reprotoxic and embryotoxic effects and remains without a standard toxicological reference value (Nakano, 2009).

Technologies using cadmium telluride (CdTe) generate some controversy for two main reasons: a) the presence of cadmium $(\mathrm{Cd})$, a metal classified as a group 1 carcinogen by the International Agency for Research on Cancer (IARC, 1997) and b) little documentation exists about the extent of their particularly chronic potential toxicity (Norwegian Geotechnical 
Institute [NGI], 2010). These concerns also include emerging CdTe and CdSe-based solar nanotechnologies (Peyrot et al., 2009; Werlin et al., 2011).

The other element worth considering is the limited number of manufacturers using CdTe, which limits the scope of studies based mainly on data supplied by the manufacturers. The sector handling cadmium salts suffers from a confusion of nomenclature (Classification \& Labelling [C\&L]) since the physical and chemical properties of $\mathrm{Cd}$ salts are quite different from $\mathrm{Cd}$ just as the nanoparticles of cadmium salts differ from $\mathrm{Cd}$ salts in a thin layer (Fraunhofer Institute, 2010; NGI, 2010).

However, this controversy does not seem to have influenced the Council of the European Union, which will maintain exception concerning $\mathrm{Cd}$ use in PV modules in RoHS (Restriction of Hazardous Substances) so that the ambitious targets set by the EU for renewable energy and energy efficiency can be achieved (Council of the European Union, 2011b).

Nevertheless, current data attribute a lower acute toxicity to CdTe than to elemental Cd (Zayed \& Philippe, 2009). Toxicity studies of CdTe nanoparticles are contradictory and inconclusive at this time although the nanocrystals' small size would be a priori more damaging thus high cytotoxicity is suspected (Su et al., 2010).

During the operation of CdTe solar panels, the risk of emission in case of breakage or fire would be considered negligible (Steinberger, 1997, as cited in Nieuwlaar \& Aselma, 1997; Fthenakis, 2003; Fthenakis et al., 2005b, Raugei \& Fthenakis, 2010). Optimistic findings concerning the risk of CdTe emission in case of fire should be reviewed since, although established according to standard procedures, they were provided on the basis of flame temperatures between 750 and $900^{\circ} \mathrm{C}$.

However, in building fires where temperatures in the thermal plume are between 600 and $1,000^{\circ} \mathrm{C}$, those in the flame can reach $2,000^{\circ} \mathrm{C}$ (Fraunhofer Institute, 2010; Gay \& Wizenne, 2010). Since the risk of emission in case of accident is not clearly defined, better protection of workers responsible for installation and maintenance of PV systems is required.

The dismantling and recycling of PV systems can be problematic because of the potential risks associated with handling hazardous toxic compounds, especially polybrominated diphenyl ethers (PBDEs) used as flame retardants including inverters incorporated into photovoltaic systems (SVTC, 2009). The potential toxicity of PBDEs such as the carcinogenic risk due to bioaccumulation in the body is not yet clarified (ATSDR, 2004).

Other major health concerns inherent in the PV industry are to be considered in the tally of potential risks to human health. These are the risks associated with manufacturing and recycling processes for lead batteries, which involve handling a number of hazardous compounds such as, in addition to lead, heavy metals harmful to the central nervous, endocrine and cardiovascular systems, sodium nitrite, sulphur dioxide, arsenic and sulphuric acid (Vest, 2002).

\section{Environmental impacts}

Throughout the life cycle, the PV industry can generate potentially toxic compounds, either during normal production or during accidental situations that could be released into the atmosphere, in solid or liquid effluents. The possible consequences would include alterations in the quality of the air, the soil and the water, with potential impacts on biota (Electric Power Research Institute, 2003; SVTC, 2009). 
The vast majority of the studies on ecotoxicity and potential environmental impacts essentially pertain to the plant manufacturing phases, whereas little data is available with respect to the possible direct emissions or releases during operation as well as during the dismantling, the processing of waste and the recycling of the solar panels.

In terms of atmospheric emissions, the principal pollutants are essentially sulphur oxides (SOx), nitrogen oxides (NOx) and certain heavy metals such as arsenic, cadmium or mercury (Fthenakis, 2009; SVTC, 2009). Table 3 compares the average SOx and NOx atmospheric emissions from PV systems to those from various fossil fuels used to produce electricity. The results provide eloquent evidence that PV systems are clearly advantageous comparing to various fossil fuels. The data concerning PV systems varies according to the technologies used, the energy performances of the solar cells, the capacities of the systems, the impact assessment methods used and, therefore, the databases used.

\begin{tabular}{|c|c|c|c|}
\hline Energy system & $\begin{array}{l}\text { SOx } \\
(\mathrm{g} / \mathrm{kWh})\end{array}$ & $\begin{array}{l}\text { NOx } \\
(\mathrm{g} / \mathrm{kWh})\end{array}$ & References \\
\hline Photovoltaic & 0.05 to 0.36 & 0.025 to 0.34 & $\begin{array}{l}\text { Pehnt, 2006; Fthenakis et al., 2008; } \\
\text { Hatice \& Theis, } 2011 .\end{array}$ \\
\hline Coal & 5.2 to 12.0 & 1.3 to 4.5 & $\begin{array}{l}\text { Gagnon et al, 2002; Fthenakis et al., } \\
\text { 2008; Jaramillo et al., 2007; Hatice \& } \\
\text { Theis, } 2011 .\end{array}$ \\
\hline Heavy fuel & 1.1 to 8.0 & 0.5 to 1.5 & $\begin{array}{l}\text { Gagnon et al., 2002; Hatice \& Theis, } \\
2011 .\end{array}$ \\
\hline Diesel generator & 0.2 to 1.3 & 0.3 to 12 & $\begin{array}{l}\text { Gagnon et al., 2010; Hatice and } \\
\text { Theis, } 2011 .\end{array}$ \\
\hline $\begin{array}{l}\text { Liquid or solid } \\
\text { natural gas }\end{array}$ & 0.14 to 1.8 & 0.3 to 4.5 & Jaramillo et al., 2007 \\
\hline
\end{tabular}

Table 3. Average SOx and NOx atmospheric emissions associated with energy systems

The PV industry also produces ammonia emissions $\left(\mathrm{NH}_{3}\right)$ and volatile organic compounds (VOCs) (Pehnt, 2006; Fthenakis et al., 2010), but the existing data cannot be used to provide a rigorous comparative assessment. If there is a stage that could be crucial for the PV industry, it would be the end of the systems' lifecycle. Indeed, this could be the source of environmental and ecotoxicity concerns. In fact, the potentially toxic materials involved throughout the life cycle could be found, as a result of a routine or accidental release, in the solid and/or liquid effluents that could contaminate the soil and aquatic environments (Electric Power Research Institute, 2003; SVTC, 2009).

The emerging technologies require just as much vigilance as a result of the shortage of current ecotoxicological data, which would invite more refined investigations in the future in order to keep up with the growing dynamics of the market. The cadmium-based PV industry is specifically concerned since the current data seems to indicate that CdTe nanoparticles have the potential of bioaccumulation in aquatic organisms (Peyrot et al., 
2009) and there is a possible bioamplification of CdSe nanoparticles (Werlin et al., 2011). Overall, there is a consensus that the evaluations performed to date seem to give the PV industry much more credit than fossil fuels, but the fragmentary nature of the results indicate that more in-depth investigation is required.

\section{Sustainable development: Issues and prospects}

The current vitality of the photovoltaic sector is taking place in a context marked by the need to review energy policies given both the increasing spectre and the growing number of the obvious consequences of climate change. In fact, the current policies serve only to draw sombre and unfavourable prognoses, resulting in particular from a lack of balance between a high rate of energy consumption and a problematic supply of conventional fossil energies associated with highly volatile prices and market instability (Bradford, 2006; Labouret \& Villoz, 2009).

The current concept of sustainable development is positioned as an enlightened response to major concerns, based on the fact that it reconciles, inasmuch as possible, three parameters which have been completely divergent to date: the economic efficiency, the social equity and the socio-economic development and, finally, the preservation of the ecosystems. The compromises sought through sustainable development require the implementation of several complex actions focussed on a fundamental objective: to ensure a balance between the energy offer and demand for current generations while respecting the resilience of the biosphere. It is, therefore, a response to real, current concerns that could compromise the wellbeing of future generations (International Union for Conservation of Nature, 2006).

Applied to the energy sector, such actions involve the implementation of strategies that are essentially corrective in nature and are part of a dynamic process based on the guiding principal of using renewable natural resources. Given this more functional vision and, based on the economic, health, safety and environmental profiles of PVs, as assessed and presented throughout the chapter, it is possible to provide an overall appreciation of the extent to which the photovoltaic industry respects different principles of sustainable development, inspired by those defined by the Ministry of the Environment of the Province of Québec, Canada (MDDEP, n.d.). This assessment is based on the current state of knowledge for an industrial sector extremely fertile in terms of technical and technological developments.

Table 4 aligns the PV industry with several principles of sustainable development. It can be considered as a barometer of human and equitable sustainable development. It also summarizes the extent to which different principles of sustainable development are respected. Although the results may be considered favourable, recommendations are issued in order to enhance the respect for the various principles.

Despite the universality of the sun as a resource and the fact that it is inexhaustible and safe, there are still many issues. Whether they are technical or technological, they will require a solid political focussing on subsidy systems and financial accessibility, strong programs to integrate photovoltaic systems in buildings, and administrative flexibility to ensure that the sector is dynamic (Bradford, 2006; EPIA/Greenpeace, 2011).

Moreover, a major issue concerns the social acceptability of PV systems, not only as a source of reliable energy but also as a system that can easily accompany daily life at a reasonable cost, while being integrated into local architecture without major visual impacts. 


\begin{tabular}{|c|c|c|}
\hline $\begin{array}{l}\text { Several } \\
\text { principles }\end{array}$ & Level of adherence & Recommendations \\
\hline $\begin{array}{l}\text { Economic } \\
\text { efficiency }\end{array}$ & $\begin{array}{l}\text { Average } \\
\text { Price of solar electricity } \\
\text { still not competitive. }\end{array}$ & $\begin{array}{l}\text { To increase efforts in research and } \\
\text { development, standardization of } \\
\text { manufacturing procedures, more encouraging } \\
\text { redemption policies, better penetration of PV } \\
\text { systems, development of smart grids, long- } \\
\text { lasting batteries. }\end{array}$ \\
\hline $\begin{array}{l}\text { Health } \\
\text { and safety }\end{array}$ & $\begin{array}{l}\text { Average to good } \\
\text { Possible accidents, } \\
\text { reduction of GHG, toxic } \\
\text { substances. }\end{array}$ & $\begin{array}{l}\text { To increase occupational health and safety, } \\
\text { technological innovations, reduction even } \\
\text { elimination of potentially toxic compounds, } \\
\text { policy to reduce emissions and spills, emission } \\
\text { control, performance of exhaustive risk } \\
\text { analyses. }\end{array}$ \\
\hline $\begin{array}{l}\text { Quality } \\
\text { of life }\end{array}$ & $\begin{array}{l}\text { Good to very good } \\
\text { No eco-visibility, good } \\
\text { integration in space. }\end{array}$ & $\begin{array}{l}\text { To reduce hybrid systems using diesel } \\
\text { generators. }\end{array}$ \\
\hline $\begin{array}{l}\text { Precaution } \\
\text { Prevention }\end{array}$ & $\begin{array}{l}\text { Average } \\
\text { Use of potentially toxic } \\
\text { components. }\end{array}$ & $\begin{array}{l}\text { To refine the assessment of the life cycle. } \\
\text { Organization of the waste management and } \\
\text { recycling sector. }\end{array}$ \\
\hline $\begin{array}{l}\text { Subsidiarity/ } \\
\text { delegation }\end{array}$ & $\begin{array}{l}\text { Average } \\
\text { Administrative } \\
\text { processes still difficult. }\end{array}$ & $\begin{array}{l}\text { To implement a one-stop-shop system to } \\
\text { facilitate administrative procedures. }\end{array}$ \\
\hline $\begin{array}{l}\text { Equity and } \\
\text { social solidarity }\end{array}$ & $\begin{array}{l}\text { Average to good } \\
\text { Solar resource } \\
\text { ubiquitous; onerous } \\
\text { systems. }\end{array}$ & $\begin{array}{l}\text { To generalize rural electrification in } \\
\text { developing countries. }\end{array}$ \\
\hline $\begin{array}{l}\text { Environmental } \\
\text { protection }\end{array}$ & $\begin{array}{l}\text { Average to good } \\
\text { There is little } \\
\text { documentation about } \\
\text { certain emissions. }\end{array}$ & $\begin{array}{l}\text { Technological innovation to limit the use of } \\
\text { fossil energy and raw materials, increased } \\
\text { contribution of manufacturers and better } \\
\text { organization of the photovoltaic sector. }\end{array}$ \\
\hline $\begin{array}{l}\text { Preservation of } \\
\text { biodiversity and } \\
\text { respect the } \\
\text { ecosystems }\end{array}$ & $\begin{array}{l}\text { Average } \\
\text { Clearly advantageous } \\
\text { compared to fossil } \\
\text { energies, lack of data } \\
\text { about emissions, waste } \\
\text { and recycling. }\end{array}$ & $\begin{array}{l}\text { Reduction of potentially toxic compounds, } \\
\text { more elaborate analyses of toxicological and } \\
\text { ecotoxicological risks. }\end{array}$ \\
\hline
\end{tabular}

Table 4. Aligning the photovoltaic industry with the principles of sustainable development

The informed acceptance of the public, including the public authorities, would have a definitive impact on the decision-making powers (Hirschl, 2005). Information, awareness raising and education would serve to optimize the understanding, reception and adaption of PV systems. 


\section{Conclusion}

Despite the fact that photovoltaic conversion is still under developed, it is certainly a technology that will progress in a sustained manner since the prospects of this technology are favourable and appealing. Generating few or no greenhouse gases during the operating stage, producing no sound pollution, able to be integrated both aesthetically and functionally into the urban landscape, it should generate more interest and surpass, in an intelligent manner, the technical and technological limitations.

It is crucial to back research and development on persistent considerations to potential health effects and environmental impacts. This is also a means for driving progress in a sector that has already reached the boiling point. Humankind, which absolutely must deal with the depletion of fossil resources and the increasingly obvious consequences of greenhouse gas emissions, has neither the means nor the time to waffle.

The conciliation of the photovoltaic industry with the principles of sustainable development, its integration in the clean energy mix, based on social acceptability and international solidarity are obvious requirements. PV conversion should be able to develop an advantageous place both in the global energy landscape and in the urban landscape while being the preferred candidate for energy equity despite the unequal distribution of solar layer around the globe.

\section{References}

Aladjidi, G. \& Rolland, B. (2010). Photovoltaique : Idées Reçues et Enjeux Industriels, In Mines Revues des Ingénieurs, Dossier les Énergies Renouvelables, No. 446, pp. 29-31 (May-June 2010), 02.03.2011, Available from http://www.mines-energie.org/Dossiers/ENR2010_16.pdf

Antony, F. ; Durschner, C. \& Remmers, K.-H. (2010). Le Photovoltaique pour Tous, Conception et Réalisation d'Installations (2ème Édition), Édition Observ'ER, ISBN-13 : 978-2913620-48-3, Paris, France

ATSDR (2003). Toxicological Profile for Selenium, In Agency for Toxic Substances and Disease Registry, Toxic Substances Portal, 12.07.2011, Available from http:/ / www.atsdr.cdc.gov/ toxprofiles/tp.asp?id=153\&tid=28

ATSDR (2004). Toxicological Profile for Polybrominated Biphenyls and Polybrominated Diphenyls Ethers, In Agency for Toxic Substances and Disease Registry, Toxic Substances Portal, 13.07.2011, Available from http://www.atsdr.cdc.gov/toxprofiles/tp68-c8.pdf

Bradford, T. (2006). Solar Revolution, the Economic Transformation of the Global Energy Industry, The MIT Press, ISBN 978-0-262-02604-8, Cambridge, USA

British Petroleum Global (June 2011). Statistical Review of World Energy 2011, Review by Type of Energy: Electricity, In B.P. Global, Reports and Publications, 02.06.2011, Available from http://www.bp.com

Butti, K. \& Perlin J. (1980). A Golden Thread. 2500 Years of Solar Architecteure and Technology, Van Nostrand Reinhold Company, ISBN 0-442-24005-8, USA

Centre National de Recherche Scientifique (n.d.). Naissance, Vie et Mort des Étoiles, In Saga Sciences, Dossier Multimédia : Big Bang Des Origines de l'Univers aux Origines de la Vie, 2.06.2011, Available from 
http://www.cnrs.fr/cw/dossiers/dosbig/decouv/xchrono/etoiles/niv1_1.htm

Cha, A.E. (March 2008). Solar Energy Firms Leave Waste Behind in China, In The Washington Post Foreign Service, 10.07.2011, Available from

http:/ / www.washingtonpost.com/wp-dyn/content/article/2008/03/08/

AR2008030802595.html?sub=new

Chabreuil, M. (June 2010). Les Cellules de Grätzel font Reparler d'Elles, In Techniques de l'Ingénieur, Environnement, Sécurité et Énergie, 05.04.2011, Available from http://www.techniques-ingenieur.fr/actualite/environnement-securite-energiethematique_191/les-cellules-de-gratzel-refont-parler-d-elles article_7340/

Chataing, H. (October 2009). Nouveau Record Mondial : Sharp Développe une Cellule Photovoltaïque d'un Rendement de Conversion de 35,8\%, In Bulletinelectronique.com, 05.04.2011, Available from http://www. bulletinselectroniques.com/actualites/60906.htm

Council of the European Union (2011a). Council Revises Rules on Recycling of Electronic Devices, In Presse 58, No. 7632/11 (March 14, 2011), 01. 07.2011, Availaible from http://www.consilium.europa.eu/uedocs/cms_data/docs/pressdata /en/envir/119877.pdf

Council of the European Union (2011b). Council Tightens Rules on Hazardous Substances in Electrical and Electronic Equipment, In Europa, Press Released Rapid, Press 156 (May 27, 2011), 01.07.2011, Available from http://europa.eu/rapid/pressReleasesAction.do?reference=PRES/11/156\&type= HTML

Dones, R.; Heck ,T. \& Hirschberg, S. (2003). Greenhouse Gas Emissions from Energy System: Comparison and Overview, In Paul Scherrer Institute, Technology Assessment, 0.07.2007, Available from

http://gabe.web.psi.ch/pdfs/ Annex_IV_Dones_et_al_2003.pdf

Ecoinvent (2010). Implementation of Life Cycle Impact Assessment Methods, Data v2.2, In Ecoinvent centre, Swiss Centre for Life Cycle Inventories, 06.07.2011, Available from http://www.ecoinvent.org/fileadmin/ documents/en/ 03_LCIA-Implementationv2.2.pdf

Electric Power Research Institute (2003). Potential Health and Environmental Impacts Associated With the Manufacture and Use of Photovoltaic Cells, In The California Energy Commission, 09.07.2011, Available from http:/ / www.energy.ca.gov/reports/500-04-053.PDF

EPIA (2011). Global Market Outlook for Photovoltaic until 2015, In European Photovoltaic Indsutry Association Publications, 03.03.2011, Available from http:/ / www.epia.org/index.php?id=18

EPIA/Greenpeace (2011). Solar Generation 6, Solar Photovoltaic Electricity Empowering the World, In European Photovoltaic Industry Association Publications, 28.02.2011, Available from http:/ / www.epia.org/ index .php?id=18

Evans, A., Strezov V. \& Evans, T. (2010). Comparing the Sustainability Parameters of Renewable, Nuclear and Fossil Fuel Electricity Generation Technologies, In World Energy Council for Sustainable Energy, Congress Papers, Montréal 2010, 27.06.2011, Available from 
http:/ / www.worldenergy.org/documents/ congresspapers/272.pdf

Fraunhofer Institute (2010). Scientific Comment of Fraunhofer to Life Cycle Assessment of CdTe Photovoltaic's, In Fraunhofer Institute for mechanics of Materials IWN, 27.06.2011, Available from http://www.en.iwm. fraunhofer.de/news/details/id/149/

Freitas, J., Grova, I.; Akcelrud, L.; Arici, E.; Sariciftci, N. \& Nogueira, A. (2010). The Effects of CdSe Incorporation into Bulk Heterojunction Solar Cells, Journal of Materials Chemistry, Vol. 20, Issue 23 (April 2010), pp. 4845-4853

Fthenakis, V.M. (2003). Overview of Potential Hazards, In Practical Handbook of Photovoltaics: Fundamentals and Applications, T. Markvart and L. Castaner, (Ed.), pp. 857-868, Elsevier, ISBN 1-856-17390-9, Retrieved from http://www.nrel.gov/pv/thin_film/docs/pv_handbook_chapter_v-1.pdf

Fthenakis, V.M. (2009). Sustainability of Photovoltaics: The case for Thin-Film Solar Cells, Renewable and Sustainable Energy Reviews, Vol. 13, Issue 9 (December 2009), pp. 27462750

Fthenakis, V.M. \& Kim , H.C. (2005). Energy Use and Greenhouse Gas Emissions in the Life Cycle of Thin Film CdTe Photovoltaics, Proceedings of Symposium G-Life Cycle Analysis, MRS Fall Meeting, Boston, MS, USA, November 29-December 2, 2005

Fthenakis, V. \& Alsema, E. (2006). Photovoltaics Energy Payback Times, Greenhouse Gas Emissions and External Costs: 2004-early 2005 status, Progress in Photovoltaics: Research and Applications, Vol. 14, Issue 3 (May 2006), pp. 275-280

Fthenakis, V.M. \& Kim, H.C. (2011). Photovoltaics: Life-Cycle Analyses, Solar Energy, Vol. 58, Issue 8 (August 2011), pp. 1609-1628

Fthenakis, V.M.; Alsema, E.A. \& de Wild-Scholten, M.J. (2005a). Life Cycle Assessment of Photovoltaics : Perception, Needs and Challenges, Proceedings of 31st IEEE Photovoltaic Specialists Conference, Orlando, Florida, January 3-7, 2005

Fthenakis, V.M., Kim H.C. \& Alsema, E. (2008). Emissions from Photovoltaic Life Cycles, Environmental Science and Technology, Vol. 42, No. 6 (February 2008), pp. 21682174

Fthenakis, V.M., Fuhrmann, M.; Heiser, J.; Lanzirotti, A.; Fitts J.\& Wang, W. (2005b). Emissions and Encapsulation of Cadmium in CdTe PV Modules During Fires, Progress in Photovoltaics: Research and Applications, Vol. 13, Issue 8 (December 2008), pp. 713-723,

Fthenakis, V.; D.Clark, D.; Mehran, M.; Phil, C.; Ridgeway, R., Forest, H.; Cooper, D. \& Maroulis, P. (2010). Life Cycle Nitrogen Trifluoride Emissions from Photovoltaics, Environmental Science and Technology, Vol. 44, No. 22 (October 2010), pp 8750-8757

Gaiddon, B.; Kaan, H. \& Munro, D. (2009). Photovoltaics in the Urban Environment, Lessons Learnt from Large-Scale Projects, Earthscan, ISBN 978-1-84407-771-7, London, England

Gagnon, L.; Bélanger, C. \& Uchiyama, Y. (2002). Life-cycle Assessment of Electricity Generation Options: The Status of Research in Year 2001, Energy Policy, Vol. 30, Issue 14 (November 2002), pp. 1267-1276 
Gay, L. \& Wizenne, E. (August 2010). Sciences de l'Ingénieur en Incendie, In Ensta ParisTech, 14.03.2011, Available from http://wwwdfr.ensta.fr/Cours/ docs/A3-1/ A31_cours_incendie_part1.pdf

Goetzberger, A. \& Hoffman, V.U. (2005). Photovoltaic Solar Energy Generation, Springer Series in Optical Sciences, v. 112, SpringerLink, ISBN 3540266283 (electronic bk.), Retrieved from http://www.springerlink.com /content/978-3-540-236764/\#section=570748\&page $=1$

Guillemoles, J.F. (2010). The Quest for Very High Efficiency in Photovoltaic Energy Conversion, Europhysics News, Vol. 41, No. 2 (March-April 2010), pp. 19-22

Hatice, S \& Theis, T.L. (2010). An Environmental Impact Assessment of Quantum dot Photovoltaics (QDPV) from Raw Material Acquisition Through Use, Journal of Cleaner Production, Vol. 19, Issue 1 (January 2011), pp. 21-31

Held, M. \& Ilg, R. (2011). Update of Environmental Indicators and Energy Payback Time of CdTe PV Systems in Europe, Progress in Photovoltaics : Research and Application, Vol. 19, Issue 5 (January 2011), pp. 614-626

Hirschl, B. (2005). Acceptability of Solar Power Systems, A Study on Acceptability of Photovoltaics with Special Regard to the Role of Design, In Institute for Ecological Economy Research, 15.07.2011, Available from

http://www.ioew. de/uploads/tx_ukioewdb/IOEW-R_180_Acceptability_ of_ Solar_Power_systems.pdf

IARC (1997). Beryllium, Cadmium, Mercury, and Exposures in the Glass Manufacturing Industry, In IARC Monographs on the Evaluation of Carcinogenic Risks to Human, Vol. 58 (Updated 22/08/1997), 12.07.2011, Available from http:/ / monographs.iarc.fr/ENG/Monographs/vol58/ volume58.pdf

IARC (1998). Silica and Some Silicates, In IARC Monographs on the Evaluation of Carcinogenic Risks to Human, Vol. 42, 12.07.2011, Available from http:/ / monographs.iarc.fr/ENG/Monographs/vol42/volume42.pdf

IEA-PVPS (2006). Compared Assessment of Selected Environmental Indicators of Photovoltaic Electricity in OECD Cities, In PhotoVoltaic Technology Platform, Publications, 05.03.2011, Available from: http://www.eupvplatform.org /publications/brochures.html

IEA-PVPS (2009). Methodology Guidelines on Life Cycle Assessment of Photovoltaic Electricity, In International Energy Agency Photovoltaic Power System Program, 04.07.2011, Available from http://www.iea-pvps-task12.org/fileadmin/ IEAPVPS_Docs/Images/LCA_guidelines-8-2-10.pdf

IEA-PVPS (April 2011). PVPS Annual report 2010, Implementing Agreement on Photovoltaic Power Systems, In International Energy Agency Photovoltaic Power System Program, 04.07.2011, Available from: http://www.iea-pvps.org/ index.php?id=6

International Union for Conservation of Nature (2006). The Future of Sustainability, Rethinking Environment and Development in the Twenty-first Century, In IUCN, 17.07.2011, Available from

http://cmsdata.iucn.org/downloads/ iucn_future_of_sustanability.pdf 
Jaeger-Waldau, A. ( 2010). PV Statut Report, In JTC Scientific and Technical Reports (EUR Collection) 28.02.2011, Available from http:// publications.jrc. ec.europa.eu/repository/handle/

Jaramillo, P.; Griffin, W.M. \& Matthews, H.S. (2007). Comparative Life-Cycle Air Emissions of Coal, Domestic Natural Gas, LNG, and SNG for Electricity Generation, Environmental Science and Technology, Vol. 41, No. 17 (July 2007), pp. 6290-6296

Kaldellis, J.K.; Zafirakis, D. \& Kondili, E. (2010). Energy pay-back period analysis of standalone photovoltaic systems, Renewable Energy, Vol. 3, Issue 7 (July 2010), pp. 14441454

Krauter, S. \& Rüther R. (2004). Consideration for the Calculation of Greenhouse Gas Reduction by Photovoltaic Solar Energy, Renewable Energy, Vol. 29, Issue 3 (March 2004), pp. 345-355

Krauter, S.C.W. (2006). Solar Electric Power Generation - Photovoltaic Energy Systems [electronic resource] : Modeling of Optical and Thermal Performance, Electrical Yield, Energy Balance, Effect on Reduction of Greenhouse Gas Emissions, SpringerLink, ISBN 354031346X (electronic bk.) Retrieved from

http://www.springerlink.com/content/k20311/\#section=476234\&page=1

Labouret, A. \& Villoz, M. (2009). Énergie Solaire Photovoltaïque (4th Édition), Dunod, ISBN 978-2-10-052200-2, Paris, France

Lhomme, J.-C. (2004). Les Énergies Renouvelables, (2nd Edition), Delachaux and Niestlé Edition, ISBN : 2-603-01484-6, Paris, France

MDDEP (n.d.). Les Principes du Développement Durable: Un Guide pour l'Action, In Développement Durable, Environnement et Parcs, Québec, 28.02.2011, Available from http://www.mddep.gouv.qc.ca/developpement/principes. pdf

Miquel, C. (2009). Systèmes Photovoltaiques : Fabrication et Impact Environnemental, In Hespul, Énergie Renouvelables et Efficacité énergétique, Publications Photovoltaïques, 27.02.2011, Available from

http://www. photovoltaique.info/IMG/pdf/PV_Fab_Envt_final_26082009.pdf

Nakano, A.; Omae, K.; Tanaka, A.; Hirata,M.; Michikawa, T.; Kikuchi, Y.; Yoshioka, N.; Nishiwaki, Y. \& T. Chonan, T. (2009). Causal Relationship between Indium Compound Inhalation and Effet on the Lung, Journal of Occupational Health, Vol. 51, No. 6 (November 2009), pp. 513-521

Neff, T.L. (1979). Social Cost factors abd the Development of Photovoltaics Energy Systems, In Dspace@MIT, 05.07.2011, Available from http://dspace.mit.edu /handle/1721.1/35167

Ngai, E. (June 2010). Q2 2010 / Silane Safety, In Specialty Gas Report, 11.07.2011, Available from http://www.specialtygasreport.com/features/429

Nieuwlaar, E. \& Aselma, E. (1997). Environmental Aspects of PV Power Systems, Proceedings of IEA PVPS Task 1 Workshop, ISBN 90-73958-32-6, Ultrecht, The Netherlands, June 25-27, 1997

Norwegian Geotechnical Institute (2010). Environmental Risks Regarding The Use and Final Disposal of CdTe Modules, In California Department of Toxic Substances Control, 03.07.2011, Available from 
http:/ / www.dtsc.ca.gov/LawsRegsPolicies/upload/Norwegian-GeotechnicalInstitute-Study.pdf

Nozik, A.; Beard, M.C.; Luther, J.M.; Law, M.; Ellingson, R.J. and and Johnson, J.C. (2010). Semiconductor Quantum Dots and Quantum Dot Arrays and Applications of Multiple Exciton Generation to Third-Generation Photovoltaic Solar Cells, Chemicals Reviews, Vol. 110, Issue 11 (November 2009) pp 6873-6890

Observ'ER (2010). Worlwide Electricity Production from Renewable Energy Sources. Stats and Figures series. 12TH inventory. Edition 2010, In Observ'ER, L'observatoire des Énergies Renouvelables27.06.2011, Available from http://www.energiesrenouvelables.org/observer/html/inventaire/Eng/ methode.asp

Pehnt, M. (2006). Dynamic Life Cycle Assessment (LCA) of renewable energy technologies, Renewable Energy, Vol. 31, Issue 1 (January 2006), pp. 55-71

Peyrot, C., Gagnon, C.; Gagné, F.; Willkinson , K.J.; Turcotte P. \& Sauvé, S. (2009). Effects of Cadmium Telluride Quantum Dots on Cadmium Bioaccumulation and Metallothionein Production to the Freshwater Mussel, Elliptio complanata, Comparative Biochemistry and Physiology, Part C: Toxicology \& Pharmacology, Vol. 150, Issue 2 (August 2009), pp.246-251

Posorski , R.; Bussman, M. \& Menke, C. (2003). Does the Use of Solar Home Systems (SHS) Contribute to Climate Protection? Renewable Energy, Vol. 28, Issue 7 (June 2003), pp 1061-1080

Prather, M.J. \& Hsu. J. (2008). NF3, the Greenhouse Gas Missing from Kyoto, In American Geophysical Union, Geophysical Research Letters, Vol. 35, L12810, 3pp., 09.07.2011, Available from http:/ / web.viu.ca/earle/geol-412/2008GL034542.pdf

PVCycle (2011). European Association for the Recovery of Photovoltaic Modules, Annual Report 2010, In PVCycle Association, Publications, 05.07.2011, Available from http://www.pvcycle.org/fileadmin/pvcycle_docs/documents/Annual\%20report $\%$ 20FINAL.pdf

PVResources (2011). Photovoltaic Economics, In pvresources.org (last time updated 07.02.2011), 25.06.2011, Available from

http://www.pvresources.com/ en/economics.php

Radziemskai, E.; Ostrowski, P.; Cenian, A. \& Sawczak, M. (2010). Chemical, Thermal and Laser Process in Recycling of Photovoltaic Silicon Solar Cells and Modules, Ecological Chemistry and Engineering S, Vol. 17, No. 3 (2010), pp. 385-391

Raugei, M. \& Fthenakis, V.M. (2010). Cadmium Flows and Emissions from CdTe PV: Future Expectations, Energy Policy, Vol. 38, Issue 9 (September 2010), pp. 5223-5228

Reich, N.H. ; Alsema, E.A. ; van Sark W.G.J.H.M. ; Turkenburg W.C. \& Sinke, W.C. (2011). Greenhouse Gas Emissions Associated with Photovoltaic Electricity from Crystalline Silicon Modules under Various Energy Supply Options. Progress in Photovoltaics: Research and Applications, Vol. 19, Issue 5 (August 2011), pp. 603-613

Right To Know (2010). Hasardous Substances Fact Sheet : Silicon Tetrachloride, In New Jersey Department Of Health and Senior Services, 10.07.2011, Available from nj.gov/health/eoh/rtkweb/documents/fs/1666.pdf 
Sander, K.; Schilling, S.; Reinschmidt, J.; Wambach, K.; Schlenker, S.; Müller, A.; Springer, J.; Fouquet, D.; Jelitte, A.; Stryi-Hipp, G. \& Chrometzka, T. (2007). Study on the Development of a Take-Back-and Recovery System for Photovoltaic Products, In PVCycle Association, Publications, 05.07.2011, Available from http://www.pvcycle.org/fileadmin/pvcycle_docs/documents/publications/Rep ort_PVCycle_Download_En.pdf

Singh, M. (1998). L'Énergie Solaire, Comment Vivre en Paix avec la Nature, Édition du Club France Loisirs with permission of M. Madanjeet Singh and UNESCO, ISBN 2-74411495-2, France

SolarServer (June 2011). PVX Spot Market Price Index Solar PV Modules, Price Trends June 2011, In SolarServer, Online Portal to Solar Energy, 06.07.2011, Available from http://www.solarserver.com/service/pvx-spot-market-price-index-solar-pvmodules.html

Stoppato, A. (2008). Life Cycle Assessment of Photovoltaic Electricity Generation, Energy, Vol. 33, Issue 2 (February 2008), pp. 224-232

Su, Y., Hu, M.; Fan, C.; He, Y.; Li, Q.; Li, W.; Wang, L.; Shen P. \& Huang, Q. (2010). The Cytotoxicity of CdTe Quantum Dots and the Relative Contributions from Released Cadmium Ions and Nanoparticle Properties, Biomaterials, Vol. 31, Issue 18 (June 2010), pp. 4829-4834

SVTC (2009). Towards a Just and Sustainable Solar Energy Industry, In Silicon Valley Toxics Coalition, Resources, Report, 10.07.2011, Available from http://svtc.org/wp-content/uploads/Silicon_Valley_Toxics_Coalition__Toward_a_Just_and_Sust.pdf

Vaille, C. (Juillet 2009). Les Avantages du Solaire Thermique, histoire et perspectives, In Bulletinelectronique.com, 27.06.2011, Available from http://www. bulletinselectroniques.com/actualites/060/60154.htm

Vest, H. (2002). Fundamentals of the Recycling of Lead-Acid Batteries, In Infogate/ Deutschen Gesellschaft für Technische Zusammenarbeit (GTZ) GmbH, 27.06.2011, Available from http://www.bvsde.paho.org/bvsacd/cd48/ E017E_2002.pdf

Weisser, D. (2007). A Guide to Life-Cycle Greenhouse Gas (GHG) Emissions from Electric Supply Technologies, Energy, Vol. 32, Issue 9, pp 1543-1559

Wild-Scholten, M.J.; Sturm, M.; Butturi, M.A. ; Noack, M.; Heasman, K. \& Timo G. (2010). Environmental Sustainability of Concentrator PV Systems: Preliminary LCA Results of the Apollon Projects, Proceedings from 25th European Photovoltaic Solar Energy Conference and Exhibition, Valencia, Spain, 6-10 September 2010

Werlin, R.; Priester, J.H.; Mielke, R.E.; Kramer, S.; Jackson, S.; Stoimenov, P.K.; Stucky, G.D.; Cherr, G.N.; Orias, E. \& P.A. Holden, P.A. (2011). Biomagnification of Cadmium Selenide Quantum Dots in a Simple Experimental Microbial Food Chain, Nature Nanotechnology, Vol. 6, Issue 1 (January 2011), pp. 65-71

Xakalashe, B.S. \& Tangstad, M. (2011). Silicon Processing: from Quartz to Crystalline Silicon Solar Cells, Proceedings of Southern African Institute of Mining and Metallurgy, pp. 83100, Johannesburg, South Africa, 6-9 March, 2011 
Yassin, A.; Yebesi F. \& Tingle, R. (2005). Occupational Exposure to Crystalline Silica Dust in the United States: 1988-2003, Environmental Health Perspectives, Vol. 113, No. 3 (March 2005), pp. 255-260

Zayed, J. \& Phillipe, S. (2009). Acute Oral and Inhalation Toxicities in Rats With Cadmium Telluride, International Journal of Toxicology, Vol. 28, Issue 4 (July 2009), pp. 259265 



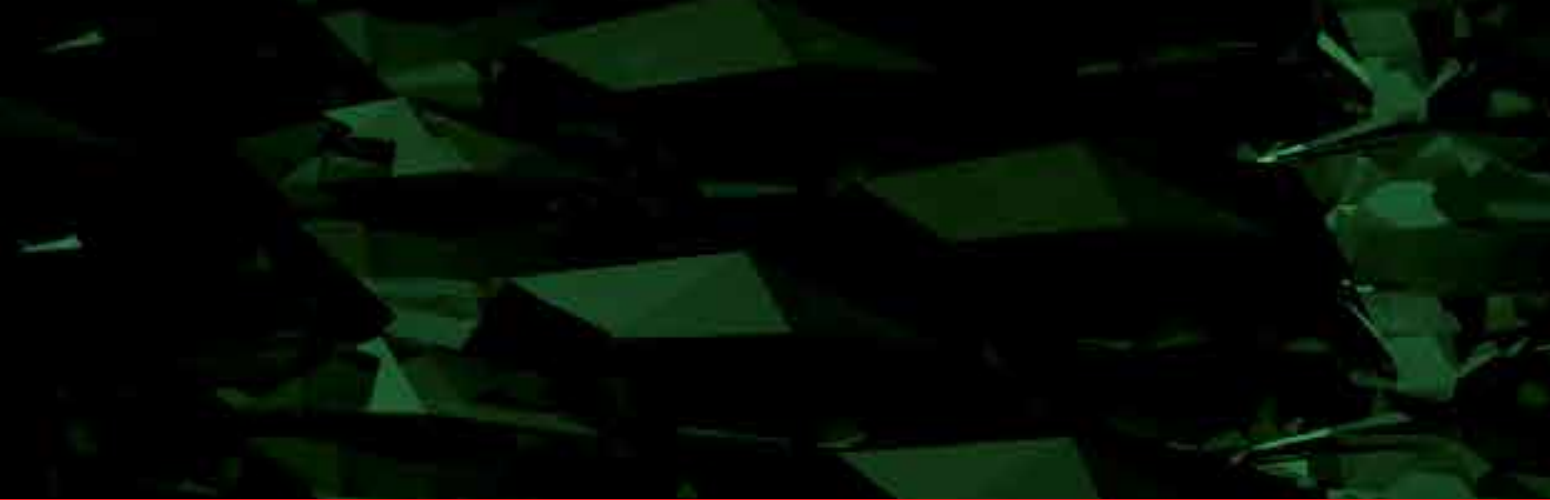

\section{Edited by Majid Nayeripour and Mostafa Kheshti}

Worldwide attention to environmental issues combined with the energy crisis force us to reduce greenhouse emissions and increase the usage of renewable energy sources as a solution to providing an efficient environment. This book addresses the current issues of sustainable growth and applications in renewable energy sources. The fifteen chapters of the book have been divided into two sections to organize the information accessible to readers. The book provides a variety of material, for instance on policies aiming at the promotion of sustainable development and implementation aspects of RES.

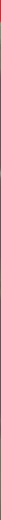

